TEMPORAL VARIABILITY IN CHEMICAL CYCLING OF THE SUBTERRANEAN ESTUARY AND ASSOCIATED CHEMICAL LOADING TO THE COASTAL OCEAN

By

Meagan Joan Eagle Gonneea

B.S., Stanford University, 2003

M.S., Stanford University, 2004

Submitted in partial fulfillment of the requirements for the degree of Doctor of Philosophy

at the

MASSACHUSETTS INSTITUTE OF TECHNOLOGY

and the

WOODS HOLE OCEANOGRAPHIC INSTITUTION

February 2014

(C2014 Meagan Joan Eagle Gonneea

All rights reserved.

The author hereby grants to MIT and WHOI permission to reproduce and to distribute publicly paper and electronic copies of this thesis document in whole or in part in any medium now known or hereafter created.

Signature of Author

Joint Program in Oceanography/Applied

Ocean Science and Engineering Massachusetts Institute of Technology and Woods Hole Oceanographic Institution Submitted September 27, 2013

Certified by

Dr. Matthew A. Charette Thesis Supervisor

Accepted by

Dr. Elizabeth Kujawinski

Chair, Joint Committee for Chemical Oceanography

Woods Hole Oceanographic Institution 
Temporal variability in chemical cycling of the subterranean estuary and associated chemical loading to the coastal ocean

By

\section{Meagan Eagle Gonneea}

Submitted to the Department of Marine Chemistry and Geochemistry, Massachusetts Institute of Technology-Woods Hole Oceanographic Institution Joint Program in Chemical Oceanography on September 27, 2013

In partial fulfillment of the requirements for the degree of Doctor of Philosophy

\section{Thesis Abstract}

At the land-ocean interface, terrestrial groundwater interacts with seawater to form a subterranean estuary, which can play host to dynamic biogeochemical cycling of nutrients, trace metals and radionuclides. This chemically altered groundwater enters the ocean through submarine groundwater discharge (SGD), a process that is driven by a number of physical processes acting on aquifers and the coastal ocean. In this thesis, seasonal variability in chemical cycling and associated loading to the coastal ocean was observed in a monthly time series within the Waquoit Bay (MA, USA) subterranean estuary. The position of the aquifer mixing zone moved seaward with an increase in hydraulic gradient, resulting in low salinity conditions and reduced mixing, while a decrease in gradient led to landward movement, high salinity groundwater and enhanced mixing. At this location, seasonal variability in sea level, not groundwater level, was the dominant variable driving the hydraulic gradient and therefore SGD. Fluxes of sediment bound cations to the ocean increased coincidently with sea level rise due to desorption. There was enhanced nitrogen attenuation during winter, potentially due to longer groundwater residence times, with greater nutrient delivery to coastal waters during the spring and summer bloom. Interannual climate fluctuations that control sea level and precipitation may ultimately control the timing and magnitude of chemical and water flux via SGD.

In addition to temporal variability, aquifer lithology influences chemical export. This thesis also demonstrates that SGD from karst subterranean estuaries may play a role in local and global element budgets. The potential for the chemical signature of SGD to be recorded in the coral record was tested through a combination of coral culture experiments and field and modeling studies in the Yucatan Peninsula. Coral barium was well correlated with precipitation for a twelve-year record, with coral geochemistry reflecting the passage of a hurricane in 2002. While additional complexities in deciphering coral records remain, this proxy offers the potential to extend SGD records into the past.

Thesis Supervisor: Matthew A. Charette

Title: Senior Scientist, Woods Hole Oceanographic Institution 


\section{Acknowledgements}

The past five years have been an exciting time. No person can complete such a monumental undertaking on their own. It is the support system that we build that allows us achieve such feats.

I would first like to thank my advisor, Matt Charette. I have worked with Matt for nine yearslonger than most PhD students spend with their advisors! This attests to both the great research Matt does and to my appreciation for his dedication and flexibility as an advisor. I worked in Matt's lab as a research technician on SGD projects around the world, gaining the field, analytical and writing skills that are so valuable to me today. I guess Matt made his job look too easy - after four years in a research position, I decided to pursue my doctoral degree. I am very glad that Matt encouraged me to stay at WHOI and work on further SGD/STE studies. Finishing a PhD is a lot of work - doing it with children requires an advisor who is understanding and supportive. Matt was always quick to respond to questions, edited papers overnight and encouraged me to pursue multiple research paths. In addition, Matt traveled on many of the field trips. He was always elected driver (none of us wanted to be responsible for a vehicle on the rough Mexican roads), had to swim to get the underwater spring sample (only one with a snorkel) or left to sample along the isolated Chilean river (puma hunting grounds)! Professionally Matt has embodied what it means to be a research scientist who is a leader in his field, while personally he has demonstrated how to juggle the demands of this profession with family. Thank you Matt.

I started as a technician at the same time as Paul Henderson. We worked closely together, both in the field and in the lab. He is the perfect person to have with you in the field-from running out of food (in a remote corner of Panama), to getting gear stuck in the beach (pretty much everywhere), diving to sample coral or reviving you with a bottle full of water (I only fainted once I swear!). Paul was always positive in the field, can fix pretty much anything and is always happy to help with any request.

Anne Cohen played a huge part in getting the coral paleo SGD portion of my thesis off the ground. She has always been enthusiastic about the project, offering insight into coral biology and chemistry. She worked with Matt and I to write NSF proposals, facilitated my coral growth experiments and helped me find appropriate corals to use in development of this proxy. Anne has also been a great source of career advice and always has encouraging comments!

The work I did on groundwater chemistry and discharge in Waquoit Bay would not have been possible without Ann Mulligan's insight and modeling efforts. She answered my hydrology questions and helped analyze and publish the Waquoit Bay time series results.

I would like to thank the remainder of my committee, including Bernhard Peucker-Ehrenbrink, Delia Oppo and Charlie Harvey, for offering their perspective on a wide range of topics, and keeping me grounded and focused through the many directions my thesis seemed to take. Carl Lamborg was a great defense chair-thanks to all!

Woods Hole Oceanographic Institution is a wonderful place to study the sea and its margins! The abundance of research on all aspects of oceanography has really benefitted my thesis research. Glen Gawarkiewicz helped me with sea level questions. Bill Jenkins was generous with his time when I had a modeling or statistics questions and the modeling class he, Scott Doney and David Glover taught was one of the best classes of my graduate career. David Glover answered many Matlab questions, both conceptual and practical! I first went to Phoebe Lam for career advice when I was applying for graduate school and she has made her door open ever since. Jeff Seewald offered his lab to me when I need to run some last minute samples.

I have made frequent use of the WHOI ICP Facility. Scot Birdwhistell has helped me analyze the many water and coral samples found in this thesis. Without his help, the following work would not have been possible.

Liz Drenkard taught me to grow corals and then babysat my experiments in Bermuda! Without her help and guidance, the coral growth experiments could not have happened. It is wonderful when we get to do science with our friends!

Samantha de Putron hosted me at BIOS during the coral experiments. It was definitely an adventure (growing the corals and nearly sinking!) and has given me a richer appreciation of the 
complexity of working with living creatures. Corals are not perfect marine chemists, no matter how much I would like them to be!

There are a host of other people who have joined me in the field-Crystal Breier in Mexico and Waquoit; Qian Liu, Adam Rago, Grace Rago, Gillian Smith, DeAnna McCadney and Paul Morris in Waquoit; Alex Rao, Sara Morales-Ojeda, Simon Richards, and Jess Fitzsimmons in Mexico.

I would also like to thank Henrieta Dulaiova, for inspiring me with radiochemistry. Adina Paytan started as my undergraduate advisor and has since become a colleague and friend.

Waquoit Bay National Estuarine Research Reserve was the host to all of my Waquoit Bay research. I want to recognize Chris Weidman and MaryKay Fox for making this site so accessible, for hosting the time series wells for so long and for sharing their knowledge of WBNERR.

The Academic Programs office, including Jim Yoder, Christine Charette, Julia Westwater and Lea Fraser, really helped along the way. In particular I need to thank Jim and Christine for helping make the JP student childcare accommodations a reality. Hopefully other students (crazy enough) to study in the Joint Program with children will benefit from this policy. Towards the end, Julia and Lea helped with my many questions.

The MC\&G administrative staff are the best in the world. I will miss you Donna Mortimer, Sheila Clifford and Mary Murphy!

I would not have been able to complete this $\mathrm{PhD}$ without my WHOI/MIT friends. Maureen and Crystal were great lunch buddies - thanks for the reminder that it is ok to eat somewhere other than in front of my computer! Britta, Evan, Ben and Dan always had time when I had a problem, scientific or otherwise. Jess was my study partner through generals and my conference roommate. Thanks for being such great listeners!

I have a wonderful family, all of whom have helped make this $\mathrm{PhD}$ happen. Despite the distance (Alaska and Washington), all have supported me: my aunt Linda and uncle Jim watched the kids while I traveled, my Dad came back and dropped trees for us, my grandfather Verne (who celebrated his $101^{\text {st }}$ birthday right before my thesis defense!) always let me know how proud he was, my sister Shanlee came to cheer me on in the final month of writing, my brother Brennon and sister-in-law Susan watched over Tarun this summer during his long Alaskan vacation so I could write. I need to particularly thank my Mom and stepdad Eric. They shared with me their love of the ocean in a special way-we sailed across it! I guess six years on a sailboat didn't hurt me academically Mom! My Mom flew to the Cape every time I needed to travel for field work or to conferences to help take care of my children. She offered endless encouragement (and sometimes advice!) and has been my best friend throughout. Eric essentially rebuilt the bottom of our house and guided me through many long-distance fix-its! Thank you for always supporting me. I could not have done this without you.

The five years of my $\mathrm{PhD}$ research intersected with a large portion of Tarun and Taleena's childhood. I started this program when Tarun was four and Taleena was nine months old. Doing a PhD with two children was definitely a challenge, but a rewarding one. We had movie nights in the ICP lab while I was running samples and lots of weekend trips to WHOI. I would not have been able to do this without my husband Jay's support. I think that he has spent most of his vacation days in the past five years watching children, not taking a vacation! Thank you for allowing me to pursue this dream.

\section{I dedicate this work to my children, Tarun and Taleena. I hope that the research presented here, and that of my fellow scientists, will in some way make your future a better and brighter place.}

This research was supported by a National Defense Science and Engineering Graduate Fellowship, a National Estuarine Research Reserve Graduate Fellowship from the National Oceanic and Atmospheric Administration, and grants from the U.S. Geological Survey (G10AC00210) and the U.S. National Science Foundation (OCE-0425061, OCE-0751525 and OCE-0524994). Additional funds were provided by the WHOI Academic Programs Office, WHOI Ocean and Climate Change Institute, and MIT endowed funds. 


\section{Table of Contents}

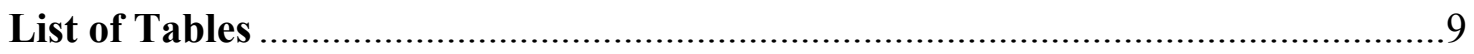

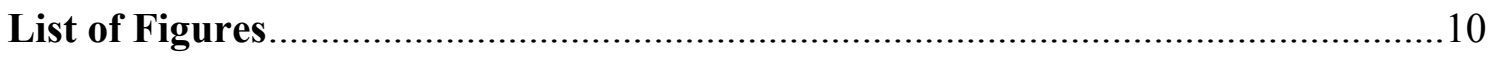

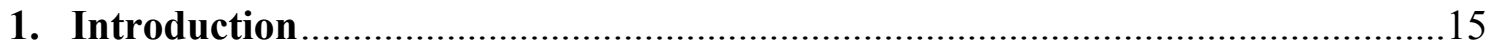

2. Climate-driven sea level anomalies modulate coastal groundwater

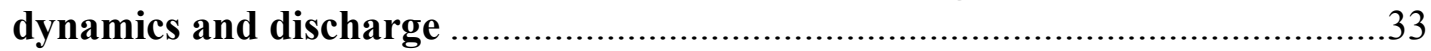

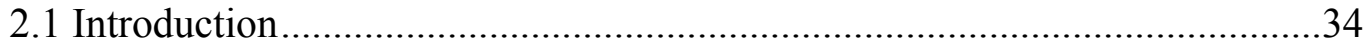

2.2 Methods and Study Site ............................................................................34

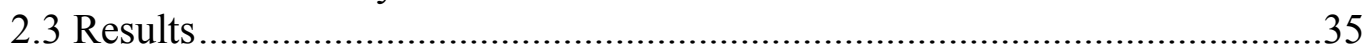

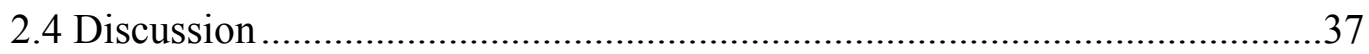

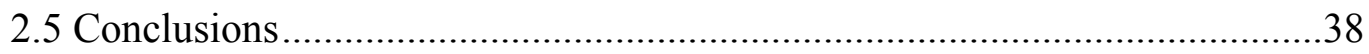

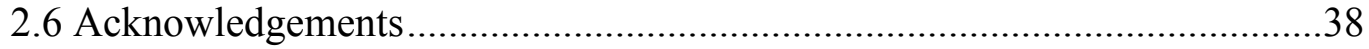

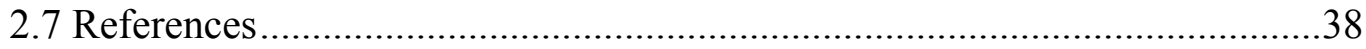

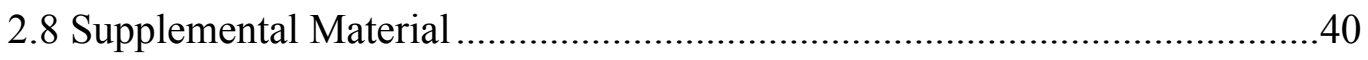

3. Seasonal cycles in radium and barium within a subterranean estuary:

Implications for groundwater derived chemical fluxes to surface waters..........55

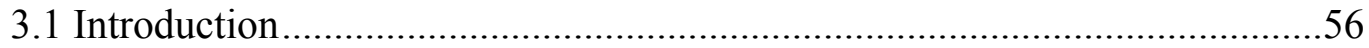

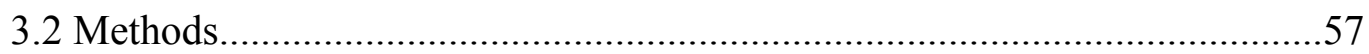

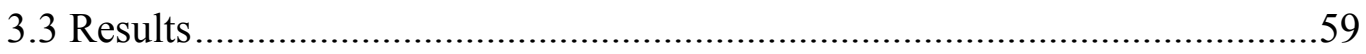

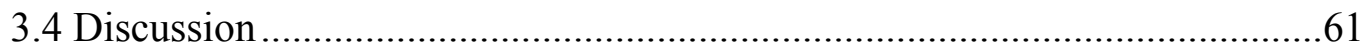

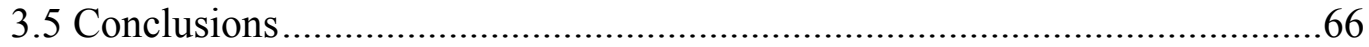

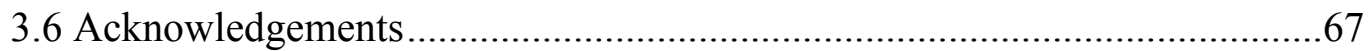

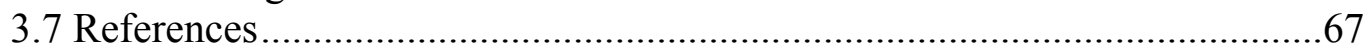

3.8 Supplemental Material ...............................................................................

4. Seasonal variability in nutrient dynamics within a sandy

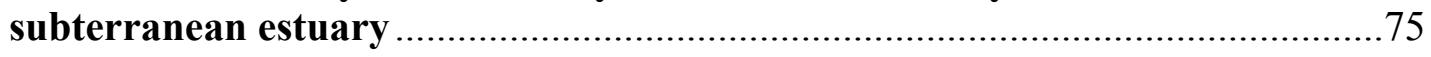

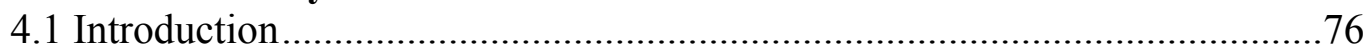

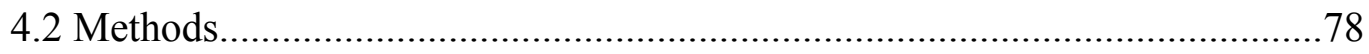

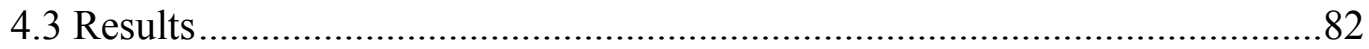

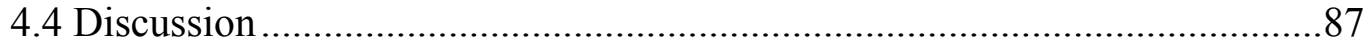

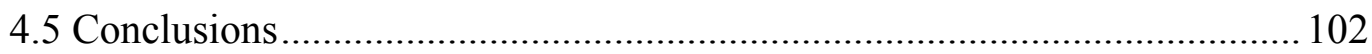

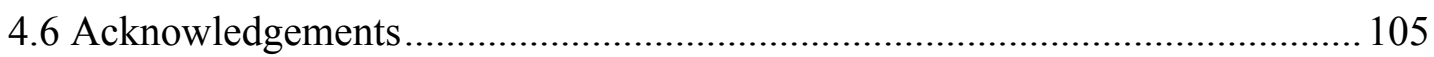

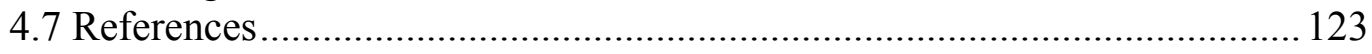

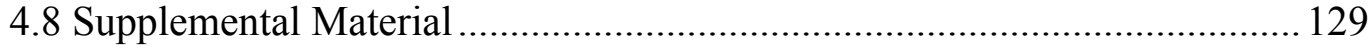


5. Trace element geochemistry of groundwater in a karst subterranean estuary

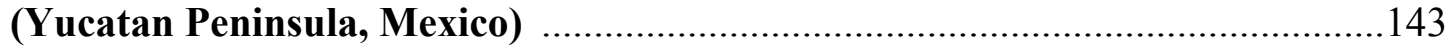

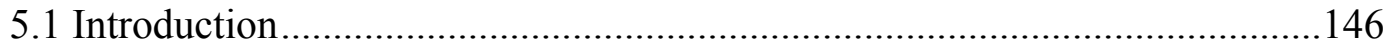

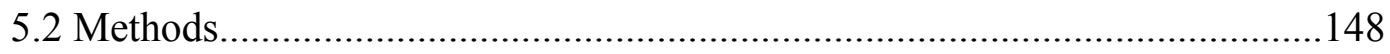

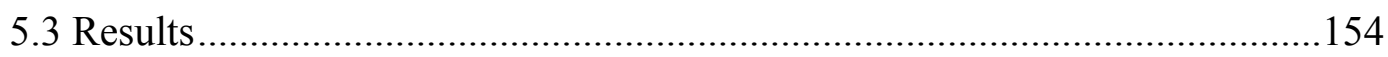

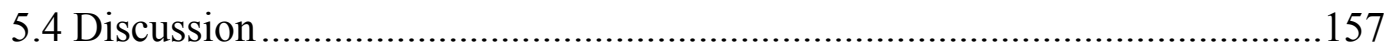

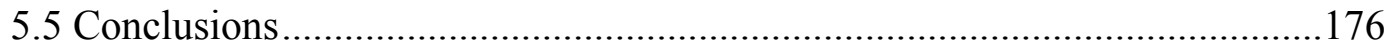

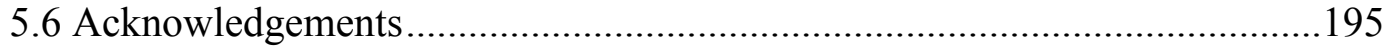

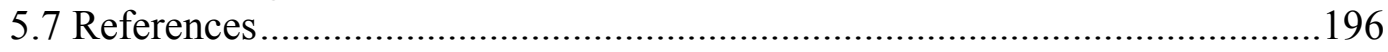

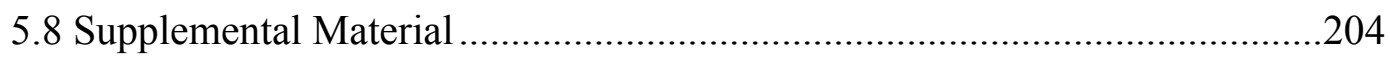

6. A reevaluation of the coral $\mathrm{Ba} / \mathrm{Ca}$ environmental proxy: A submarine

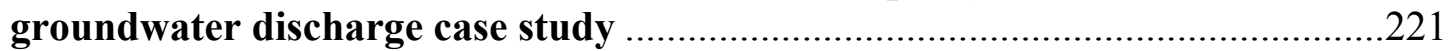

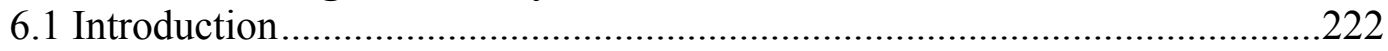

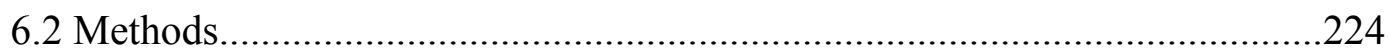

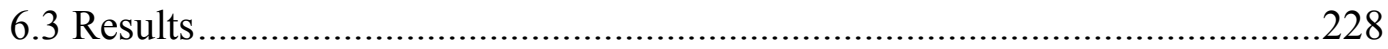

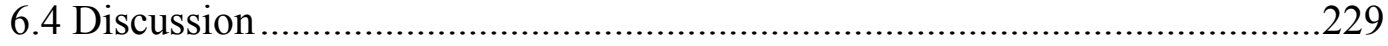

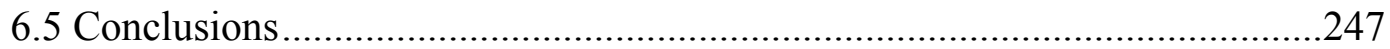

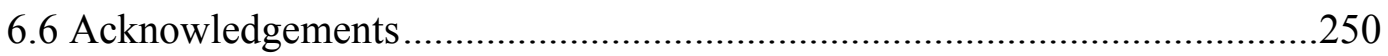

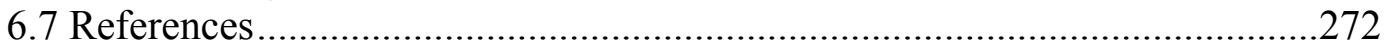

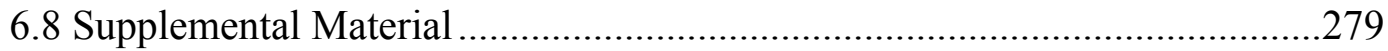

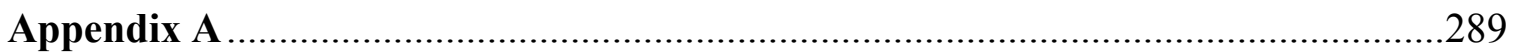

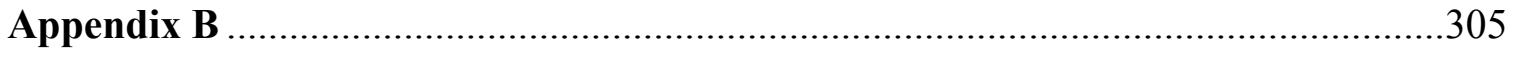

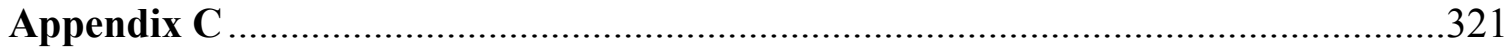




\section{List of Tables}

\section{Chapter 3}

Table 1: Water, Ba and ${ }^{226} \mathrm{Ra}$ budget for the Waquoit Bay subterranean estuary .............65

Table S1: ${ }^{226} \mathrm{Ra}$ and $\mathrm{Ba}$ v. salinity and $\mathrm{pH}$ changes at two depths...................................73

\section{Chapter 4}

Table 1: Subterranean estuary nutrient fluxes in 2003, 2004 and 2005.........................121

Table 2: Terrestrial and marine nutrient inventories...................................................122

\section{Chapter 5}

Table 1: Yucatan and global limestone Ba, Sr, U, Mn and Ra..... 191

Table 2: Element radius, calcite partition coefficient and predicted dissolved $\mathrm{E} / \mathrm{Ca}$......192

Table 3: Radium-tracer based submarine groundwater discharge estimates ....................193

Table 4: Yucatan Peninsula and global karst trace element flux ....................................194

Table S1: Certified Reference Material elemental concentrations ....................................205

Table S2: Yucatan groundwater and surface water samples ..........................................206

Table S3: Conservative mixing relationships ..........................................................218

\section{Chapter 6}

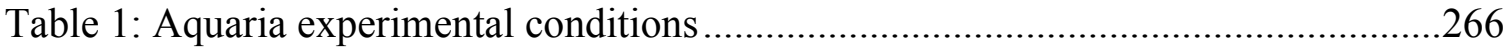

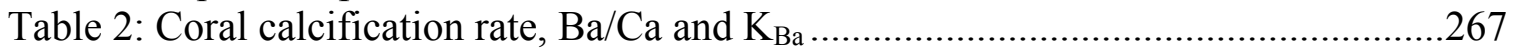

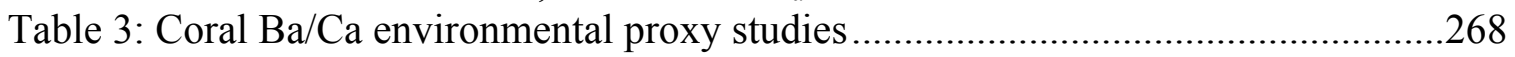

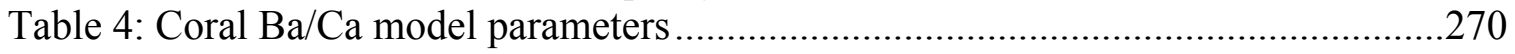

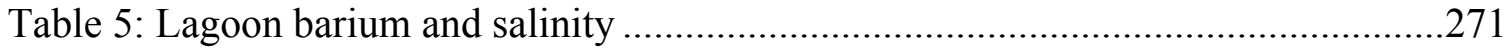

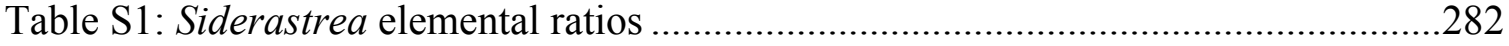

\section{Appendix B}

Table 1: Guam Porites elemental ratios.

\section{Appendix C}

Table 1: Straits of Magellan (Chile) groundwater, estuarine and surface samples 


\section{List of Figures}

\section{Chapter 2}

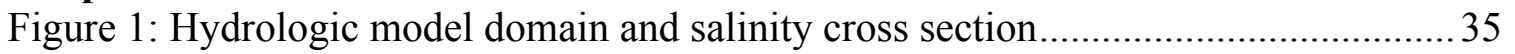

Figure 2: Salinity, head gradient and mean sea level anomaly .................................... 36

Figure 3: Hydrodynamic models of groundwater discharge and salinity .........................37

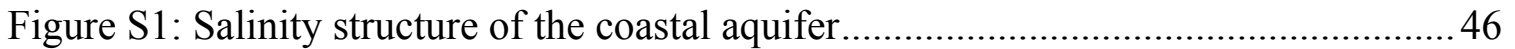

Figure S2: Tidal time series of salinity and mean sea level.......................................47

Figure S3: Coastal aquifer salinity, coastal groundwater levels and sea levels................48

Figure S4: Mean sea level anomaly and solar annual tidal component.........................49

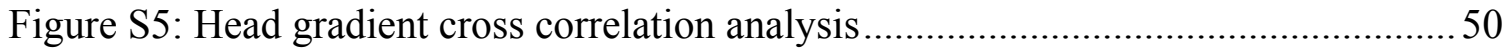

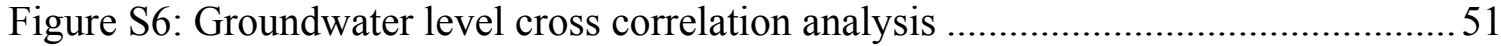

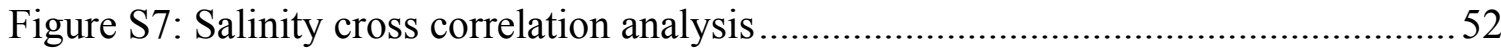

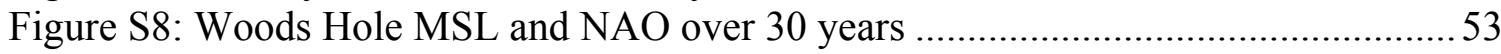

\section{Chapter 3}

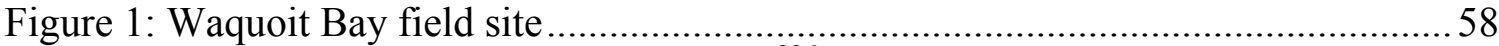

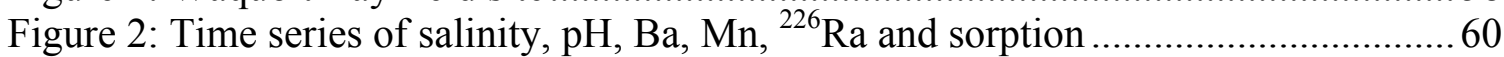

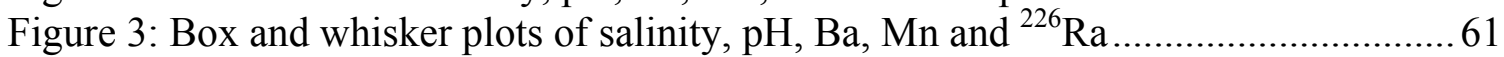

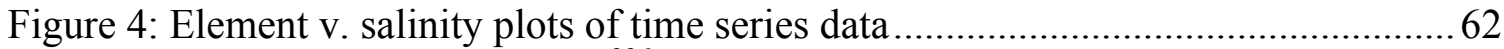

Figure 5: Salinity and $\mathrm{pH}$ v. Ba and ${ }^{226} \mathrm{Ra}$ at two depths .........................................6. 63

Figure 6: Submarine groundwater discharge and ${ }^{226} \mathrm{Ra}$ flux .....................................65

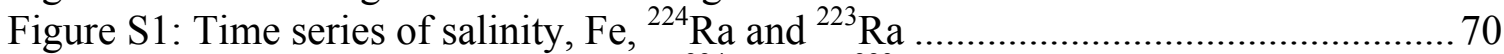

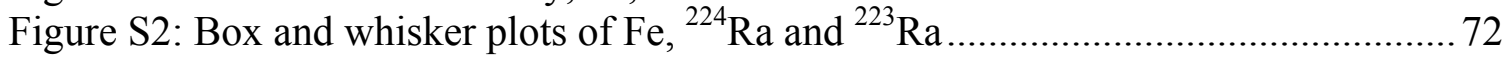

\section{Chapter 4}

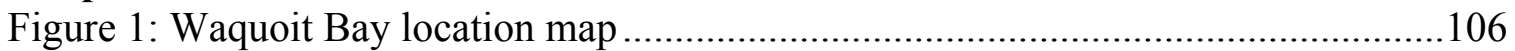

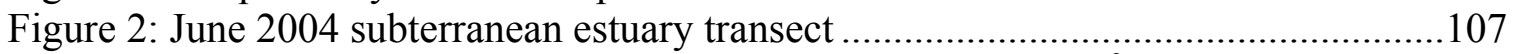

Figure 3: Time series of salinity, $\mathrm{NO}_{3}{ }^{-}+\mathrm{NO}_{2}{ }^{-}, \mathrm{NH}_{4}{ }^{+}, \mathrm{Mn}$ and $\mathrm{PO}_{4}{ }^{3-} \ldots \ldots \ldots \ldots \ldots \ldots \ldots \ldots . . . . . . . . . . .110$

Figure 4: Modeled marine groundwater fraction v. mean sea level .............................111

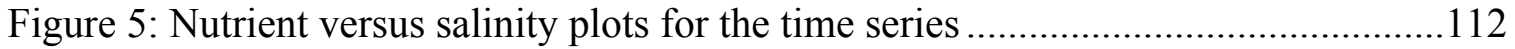

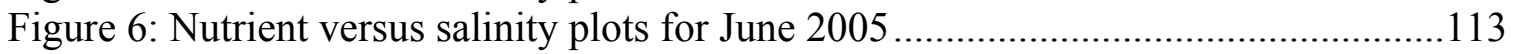

Figure 7: Depth profiles of $\mathrm{NH}_{4}{ }^{+}$and $\mathrm{NO}_{3}{ }^{-}$at three time periods .................................114

Figure 8: Mixing zone $\mathrm{NO}_{3}{ }^{-}+\mathrm{NO}_{2}{ }^{-}$with salinity and $\mathrm{O}_{2}$ indicated ............................115

Figure 9: Fraction of $\mathrm{NO}_{3}{ }^{-}+\mathrm{NO}_{2}{ }^{-}$in mixing zone to $\mathrm{NH}_{4}{ }^{+}$lost..................................116

Figure 10: Terrestrial and marine groundwater profiles DIN and $\mathrm{PO}_{4}{ }^{3-}$.......................117

Figure 11: Depth profile of $\mathrm{PO}_{4}{ }^{3-}$ and $\mathrm{Mn}$ at two time periods .....................................118

Figure 12: Water and sediment $\mathrm{Fe}, \mathrm{Mn}, \mathrm{PO}_{4}{ }^{3-}, \mathrm{pH}$ and salinity depth profiles ................119

Figure 13: Subterranean estuary nutrient budget in winter and summer ........................120

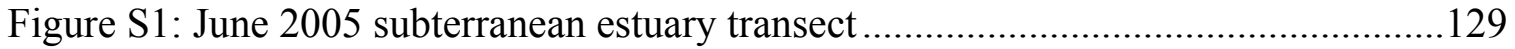

Figure S2: March 2003 subterranean estuary transect..............................................132

Figure S3: April 2005 subterranean estuary transect $80 \mathrm{~m}$ west ...................................135

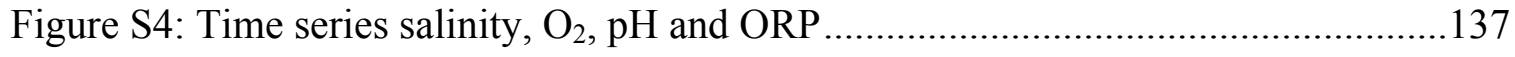




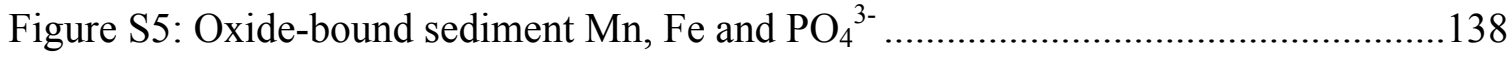

Figure S6: Marine groundwater fraction and $\mathrm{NO}_{3}{ }^{-}+\mathrm{NO}_{2}{ }^{-}$addition to mixing zone ......139

Figure S7: $\mathrm{NH}_{4}{ }^{+}$v. salinity in deep subterranean estuary.......................................... 140

Figure S8: Terrestrial and marine nutrient fluxes into the subterranean estuary .............141

\section{Chapter 5}

Figure 1: Yucatan Peninsula field site

Figure 2: Salinity v. Ba, U, Sr, Mn, and $\mathrm{Ca}$

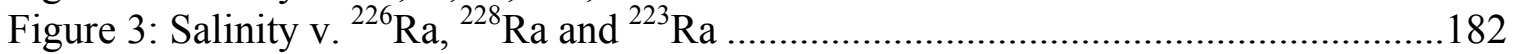

Figure 4: Ca v. DIC for terrestrial groundwater and PHREEQ model predictions ..........183

Figure 5: Respiration enhanced $\mathrm{Ca}$ dissolution and terrestrial groundwater ...................184

Figure 6: $\mathrm{Ba} / \mathrm{Ca}, \mathrm{Sr} / \mathrm{Ca}, \mathrm{Mn} / \mathrm{Ca}$ and $\mathrm{U} / \mathrm{Ca}$ in terrestrial groundwater ..............................185

Figure 7: ${ }^{226} \mathrm{Ra} / \mathrm{Ca},{ }^{228} \mathrm{Ra} / \mathrm{Ca}$ and ${ }^{223} \mathrm{Ra} / \mathrm{Ca}$ in terrestrial groundwater...........................186

Figure 8: Calcite saturation index upon groundwater-seawater mixing ..........................187

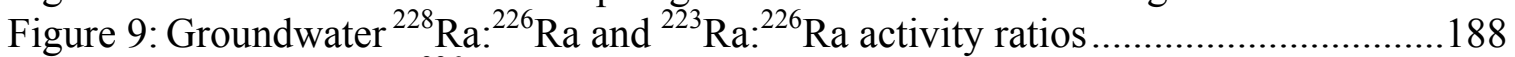

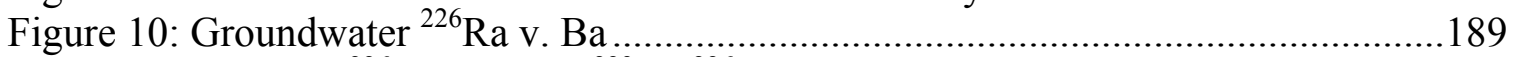

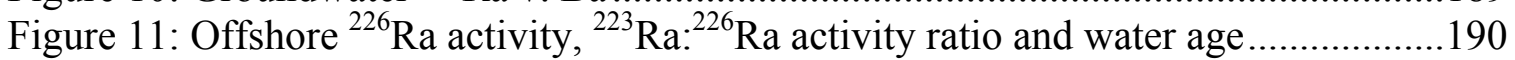

Figure S1: DIC v. pH, T-alk v. pH and T-alk v. DIC ..................................................204

\section{Chapter 6}

Figure 1: Coral v. water $\mathrm{Ba} / \mathrm{Ca}$ for Favia fragum polyps ........................................251

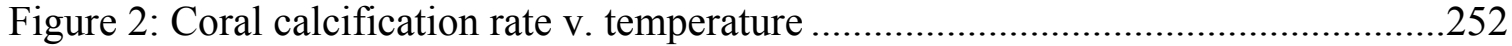

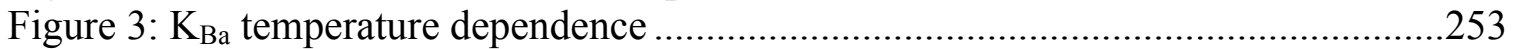

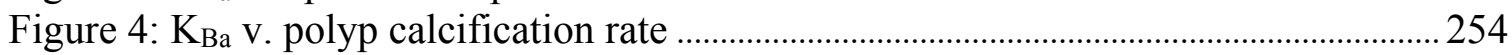

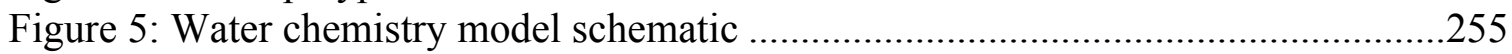

Figure 6: Modeled coral $\mathrm{Ba} / \mathrm{Ca}$ for groundwater and river discharge and upwelling .....256

Figure 7: Modeled coral $\mathrm{Ba} / \mathrm{Ca}$ sensitivity to changes in input and residence time ........257

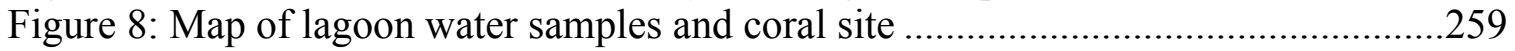

Figure 9: Ba v. salinity for Yucatan coastal ocean .....................................................260

Figure 10: Puerto Morelos lagoon salinity and precipitation........................................261

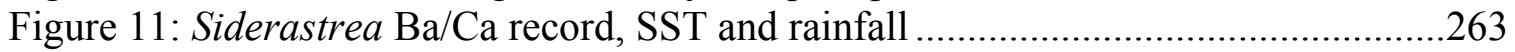

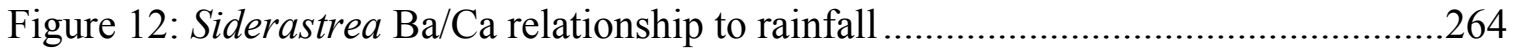

Figure 13: Dissolved $\mathrm{Ba} / \mathrm{Ca}$ predicted by Rayleigh model........................................265

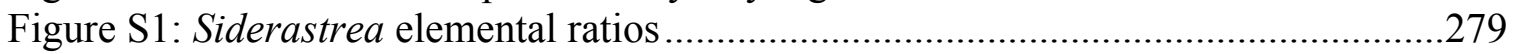

Figure S2: Sea surface temperature and Rayleigh model results..................................280

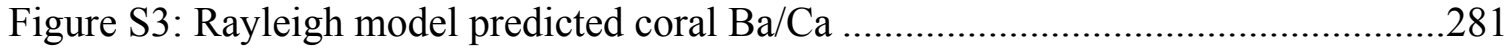

\section{Appendix A}

Figure 1: CT image of North Carolina Solenastrea slab ..........................................295

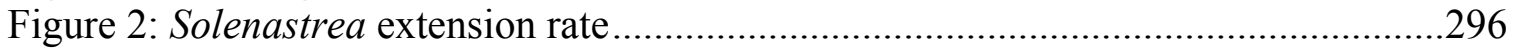

Figure 3: Element:element plots for Solenastrea coral................................................297

Figure 4: Eighty-year record of elemental ratios for Solenastrea coral.........................298

Figure 5: Solenastrea $\mathrm{Ba} / \mathrm{Ca}$ and Rayleigh fractionation model predicted values ..........299

Figure 6: Potential environmental influences on Solenastrea elemental ratios ...............300 


\section{Appendix B}

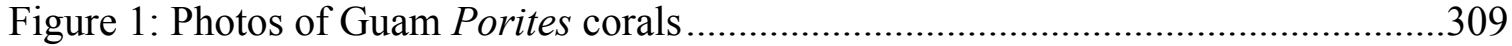

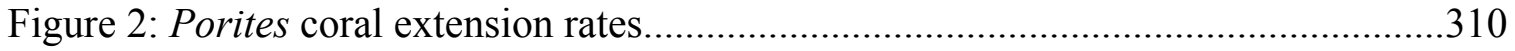

Figure 3: Element:element plots for Tumon Bay (Guam) Porites ..................................311

Figure 4: Sixteen-year record of elemental ratios for Porites coral................................312

Figure 5: Porites $\mathrm{Ba} / \mathrm{Ca}$ and Rayleigh fractionation model predicted values..................313

Figure 6: Barium and nitrogen in Guam groundwater and surface water.......................314

\section{Appendix C}

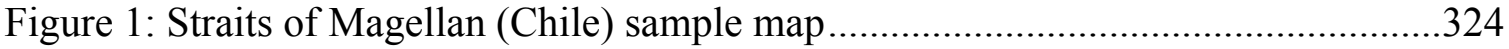

Figure 2: Groundwater, estuarine water and the surface water trace metals ..................325

Figure 3: Groundwater, estuarine water and the surface water radium isotopes .............326

Figure 4: Groundwater, estuarine water and the surface water nutrients ........................327

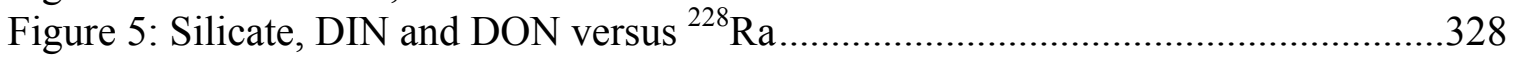




\section{Introduction}

\subsection{Overview}

Water flow from continents is one of the primary mechanisms for delivering terrestrial material, whether naturally occurring or anthropogenically modified, to the oceans. Traditionally surface water flow, including rivers, streams and run-off, was considered to be the primary transport mechanism. A subtler, but equally important connection, occurs underground. Submarine groundwater discharge (SGD) is the flow of water on continental margins from the sea floor into the coastal ocean encompassing any chemical composition or driving force (Burnett et al., 2003). This includes terrestrially sourced water driven by elevated inland water levels as well as marine groundwater recirculating through the coastal aquifer (Michael et al., 2005; Robinson et al., 2006; Santos et al., 2009a). Tidal and wave pumping results in additional seawater exchange across the sediment-water interface on short time scales (Li et al., 2008; Li et al., 2009; Robinson et al., 2007; Xin et al., 2010). 
Globally an estimated $2,400 \mathrm{~km}^{3}$ of terrestrial groundwater flows to the ocean each year (Zekster et al., 2006), approximately $6 \%$ of river discharge $\left(38,000 \mathrm{~km}^{3} \mathrm{y}^{-1}\right.$; Peucker-Ehrenbrink et al., 2010). However, geochemical tracer based estimates of total SGD (terrestrial plus marine origin) are estimated to be $20,000-40,000 \mathrm{~km}^{3} \mathrm{y}^{-1}$ for the Atlantic Ocean alone (Moore et al., 2008). Clearly, recirculation through coastal aquifers and along ocean margins is a large-scale process with the potential to influence global ocean chemistry.

This complex exchange of water within coastal aquifers results in a dynamic region with gradients in salinity, nutrients, dissolved trace metals and radionuclides known as the subterranean estuary (Moore, 1999). Biogeochemical cycling within the subterranean estuary (STE) modifies the chemical load of groundwater prior to discharge to the coastal ocean. Examples of this include attenuation of large terrestrial nitrogen and phosphorous fluxes (Kroeger and Charette, 2008; Loveless and Oldham, 2010; Slomp and Van Cappellen, 2004), enhanced iron loading (Windom et al., 2006), seawater uranium removal (Charette and Sholkovitz, 2006; Santos et al., 2011), and coastal ocean radionuclide enrichment (both naturally occurring and as a contaminant, (Charette et al., 2013; Moore, 1996; Moore and Shaw, 1998)). Thus chemical cycling that occurs during groundwater transit through the subterranean estuary ultimately determines the total chemical load to the coastal ocean via submarine groundwater discharge.

Chemical fluxes associated with submarine groundwater discharge are important on both local and global scales. For instance, in regional studies submarine groundwater discharge has been implicated as a source of nutrients fueling coastal eutrophication in regions as diverse as Cape Cod (USA) (Charette et al., 2001; Valiela et al., 1992), the 
Yucatan Peninsula (Mexico) (Herrera-Silveira et al., 2002) and Australia (Santos et al., 2013). In one example of the influence of SGD on global scales, Beck et al. (2013) confirmed the finding of Basu et al. (2001) that the marine strontium budget reflects contributions from terrestrial groundwater, while demonstrating that isotopic exchange within the subterranean estuary may be an additional potential control on the ocean ${ }^{87} \mathrm{Sr} /{ }^{86} \mathrm{Sr}$ ratio.

Submarine groundwater discharge is ubiquitous and occurs on every continent (including Antarctica!) (Basu et al., 2001; Beck et al., 2007; Breier et al., 2010; Burnett et al., 2007; de Sieyes et al., 2008; Einsiedl, 2012; El-Gamal et al., 2012; Garcia-Solsona et al., 2010; Knee et al., 2010; Lee and Kim, 2007; Moore, 1997; Niencheski et al., 2007; Paytan et al., 2006; Peterson et al., 2009; Povinec et al., 2012; Santos et al., 2013; Uemura et al., 2011; Weinstein et al., 2011; Windom et al., 2006). There is a large range in estimated rates, per meter of shoreline from $10^{-2}$ to $10^{2} \mathrm{~m}^{3} \mathrm{~d}^{-1}$, controlled by such factors as inland recharge, tidal range, wave height and aquifer hydrogeology. While there is a paucity of SGD studies on seasonal time scales, temporal variability appears to be important (Breier et al., 2010; Charette, 2007; Kelly and Moran, 2002; Santos et al., 2009c). For instance, Charette (2007) saw a four-fold increase in total SGD from summer to winter in a New England salt marsh.

The overarching theme of my $\mathrm{PhD}$ research is chemical transport to the ocean via submarine groundwater discharge. I address this topic using several approaches. In Chapter 2, I combine time series geochemical observations of the subterranean estuary over four years with hydrodynamic modeling to evaluate both the magnitude and the physical drivers of seasonal variability in SGD. In Chapters 3 through 5, I evaluate 
geochemical cycling of trace metals (including barium, strontium, uranium, manganese and iron), radionuclides (radium isotopes) and nutrients (nitrogen, phosphorous and silicate) in two separate subterranean estuary environments (aluminosilicate sand and karst). Finally, Chapter 6 considers the use of coral barium to calcium ratios to track past temporal variability in submarine groundwater discharge. Specifically, the questions I sought to address were:

1. What are the physical drivers of seasonal variability in groundwater discharge within a sandy subterranean estuary such as Waquoit Bay?

2. What key processes control distributions of trace metals, radionuclides and nutrients within subterranean estuaries of varying lithologies (sand and karst)? How does seasonal variability in submarine groundwater discharge affect this cycling?

3. Within the constraints of water chemistry observations and current models of coral elemental incorporation, can coral elemental ratios be utilized to trace groundwater discharge in the past?

Seasonal scale variability in submarine groundwater discharge is thought to result from changes in the aquifer hydraulic head driven by inland groundwater levels, while short-term variability is dominated by tide and wave pumping (Anderson and Emanuel, 2010; Michael et al., 2005; Robinson et al., 2006). The results of Chapter 2 represent a paradigm shift from such traditional thinking. The time series presented is the first to monitor and evaluate the regional scale mixing zone over such an extended period (four years). Seasonal sea level anomalies drive movement of the interface between terrestrial and marine groundwater, which in turn controls the timing, magnitude and salinity of 
groundwater discharge. Finally, this work demonstrates that regional scale climate variability, in my case the El Niño Southern Oscillation and North Atlantic Oscillation indices, influences coastal aquifer dynamics and groundwater discharge via their control on regional sea level. Furthermore, given the observed importance of sea level on these processes, previous predictions of the effect of climate oscillations on groundwater discharge that focused only on precipitation and aquifer recharge may underestimate the SGD response to climate change (Anderson and Emanuel, 2010).

Since SGD occurs over large areas and is spatially and temporally heterogeneous, quantifying the magnitude of discharge has been a complex and difficult question (Moore, 2010). W.S. Moore (1996) reported a large flux of radium (Ra) off the coast of the United States, which could only be accounted for by large inputs through SGD. The Ra activity of coastal waters is a function of inputs from SGD, rivers and benthic sources, exchange with offshore waters and radioactive decay (Moore, 2003). Thus, if the Ra inventory and residence time of coastal water is known, it is possible to determine the Ra flux. Furthermore, if the groundwater Ra end member can be quantified, the Ra flux can be transformed into a submarine groundwater discharge rate. Currently the skill of the Ratracer based approach to quantifying SGD is limited by large variability in groundwater Ra. To this end, the results of Chapter 3 show that there is large temporal variability in groundwater Ra related to movement of the salinity interface within the coastal aquifer. As a result, water flux and Ra flux may not be coupled. Furthermore, a local sea level rise of $\sim 11 \mathrm{~mm}$ over the course of the time series resulted in enhanced flux of Ra and $\mathrm{Ba}$ from the Waquoit Bay subterranean estuary, implicating future sea level rise in enhanced chemical loading via SGD to the coastal zone. 
Important geochemical processes within the subterranean estuary include ion exchange driven sorption/desorption (Charette and Sholkovitz, 2006; Gonneea et al., 2008; Webster et al., 1995), redox processes (Beck et al., 2010; Santos et al., 2011), mineral dissolution and precipitation (Charette et al., 2005; Perry et al., 2009; Spiteri et al., 2006), radioactive production and decay (Dulaiova et al., 2008; Michael et al., 2011; Rama and Moore, 1996) and biologically mediated reactions, including denitrification, anammox, and ammonification (Kroeger and Charette, 2008; Santoro, 2010; Santos et al., 2012; Spiteri et al., 2008). In Chapters 3 through 5, I explore the extent to which such reactions modify the groundwater-associated chemical flux and the role mixing between terrestrial and marine groundwater plays in such interactions. I find that salinity dependent sorption/desorption reactions and the formation of manganese and iron oxide coatings on sediments at redox boundaries are particularly important in the sandy Waquoit Bay subterranean estuary. Conversely, dissolution is the primary control on terrestrial groundwater trace metal and radionuclide concentrations in the karst subterranean estuary of the Yucatan Peninsula. At this site, dissolution is enhanced by respiration of organic matter, thereby elevating groundwater chemical load. I additionally include preliminary results from a STE/SGD study in the Straits of Magellan, Chile (Appendix C), which exhibit many of the same geochemical cycling processes described in Chapters 3 through 5.

Concurrent with coastal population growth, the coastal zone has experienced detrimental impacts including ecosystem and habitat loss, overfishing, structural modification, excessive groundwater pumping, eutrophication and harmful algal blooms (Doney, 2010; Jackson et al., 2001; Waycott et al., 2009). Nutrient transport via 
submarine groundwater discharge has been implicated as a potential driver of ecosystem deterioration and harmful algal blooms in several studies (Hu et al., 2006; Valiela et al., 1992). While attenuation of nitrogen and phosphorous is observed as groundwater transits the subterranean estuary, it is unclear how variable removal rates are and what might cause such variability (Kroeger and Charette, 2008; Santos et al., 2009b). Microbial populations are associated with specific redox gradients within the subterranean estuary and migrate in concert with these regions (Rogers and Casciotti, 2010; Saenz et al., 2012; Santoro, 2010). Chapter 4 demonstrates that while total flux into the subterranean aquifer is greater in the winter than summer, due to enhanced terrestrial nitrogen inputs, $\mathrm{N}$ attenuation rates are seven times lower in summer. I hypothesize that enhanced mixing and reduced groundwater residence time during the summer, coincident with elevated mean sea level, may result in nutrient transport through the subterranean estuary that is faster than the rates of nutrient transformation. One implication of greater nutrient loading in summer months is that nutrients are entering a coastal water body during peak algal growth, thus may be exacerbating eutrophic conditions in coastal estuaries.

Temporal variability in submarine groundwater discharge on longer time scales than the seasonal studies presented in Chapters 2 through 5 is currently only addressed through hydrologic modeling. There have been several attempts to utilize coral elemental ratios as proxies for terrestrial inputs to the ocean, but these studies rely on trend-fitting techniques and correlations (Horta-Puga and Carriquiry, 2012; McCulloch et al., 2003; Prouty et al., 2009). In Chapter 6, I attempt to quantify the link between groundwater discharge, coastal ocean chemistry and coral chemistry through combined coral culture experiments, ocean chemistry observations and modeling, and a current model of coral 
elemental incorporation. The Ba to calcium $(\mathrm{Ba} / \mathrm{Ca})$ elemental record of a Siderastrea coral demonstrates good agreement with precipitation, on both yearly time scales and in response to extreme events such as hurricanes, over a twelve-year record. Thus, corals have the potential to provide multi-decadal records of submarine groundwater discharge in locations where SGD controls the Ba signature of coastal waters. I explore coral $\mathrm{Ba} / \mathrm{Ca}$ records from two additional sites where $\mathrm{Ba} / \mathrm{Ca}$ may work as an SGD proxy (North Carolina; Appendix A) and where the application does not look promising (Guam; Appendix B).

This work reveals that submarine groundwater discharge is dynamic across multiple time scales, including seasonal and interannual. There are large shifts in geochemical cycling within the subterranean estuary in concert with climatically sensitive sea level and precipitation oscillations. As a result, chemical loading to the ocean via SGD is temporally variable, such that the timing of chemical flux may amplify negative impacts on coastal ecosystems. This work provides a framework for detecting and interpreting temporal changes within the subterranean estuary and subsequent submarine groundwater discharge.

Despite the significant progress reported herein, important questions remain in this field. To further constrain SGD's role in global ocean element budgets, studies are needed in areas that have been traditionally under sampled, including fractured bedrock, shale and volcanic STEs, which may contribute up to $64 \%$ of total terrestrial SGD to the ocean (Zekster et al., 2006). Furthermore, this potential source may not be at steady state (e.g. Beck et al., 2013). Enhanced chemical loading coincident with sea level rise (Chapter 3) is likely occurring globally, however this phenomenon is currently 
unconstrained due to a lack of knowledge of SGD-derived trace element fluxes due to salt water intrusion across a wide-range of sediment types.

Our understanding of the SGD response to climate change, including impacts on both precipitation and sea level fluctuations, is evolving. To this end, future studies must ground truth numerical models with field data. At the same time, model results should inform STE sampling campaigns to best target knowledge gaps. In particular, hydrologic models predict long groundwater transit times in portions of the STE not impacted by tides and waves (Abarca et al., 2013; Michael et al., 2005). The few studies that have utilized chemical tracers of flow show much shorter residence times of this water in the STE, which is a primary driver of chemical transformation rates and therefore fluxes to receiving water bodies (Michael, 2004; Rao et al., 2012; Santos et al., 2009a).

Finally, constraining SGD rates on interannual, decadal and centennial time scales will enhance our understanding of this phenomenon. The coral SGD paleo proxy explored in this thesis may enable SGD records on such time scales in appropriate locations. However, climate fluctuations on longer time scales (e.g. glacial-interglacial) may have had a large impact on SGD chemical fluxes. Over these time scales sea level varied on the order of tens of meters (Siddall et al., 2003), repeatedly exposing and inundating the continental shelves, and by proxy the area of the subterranean estuary. Currently, we are unable to constrain the impact of sea level oscillation of this magnitude on SGD-derived chemical fluxes over such long time scales yet the process studies described herein suggest that they may be important.

The study of the subterranean estuary has evolved rapidly since Moore's seminal 1999 paper. This thesis contributes to these efforts by highlighting the important role this 
land-ocean interface plays in both the timing and delivery of nutrients, trace metals and radionuclides to the coastal ocean. Since the coastal zone experiences multiple stressors associated with population growth, structural modification and habitat loss, the study of SGD will aid in mitigating these impacts now and in the future. 


\section{References}

Abarca, E., Karam, H.N., Hemond, H.F., Harvey, C.F., 2013. Transient groundwater dynamics in a coastal aquifer: The effects of tides, the lunar cycle and the beach profile. Water Resour. Res., 10.1002/wrcr.20075.

Anderson, W.P., Emanuel, R.E., 2010. Effect of interannual climate oscillations on rates of submarine groundwater discharge. Water Resour. Res., doi: 10.1029/2009wr008212.

Basu, A.R., Jacobsen, S.B., Poreda, R.J., Dowling, C.B., Aggarwal, P.K., 2001. Large groundwater strontium flux to the oceans from the bengal basin and the marine strontium isotope record. Science 293, 1470-1473.

Beck, A.J., Charette, M.A., Cochran, J.K., Gonneea, M.E., Peucker-Ehrenbrink, B., 2013. Dissolved strontium behavior in the subterranean estuary- Implications for the Sr isotope budget of the global ocean. Geochim. Cosmochim. Acta, doi.org/10.1016/j.gca.2013.1003.1021.

Beck, A.J., Cochran, J.K., Sanudo-Wilhelmy, S.A., 2010. The distribution and speciation of dissolved trace metals in a shallow subterranean estuary. Mar. Chem. 121, 145-156.

Beck, A.J., Rapaglia, J.P., Cochran, J.K., Bokuniewicz, H.J., 2007. Radium mass-balance in Jamaica Bay, NY: Evidence for a substantial flux of submarine groundwater. Mar. Chem. 106, 419-441.

Breier, J.A., Breier, C.F., Edmonds, H.N., 2010. Seasonal dynamics of dissolved Ra isotopes in the semi-arid bays of south Texas. Mar. Chem. 122, 39-50.

Burnett, W.C., Bokuniewicz, H., Huettel, M., Moore, W.S., Taniguchi, M., 2003. Groundwater and pore water inputs to the coastal zone. Biogeochemistry 66, 3-33.

Burnett, W.C., Wattayakorn, G., Taniguchi, M., Dulaiova, H., Sojisuporn, P., Rungsupa, S., Ishitobi, T., 2007. Groundwater-derived nutrient inputs to the Upper Gulf of Thailand. Cont. Shelf Res. 27, 176-190.

Charette, M.A., 2007. Hydrologic forcing of submarine groundwater discharge: Insight from a seasonal study of radium isotopes in a groundwater-dominated salt marsh estuary. Limnol. Oceanogr. 52, 230-239.

Charette, M.A., Breier, C.F., Henderson, P.B., Pike, S.M., Rypina, II, Jayne, S.R., Buesseler, K.O., 2013. Radium-based estimates of cesium isotope transport and total direct ocean discharges from the Fukushima Nuclear Power Plant accident.

Biogeosciences 10, 2159-2167. 
Charette, M.A., Buesseler, K.O., Andrews, J.E., 2001. Utility of radium isotopes for evaluating the input and transport of groundwater-derived nitrogen to a Cape Cod estuary. Limnol. Oceanogr. 46, 465-470.

Charette, M.A., Sholkovitz, E.R., 2006. Trace element cycling in a subterranean estuary: Part 2. Geochemistry of the pore water. Geochim. Cosmochim. Acta 70, 811-826.

Charette, M.A., Sholkovitz, E.R., Hansel, C.M., 2005. Trace element cycling in a subterranean estuary: Part 1. Geochemistry of the permeable sediments. Geochim. Cosmochim. Acta 69, 2095-2109.

de Sieyes, N.R., Yamahara, K.M., Layton, B.A., Joyce, E.H., Boehm, A.B., 2008. Submarine discharge of nutrient-enriched fresh groundwater at Stinson Beach, California is enhanced during neap tides. Limnol. Oceanogr. 53, 1434-1445.

Doney, S.C., 2010. The Growing Human Footprint on Coastal and Open-Ocean Biogeochemistry. Science 328, 1512-1516.

Dulaiova, H., Gonneea, M.E., Henderson, P.B., Charette, M.A., 2008. Geochemical and physical sources of radon variation in a subterranean estuary - Implications for groundwater radon activities in submarine groundwater discharge studies. Mar. Chem. $110,120-127$.

Einsiedl, F., 2012. Sea-water/groundwater interactions along a small catchment of the European Atlantic coast. Appl. Geochem. 27, 73-80.

El-Gamal, A.A., Peterson, R.N., Burnett, W.C., 2012. Detecting Freshwater Inputs via Groundwater Discharge to Marina Lagoon, Mediterranean Coast, Egypt. Estuaries Coasts $35,1486-1499$.

Garcia-Solsona, E., Garcia-Orellana, J., Masque, P., Rodellas, V., Mejias, M., Ballesteros, B., Dominguez, J.A., 2010. Groundwater and nutrient discharge through karstic coastal springs (Castello, Spain). Biogeosciences 7, 2625-2638.

Gonneea, M.E., Morris, P.J., Dulaiova, H., Charette, M.A., 2008. New perspectives on radium behavior within a subterranean estuary. Mar. Chem. 109, 250-267.

Herrera-Silveira, J.A., Medina-Gomez, I., Colli, R., 2002. Trophic status based on nutrient concentration scales and primary producers community of tropical coastal lagoons influenced by groundwater discharges. Hydrobiologia 475, 91-98.

Horta-Puga, G., Carriquiry, J.D., 2012. Coral Ba/Ca molar ratios as a proxy of precipitation in the northern Yucatan Peninsula, Mexico. Appl. Geochem. 27, 1579-1586. 
Hu, C.M., Muller-Karger, F.E., Swarzenski, P.W., 2006. Hurricanes, submarine groundwater discharge, and Florida's red tides. Geophys. Res. Lett., doi:

$10.1029 / 2005 \mathrm{~g} 1025449$.

Jackson, J.B.C., Kirby, M.X., Berger, W.H., Bjorndal, K.A., Botsford, L.W., Bourque, B.J., Bradbury, R.H., Cooke, R., Erlandson, J., Estes, J.A., Hughes, T.P., Kidwell, S., Lange, C.B., Lenihan, H.S., Pandolfi, J.M., Peterson, C.H., Steneck, R.S., Tegner, M.J., Warner, R.R., 2001. Historical overfishing and the recent collapse of coastal ecosystems. Science 293, 629-638.

Kelly, R.P., Moran, S.B., 2002. Seasonal changes in groundwater input to a well-mixed estuary estimated using radium isotopes and implications for coastal nutrient budgets. Limnol. Oceanogr. 47, 1796-1807.

Knee, K.L., Street, J.H., Grossman, E.E., Boehm, A.B., Paytan, A., 2010. Nutrient inputs to the coastal ocean from submarine groundwater discharge in a groundwater-dominated system: Relation to land use (Kona coast, Hawaii, USA). Limnol. Oceanogr. 55, 1105 1122.

Kroeger, K.D., Charette, M.A., 2008. Nitrogen biogeochemistry of submarine groundwater discharge. Limnol. Oceanogr. 53, 1025-1039.

Lee, Y.W., Kim, G., 2007. Linking groundwater-borne nutrients and dinoflagellate redtide outbreaks in the southern sea of Korea using a Ra tracer. Estuar. Coast. Shelf Sci. 71, 309-317.

Li, H., Boufadel, M.C., Weaver, J.W., 2008. Tide-induced seawater-groundwater circulation in shallow beach aquifers. J. Hydrol. 352, 211-224.

Li, X.Y., Hu, B.X., Burnett, W.C., Santos, I.R., Chanton, J.P., 2009. Submarine Ground Water Discharge Driven by Tidal Pumping in a Heterogeneous Aquifer. Ground Water 47, 558-568.

Loveless, A.M., Oldham, C.E., 2010. Natural attenuation of nitrogen in groundwater discharging through a sandy beach. Biogeochemistry 98, 75-87.

McCulloch, M., Fallon, S., Wyndham, T., Hendy, E., Lough, J., Barnes, D., 2003. Coral record of increased sediment flux to the inner Great Barrier Reef since European settlement. Nature 421, 727-730.

Michael, H.A., Charette, M.A., Harvey, C.F., 2011. Patterns and variability of groundwater flow and radium activity at the coast: A case study from Waquoit Bay, Massachusetts. Mar. Chem. 127, 100-114.

Michael, H.A., Mulligan, A.E., Harvey, C.F., 2005. Seasonal oscillations in water exchange between aquifers and the coastal ocean. Nature 436, 1145-1148. 
Michael, H.A., 2004. Seasonal dynamics in coastal aquifers: investigations of submarine groundwater discharge through field measurements and numerical models. Doctoral thesis, Massachusetts Institute of Technology.

Moore, W.S., 1996. Large groundwater inputs to coastal waters revealed by Ra-226 enrichments. Nature 380, 612-614.

Moore, W.S., 1997. High fluxes of radium and barium from the mouth of the GangesBrahmaputra river during low river discharge suggest a large groundwater source. Earth Planet. Sci. Lett. 150, 141-150.

Moore, W.S., 1999. The subterranean estuary: a reaction zone of ground water and sea water. Mar. Chem. 65, 111-125.

Moore, W.S., 2003. Sources and fluxes of submarine groundwater discharge delineated by radium isotopes. Biogeochemistry 66, 75-93.

Moore, W.S., 2010. The Effect of Submarine Groundwater Discharge on the Ocean. Annu. Rev. Mar. Sci. 2, 59-88.

Moore, W.S., Sarmiento, J.L., Key, R.M., 2008. Submarine groundwater discharge revealed by Ra-228 distribution in the upper Atlantic Ocean. Nat. Geosci. 1, 309-311.

Moore, W.S., Shaw, T.J., 1998. Chemical signals from submarine fluid advection onto the continental shelf. J. Geophys. Res.-Oceans 103, 21543-21552.

Niencheski, L.F.H., Windom, H.L., Moore, W.S., Jahnke, R.A., 2007. Submarine groundwater discharge of nutrients to the ocean along a coastal lagoon barrier, Southern Brazil. Mar. Chem. 106, 546-561.

Paytan, A., Shellenbarger, G.G., Street, J.H., Gonneea, M.E., Davis, K., Young, M.B., Moore, W.S., 2006. Submarine groundwater discharge: An important source of new inorganic nitrogen to coral reef ecosystems. Limnol. Oceanogr. 51, 343-348.

Perry, E., Paytan, A., Pedersen, B., Velazquez-Oliman, G., 2009. Groundwater geochemistry of the Yucatan Peninsula, Mexico: Constraints on stratigraphy and hydrogeology. J. Hydrol. 367, 27-40.

Peterson, R.N., Burnett, W.C., Glenn, C.R., Johnson, A.G., 2009. Quantification of pointsource groundwater discharges to the ocean from the shoreline of the Big Island, Hawaii. Limnol. Oceanogr. 54, 890-904.

Peucker-Ehrenbrink, B., Miller, M.W., Arsouze, T., Jeandel, C., 2010. Continental bedrock and riverine fluxes of strontium and neodymium isotopes to the oceans. Geochem. Geophys. Geosyst., doi:10.1029/2009gc002869. 
Povinec, P.P., Burnett, W.C., Beck, A., Bokuniewicz, H., Charette, M., Gonneea, M.E., Groening, M., Ishitobi, T., Kontar, E., Liong Wee Kwong, L., Marie, D.E.P., Moore, W.S., Oberdorfer, J.A., Peterson, R., Ramessur, R., Rapaglia, J., Stieglitz, T., Top, Z., 2012. Isotopic, geophysical and biogeochemical investigation of submarine groundwater discharge: IAEA-UNESCO intercomparison exercise at Mauritius Island. J. Environ. Radioact. 103, 24-45.

Prouty, N.G., Jupiter, S.D., Field, M.E., McCulloch, M.T., 2009. Coral proxy record of decadal-scale reduction in base flow from Moloka'i, Hawaii. Geochem. Geophys. Geosyst., doi:Q1201810.1029/2009gc002714.

Rama, Moore, W.S., 1996. Using the radium quartet for evaluating groundwater input and water exchange in salt marshes. Geochim. Cosmochim. Acta 60, 4645-4652.

Rao, A.M.F., Charette, M.A., 2012. Benthic nitrogen fixation in an eutrophic estuary affected by groundwater discharge. J. Coast. Res., 28: 477-485.

Robinson, C., Gibbes, B., Carey, H., Li, L., 2007. Salt-freshwater dynamics in a subterranean estuary over a spring-neap tidal cycle. J. Geophys. Res.-Oceans 112.

Robinson, C., Gibbes, B., Li, L., 2006. Driving mechanisms for groundwater flow and salt transport in a subterranean estuary. Geophys. Res. Lett., doi:10.1029/2005g1025247.

Rogers, D.R., Casciotti, K.L., 2010. Abundance and Diversity of Archaeal Ammonia Oxidizers in a Coastal Groundwater System. Appl. Environ. Microbiol. 76, 7938-7948.

Saenz, J.P., Hopmans, E.C., Rogers, D., Henderson, P.B., Charette, M.A., Schouten, S., Casciotti, K.L., Damste, J.S.S., Eglinton, T.I., 2012. Distribution of anaerobic ammoniaoxidizing bacteria in a subterranean estuary. Mar. Chem. 136, 7-13.

Santoro, A.E., 2010. Microbial nitrogen cycling at the saltwater-freshwater interface. Hydrogeol. J. 18, 187-202.

Santos, I.R., Burnett, W.C., Chanton, J., Dimova, N., Peterson, R.N., 2009a. Land or ocean?: Assessing the driving forces of submarine groundwater discharge at a coastal site in the Gulf of Mexico. J. Geophys. Res.-Oceans, doi:10.1029/2008jc005038.

Santos, I.R., Burnett, W.C., Dittmar, T., Suryaputra, I., Chanton, J., 2009b. Tidal pumping drives nutrient and dissolved organic matter dynamics in a Gulf of Mexico subterranean estuary. Geochim. Cosmochim. Acta 73, 1325-1339.

Santos, I.R., Burnett, W.C., Misra, S., Suryaputra, I.G.N.A., Chanton, J.P., Dittmar, T., Peterson, R.N., Swarzenski, P.W., 2011. Uranium and barium cycling in a salt wedge subterranean estuary: The influence of tidal pumping. Chemical Geology 287, 114-123. 
Santos, I.R., de Weys, J., Tait, D.R., Eyre, B.D., 2013. The Contribution of Groundwater Discharge to Nutrient Exports from a Coastal Catchment: Post-Flood Seepage Increases Estuarine N/P Ratios. Estuaries Coasts 36, 56-73.

Santos, I.R., Dimova, N., Peterson, R.N., Mwashote, B., Chanton, J., Burnett, W.C., 2009c. Extended time series measurements of submarine groundwater discharge tracers (Rn-222 and CH4) at a coastal site in Florida. Mar. Chem. 113, 137-147.

Santos, I.R., Eyre, B.D., Glud, R.N., 2012. Influence of porewater advection on denitrification in carbonate sands: Evidence from repacked sediment column experiments. Geochim. Cosmochim. Acta 96, 247-258.

Siddall, M., Rohling, E.J., Almogi-Labin, A., Hemleben, Ch., Meischner, D., Schmelzer, I., Smeed, D.A., 2003. Sea-level fluctuations during the last glacial cycle. Nature, 423:853-858.

Slomp, C.P., Van Cappellen, P., 2004. Nutrient inputs to the coastal ocean through submarine groundwater discharge: controls and potential impact. J. Hydrol. 295, 64-86.

Spiteri, C., Regnier, P., Slomp, C.P., Charette, M.A., 2006. pH-Dependent iron oxide precipitation in a subterranean estuary. J. Geochem. Explor. 88, 399-403.

Spiteri, C., Slomp, C.P., Charette, M.A., Tuncay, K., Meile, C., 2008. Flow and nutrient dynamics in a subterranean estuary (Waquoit Bay, MA, USA): Field data and reactive transport modeling. Geochim. Cosmochim. Acta 72, 3398-3412.

Uemura, T., Taniguchi, M., Shibuya, K., 2011. Submarine groundwater discharge in Lutzow-Holm Bay, Antarctica. Geophys. Res. Lett., doi:10.1029/2010gl046394.

Valiela, I., Foreman, K., Lamontagne, M., Hersh, D., Costa, J., Peckol, P., Demeoandreson, B., Davanzo, C., Babione, M., Sham, C.H., Brawley, J., Lajtha, K., 1992. Couplings of watersheds and coastal waters - sources and consequences of nutrient enrichment in Waquoit Bay, Massachusetts Estuaries 15, 443-457.

Waycott, M., Duarte, C.M., Carruthers, T.J.B., Orth, R.J., Dennison, W.C., Olyarnik, S., Calladine, A., Fourqurean, J.W., Heck, K.L., Hughes, A.R., Kendrick, G.A., Kenworthy, W.J., Short, F.T., Williams, S.L., 2009. Accelerating loss of seagrasses across the globe threatens coastal ecosystems. Proceedings of the National Academy of Sciences 106, 12377-12381.

Webster, I.T., Hancock, G.J., Murray, A.S., 1995. Modeling the effect of salinity on radium desorption from sediments. Geochim. Cosmochim. Acta 59, 2469-2476.

Weinstein, Y., Yechieli, Y., Shalem, Y., Burnett, W.C., Swarzenski, P.W., Herut, B., 2011. What Is the Role of Fresh Groundwater and Recirculated Seawater in Conveying Nutrients to the Coastal Ocean? Environ. Sci. Technol. 45, 5195-5200. 
Windom, H.L., Moore, W.S., Niencheski, L.F.H., Jahrike, R.A., 2006. Submarine groundwater discharge: A large, previously unrecognized source of dissolved iron to the South Atlantic Ocean. Mar. Chem. 102, 252-266.

Xin, P., Robinson, C., Li, L., Barry, D.A., Bakhtyar, R., 2010. Effects of wave forcing on a subterranean estuary. Water Resour. Res., doi:10.1029/201wr009632.

Zekster, I.S., Everett, L.G., Dzhamalov, R.G., 2006. Submarine Groundwater. CRC Press, p. 466. 


\section{Chapter 2:}

\section{Climate-driven sea level anomalies modulate coastal groundwater dynamics and discharge}

This chapter was originally published in Geophysical Research Letters by John Wiley \& Sons and the American Geophysical Union and is reprinted here with their permission.

Climate-driven sea level anomalies modulate coastal groundwater dynamics and discharge. Geophysical Research Letters. M.E. Gonneea, A.E. Mulligan and M.A. Charette. 2013. doi: 10.1002/grl.50192. 


\title{
Climate-driven sea level anomalies modulate coastal groundwater dynamics and discharge
}

\author{
Meagan Eagle Gonneea, ${ }^{1}$ Ann E. Mulligan, ${ }^{2}$ and Matthew A. Charette ${ }^{1}$ \\ Received 11 January 2013; revised 18 January 2013; accepted 22 January 2013.
}

[1] To better understand the physical drivers of submarine groundwater discharge (SGD) in the coastal ocean, we conducted a detailed field and modeling study within an unconfined coastal aquifer system. We monitored the hydraulic gradient across the coastal aquifer and movement of the mixing zone over multiple years. At our study site, sea level dominated over groundwater head as the largest contributor to variability in the hydraulic gradient and therefore SGD. Model results indicate the seawater recirculation component of SGD was enhanced during summer while the terrestrial component dominated during winter due to seasonal changes in sea level driven by a combination of long period solar tides, temperature and winds. In one year, sea level remained elevated year round due to a combination of ENSO and NAO climate modes. Hence, predicted changes in regional climate variability driven sea level may impact future rates of SGD and biogeochemical cycling within coastal aquifers. Citation: Gonneea, M. E., A. E. Mulligan, and M. A. Charette (2013), Climate-driven sea level anomalies modulate coastal groundwater dynamics and discharge, Geophys. Res. Lett., 40 doi:10.1002/grl.50192.

\section{Introduction}

[2] Unconfined coastal aquifers contain two interacting water masses: terrestrial and marine groundwater [Moore, 1999]. The former is supplied by inland recharge and overlies a salt wedge comprised of marine groundwater, with dispersive mixing occurring at the interface [Cooper, 1959] (Fig. 1). In addition, an upper saline plume associated with tidal and wave driven circulation occurs in the shallow intertidal region [Li et al., 2008; Li et al., 2009; Robinson et al., 2007; Xin et al., 2010]. Circulation and surface water exchange within these systems is driven by the hydraulic gradient between the aquifer and sea level (i.e $d h / d l=\left(h_{g}-h_{s}\right) / l$, where $h_{g}$ is the groundwater hydraulic head, $h_{s}$ is sea level, both corrected for variable density according to Post et al., 2007, and $l$ is the horizontal distance over which the gradient is calculated) [Michael et al., 2005; Mulligan and Charette, 2006; Robinson et al., 2006].

[3] In many locations, groundwater discharge across the ocean-aquifer interface represents a significant water flux

\footnotetext{
Additional supporting information may be found in the online version of this article.

${ }^{1}$ Department of Marine Chemistry and Geochemistry, Woods Hole Oceanographic Institution, Woods Hole, Massachusetts, USA.

${ }^{2}$ Marine Policy Center, Woods Hole Oceanographic Institution, Woods Hole, Massachusetts, USA

Corresponding author: M. A. Charette, Department of Marine Chemistry and Geochemistry, Woods Hole Oceanographic Institution, Woods Hole, MA, USA. (mcharette@whoi.edu)

C2013. American Geophysical Union. All Rights Reserved. 0094-8276/13/10.1002/grl.50192
}

carrying terrestrially-derived dissolved constituents [Moore, 2010]. However, uncertainty remains concerning the total water and chemical flux via SGD on local to global scales, due in part to the presence of hydrodynamically complex and chemically dynamic coastal aquifers where sharp redox and salinity gradients lead to active biogeochemical cycling of nutrients [Kroeger and Charette, 2008; Slomp and Van Cappellen, 2004], trace metals [Beck et al., 2007; Charette and Sholkovitz, 2006; Gonneea et al., 2008; Santos et al., 2011] and anthropogenically-sourced contaminants [Bone et al., 2006; Bone et al., 2007; Lee et al., 2011]. Field studies and hydrologic modeling of coastal aquifers have largely focused on flow driven by short-time scale tides and waves, while little is known about the spatial and temporal response of the deeper mixing zone (hereafter referred to as the "mixing zone") to hydraulic gradient perturbations caused by groundwater and sea level oscillations.

[4] To address this dearth of knowledge, we established a time series within a coastal aquifer mixing zone between terrestrial and marine groundwater to observe changes in regional scale mixing over multiple years. To do this we monitored groundwater salinity within the coastal aquifer concurrently with groundwater levels at various distances inland and sea level. The goal of this study was to observe how the mixing zone of the coastal aquifer responded to terrestrial and marine forcings on monthly to interannual time scales. Lastly, we utilized a hydrologic model to simulate mixing within the coastal aquifer and subsequent groundwater discharge to the ocean either driven by terrestrial or terrestrial plus marine forcing over these same time scales.

\section{Methods and Study Site}

[5] Waquoit Bay is a shallow estuary on the southern shore of Cape Cod, MA, USA. Within the coastal aquifer there is a well-defined region of mixing between terrestrial and marine groundwater (Figs. 1 and S1 and supporting information). A variety of chemical processes, including ion exchange (adsorption/desorption reactions) and redox cycling, are active within the salinity interface [Charette and Sholkovitz, 2006]. A series of wells with a $2.5 \mathrm{~cm}$ screened interval were installed at eight depths across the mixing zone of the coastal aquifer ranging from 2.2 to $5.2 \mathrm{~m}$ below mean sea level (MSL) (Fig. 1). Salinity was sampled every month from Oct. 2004 to Oct. 2007 and June 2009 to June 2010 during the same tidal cycle and phase ( 4 hours past high tide, $\sim 3$ days before the monthly spring tide) to reduce the potential variability associated with tidal fluctuations (which we determined to be minimal based on an hourly time series over the course of a falling tide, Fig. S2). Salinity samples were collected after pumping approximately $1 \mathrm{~L}$ (6 to 13 well volumes) and measured with a Guideline AutoSal instrument. Groundwater levels 


\section{GONNEEA ET AL.: COASTAL GROUNDWATER DYNAMICS AND SEA LEVEL}

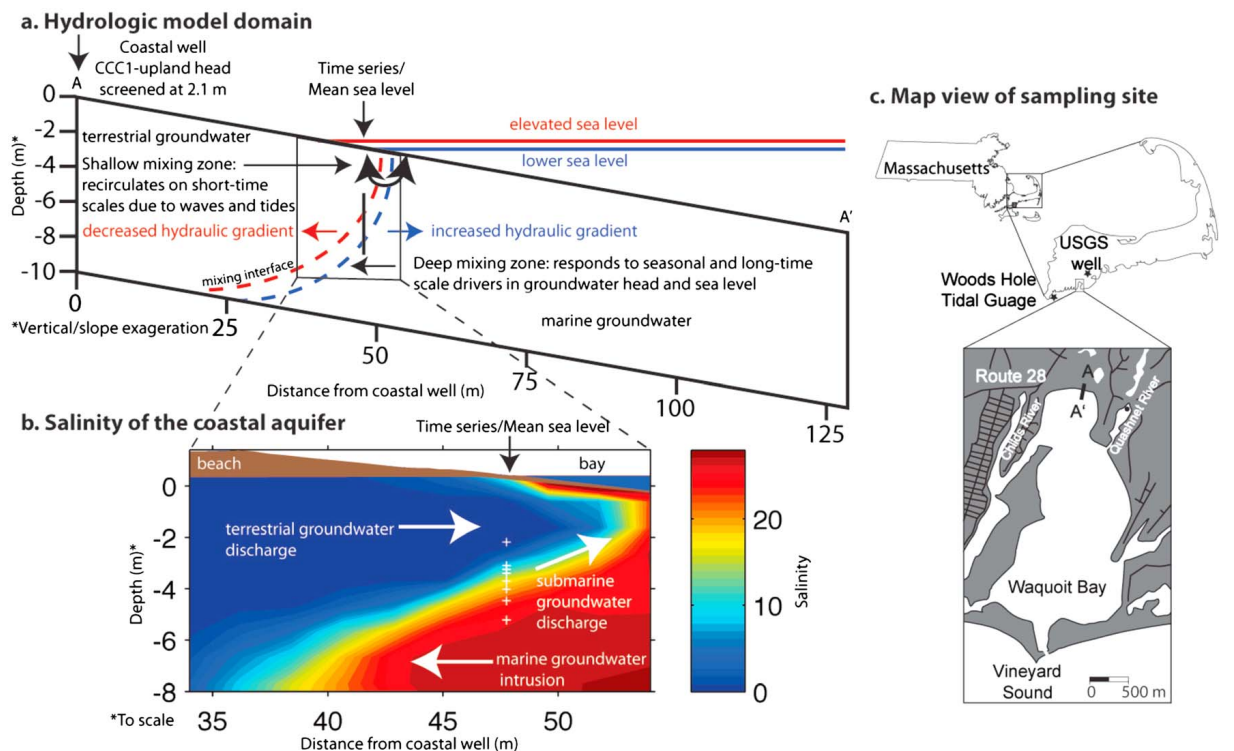

Figure 1. Hydrologic model domain and salinity cross-section of the Waquoit Bay coastal aquifer, Cape Cod, MA, USA in June 2004. The hydrologic model (a) extends from the coastal well seaward $130 \mathrm{~m}$. In June 2004, a 2-D transect of the coastal aquifer (b) revealed that terrestrial groundwater overlaid marine groundwater, with the mixing region between the two marked by dynamic chemical alteration of groundwater discharging to the coastal ocean. Seasonal movement of the deep interface between terrestrial and marine groundwater was monitored monthly in wells 2.2 to $5.2 \mathrm{~m}$ below MSL (black line in (a) and white crosses in (b)) placed below the depth of shallow mixing induced by tidal and wave influence. The hydraulic gradient was calculated between $\mathrm{CCC} 1$ (screened at $2.1 \mathrm{~m}$ ) and the location of MSL. Map overview of study site is shown in (c). Note vertical/slope exaggeration in (a).

were monitored at a nearshore well (CCC1; $46 \mathrm{~m}$ from MSL) and averaged over the monthly sampling resolution of the salinity time series; monthly measurements were made of inland groundwater levels (USGS \#413525070291904; $10 \mathrm{~km}$ from MSL). Sea level was measured at NOAA's Woods Hole sea level station (\#8447930) and monthly average sea level anomaly is used here for comparison with time series data.

[6] We utilized a numerical simulation model constructed with the USGS SEAWAT code [Langevin et al., 2008] that was designed to represent conditions within coastal permeable sand aquifers such as at Waquoit Bay. This model is a 2D vertical cross-section that simulates an unconfined aquifer and variable-density flow with vertical and horizontal gradients with additional details available in Mulligan et al., 2011. The simulator was not fully calibrated to field data because the intent was not to exactly reproduce the full salinity time series but rather to simulate the effect of sea level on SGD from a typical unconfined coastal aquifer. The simulation model is a two-dimensional cross section of a homogeneous unconfined aquifer below a sloping beach $(0.08 \mathrm{~m} / \mathrm{m})$ where the simulated domain measures $130 \mathrm{~m}$ long and $10 \mathrm{~m}$ deep. No recharge was simulated and therefore a no flow condition was applied along the top boundary on the landward side, as well as along the bottom and seaward edge of the domain. General heads and drains are used to represent the top boundary on the bay side. Transport boundary conditions were restricted to relative concentrations of $\mathrm{C}=1$ (density of $1024 \mathrm{~kg} \mathrm{~m}^{-3}$ ) within the bay and $\mathrm{C}=0$ (density of $999 \mathrm{~kg} \mathrm{~m}^{-3}$ ) for terrestrial groundwater. Mixing between these waters results in variable density flow. The head at the upland boundary was allowed to vary according to the measured record at the nearshore monitoring well (CCC1); head data from different depths within the surficial aquifer at this location indicate there is no vertical gradient. The marine boundary was simulated in one of two ways: as a constant value of mean sea level $(0 \mathrm{~m})$, or using average monthly sea level from NOAA's Woods Hole tidal station (data available at http://tidesandcurrents.noaa.gov) Within each 15-day stress period, tidal and upland boundary conditions remain constant, but these values can vary from one stress period to the next. Due to computational demand, neither model incorporated short-time scale sea level oscillations (i.e. tides). Groundwater discharge to the ocean and marine water intrusion into the aquifer were calculated across the entire model domain. Simulations were established to run for the equivalent of Jan. 2005 to June 2007.

\section{Results}

[7] At this site, over an average seasonal cycle, sea level is at a minimum during winter and maximum during summer/ fall due to both the annual solar tide component and thermosteric sea level variability resulting from seasonal temperature and wind dynamics [Tsimplis and Woodworth, 1994] (Fig. S4). The period from 2009-2010 was marked by a positive sea level anomaly, whereby sea level was elevated for an entire year, without the typical winter low 


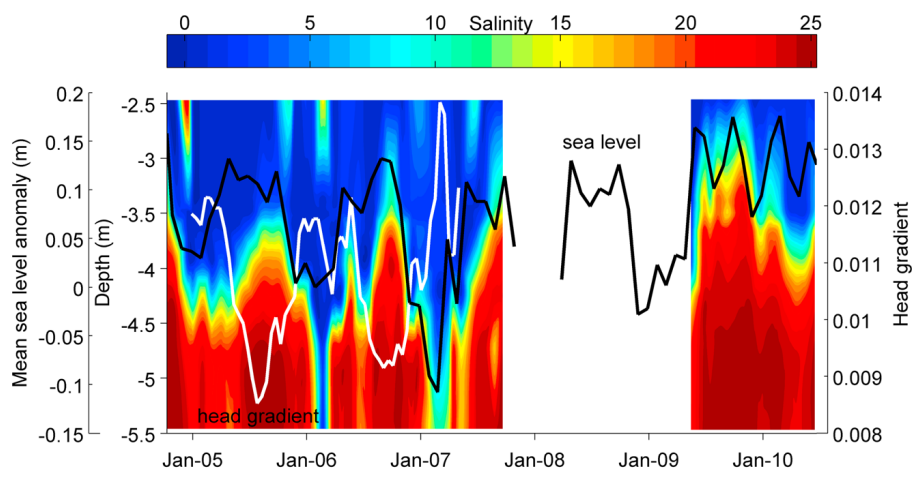

Figure 2. Salinity, the corresponding head gradient of the coastal aquifer and the mean sea level anomaly. The salinity peaks in the summer from 2004 to 2007, however it remains elevated from June 2009 through June 2010 (no data between Nov. 2007 and May 2009). The coastal hydraulic gradient (white line, right axis) was calculated between the coastal well groundwater level (CCC1) and sea level (black line, left most axis) corrected for variable density. Salinity excursions within the upper fresh portion of the aquifer $(<2.5 \mathrm{~m})$ were observed periodically and likely resulted from infiltration of bay water due to tidal and wave pumping. Data contoured with a MATLAB cubic interpolation.

sea level. In Waquoit Bay, coastal groundwater levels did not display a consistent seasonal signal from 2004-07. The amplitude of variability in coastal groundwater levels $(10 \mathrm{~cm}$, Fig. S3b) was smaller than the seasonal sea level anomaly $(20 \mathrm{~cm}$, Fig. S3c). Since head gradient is calculated as the difference between groundwater and sea level, adjusted for variable density, if one of these varies to a greater degree than the other, it is possible for that parameter to have a disproportionate control on the magnitude of the head gradient. A time series cross correlation between hydraulic gradient and sea level, coastal and inland groundwater levels (for 2004-07) revealed that the highest correlation with sea level $(\mathrm{r}=-0.66 ; 95 \%$ confidence level) occurred at zero lag. In contrast, coastal groundwater levels were not significantly correlated to the hydraulic gradient (Fig. S5).

[8] The position of the mixing zone in the coastal aquifer was monitored for 4 years (Fig. 1). The monitoring wells were ideally positioned to capture vertical and lateral movement of the mixing zone, since the slope of the mixing zone boundary at this location is stable (Fig. S1). In addition, the salinity of the monitoring wells did not respond to changes in sea level driven by tides (Fig. S2). Hence, we expect the wells to capture movement of the mixing zone in response to changes in the hydraulic gradient on longer time scales (greater than hours).

[9] The mixing zone oscillated vertically between high and low salinity with a period of approximately one year for the first three years of measurement (Fig. 2). Landward intrusion of marine groundwater typically occurred in the summer and fall, with the exception of the period between June 2009 and June 2010, when salinity remained elevated year-round signaling a prolonged intrusion of marine groundwater. To better understand the mechanisms driving seasonal mixing dynamics in the coastal aquifer, we performed a time series cross correlation of groundwater salinity and: (1) the coastal hydraulic gradient, (2) groundwater head $46 \mathrm{~m}$ inland of MSL (CCC1), (3) groundwater head $10 \mathrm{~km}$ inland of MSL (USGS well) and (4) local MSL (Fig. S7). We found that the maximum correlation between salinity and both hydraulic gradient $(r=-0.49)$ and sea level $(r=0.56)$ occurred at zero lag. An increase in hydraulic gradient will lead to a decrease in salinity, thus be negatively correlated, while an increase in sea level should lower the hydraulic gradient and increase salinity, leading to a positive correlation. Notably, there was no significant correlation between coastal ( $46 \mathrm{~m}$ from MSL) groundwater head and salinity (Fig. S7). Rather, the salinity of the mixing zone was negatively correlated with inland groundwater levels $(\mathrm{r}=-0.54)$ with a 60 -day lag. Based on this analysis, we suggest that the position of the mixing zone responds on time scales of days to weeks to sea level fluctuations and is largely controlled by the amplitude of seasonal sea level oscillations.

[10] To explore the potential impact of sea level on groundwater flow to the ocean, we constructed a numerical model of groundwater flow and salt transport in an unconfined coastal aquifer using the USGS code SEAWAT [Langevin et al., 2008; Mulligan et al., 2011]; we used the model to run two separate simulations. In the first simulation, the marine boundary was held constant at MSL, while in the second the marine boundary was specified as the monthly average sea level from the Woods Hole tidal gauge. In both simulations, the monthly average head data from a coastal well (CCC1, Fig. 1) was used as the transient upland fresh water boundary. The choice of these two simulations allows us to separate and evaluate the effects of oscillating groundwater head and sea level on both mixing in the coastal aquifer and subsequent groundwater discharge.

[11] In the simulation with static sea level, the salinity of SGD was low and there was minimal temporal variability in the fluid flux (Fig. 3a). In the simulation that incorporated the observed sea level record, there was a dynamic seasonal response in both the magnitude and salinity of SGD due mainly to a wider range in the hydraulic gradient (Fig. 3b). Total SGD (terrestrial plus marine groundwater) peaked in summer/fall, as previously observed [Michael et al., 2003, 2005], while the terrestrial component was greatest in the winter. One of the most striking differences between the two models was the amount of marine groundwater intrusion 

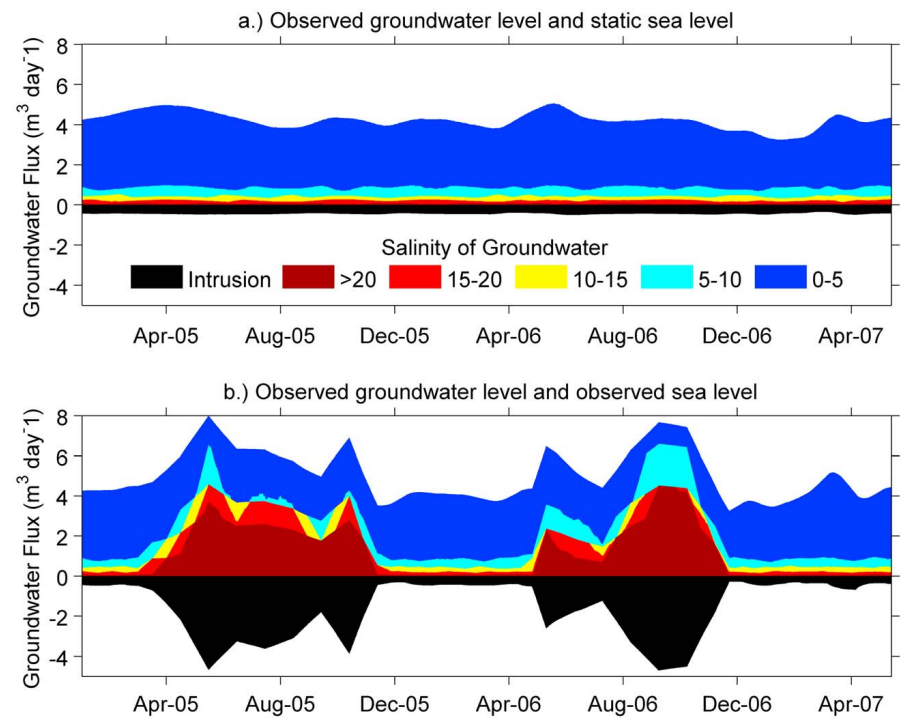

Figure 3. Hydrodynamic models of groundwater discharge and salinity across a sandy coastal aquifer. The groundwater discharge results were integrated over the $130 \mathrm{~m}$ study domain and binned into five different groups based on the salinity of the discharging water (represented by separate colors) and intrusion of bay water into the aquifer (black). The width of each color corresponds to the fraction of total SGD within each salinity range. The upland freshwater boundary in both models is the groundwater level at CCC1, $46 \mathrm{~m}$ from mean sea level. The marine boundary in (a) is static while in (b) the marine boundary was driven by the Woods Hole sea level record. The magnitude of fresh discharge was similar between the two models; however allowing the marine boundary to vary with sea level induced greater intrusion of marine groundwater. This led to increased mixing between terrestrial and marine groundwater and discharge of this mixed salinity water. In the model with the observed sea level record, total SGD peaked in summer and fall, while terrestrial SGD peaked during winter and spring, when there was relatively less marine SGD.

and subsequent mixing and discharge that occurred once the hydraulic gradient included variability in sea level. Marine groundwater cycled rapidly through the coastal aquifer, resulting in minimal lag between intrusion and discharge with enhanced mixing between terrestrial and marine groundwater.

\section{Discussion}

[12] In Waquoit Bay, the salinity distribution of the coastal aquifer can be directly attributed to changes in the monthly-averaged hydraulic gradient between the nearshore groundwater head and sea level. An increase in hydraulic gradient led to an overall seaward movement of the interface, resulting in lower salinity groundwater, while a decrease in gradient led to landward movement of the interface and higher salinity groundwater at this location. Previously, oscillations in inland groundwater levels driven by groundwater recharge were proposed to drive fluctuations of the hydraulic gradient across the coastal aquifer on seasonal time scales [Anderson and Emanuel, 2008; 2010; Michael et al., 2005].

[13] Throughout the four-year record, positive sea level anomalies coincided with periods of high salinity within the aquifer (Fig. 2). In 2009 to 2010, the sea level anomaly was positive and the seasonal signal was dampened resulting in prolonged marine groundwater intrusion for over a year. This positive sea level anomaly was observed at tide gauges from Maine to New York (Fig. S4a), thus had the potential to impact coastal groundwater dynamics on a regional scale [Sweet and Zervas, 2011]. While we did not measure groundwater head at the coast during this period, the response of the mixing zone is consistent with sea level as the dominant forcing of the hydraulic gradient. The hydraulic gradient in turn modulates SGD from unconfined aquifers as observed in the simulations. Given these results, in regions similar to Waquoit Bay (low relief, sandy unconfined aquifer), the future hydrologic response of coastal aquifers may be dependent on the sensitivity of sea level to climate change. The U.S. East Coast average annual sea level cycle results in a winter minimum and summer/fall maximum with tidal stations along the entire U.S. East Coast demonstrating coherent sea level records (Fig. S4a). The yearly period of this signal is in phase with the solar annual tidal component for the 2004-2008 portion of the record (Fig. S3b), though the actual mean sea level was higher than the predicted long period component, and the periodicity broke down during 2009-2010.

[14] This deviation from a seasonal cycle and recent trends in sea level increase have been attributed in part to changes in the North Atlantic Oscillation (NAO) [Llovel et al., 2011] and El Niño Southern Oscillation (ENSO) [Sweet and Zervas, 2011] through changes in sea surface temperatures and wind intensity and direction. El Niño and the NAO are naturally occurring modes of atmospheric variability that can affect ocean heat content, circulation, and salinity [Hurrell and 
Deser, 2009; Kolker and Hameed, 2007]. The location and intensity of these atmospheric centers of action vary on seasonal and interannual time scales [Hurrell and Deser, 2009]. Sweet and Zervas, 2011 suggest that our 2009 to 2010 record overlapped with a very strong El Niño phase of ENSO, which was marked by increased northeasterly winds over the Gulf of Maine region, leading to increased coastal set up resulting in elevated positive sea level anomalies. During the same time period, the phase of the NAO, which is anti-correlated to sea level in this region, was negative [Kolker and Hameed, 2007; Llovel et al., 2011]. In a cross correlation regression between Woods Hole MSL and the NAO index for the past 30 years (1980-2011), the highest correlation $(r=0.46)$ occurs at zero lag (Fig. S8). On decadal time scales, shifts in the position and intensity of Atlantic atmospheric high and low pressure regions which define the NAO account for $63 \%$ of annual mean sea level variability [Kolker and Hameed, 2007].

[15] Since the mixing zone moves in response to sea level changes, processes capable of influencing sea level over time scales of weeks or greater (e.g. the annual tidal component or sustained winter storms [Wilson et al., 2011]) have the potential to directly impact chemical cycling within the mixing zone of unconfined coastal aquifers and subsequent chemical loading to the coastal ocean. Mixing between terrestrial and marine groundwater within coastal aquifers results in large geochemical gradients in oxygen, nutrients and trace metals. Oscillation of the saltwater interface will result in movement of redox and ion exchange boundaries within the coastal aquifer [Santos et al., 2011]. Redox sensitive elements such as iron and manganese [Charette and Sholkovitz, 2006], and contaminant metals such as mercury [Bone et al., 2007] and copper [Beck et al., 2010], will tend to migrate with the movement of the interface, which can result in either net storage or release of these elements from aquifer sediments and therefore can influence their impact on receiving water bodies.

[16] To this end, the seasonally variable magnitude and salinity of SGD predicted by the hydrologic model will affect both the magnitude and timing of chemical loading associated with SGD. Our results now provide a driving mechanism for previous studies that reported maximum SGD and associated nutrient flux rates in the summer [Kelly and Moran, 2002; Moore and Shaw, 2008], a paradoxical observation since at that time groundwater elevation is typically at a minimum. These sites (Rhode Island and the South Atlantic Bight) experience a similar annual sea level cycle, with high sea level during the summer. Furthermore, our findings have implications for biogeochemical processes within the coastal aquifer, which have been shown to modulate input of terrestrial nitrogen to the coastal ocean [Kroeger and Charette, 2008]. For example, the model predicts enhanced mixing between terrestrial and marine groundwater during summer months (Fig. 3), which may lead to greater removal of fixed nitrogen prior to discharge via increased denitrification. Thus, sea level driven biogeochemical processes within coastal aquifers may alleviate some nitrogen loading during summer months when the eutrophication-related ecosystem impacts are at their peak. Conversely, enhanced flux of terrestrial groundwater during the winter may result in greater export of nitrogen to the open ocean, allowing fixed nitrogen to transit coastal aquifers and estuaries at a time when near shore surface water removal processes are minimal [Salisbury et al., 2008]. This flux of nutrients may help to fuel spring blooms over the continental shelf [Townsend, 1998].

\section{Conclusions}

[17] Our results provide a conclusive link between largescale climate mode forcing (ENSO/NAO) of sea level and both submarine groundwater discharge and biogeochemical cycling within unconfined coastal aquifers such as at Waquoit Bay. Changes in sea level lead to movement of the saltwater interface and directly affect model-predicted mixing between terrestrial and marine groundwater within the coastal aquifer. Furthermore, sustained positive sea level anomalies [Sallenger et al., 2012; Yin et al., 2009] will lead to significant saltwater intrusion into fresh aquifers, with the potential for dramatic impacts on the fresh water reserves of coastal communities. With predicted future increases in regional climate variability, these findings have important implications for the role of submarine groundwater discharge and coastal aquifer biogeochemical cycling in water resource management and coastal marine ecology.

[18] Acknowledgments. The authors thank Paul Henderson, Crystal Breier and Qian Liu for assistance with the Waquoit Bay time series study. Glen Gawarkiewicz provided insight on the influence of climate on sea level along the U.S. East Coast. This work is a result of research sponsored by along the U.S. East Coast. This work is a result of research sponsored by
the NSF Chemical Oceanography program (OCE- 0425061 to M.C. and the NSF Chemical Oceanography program (OCE- 0425061 to M.C. and
A.M. and OCE- 0751525 to M.C.) and an NDSEG graduate fellowship (to M.G.). This research was conducted in the National Estuarine Reserve System under an award (to M.G.) from the Estuarine Reserves Division, Office of Ocean and Coastal Resource Management, National Ocean Service, National Oceanic and Atmospheric Administration.

\section{References}

Anderson, W. P., and R. E. Emanuel (2008), Effect of interannual and interdecadal climate oscillations on groundwater in North Carolina, Geophys. Res. Lett., 35(23), doi: 10.1029/2008g1036054.

Anderson, W. P., and R. E. Emanuel (2010), Effect of interannual climate oscillations on rates of submarine groundwater discharge, Water Resour. Res., 46, doi: 10.1029/2009wr008212.

Beck, A. J., J. K. Cochran, and S. A. Sanudo-Wilhelmy (2010), The distribution and speciation of dissolved trace metals in a shallow subterranean estuary, Mar. Chem., 121(1-4), 145-156.

Beck, A. J., Y. Tsukamoto, A. Tovar-Sanchez, M. Huerta-Diaz, H. J. Bokuniewicz, and S. A. Sanudo-Wilhelmy (2007), Importance of geochemical transformations in determining submarine groundwater discharge-derived trace metal and nutrient fluxes, Appl. Geochem., 22(2), 477-490.

Bone, S. E., M. E. Gonneea, and M. A. Charette (2006), Geochemical cycling of arsenic in a coastal aquifer, Environ. Sci. Technol., 40(10), 3273-3278. Bone, S. E., M. A. Charette, C. H. Lamborg, and M. E. Gonneea (2007), Has submarine groundwater discharge been overlooked as a source of mercury to coastal waters?, Environ. Sci. Technol., 41(9), 3090-3095.

Charette, M. A., and E. R. Sholkovitz (2006), Trace element cycling in a subterranean estuary: Part 2. Geochemistry of the pore water, Geochim. Cosmochim. Acta, 70(4), 811-826.

Cooper, H. H. (1959), A hypothesis concerning the dynamic balance of fresh water and salt water in a coastal aquifer, J. of Geophys.l Res. 64 , 461-467.

Gonneea, M. E., P. J. Morris, H. Dulaiova, and M. A. Charette (2008), New perspectives on radium behavior within a subterranean estuary, Mar. Chem., 109(3-4), 250-267.

Hurrell, J. W., and C. Deser (2009), North Atlantic climate variability: The role of the North Atlantic Oscillation, J. Mar. Syst., 78(1), 28-41.

Kelly, R. P., and S. B. Moran (2002), Seasonal changes in groundwater input to a well-mixed estuary estimated using radium isotopes and implications for coastal nutrient budgets, Limnol. Oceanogr., 47(6), 1796-1807.

Kolker, A. S., and S. Hameed (2007), Meteorologically driven trends in sea level rise, Geophys. Res. Lett., 34(23), doi:10.1029/2007gl031814.

Kroeger, K. D., and M. A. Charette (2008), Nitrogen biogeochemistry of submarine groundwater discharge, Limnol. Oceanogr., 53(3), 1025-1039. 


\section{GONNEEA ET AL.: COASTAL GROUNDWATER DYNAMICS AND SEA LEVEL}

Langevin, C. D., D. T. T Jr., A. M. Daussman, M. C. Sukop, and W. Guo (2008), SEAWAT Version 4: A computer program for simulation of multi-species solute and heat transport, in U. S. Geological Survey Techniques and Methods Book 6, edited, p. 39.

Lee, Y. G., M. Rahman, G. Kim, and S. Han (2011), Mass Balance of Tota Mercury and Monomethylmercury in Coastal Embayments of a Volcanic Island: Significance of Submarine Groundwater Discharge, Environ. Sci Technol., 45(23), 9891-9900.

Li, H., M. C. Boufadel, and J. W. Weaver (2008), Tide-induced seawater-groundwater circulation in shallow beach aquifers, J. Hydrol., 352(1-2), 211-224.

Li, X. Y., B. X. Hu, W. C. Burnett, I. R. Santos, and J. P. Chanton (2009), Submarine Ground Water Discharge Driven by Tidal Pumping in Heterogeneous Aquifer, Ground Water, 47(4), 558-568.

Llovel, W., B. Meyssignac, and A. Cazenave (2011), Steric sea leve variations over 2004-2010 as a function of region and depth: Inference on the mass component variability in the North Atlantic Ocean, Geophys. Res. Lett., 38, doi: 10.1029/2011g1047411.

Michael, H. A., J. S. Lubetsky, and C. F. Harvey (2003), Characterizing submarine groundwater discharge: a seepage meter study in Waquoit Bay, Massachusetts, Geophys. Res. Lett., 30(6), doi:10.1029/2002gl016000.

Michael, H. A., A. E. Mulligan, and C. F. Harvey (2005), Seasonal oscillations in water exchange between aquifers and the coastal ocean, Nature, 436(7054), 1145-1148

Moore, W. S. (1999), The subterranean estuary: a reaction zone of ground water and sea water, Mar. Chem., 65(1-2), 111-125.

Moore, W. S., and T. J. Shaw (2008), Fluxes and behavior of radium isotopes, barium, and uranium in seven Southeastern US rivers and estuaries, Mar. Chem., 108(3-4), 236-254.

Moore, W. S. (2010), The Effect of Submarine Groundwater Discharge on the Ocean, Annu. Rev. Mar. Sci., 2, 59-88.

Mulligan, A. E., and M. A. Charette (2006), Intercomparison of submarine groundwater discharge estimates from a sandy unconfined aquifer, J. Hydrol., 327(3-4), 411-425.

Mulligan, A. E., C. Langevin, and V. E. A. Post (2011), Tidal Boundary Conditions in SEAWAT, Ground Water, 49(6), 866-879.

Post, V., H. Kooi and C. Simmons (2007), Using hydraulic head measurements in variable-density ground water flow analyses, Ground Water, 45, doi:10.1111/j.1745-6584.2007.00339.x.
Robinson, C., B. Gibbes, and L. Li (2006), Driving mechanisms for groundwater flow and salt transport in a subterranean estuary, Geophys. Res. Lett., 33(3), doi: 10.1029/2005g1025247.

Robinson, C., L. Li, and D. A. Barry (2007), Effect of tidal forcing on subterranean estuary, Adv. Water Resour., 30(4), 851-865.

Salisbury, J. E., D. Vandemark, C. W. Hunt, J. W. Campbell, W. R. McGillis, and W. H. McDowell (2008), Seasonal observations of surface water in two Gulf of Maine estuary-plume systems: Relationships between watershed attributes, optical measurements and surface pCO(2), Estuar. Coast. Shelf Sci., 77(2), 245-252.

Sallenger, A. H., K. S. Doran, and P. A. Howd (2012), Hotspot of accelerated sea-level rise on the Atlantic coast of North America, Nat. Clim. Change, doi: $10.1038 /$ nclimate1597.

Santos, I. R., W. C. Burnett, S. Misra, I. G. N. A. Suryaputra, J. P. Chanton, T. Dittmar, R. N. Peterson, and P. W. Swarzenski (2011), Uranium and barium cycling in a salt wedge subterranean estuary: The influence of tidal pumping, Chem. Geol., 287(1-2), 114-123.

Slomp, C. P., and P. Van Cappellen (2004), Nutrient inputs to the coastal ocean through submarine groundwater discharge: controls and potential impact, J. Hydrol., 295(1-4), 64-86.

Sweet, W. V., and C. Zervas (2011), Cool-Season Sea Level Anomalies and Storm Surges along the U.S. East Coast: Climatology and Comparison with the 2009/10 El Nino, Mon. Weather Rev., 139(7), 2290-2299.

Townsend, D. W. (1998), Sources and cycling of nitrogen in the Gulf of Maine, J. Mar. Syst., 16(3-4), 283-295.

Tsimplis, M. N., and P. L. Woodworth (1994), The global distribution of the seasonal sea-level cycle calculated from coastal tide-gauge data, J. Geophys. Res.-Oceans, 99(C8), 16031-16039.

Wilson, A. M., W. S. Moore, S. B. Joye, J. L. Anderson, and C. A. Schutte (2011), Storm-driven groundwater flow in a salt marsh, Water Resour Res., 47.

Xin, P., C. Robinson, L. Li, D. A. Barry, and R. Bakhtyar (2010), Effects of wave forcing on a subterranean estuary, Water Resour. Res., 46, doi:10.1029/2010wr009632.

Yin, J. J., M. E. Schlesinger, and R. J. Stouffer (2009), Model projections of rapid sea-level rise on the northeast coast of the United States, Nat Geosci., 2(4), 262-266. 


\section{Supplemental Material}

From Gonneea et al. "Sea level anomalies modulate coastal groundwater dynamics"

\section{Text S1:}

Salinity structure of the Waquoit Bay coastal aquifer

Cross-sectional transects of the salinity structure of the Waquoit Bay coastal aquifer have been measured numerous times (Fig. S1). These transects were completed over $\sim 10$ days, at various stages of the tide and in various wave conditions. While there is some variability in the structure/extent of the upper mixing zone, which is driven by short-time scale tides and waves, the slope of the mixing interface is stable across the three years (slope $=0.29 \pm 0.01$, April 2003, June 2004 and June 2005). Locations of samples are noted in black squares, while white squares mark the position of the monitoring well used for the time series, which is approximately located at mean sea level. The time series monitoring wells are within the stable region, thus salinity oscillations during the time series reflect lateral movement of the deep mixing zone, not shifts near the upper mixing zone where the interface has the highest slope. Note horizontal distance in Fig. S1 is measured from the coastal well CCC1, the location of the upland head in the model simulations (Fig. 1).

In addition, the salinity of the wells was monitored over a falling tide (October 15, 2004), to determine if salinity of the deep mixing zone varied across a tidal cycle (Fig. S2). The salinity was stable despite a $0.8 \mathrm{~m}$ drop in sea level. Based on this evidence, we expect the position of the deep mixing zone to respond to changes in the hydraulic gradient on time scales longer than hours and to processes that are sustained on the order 
of days to weeks to months. Thus, tidal components and wave conditions that lead to sea level variability on longer time scales (i.e. the annual tidal components or sustained winter storms), may impact the position of the interface, since they likely impact mean sea level on this time scale.

\section{Groundwater levels, sea level anomaly and aquifer salinity}

Seasonal oscillations in inland groundwater levels (i.e. USGS well $10 \mathrm{~km}$ from MSL) driven by groundwater recharge have been proposed to be the dominant forcing of the coastal aquifer hydraulic gradient [Anderson and Emanuel, 2008, 2010; Michael et al., 2005]. In this conceptual model, seasonal variability in precipitation and evapotranspiration rates result in seasonally variable aquifer recharge, with a time lag in aquifer head response due to 1) time for recharge to percolate into the aquifer, and/or 2) time for landward recharge to equilibrate with groundwater discharge at the coast [Michael et al., 2005]. In the case of the Waquoit Bay coastal aquifer, this model predicts seaward movement of the interface and an increase in terrestrial SGD during spring/summer following the winter peak in recharge. Conversely, following peak summer evapotranspiration rates, the groundwater level would correspondingly decrease and the interface would move landward during fall and winter.

In support of this conceptual model, both field data and numerical modeling at Waquoit Bay have demonstrated that there is a time lag between peak recharge and peak inland aquifer levels of approximately three to five months [Michael et al., 2005]. Direct measurements of SGD with manual seepage meters in summer (June 2002 and 2003) and via in situ hydraulic gradients in winter (February 2004) indicated greater SGD in 
summer [Michael, 2004; Michael et al., 2003, 2005], but remain inconclusive since sea ice cover during the winter prevented measurement of hydraulic gradients in the region where the greatest groundwater discharge had been observed in the summer. It is important to note that this conceptual model, which has been used previously to design numerical models of seasonal coastal aquifer dynamics, also assumes either 1) sea level varies symmetrically about mean sea level (MSL) such that longer-term MSL does not change over time [Lu and Luo, 2010; Michael et al., 2005], or 2) seasonal sea level variations serve to reinforce the seasonal pattern delineated above.

Here we calculate the head gradient according to the procedure outlined in Post et al. [2007], since consideration must be given to the variable density ground and bay water. We utilized cross correlation analysis to better understand how the various time series were related. All time series were first set to a specific sampling interval (15 days for the head gradient comparison between sea level and head gradient (Fig. S5a) and 30 days for the comparison between salinity and sea level, USGS and CCC1 groundwater levels (Figs. S5b-c, S6 and S7)). The data was then standardized to a mean of 0 and standard deviation of 1 . Each time series was first auto correlated to determine the effective sample number according to:

$N^{*}=\frac{N \Delta t}{T}$

where $\mathrm{N}$ is the number of measurements, $\Delta \mathrm{t}$ is the time interval between points and $T$ is the integral time scale of the data series, given by: $T=C_{y}^{0^{-1}} \sum_{k=0}^{N-n k-1} \Delta t / 2\left[C_{y}\left(n_{k}+\Delta t\right)+C_{y}\left(n_{k}\right)\right]$ 
where $\mathrm{C}_{\mathrm{y}}$ is the autocovariogram, normalized to the autocovariance at zero lag, of the time series and $\mathrm{n}_{\mathrm{k}}$ is the $\mathrm{k}^{\text {th }}$ lag of $\mathrm{n}$ [Glover et al., 2011]. The Matlab xcorr function was used to perform the analysis. In the cross correlation analysis, one variable was considered independent and one was dependent. For example, in Fig. S5a, sea level is the independent variable while head gradient is dependent, since sea level can influence head gradient, but head gradient will not alter sea level. Thus, positive lags indicate that the dependent value occurs after a change in the independent value, i.e. the head gradient response is lagged in time compared to sea level. Framed in this context, a negative lag does not have a physically consistent meaning and is not shown. Only lags out to N/4 are shown for each analysis. The $95 \%$ confidence interval was calculated as: $|r|=\frac{1.96}{\sqrt{N^{*}-n-3}}$

where $\mathrm{r}$ is the correlation, 1.96 is the $\mathrm{Z}$-score for a $95 \%$ confidence interval, $\mathrm{N}^{*}$ is the number of independent measurements, and $\mathrm{n}$ is the number of lags [Glover et al., 2011]. This confidence interval is noted in all cross correlation plots as a dashed line. Note that this type of analysis may show high correlations of opposite sign that are lagged half of the period of the correlation. For instance, if two time series are in phase at 0 lag and both oscillate with a seasonal signal, they likely have a negative correlation when one is lagged 6 months in relation to the other.

The monthly groundwater level $3 \mathrm{~km}$ inland from Waquoit Bay (USGS monitoring well \#413525070291904) showed an approximately seasonal oscillation in groundwater level of $\sim 1 \mathrm{~m}$, however the timing of the peak in groundwater levels was not constant, ranging from late spring (2004 to 2008) to fall (2008 to 2010, Fig. S3a), 
suggesting that the seasonality of groundwater levels on Cape Cod may not be primarily controlled by evapotranspiration, as previously proposed, but also by precipitation. For a portion of the time series (Jan. 2005 to June 2007), groundwater levels directly at the coast $(\mathrm{CCC} 1$ and $\mathrm{CCC} 2)$ were dampened $(\sim 10 \mathrm{~cm})$ (Fig. S3b). The cross correlation analysis revealed that coastal groundwater levels are correlated to sea level $(r=0.66)$ with a lag of 15 days and inland (USGS) groundwater levels $(\mathrm{r}=0.76)$ at a lag of 45 days (Fig. S6).

A similar cross correlation of the time series salinity data with 1) head gradient, 2) sea level, 3) coastal (CCC1) groundwater level and 4) inland (USGS) groundwater levels revealed the highest correlation between sea level $(r=0.56)$ and head gradient $(r=-0.49)$ at 0 lag (Fig. S7). There was no significant correlation between salinity and coastal groundwater head, while the inland groundwater head was correlated to salinity with a two month lag $(\mathrm{r}=-0.54)$. Thus, while the previously proposed conceptual model of Michael et al. (2005) agrees with our analysis of coastal and inland groundwater levels, dynamic movement of the saltwater interface appears to be dominated by seasonal sea level oscillations as discussed in depth in the main text. 


\section{References:}

Anderson, W. P., and R. E. Emanuel (2008), Effect of interannual and interdecadal climate oscillations on groundwater in North Carolina, Geophys. Res. Lett., 35(23), doi: 10.1029/2008g1036054.

Anderson, W. P., and R. E. Emanuel (2010), Effect of interannual climate oscillations on rates of submarine groundwater discharge, Water Resour. Res., 46, doi:

10.1029/2009wr008212.

Glover, D.M., Jenkins, W.J. and Doney, S.C. 2011. Modeling Methods for Marine Science. Cambridge University Press. ISBN-13: 978-0521867832. pp. 571.

Michael, H. A., J. S. Lubetsky, and C. F. Harvey (2003), Characterizing submarine groundwater discharge: a seepage meter study in Waquoit Bay, Massachusetts, Geophys. Res. Lett., 30(6), doi:10.1029/2002g1016000.

Michael, H. A. (2004), Seasonal dynamics in coastal aquifers: investigations of submarine groundwater discharge through field measurements and numerical models, $\mathrm{PhD}$ thesis, Massachusetts Institute of Technology.

Michael, H. A., A. E. Mulligan, and C. F. Harvey (2005), Seasonal oscillations in water exchange between aquifers and the coastal ocean, Nature, 436(7054), 1145-1148.

Lu, C. H., and J. Luo (2010), Dynamics of freshwater-seawater mixing zone development in dual-domain formations, Water Resour. Res., 46, doi:10.1029/2010wr009344.

Post, V., H. Kooi and C. Simmons (2007), Using hydraulic head measurements in variable-density ground water flow analyses, Ground Water, 45, doi:10.1111/j.17456584.2007.00339.x. 


\section{Supplementary Figures}
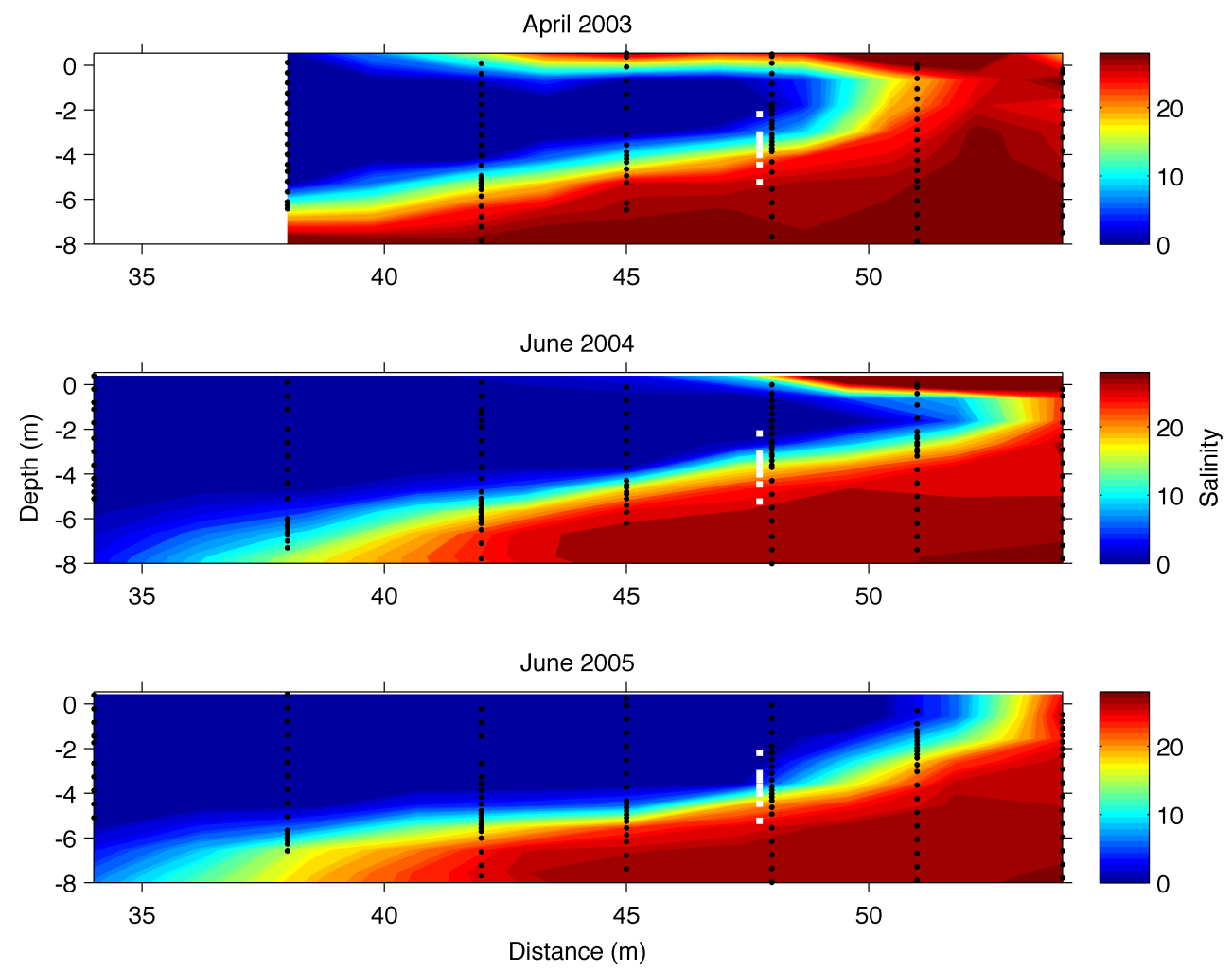

Fig. S1: Salinity structure of the coastal aquifer in April 2003, June 2004 and June 2005. 

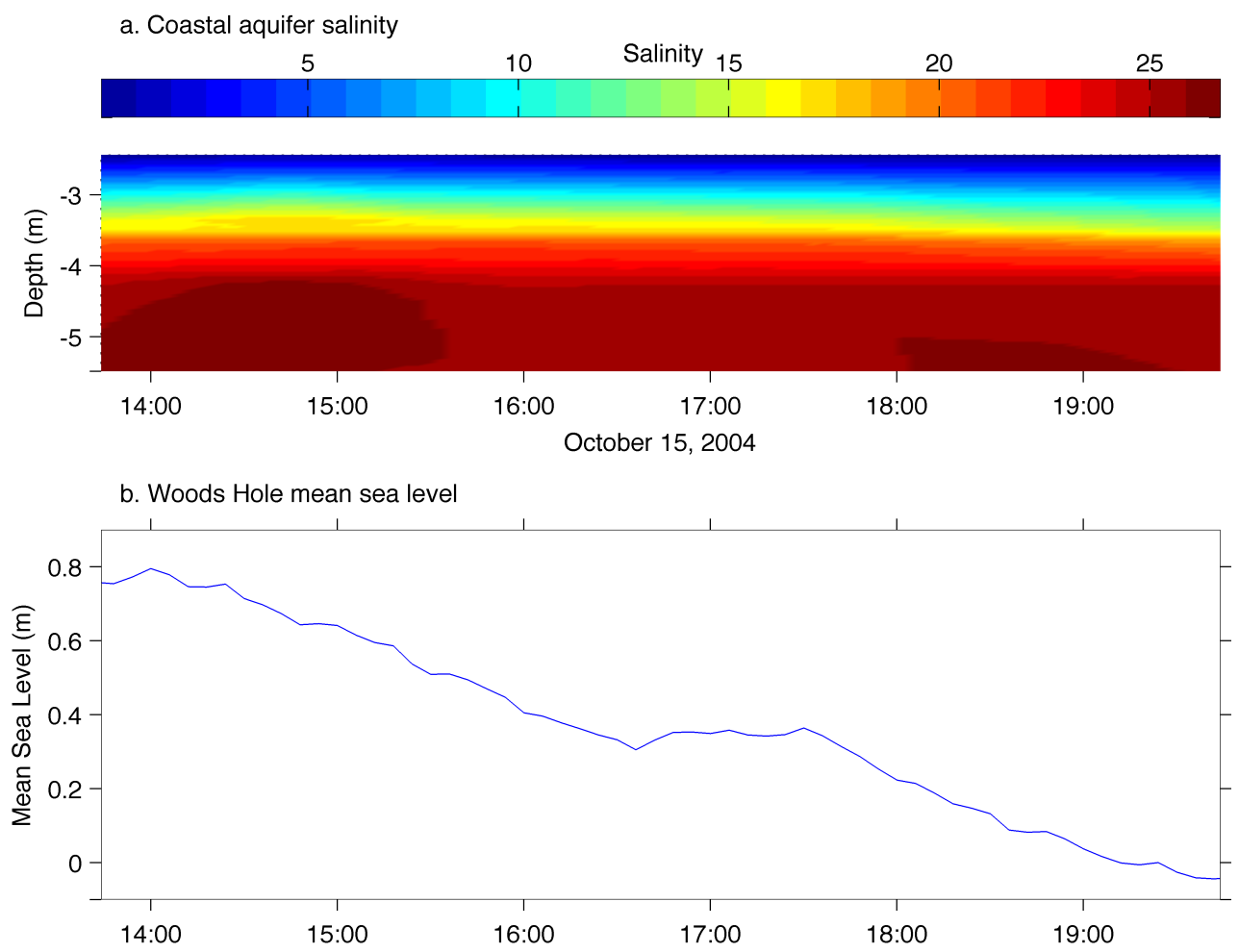

Fig. S2: a) Tidal time series of salinity at monitoring wells and b) 6-minute Woods Hole mean sea level during the same time period. 

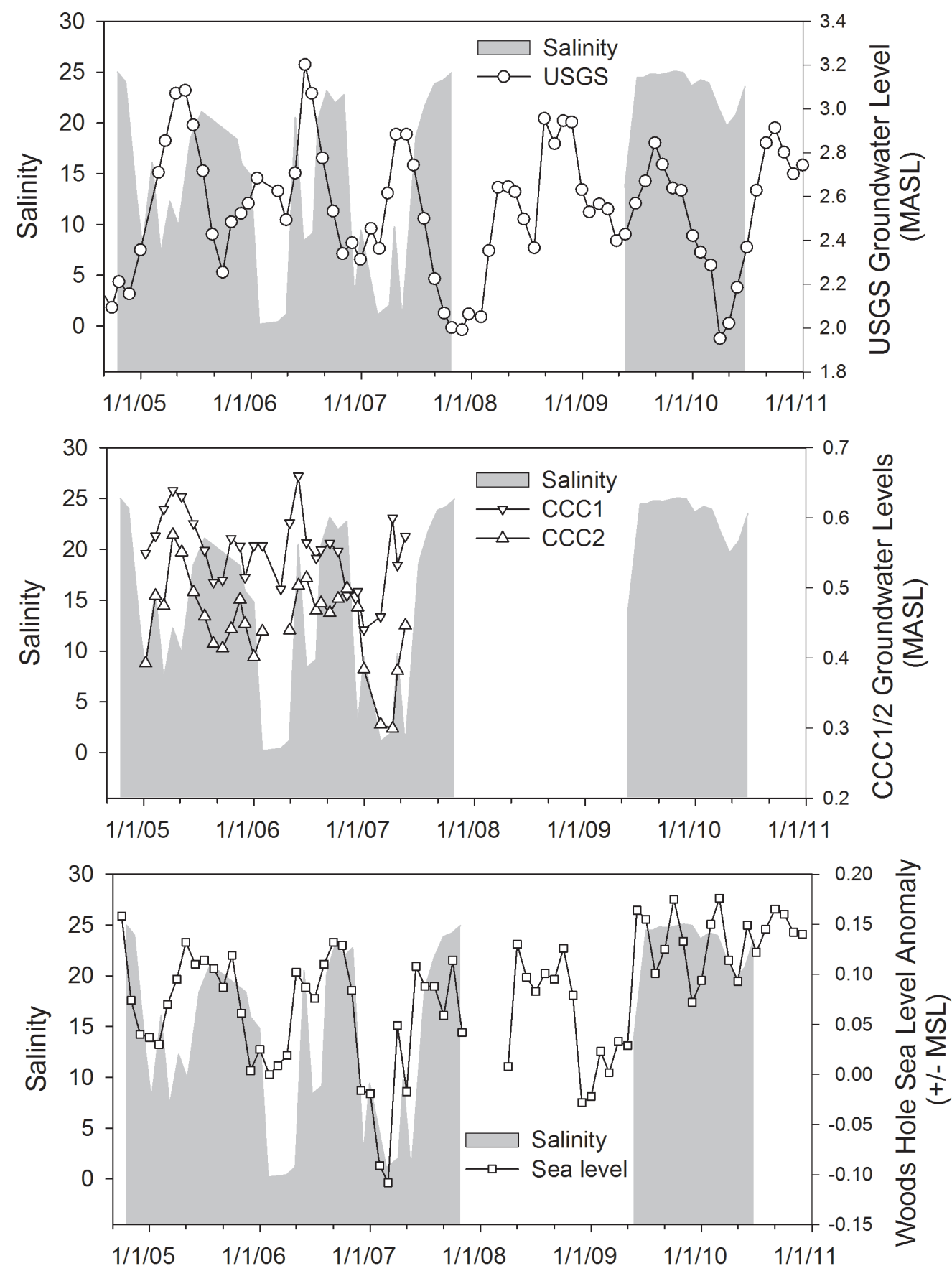

Fig. S3: Relationship between coastal aquifer salinity and inland and coastal groundwater levels and sea level. 

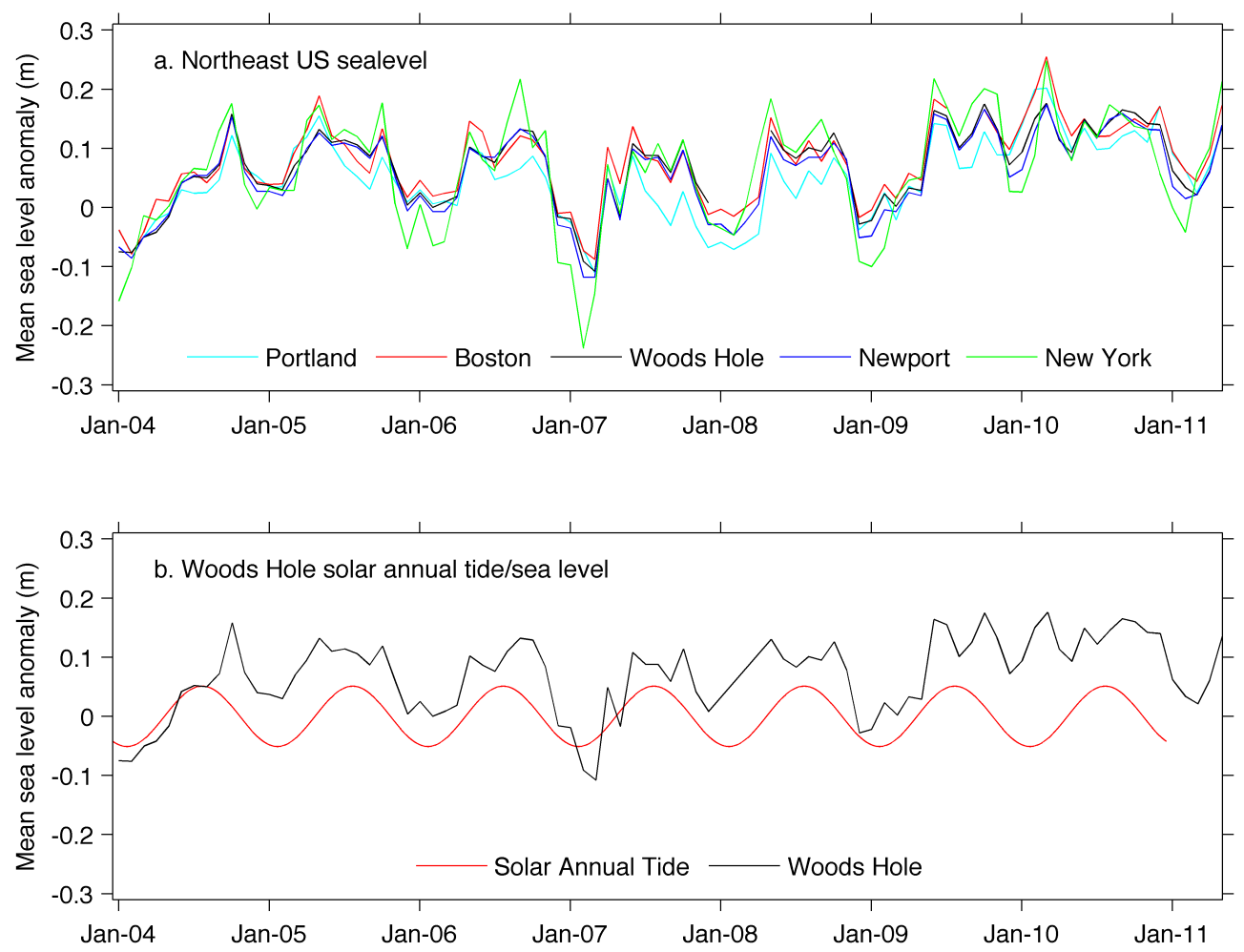

Fig. S4: a) Mean sea level anomaly along the northeast US coast Jan. 2004 to May 2011 and b.) Woods Hole, MA predicted sea level due to the solar annual tidal component and measured sea level. 


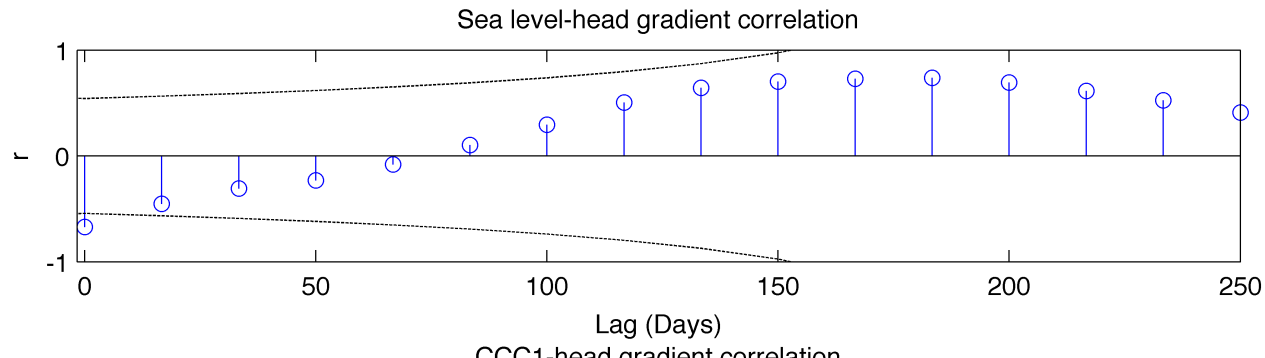

CCC1-head gradient correlation

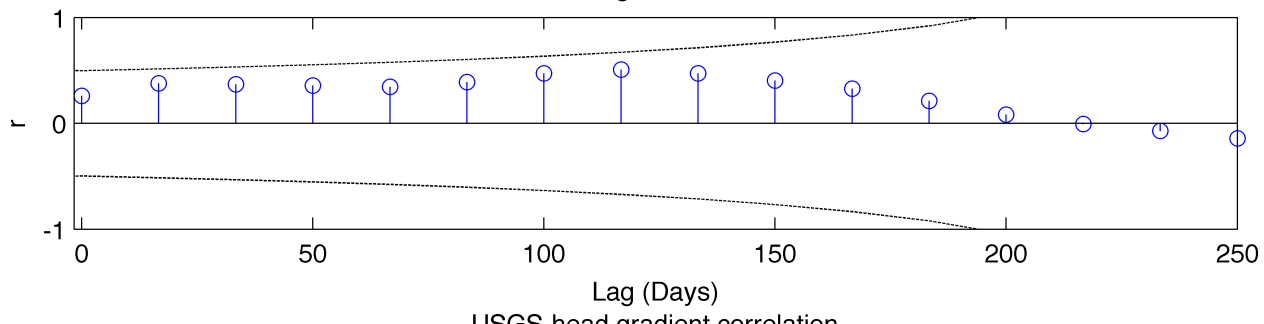

USGS-head gradient correlation

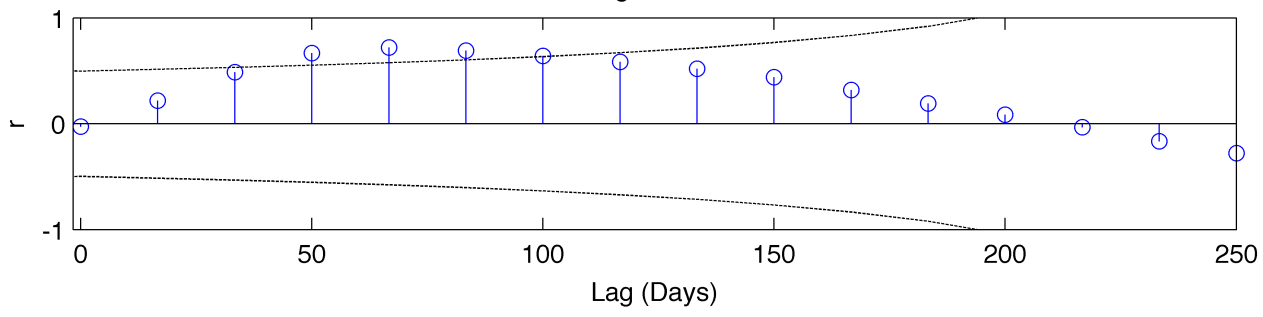

Fig. S5: Cross correlation analysis of head gradient and a) sea level, b) CCC1 coastal (46 $\mathrm{m}$ from MSL) groundwater levels and c) USGS inland (10 km from MSL) groundwater levels. 95\% confidence intervals are shown in dashed lines. 

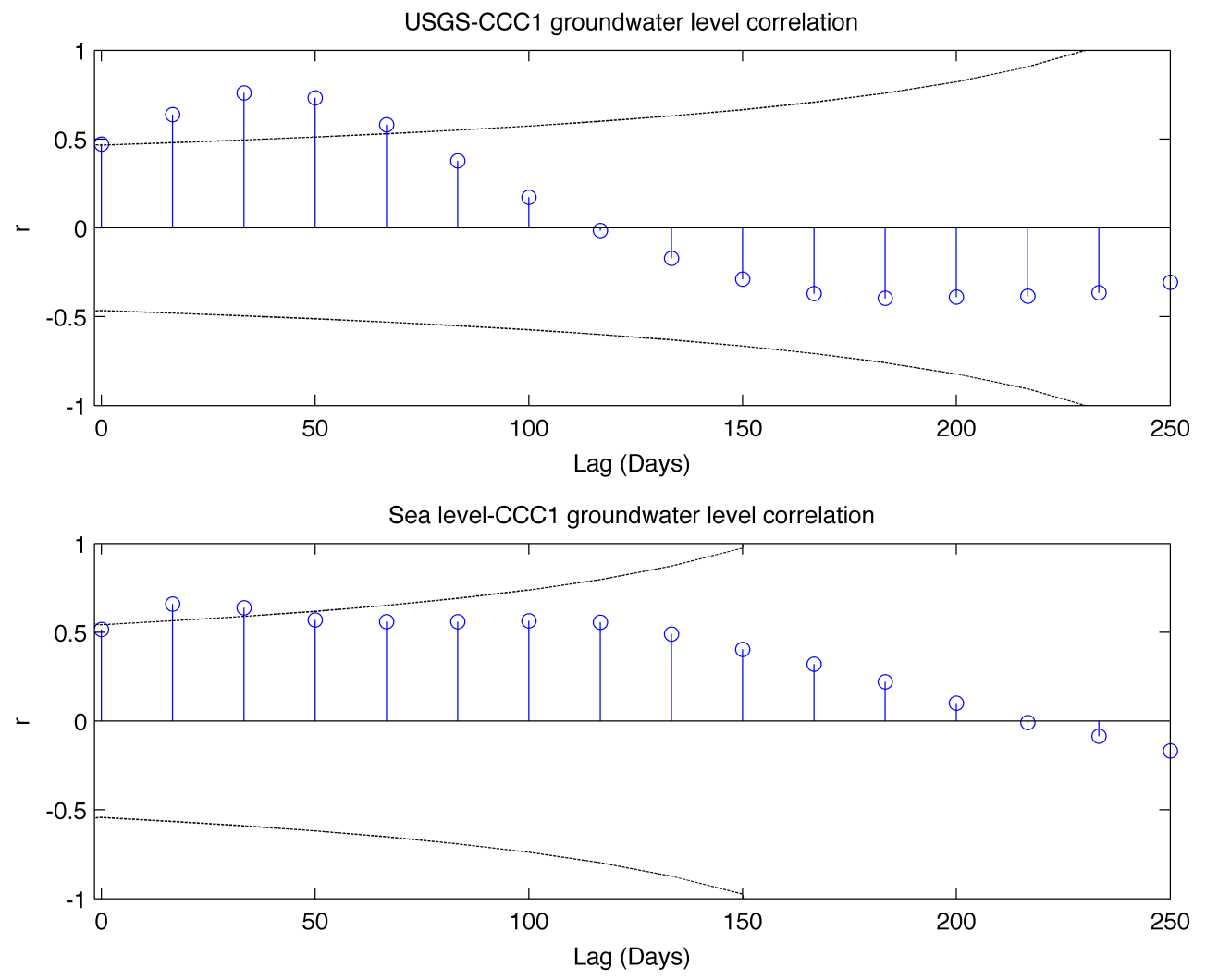

Fig. S6: Cross correlation analysis for coastal (46 m from MSL) groundwater levels and a) inland (USGS, $10 \mathrm{~km}$ from MSL) groundwater and b) MSL. 95\% confidence intervals are shown in dashed lines. 

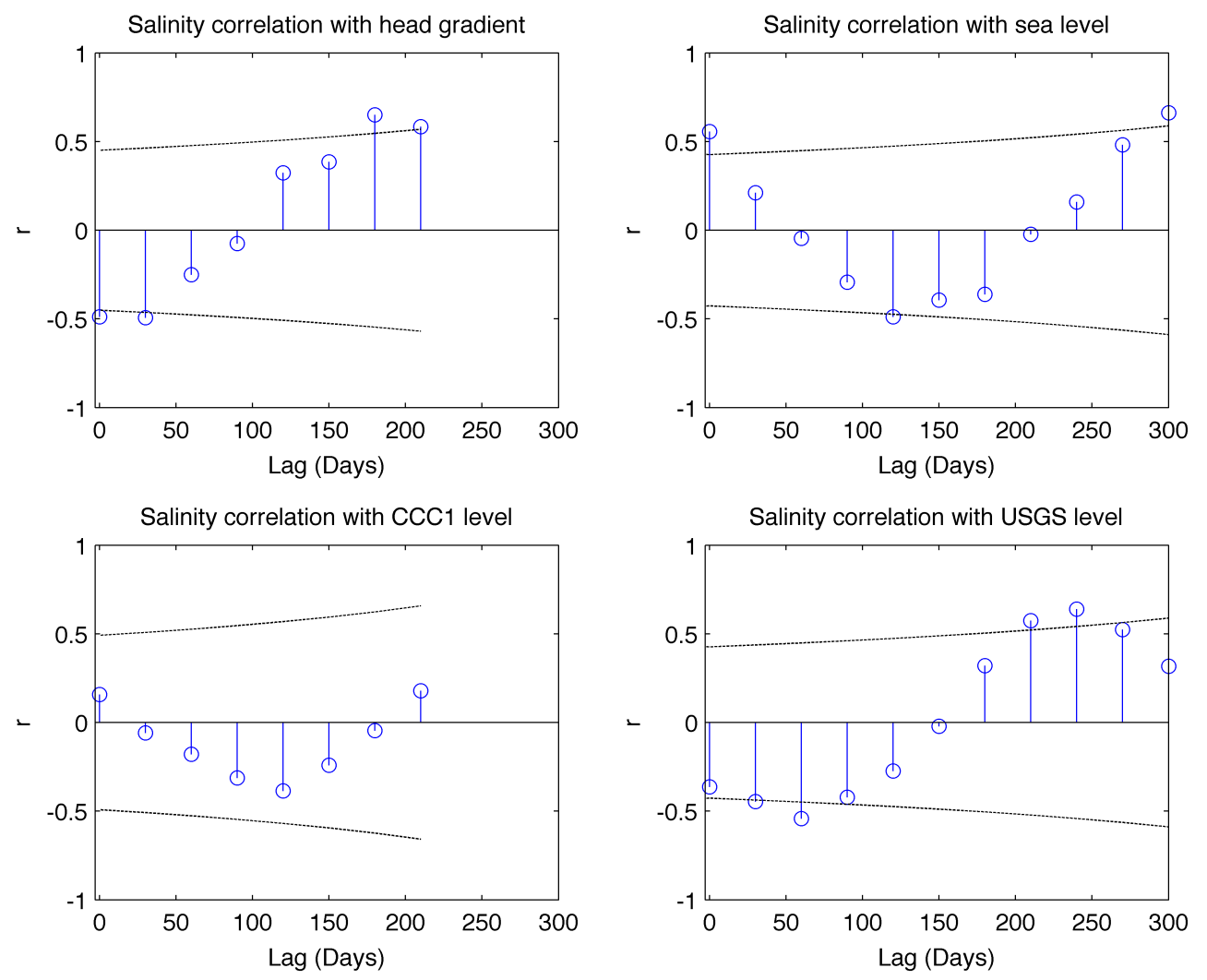

Fig. S7: Cross correlation analysis for salinity and a) head gradient between $\mathrm{CCC} 1$ and MSL, b) sea level, c) coastal CCC1 groundwater levels and d) inland USGS groundwater levels. 95\% confidence intervals are shown in dashed lines. 

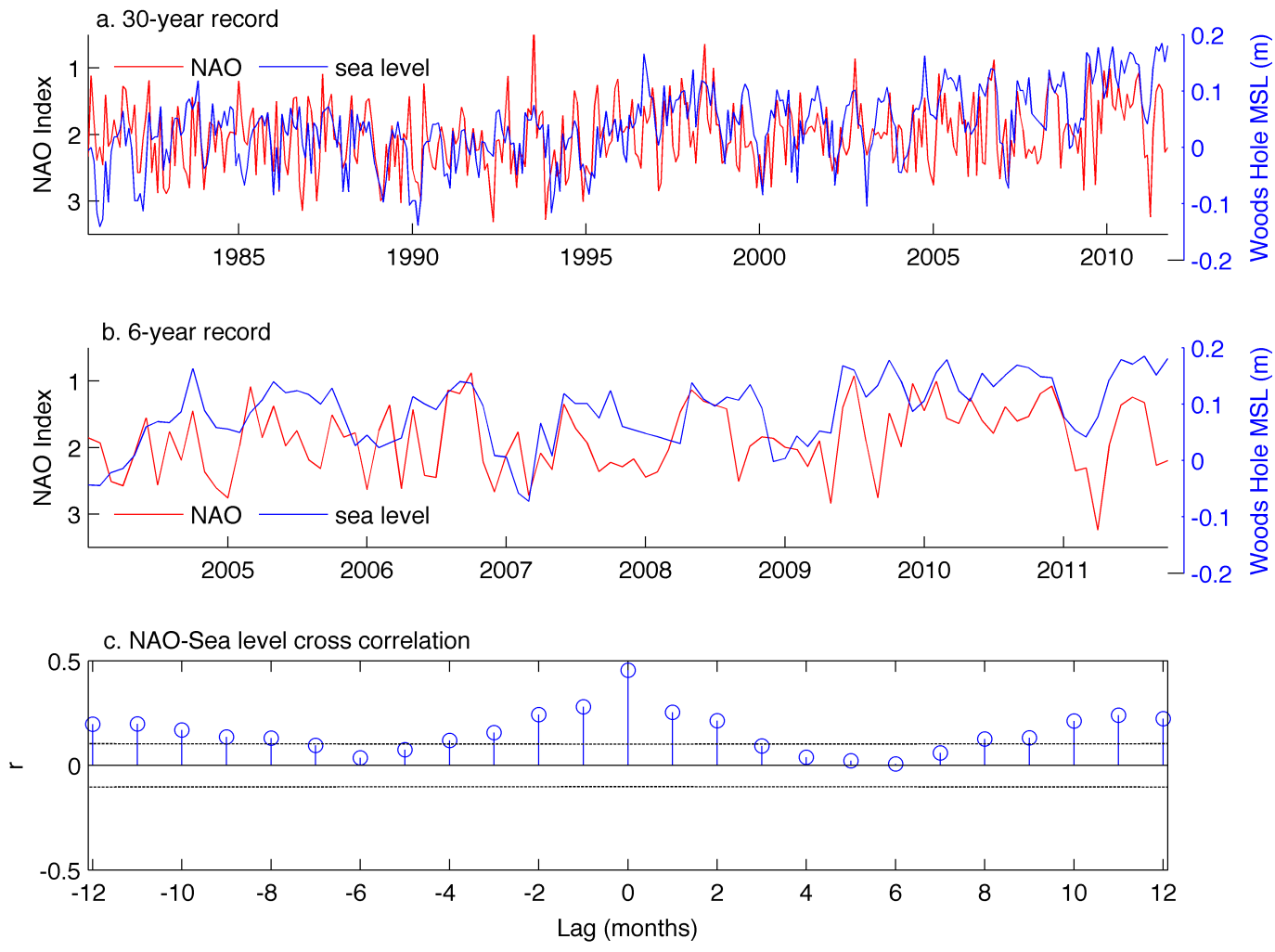

Fig. S8: Mean sea level anomaly from Woods Hole, MA, and three-month running mean NAO index from a) Jan. 1980 to Oct. 2011 and b) Jan. 2004 to Oct. 2011, and c) cross correlation between sea level and NAO. 95\% confidence intervals are shown in dashed lines. 


\section{Chapter 3:}

\section{Seasonal cycles in radium and barium within a subterranean estuary: Implications for groundwater derived chemical fluxes to surface waters}

This chapter was originally published in Geochimica et Cosmochimica Acta by Elsevier and is reprinted here with their permission.

Seasonal cycles in radium and barium within a subterranean estuary: Implications for groundwater derived chemical fluxes to surface waters. Geochimica Cosmochimica Acta. M.E. Gonneea, A.E. Mulligan, and M.A. Charette. (2013).

doi:10.1016/j.gca.2013.05.034. 
Geochimica et Cosmochimica Acta

www.elsevier.com/locate/gca

\title{
Seasonal cycles in radium and barium within a subterranean estuary: Implications for groundwater derived chemical fluxes to surface waters
}

\author{
Meagan Eagle Gonneea ${ }^{\mathrm{a}, *}$, Ann E. Mulligan ${ }^{\mathrm{b}}$, Matthew A. Charette ${ }^{\mathrm{a}}$ \\ ${ }^{a}$ Department of Marine Chemistry and Geochemistry, Woods Hole Oceanographic Institution, 266 Woods Hole Road, MS 25, Woods Hole, \\ MA 02543, United States \\ ${ }^{\mathrm{b}}$ Marine Policy Center, Woods Hole Oceanographic Institution, 266 Woods Hole Road, MS 41, Woods Hole, MA 02543, United States
}

Received 27 January 2012; accepted in revised form 27 May 2013; Available online 5 June 2013

\begin{abstract}
There is increasing evidence that submarine groundwater discharge (SGD) is an important source of water and dissolved materials to the ocean. One of the primary tracers of this process is the quartet of radium isotopes $\left({ }^{223} \mathrm{Ra},{ }^{224} \mathrm{Ra},{ }^{226} \mathrm{Ra}\right.$ and ${ }^{228} \mathrm{Ra}$ ), whereby excess activities in surface waters can often be attributed to an input supplied via SGD. This approach requires the radium end member activity to be well constrained, however, natural variability in groundwater radium may span several orders of magnitude. Therefore, this variability is usually the main driver of uncertainties in volumetric SGD estimates. To investigate the physical and biogeochemical controls on groundwater radium activities, we conducted a three-year time series of radium and barium, a chemical analogue for radium, within the subterranean estuary of a coastal aquifer (Waquoit Bay, MA, USA). Gonneea et al. (2013) demonstrated that movement of the salinity interface within the subterranean estuary is driven by changes in the hydraulic gradient between groundwater level and sea level height. For Waquoit Bay, seasonal scale sea level change, not groundwater level, was the main driver in hydraulic gradient fluctuations. Seasonal changes in groundwater chemistry can be attributed to the resulting movement of the salinity transition zone between terrestrial and marine groundwater. Landward movement of the interface results in a large release of radium isotopes (226$\left.\mathrm{Ra}=1400 \mathrm{dpm} 100 \mathrm{~L}^{-1}\right)$ and barium $\left(3000 \mathrm{nmol} \mathrm{kg}{ }^{-1}\right)$ associated with an increase in groundwater salinity. The magnitude of these releases cannot be explained by in situ production or weathering alone, but is likely due to salinity driven desorption from surface-bound sediment inventory. The timing of these peak concentrations is not always in phase with model-derived estimates of SGD; as a result, the groundwater concentration rather than the water flux is the main driver of Ra and Ba inputs to Waquoit Bay surface waters. The behavior of the subterranean estuary as an ion exchange reservoir has important implications for the timing and flux of various nutrients and pollutants that transit this region prior to discharge. In addition to modulating chemical fluxes via submarine groundwater discharge on seasonal time scales, transgression of the subterranean estuary may alter the input of chemicals to the ocean on decadal and longer time scales. During this study, the observed excess flux of ${ }^{226} \mathrm{Ra}$ and $\mathrm{Ba}$ from the subterranean estuary can be accounted for with sorbed sediment pools and accelerating rates of sea level rise in this region.

(c) 2013 Elsevier Ltd. All rights reserved.
\end{abstract}

Abbreviations: $S G D$, submarine groundwater discharge; $S T E$, subterranean estuary; STZ, salinity transition zone

* Corresponding author. Tel.: +1 5082893236.

E-mail addresses: mgonneea@whoi.edu (M.E. Gonneea), amulligan@whoi.edu (A.E. Mulligan), mcharette@whoi.edu (M.A. Charette).

\section{INTRODUCTION}

Groundwater discharge at the land-ocean interface is driven by a variety of physical processes (Robinson et al., 2006; Mulligan and Charette, 2009; Michael et al., 2011). Fresh, terrestrially-derived groundwater flows to the coast, 
where it mixes with seawater that has inundated the coastal aquifer (marine groundwater), resulting in a deep circulation cell that rises along the density stratified salinity transition zone (STZ) and discharges to surface waters (Moore, 1999; Michael et al., 2005; Charette, 2007). In addition, short temporal period tidal and wave pumping result in seawater exchange at the sediment-water interface of the subterranean estuary (Robinson et al., 2006; Li et al., 2009; Xin et al., 2010; Abarca et al., 2013).

Water discharging across the ocean-aquifer boundary has a unique chemistry since it is a complex mixture of terrestrial and marine groundwater that has experienced a range of different residence times within the subterranean estuary (STE), the below ground analogue to surface estuaries with similarly dynamic salinity and chemical gradients (Moore, 1999). Trace metal and radionuclide cycling within subterranean estuaries is expected to have a large influence on total chemical flux discharging via submarine groundwater discharge (SGD). Much of our knowledge of chemical cycling within this zone is derived from studies based on single time points, with little known about the time scale or magnitude of temporal variability (Bone et al., 2006; Charette and Sholkovitz, 2006; Paytan et al., 2006; Windom et al., 2006; Beck et al., 2007; Perry et al., 2009; Beck et al., 2010; Santos et al., 2011). Recently Gonneea et al. (2013) showed that seasonal-scale variability in the coastal hydraulic gradient results in dynamic movement of the STZ and corresponding changes in the chemical environment of the subterranean estuary.

Such seasonal variability is particularly relevant to radioisotopic tracers that have extended our capability to quantify SGD (Moore, 2003). These tracers, which include the radium quartet $\left({ }^{223} \mathrm{Ra} t_{1 / 2}=3.66 \mathrm{~d},{ }^{224} \mathrm{Ra} t_{1 / 2}=11.4 \mathrm{~d}\right.$, ${ }^{228} \mathrm{Ra} t_{1 / 2}=5.75 \mathrm{y}$ and ${ }^{226} \mathrm{Ra} t_{1 / 2}=1,600 \mathrm{y}$ ), are enriched in groundwater, up to several orders of magnitude above ambient seawater, and upon discharge to coastal waters their activity is a function only of mixing and decay. However, to refine the utility of radium isotopes as SGD tracers, it is necessary to understand their geochemical cycling within the subterranean estuary. Indeed, estimates of SGD based on radium tracers can only be resolved to the level that groundwater end member radium activities can be constrained, and variability in groundwater radium activity remains the largest source of uncertainty in radium tracer based SGD calculations (Charette, 2007; Ferrarin et al., 2008; Moore et al., 2008; Breier et al., 2010). Several studies to date have identified a seasonal aspect to SGD based on seasonal changes in radium inventories of surface waters (Kelly and Moran, 2002; Hougham et al., 2008; Breier et al., 2010). Seasonal cycles in surface water radium inventories may result either from a change in water flux with no concurrent change in the groundwater end member activity, from a steady water flux and dynamic groundwater end member, or some combination of the two. Thus, it is imperative to understand radium cycling within the STE to make accurate estimates of groundwater discharge based on radium tracers.

Most previous research on radium cycling within aquifers has focused predominantly on inland aquifers without dynamic mixing zones (Tricca et al., 2001; Ku et al., 2009).
In these aquifers, the dominant source of radium is via in situ production from uranium and thorium parents (Porcelli, 2008). This is ultimately true of coastal groundwater systems as well, however, the large inventory of radium observed within coastal groundwater, particularly for the long-lived isotopes ${ }^{226} \mathrm{Ra}$ and ${ }^{228} \mathrm{Ra}$, cannot be supported only by decay and recoil from aquifer sediments immediately at the coast (Rama and Moore, 1996). Indeed, modeling studies that have attempted to evaluate $\mathrm{Ra}$ cycling within the STE have demonstrated that even relatively simple one-dimensional advective transport models are underconstrained in terms of the chemical processes affecting $\mathrm{Ra}$ distribution, particularly for the longer lived isotopes (Krest and Harvey, 2003; Michael et al., 2011; Kiro et al., 2012). This is due in part to the main factors that influence radium partitioning between the dissolved and solid phases (see recent review by Beck and Cochran, 2013). The salinity of groundwater has long been recognized as a major influence on the radium partition coefficient (Elsinger and Moore, 1980; Webster et al., 1995; Gonneea et al., 2008). In addition, the presence of $\mathrm{Mn}-\mathrm{Fe}$ oxides has been shown to increase radium adsorption both in laboratory experiments (Moore and Reid, 1973; Koulouris, 1996; Beck and Cochran, 2013) and for in situ aquifer sediments (Gonneea et al., 2008). Recent work by Beck and Cochran (2013) suggests groundwater $\mathrm{pH}$ may potentially exert a similar magnitude control on radium partitioning within the subterranean estuary as groundwater salinity. To gain insight into the mechanisms that control both temporal variability and the large and sustained flux of radium isotopes from coastal aquifers, we evaluate both radium and barium (Ba) cycling within the STE across a three-year time series of groundwater chemistry. Ba serves as a chemical analogue to $\mathrm{Ra}$ in terms of sorption and redox chemistry, yet is not influenced by radioactive production/decay processes.

Within the Waquoit Bay subterranean estuary the dynamic seasonal movement of the STZ responds to oscillations in the aquifer hydraulic gradient that are dominated by seasonal scale sea level variability (Gonneea et al., 2013). Sediments within the mixing zone are alternately inundated with terrestrial and marine groundwater over the course of a year. This study explores the chemical cycling induced by these seasonal changes. Here we present the first monthly time series measurements of radium and barium within a permeable sand subterranean estuary. We will evaluate the relative importance of the geochemical controls known to affect radium cycling within the Waquoit Bay STE on seasonal time scales. Finally, to place the chemical cycling of $\mathrm{Ra}$ and $\mathrm{Ba}$ within the STE in the context of chemical fluxes via SGD, we use model derived groundwater fluxes and salinity to calculate total fluxes of $\mathrm{Ra}$ and $\mathrm{Ba}$ via SGD on the same monthly resolution as the groundwater time series.

\section{METHODS}

\subsection{Field site}

Waquoit Bay is a shallow estuary on the southern shore of Cape Cod, MA (Fig. 1). In this region, surface geology is 


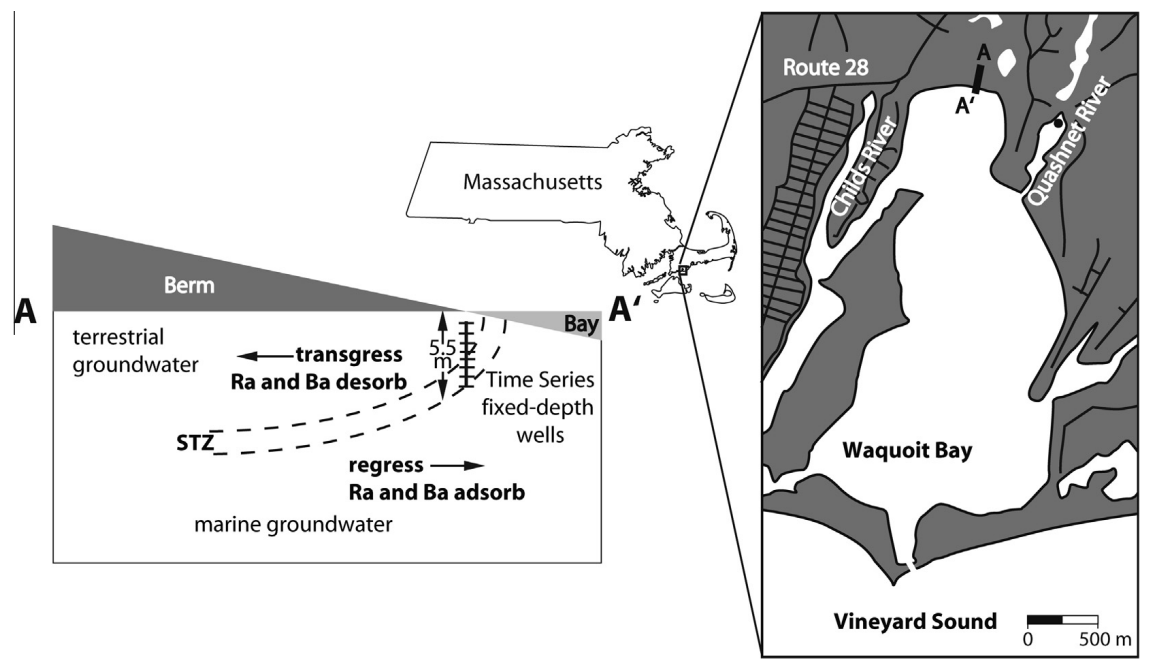

Fig. 1. Waquoit Bay, MA, USA. The time series wells were installed within the mixing zone of the subterranean estuary and sampled monthly during the three-year time series. STZ is the salinity transition zone where mixing between terrestrial and marine groundwater occurs. The STZ moves in response to the hydraulic gradient across the subterranean estuary. During periods of high hydraulic gradient (generally low sea level), the salinity interface moves seaward and $\mathrm{Ra}$ and $\mathrm{Ba}$ adsorb onto sediments, while during low hydraulic gradient, the interface moves landward, causing release of these elements.

dominated by sand and gravel glacial outwash plains formed during the last glaciation $\sim 14,000$ years ago. The upper $10 \mathrm{~m}$ of the Cape Cod aquifer, where the Waquoit Bay subterranean estuary is located, consists of fairly homogenous permeable sediments (Cambareri and Eichner, 1998). Boreholes drilled through the STE of Waquoit Bay reveal fine to coarse sand $(0-10 \mathrm{~m})$ underlain by fine to very fine sand and silt (Cambareri and Eichner, 1998). Grain size analysis of three sediment cores from the top $8 \mathrm{~m}$ within the STE indicates that the shallow sediment has a grain size range from 450 to 650 microns with no vertical structure apparent (Charette, unpublished data). The primary sand grains are quartz, with $<1 \%$ of plagioclase along with traces of clinopyroxene, amphibole, white mica, magnetite and at least one other oxide (goethite or hematite) (Charette et al., 2005). Polymineralic fragments in the sands probably represent granite, schist, amphibolite and gabbro. Within the Waquoit Bay subterranean estuary, there are well-defined regions of Fe-oxides (Charette et al., 2005) and Mn-oxides that have been shown to sorb radium (Dulaiova et al., 2008; Gonneea et al., 2008).

These highly permeable sediments result in high groundwater recharge, with about half of precipitation becoming recharge (Cambareri and Eichner, 1998). Precipitation averaged $126 \mathrm{~cm} \mathrm{y}^{-1}$ from 2004 to 2007 with no clear seasonal cycle in rainfall (may be accessed at http://cis.whoi.e$\mathrm{du} /$ science/PO/climate/index.cfm). Since rates of evapotranspiration peak in summer months, the greatest potential for groundwater recharge occurs during the winter and spring (Michael et al., 2005). Waquoit Bay experiences diurnal tides with an average tidal range of $1.2 \mathrm{~m}$. At the head of Waquoit Bay there is a well-defined subter- ranean estuary with a salinity transition zone that occurs over a narrow region ( $1 \mathrm{~m}$ thick (Charette et al., 2005)). The salinity interface moves on seasonal time scales, which results in a variety of chemical processes, including ion exchange (adsorption/desorption reactions) and redox cycling (Charette and Sholkovitz, 2006; Gonneea et al., 2008; Abarca et al., 2013; Beck and Cochran, 2013). Terrestrial groundwater discharge accounts for approximately $80 \%$ of the flow through the subterranean estuary at the head of the bay (Mulligan and Charette, 2006). Further out in the bay ( $>100 \mathrm{~m}$ from mean sea level), where tidal and wave pumping dominate, the discharge consists of recirculated seawater. SGD from this location is not considered here since it does not transit the subterranean estuary and is unlikely to be an important flux term for the long-lived radium isotopes (Michael et al., 2011).

\subsection{Field methods}

A series of AMS ${ }^{\mathrm{rm}}$ Dedicated Gas Vapor Probe Tips were installed with an AMS ${ }^{\mathrm{TM}}$ Retract-a-Tip probe system modified for long-term installation at the head of Waquoit Bay within the subterranean estuary in October 2004 (Fig. 1, Charette and Allen (2006)). When the metal walls of the piezometer are withdrawn from the ground, a stainless steel well point attached to $1 / 4$ inch nylon tubing remains. The well points, each with a screened interval of $2.5 \mathrm{~cm}$, were installed at eight depths below the beach surface across the subterranean estuary ranging from 2.4 to $5.4 \mathrm{~m}$. Samples were collected every month from October 2004 to October 2007 during the same tidal cycle and phase (four hours past high tide, $\sim 3$ days before the monthly 
spring tide) to reduce the potential variability associated with tidal fluctuations, although the salinity mixing zone discussed here does not respond on tidal time scales (Gonneea et al., 2013). Dissolved oxygen, pH, Eh and salinity were measured with a YSI ${ }^{\mathrm{TM}}$ sonde after pumping approximately $1 \mathrm{~L}$ (6-13 well volumes, flow rate approximately $200 \mathrm{ml} \mathrm{min}^{-1}$ ). Samples were then collected for salinity, trace metals, and radium isotopes $(4 \mathrm{~L})$. Salinity, $\mathrm{pH}$, Eh and dissolved oxygen were stable throughout the sampling, as verified by $\mathrm{YSI}^{\mathrm{TM}}$ readings, thus we assume that water was being extracted from the same density horizon, and not across density gradients (i.e. not from different depths at this fixed location).

A sediment core down to $7 \mathrm{~m}$ was collected in June 2006 from the region of the groundwater time series. Collection and geochemical analysis of this core has been described previously and is presented here to aid interpretation of groundwater geochemical cycling (Dulaiova et al., 2008; Gonneea et al., 2008). All sediment trace metal data is for the fraction associated with amorphous and crystalline oxides, as defined by a hydroxylamine hydrochloride and acetic acid chemical leach, with the exception of ion exchangeable, organic and oxide associated fractions used to calculate sediment inventory (Hall et al., 1996). All radionuclide data is for the whole sediment, with the exception of the adsorbed ${ }^{226} \mathrm{Ra}$ values used to calculate sediment inventory (Dulaiova et al., 2008; Gonneea et al., 2008)

\subsection{Laboratory methods}

Radium isotopes were extracted with Mn fibers, rinsed with Ra-free water to remove salts that interfere with counting (Sun and Torgersen, 1998), partially dried and placed within a delayed coincidence counter to measure ${ }^{224} \mathrm{Ra}$ and ${ }^{223} \mathrm{Ra}$ (Moore and Arnold, 1996). The fibers were counted at four weeks to correct for ${ }^{228} \mathrm{Th}$ supported ${ }^{224} \mathrm{Ra}$ on the fibers. Samples were then ashed $\left(820^{\circ} \mathrm{C}, 16 \mathrm{~h}\right)$, homogenized and capped with epoxy, prior to being placed within a well-type gamma spectrometer to measure ${ }^{226} \mathrm{Ra}$ (via ${ }^{214} \mathrm{~Pb}$ at $351.9 \mathrm{keV}$ ) and ${ }^{228} \mathrm{Ra}$ (via ${ }^{228} \mathrm{Ac}$ at $911 \mathrm{keV}$ ) (Charette et al., 2001). All detectors were standardized using a NIST-certified Standard Reference Material sorbed to Mn fibers and prepared in the same manner as the samples. Detection limits calculated with the Currie Hypothesis test for these samples were $0.2 \mathrm{dpm}\left(5 \mathrm{dpm} 100 \mathrm{~L}^{-1}\right.$ for $4 \mathrm{~L}$ groundwater samples) (De Geer, 2004). ${ }^{224} \mathrm{Ra}$ and ${ }^{228} \mathrm{Ra}$ activities were decay corrected to the time of collection.

${ }^{223} \mathrm{Ra}$ activities were at or near detection for a significant portion of the time series so are not reported here. Sediment ${ }^{226} \mathrm{Ra}\left(\operatorname{via}{ }^{214} \mathrm{~Pb}\right.$ at $\left.351.9 \mathrm{keV}\right),{ }^{228} \mathrm{Ra}\left(\mathrm{via}{ }^{228} \mathrm{Ac}\right.$ at $338 \mathrm{keV}$ ) and ${ }^{224} \mathrm{Ra}$ (via ${ }^{212} \mathrm{~Pb}$ at $238 \mathrm{keV}$ ) activities were measured on planar-type gamma spectrometers after aging epoxied samples for at least 3 weeks to ensure secular equilibrium between ${ }^{226} \mathrm{Ra}$ and its daughter radionuclides. The program GESPECOR, a Monte Carlo based software used for calibration of pure Ge detectors, was used to calibrate the detector.

Salinity was measured with a Guideline AutoSal instrument. Groundwater concentrations of dissolved $\mathrm{Mn}, \mathrm{Fe}$ and $\mathrm{Ba}$ were analyzed via inductively coupled mass spec- trometry on a Finnigan Element II high resolution ICPMS at Woods Hole Oceanographic Institution. Each sample was diluted 1:20 with $1 \mathrm{~N}$ Optima nitric acid. Indium (In) was used as an internal standard to account for instrument drift and matrix effects of the solution. Count rates for all elements were normalized to In measured in samples and standards.

\subsection{Hydrology model}

Groundwater flux through the STE at Waquoit Bay was evaluated with a simulation model of groundwater flow and salt transport using the USGS code SEAWAT (Mulligan et al., 2011). The model was used to represent conditions at Waquoit Bay but was not calibrated to field data, hence results are considered approximate and largely qualitative. However, model sensitivity was sufficient to evaluate the importance of water flux versus groundwater concentration on radium and barium chemical fluxes via submarine groundwater discharge.

Briefly, the simulation model is a two-dimensional cross section of a homogeneous unconfined aquifer below a sloping beach $(0.08 \mathrm{~m} / \mathrm{m})$. The simulated domain measures $130 \mathrm{~m}$ long and $10 \mathrm{~m}$ deep. Flow boundary conditions include variable head along the upland margin and seaward edge, with no flow across the bottom of the domain and no recharge across the top boundary. The upland boundary is coincident with the location of an observation well, $\mathrm{CCC} 1$, which was monitored at 15 -min intervals during most of the geochemical sampling (Gonneea et al., 2013). Monthly average groundwater levels at this well were specified as the upland boundary. The marine boundary was specified as the monthly average sea level from the NOAA Woods Hole tidal gauge (available at http://tidesandcurrents.noaa.gov/sta-

tion_info.shtml?stn $=8447930 \% 20$ Woods $\% 20$ Hole, $\% 20$ -

MA) for the period from January 2005 to May 2007. No sea level data from Waquoit Bay exist for the duration of the field campaign and so the Woods Hole gauge is used as a surrogate. Linear interpolation between monthly groundwater levels and sea level data points was used to estimate boundary conditions at 15-day intervals to coincide with the stress periods used in the model. Within each 15-day stress period, tidal and upland boundary conditions remain constant but these values can vary from one stress period to the next. Simulations were run for the equivalent of 2.3 y (January 2005 to May 2007), the length of time data were available to define the upland boundary condition. Model-derived SGD results were averaged over 30 days to coincide with the time series chemical data and binned into five different groups based on the salinity of the discharging water. Additional details of the domain and SEAWAT-specific model parameters can be found in Mulligan et al. (2011).

\section{RESULTS}

The time series offers a window into the chemistry of the subterranean estuary at a fixed point over three years. When plotted as a time series, with time on the $x$-axis, 
movement of the salinity transition zone appears as a vertical oscillation between periods of high and low salinity at this fixed location. Results from the three-year time series are presented in contour plots in Fig. 2 to highlight the seasonal oscillations in the various parameters, in box and whisker plots in Fig. 3 to demonstrate the depth dependence and the total variability observed in the parameters and as element versus salinity and $\mathrm{pH}$ to reveal trends sensitive to those parameters in Fig. 4.

\subsection{Salinity transition zone}

The salinity of the subterranean estuary oscillated throughout the three-year time series and ranged from 0 to 28 (Fig. 2a). At this location within the STE, the depth range that experienced the largest salinity excursions from a baseline low salinity was $3.1-4.1 \mathrm{~m}$ (Fig. 3a). At this depth, the salinity was below 2 at least $50 \%$ of the time. Above this, the STE was dominated by terrestrial groundwater throughout the measurement period, while below $4.1 \mathrm{~m}$, the salinity increased with depth, indicating the increasing dominance of marine groundwater. Salinity excursions within the upper fresh portion of the STE were observed periodically throughout the time series (November 2004, October 2005, February 2006 and June 2007) and likely resulted from infiltration of bay water during a high tide and subsequent density driven mixing into the upper STE. In addition, during February 2006, the entire STE was dominated by terrestrial groundwater, possibly due to the sustained high hydraulic gradient from Decem- ber 2005 to March 2006 (Gonneea et al., 2013). Salinity maximums occurred throughout the entire vertical section of the STE in October 2004, June-December 2005, May 2006, August-November 2006 and August 2007. pH does not show as pronounced seasonal variability as salinity. $\mathrm{pH}$ is generally $7-8$ in the deep marine groundwater, and lower (5-6) in the terrestrial groundwater and mixing zone (Fig. 2b). The region above $4.1 \mathrm{~m}$ tends to have the largest dynamic range in $\mathrm{pH}$ (Fig. 3b).

\subsection{Trace metals and radium}

Groundwater Ra activities fluctuated in concert with the salinity changes in the STE. ${ }^{226}$ Ra ranged from below detection $\left(5 \mathrm{dpm} 100 \mathrm{~L}^{-1}\right.$, with approximately $20 \%$ of the time series radium samples below detection, mostly terrestrial groundwater samples) to $1400 \mathrm{dpm} 100 \mathrm{~L}^{-1}$ (Fig. 2c). Estuarine release at intermediate salinities is apparent, with peak activities around salinity 15 (Fig. 4c). A radium sorption edge is apparent, with no ${ }^{226} \mathrm{Ra}$ activity $>200 \mathrm{dpm} 100 \mathrm{~L}^{-1}$ above $\mathrm{pH} 6$, indicating that $\mathrm{pH}$ is a potential control on radium activities within the STE (Fig. 4d). Activities within the marine groundwater were relatively constant at 30 to $130 \mathrm{dpm} 100 \mathrm{~L}^{-1}$, while the largest releases were observed in the sediment from 3.1 to $4.1 \mathrm{~m}$ that was inundated by terrestrial groundwater at least $50 \%$ of the time (Fig. 3c). Groundwater ${ }^{224} \mathrm{Ra}$ and ${ }^{228} \mathrm{Ra}$ displayed similar seasonal oscillations and activity extremes, from detection to maximum activities of 11,600 and $5300 \mathrm{dpm} 100 \mathrm{~L}^{-1}$, respectively (Supplementary Figs. 1

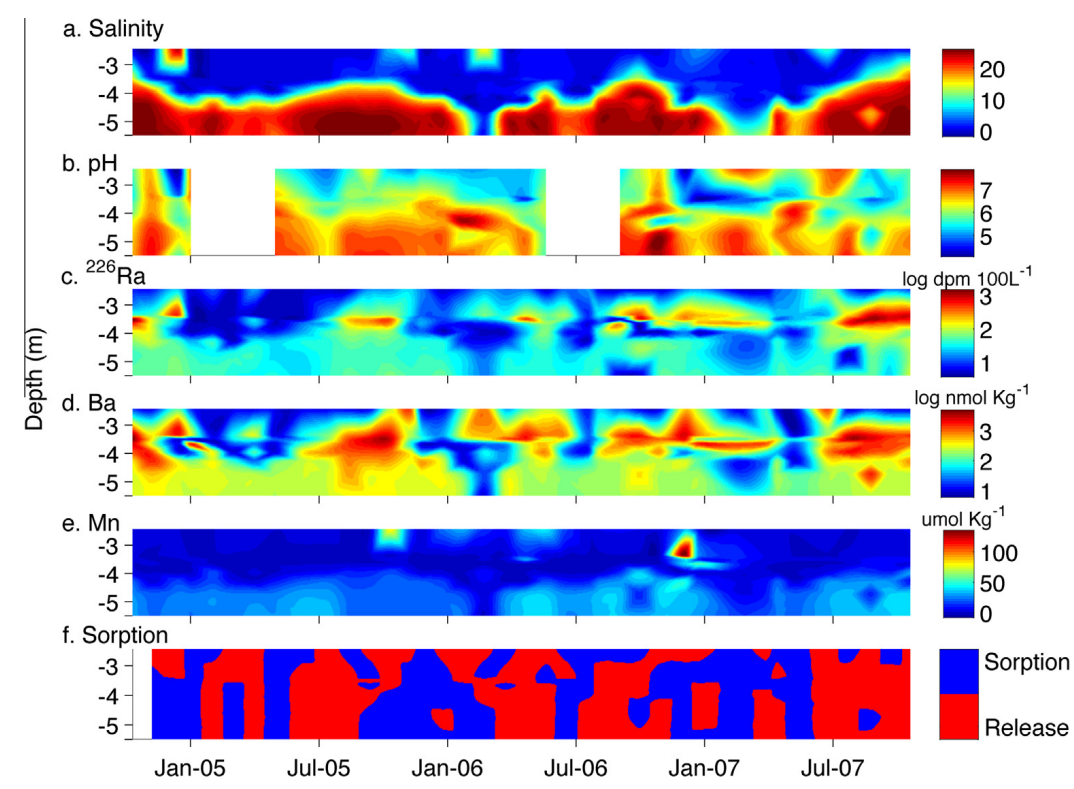

Fig. 2. Time series data from October 2004 to October 2007 for (a) salinity, (b) $\mathrm{pH}$, (c) dissolved ${ }^{226} \mathrm{Ra}$, (d) dissolved barium and (e) dissolved manganese. Also shown (f) is the sorption potential, as determined by the change in salinity from time point $t_{n+1}-t_{n}$. Note the log scale in (b) and (c). Data were contoured in Matlab using a cubic interpolation. 

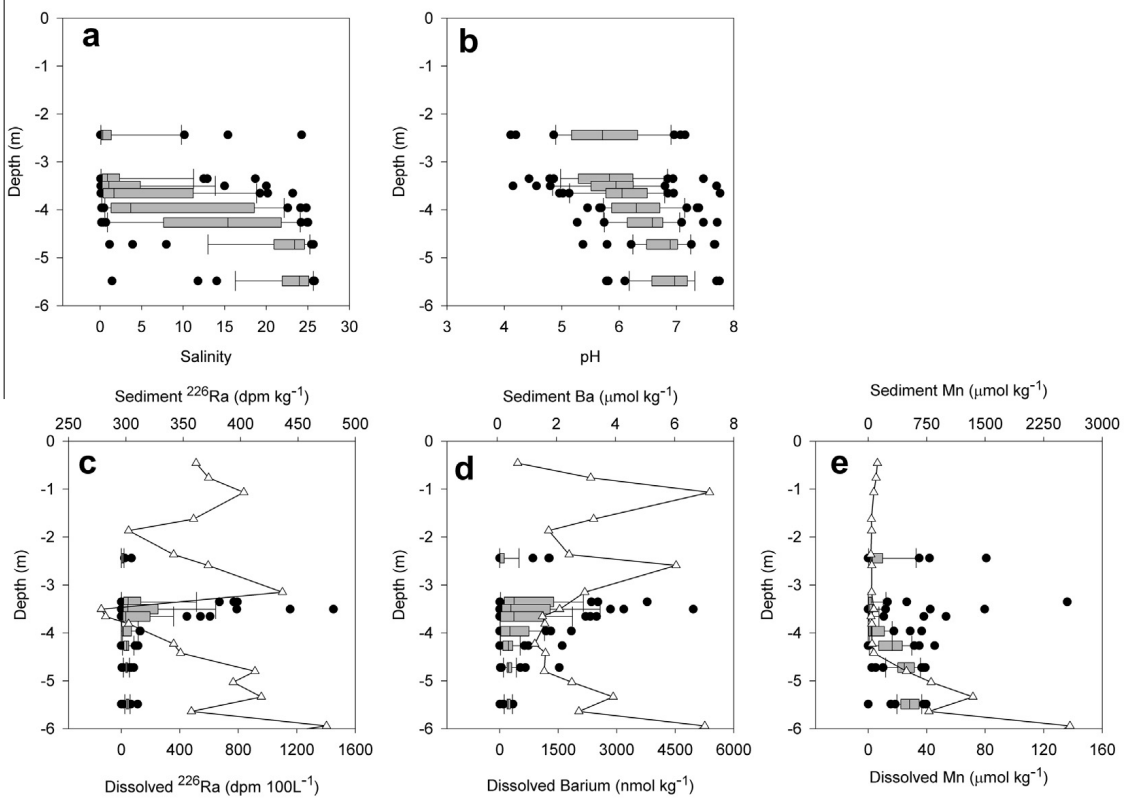

Fig. 3. Box and whisker plots of (a) salinity, (b) $\mathrm{pH}$, (c) dissolved and total sediment ${ }^{226} \mathrm{Ra}$, (d) dissolved and sediment surface oxide associated $\mathrm{Ba}$ and (e) dissolved and sediment surface oxide associated $\mathrm{Mn}$. These plots contain all data points over the three-year time series for each depth. The gray box marks the 25th, 50th and 75th percentile of samples, with the 5th and 95th percentile of samples marked by the lines extending from the box. Outliers are plotted as points. The sediment profiles were collected in June 2006 and are shown here to provide sediment geochemical background for interpreting the time series water chemistry (Gonneea et al., 2008).

and 2). Total sediment radium showed little variation with depth and averaged $370 \pm 60 \mathrm{dpm} \mathrm{kg}^{-1}$ for ${ }^{226} \mathrm{Ra}$ $410 \pm 90 \mathrm{dpm} \mathrm{kg}^{-1}$ for ${ }^{228} \mathrm{Ra}$, and $700 \pm 160 \mathrm{dpm} \mathrm{kg}^{-1}$ for ${ }^{224} \mathrm{Ra}$ (supported by ${ }^{228} \mathrm{Th}$ ). We assume that ${ }^{224} \mathrm{Ra}$ is in secular equilibrium with ${ }^{228} \mathrm{Th}$ since sediments were aged at least three weeks prior to counting.

Like its alkaline earth counterpart $(\mathrm{Ra})$, dissolved $\mathrm{Ba}$ concentrations also oscillated with the movement of the STZ from less than 10 to greater than $3,000 \mathrm{nmol} \mathrm{kg}^{-1}$ (Fig. 2d). The greatest $\mathrm{Ba}$ increase occurred during high salinity periods in the band of sediments from 3.1 to $4.1 \mathrm{~m}$. Dissolved Ba was relatively constant (100$400 \mathrm{nmol} \mathrm{kg}^{-1}$ ) in the high salinity portion of the STE (Fig. 3d). As with ${ }^{226} \mathrm{Ra}$, peak concentrations of $\mathrm{Ba}$ are observed around salinity 15 (Fig. 4a). However, estuarine release is apparent from a salinity of $\sim 2$.

Oscillations between high and low concentrations were observed in the dissolved $\mathrm{Mn}$ and Fe records (Fig. 2e and Supplemental Fig. 1). Dissolved Mn tracked the increase in salinity as the salinity transition zone moved landward and seaward. Note however that the dissolved Mn was high $\left(30 \mu \mathrm{mol} \mathrm{kg}{ }^{-1}\right)$ only within the core of the high salinity zone (depth $>4 \mathrm{~m}$ ), a region that was marked by sediment coated with Mn-oxides (Figs. 3e and 4e). Above this region, there were minimal fluctuations in dissolved $\mathrm{Mn}$ with a few large excursions $\left(80-140 \mu \mathrm{mol} \mathrm{kg}^{-1}\right)$ above the relatively constant $<1 \mu \mathrm{mol} \mathrm{kg}{ }^{-1}$ background (Fig. 4e). Dissolved
Fe was also quite low, at or below detection $\left(0.1 \mu \mathrm{mol} \mathrm{kg}^{-1}\right)$ for the majority of the time series. Dissolved Fe increased to $20-80 \mu \mathrm{mol} \mathrm{kg}{ }^{-1}$ several times at shallow depths, coincident with the first occurrence of surface adsorbed Fe-oxides on the sediment (Supplemental Fig. 2).

\section{DISCUSSION}

\subsection{Periodic release of radium and barium via ion exchange}

Large releases of radium and barium into the groundwater were observed in the subterranean estuary of Waquoit Bay and corresponded to fluctuations in salinity. The salinity of the STE at the time series location fluctuated as the salinity transition zone moved in response to changes in the hydraulic gradient (Gonneea et al., 2013). Periods dominated by marine groundwater corresponded to low hydraulic gradients and landward movement of the STZ, while increases in the hydraulic gradient resulted in seaward movement of the STZ and freshening at the time series location. The radium and barium partition coefficients $\left(K_{\mathrm{d}}\right.$, the ratio of adsorbed to dissolved species) are a function of salinity, such that low salinity periods favor the adsorbed phase, while an increase in salinity results in a greater dissolved fraction (in these sediments in situ $\mathrm{Ra} K_{\mathrm{d}} \approx 1000$ $\left(\mathrm{Lkg}^{-1}\right)$ at salinity 0 and $K_{\mathrm{d}} \approx 90\left(\mathrm{Lkg}^{-1}\right)$ at salinity 20 (Gonneea et al., 2008) and $\mathrm{Ba} K_{\mathrm{d}} \approx 1000\left(\mathrm{Lkg}^{-1}\right)$ for glacial/flu- 

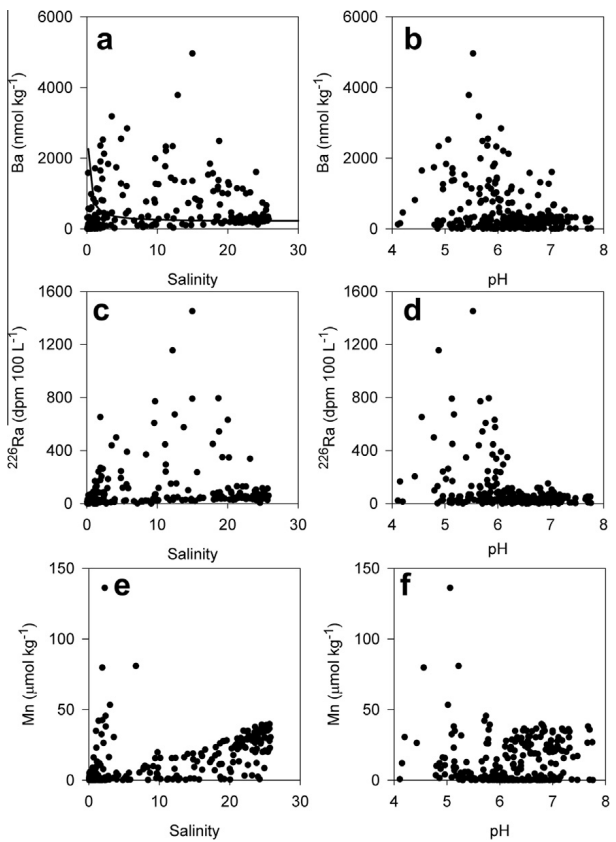

Fig. 4. Element versus salinity plots for (a) Ba, (c) ${ }^{226} \mathrm{Ra}$ and (e) $\mathrm{Mn}$ and element versus $\mathrm{pH}$ plots for (b) $\mathrm{Ba}$, (d) ${ }^{226} \mathrm{Ra}$ and (f) $\mathrm{Mn}$. These plots contain all data points over the three-year time series for each depth. Estuarine release of $\mathrm{Ba}$ and ${ }^{226} \mathrm{Ra}$ is evident at intermediate salinities in (a) and (c). The sorption edge for ${ }^{226} \mathrm{Ra}$ is apparent at $\mathrm{pH} 6$ in (d). Theoretical barite saturation is shown in (a).

vial material (Grutter et al., 1992)). In addition, $K_{\mathrm{d}}$ may be inversely related to the groundwater $\mathrm{pH}$, with greater dissolved Ra expected at lower $\mathrm{pH}$ (Beck and Cochran, 2013).

To determine whether $\mathrm{pH}$ or salinity controlled the dissolved $\mathrm{Ra}$ and $\mathrm{Ba}$ concentrations over the time series, we examined the relationship between changes in salinity and $\mathrm{pH}$ and dissolved $\mathrm{Ba}$ and ${ }^{226} \mathrm{Ra}$ across the wide concentration ranges present in the STE. A change is defined as the difference in the parameter (i.e. salinity, $\mathrm{pH},{ }^{226} \mathrm{Ra}$ or $\mathrm{Ba}$ ) from time point $\mathrm{n}$ to time point $n+1$. Thus a positive value indicates an increase in that parameter with time (Fig. 5). According to the $K_{\mathrm{d}}$ dependence described above, we expect an increase in salinity to desorb radium and barium, i.e. a positive relationship between changes in salinity and dissolved concentrations, while an increase in $\mathrm{pH}$ will result in sorption, i.e. a negative relationship between $\mathrm{pH}$ and changes in dissolved concentrations. We observe a positive trend between changes in salinity and changes in ${ }^{226} \mathrm{Ra}$ and Ba (Fig. 5 and Supplemental Table 1). However, this relationship varies with location in the subterranean estuary. For example, there is a much lower slope between salinity changes and corresponding $\mathrm{Ba}$ and ${ }^{226} \mathrm{Ra}$ changes within the region of $\mathrm{Mn}-\mathrm{Fe}$ oxide coated sediments $(5.5 \mathrm{~m}) \mathrm{com}-$ pared to sediments above this region, likely due to the high affinity of Mn-oxide coated sediments for $\mathrm{Ba}$ and $\mathrm{Ra}$. While we observe the expected negative relationship between changes in $\mathrm{pH}$ and dissolved ${ }^{226} \mathrm{Ra}$ and $\mathrm{Ba}$, this relationship is never significant (Fig. 5 and Supplemental Table 1). Further evidence that changes in $\mathrm{pH}$ are not associated with sorption and release of $\mathrm{Ba}$ and $\mathrm{Ra}$ is provided by the lack of $\mathrm{Ba}$ and $\mathrm{Ra}$ variability at $2.4 \mathrm{~m}$, where the $\mathrm{pH}$ range is the most dynamic (5-7), but low salinity is maintained. Given the occurrence of the highest dissolved $\mathrm{Ba}$ and $\mathrm{Ra}$ within the region of the largest salinity gradients over time (3.1$4.1 \mathrm{~m}$ ) and the significant positive relationship between changes in salinity and ${ }^{226} \mathrm{Ra}$ (from 3.4 to $4.2 \mathrm{~m}$ ) and $\mathrm{Ba}$ (at $3.4,4.0$ and $5.0 \mathrm{~m}$ ), we conclude that ion exchange reactions were driving the large seasonal releases of these elements. These adsorption/desorption reactions occur on a timescale of hours such that the dissolved Ra in groundwater is expected to reach equilibrium rapidly with the sediment Ra pool (Gonneea et al., 2008).

The similar behavior of $\mathrm{Ba}$ and $\mathrm{Ra}$, which suggests that they had the same source and were driven by similar processes, has been observed previously in the STE (Charette et al., 2005; Gonneea et al., 2008; Kiro et al., 2012). Considering the three orders of magnitude range in $\mathrm{Ba}$ and ${ }^{226} \mathrm{Ra}$ concentrations, these elements were well correlated over time and at different depths and groundwater salinities within the STE (all data $r^{2}=0.5, p<0.0001$ ). Hence, ${ }^{226} \mathrm{Ra}$ was behaving like a stable element, and therefore its cycling did not appear to be controlled by production from its sediment-bound parent ${ }^{230} \mathrm{Th}$. Modeling results in the Waquoit coastal aquifer further support this conclusion. Michael et al. (2011) determined steady state ${ }^{226} \mathrm{Ra}$ activities as a function of different production and retardation rates along a flow path (i.e. as a function of time) within both the terrestrial and marine groundwater regions of the subterranean estuary. This model was not able to reproduce the spatial variability evident in Waquoit Bay subterranean estuary solely as a function of the groundwater residence time and salinity, likely due subsurface heterogeneity in production/retardation factors and nonsteady-state conditions (Michael et al., 2011). This is in contrast to a similar study of the Dead Sea aquifer, where the groundwater ${ }^{226} \mathrm{Ra}$ activity was explained by mixing between modified Dead Sea water mixing with Ra-poor terrestrial water (Kiro et al., 2012).

We hypothesize that the sediments of the subterranean estuary were acting as a geochemical capacitor for ${ }^{226} \mathrm{Ra}$ and $\mathrm{Ba}$ on seasonal time scales as previously proposed for the Ganges-Brahmaputra River Delta by Moore (1997). During periods of low hydraulic gradient across the STE, landward transgression of the STZ inundated sediments that had previously been bathed in fresh water with high salinity water. This salinity increase led to $\mathrm{Ba}$ and ${ }^{226} \mathrm{Ra}$ desorption from sediments as a result of the lower partition coefficient for these elements at high salinity. When the hydraulic gradient increased, the flux of fresh water over these sediments resulted in an increase in sorption, due to both the decrease in salinity (and concurrent increase in the partition coefficient) and the prior removal of $\mathrm{Ba}$ and

${ }^{226} \mathrm{Ra}$ from sediment surfaces during periods of high salinity (i.e. there was an increase in the ion exchange capacity). 

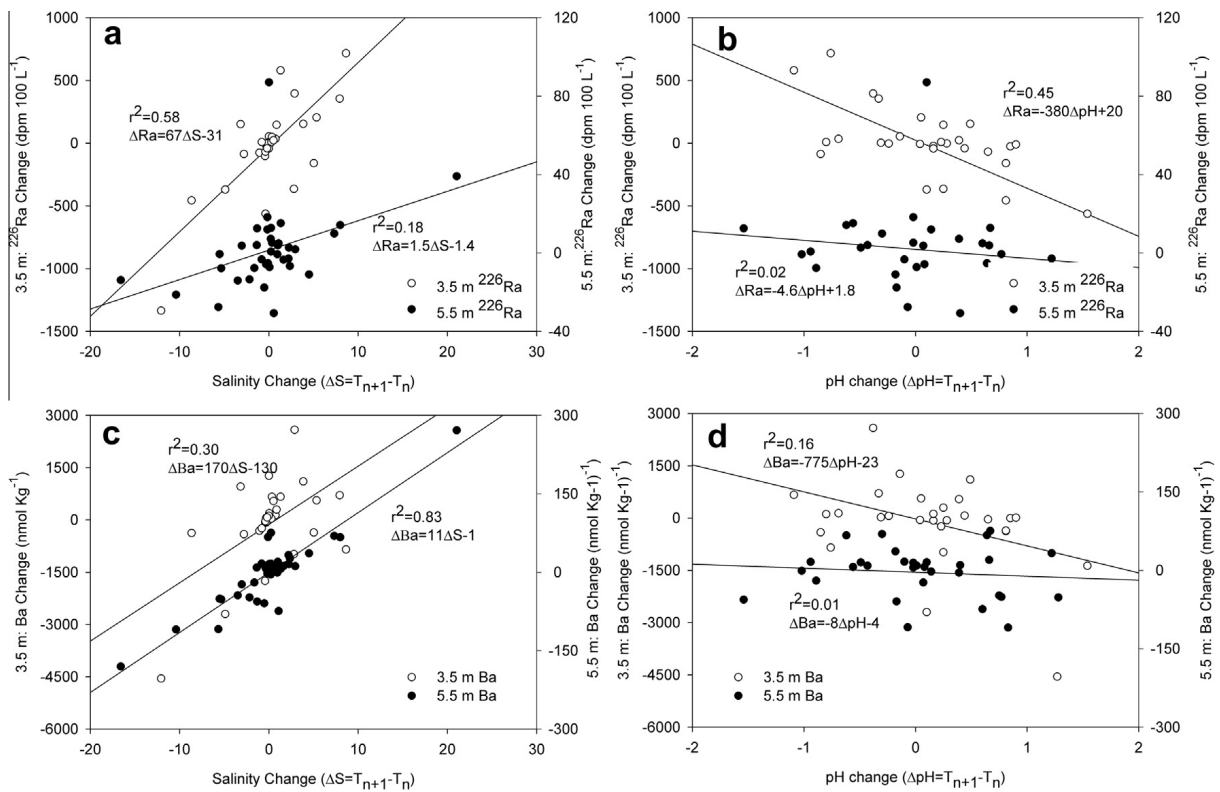

Fig. 5. Temporal changes between groundwater salinity and (a) ${ }^{226} \mathrm{Ra}$ and (c) $\mathrm{Ba}$ and $\mathrm{pH}$ and (b) ${ }^{226} \mathrm{Ra}$ and (d) Ba during the three-year time series from two depths within the subterranean estuary. The record at $3.5 \mathrm{~m}$ was within the region of greatest salinity, $\mathrm{pH}$, Ba and $\mathrm{Ra}$ variability, while $5.5 \mathrm{~m}$ was within the $\mathrm{Mn}-\mathrm{Fe}$ oxide region. The change in salinity and $\mathrm{pH}$ is defined as $\Delta \mathrm{S}$ or $\Delta \mathrm{pH}=t_{n+1}-t_{n}$, where $t$ is the time point and $n$ is the number, whereby a positive value indicates the salinity or $\mathrm{pH}$ has increased between time points. $\Delta$ Salinity is positively correlated with changes in both ${ }^{226} \mathrm{Ra}$ and $\mathrm{Ba}$. The negative relationship between changes in $\mathrm{pH}$ and both ${ }^{226} \mathrm{Ra}$ and $\mathrm{Ba}$ is poorly correlated. The relationship between $\Delta \mathrm{S}$ and ${ }^{226} \mathrm{Ra}$ and Ba varies based on location (depth) within the subterranean estuary, indicating a potential control by sediment geochemistry on the sensitivity of the partition coefficient $\left(K_{\mathrm{d}}\right)$ to changes in salinity. Note different axes for data from each depth. Supplemental Table 1 includes the relationship and correlation coefficient for these relationships for all depths.

Previous studies of the STE of Waquoit Bay have highlighted the importance of redox cycling of $\mathrm{Mn}$ and $\mathrm{Fe}$ oxides to alkaline earth elements (such as $\mathrm{Ba}$ and $\mathrm{Ra}$ ) that have an affinity to sorb to these oxide phases (Charette and Sholkovitz, 2006; Dulaiova et al., 2008; Gonneea et al., 2008). While surface bound $\mathrm{Ra}$ and $\mathrm{Ba}$ on sediments are not directly controlled by groundwater redox conditions, these elements do have an affinity for $\mathrm{Mn}$ and $\mathrm{Fe}$ oxides and thus were found in the core of the reducing marine groundwater (Spiteri et al., 2006; Gonneea et al., 2008). Our data support the idea that the Mn oxide cycle responded to seasonal oscillations in salinity, as the region with elevated dissolved Mn fluctuated concurrently with salinity (Fig. 2e). The highest concentration of dissolved Mn was found within the region of the subterranean estuary dominated by marine groundwater, at depths greater than $4.5 \mathrm{~m}$ for much of the year, and coincided with the region of high sediment bound Mn-oxides. This region of $\mathrm{Mn}$ oxides likely helped maintain the relatively constant ${ }^{226} \mathrm{Ra}$ activities found in the saline region of the subterranean estuary due to effective scavenging of ${ }^{226} \mathrm{Ra}$, as the $\mathrm{Mn}$ oxide region has about three times the adsorbed ${ }^{226} \mathrm{Ra}$ compared to sediments in other portions of the STE (Gonneea et al., 2008). Beck and Cochran (2013) suggest that the presence of sediment Mn-Fe oxide coatings effectively buffer dissolved concentrations, as we observe here in the $\mathrm{Mn}$ and $\mathrm{Fe}$ curtain regions of the subterranean estuary, where dissolved ${ }^{226} \mathrm{Ra}$ and $\mathrm{Ba}$ are elevated but temporally stable. However, there is no evidence for $\mathrm{Mn}$ oxide dissolution (i.e. high dissolved $\mathrm{Mn}$ ) in the region between 3.1 and $4.1 \mathrm{~m}$ concurrent with the dynamic cycling of $\mathrm{Ba}$ and $\mathrm{Ra}$. Thus dissolution and precipitation of $\mathrm{Mn}$ oxides do not appear to be driving the large seasonal releases of $\mathrm{Ba}$ and $\mathrm{Ra}$. However, it is the presence of $\mathrm{Mn}$ $\mathrm{Fe}$ oxides on sediments throughout the subterranean estuary that resulted in increased partitioning between the adsorbed and dissolved phase since sediments coated with oxides have higher $K_{\mathrm{d}}$ 's than sediments without these oxides (Gonneea et al., 2008; Beck and Cochran, 2013). Subterranean estuary sediments outside the extremely enriched $\mathrm{Fe}$ and $\mathrm{Mn}$ curtains have adsorbed $\mathrm{Mn}$ of 50 $100 \mu \mathrm{mol} \mathrm{kg}{ }^{-1}$ and adsorbed $\mathrm{Fe}$ of $3000-8000 \mu \mathrm{mol} \mathrm{kg}{ }^{-1}$. Indeed, we propose that it is the increase in $\mathrm{Fe}-\mathrm{Mn}$ oxides on sediments within the STE compared to inland aquifer sediments that is responsible for these sediments sorbing radium and barium from terrestrial groundwater flowing into the subterranean estuary. Recently Beck and Cochran (2013) reported a 4-5-fold increase in Mn and Fe content over eight months in "pristine" sands deposited on a Virginia beach for replenishment, demonstrating that sediment alteration within the coastal subterranean estuary occurs rapidly. 
We also considered the importance of barite $\left(\mathrm{BaSO}_{4}\right)$ formation on scavenging $\mathrm{Ra}$ from solution, since this mechanism has been shown to be important in ocean sediments (Paytan et al., 1996), laboratory experiments (Beck and Cochran, 2013) and in the Dead Sea aquifer (Kiro et al., 2012). If such a mechanism were important we would expect removal of dissolved $\mathrm{Ba}$ and $\mathrm{Ra}$ concurrently with an increase in salinity. In fact, the opposite is observed, with an increase in salinity concurrent with groundwater $\mathrm{Ba}$ and $\mathrm{Ra}$ concentrations, at times above barite saturation. $\mathrm{Ba}$ concentrations that exceed theoretical barite saturation have been observed many times in the subterranean estuary, perhaps due to slow kinetics of barite precipitation or stabilization with organic ligands (Shaw et al., 1998; Windom and Niencheski, 2003; Charette and Sholkovitz, 2006; Santos et al., 2011). Thus, barite formation does not appear to control dissolved $\mathrm{Ba}$ and $\mathrm{Ra}$ within the time series data presented here.

\subsection{Potential Ra and Ba fluxes to Waquoit Bay surface waters}

We evaluated the influence of temporally changing groundwater end members on SGD-associated fluxes to Waquoit Bay surface waters by combining the results of the hydrodynamic model with the time series chemical data. Given the dynamic character of the salinity transition zone, the end member chemistry of discharging water was expected to be a mixture of water from different regions of the STE, as has been shown previously by Michael et al. (2011). The results from the hydrodynamic model provided both total flux and the salinity of that flux. Thus, we divided the groundwater flux into different pools based on the salinity of the discharging water. To do this, the modeled groundwater discharge was sorted into five different salinity groups $(0-5,>5-10,>10-15,>15-20$ and $>20)$. Groundwater-derived $\mathrm{Ra}$ and $\mathrm{Ba}$ fluxes were then calculated by multiplying average groundwater radium and barium concentrations times water fluxes within the same salinity groups. Fluxes were determined for each month from January 2005 through May 2007 (Fig. 6).

Such a salinity-weighted approach to determining groundwater chemical fluxes assumes that the chemistry of the groundwater sampled corresponds to the chemistry of the modeled water flux for each salinity group. Michael et al. (2011) demonstrated that the Ra activity of groundwater was closely tied to the sampling location within the STE. The ${ }^{226}$ Ra activity reported by Michael et al. (2011) for different regions within the STE tend to correspond to similar salinity groups used in the present study, with the exception of ${ }^{226} \mathrm{Ra}$ activity used for the $>20$ salinity marine groundwater. In the time series data presented here, ${ }^{226} \mathrm{Ra}$ in the $>20$ salinity fraction was $41 \pm 7.7 \mathrm{dpm} 100 \mathrm{~L}^{-1}$, a value much closer to the activity Michael et al. (2011) reported for discharge away from the mixing zone $\left(\sim 23 \mathrm{dpm} 100 \mathrm{~L}^{-1}\right)$ than the activity of the deep marine groundwater $\left(\sim 290 \mathrm{dpm} 100 \mathrm{~L}^{-1}\right)$ below the mixing zone (Michael et al., 2011). Thus the fluxes presented here associated with the marine groundwater end member may be underestimates if much of the saline discharge originates below the mixing zone.

To calculate the chemical flux of $\mathrm{Ra}$ and $\mathrm{Ba}$ associated with groundwater discharge, we only considered water discharging across the full mixing zone of the model (the region beginning at the $\mathrm{CCCl}$ well and extending $130 \mathrm{~m}$ seaward, see Gonneea et al. (2013) for further details). We did not consider recirculated water being pumped in and out of sediments further out in the bay (i.e. $>100 \mathrm{~m}$ from mean sea level), which may be a significant flux of recirculated seawater. This water flux was not considered in the present study because it has the same ${ }^{226} \mathrm{Ra}$ activity as bay water (Michael et al., 2011) and thus likely had no net effect on the ${ }^{226} \mathrm{Ra}$ flux associated with groundwater transport through the STE.

There is a strong seasonality in the modeled water flux and salinity of discharging water (Fig. 6). The average shoreline normalized terrestrial groundwater flux was $3.4 \pm 0.46$ (minimum 2.6, maximum 4.6) $\mathrm{m}^{3} \mathrm{~m}^{-1}$ day $^{-1}$ and varied little with time. There was a large temporal variability in discharge of marine groundwater of $1.6 \pm 1.4$ (minimum 0.39 , maximum 4.7$) \mathrm{m}^{3} \mathrm{~m}^{-1}$ day $^{-1}$ and associated submarine groundwater recharge (SGR), the inflow of bay water into the STE. Model-derived groundwater fluxes of both terrestrial (salinity of 0 ) and marine (bay water salinity of 30 ) fluxes compare well with previously reported estimates. Terrestrial groundwater discharge rates along the head of Waquoit Bay determined from a variety of techniques are reported to be $1.6-1.8 \mathrm{~m}^{3} \mathrm{~m}^{-1}$ day $^{-1}$ (recharge method, Cambareri and Eichner (1998)), $3.5 \mathrm{~m}^{3}$ $\mathrm{m}^{-1}$ day $^{-1}$ (seepage meters, Michael (2004)) and $4.0 \mathrm{~m}^{3} \mathrm{~m}^{-1}$ day $^{-1}$ (Darcy method, Mulligan and Charette (2006)). Marine groundwater discharge estimates are more variable between $0.6 \mathrm{~m}^{3} \mathrm{~m}^{-1}$ day $^{-1}$ (radium isotopes, Mulligan and Charette (2006)) and $6.9 \mathrm{~m}^{3} \mathrm{~m}^{-1}$ day $^{-1}$ (seepage meters, Michael (2004)).

Groundwater radium activities and barium concentrations were not in phase with the water flux, with maximum concentrations occurring in October 2005, May 2006, December 2006, and July 2007 (Figs. 2 and 6). Water fluxes peaked from May to October 2005 and 2006. Since the magnitude of the change in groundwater radium activities and barium concentrations was greater than the relative change in water flux, the amount of radium and barium exported to the bay was dominated by the changes in STE radium activities and barium concentrations. The range in ${ }^{226} \mathrm{Ra}$ and $\mathrm{Ba}$ fluxes was $110-5710 \mathrm{dpm} \mathrm{m}^{-1} \mathrm{~d}^{-1}$ and $0.1-$ $8.4 \mathrm{mmol} \mathrm{m}^{-1} \mathrm{~d}^{-1}$. This ${ }^{226} \mathrm{Ra}$ flux compares well to a previous flux of $1080 \mathrm{dpm} \mathrm{m}^{-1} \mathrm{~d}^{-1}$ in July 2003 reported by Mulligan and Charette (2006). Integrating across the $2 \mathrm{y}$ of model and time series data (January 2005 to December 2006), the shoreline normalized radium and barium fluxes were $67-84 \times 10^{4} \mathrm{dpm} \mathrm{m}^{-1} \mathrm{y}^{-1}$ for ${ }^{226} \mathrm{Ra}, 160-280 \times 10^{4}$. $\mathrm{dpm} \mathrm{m}^{-1} \mathrm{y}^{-1}$ for ${ }^{228} \mathrm{Ra}, 300-430 \times 10^{4} \mathrm{dpm} \mathrm{m}^{-1} \mathrm{y}^{-1}$ for ${ }^{224} \mathrm{Ra}$, and $0.59-0.70 \mathrm{~mol} \mathrm{~m}^{-1} \mathrm{y}^{-1}$ for Ba (Table 1).

Potential uncertainty in these chemical flux measurements may stem from either variability in water flux or end member concentration. As discussed above, water fluxes are well within previously reported values, giving us some confidence in this parameter. Uncertainty in end 

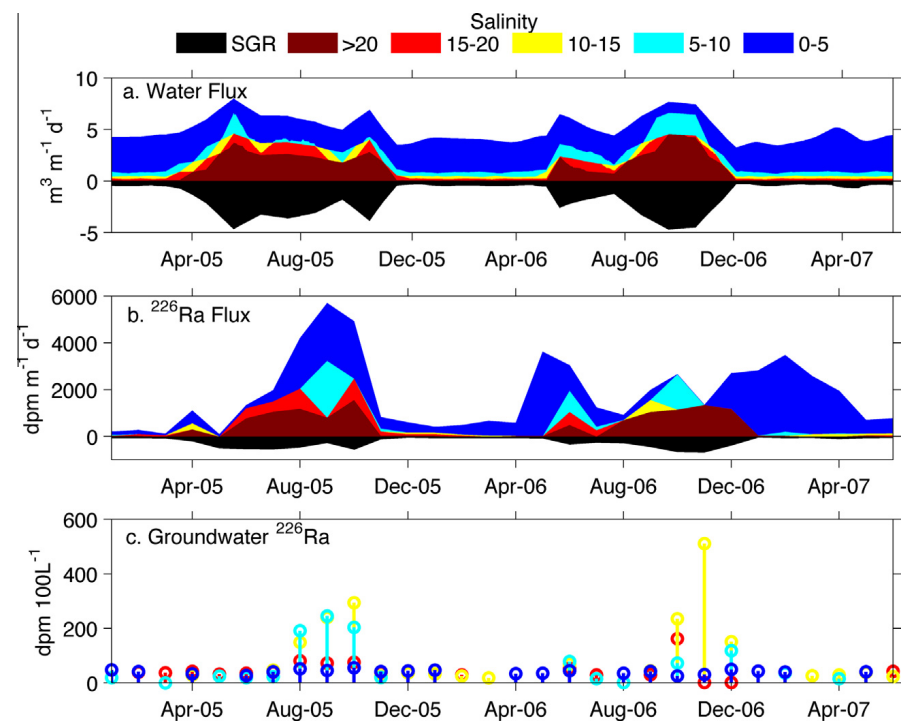

Fig. 6. (a) Model derived submarine groundwater discharge, (b) ${ }^{226} \mathrm{Ra}$ flux calculated with water fluxes from the hydrologic model and (c) contemporaneous ${ }^{226} \mathrm{Ra}$ end member activities. The water and ${ }^{226} \mathrm{Ra}$ fluxes and ${ }^{226} \mathrm{Ra}$ groundwater activities are divided into five different salinity end members. Ra flux is not in phase with water flux throughout much of the record since the groundwater end member variability dominates the radium flux term.

Table 1

Water, Ba and ${ }^{226} \mathrm{Ra}$ budget for the Waquoit Bay subterranean estuary.

\begin{tabular}{|c|c|c|c|c|c|c|}
\hline & \multicolumn{2}{|c|}{ Water flux $\left(\mathrm{m}^{3} \mathrm{~m}^{-1} \mathrm{y}^{-1}\right)$} & \multicolumn{2}{|c|}{ Ba flux $\left(\mathrm{mol} \mathrm{m}^{-1} \mathrm{y}^{-1}\right)$} & \multicolumn{2}{|c|}{${ }^{226} \mathrm{Ra}$ flux $\left(10^{4} \mathrm{dpm} \mathrm{m}^{-1} \mathrm{y}^{-1}\right)$} \\
\hline & Year $1^{\mathrm{a}}$ & Year 2 & Year 1 & Year 2 & Year 1 & Year 2 \\
\hline \multicolumn{7}{|l|}{ Input to STE } \\
\hline Terrestrial groundwater ${ }^{\mathrm{b}}$ & 1200 & 1200 & 0.15 & 0.14 & 18 & 18 \\
\hline Submarine groundwater recharge $(\mathrm{SGR})^{\mathrm{c}}$ & 730 & 620 & 0.05 & 0.04 & 11 & 9.3 \\
\hline \multicolumn{7}{|l|}{ Output from the STE } \\
\hline Submarine groundwater discharge & 1930 & 1820 & 0.70 & 0.59 & 67 & 84 \\
\hline \multicolumn{7}{|l|}{ Excess flux from STE } \\
\hline (output-input) & - & - & 0.50 & 0.41 & 38 & 57 \\
\hline$\%$ of input & - & - & 250 & 230 & 130 & 210 \\
\hline
\end{tabular}

${ }^{a}$ Hydrologic model year $1 / 2$ driven by 2005/2006 groundwater and sea level records. All fluxes are normalized to per meter of shoreline. To scale fluxes to the entire head of Waquoit Bay for comparison with previous work (i.e. Mulligan and Charette, 2006; Michael et al., 2011), multiply by $610 \mathrm{~m}$.

${ }^{\text {b }}$ Terrestrial groundwater end member used was: Ba $120 \mathrm{nmol} \mathrm{kg}{ }^{-1}$ and ${ }^{226} \mathrm{Ra} 15 \mathrm{dpm} 100 \mathrm{~L}^{-1}$ (Charette and Sholkovitz, 2006; Gonneea et al., 2008).

${ }^{c}$ Waquoit Bay water (source of recirculating marine groundwater) Ba is $70 \mathrm{nmol} \mathrm{kg}{ }^{-1}$ and ${ }^{226} \mathrm{Ra}_{15} \mathrm{dpm} 100 \mathrm{~L}^{-1}(\mathrm{Charette}$ et al., 2001 ; Charette and Sholkovitz, 2006; Charette, unpublished data).

member concentrations is difficult to determine since $\mathrm{Ba}$ and ${ }^{226} \mathrm{Ra}$ concentrations were under sampled - that is there were only eight measurements at each sampling time point. While this approach allows us to account for temporal variability, which we found to be large, we cannot determine the full range of potential $\mathrm{Ba}$ and ${ }^{226} \mathrm{Ra}$ values within the STE at each time point. We discuss in the next section how the chosen end members impact our evaluation of the ${ }^{226} \mathrm{Ra}$ and $\mathrm{Ba}$ budgets of the subterranean estuary.

\subsection{Seasonal budgets of ${ }^{226} \mathrm{Ra}$ and Ba within the subterranean estuary}

Since the dynamic temporal scale of the subterranean estuary was seasonal, we expect fluxes into and out of the 
system to be equal over the course of a year if the system is at steady state. To determine if the subterranean estuary $\mathrm{Ba}$ and ${ }^{226} \mathrm{Ra}$ budgets were in balance during the two complete years with water flux data, we calculated inputs to the STE from both terrestrial groundwater and recharging marine groundwater (Table 1). Input to the STE from terrestrial groundwater was calculated using the fresh water flux from the hydrologic model and terrestrial groundwater end member $\mathrm{Ba}$ and ${ }^{226} \mathrm{Ra}$ concentrations. Groundwater flowing into the Waquoit Bay subterranean estuary has a Ba concentration of $60 \pm 60 \mathrm{nmol} \mathrm{kg}^{-1}(n=44$, measured across multiple years and seasons) and a ${ }^{226} \mathrm{Ra}$ activity of $11 \pm 4 \mathrm{dpm} 100 \mathrm{~L}^{-1}(n=14)$ (Charette unpublished data; Charette and Sholkovitz, 2006; Gonneea et al., 2008). We used end member concentrations of $120 \mathrm{nmol} \mathrm{kg}^{-1}$ (Ba) and $15 \mathrm{dpm} 100 \mathrm{~L}^{-1}\left({ }^{226} \mathrm{Ra}\right)$ to ensure we considered maximum potential fluxes into the STE. The input from submarine groundwater recharge was derived from the bay water $\mathrm{Ba}$ and ${ }^{226} \mathrm{Ra}$ end member concentrations and the SGR flux in the hydrologic model (Table 1). Bay water $\mathrm{Ba}$ and ${ }^{226} \mathrm{Ra}$ has likewise been measured in multiple seasons and years and is $56 \pm 14 \mathrm{nmol} \mathrm{kg}^{-1}(n=68)$ and $11 \pm 4 \mathrm{dpm} 100 \mathrm{~L}^{-1}$ $(n=53)$ (Charette unpublished data; Charette et al., 2001; Charette and Sholkovitz, 2006). Again, to ensure maximum fluxes into the STE, we used $70 \mathrm{nmol} \mathrm{Ba} \mathrm{kg}{ }^{-1}$ and $15 \mathrm{dpm}$ ${ }^{226} \mathrm{Ra} 100 \mathrm{~L}^{-1}$ as end member concentrations.

This simple model of $\mathrm{Ba}$ and ${ }^{226} \mathrm{Ra}$ within the STE suggests that there is an excess flux (i.e. flux out-flux in) out of the subterranean estuary of both $\mathrm{Ba}$ and ${ }^{226} \mathrm{Ra}$ equivalent to $130-250 \%$ of total inputs (Table 1). Changes in either terrestrial or marine groundwater fluxes are unlikely to balance the input deficit, since any increase in these water fluxes results in a concurrent increase in SGD and associated export of $\mathrm{Ba}$ and ${ }^{226} \mathrm{Ra}$. Weathering and production via decay of ${ }^{230} \mathrm{Th}$ (in the case of ${ }^{226} \mathrm{Ra}$ ) are also too small to account for the imbalance. In situ production is estimated at only $0.007 \%$ of the excess ${ }^{226} \mathrm{Ra}$ flux $\left(44 \mathrm{dpm}{ }^{226-}\right.$ $\mathrm{Ra} \mathrm{m}^{-1} \mathrm{y}^{-1}$, where production of ${ }^{226} \mathrm{Ra}=\mathrm{A}^{230} \mathrm{Th} \times$ $\lambda^{226} \mathrm{Ra} / K_{\mathrm{d}}$, with an estimated ${ }^{230} \mathrm{Th}$ of $400 \mathrm{dpm} \mathrm{kg}{ }^{-1}$ and $K_{\mathrm{d}}$ of $1000 ; 130 \mathrm{~m}$ wide interface, $10 \mathrm{~m}$ deep). The Ba flux from weathering is approximately $0.05 \%$ of the excess $\mathrm{Ba}$ flux $\left(2.9 \times 10^{-4} \mathrm{~mol} \mathrm{~m}^{-1} \mathrm{y}^{-1}\right.$, calculated from an average grain size of 550 microns and $\mathrm{Ba}$ weathering rate of $2.7 \times 10^{-10} \mathrm{~mol} \mathrm{~m}^{-2} \mathrm{y}^{-1}$ (Bowen, 1979; White, 2003)).

Alternatively, the terrestrial groundwater and/or the bay water $\mathrm{Ba}$ and ${ }^{226} \mathrm{Ra}$ end members used in this budget may be too low. Michael et al. (2011) predicted equilibrium values for ${ }^{226} \mathrm{Ra}$ within the fresh portion of the STE to be $30 \mathrm{dpm} 100 \mathrm{~L}^{-1}$, which is twice our average value, but would still result in ${ }^{226} \mathrm{Ra}$ inputs to the STE equaling only of $54-70 \%$ of total ${ }^{226} \mathrm{Ra}$ export via SGD. The SGR input of $\mathrm{Ba}$ and ${ }^{226} \mathrm{Ra}$ was only $22-38 \%$ of total inputs, thus the bay end member values would need to be much larger to bring the $\mathrm{Ba}$ and ${ }^{226} \mathrm{Ra}$ budget into balance. The budget as calculated here already uses end members at the high end of previously measured values, thus inputs to the subterranean estuary are unlikely to be larger.

This large groundwater $\mathrm{Ba}$ and ${ }^{226} \mathrm{Ra}$ flux imbalance may result from a net sea level rise over the sampling time period, since sea level appears to be the main control of the movement of the salinity mixing zone (Gonneea et al., 2013). Sea level rise would result in sediments with large adsorbed pools of $\mathrm{Ra}$ and $\mathrm{Ba}$ being inundated repeatedly with marine groundwater, thereby releasing these elements into solution as hypothesized previously by Shaw et al. (1998). Indeed, mean sea level rise was $0.5 \mathrm{~cm} \mathrm{y}^{-1}$ from 1990 to 2007 , with a large step-wise increase in mean sea level of $5 \mathrm{~cm}$ between the periods of 2000-2004 and 2005-2006, the duration of this study (NOAA, 2012). The northeast coast of the United States is experiencing accelerating sea level rise, accounting for the observed dynamic sea level during this study (Sallenger et al., 2012). It is apparent that in addition to yearly seasonal oscillations in ${ }^{226} \mathrm{Ra}$ and $\mathrm{Ba}$ flux there are additional releases of these chemically reactive materials. During the preceding lower sea level stands, these elements were stored in the STE and are currently being released and exported via SGD.

We can compare the excess flux to the desorbable sediment pool of ${ }^{226} \mathrm{Ra}$ and $\mathrm{Ba}$ in the STE. Given the above mentioned sea level rise $(5 \mathrm{~cm})$ just prior to beginning our field sampling, approximately $6.5 \mathrm{~m}^{3}$ of aquifer per meter of shoreline was newly inundated across our model domain $(130 \mathrm{~m})$. The desorbable ${ }^{226} \mathrm{Ra}$ pool in that volume of aquifer (calculated from $100 \mathrm{dpm} \mathrm{kg}^{-1}$ dry sediment, $2.6 \mathrm{~g} \mathrm{~cm}^{-1}$ sediment density and 0.25 sediment porosity, Gonneea et al., 2008) is $126 \times 10^{4} \mathrm{dpm}, 3-4$ times greater than observed excess fluxes. Likewise, the desorbable pool of $\mathrm{Ba}$ $\left(110 \mu \mathrm{mol} \mathrm{kg}{ }^{-1}\right.$ dry sediment, Charette, unpublished data) present in the same aquifer volume is $1.41 \mathrm{~mol}$, about 2 times greater than the observed excess fluxes. Therefore, the observed sea-level rise could account all of the excess ${ }^{226} \mathrm{Ra}$ and $\mathrm{Ba}$ flux observed in this study.

Our knowledge of sediment geochemistry both in the subterranean estuary and beyond is limited. Sorbed ${ }^{226} \mathrm{Ra}$ at one location within the Mn-curtain of Waquoit Bay reached $320 \mathrm{dpm} \mathrm{kg}^{-1}$, while sorbed $\mathrm{Ba}$ of $300-$ $400 \mu \mathrm{mol} \mathrm{kg}{ }^{-1}$ has been observed on coastal and inland sediments (Gonneea et al., 2008; Charette, unpublished data). It is possible that the sediment pools of ${ }^{226} \mathrm{Ra}$ and $\mathrm{Ba}$ are larger than calculated here and thus accelerating sea level rise may result in greater export of ion exchangeable elements such as these. This finding highlights that there may be a potential increase in chemical flux via submarine groundwater discharge as sea level rises in concert with predicted climate change.

\section{CONCLUSIONS}

Radium fluxes to surface waters at the head of Waquoit Bay are a function of two parameters, the volume flux of water and the end member radium activity of that water. In the time series data presented here, temporal variability in radium concentrations was much greater than the corresponding change in water flux. As a result, radium fluxes were at times anti-phased with water fluxes. This conclusion highlights the importance of determining a groundwater end member radium concentration contemporaneously with any radium tracer calculation of submarine groundwater discharge. An increased flux of radium cannot a priori be assumed to indicate an increase in submarine groundwa- 
ter discharge without understanding how radium cycling within the subterranean estuary affects the radium activity of the discharging water.

This temporal disconnect between water and radium fluxes has important implications for studies that utilize radium tracer budgets to determine seasonal variability in SGD. Recently Moore and Shaw (2008) observed an increased radium flux during the summer months in coastal estuaries off the U.S. Atlantic coast and attributed this to an increase in SGD due to increased marsh interactions (e.g. bioirrigation) in the summer time and to a lag between precipitation and SGD. Kelly and Moran (2002) measured seasonally variable radium fluxes to the Pettaquamscutt Estuary, Rhode Island, and observed the highest fluxes of radium in the summer. Groundwater radium values for this study were measured once (in August) and used to calculate SGD values, which they concluded were higher in the summer than the winter, in phase with the radium flux. A recent study in this same region collected groundwater during different seasons and recognized that variability in the pore water activity likely accounted for some of the increased radium flux observed (Hougham et al., 2008). Increases in radium fluxes, such as reported here and in the works listed above, may not be due solely to an increase in submarine groundwater discharge, but also to an increase in the en member radium activity. Thus these findings highlight the importance of understanding the background hydrology of the system under study when applying radium tracers of SGD. Furthermore, the assumption of temporally constant radium activities is clearly invalid in the face of significant temporal salinity changes within the subterranean estuary. Additional time series measurements of groundwater chemistry in other subterranean estuaries would confirm the role seasonal cycling plays in groundwater radium and barium concentrations within coastal aquifer systems.

Temporal variability in groundwater radium and barium concentrations ranged over three orders of magnitude during a three-year time series of the subterranean estuary of Waquoit Bay. These fluctuations resulted from movement of the salinity interface resulting in a narrow region (approximately $1 \mathrm{~m}$ vertical extent) that experiences large fluctuations in water chemistry (Gonneea et al., 2013). Concurrent with an increase in salinity within this dynamic region are large releases of the alkaline earth elements $\mathrm{Ba}$ and $\mathrm{Ra}$, suggesting that ion exchange reactions are the most important process controlling seasonal variability and that the subterranean estuary acts as an ion exchange reservoir for these elements on seasonal time scales. $\mathrm{Ra}$ and $\mathrm{Ba}$ are added to terrestrial groundwater upland of the subterranean estuary and are then transported to the salinity-mixing zone of the subterranean estuary. Here $\mathrm{Ba}$ and $\mathrm{Ra}$ are concentrated onto sediments at the coast due to $\mathrm{Mn}-\mathrm{Fe}$ oxides coatings, and then are released or sorbed due to changes in groundwater salinity.

The behavior of the subterranean estuary as an "ion capacitor" has important implications for the timing of the release of chemically reactive constituents via submarine groundwater discharge. For example, SGD-derived fluxes of contaminants to surface waters involved in salinity or redox driven reactions could be modulated in a simila way (e.g. mercury (Bone et al., 2007) and arsenic (Bone et al., 2006; Jung et al., 2009)). These processes may also result in the uncoupled transport of anions and cations, as has been observed for nitrate and phosphate (de Sieyes et al., 2008; Slomp and Van Cappellen, 2004).

On the time scale of this study, export of $\mathrm{Ba}$ and $\mathrm{Ra}$ from the subterranean estuary cannot be balanced with respect to known imports. We contend that this is a result of long term storage of these cations within the sediments of the STE as has been hypothesized elsewhere (Moore and Shaw, 1998; Shaw et al., 1998) and subsequent release during the current period of accelerating sea level rise (Yin et al., 2009; Sallenger et al., 2012). Super imposed upon seasonal oscillations in groundwater chemistry in sync with sea level fluctuations are other perturbations in sea level, caused by wind and ocean circulation changes coincident with El Niño and North Atlantic Oscillation (NAO) dynamics (Llovel et al., 2011; Sweet and Zervas, 2011). Interannual climate fluctuations that control sea level and precipitation (e.g. El Niño Southern Oscillation and $\mathrm{NAO}$ ), and thus the position of the mixing zone within the subterranean estuary, may ultimately control the timing and magnitude of chemical and water flux via submarine groundwater discharge. Our results may also require a reevaluation of any trace element mass balance models (e.g. Sr (Basu et al., 2001; Beck et al., in press) and U (Dunk et al., 2002)) for the ocean that rely on a steady-state contribution from terrestrial sources such as SGD.

\section{ACKNOWLEDGEMENTS}

The authors thank Paul Henderson, Gillian Smith, DeAnna McCadney and Grace Rago for assistance in the field and laboratory. Scot Birdwhistell of the WHOI ICP-MS Facility assisted with trace metal analyses. We extend our continued appreciation to the director and staff of the Waquoit Bay National Estuarine Research Reserve for their assistance with logistics during field sampling. Comments by Associate Editor Tim Shaw and two anonymous reviewers greatly improved this work. This research was sponsored by NSF (OCE-0425061 to M.A.C. and A.E.M. and OCE-0751525 to M.A.C.). M.E.G. was supported by an NDSEG graduate fellowship and was awarded a graduate fellowship from the Estuarine Reserves Division, Office of Ocean and Coastal Resource Management, National Ocean Service, National Oceanic and Atmospheric Administration.

\section{APPENDIX A. SUPPLEMENTARY DATA}

Supplementary data associated with this article can be found, in the online version, at http://dx.doi.org/10.1016/ j.gca.2013.05.034

\section{REFERENCES}

Abarca E., Karam H. N., Hemond H. F. and Harvey C. F. (2013) Transient groundwater dynamics in a coastal aquifer: the effects of tides, the lunar cycle and the beach profile. Water Resour. Res.. http://dx.doi.org/10.1002/wrcr.20075.

Basu A. R., Jacobsen S. B., Poreda R. J., Dowling C. B. and Aggarwal P. K. (2001) Large groundwater strontium flux to the 
oceans from the Bengal basin and the marine strontium isotope record. Science 293, 1470-1473.

Beck A. J., Charette M. A., Cochran J. K., Gonneea M. E. and Peucker-Ehrenbrink B. (2013) Dissolved strontium behavior in the subterranean estuary - implications for the $\mathrm{Sr}$ isotope budget of the global ocean. Geochim. Cosmochim. Acta, http:// dx.doi.org/10.1016/j.gca.2013.1003.1021.

Beck A. J., Cochran J. K. and Sanudo-Wilhelmy S. A. (2010) The distribution and speciation of dissolved trace metals in a shallow subterranean estuary. Mar. Chem. 121, 145-156.

Beck A. J. and Cochran M. A. (2013) Controls on solid-solution partitioning of radium in saturated marine sands. Mar. Chem., http://dx.doi.org/10.1016/j.marchem.2013.01.008.

Beck A. J., Tsukamoto Y., Tovar-Sanchez A., Huerta-Diaz M., Bokuniewicz H. J. and Sanudo-Wilhelmy S. A. (2007) Importance of geochemical transformations in determining submarine groundwater discharge-derived trace metal and nutrient fluxes. Appl. Geochem. 22, 477-490.

Bone S. E., Charette M. A., Lamborg C. H. and Gonneea M. E. (2007) Has submarine groundwater discharge been overlooked as a source of mercury to coastal waters? Environ. Sci. Technol. 41, 3090-3095

Bone S. E., Gonneea M. E. and Charette M. A. (2006) Geochemical cycling of arsenic in a coastal aquifer. Environ. Sci. Technol. 40, 3273-3278.

Bowen H. J. M. (1979) Environmental Chemistry of the Elements. Academic Press, London, UK and New York, NY, USA.

Breier J. A., Breier C. F. and Edmonds H. N. (2010) Seasonal dynamics of dissolved $\mathrm{Ra}$ isotopes in the semi-arid bays of south Texas. Mar. Chem. 122, 39-50.

Cambareri T. C. and Eichner E. M. (1998) Watershed delineation and ground water discharge to a coastal embayment. Ground Water 36, 626-634.

Charette M. A. (2007) Hydrologic forcing of submarine groundwater discharge: insight from a seasonal study of radium isotopes in a groundwater-dominated salt marsh estuary. Limnol. Oceanogr. 52, 230-239.

Charette M. A. and Allen M. C. (2006) Precision ground water sampling in coastal aquifers using a direct-push, shielded-screen well-point system. Ground Water Monit. Remediat. 26, 87-93.

Charette M. A., Buesseler K. O. and Andrews J. E. (2001) Utility of radium isotopes for evaluating the input and transport of groundwater-derived nitrogen to a Cape Cod estuary. Limnol. Oceanogr. 46, 465-470.

Charette M. A. and Sholkovitz E. R. (2006) Trace element cycling in a subterranean estuary: Part 2. Geochemistry of the pore water Geochim Cosmochim Acta 70, 811-826.

Charette M. A., Sholkovitz E. R. and Hansel C. M. (2005) Trace element cycling in a subterranean estuary: Part 1 . Geochemistry of the permeable sediments. Geochim. Cosmochim. Acta 69 , 2095-2109.

De Geer L.-E. (2004) Currie detection limits in gamma-ray spectroscopy. Appl. Radiat. Isotopes 61, 151-160.

de Sieyes N. R., Yamahara K. M., Layton B. A., Joyce E. H. and Boehm A. B. (2008) Submarine discharge of nutrient-enriched fresh groundwater at Stinson Beach, California is enhanced during neap tides. Limnol. Oceanogr. 53, 1434-1445.

Dulaiova H., Gonneea M. E., Henderson P. B. and Charette M. A. (2008) Geochemical and physical sources of radon variation in a subterranean estuary - implications for groundwater radon activities in submarine groundwater discharge studies. Mar. Chem. 110, 120-127.

Dunk R. M., Mills R. A. and Jenkins W. J. (2002) A reevaluation of the oceanic uranium budget for the Holocene. Chem. Geol. 190, 45-67.
Elsinger R. J. and Moore W. S. (1980) Ra-226 behavior in the PeeDee River Winyah Bay Estuary. Earth Planet. Sci. Lett. 48, 239-249.

Ferrarin C., Rapaglia J., Zaggia L., Umgiesser G. and Zuppi G. M. (2008) Coincident application of a mass balance of radium and a hydrodynamic model for the seasonal quantification of groundwater flux into the Venice Lagoon, Italy. Mar. Chem. 112, 179-188.

Gonneea M. E., Morris P. J., Dulaiova H. and Charette M. A. (2008) New perspectives on radium behavior within a subterranean estuary. Mar. Chem. 109, 250-267.

Gonneea M. E., Mulligan A. and Charette M. A. (2013) Climatedriven sea level anomalies modulate coastal groundwater dynamics and discharge. Geophys. Res. Lett, http:// dx.doi.org/10.1002/grl.50192.

Grutter A., Vongunten H. R. and Rossler E. (1992) Sorption of barium on unconsolidated glaciofluvial deposits and clayminerals. Radiochim. Acta. 58-9, 259-265.

Hall G. E. M., Vaive J. E., Beer R. and Hoashi M. (1996) Selective leaches revisited, with emphasis on the amorphous Fe oxyhydroxide phase extraction. J. Geochem. Explor. 56, 59-78.

Hougham A. L., Moran S. B., Masterson J. P. and Kelly R. P. (2008) Seasonal changes in submarine groundwater discharge to coastal salt ponds estimated using Ra-226 and Ra-228 as tracers. Mar. Chem. 109, 268-278.

Jung H. B., Charette M. A. and Zheng Y. (2009) Field, laboratory, and modeling study of reactive transport of groundwater arsenic in a coastal aquifer. Environ. Sci. Technol. 43, 53335338 .

Kelly R P and Moran S. B (2002) Seasonal changes in groundwater input to a well-mixed estuary estimated using radium isotopes and implications for coastal nutrient budgets. Limnol. Oceanogr. 47, 1796-1807.

Kiro Y., Yechieli Y., Voss C. I., Starinsky A. and Weinstein Y. (2012) Modeling radium distribution in coastal aquifers during sea level changes: the Dead Sea case. Geochim. Cosmochim. Acta 88, 237-254.

Koulouris G. (1996) Sorption and distribution of 226-Ra in an electrolytic manganeses dioxide column in the presence of other ions. J. Radioanal. Nucl. Chem. 212, 131-141.

Krest J. M. and Harvey J. W. (2003) Using natural distributions of short-lived radium isotopes to quantify groundwater discharge and recharge. Limnol. Oceanogr. 48, 290-298.

Ku T. L., Luo S., Goldstein S. J., Murrell M. T., Chu W. L. and Dobson P. F. (2009) Modeling non-steady state radioisotope transport in the vadose zone - a case study using uranium isotopes at Pena Blanca, Mexico. Geochim. Cosmochim. Acta 73, 6052-6064.

Li X. Y., Hu B. X., Burnett W. C., Santos I. R. and Chanton J. P. (2009) Submarine ground water discharge driven by tidal pumping in a heterogeneous aquifer. Ground Water 47, 558568

Llovel W., Meyssignac B. and Cazenave A. (2011) Steric sea level variations over 2004-2010 as a function of region and depth: inference on the mass component variability in the North Atlantic Ocean. Geophys. Res. Lett. 38.

Michael H. A. (2004) Seasonal Dynamics in Coastal Aquifers: Investigations of Submarine Groundwater Discharge Through Field Measurements and Numerical Models. Massachusetts Institute of Technology.

Michael H. A., Charette M. A. and Harvey C. F. (2011) Patterns and variability of groundwater flow and radium activity at the coast: a case study from Waquoit Bay, Massachusetts. Mar. Chem. 127, 100-114. 
Michael H. A., Mulligan A. E. and Harvey C. F. (2005) Seasonal oscillations in water exchange between aquifers and the coastal ocean. Nature 436, 1145-1148.

Moore W. S. (1997) High fluxes of radium and barium from the mouth of the Ganges-Brahmaputra river during low river discharge suggest a large groundwater source. Earth Planet. Sci. Lett. 150, 141-150.

Moore W. S. (1999) The subterranean estuary: a reaction zone of ground water and sea water. Mar. Chem. 65, 111-125.

Moore W. S. (2003) Sources and fluxes of submarine groundwater discharge delineated by radium isotopes. Biogeochemistry $\mathbf{6 6}$, 75-93.

Moore W. S. and Arnold R. (1996) Measurement of Ra-223 and $\mathrm{Ra}-224$ in coastal waters using a delayed coincidence counter. $J$. Geophys. Res. Oceans 101, 1321-1329.

Moore W. S. and Reid D. F. (1973) Extraction of radium from natural waters using manganese-impregnated acrylic fibers. $J$ Geophys. Res. 78, 8880-8886.

Moore W. S., Sarmiento J. L. and Key R. M. (2008) Submarine groundwater discharge revealed by Ra-228 distribution in the upper Atlantic Ocean. Nat. Geosci. 1, 309-311.

Moore W. S. and Shaw T. J. (1998) Chemical signals from submarine fluid advection onto the continental shelf. $J$ Geophys. Res. Oceans 103, 21543-21552.

Moore W. S. and Shaw T. J. (2008) Fluxes and behavior of radium isotopes, barium, and uranium in seven Southeastern US rivers and estuaries. Mar. Chem. 108, 236-254.

Mulligan A. E. and Charette M. A. (2006) Intercomparison of submarine groundwater discharge estimates from a sandy unconfined aquifer. J. Hydrol. 327, 411-425.

Mulligan A. E. and Charette M. A. (2009) Groundwater flow to the coastal ocean. In Encyclopedia of Ocean Sciences (eds. H. S. John, K. T. Karl and A. T. Steve). Academic Press, Oxford, pp. 88-97.

Mulligan A. E., Langevin C. and Post V. E. A. (2011) Tidal boundary conditions in SEAWAT. Ground Water 49, 866-879.

NOAA (2012) NOAA Tidal Data: Woods Hole Station 8447930 Available from: http://tidesandcurrents.noaa.gov/station info.shtml?stn $=8449130 \% 20$ Nantucket $\% 20$ Island, $\% 20 \mathrm{MA}$ (accessed on October 1, 2012)

Paytan A., Moore W. S. and Kastner M. (1996) Sedimentation rate as determined by Ra-226 activity in marine barite. Geochim. Cosmochim. Acta 60, 4313-4319.

Paytan A., Shellenbarger G. G., Street J. H., Gonneea M. E., Davis K., Young M. B. and Moore W. S. (2006) Submarine groundwater discharge: an important source of new inorganic nitrogen to coral reef ecosystems. Limnol. Oceanogr. 51, 343348 .

Perry E., Paytan A., Pedersen B. and Velazquez-Oliman G. (2009) Groundwater geochemistry of the Yucatan Peninsula, Mexico: constraints on stratigraphy and hydrogeology. J. Hydrol. 367, $27-40$.

Porcelli D. (2008) Investigating groundwater processes using Uand Th-series nuclides. In Radioactivity in the Environment (eds. S. Krishnaswami and J. K. Cochran). Elsevier, pp. 105-153 (Chapter 4).
Rama and Moore W. S. (1996) Using the radium quartet for evaluating groundwater input and water exchange in salt marshes. Geochim. Cosmochim. Acta 60, 4645-4652.

Robinson C., Gibbes B. and Li L. (2006) Driving mechanisms for groundwater flow and salt transport in a subterranean estuary. Geophys. Res. Lett. . http://dx.doi.org/10.1029/2005gl025247.

Sallenger A. H., Doran K. S. and Howd P. A. (2012) Hotspot of accelerated sea-level rise on the Atlantic coast of North America. Nature Clim. Change 2, 884-888.

Santos I. R., Burnett W. C., Misra S., Suryaputra I. G. N. A., Chanton J. P., Dittmar T., Peterson R. N. and Swarzenski P. W. (2011) Uranium and barium cycling in a salt wedge subterranean estuary: the influence of tidal pumping. Chem. Geol. 287, 114-123.

Shaw T. J., Moore W. S., Kloepfer J. and Sochaski M. A. (1998) The flux of barium to the coastal waters of the southeastern USA: the importance of submarine groundwater discharge. Geochim. Cosmochim. Acta 62, 3047-3054.

Slomp C. P. and Van Cappellen P. (2004) Nutrient inputs to the coastal ocean through submarine groundwater discharge: controls and potential impact. J. Hydrol. 295, 64-86.

Spiteri C., Regnier P., Slomp C. P. and Charette M. A. (2006) pHDependent iron oxide precipitation in a subterranean estuary. J. Geochem. Explor. 88, 399-403.

Sun Y. and Torgersen T. (1998) Rapid and precise measuremen method for adsorbed Ra-224 on sediments. Mar. Chem. 61, $163-171$.

Sweet W. V. and Zervas C. (2011) Cool-season sea level anomalie and storm surges along the U.S. East Coast: climatology and comparison with the 2009/10 El Nino. Mon. Weather Rev. 139 , 2290-2299.

Tricca A., Wasserburg G. J., Porcelli D. and Baskaran M. (2001) The transport of $\mathrm{U}$ - and Th-series nuclides in a sandy unconfined aquifer. Geochim. Cosmochim. Acta 65, 1187-1210.

Webster I. T., Hancock G. J. and Murray A. S. (1995) Modeling the effect of salinity on radium desorption from sediments. Geochim. Cosmochim. Acta 59, 2469-2476.

White A. F. (2003) Natural weathering rates of silicate minerals. In Treatise on Geochemistry (eds. D. H. Heinrich and K. T. Karl) Pergamon, Oxford, pp. 133-168.

Windom H. and Niencheski F. (2003) Biogeochemical processes in a freshwater-seawater mixing zone in permeable sediments along the coast of Southern Brazil. Mar. Chem. 83, 121-130.

Windom H. L., Moore W. S., Niencheski L. F. H. and Jahrike R. A. (2006) Submarine groundwater discharge: a large, previously unrecognized source of dissolved iron to the South Atlantic Ocean. Mar. Chem. 102, 252-266.

Xin P., Robinson C., Li L., Barry D. A. and Bakhtyar R. (2010) Effects of wave forcing on a subterranean estuary. Water Resour. Res. 46.

Yin J. J., Schlesinger M. E. and Stouffer R. J. (2009) Model projections of rapid sea-level rise on the northeast coast of the United States. Nat. Geosci. 2, 262-266.

Associate editor: Timothy J. Shaw 


\section{Supplemental Material}

From Gonneea et al. "Seasonal cycles in radium and barium within a subterranean estuary"

\section{Supplemental Figures}

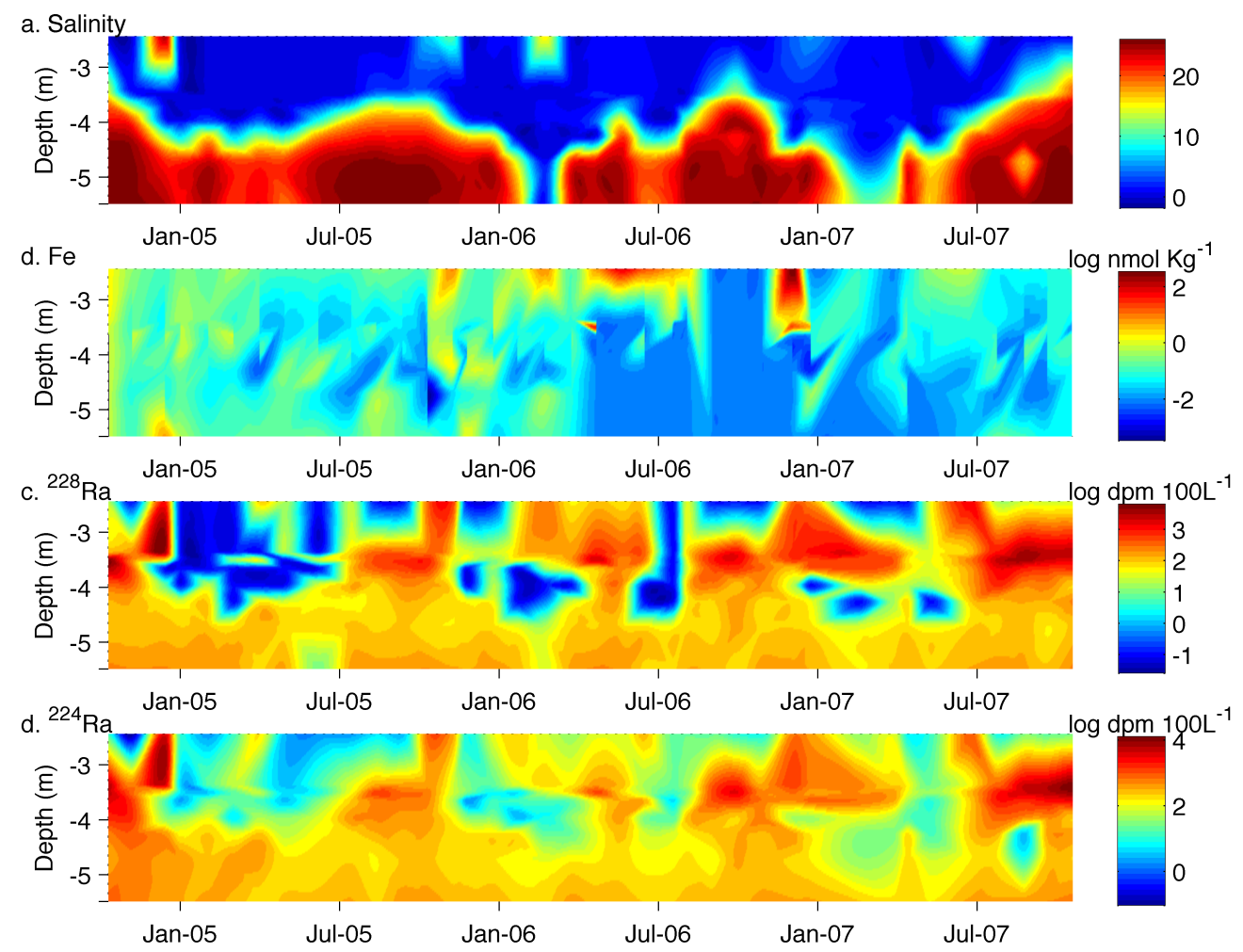

Supplemental Figure 1: Time series data from October 2004 to October 2007 for a)

salinity, b) dissolved Fe, c) ${ }^{224} \mathrm{Ra}$ and d) ${ }^{228} \mathrm{Ra}$. Note the log scale in b, c and d. Data were contoured in Matlab using a cubic interpolation. 
Supplemental Figure 2: Box and whisker plots of a) dissolved and sediment surface oxide associated Fe, b) dissolved ${ }^{224} \mathrm{Ra}$ and d) dissolved ${ }^{228} \mathrm{Ra}$. These plots contain all data points over the three-year time series for each depth. The gray box marks the $25^{\text {th }}$, $50^{\text {th }}$ and $75^{\text {th }}$ percentile of samples, with the $5^{\text {th }}$ and $95^{\text {th }}$ percentile of samples marked by the lines extending from the box. Outliers are plotted as points. The sediment profiles were collected in June 2006 and are shown here to provide sediment geochemical background for interpreting the time series water chemistry (Gonneea et al., 2008). 

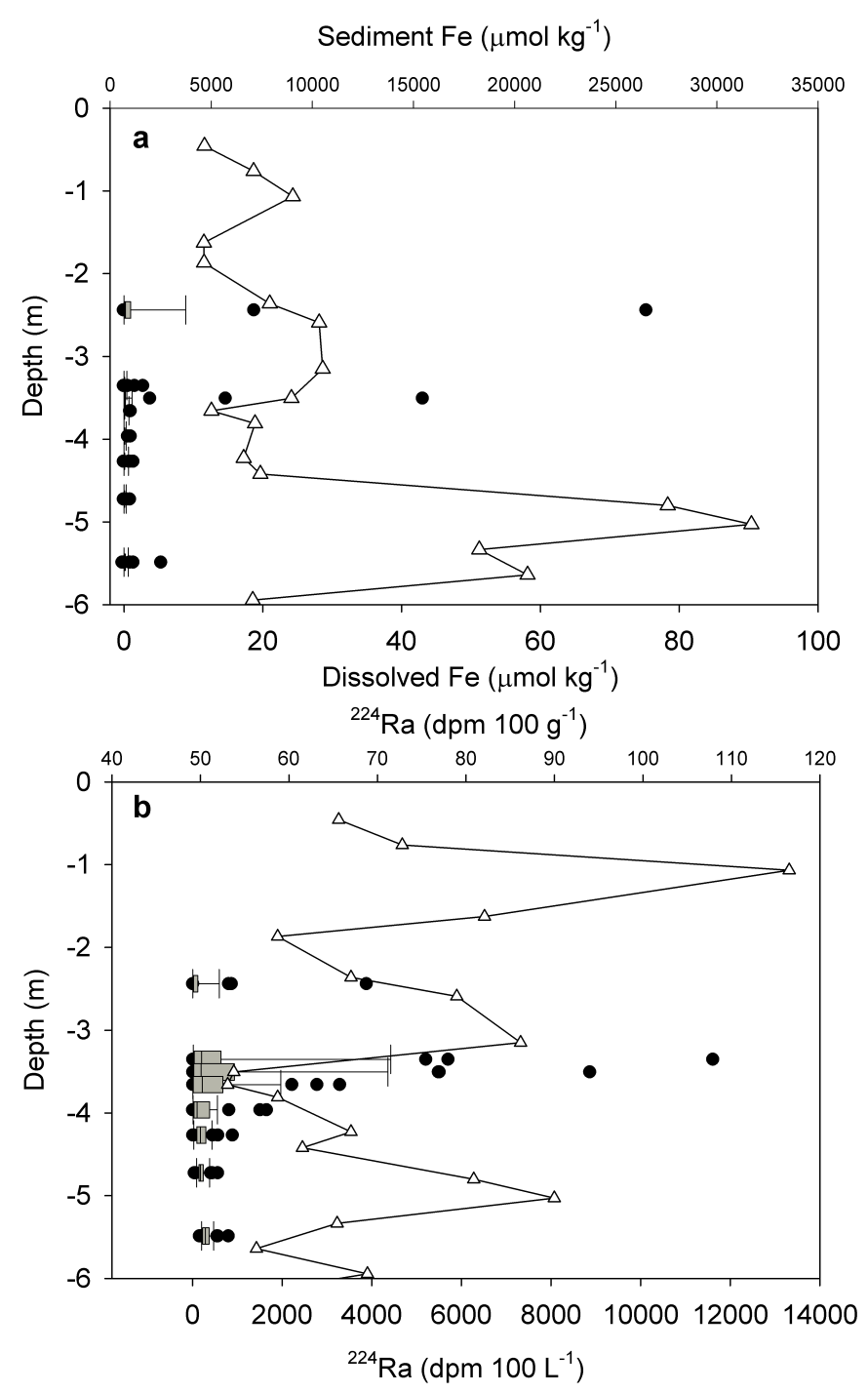

${ }^{228} \mathrm{Ra}\left(\mathrm{dpm} 100 \mathrm{~g}^{-1}\right.$ )

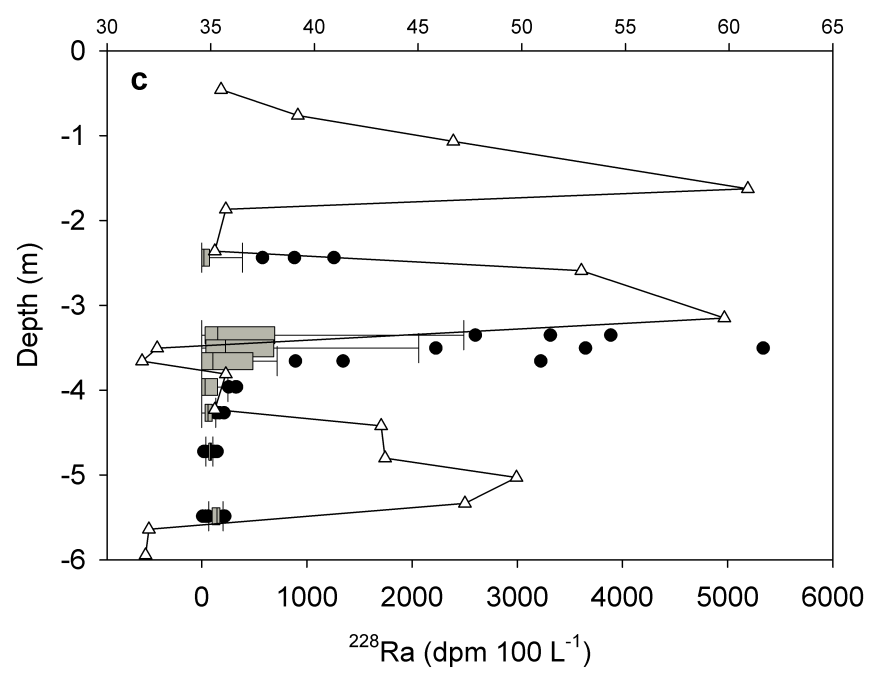




\section{Supplemental Table}

\begin{tabular}{|c|c|c|c|c|c|c|c|c|}
\hline \multirow[b]{2}{*}{ Depth } & \multicolumn{4}{|c|}{$\Delta^{226} \mathrm{Ra}$} & \multicolumn{4}{|c|}{$\Delta \mathbf{B a}$} \\
\hline & \multicolumn{2}{|c|}{ salinity } & \multicolumn{2}{|l|}{ pH } & \multicolumn{2}{|c|}{ salinity } & \multicolumn{2}{|l|}{ pH } \\
\hline & formula & $\mathbf{r}^{2}$ & formula & $\mathbf{r}^{2}$ & formula & $\mathbf{r}^{2}$ & formula & $\mathbf{r}^{2}$ \\
\hline $2.4 \mathrm{~m}$ & $1.1 \Delta \mathrm{S}$ & 0.24 & $-2.6 \Delta \mathrm{pH}-0.1$ & 0.02 & $37 \Delta S-1$ & 0.35 & $-53 \Delta \mathrm{pH}+5$ & 0.01 \\
\hline $3.4 \mathrm{~m}$ & $35 \Delta S+15$ & 0.44 & $-130 \Delta \mathrm{pH}+30$ & 0.33 & $190 \Delta S-90$ & 0.36 & $-770 \Delta \mathrm{pH}-40$ & 0.34 \\
\hline $3.5 \mathrm{~m}$ & $70 \Delta S-30$ & 0.58 & $-380 \Delta \mathrm{pH}+20$ & 0.45 & $170 \Delta S-130$ & 0.29 & $-770 \Delta \mathrm{pH}-20$ & 0.16 \\
\hline $3.7 \mathrm{~m}$ & $20 \Delta S-8$ & 0.44 & $-55 \Delta \mathrm{pH}-4$ & 0.05 & $90 \Delta S-50$ & 0.32 & $-470 \Delta \mathrm{pH}-20$ & 0.12 \\
\hline $4.0 \mathrm{~m}$ & $4.5 \Delta S-2$ & 0.62 & $-3.2 \Delta \mathrm{pH}-5$ & 0.00 & $50 \Delta S-30$ & 0.52 & $60 \Delta \mathrm{pH}-35$ & 0.01 \\
\hline $4.2 \mathrm{~m}$ & $2.4 \Delta S+0.9$ & 0.56 & $-7.8 \Delta \mathrm{pH}+1.6$ & 0.04 & $17 \Delta S+2$ & 0.16 & $110 \Delta \mathrm{pH}-2$ & 0.04 \\
\hline $4.7 \mathrm{~m}$ & $1.4 \Delta \mathrm{S}+0.3$ & 0.25 & $-6.8 \Delta \mathrm{pH}-0.6$ & 0.05 & $-2 \Delta S-1$ & 0.00 & $-210 \Delta \mathrm{pH}-2$ & 0.17 \\
\hline $5.5 \mathrm{~m}$ & $1.5 \Delta \mathrm{S}-1.4$ & 0.18 & $-4.6 \Delta \mathrm{pH}+1.8$ & 0.02 & $11 \Delta S-1$ & 0.83 & $-8 \Delta \mathrm{pH}-4$ & 0.01 \\
\hline
\end{tabular}

Bold values have significance at $\mathrm{p}<0.0001$. 


\section{Chapter 4:}

Seasonal and interannual variability in nutrient dynamics within a sandy subterranean estuary 


\section{Introduction}

Despite a long-standing recognition of the deleterious impacts of anthropogenic nutrient enhancement on the coastal ocean, transport of nitrogen $(\mathrm{N})$ and phosphorous $(\mathrm{P})$ to the ocean is accelerating (Doney, 2010; Ryther and Dunstan, 1971; Valiela et al., 1997). Nitrogen is considered the limiting nutrient in coastal marine systems, although excess phosphorous may also lead to adverse ecological impacts in estuaries (Howarth and Marino, 2006). In the coastal zone, approximately half of the reactive nitrogen loading comes from diffuse, non-point sources including atmospheric deposition, surface water run-off and groundwater discharge (Galloway et al., 2004). Coastal ocean nutrient loading associated with submarine groundwater discharge has been implicated in eutrophication and the development of harmful algal blooms (Hu et al., 2006; Lee and Kim, 2007; Valiela et al., 1992).

Sources of nutrients to terrestrial and marine groundwater include atmospheric deposition, septic systems and fertilizers, and organic matter remineralization. The nutrient load associated with submarine groundwater discharge may be assessed by multiplying the groundwater end member with the SGD rate (e.g. Charette et al., 2001; Niencheski et al., 2007; Null et al., 2012; Paytan et al., 2006; Weinstein et al., 2011), though flow through the subterranean estuary (STE), a region of dynamic mixing between discharging terrestrial water and marine intrusion, may modify the groundwater nutrient load (Moore, 1999; Slomp and Van Cappellen, 2004).

Nutrient transformations occur along the salinity, oxygen $\left(\mathrm{O}_{2}\right)$ and redox boundaries within the subterranean estuary (Beck et al., 2007; Charette and Sholkovitz, 2006; Gonneea et al., 2013b; Kroeger and Charette, 2008; Santos et al., 2011). For 
example, Kroeger and Charette (2008) report as much as 65\% loss in dissolved inorganic nitrogen (DIN) within terrestrial groundwater flowing through a sandy subterranean estuary, while Weinstein et al. (2011) did not observe any reduction. The subterranean estuary is largely invoked as a P sink due to sorption onto Fe-Mn oxides/hydroxides (Charette and Sholkovitz, 2006; Loveless and Oldham, 2010; Santos et al., 2013; Slomp and Van Cappellen, 2004).

Variability in STE nutrient cycling may be due to differences in aquifer lithology, submarine groundwater discharge rates and associated water residence times, the proportion of mixing between marine and terrestrial end members, and whether the nutrient source is primarily terrestrial (new) or marine (recycled) (Beck et al., 2007; Kroeger and Charette, 2008; Michael et al., 2011; Santos et al., 2009). In particular, mixing between terrestrial and marine groundwater pools and total discharge rates are likely to impact the supply of reactants, including $\mathrm{O}_{2}$, inorganic nitrogen $\left(\mathrm{NO}_{3}{ }^{-}, \mathrm{NO}_{2}{ }^{-}\right.$, $\mathrm{NH}_{4}{ }^{+}$) and phosphorous $\left(\mathrm{PO}_{4}{ }^{3-}\right)$, in turn modulating groundwater derived fluxes to the coastal ocean.

The ecosystem of Waquoit Bay, a coastal estuary on Cape Cod, MA, USA, is particularly negatively impacted by nutrient loading associated with submarine groundwater discharge (Bowen et al., 2007; Valiela et al., 1992; Valiela et al., 2000). For example, virtually all the eelgrass, and with it its ecosystem service to juvenile fish and shellfish, has disappeared from Waquoit Bay coincident with enhanced water column algal growth following increasing nitrogen loads to the watershed (Valiela et al., 1992; Costello and Kenworthy, 2011). The prevalence of septic systems on Cape Cod has resulted in groundwater nitrogen loads that are elevated compared to aquifers in regions 
with centralized wastewater treatment. In this study we evaluate nutrient and groundwater flow dynamics across different years and seasons in a sandy subterranean estuary (Waquoit Bay, USA) to determine seasonal variability in nutrient delivery to the STE, nutrient removal within the STE and subsequent fluxes to the coastal ocean. We explore the potential influence of seasonally variable groundwater mixing and discharge by coupling numerical estimates of groundwater flow to nutrient loads transported through the subterranean estuary.

\section{Methods}

\subsection{Field site}

Waquoit Bay is a shallow estuary on the southern shore of Cape Cod, MA (Figure 1). In this region, surface geology is dominated by sand and gravel glacial outwash plains formed during the last deglaciation $\sim 14,000$ years ago. As a result, the upper $10 \mathrm{~m}$ of the Cape Cod aquifer, where the Waquoit Bay subterranean estuary is located, consists of fairly homogenous permeable sediments with a grain size of 450-650 microns; a fine sand and silt layer with a lower hydraulic conductivity sits below $\sim 10 \mathrm{~m}$ (Cambareri and Eichner, 1998).

These highly permeable sediments result in high groundwater recharge, with about half of precipitation becoming recharge (Cambareri and Eichner, 1998).

Precipitation averaged $135 \mathrm{~cm} \mathrm{y}^{-1}$ from 2004 to 2010 (http://cis.whoi.edu/science/PO/climate/index.cfm). The greatest groundwater recharge occurs during the winter and spring when evapotranspiration rates are minimal, resulting in elevated groundwater levels during this time (Michael et al., 2003). At the head of Waquoit Bay there is a well-defined subterranean estuary with a salinity transition zone 
that occurs over a narrow region ( $\sim 1 \mathrm{~m}$ thick, Charette et al., 2005). The salinity interface moves on seasonal time scales, which results in migration of ion exchange (adsorption/desorption) and redox boundaries (Abarca et al., 2013; Gonneea et al., 2013a; Gonneea et al., 2013b). Within the Waquoit Bay subterranean estuary, there are welldefined regions of Fe-oxides (Charette et al., 2005) and Mn-oxides (Dulaiova et al., 2008; Gonneea et al., 2008).

\subsection{Field methods}

Groundwater samples were collected in the Waquoit Bay subterranean estuary in March 2003 (Kroeger and Charette, 2008), June 2004, April, June, September and November 2005, June 2006 and June 2007. Only during March 2003, June 2004 and April and June 2005 were full transects sampled (6-7 profiles to a depth of $\sim 10 \mathrm{~m}$, spanning $20 \mathrm{~m}$ of the STE, Figures 2 and S1-S3). The April 2005 transect was located 80 $\mathrm{m}$ west, in a region where hydraulic gradients are elevated compared to the site of the other transects and the time series well (transect B in Figure 1) (Michael et al., 2003; Mulligan and Charette, 2006). Groundwater was collected with a push-point piezometer system modified for use within the subterranean estuary (Charette and Allen, 2006). Dissolved oxygen, $\mathrm{pH}$, oxidative reductive potential (ORP) and salinity were measured with a YSI ${ }^{\mathrm{TM}}$ sonde. Prior to field sampling, the probes were calibrated using Ricca $^{\mathrm{TM}} \mathrm{pH}$, redox and conductivity standards. Oxygen was calibrated against atmospheric values. Samples were collected for salinity, nutrients and trace metals $\left(0.45 \mu \mathrm{m}\right.$ filtered, $\mathrm{NO}_{3}{ }^{-}$, $\mathrm{NH} 4^{+}, \mathrm{PO}_{4}^{-3}, \mathrm{Fe}$ and $\left.\mathrm{Mn}\right) . \mathrm{PO}_{4}^{-3}$ samples were acidified with $8 \mu \mathrm{L}$ sulfuric acid per 15 $\mathrm{mL}$ upon collection. Nutrient samples were initially stored on ice and frozen within three 
hours of collection. Trace metal samples were acidified to $\mathrm{pH} 2$ with $8 \mathrm{~N}$ double-distilled nitric acid.

The well nest used to sample the subterranean estuary from 2004-2010 has been described previously (Gonneea et al., 2013a; Gonneea et al., 2013b). Briefly, a series of AMS $^{\text {TM }}$ Dedicated Gas Vapor Probe Tips were installed at depths ranging from 2.4 to 5.4 $\mathrm{m}$ within the subterranean estuary in October 2004 (Fig. 1). The wells consist of a stainless steel well point ( $2.5 \mathrm{~cm}$ screened interval) attached to $1 / 4$ inch nylon tubing. Samples were collected every month from October 2004 to October 2007. Sampling resumed in May 2009, when two additional wells were installed at 0.5 and $1.5 \mathrm{~m}$, and continued until June 2010. After the wells were purged ( 1 L, or 6 to 13 well volumes at $\sim 200 \mathrm{ml} \mathrm{min}^{-1}$ ), dissolved oxygen, $\mathrm{pH}, \mathrm{ORP}$ and salinity were measured with a YSITM sonde. Dissolved oxygen, $\mathrm{pH}$ and ORP probes were not working properly for some sampling events (including during 2009-2010), as ascertained by laboratory calibration prior to field work, hence YSI data is not available for all sampling periods. Salinity was stable throughout the sampling, as confirmed by YSI ${ }^{\mathrm{TM}}$ readings, thus we assume that water was being extracted from the same density horizon, and not across density gradients (i.e. not from different depths at this fixed location). Samples for salinity, nutrients and trace metals were collected as described above. Sampling was performed during the same tidal cycle and phase each month (four hours past high tide, $\sim 3$ days before the monthly spring tide) although the regional mixing zone discussed here does not vary on tidal time scales (Gonneea et al., 2013a).

A sediment core was collected in June 2006 from the subterranean estuary (Dulaiova et al., 2008; Gonneea et al., 2008). Trace metal and adsorbed phosphate data 
are presented here to provide sediment chemistry background for interpreting groundwater results. All sediment $\mathrm{Mn}, \mathrm{Fe}$ and $\mathrm{PO}_{4}^{-3}$ data are for the fraction associated with amorphous and crystalline oxides/hydroxides, as defined by a hydroxylamine hydrochloride and acetic acid leach (Hall et al., 1996). Note that the well cluster used in the time series is generally outside the region of dynamic dissolved iron cycling (Charette and Sholkovitz, 2006), but within the region of variable manganese (Gonneea et al., 2008; Gonneea et al., 2013b).

\subsection{Laboratory methods}

Salinity was measured with a Guideline AutoSal conductivity meter. Groundwater dissolved $\mathrm{Mn}$ and Fe were analyzed via inductively coupled mass spectrometry on a Finnigan Element II magnetic sector ICP-MS at Woods Hole Oceanographic Institution ICPM-MS Facility. Each sample was diluted 1:20 with $1 \mathrm{~N}$ Optima nitric acid. Indium (In) was used as an internal standard to account for instrument drift and matrix effects of the solution. Count rates for all elements were normalized to In measured in samples and gravimetrically prepared standards. The standard slope and intercept were calculated from a linear regression and used to convert sample count ratios to concentrations. We analyzed external standards to check these calibrations. The river standard SLRS-4 Fe and estuarine standard SLEW-3 Mn concentrations were closest to the samples analyzed here: Fe, $1.9 \pm 0.1 \mu \mathrm{mol} \mathrm{kg}{ }^{-1}$ (reported value, $1.84 \pm 0.10 \mu \mathrm{mol} \mathrm{kg}^{-1}$ ) and $\mathrm{Mn}, 30 \pm 4$

$\mu \mathrm{mol} \mathrm{kg}{ }^{-1}$ (reported value, $\left.29 \pm 4.0 \mu \mathrm{mol} \mathrm{kg}^{-1}\right)( \pm$ refers to one standard deviation throughout). Nutrients were measured on a Lachat Instruments QuickChem 8000 injection analyzer using standard colorimetric techniques. 


\subsection{Hydrologic model}

We employed a numerical simulation model (USGS SEAWAT code) that was designed to represent conditions within coastal permeable sand aquifers such as at Waquoit Bay (Langevin et al., 2008; Mulligan et al., 2011). Results from this model have been reported previously and are included here to help interpret both the hydrologic influence on nutrient cycling and to determine nutrient fluxes associated with groundwater discharge (Gonneea et al., 2013a; Gonneea et al., 2013b). Briefly, this model simulates variable-density flow within a two-dimensional cross-section of an unconfined aquifer below a sloping beach $(0.08 \mathrm{~m} / \mathrm{m})$ where the domain measures $130 \mathrm{~m}$ long and $10 \mathrm{~m}$ deep. The upland boundary was set as the groundwater head at a coastal monitoring well (50 $\mathrm{m}$ from MSL), while the marine boundary was the average monthly sea level from NOAA's Woods Hole tidal station (data available at http://tidesandcurrents.noaa.gov). This model does not incorporate short-time scale sea level oscillations (i.e. tides or waves). Groundwater discharge to the bay and marine water intrusion into the aquifer were calculated across the entire model domain from January 2005 to June 2007. Further details on the model can be found in Mulligan et al. (2011) and Gonneea et al. (2013a).

\section{Results}

\subsection{Subterranean estuary transects}

Within the subterranean estuary, a lens of terrestrial groundwater overlies intruding marine groundwater (Figures 2, S1-S3). A region of high $\mathrm{NH}_{4}{ }^{+}(100-200 \mu \mathrm{M})$ lies above $\mathrm{NO}_{3}{ }^{-}$plume (up to $150 \mu \mathrm{M}$ ) within the terrestrial groundwater plume (Kroeger and Charette, 2008). The main form of inorganic nitrogen present in the deep 
marine groundwater is $\mathrm{NH}_{4}{ }^{+}(30-50 \mu \mathrm{M})$. The upper and lower $\mathrm{NH}_{4}{ }^{+}$plumes are separated by the salinity mixing zone so each has a distinct terrestrial and marine origin. Within the reduced terrestrial plume (high $\mathrm{NH}_{4}{ }^{+}$) dissolved Fe may reach $200 \mu \mathrm{mol} \mathrm{kg}$. Phosphate is elevated in marine groundwater $(5-15 \mu \mathrm{M})$, coincident with the region of high dissolved Mn. There is another region of elevated phosphate (1-5 $\mu \mathrm{M})$ coincident with the terrestrial $\mathrm{NH}_{4}{ }^{+}$plume. Manganese (Mn) is elevated within the salinity mixing zone and reached 20-40 $\mu \mathrm{mol} \mathrm{kg}{ }^{-1}$ in June 2004 compared to $20-30 \mu \mathrm{mol} \mathrm{kg}^{-1}$ in June 2005 and March 2003 (Mn not measured in April 2005). The dissolved iron plume associated with the terrestrial groundwater (Testa et al., 2002) extended further offshore in June 2004 compared to the other time periods (Fe not measured in April 2005).

Dissolved oxygen levels within groundwater were typically $<100 \mu \mathrm{M}$, with the exception of April 2005 (higher terrestrial groundwater flow site) when $\mathrm{O}_{2}$ reached 400 $\mu \mathrm{M}$ in terrestrial groundwater. There are patches of elevated $\mathrm{O}_{2}$ at depth during the other time periods, which do not appear to be related to other variables (i.e. salinity, temperature). Both terrestrial and marine groundwater likely enter the STE fully saturated with $\mathrm{O}_{2}$, which is a function of both salinity and temperature, but typically falls within the range of 300 to $400 \mu \mathrm{M}$ at the conditions present in the STE. Subsequent loss is likely due to reactions that consume $\mathrm{O}_{2}$, such as organic matter remineralization and oxide/hydroxide formation (Spiteri et al., 2008). $\mathrm{pH}$ is low (5-6) in terrestrial groundwater, and rises to 8-8.5 in marine groundwater. The mixing zone has a $\mathrm{pH}$ gradient from 6.5 to 7.5 in each transect (Figure 2 and S1-S3). The oxidative-reductive potential (ORP) measures the tendency for electron transfer between an inert metal (platinum) electrode and a reference (glass) electrode within the same medium. ORP is a 
qualitative measure of the groundwater redox conditions since it measures the combined effects of all redox sensitive species in solution. As such, we use it to determine only if the groundwater is reducing $(\mathrm{ORP}<0)$ or oxidizing $(\mathrm{ORP}>0)$. Terrestrial groundwater is largely oxidizing, except within the core of the $\mathrm{NH}_{4}{ }^{+}$plume, while marine groundwater is reducing. However, $\mathrm{H}_{2} \mathrm{~S}$ has never been detected in this system, so sulfate is likely not acting as an electron acceptor.

In March 2003 the mixing zone was further inland than in June 2004 and 2005. As a result, the terrestrial $\mathrm{NO}_{3}{ }^{-}$and $\mathrm{NH}_{4}{ }^{+}$and marine $\mathrm{Mn}$ and $\mathrm{NH}_{4}{ }^{+}$plumes migrated landward. Also during March 2003 the $\mathrm{NO}_{3}{ }^{-}$concentration was reduced to $\sim 50-70 \mu \mathrm{M}$ compared to $100-150 \mu \mathrm{M}$ in June 2004 and 2005 , while $\mathrm{NH}_{4}{ }^{+}$was $250 \mu \mathrm{M}$. This could be due to the main $\mathrm{NO}_{3}{ }^{-}$core migrating further inland outside the sampling domain or to removal of $\mathrm{NO}_{3}{ }^{-}$within the plume at this time. Since the mixing zone only migrated inland three meters, and the transect captured ten meters of the $\mathrm{NO}_{3}{ }^{-}$plume, the observed reduction is unlikely to be an artifact of sampling location. The terrestrial dissolved inorganic nitrogen (DIN) plume $\left(\mathrm{NO}_{3}{ }^{-}\right.$plus $\left.\mathrm{NH}_{4}{ }^{+}\right)$follows the salinity (and density) contours within the subterranean estuary, terminating at the top of the salinity mixing zone. There is a region of elevated $\mathrm{NO}_{3}{ }^{-}$above the main plume at shallow depths $(<0.5$ m) in June 2003 and April 2004. Nutrient transformations that may occur on scales $<\sim 25$ $\mathrm{cm}$ in the discharge zone were not a focus of this study and therefore may not be quantified given the spatial resolution of the samples reported here.

\subsection{Fixed well time series}

A groundwater chemistry profile was collected 52 times at a fixed location over the course of 50 months from October 2004 to October 2007 and May 2009 to June 2010. 
The monthly sampling of the fixed wells revealed that the location of the salinity mixing zone moves seasonally in response to changes in the hydraulic gradient across the coastal aquifer, which is largely driven by variability in sea level fluctuations at this location (Gonneea et al., 2013a). As the hydraulic gradient changes, these groundwater zones and the associated nutrient plumes also migrate; this appears as a vertical oscillation when concentrations at the fixed well location are plotted versus time (Figure 3). The time series wells captured the nitrate peak for most of the four years (as determined by low nitrate values above and below the plume), but only rarely did the wells coincide with the terrestrial ammonium plume (Figure 3). The deep wells always captured the enriched ammonium and phosphate region in the marine groundwater. Thus, with the time series profiles it is possible to evaluate nutrient dynamics associated with the mixing zone and marine groundwater, but not the terrestrial groundwater region at depths above 2.4 meters (2004-2007) or above $0.5 \mathrm{~m}$ (2009-2010). Temporal dynamics of the high terrestrial ammonium plume evident in the STE vertical cross sections are not discussed in the context of the monthly time series.

The salinity of the subterranean estuary oscillated throughout the time series and ranged from 0 to 28. From 2004 to 2007, there was a distinct seasonal pattern of marine groundwater rising within the STE due to intrusion during summer and fall months (Oct. 2004, June-December 2005, May 2006, August-November 2006 and August 2007) while in 2009 to 2010 salinity was elevated throughout the year (Gonneea et al., 2013a). There were brief salinity excursions within the upper portion of the STE (November 2004, October 2005, February 2006 and June 2007) presumably due to infiltration of bay water during a high tide and subsequent density-driven mixing down into the upper STE. 
We observed vertical displacement of the $\mathrm{NO}_{3}{ }^{-}$plume through time concurrent with the salinity oscillations (Figure 3b). At this location within the subterranean estuary, the average maximum nitrate concentration was $120 \pm 60 \mu \mathrm{M}$ which was observed at a depth of $3.0 \pm 0.6 \mathrm{~m}$. Note, however, for sampling periods that did not capture the entire $\mathrm{NO}_{3}{ }^{-}$plume, there is no way to ensure that the peak was truly captured and thus these values may be a minimum. The base of the $\mathrm{NO}_{3}{ }^{-}$plume was at $3.6 \pm 0.6 \mathrm{~m}$, coincident with the top of the mixing zone. The marine groundwater $\mathrm{NH}_{4}{ }^{+}$region $(31 \pm 11 \mu \mathrm{M})$ also migrated vertically, but was largely located below $4.2 \pm 0.6 \mathrm{~m}$. The $\mathrm{PO}_{4}{ }^{3-}$ plume $(8.3 \pm 3$ $\mu \mathrm{M})$ did not migrate vertically past $4.3 \mathrm{~m}$. Gonneea et al. (2013b) describe Mn and Fe behavior during the groundwater time series. Dissolved Mn followed the marine groundwater pool, similarly to $\mathrm{PO}_{4}{ }^{3-}$. The location of the time series wells was above the region of enriched dissolved Fe within marine groundwater, so Fe was below detection $\left(0.1 \mu \mathrm{mol} \mathrm{kg}{ }^{-1}\right)$ during much of the time series. The time series dissolved oxygen, $\mathrm{pH}$ and ORP data follow similar salinity trends as discussed for the transect data. Terrestrial groundwater is oxidizing, with $\mathrm{O}_{2}$ typically $50-200 \mu \mathrm{M}$ and $\mathrm{pH}<6.5$, while marine groundwater has 10-100 $\mu \mathrm{M} \mathrm{O}_{2}$ and $\mathrm{pH}$ 7-8 (Figure S4).

\subsection{Hydrologic Model}

Groundwater flow through the Waquoit Bay subterranean estuary has been studied through modeling, physical measurements and chemical tracer approaches. The model results used in the present study are discussed in Gonneea et al. (2013a,b). During the period from January 2005 to May 2007, terrestrial fluxes were $3.4 \pm 0.46 \mathrm{~m}^{3} \mathrm{~m}^{-1}$ day $^{-1}$ and marine groundwater discharge ranged between 0.39 (winter) and 4.7 (summer) $\mathrm{m}^{3} \mathrm{~m}^{-}$

${ }^{1}$ day $^{-1}$. The terrestrial discharge rates are similar to other estimates that report fluxes of 
1.6-1.8 $\mathrm{m}^{3} \mathrm{~m}^{-1}$ day $^{-1}$ (recharge method [Cambareri and Eichner, 1998]), $3.5 \mathrm{~m}^{3} \mathrm{~m}^{-1}$ day $^{-1}$ (seepage meters [Michael et al., 2003]) and $4.0 \mathrm{~m}^{3} \mathrm{~m}^{-1}$ day $^{-1}$ (Darcy method [Mulligan and Charette, 2006]). Abarca et al. (2013) report much lower terrestrial groundwater discharge of $0.25 \mathrm{~m}^{3} \mathrm{~m}^{-1}$ day $^{-1}$ (hydrologic model TRANSDENS) likely due to the much lower hydraulic conductivity used in that model $\left(15 \mathrm{~m} \mathrm{~d}^{-1}\right)$ compared to other modeling studies at this location (43-54 $\mathrm{m} \mathrm{d}^{-1}$ [Michael et al., 2005; Mulligan and Charette, 2006; Mulligan et al., 2011]). This lower hydraulic conductivity was determined from agreement between the hydrologic model and salinity oscillations within the shallow tidally induced recirculation zone (Abarca et al., 2013). If such a low hydraulic conductivity is more appropriate than that determined by aquifer slug tests (Cambareri and Eichner, 1998; Mulligan and Charette, 2006), then terrestrial groundwater discharge rates would be overestimated in the present study and others that use similar hydraulic conductivity values (i.e. Michael et al., 2003; Mulligan and Charette, 2006). Marine groundwater discharge (and recharge) estimates are more variable with values ranging from $0.6 \mathrm{~m}^{3} \mathrm{~m}^{-1} \mathrm{day}^{-1}$ (radium isotopes [July 2003, Mulligan and Charette, 2006]) to 6.9$15.0 \mathrm{~m}^{3} \mathrm{~m}^{-1}$ day $^{-1}$ (seepage meters [July 1999 and August 2000, Michael et al., 2003]).

\section{Discussion}

\subsection{Groundwater mixing within the subterranean estuary}

The results of the hydrologic model demonstrate that submarine groundwater discharge in Waquoit Bay was seasonally dynamic; in particular the amount of submarine groundwater recharge (SGR) from the bay into the aquifer varied from 0.39 and $4.7 \mathrm{~m}^{3}$ $\mathrm{m}^{-1}$ day $^{-1}(10-70 \%$ of total SGD, Gonneea et al., 2013a). Gonneea et al. (2013a) demonstrated that sea level was the dominant control on both the position of the mixing 
zone and the rate of submarine groundwater discharge. Both movement of the salinity interface and the flux of water through the subterranean estuary may impact nutrient cycling. We can use the hydrologic model results to determine the degree of mixing that occurred within the subterranean estuary prior to discharge, defined here as:

1) $f_{\text {marine }}=\frac{S G D_{\text {marine }}}{S G D_{\text {total }}}$

where $f_{\text {marine }}$ is the fraction of total SGD derived from submarine groundwater recharge; as this number increases, there is more mixing between terrestrial and marine groundwater (Gonneea et al., 2013a). Since the terrestrial groundwater flux was relatively invariant with time, the amount of marine groundwater discharge was the primary driver of variability in total discharge. We hypothesize that as groundwater discharge rates increased concurrently with $\mathrm{f}_{\text {marine, }}$ there was a shorter water residence time within the mixing zone of the STE.

We find there is a good relationship between $f_{\text {marine }}$ from numerical model results and sea level, due to the dominant role sea level plays in determining the hydraulic gradient across this subterranean estuary (data:model fit has a reduced- $\chi^{2}$ of 1.3 with assumed uncertainty in $\mathrm{f}_{\text {marine }}$ of 0.03 , Figure 4) (Gonneea et al., 2013a). We use the relationship between sea level and $\mathrm{f}_{\text {marine }}$ of the hydrologic model results (January 2005 to June 2007) to extrapolate what degree of mixing between marine and terrestrial groundwater occurred during the portions of the time series without water flux estimates (October 2004 to December 2004, July 2007 to October 2007 and May 2009 to June 2010). Following sea level, $f_{\text {marine }}$ was generally high during the summer and low during the winter, except during the 2009-2010 period when sea level was elevated for a year and a half coincident with El Niño associated wind intensification and direction shift 
along the U.S. northeast coast (Sweet and Zervas, 2011). We use the $\mathrm{f}_{\text {marine }}$ parameter in the following discussion to test for hydrologic control on geochemical processes within the STE.

\subsection{Temporal variability in nutrient distributions}

Within the Waquoit Bay subterranean estuary, terrestrial groundwater with high $\mathrm{NH}_{4}{ }^{+}$overlies a region of elevated $\mathrm{NO}_{3}{ }^{-} ; \mathrm{NH}_{4}{ }^{+}$is the primary nitrogen species carried by marine groundwater (Kroeger and Charette, 2008). The mixing zone, which is also a redox boundary, occurs over small spatial scales ( $\sim 1$ meter vertical extent). Previous work at this site reported both complete removal of terrestrially-sourced $\mathrm{NO}_{3}{ }^{-}$across the top of the mixing zone and largely conservative behavior of marine $\mathrm{NH}_{4}{ }^{+}$to the top of the mixing zone where dissolved inorganic nitrogen (DIN, the sum of $\mathrm{NO}_{3}{ }^{-}$and $\mathrm{NH}_{4}{ }^{+}$)

concentrations were low $\left(<1 \mu \mathrm{mol} \mathrm{L}{ }^{-1}\right.$, Kroeger and Charette, 2008). Additionally, $\mathrm{PO}_{4}{ }^{3-}$ was elevated in marine groundwater above bay water levels (8-12 compared to 1-2 $\mu \mathrm{mol}$ $\mathrm{L}^{-1}$ respectively) and in terrestrial groundwater in contact with the iron curtain (up to 8 $\mu \mathrm{mol} \mathrm{L}{ }^{-1}$, Charette and Sholkovitz, 2006). Here we explore how these patterns vary in time and the implications for nutrient attenuation within the STE.

\subsubsection{Nitrogen distribution and speciation in terrestrial groundwater}

We utilize depth profiles and nutrient versus salinity plots to characterize DIN associations for both transect and time series data (Figures 5-7). As shown by Kroeger and Charette (2008) (based on the March 2003 transect), nitrate was always attenuated to some extent within terrestrial groundwater upon mixing with marine groundwater, as evidenced by the non-conservative $\mathrm{NO}_{3}{ }^{-}$versus salinity distribution (Figures 5 and 6). 
The three additional transects in June 2004 and April and June 2005 confirm these patterns.

Two processes may be responsible for the observed $\mathrm{NO}_{3}{ }^{-}$removal. Denitrification is the oxidation of organic carbon with $\mathrm{NO}_{3}{ }^{-}$resulting in gaseous $\mathrm{N}_{2}$ (Hulth et al., 1999). This process is most commonly observed in anoxic sediments, however, denitrification has also been reported for oxic environments where anoxic microenvironments are thought to develop, typically associated with sediment or suspended particle surfaces and/or biofilms (Gao et al., 2010; Liu et al., 2013; Rao et al., 2008). Indeed Gao et al. (2010) observed denitrification in sediments with porewater oxygen concentrations up to $90 \mu \mathrm{M}$.

An alternative mechanism for $\mathrm{NO}_{3}{ }^{-}$removal is anaerobic ammonium oxidation (anammox), whereby $\mathrm{NH}_{4}{ }^{+}$is oxidized with $\mathrm{NO}_{2}{ }^{-}$, ultimately resulting in the simultaneous loss of both $\mathrm{NH}_{4}{ }^{+}$and $\mathrm{NO}_{3}{ }^{-}$. Anammox is thought to be strictly anaerobic and largely limited by the supply of $\mathrm{NO}_{3}{ }^{-}$(van de Graaf et al., 1995). There is some evidence, however, that anammox may occur in environments with up to $20 \mu \mathrm{M}$ oxygen (Kalvelage et al., 2011). Sáenz et al. (2012) found evidence of ammonia-oxidizing bacteria associated with sediments coincident with groundwater redox boundaries within the mixing zone of the Waquoit Bay subterranean estuary. If anammox does occur at the mixing zone boundary, it must be due to rapid reaction rates relative to physical transport when $\mathrm{NO}_{3}{ }^{-}$and $\mathrm{NH}_{4}{ }^{+}$do not co-occur within the STE (Figures 5 and 6).

However, we observed periods where $\mathrm{NO}_{3}{ }^{-}$and $\mathrm{NH}_{4}{ }^{+}$overlapped, both immediately above and within the mixing zone (Figure 6). During $40 \%$ of the time series sampling periods, $\mathrm{NO}_{3}{ }^{-}$removal was not complete by the first occurrence of salinity and 
thus overlapped with $\mathrm{NH}_{4}{ }^{+}$, so we infer that terrestrial $\mathrm{NO}_{3}{ }^{-}$was entrained into the marine groundwater (Figures 5 and 7). Oxygen levels during 65\% of the time points when $\mathrm{NO}_{3}{ }^{-}$ and $\mathrm{NH}_{4}{ }^{+}$co-occur in the mixing zone (as defined by samples with salinity $>2, \mathrm{NO}_{3}{ }^{-}$and $\left.\mathrm{NH}_{4}{ }^{+}>2 \mu \mathrm{M}\right)$ were below the denitrification threshold $\left(\mathrm{O}_{2}=90 \mu \mathrm{M}\right)$ and $30 \%$ were below the anammox threshold $\left(\mathrm{O}_{2}=20 \mu \mathrm{M}\right)$, suggesting that these processes may be operating within the STE (Figure 8). The occurrence of terrestrial $\mathrm{NO}_{3}{ }^{-}$within the salinity mixing zone coincided with periods of enhanced mixing (Figure 9). In this instance, it is likely that the rate at which $\mathrm{NO}_{3}{ }^{-}$was added to the mixing zone was faster than the microbial community can convert $\mathrm{NO}_{3}{ }^{-}$to $\mathrm{N}_{2}$ either by denitrification or anammox.

\subsubsection{Nitrogen distribution and speciation in marine groundwater and the mixing zone}

Typical $\mathrm{NH}_{4}{ }^{+}$concentrations were $<1 \mu \mathrm{M}$ in bay water (see top sample in Figure 10), but marine groundwater had an elevated $\mathrm{NH}_{4}{ }^{+}$load within the subterranean estuary, presumably due to organic matter degradation and ammonification potentially within organic matter rich sediments in the recharge zone. Within the mixing zone, $\mathrm{NH}_{4}{ }^{+}$ exhibited both periods of conservative behavior and non-conservative removal. We base this conclusion of non-conservative removal on $\mathrm{NH}_{4}{ }^{+}$concentrations that fell below a mixing line defined by a constant marine end member (38 $\mu \mathrm{M}$ at salinity 25$)$ and total $\mathrm{NH}_{4}{ }^{+}$removal within terrestrial groundwater at the top of the mixing zone. This occurs during 30 of the time series sampling periods (see 2/23/2010 profile in Figure 7). An alternative interpretation of salinity: $\mathrm{NH}_{4}{ }^{+}$data is that the marine groundwater $\mathrm{NH}_{4}{ }^{+}$end member was temporally variable, and a separate mixing relationship should be fit to each time period. We use two lines of evidence to support the proposed marine groundwater 
$\mathrm{NH}_{4}{ }^{+}$end member. First, marine groundwater $\mathrm{NH}_{4}{ }^{+}$concentrations consistently displayed the proposed end member value, regardless of season, year or location within the STE even if removal as apparent within the mixing zone (Figure S7). Second, during some periods when $\mathrm{NH}_{4}^{+}$loss was evident there was concurrent production of $\mathrm{NO}_{2}{ }^{-}+\mathrm{NO}_{3}{ }^{-}$in the mixing zone. This $\mathrm{NO}_{2}{ }^{-}+\mathrm{NO}_{3}{ }^{-}$must come from local $\mathrm{NH}_{4}{ }^{+}$conversion, implying a greater original $\mathrm{NH}_{4}{ }^{+}$concentration, accounting for the observed $\mathrm{NH}_{4}{ }^{+}$deficit. The oxidized forms of nitrogen are largely below detection both above the mixing zone and in intruding bay water so their occurrence within the mixing zone must follow in situ production when mixing from the terrestrial plumes can be excluded. We discuss this last observation below.

Oxygen levels within the mixing zone were typically 10 to $200 \mu \mathrm{M}$, thus we infer that $\mathrm{NH}_{4}{ }^{+}$removal occurred via nitrification (Hulth et al., 1999). In addition, ammonia oxidizing archaea are present within the mixing zone of the Waquoit Bay STE (Rogers and Casciotti, 2010). Nitrification is not sensitive to oxygen levels, since the decrease in reaction rate under oxygen-limited conditions is countered by biomass increase, resulting in minimal net impact on overall nitrification (Hanaki et al., 1990). Nitrate is a byproduct of nitrification and there was a concurrent increase in $\mathrm{NO}_{3}{ }^{-}+\mathrm{NO}_{2}{ }^{-}$with $\mathrm{NH}_{4}{ }^{+}$removal in many of the sampling periods when non-conservative $\mathrm{NH}_{4}{ }^{+}$loss was observed (see 12/1/2009 profile in Figure 7). It is possible to differentiate downward mixing of terrestrial $\mathrm{NO}_{3}{ }^{-}+\mathrm{NO}_{2}{ }^{-}$from in situ production based on the nutrient depth profiles. When $\mathrm{NO}_{3}{ }^{-}+\mathrm{NO}_{2}{ }^{-}$mixed conservatively, there was a linear decrease from the terrestrial plume at shallow depths down into the mixing zone. When $\mathrm{NO}_{3}{ }^{-}+\mathrm{NO}_{2}{ }^{-}$was produced within 
the mixing zone, elevated concentrations were observed at the base of the mixing zone after all terrestrial $\mathrm{NO}_{3}{ }^{-}+\mathrm{NO}_{2}{ }^{-}$has been depleted at the top of the mixing zone (Figure 7).

When the concentration of $\mathrm{NO}_{3}{ }^{-}+\mathrm{NO}_{2}{ }^{-}$within the mixing zone is equal to the $\mathrm{NH}_{4}{ }^{+}$removal, there is no net loss of nitrogen. However the proportion of $\mathrm{NO}_{3}{ }^{-}+\mathrm{NO}_{2}{ }^{-}$ potentially produced via nitrification compared to $\mathrm{NH}_{4}{ }^{+}$lost was variable $(<1 \%$ to $>100 \%$ ). Values greater than $100 \%$ may be indicative of advection of $\mathrm{NO}_{3}{ }^{-}+\mathrm{NO}_{2}{ }^{-}$ produced beyond the site of the time series profile into this location (Figure 9).

During periods of reduced mixing and longer residence times within the STE, there was minimal accumulation of $\mathrm{NO}_{3}{ }^{-}+\mathrm{NO}_{2}{ }^{-}$. As mixing increased, there were periods when the sum of $\mathrm{NO}_{3}{ }^{-}+\mathrm{NO}_{2}{ }^{-}$within the mixing zone was equal to the $\mathrm{NH}_{4}{ }^{+}$ removed (Figure 9). However, oxidized forms of nitrogen were not observed in the mixing zone during the summer of 2005 , when mixing did increase, indicating that there were potentially additional controls on reaction and mixing rates. We surmise that denitrification was usually closely coupled with nitrification in the mixing zone when mixing rates were low, but may have become decoupled as the exchange between terrestrial and marine groundwater increased (Figure 9). Oxygen levels during periods when $\mathrm{NO}_{3}{ }^{-}+\mathrm{NO}_{2}{ }^{-}$accumulation was observed in the mixing zone were potentially low enough $(<90 \mu \mathrm{M})$ in many of the cases to allow denitrification to occur (Figure 8). Thus, this accumulation may be an indication of nitrification rates exceeding denitrification.

\subsubsection{Phosphate and manganese}

Both $\mathrm{PO}_{4}{ }^{3-}$ removal and release were apparent within the four full STE transects and the time series water chemistry. As with $\mathrm{NH}_{4}{ }^{+}$, we assume a constant marine end member (10 $\mu \mathrm{M}$ at salinity 25$)$ to evaluate non-conservative behavior (Figure 5). During 
some periods there was $\mathrm{PO}_{4}{ }^{3-}$ removal across the mixing zone and a concurrent nonconservative loss of $\mathrm{Mn}$ (see 9/7/2006 profile in Figure 11) We hypothesize that $\mathrm{PO}_{4}{ }^{3-}$ adsorbed onto $\mathrm{Fe}$ and Mn-oxides/hydroxides, which form as the groundwater oxygen levels increased upon mixing with terrestrial water (Figure 11). Other time periods are marked by Mn removal and $\mathrm{PO}_{4}{ }^{3-}$ release (see 4/6/2005 profile in Figure 11). The $\mathrm{pH}$ within terrestrial groundwater during 9/7/2006 was lower (5.25) than in 4/6/2005 (5.25) when $\mathrm{PO}_{4}{ }^{3-}$ removal occurred. Within the full STE transects, removal was greatest in the region of the STE closest to the marine recharge zone, with release observed in the mixing zone further inland. This was likely due to the competing influence of $\mathrm{pH}$ and salinity on $\mathrm{PO}_{4}{ }^{3-}$ adsorption onto Mn-oxides/hydroxides.

Phosphate adsorption is strongly $\mathrm{pH}$ dependent. In laboratory experiments, $100 \%$ of the $\mathrm{PO}_{4}{ }^{3-}$ is sorbed at $\mathrm{pH}$ values below six, decreasing to $80 \%$ sorption at $\mathrm{pH} 7$ and $65 \%$ at $\mathrm{pH} 8$ (Zhang et al., 2009). Phosphate sorption is enhanced at higher ionic strength. Adsorption of anions that sorb via outer-sphere association is suppressed at higher ionic strength, while sorption of anions that sorb via inner-sphere association is either unaffected or weakly enhanced at higher ionic strength (Zhang et al., 2009). Since laboratory experiments indicate slightly higher sorption at elevated ionic strength, $\mathrm{PO}_{4}{ }^{3-}$ is likely bonding to Mn-oxides/hydroxides as inner-sphere surface complexes (Zhang et al., 2009).

Marine groundwater typically has a $\mathrm{pH}$ range of 7 to 8 , while terrestrial water ranges from 5-7 within the Waquoit STE. Elevated dissolved $\mathrm{PO}_{4}{ }^{3-}$ was observed where groundwater had a low salinity and $\mathrm{pH} \sim 7$ (Figure 12). Further evidence that $\mathrm{PO}_{4}{ }^{3-}$ sorbed onto Mn-oxides/hydroxides is provided in the sediment oxide associated- $\mathrm{PO}_{4}{ }^{3-}\left(\mathrm{SPO}_{4}{ }^{3-}\right)$ 
profile (Figure 12). Sediment bound $\mathrm{PO}_{4}{ }^{3-}(\mathrm{sP})$ was elevated within the high Mn oxide region $(\mathrm{sMn})$, which is coincident with groundwater of high ionic strength and $\mathrm{pH}$ of 7 to 8. This elevated sP was located below the iron oxide/hydroxide peak, which had very low sP (Figure 12). Molar ratios of sP:sMn in this region were 5-20, while throughout the remainder of the profile they were $<1$. Similarly, molar ratios of sP:sFe were quite high in this region. The dissolved $\mathrm{dP}: \mathrm{dMn}$ ratio was low coincident with this region of high sorbed sP:sMn ratios, indicating preferential sorption of dissolved $\mathrm{PO}_{4}{ }^{3-}$ onto sediments in contact with low $\mathrm{pH}$, low salinity groundwater. The high $\mathrm{sFe}$ region at depth has low $\mathrm{sP}$ associated with it (Figure 12). It is evident that $\mathrm{P}$ is actively cycling in the STE and while the presence of $\mathrm{Fe}$ and $\mathrm{Mn}$ oxides/hydroxides may enhance $\mathrm{P}$ sorption, the ability of the STE to act as a P sink has additional complexities.

\subsection{Subterranean estuary nutrient fluxes}

Nutrient transformations within the subterranean estuary impact the net flux of both nitrogen and phosphorous to the coastal ocean via submarine groundwater discharge. Here we evaluate nutrient input to the STE and removal during transit across the STE. In this analysis, nutrient transformations may occur anywhere along the groundwater flow path. For terrestrial groundwater, the flow lines are laminar, thus it is relatively straightforward to evaluate nutrient loss along the flow path. The circulation of marine groundwater is more complex-it enters the subterranean estuary and then flows both inland and downward in a circulation cell before rising along the salinity interface and discharging. Thus, marine groundwater may travel along numerous pathways and have a wide range of residence times within the subterranean estuary (Abarca et al., 2013; Michael et al., 2005; Robinson et al., 2006). 
To translate the previously discussed nutrient transformations into fluxes, we coupled concentrations with the model groundwater discharge rates. Nutrient flux into the STE was evaluated at the terrestrial and marine boundaries (Figure 1) over the time period we have modeled groundwater discharge rates (January 2005 to May 2007). It is only possible to evaluate nutrient attenuation along the terrestrial groundwater flow path during periods where data exists for the full STE transect (March 2003, June 2004 and April and June 2005) since the time series wells do not capture the full vertical extent of terrestrial nutrient plumes. Nutrient loss associated with mixing between terrestrial and marine groundwater end members was evaluated in both transect and time series data and transformation rates were determined for the periods that coincide with modeled discharge rates (January 2005 to May 2007).

\subsubsection{Inputs}

We explore seasonal variability in nutrient input to the STE by coupling the hydrologic model flux results to nutrient inventories from repeat measurements of terrestrial and marine groundwater profiles (locations at 0 and $20 \mathrm{~m}$ in Figure 1). Nutrient inventories were determined by integrating the $\mathrm{DIN}$ and $\mathrm{PO}_{4}{ }^{3-}$ profiles. To calculate fluxes, we computed the weighted average by dividing the inventory by the profile depth. This is necessary since the modeled groundwater flux is for the entire depth of the STE. The terrestrial groundwater DIN inventory as recorded over numerous years and seasons was $290 \pm 100 \mathrm{mmol} \mathrm{m}^{-2}$ (weighted average, $36 \pm 12 \mathrm{mmol} \mathrm{m}^{-3}(\mathrm{n}=9)$ ), Table 1 and Figure 10). The dataset is too limited to discern seasonal patterns, but if they do exist, they are likely not larger than the $35 \%$ standard deviation noted in Table 1 . Phosphate inventories were $8.3 \pm 3.5 \mathrm{mmol} \mathrm{m}^{-2}$ (weighted average $1 \pm 0.4 \mathrm{mmol} \mathrm{m}^{-3}$, Table 1 and Figure 10). 
There were fewer repeat profiles of the marine groundwater, but the three years had similar inventories (DIN: $290 \pm 30 \mathrm{mmol} \mathrm{m}^{-3}$ and $\mathrm{PO}_{4}{ }^{3-}: 64 \pm 23 \mathrm{mmol} \mathrm{m}^{-3}$, weighted average DIN : $37 \pm 4 \mathrm{mmol} \mathrm{m}^{-3}$ and $\mathrm{PO}_{4}{ }^{3-}: 8 \pm 3 \mathrm{mmol} \mathrm{m}^{-3}$ ). The $\mathrm{N}: \mathrm{P}$ ratio was much higher in the terrestrial groundwater than the marine, typical of terrestrial systems where $\mathrm{N}$ fixation elevates $\mathrm{N} / \mathrm{P}$ ratios. We use these end members coupled with the modeled terrestrial and marine groundwater fluxes into the subterranean estuary to determine total nutrient fluxes into the STE over the course of the time series observations (Figure S8). Since the end member is assumed constant, changing groundwater discharge drives all variability in fluxes. Typical terrestrial nitrogen fluxes were $109 \pm 9 \mathrm{mmol} \mathrm{m}^{-1} \mathrm{~d}^{-1}$ in the summer and $130 \pm 14 \mathrm{mmol} \mathrm{m}^{-1} \mathrm{~d}^{-1}$ in the winter, while marine fluxes were $115 \pm 34$ and $25 \pm 19 \mathrm{mmol} \mathrm{m}^{-1} \mathrm{~d}^{-1}$ in the summer and winter respectively (Figure S8). Terrestrial phosphate fluxes were $3 \pm 0.3$ (summer) and $4 \pm 0.4$ (winter) $\mathrm{mmol} \mathrm{m}^{-1} \mathrm{~d}^{-1}$, while marine fluxes were $25+8$ (summer) and $7 \pm 7$ (winter) $\mathrm{mmol} \mathrm{m}^{-1} \mathrm{~d}^{-1}$ (Figure $\mathrm{S} 8$ ). Additional uncertainty in fluxes calculated this way is at least as great as the interannual variability during each season (terrestrial DIN: $35 \%$, terrestrial $\mathrm{PO}_{4}{ }^{3-}: 40 \%$, marine DIN: $10 \%$ and marine $\mathrm{PO}_{4}{ }^{3-}: 40 \%$ ), while the uncertainty in water fluxes from the hydrologic model is harder to determine. Fluxes were also determined from the April and June 2005 transects: terrestrial nitrogen fluxes were 160 and $100 \mathrm{mmol} \mathrm{m}^{-1} \mathrm{~d}^{-1}$, respectively; marine nitrogen fluxes were 70 and $140 \mathrm{mmol} \mathrm{m}^{-1} \mathrm{~d}^{-1}$, respectively; terrestrial P fluxes were 4 and $3 \mathrm{mmol}$ $\mathrm{m}^{-1} \mathrm{~d}^{-1}$, respectively; and marine P fluxes were 10 and $26 \mathrm{mmol} \mathrm{m}^{-1} \mathrm{~d}^{-1}$, respectively (Figure 13 and Table 2). 


\subsubsection{Terrestrial groundwater nutrient attenuation}

To evaluate terrestrially sourced nutrient loss during flow across the STE, we calculated changes in the nutrient inventory in March 2003 (as reported in Kroeger \& Charette, 2008), June 2004, and April and June 2005. The terrestrial nutrient attenuation in the subterranean estuary is the difference between the DIN and $\mathrm{PO}_{4}{ }^{-}$inventory between a location $12 \mathrm{~m}$ inland from mean sea level and one $15 \mathrm{~m}$ towards the bay (see Figure 1). These location were chosen since the bottom of the profiles intersect the top of the mixing zone, thereby ensuring we captured the entire terrestrial groundwater plume. Nutrient removal that may occur in the shallow tidally influenced mixing zone is not included in this approach, but may be important. For example, Santos et al. (2009) reports production of $\mathrm{NO}_{3}{ }^{-}$within a shallow STE dominated by marine groundwater and tidal pumping, while Weinstein et al. (2011) found near complete removal of $\mathrm{NO}_{3}{ }^{-}$within a sandy STE due to a strong denitrification sink. If removal processes in the discharge zone are important, then the nutrient fluxes reported below will over estimate the actual flux.

Terrestrial DIN removal was $12-13 \%$ in June 2004 and 2005, while removal was much greater in March 2003 (71\%) and April 2005 (70\%). Nutrient fluxes could only be calculated for the 2005 transects and are simply the product of the weighted average

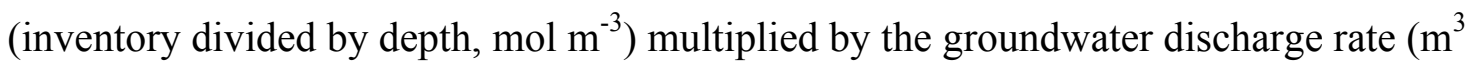
$\left.\mathrm{m}^{-1} \mathrm{~d}^{-1}\right)$. Terrestrial nitrogen flux into Waquoit Bay (inputs minus losses, assuming no further removal occurred) was $87 \mathrm{mmol} \mathrm{m}^{-1} \mathrm{~d}^{-1}$ in June 2005, while the flux in April 2005 was only $48 \mathrm{mmol} \mathrm{m}^{-1} \mathrm{~d}^{-1}$ (Table 2). Across all four transects, terrestrial $\mathrm{PO}_{4}{ }^{3-}$ removal was 45-66\%, except during April 2005, when P removal was not detected (Table 2). This may be due to the higher flow rate at the site where this transect was located, and 
therefore reduced residence time. The flux of terrestrial P into the Bay, again assuming no further loss, was 2-4 mmol m${ }^{-1} \mathrm{~d}^{-1}$. However, both release and removal of $\mathrm{PO}_{4}{ }^{3-}$ was observed in the transect data, with no clear seasonal trend (Table 2). When all four transects are considered, there appears to be net removal of $\mathrm{PO}_{4}{ }^{3-}$ within the STE. The nitrogen to phosphorous ratio (N:P) of terrestrial inputs (39) was higher than the removal ratio (12) in June 2005, although P removal was not detected in the April 2005 transect. Phosphorous is preferentially removed from the terrestrial groundwater within the subterranean estuary, likely via adsorption onto Fe-Mn oxides/hydroxides (Charette and Sholkovitz, 2002; Spiteri et al., 2008; Spiteri et al., 2006; Slomp and Van Cappellen, 2004; Zhang et al., 2009).

\subsubsection{Marine groundwater and mixing zone nutrient attenuation}

The salinity mixing zone is an additional site of $\mathrm{NO}_{3}{ }^{-}$and $\mathrm{NH}_{4}{ }^{+}$removal and active $\mathrm{PO}_{4}{ }^{3-}$ cycling. Terrestrially sourced nitrogen does not mix deeply into the salinity transition zone, thus $\mathrm{NH}_{4}{ }^{+}$, the main $\mathrm{N}$ species in the mixing zone, is of marine origin (Kroeger and Charette, 2008). We evaluated each groundwater profile collected during the 2003, 2004 and 2005 transects and the time series for non-conservative loss of $\mathrm{NH}_{4}^{+}$ and production of $\mathrm{NO}_{3}{ }^{-}$(presumably via nitrification) to determine the net DIN removal within the mixing zone. Samples that fell below the conservative mixing relationship discussed above (section 4.2.2) are indicative of $\mathrm{NH}_{4}{ }^{+}$removal. Using a standard estuarine model of chemical mixing, the difference between the DIN concentration predicted by conservative mixing and the observed concentration is the total DIN loss (e.g. Boyle et al., 1974; Beck et al., 2007; Santos et al., 2009). Note that if the marine 
groundwater end member does vary temporally, fluxes reported here may overestimate nitrogen removal.

For transect data, total loss was evaluated across all samples to determine a net mixing zone removal. Marine DIN removal across the mixing zone was not detected in the March 2003 or June 2005 transect profiles, but was observed in April and June 2005. In the April and June 2005 transects, marine nitrogen attenuation was 25 and 5\% respectively, yielding a removal rate of 18 and $7 \mathrm{mmol} \mathrm{m}^{-1} \mathrm{~d}^{-1}$ and a flux of marine nitrogen out of the STE and into the Bay of 53 and $133 \mathrm{mmol} \mathrm{m}^{-1} \mathrm{~d}^{-1}$ (Figure S8). Nonconservative loss of DIN in the mixing zone was observed in $60 \%$ of the time series profiles. For both nitrogen and phosphorous, a removal rate was calculated by multiplying marine groundwater discharge rates times the integrated difference between observed concentrations and those predicted by conservative mixing across the salinity transition zone. Removal rates using this approach can only be determined for the period from January 2004 to May 2007 where modeled groundwater discharge rates are available. Nitrogen removal determined from the time series profiles reached $25 \%$, with removal rates ranging between 0.3 and $15 \mathrm{mmol} \mathrm{m}^{-1} \mathrm{~d}^{-1}$ (Figure S8).

Phosphate profiles and salinity distributions within the mixing zone reveal periods of both $\mathrm{PO}_{4}{ }^{3-}$ removal and release. We posit that this dynamic cycling is due to sorption/desorption onto Fe and Mn oxides/hydroxides (Spiteri et al., 2006; Slomp and Van Cappellen, 2004). However, the solid phase and dissolved P data reveals additional complexities, such as very low $\mathrm{sP}$ in the high $\mathrm{sFe}$ region. Further work is needed to elucidate $\mathrm{SP}$ associations within the STE. 
There was a pattern of $\mathrm{PO}_{4}{ }^{3-}$ removal at locations near the marine recharge zone, followed by release further inland. Removal was observed in June 2004 (loss of 27\% of marine P input to STE) and April 2005 (54\%), while release is apparent in March 2003 (5\% of marine P input to STE) and June 2005 (15\%). During the time series, $\mathrm{PO}_{4}^{3-}$ removal and release occurred in roughly equal proportions. While P removal was detected in the whole transect dataset in April 2005, the single profile at the time series well location predicts net $\mathrm{P}$ release, for this period. Since $\mathrm{P}$ release was enhanced in seaward locations within the STE, such as the site of the time series, we conclude that P cycling within the STE may be under constrained in the time series profiles and thus we are not able to accurately predict $\mathrm{P}$ flux rates from these data.

\subsection{Timing of nutrient export from the STE}

Nutrient export from the STE is the difference between terrestrial and marine inputs and attenuation of these two pools upon transport through the STE.In 2005, when we have the most complete dataset, we observed a total nitrogen load to the Bay of 100 $\mathrm{mmol} \mathrm{m} \mathrm{d}^{-1}$ during the winter/spring, which was $48 \%$ new nitrogen and $220 \mathrm{mmol} \mathrm{m}^{-1}$ $\mathrm{d}^{-1}$ during the summer/fall, which was $40 \%$ new nitrogen (Figure 13). For phosphorus, the net winter/spring flux was $9 \mathrm{mmol} \mathrm{m}^{-1} \mathrm{~d}^{-1}$ and $32 \mathrm{mmol} \mathrm{m}^{-1} \mathrm{~d}^{-1}$ during the summer/fall.

The flux of marine-sourced nitrogen dominates in the summer due to both greater marine groundwater recharge, as predicted by the hydrologic model. and low nitrogen removal rates within the STE. Likewise, terrestrial nitrogen inputs to the STE peak during the winter when terrestrial fluxes are greatesr, however terrestrial nitrogen removal also peaks during the winter. Gonneea et al. (2013a) had previously hypothesized that nutrient loading would peak in the winter, following enhanced nutrient 
removal due to greater mixing in the summer as posited by Kroeger and Charette (2008). The authors based this hypothesis that enhanced mixing would result in greater nitrogen attenuation on the near total drawdown of DIN at the salinity/redox mixing boundary. In this instance, the amount of nitrogen attenuation would be limited by the delivery rate of reactant pools. The seasonal variability in the data shown here reveals additional complexity within STE nutrient cycling. The microbes that mediate removal processes may not be limited by reactant supply (including $\mathrm{O}_{2}, \mathrm{NH}_{4}{ }^{+}$and $\mathrm{NO}_{3}{ }^{-}$), but rather reaction kinetics (Santoro et al., 2010). Also, the STE may shift temporally between periods where reactant supply rate and reaction rate limit nitrogen attenuation. Thus, water residence time within the subterranean estuary may be just as important for nutrient attenuation as enhanced physical mixing across the salinity mixing zone redox gradients.

The nutrient fluxes shown in this study are five to seven times lower than reported for a STE with similar groundwater flow rates, but dominated by marine recirculation and marine nutrient sources (Santos et al., 2009). Conversely, our nutrient fluxes are an order of magnitude larger than a sandy STE with a well developed denitrification zone that has discharge rates two to four times lower than we report (Weinstein et al., 2011).

\section{Conclusions}

Groundwater chemistry within the Waquoit Bay subterranean estuary was dynamic across multiple years and seasons. Terrestrial groundwater was enriched in both the oxidized $\left(\mathrm{NO}_{3}{ }^{-}\right)$and reduced $\left(\mathrm{NH}_{4}{ }^{+}\right)$forms of nitrogen, likely due in part to anthropogenic inputs (i.e. septic systems, fertilizer applications). Attenuation of nitrogen along the terrestrial groundwater flow path was higher in the winter (70\%) than the summer (12\%). For marine groundwater, $\mathrm{NH}_{4}{ }^{+}$concentrations were enriched, likely due 
to organic matter remineralization and ammonification in organic carbon rich surficial sediments within the recharge zone. There was evidence for some loss of this recycled pool of nitrogen, effectively removing marine-sourced nitrogen within the subterranean estuary, though it was only $5-25 \%$ of marine inputs. Phosphate was also elevated within marine groundwater, with much lower N:P ratios (3-7) than the Redfield ratio (16:1), likely resulting from a combination of $\mathrm{N}$ removal and $\mathrm{P}$ release from sediment oxide/hydroxides driven by large $\mathrm{pH}$ and salinity gradients. There is evidence for both removal and release of $\mathrm{P}$ within this STE, thus the net $\mathrm{P}$ flux term is remains uncertain.

Groundwater hydrology and geochemistry are closely linked in dynamic systems such as the Waquoit Bay subterranean estuary. During the winter, the hydrologic model predicted that mixing between terrestrial and marine groundwater was generally low due to minimal marine groundwater intrusion. In the summer, the hydraulic gradient decreased and subsequently there was a much larger input of marine groundwater and associated mixing within the STE. We observed enhanced removal of both nitrogen and phosphorous, particularly from the terrestrial groundwater, when mixing was reduced and total submarine groundwater discharge was lower (winter). This result may seem counter intuitive, since the redox conditions that result from mixing between terrestrial and marine groundwater favor biological removal via denitrification and anammox. We propose, rather, that enhanced removal rates are due to longer residence times within the subterranean estuary. Such a result would imply that physical mixing processes exceed the biological transformation rates for either denitrification or anammox within the subterranean estuary during certain flow regimes. 
Alternatively, dynamic movement of the salinity transition zone concurrent with enhanced mixing may lead to a reduction in transformation rates of $\mathrm{NO}_{3}{ }^{-}$and $\mathrm{NH}_{4}{ }^{+}$as mixing zone movement shifts reactant pools away from the sediment-bound microbes that mediate these reactions. Santoro et al. (2010) found that the abundance of ammonia oxidizing bacteria and archaea shifted with changes in the redox/salinity environment of the STE on seasonal time scales, but more work is needed to understand the ability of microbial communities to reestablish themselves following periods of dynamic mixing zone movement. Other factors that may influence these reaction rates (i.e. temperature, $\mathrm{O}_{2}$ ) were either more favorable during periods of reduced removal (temperature was higher in the summer) or did not vary appreciably $\left(\mathrm{O}_{2}\right)$.

The timing of nutrient delivery to the coast has important implications for estuarine ecosystems. Terrestrial (new nutrient) fluxes into the subterranean estuary are greatest in the winter, coincident with peak removal rates, while marine (recycled) nutrient inputs peak during the summer. Total nitrogen fluxes to Waquoit Bay thus peak in the summer, when maximal algal growth is possible due to warm temperatures and long daylight hours. Further work is required to gain a greater understanding of the interplay between hydrology and biologically mediated nutrient cycling within the subterranean estuary. 
Acknowledgements: The authors thank Paul Morris, Crystal Breier, Adam Rago, Gillian Smith, DeAnna McCadney and Grace Rago for assistance in the field and laboratory. Scot Birdwhistell of the WHOI ICP-MS Facility assisted with trace metal analyses. We extend our continued appreciation to the director and staff of the Waquoit Bay National Estuarine Research Reserve for their assistance with logistics during field sampling. This research was sponsored by NSF (OCE- 0425061 to M.A.C. and A.E.M. and OCE0524994/OCE-0751525 to M.A.C.). MEG was supported by an NDSEG graduate fellowship and was awarded a graduate fellowship from the Estuarine Reserves Division, Office of Ocean and Coastal Resource Management, National Ocean Service, National Oceanic and Atmospheric Administration. 


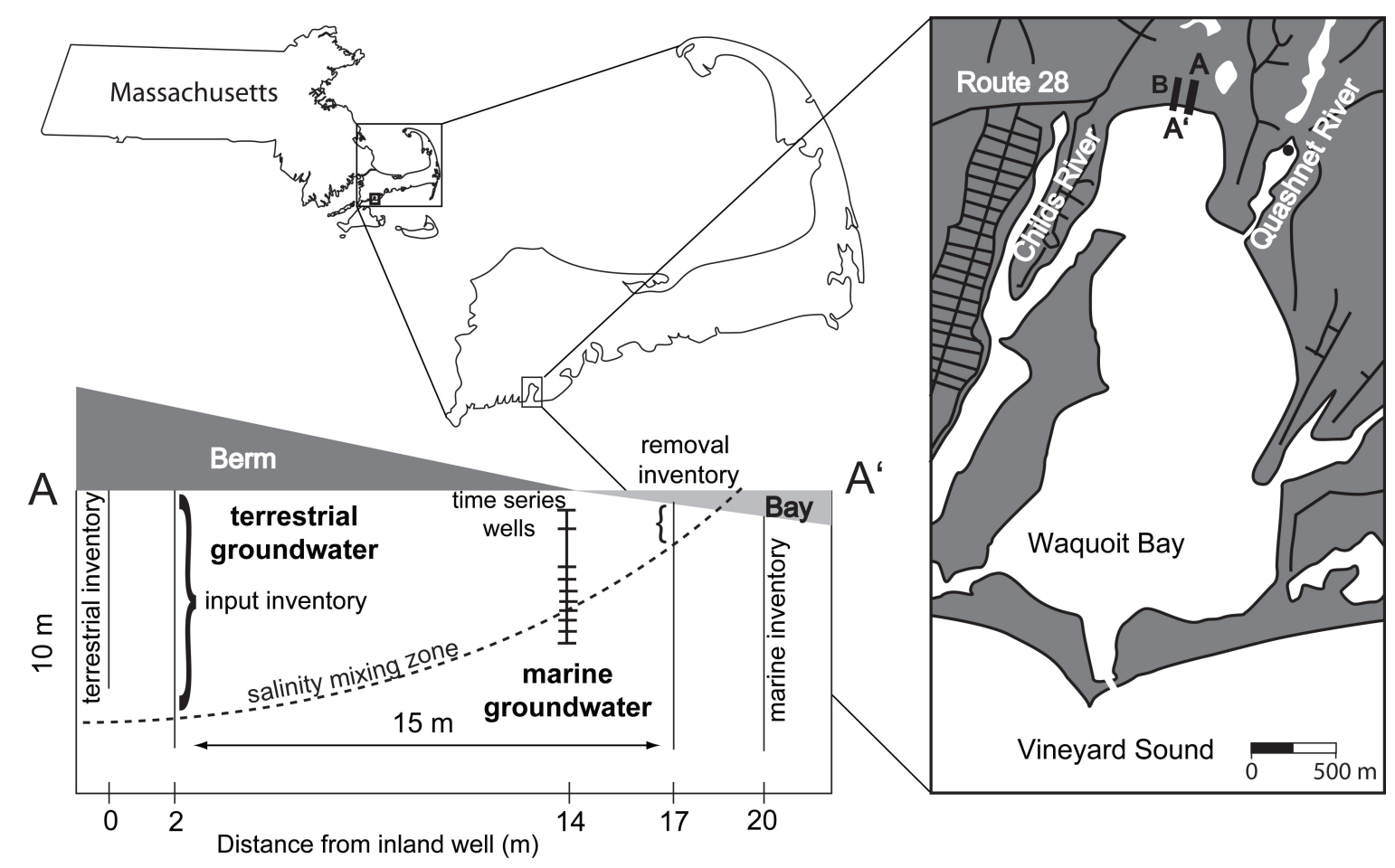

Figure 1: Waquoit Bay location map and subterranean estuary schematic. Distance in the inset panel is from the most inland well, where the terrestrial inventory was measured repeatedly. The marine nutrient flux was determined from the inventory at $20 \mathrm{~m}$. The location of the time series wells is approximately at mean sea level. During March 2003, June 2004 and June 2005 the inventory reduction along transect A between profiles at 2 and 17 meters represented total nutrient losses from the terrestrial groundwater, not accounting for any loss that may occur between $17 \mathrm{~m}$ and the discharge site. In April 2005 nutrient dynamics were evaluated in a similar way along transect B, which has a similar cross section, but has a higher upland hydraulic head. The salinity mixing zone is noted as a dashed line. 

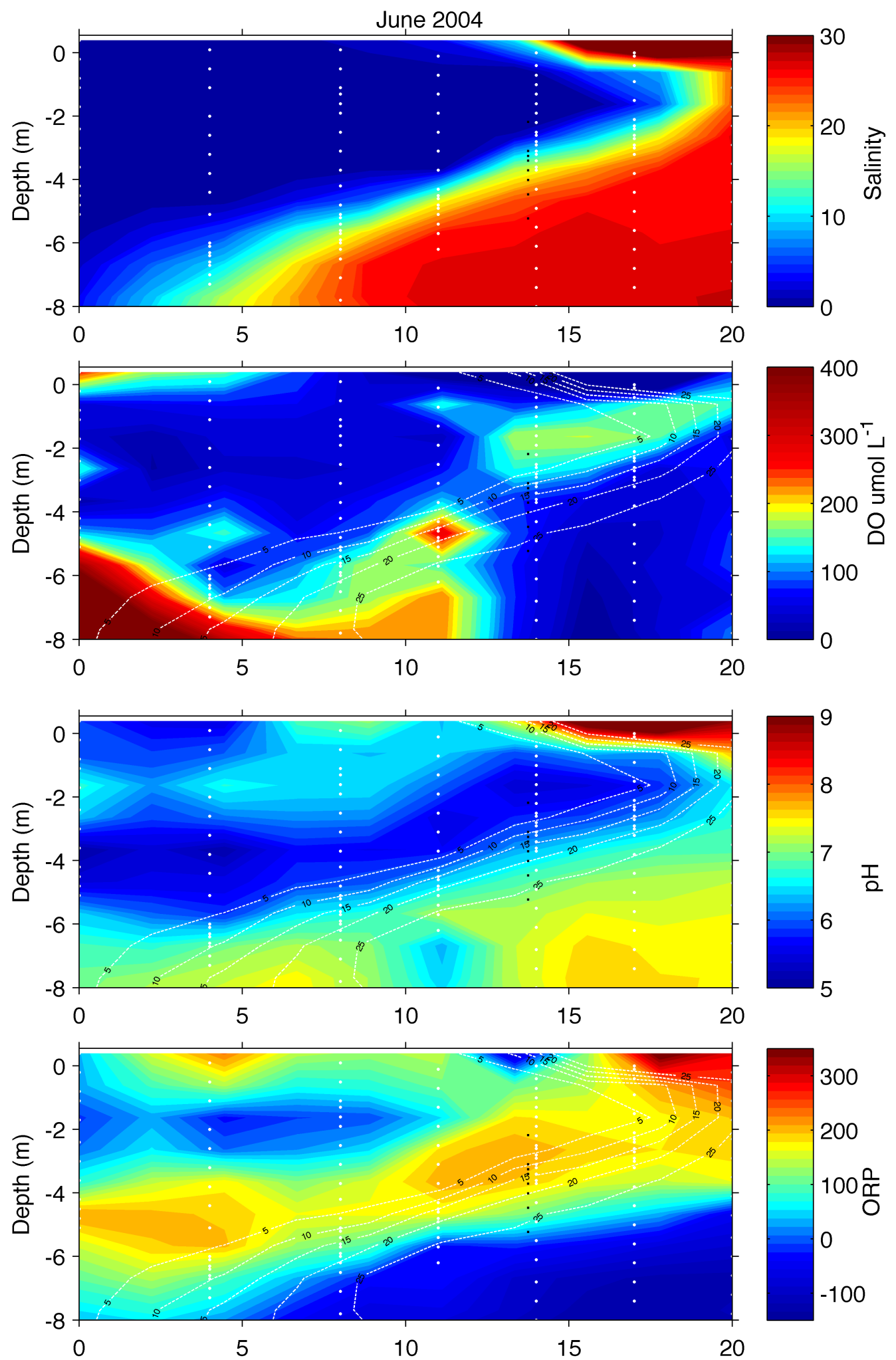

Figure 2 a-d. 

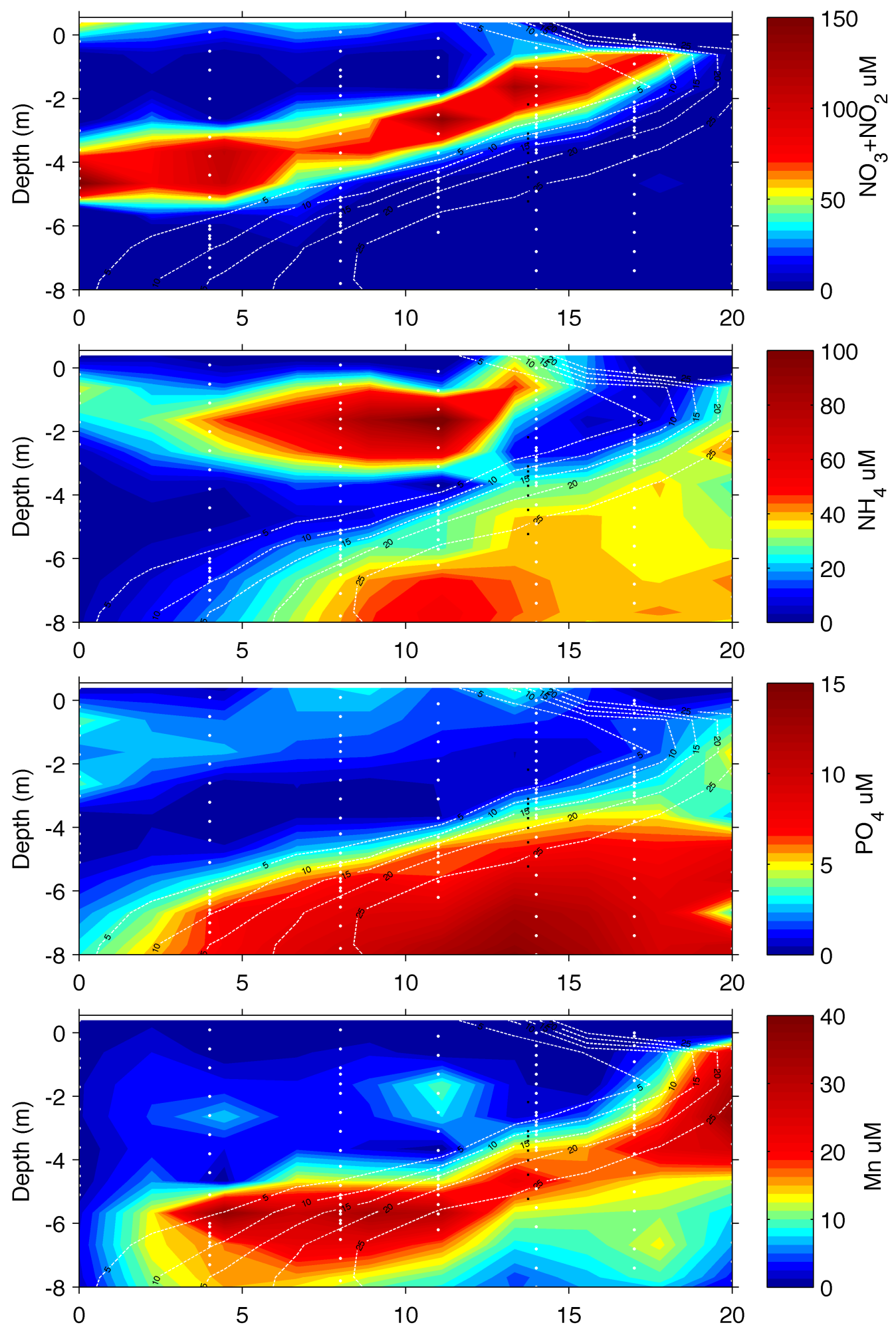

Figure 2 e-h. 


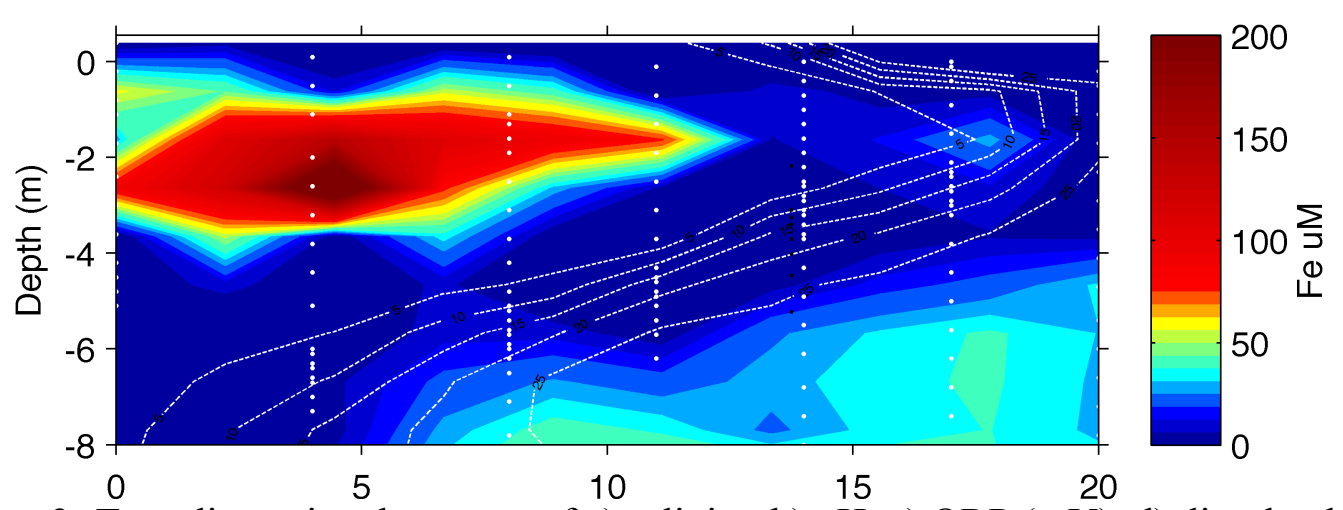

Figure 2: Two-dimensional transect of a) salinity, b) pH, c) ORP (mV), d) dissolved oxygen, e) nitrate + nitrite, f) ammonium, g) phosphate (acidified upon collection), h) manganese and i) iron in June 2004. The points used to contour the data are noted in white circles, while the location of the time series wells are black squares. Salinity contours are included as whited dashed lines. As the hydraulic gradient varies, the position of the salinity transition zone, and nitrate and ammonium plume moves. The nitrate plume (e) and region of high ammonium (f) may move in and out of the location of the time series wells. 


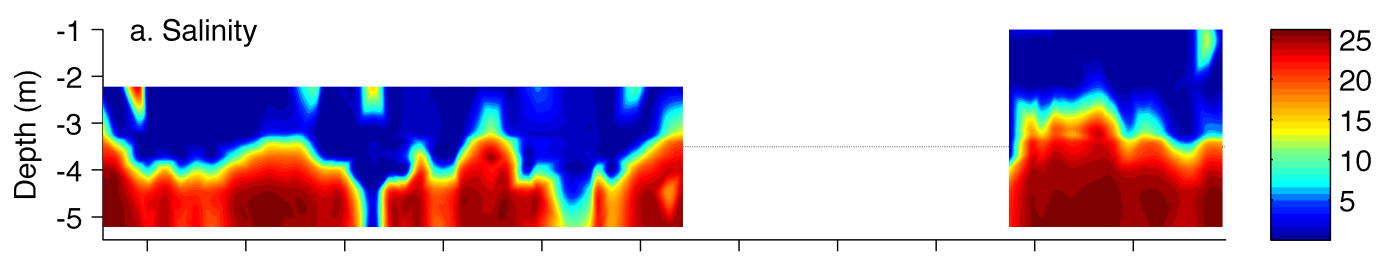

Jan-05 Jul-05 Jan-06 Jul-06 Jan-07 Jul-07 Jan-08 Jul-08 Jan-09 Jul-09 Jan-10

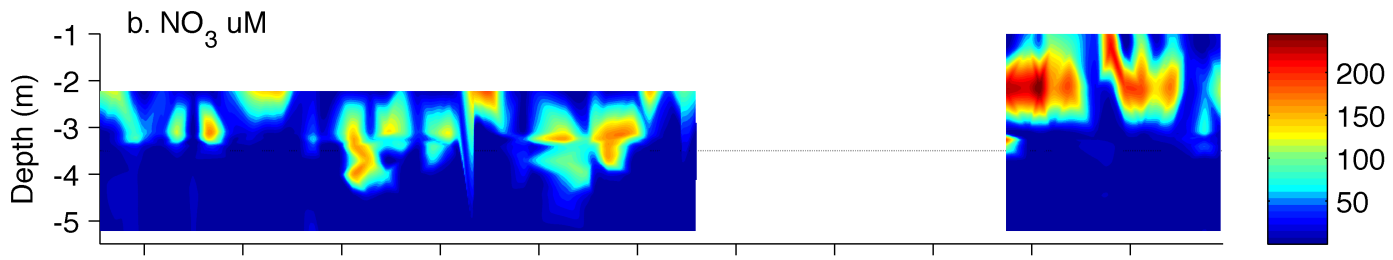

Jan-05 Jul-05 Jan-06 Jul-06 Jan-07 Jul-07 Jan-08 Jul-08 Jan-09 Jul-09 Jan-10

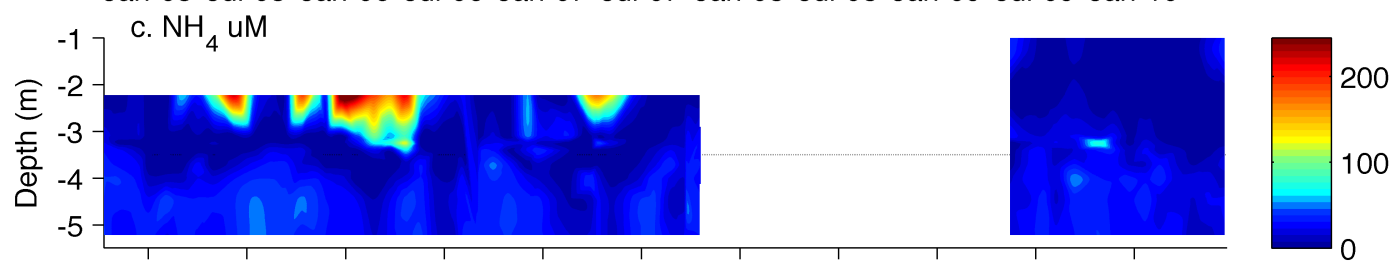

Jan-05 Jul-05 Jan-06 Jul-06 Jan-07 Jul-07 Jan-08 Jul-08 Jan-09 Jul-09 Jan-10
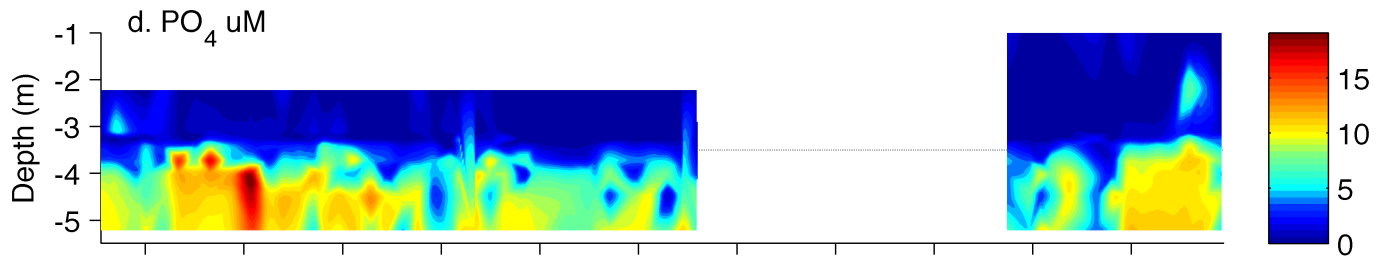

Jan-05 Jul-05 Jan-06 Jul-06 Jan-07 Jul-07 Jan-08 Jul-08 Jan-09 Jul-09 Jan-10

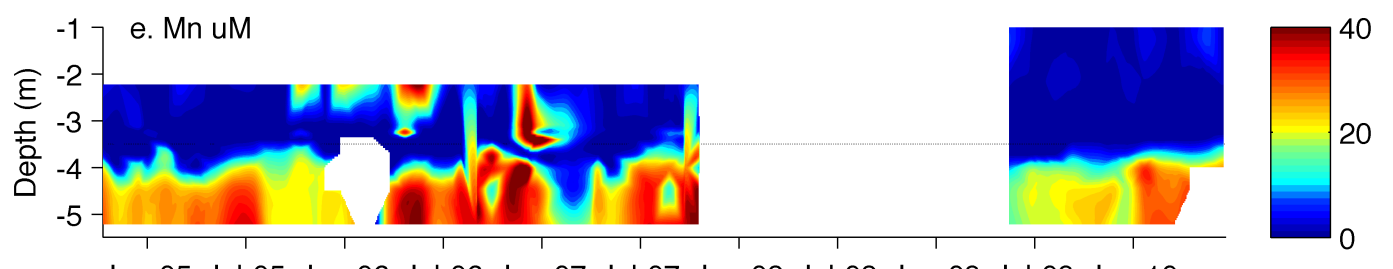

Jan-05 Jul-05 Jan-06 Jul-06 Jan-07 Jul-07 Jan-08 Jul-08 Jan-09 Jul-09 Jan-10

Figure 3: a) Salinity, b) nitrate + nitrite, c) ammonium, d) phosphate (acidified upon collection) and e) manganese from October 2004 to October 2007 and May 2009 to June 2010. 


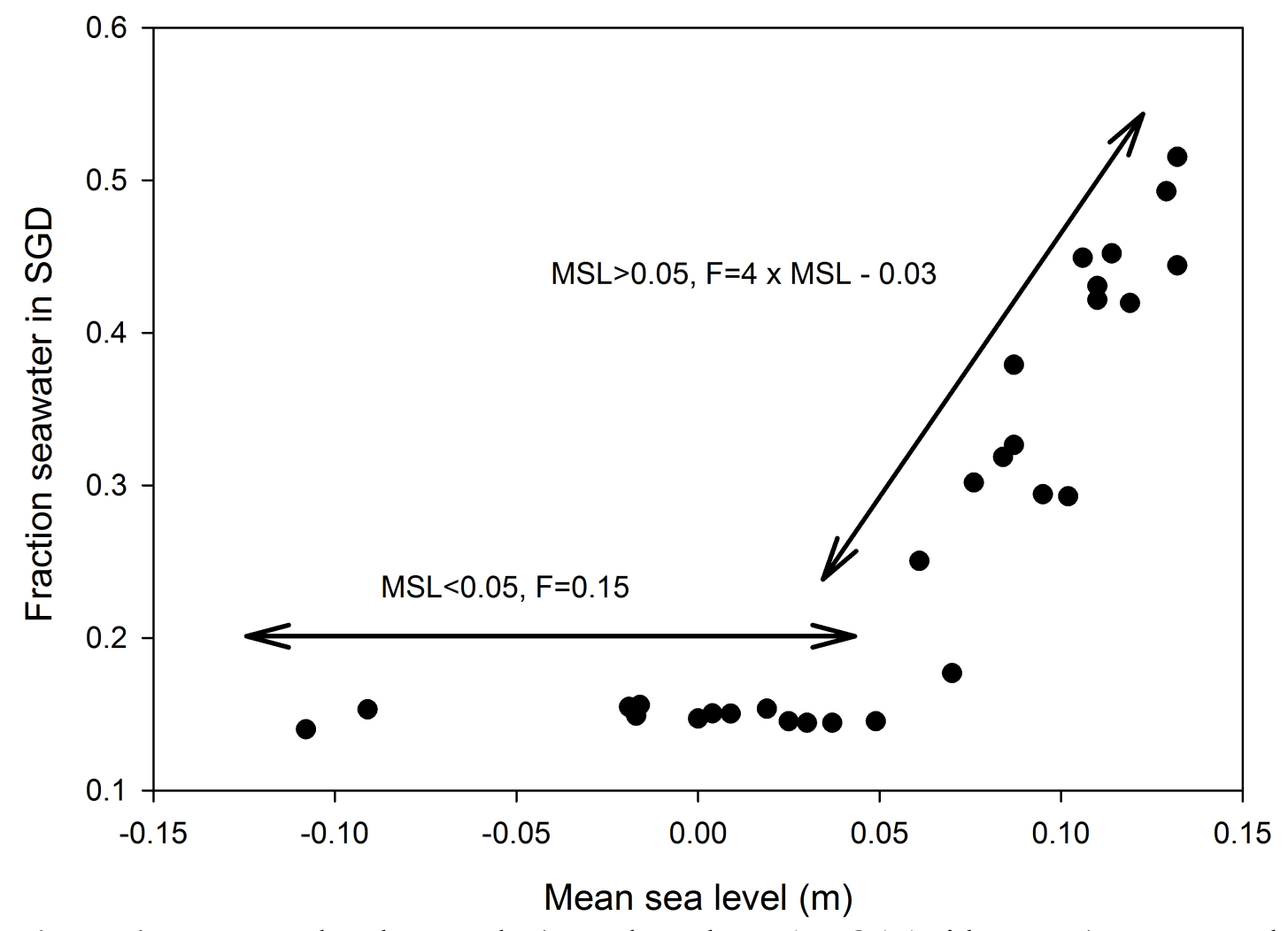

Figure 4: Mean sea level anomaly (Woods Hole, MA NOAA tide gauge) versus modeled seawater fraction of total SGD for the period from 1/2005 to 6/2007. The two relationships indicated were used together with MSL for 10/2004 to $1 / 2005,7 / 2007$ to $10 / 2007$ and $6 / 2009$ to $6 / 2010$ to predict the fraction of seawater in total SGD for those time periods. Here seawater has the density and salinity of Waquoit Bay surface water (1024 $\mathrm{kg} \mathrm{m}^{-3}$ and 30 respectively). This model has a reduced- $\chi^{2}$ fit of 1.3 with an estimated error of $\mathrm{f}=0.03$. 

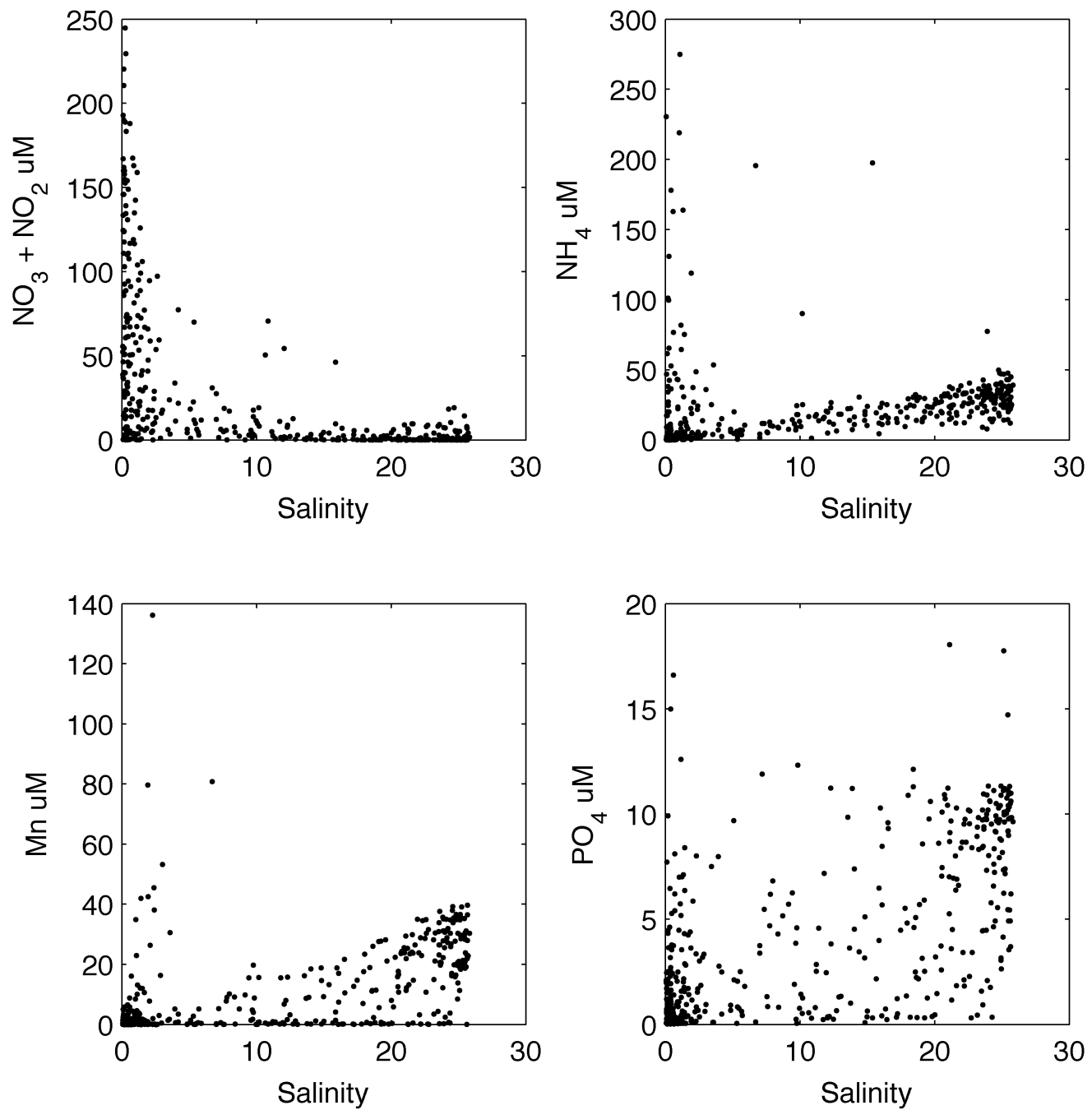

Figure 5: Nutrient versus salinity plots for $\mathrm{NO}_{3}{ }^{-}+\mathrm{NO}_{2}{ }^{-}, \mathrm{NH}_{4}{ }^{+}, \mathrm{Mn}$ and $\mathrm{PO}_{4}{ }^{3-}$ time series samples. 
June 2005
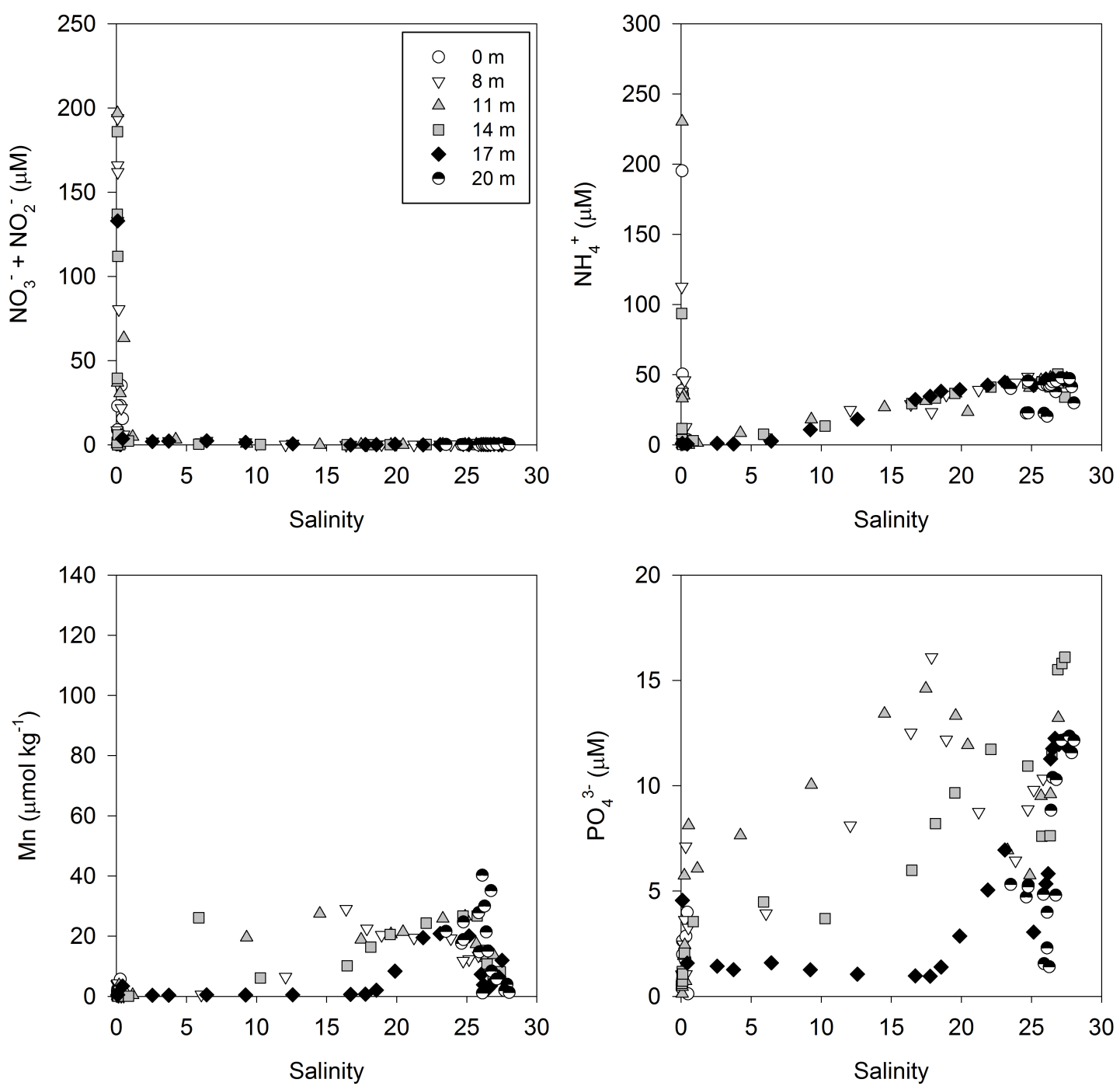

Figure 6: Nutrient versus salinity plots for $\mathrm{NO}_{3}{ }^{-}+\mathrm{NO}_{2}{ }^{-}, \mathrm{NH}_{4}{ }^{+}, \mathrm{Mn}$ and $\mathrm{PO}_{4}{ }^{3-} \mathrm{June} 2005$ transect. 

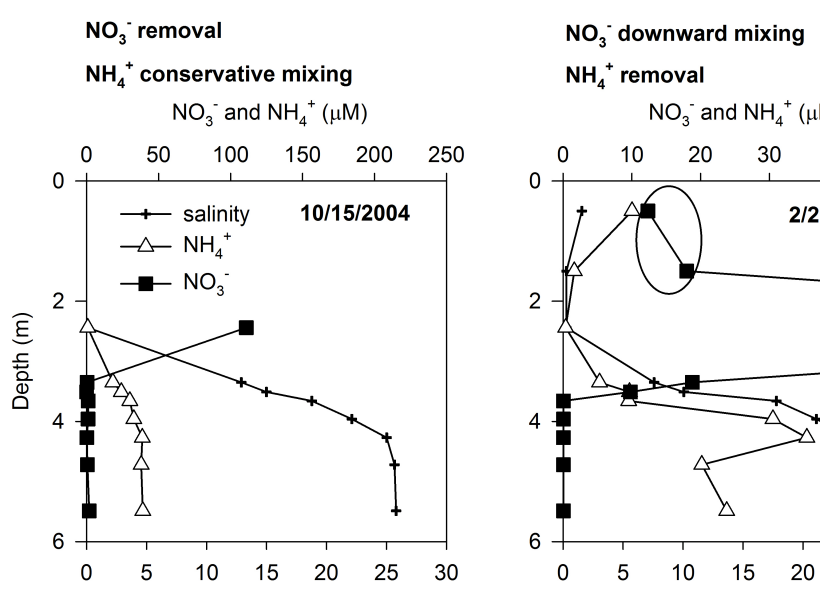

$\mathrm{NO}_{3}^{-}$and $\mathrm{NH}_{4}^{+}(\mu \mathrm{M})$
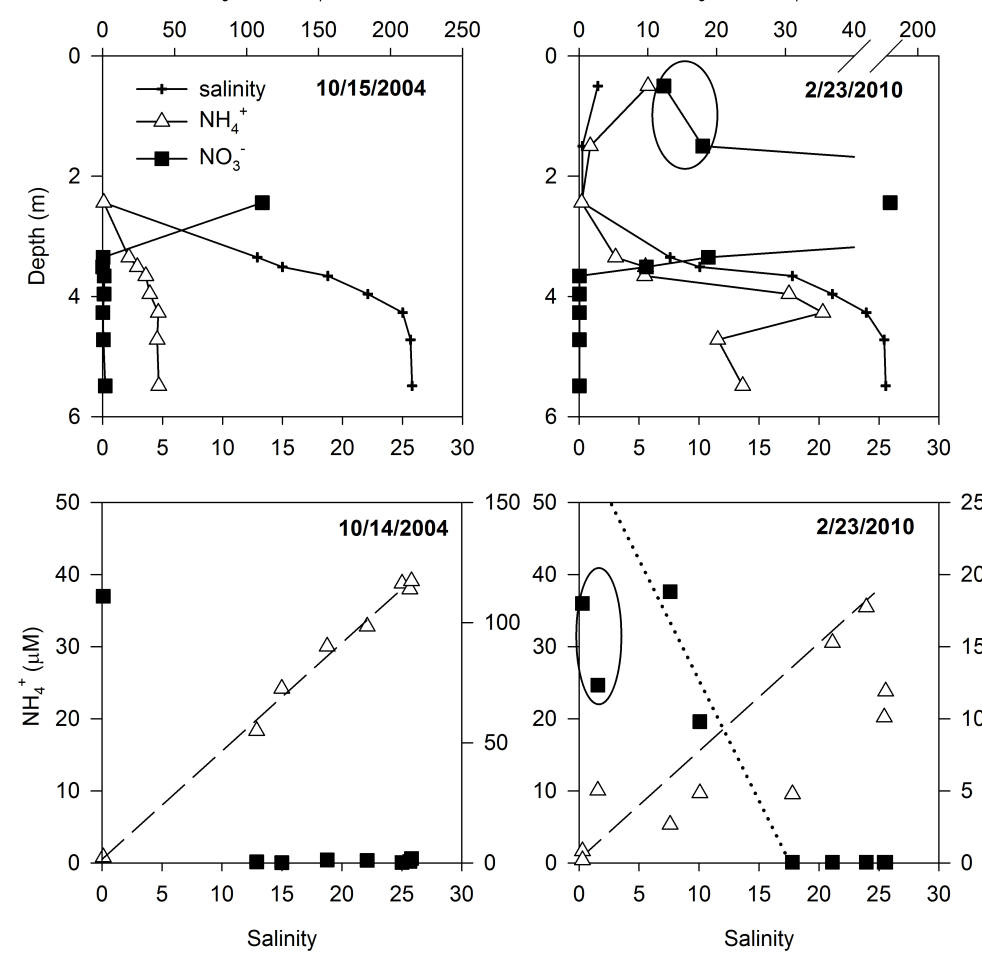

$\mathrm{NO}_{2}^{-}$or $\mathrm{NO}_{3}^{-}$production in mixing zone

$\mathrm{NH}_{4}^{+}$removal $\mathrm{NO}_{3}{ }^{-}$and $\mathrm{NH}_{4}^{+}(\mu \mathrm{M})$
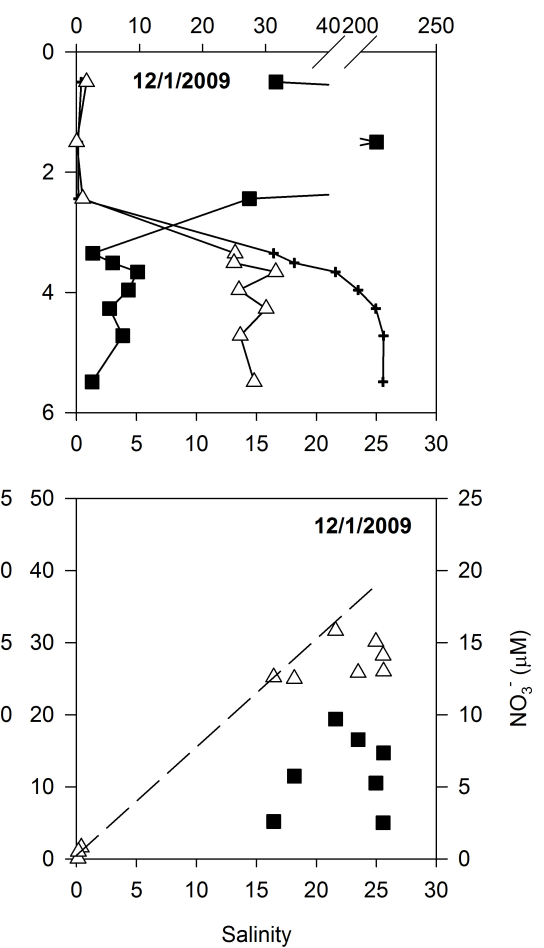

Figure 7: Examples of the observed distributions of $\mathrm{NH}_{4}{ }^{+}$and $\mathrm{NO}_{3}{ }^{-}$over the four-year time series. Removal of $\mathrm{NO}_{3}{ }^{-}$within the mixing zone is evident in all profiles.

Additionally, in $40 \%$ of the profiles $\mathrm{NO}_{3}{ }^{-}$removal is not complete until further down in the mixing zone (see $2 / 23 / 2010$ profile). In $20 \%$ of sampling periods, production of $\mathrm{NO}_{3}{ }^{-}$ $+\mathrm{NO}_{2}{ }^{-}$within the mixing zone was also observed (see 12/1/2009 profile). $\mathrm{NH}_{4}{ }^{+}$behaved conservatively across the mixing zone in $40 \%$ of the cases (10/15/2004 profile), while removal was observed the remaining times. Dashed lines are conservative mixing lines for $\mathrm{NH}_{4}{ }^{+}$, while the dotted line indicated conservative mixing of $\mathrm{NO}_{3}{ }^{-}$from the terrestrial plume above. Samples circled in 2/23/2010 plots are from the top of the high $\mathrm{NO}_{3}{ }^{-}$plume thus are not expected to fall along the dotted mixing line. Note that not all $\mathrm{NO}_{3}{ }^{-}+\mathrm{NO}_{2}{ }^{-}$ samples are shown in the salinity mixing plots for $2 / 23 / 10$ and $12 / 1 / 2009$ due to the data range. 

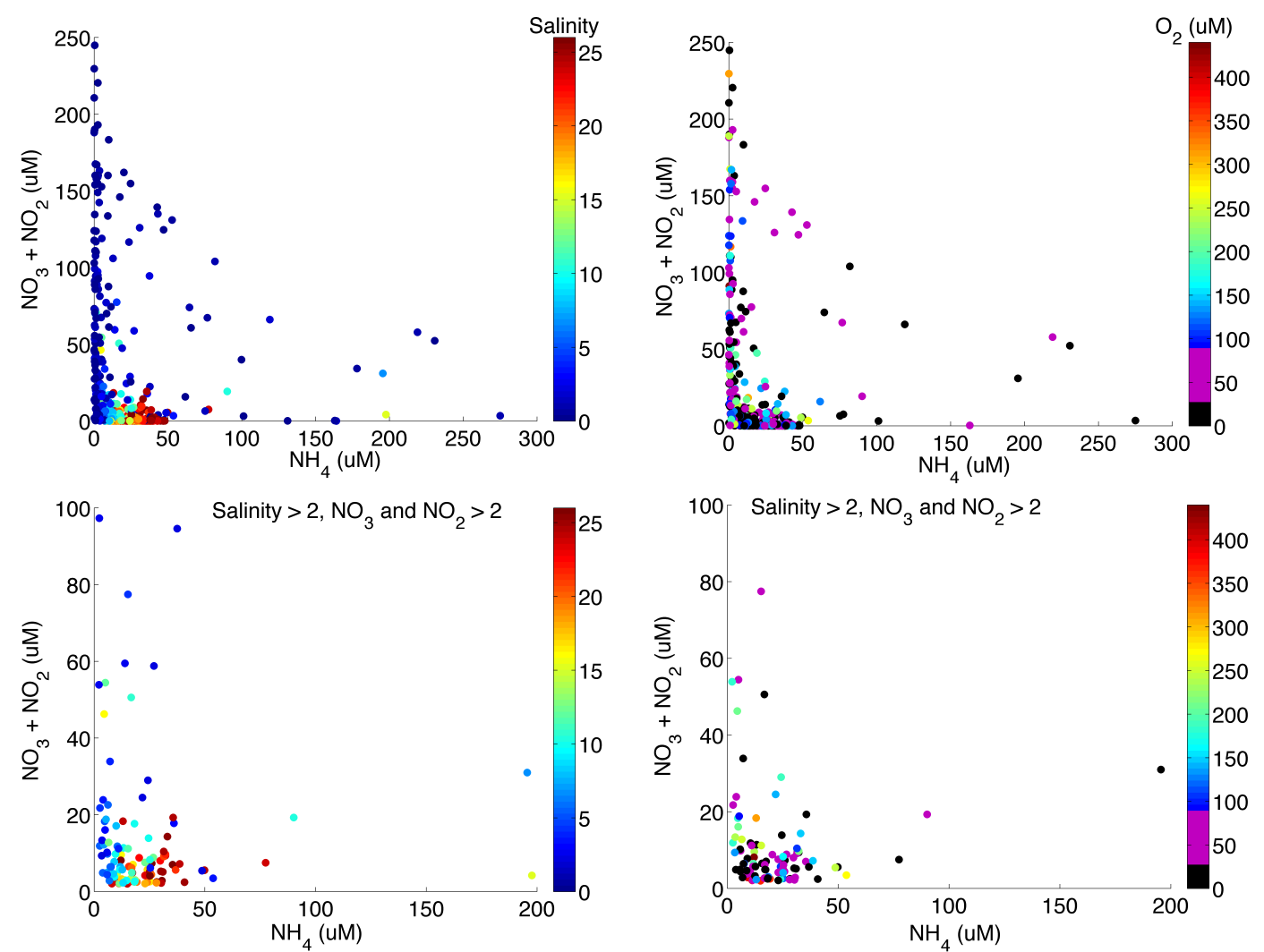

Figure 8: Nitrate v. ammonium for all time points (top panels) with color shading indicating salinity (left) or oxygen (right). Bottom panels are filtered to include only samples with a salinity $>2$ and $\mathrm{NO}_{3}{ }^{-}$and $\mathrm{NH}_{4}{ }^{+}>2 \mu \mathrm{M}$. In the oxygen panels, samples below the anammox threshold $(20 \mu \mathrm{M})$ are black, while samples above the anammox but below the denitrification threshold $(90 \mu \mathrm{M})$ are pink. 


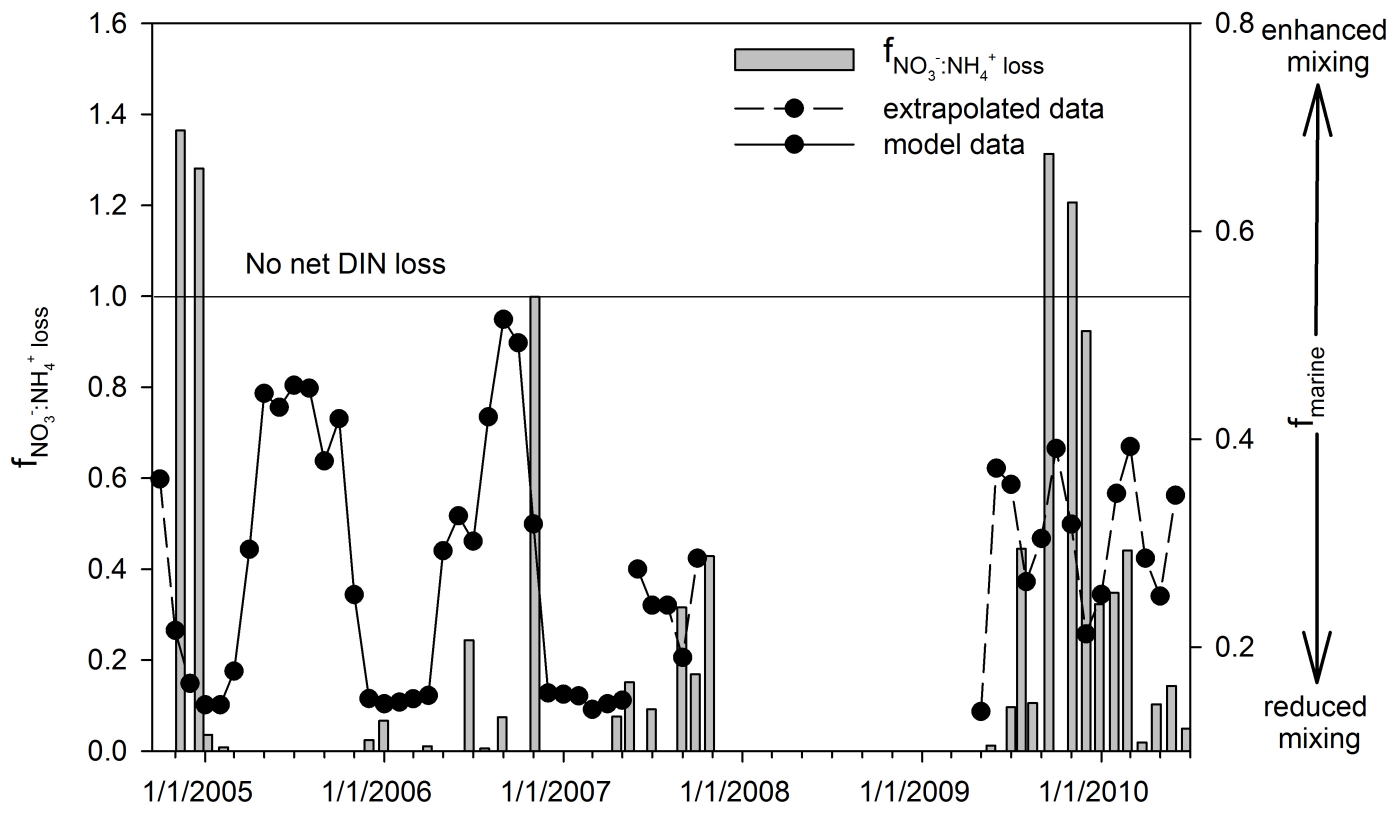

Figure 9: Accumulation of $\mathrm{NO}_{3}{ }^{-}+\mathrm{NO}_{2}{ }^{-}$within the mixing zone concurrent with $\mathrm{NH}_{4}{ }^{+}$ removal was observed coincident with periods of enhanced mixing (greater $\mathrm{f}_{\text {marine) }}$ ). Shown is the proportion of $\mathrm{NO}_{3}{ }^{-}+\mathrm{NO}_{2}{ }^{-}$produced that is still present in the mixing zone compared to $\mathrm{NH}_{4}{ }^{+}$that was removed ( $\mathrm{f}_{\mathrm{NO} 3-\mathrm{NH} 4+\text { loss }}$ ). Values greater than $100 \%$ may be due to $\mathrm{NO}_{3}{ }^{-}+\mathrm{NO}_{2}{ }^{-}$production not captured in the one dimensional time series profile. Model data was not available for 2004 and 2009-2010 hence we extrapolated $f_{\text {marine }}$ for these periods based on the relationship between mean seal level and $f_{\text {marine }}$ shown in Figure 5. 

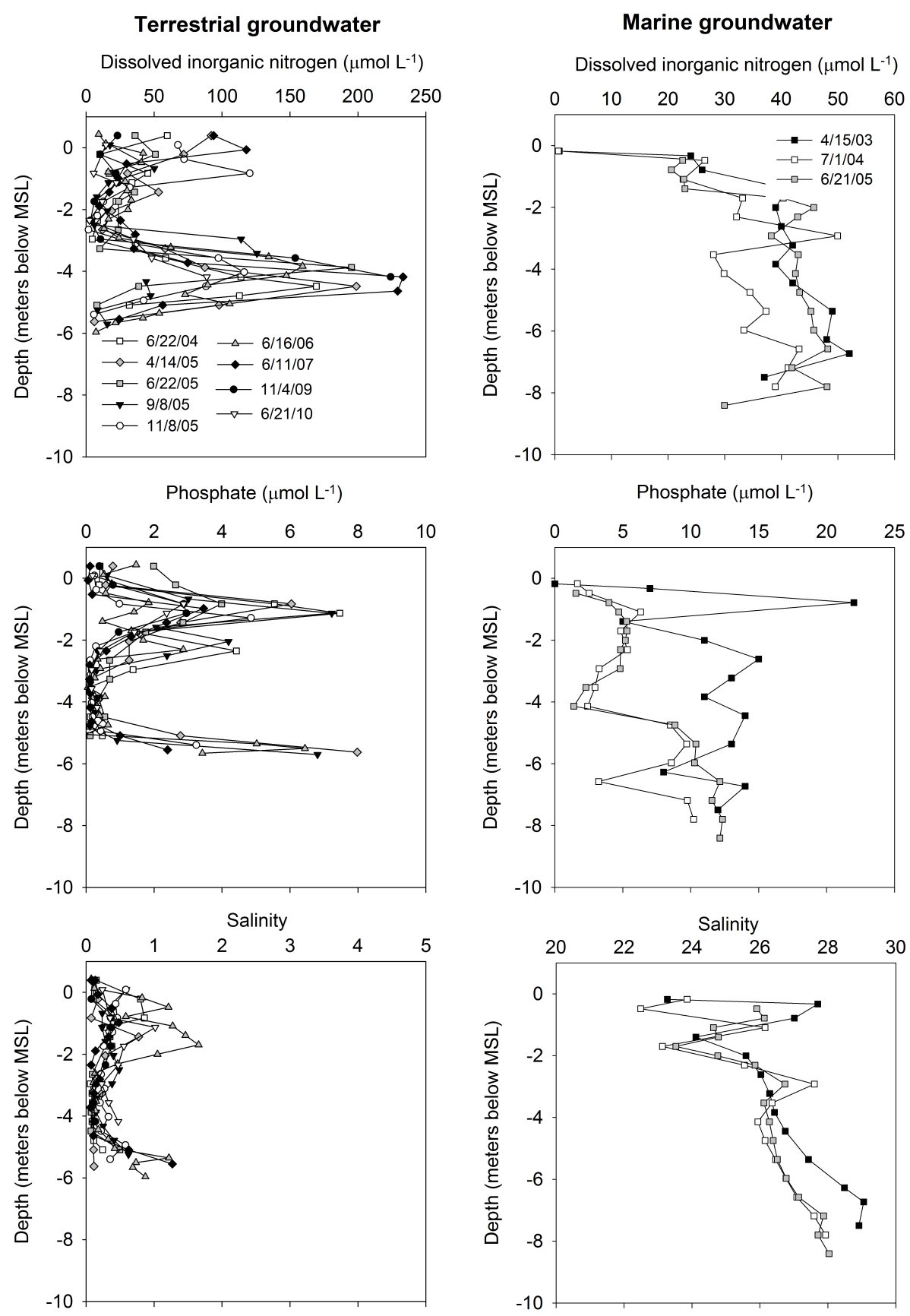

Figure 10: Terrestrial and marine groundwater profiles were collected at numerous times from 2003 to 2010. There is little variability in DIN (top), phosphate (middle) or salinity (bottom) through time. Average inventories for each profile are included in Table 1. 

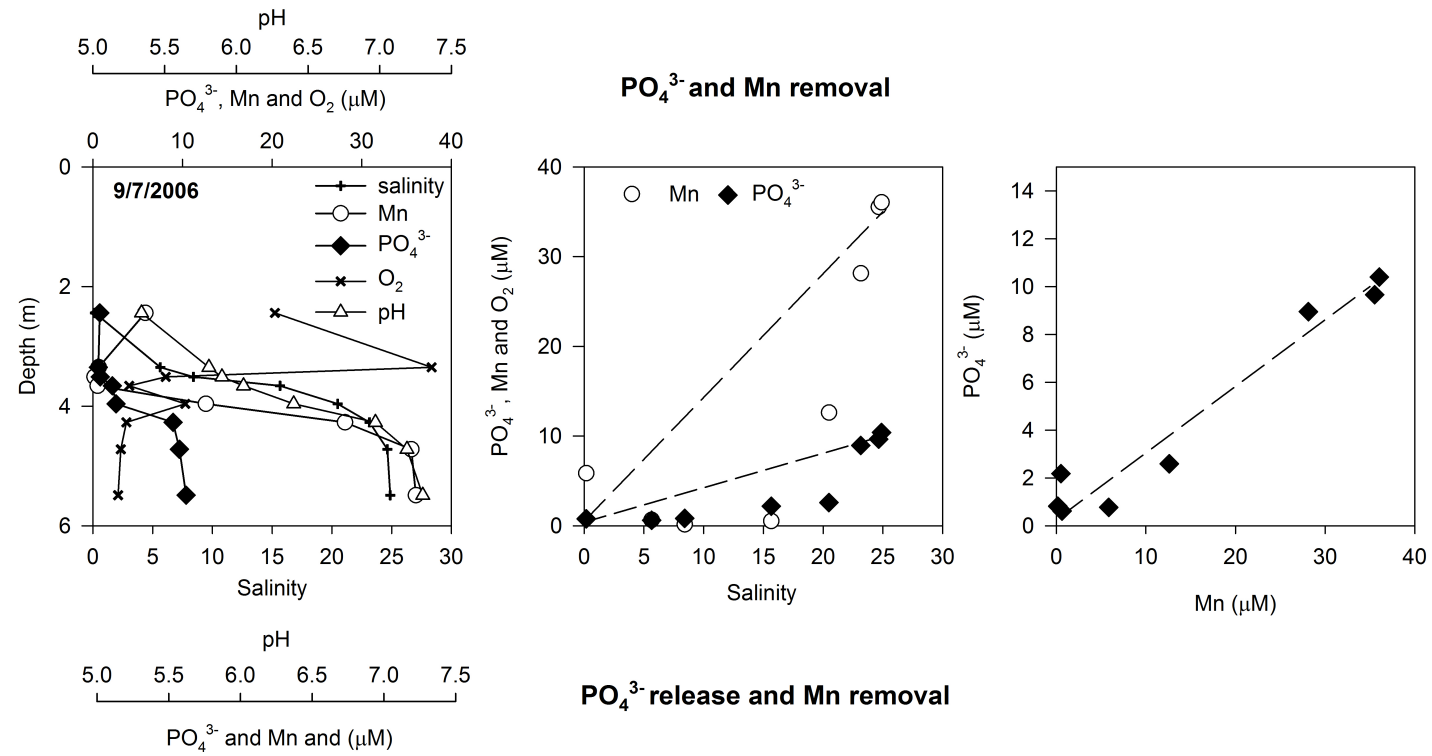

$\mathrm{PO}_{4}{ }^{3-}$ release and $\mathrm{Mn}$ removal
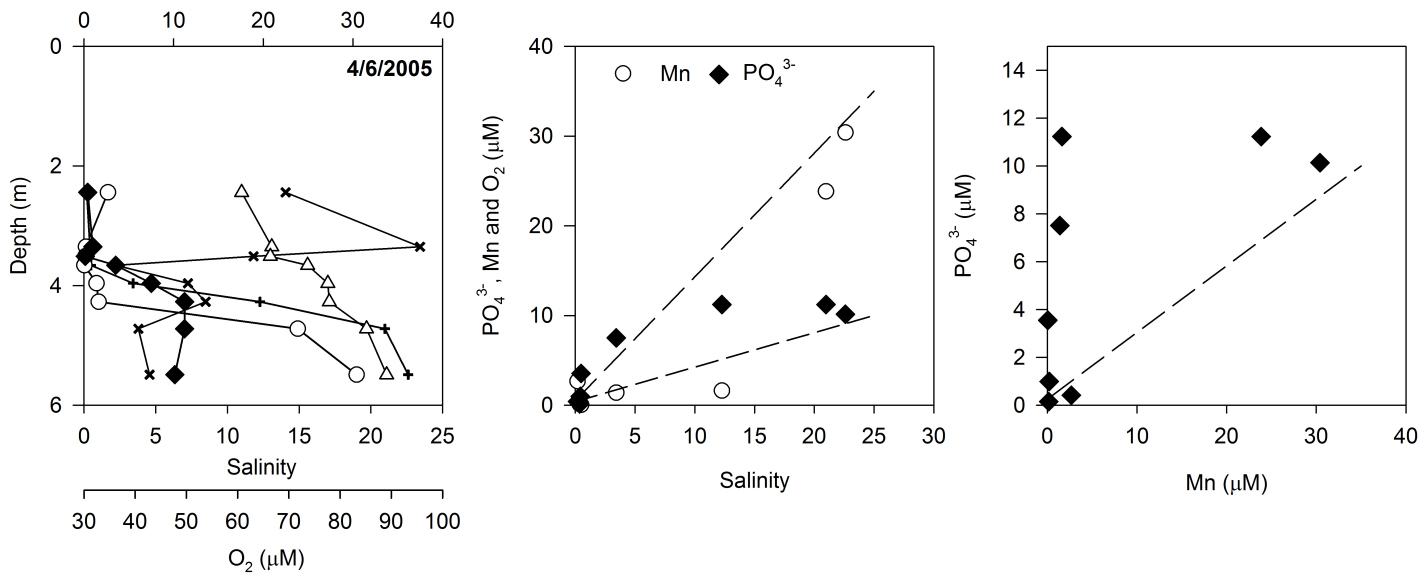

Figure 11: Concurrent $\mathrm{PO}_{4}{ }^{3-}$ and $\mathrm{Mn}$ removal within the mixing zone was apparent during approximately $50 \%$ of the time series (top panel), while $\mathrm{PO}_{4}{ }^{3-}$ release (bottom panel) coincident with $\mathrm{Mn}$ removal or conservative mixing of both $\mathrm{Mn}$ and $\mathrm{PO}_{4}{ }^{3-}$ occurred during the remainder of the time series. Dashed lines define the conservative mixing relationship for $\mathrm{PO}_{4}{ }^{3-}$ and $\mathrm{Mn}$, with samples falling below/above these lines indicative of removal/release within the mixing zone. $\mathrm{PO}_{4}{ }^{3-}$ and $\mathrm{Mn}$ covary during periods of $\mathrm{PO}_{4}{ }^{3-}$ removal, although the slope of the relationship changes over time (see Fig. 4). 

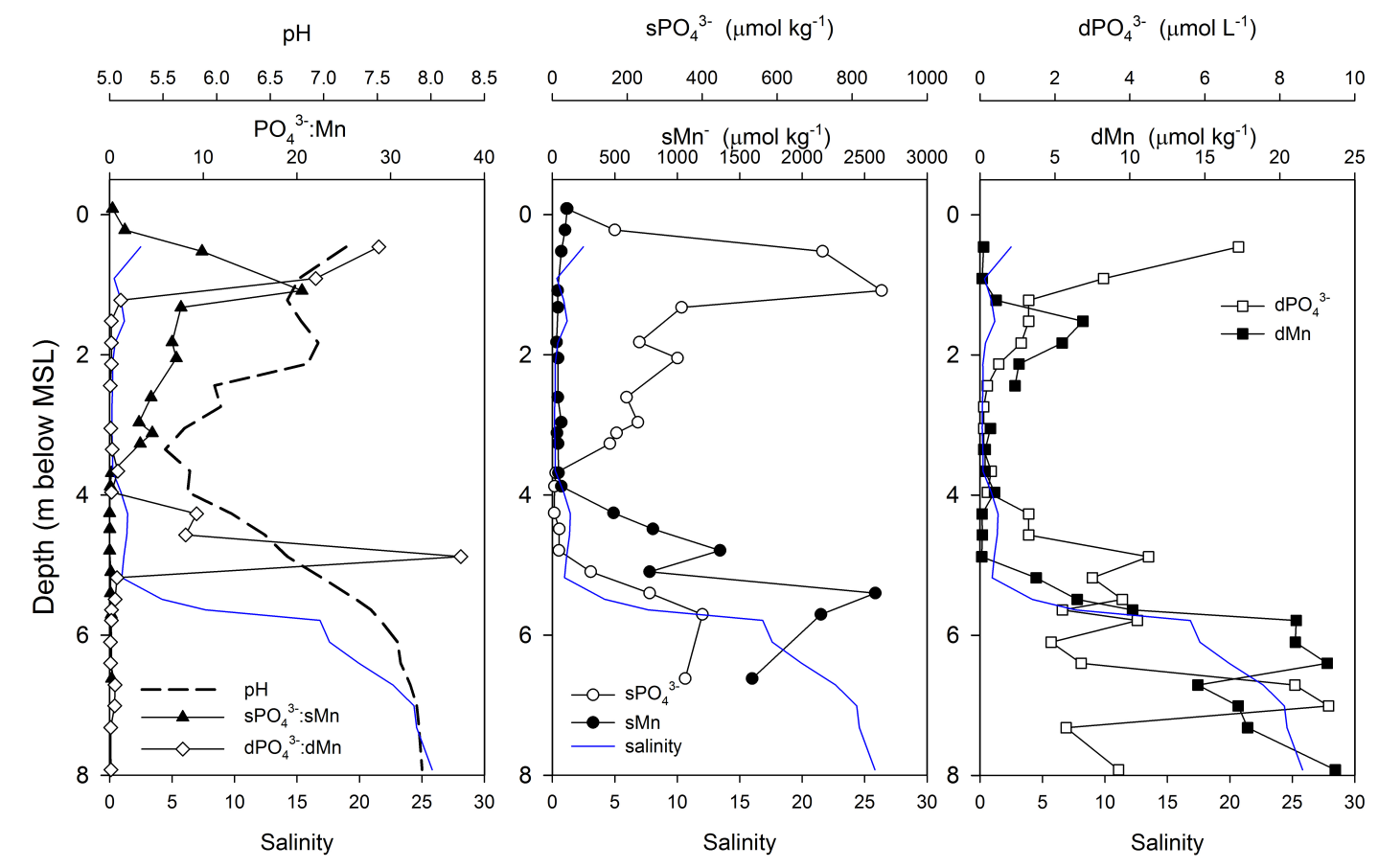

$\mathrm{pH}$

$$
\mathrm{SPO}_{4}^{3-}\left(\mu \mathrm{mol} \mathrm{kg}{ }^{-1}\right)
$$
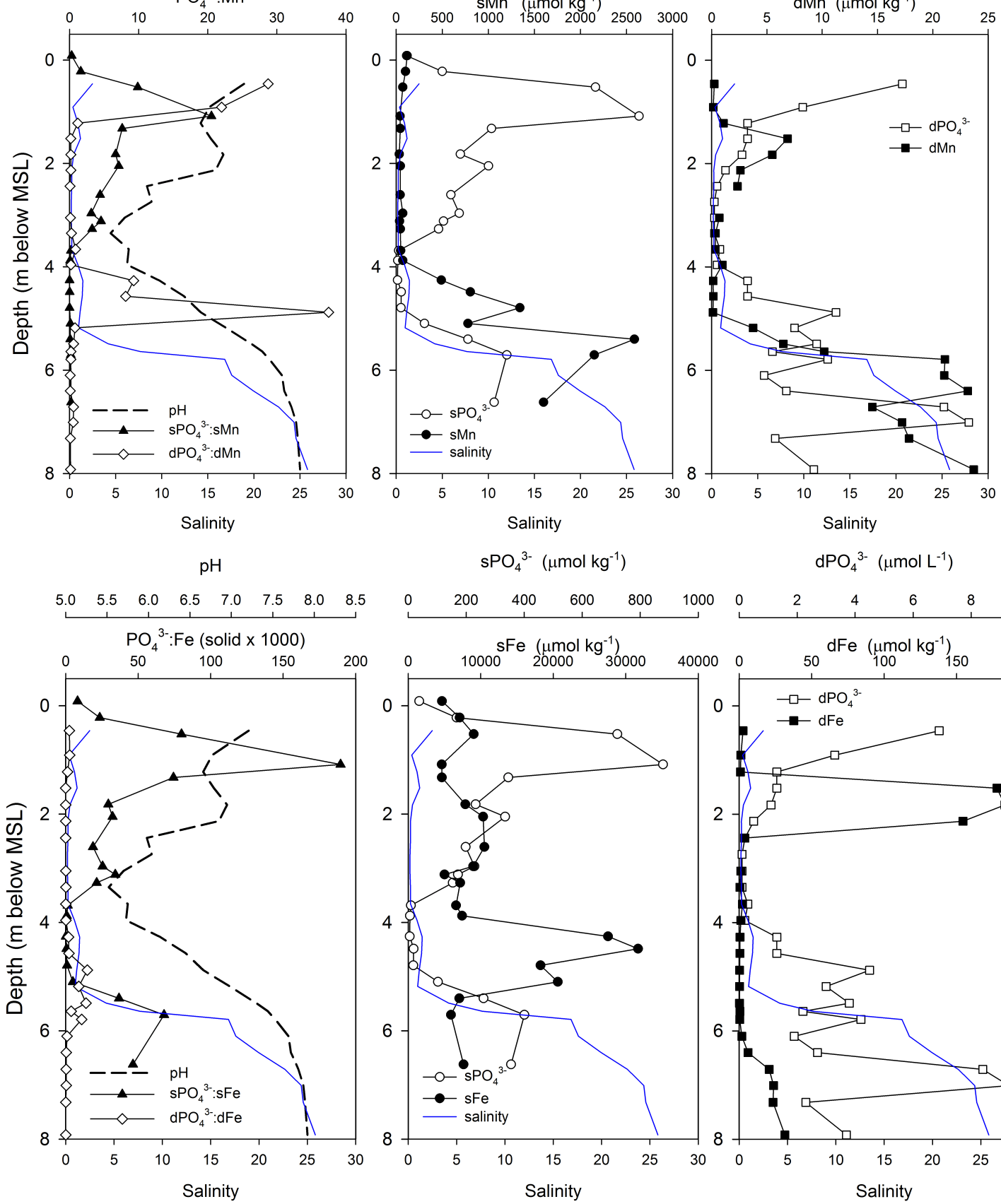

$\mathrm{dPO}_{4}{ }^{3-}\left(\mu \mathrm{mol} \mathrm{L}{ }^{-1}\right)$
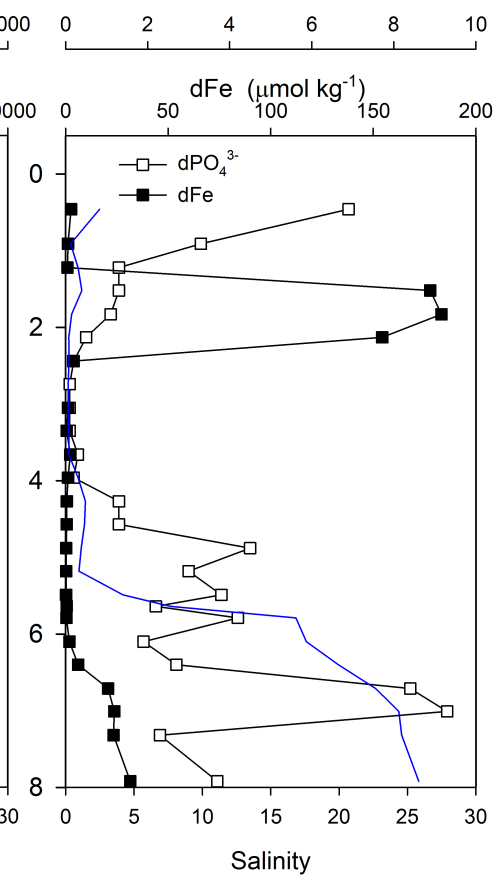

Figure 12: $\mathrm{pH}$ exerts a strong control on $\mathrm{PO}_{4}{ }^{3-}$ sorption, as is evident by the high $\mathrm{P}: \mathrm{Mn}$ and $\mathrm{P}: \mathrm{Fe}$ ratios within the terrestrial groundwater and sediment prior to the $\mathrm{pH}$ increase to $>7$ (left panels). Shown are sediment oxide associated $\mathrm{sMn}, \mathrm{sFe}$ and $\mathrm{sPO}_{4}{ }^{3-}$ (middle panels) three meters inland from the time series site and dissolved $\mathrm{dMn}, \mathrm{dFe}$ and $\mathrm{dPO}_{4}{ }^{3-}$ (right panels). Groundwater salinity is shown in each plot. 

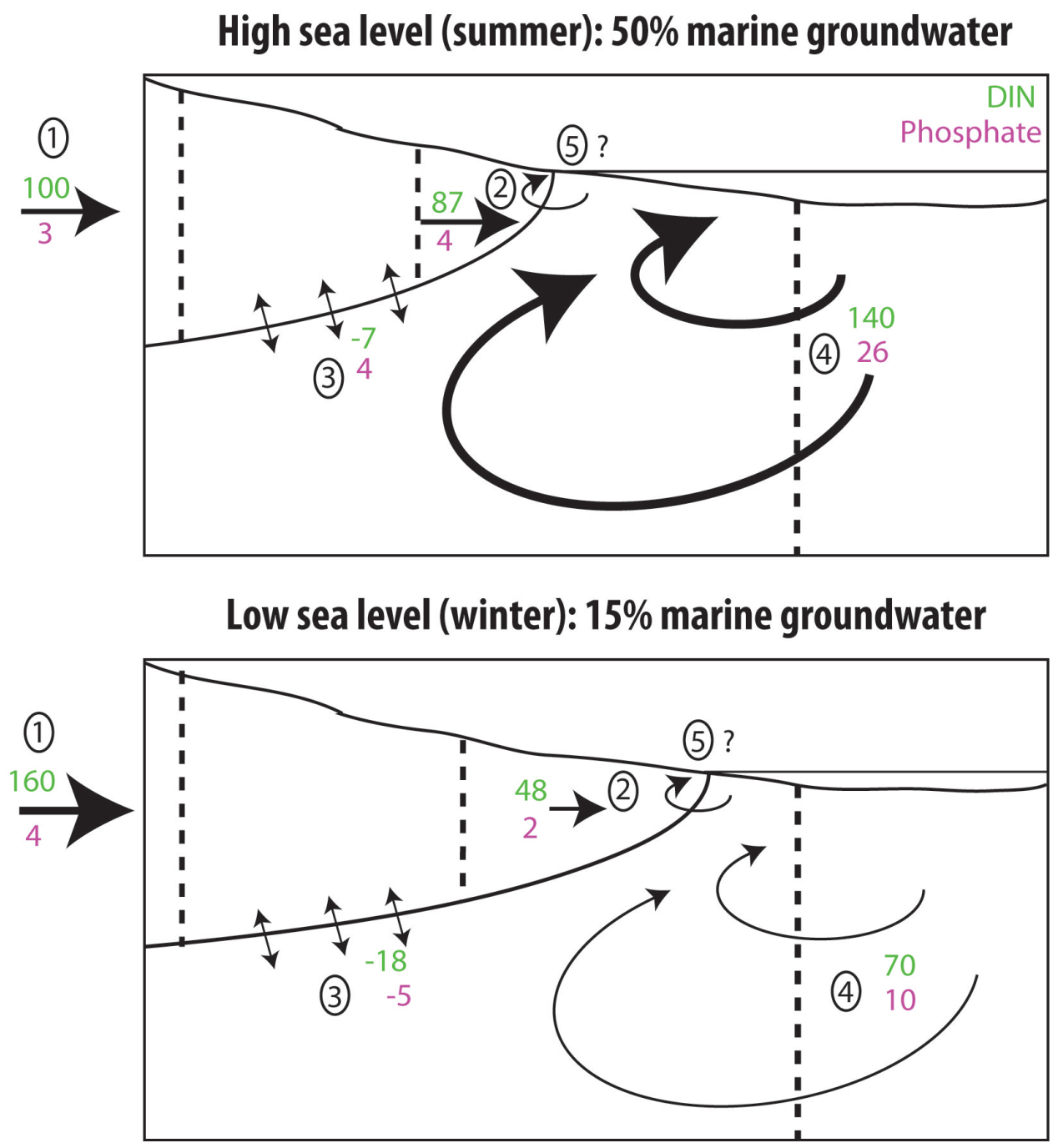

Figure 13: Nutrient transformations during winter and summer within the Waquoit Bay subterranean estuary based on April and June 2005 transects. Rates are in mmol m${ }^{-1} \mathrm{~d}^{-1}$ and values in green are DIN while pink is $\mathrm{PO}_{4}{ }^{3-}$. Processes are: (1) terrestrial groundwater input to the subterranean estuary; (2) terrestrial groundwater discharge flux from the subterranean estuary to the bay following attenuation along the laminar flow path of terrestrial groundwater, not accounting for any loss in (5); (3) transformations in the mixing zone; (4) marine groundwater input to the subterranean estuary; and (5) transformations within the shallow tidally-driven mixing zone (not quantified by this study). 
Table 1: Terrestrial and marine nutrient inventories

\begin{tabular}{|c|c|c|c|}
\hline & $\begin{array}{l}\text { DIN Inventory } \\
\left(\mathrm{mmol} \mathrm{m}^{-2}\right)\end{array}$ & $\begin{array}{c}\mathrm{PO}_{4}{ }^{3-} \text { Inventory } \\
\left.(\mathrm{mmol} \mathrm{m})^{-2}\right)\end{array}$ & $\mathbf{N}: \mathbf{P}$ \\
\hline \multicolumn{4}{|l|}{ Terrestrial } \\
\hline $3 / 24 / 03$ & 490 & 13 & 37 \\
\hline $6 / 22 / 04$ & 260 & 11 & 24 \\
\hline $4 / 14 / 05$ & 410 & 12 & 35 \\
\hline $6 / 22 / 05$ & 250 & 8.6 & 29 \\
\hline $9 / 8 / 05$ & 260 & 12 & 22 \\
\hline $11 / 8 / 05$ & 300 & 4.9 & 62 \\
\hline $6 / 16 / 06$ & 350 & 13 & 26 \\
\hline $6 / 11 / 07$ & 430 & 5.0 & 87 \\
\hline $11 / 4 / 09$ & 210 & 4.3 & 48 \\
\hline $6 / 21 / 10$ & 110 & 4.3 & 25 \\
\hline $\begin{array}{l}\text { Average } \\
\text { (deviation) }\end{array}$ & $290(100)$ & $8.3(3.5)$ & $39(21)$ \\
\hline \multicolumn{4}{|l|}{ Marine } \\
\hline $4 / 15 / 03$ & 300 & 89 & 3 \\
\hline 7/1/04 & 260 & 44 & 6 \\
\hline $6 / 21 / 05$ & 320 & 59 & 5 \\
\hline $\begin{array}{l}\text { Average } \\
\text { (deviation) }\end{array}$ & $290(30)$ & $64(23)$ & $5(1)$ \\
\hline
\end{tabular}


Table 2: Subterranean estuary nutrient fluxes calculated from transects in 2003, 2004 and 2005

\begin{tabular}{|c|c|c|c|c|c|c|c|c|}
\hline & \multicolumn{4}{|c|}{ Terrestrial groundwater } & \multicolumn{4}{|c|}{ Marine groundwater } \\
\hline & $\begin{array}{l}\text { Input } \\
\left(\mathbf{m m o l}^{-1} \mathbf{d}^{-1}\right) \\
\mathbf{m}^{-1} \mathbf{c}^{2}\end{array}$ & $\begin{array}{c}\text { STE } \\
\text { transfor } \\
\text { mation } \\
\%\end{array}$ & $\begin{array}{l}\mathrm{N}: \mathrm{P} \\
\text { input }\end{array}$ & $\begin{array}{c}\mathrm{N}: \mathrm{P} \\
\text { removal }\end{array}$ & $\begin{array}{c}\text { Input } \\
\left(\mathrm{mmol}^{-1}\right. \\
\left.\mathrm{m}^{-1} \mathrm{~d}^{-1}\right)\end{array}$ & $\begin{array}{c}\text { STE } \\
\text { transfor } \\
\text { mation } \\
\%\end{array}$ & $\begin{array}{c}\mathrm{N}: \mathrm{P} \\
\text { input }\end{array}$ & $\begin{array}{c}\mathrm{N}: \mathrm{P} \\
\text { removal }\end{array}$ \\
\hline DIN & & & & & & & & \\
\hline March & & & & & & & & \\
\hline $2003^{1}$ & na & $-71 \%$ & na & na & na & nd & 3 & na \\
\hline June & & & & & & & & \\
\hline $2004^{1}$ & na & $-12 \%$ & na & na & na & nd & 6 & na \\
\hline April & & & & & & & & \\
\hline $2005^{2}$ & 160 & $-70 \%$ & 40 & na & 70 & $-25 \%$ & 7 & na \\
\hline June & & & & & & & & \\
\hline $2005^{2}$ & 100 & $-13 \%$ & 39 & 12 & 140 & $-5 \%$ & 5 & 0.05 \\
\hline $\mathrm{PO}_{4}^{-}$ & & & & & & & & \\
\hline March & & & & & & & & \\
\hline $2003^{1}$ & na & $-66 \%$ & & & na & $+5 \%$ & & \\
\hline June & & & & & & & & \\
\hline $2004^{1}$ & na & $-51 \%$ & & & na & $-27 \%$ & & \\
\hline April & & & & & & & & \\
\hline $2005^{2}$ & 4 & nd & & & 10 & $-54 \%$ & & \\
\hline June & & & & & & & & \\
\hline $2005^{2}$ & 3 & $-45 \%$ & & & 26 & $+15 \%$ & & \\
\hline
\end{tabular}

nd, not detected; na, not applicable

${ }^{1}$ Groundwater flux rates are not available to calculate input rates.

${ }^{2}$ Model predicted groundwater discharge rates are used to estimate fluxes in April and June 2005. 


\section{References}

Abarca, E., Karam, H.N., Hemond, H.F., Harvey, C.F., 2013. Transient groundwater dynamics in a coastal aquifer: The effects of tides, the lunar cycle and the beach profile. Water Resour. Res., 10.1002/wrcr.20075.

Beck, A.J., Tsukamoto, Y., Tovar-Sanchez, A., Huerta-Diaz, M., Bokuniewicz, H.J., Sanudo-Wilhelmy, S.A., 2007. Importance of geochemical transformations in determining submarine groundwater discharge-derived trace metal and nutrient fluxes. Appl. Geochem. 22, 477-490.

Bowen, J.L., Kroeger, K.D., Tomasky, G., Pabich, W.J., Cole, M.L., Carmichael, R.H., Valiela, I., 2007. A review of land-sea coupling by groundwater discharge of nitrogen to New England estuaries: Mechanisms and effects. Appl. Geochem. 22, 175-191.

Boyle, E., Collier, R., Dengler, A.T., Edmond, J.M., Ng, A.C., and Stallard, R.F., 1974. Chemical mass-balance in estuaries. Geochim. Cosmochim. Acta 38, 1719-1728.

Cambareri, T.C., Eichner, E.M., 1998. Watershed delineation and ground water discharge to a coastal embayment. Ground Water 36, 626-634.

Charette, M.A. and Sholkovitz, E.R., 2002. Oxidative precpitation of groundwaterderived ferrous iron in the subterranean estuary of a coastal bay. Geophys. Res. Let. 29, doi:10.1029/2001g1014512.

Charette, M.A., Allen, M.C., 2006. Precision ground water sampling in coastal aquifers using a direct-push, shielded-screen well-point system. Ground Water Monit. Remediat. 26, 87-93.

Charette, M.A., Buesseler, K.O., Andrews, J.E., 2001. Utility of radium isotopes for evaluating the input and transport of groundwater-derived nitrogen to a Cape Cod estuary. Limnol. Oceanogr. 46, 465-470.

Charette, M.A., Sholkovitz, E.R., 2006. Trace element cycling in a subterranean estuary: Part 2. Geochemistry of the pore water. Geochim. Cosmochim. Acta 70, 811-826.

Charette, M.A., Sholkovitz, E.R., Hansel, C.M., 2005. Trace element cycling in a subterranean estuary: Part 1. Geochemistry of the permeable sediments. Geochim. Cosmochim. Acta 69, 2095-2109.

Costello, C.T., Kenworthy, W.J., 2011. Twelve-Year Mapping and Change Analysis of Eelgrass (Zostera marina) Areal Abundance in Massachusetts (USA) Identifies Statewide Declines. Estuaries Coasts 34, 232-242. 
Doney, S.C., 2010. The Growing Human Footprint on Coastal and Open-Ocean Biogeochemistry. Science 328, 1512-1516.

Dulaiova, H., Gonneea, M.E., Henderson, P.B., Charette, M.A., 2008. Geochemical and physical sources of radon variation in a subterranean estuary - Implications for groundwater radon activities in submarine groundwater discharge studies. Mar. Chem. $110,120-127$.

Galloway, J.N., Dentener, F.J., Capone, D.G., Boyer, E.W., Howarth, R.W., Seitzinger, S.P., Asner, G.P., Cleveland, C.C., Green, P.A., Holland, E.A., Karl, D.M., Michaels, A.F., Porter, J.H., Townsend, A.R., Vorosmarty, C.J., 2004. Nitrogen cycles: past, present, and future. Biogeochemistry 70, 153-226.

Gao, H., Schreiber, F., Collins, G., Jensen, M.M., Kostka, J.E., Lavik, G., de Beer, D., Zhou, H.Y., Kuypers, M.M.M., 2010. Aerobic denitrification in permeable Wadden Sea sediments. Isme J. 4, 417-426.

Gonneea, M.E., Morris, P.J., Dulaiova, H., Charette, M.A., 2008. New perspectives on radium behavior within a subterranean estuary. Mar. Chem. 109, 250-267.

Gonneea, M.E., Mulligan, A., Charette, M.A., 2013a. Climate-driven sea level anomalies modulate coastal groundwater dynamics and discharge. Geophys. Res. Lett., http://dx.doi.org/10.1002/grl.50192.

Gonneea, M.E., Mulligan, A., Charette, M.A., 2013b. Seasonal cycles in radium and barium within a subterranean estuary: Implications for groundwater derived chemical fluxes to surface waters. Geochim. Cosmochim. Acta, doi:10.1016/j.gca.2013.1005.1034.

Hall, G.E.M., Vaive, J.E., Beer, R., Hoashi, M., 1996. Selective leaches revisited, with emphasis on the amorphous Fe oxyhydroxide phase extraction. J. Geochem. Explor. 56, 59-78.

Hanaki, K., Wantawin, C., Ohgaki, S., 1990. Nitrification at low levels of dissolved oxygen with and without organic loading in a suspended-growth reactor. Water Res. 24, 297-302.

Howarth, R.W., Marino, R., 2006. Nitrogen as the limiting nutrient for eutrophication in coastal marine ecosystems: Evolving views over three decades. Limnol. Oceanogr. 51, 364-376.

Hu, C.M., Muller-Karger, F.E., Swarzenski, P.W., 2006. Hurricanes, submarine groundwater discharge, and Florida's red tides. Geophys. Res. Lett., doi:

$10.1029 / 2005 \mathrm{~g} 1025449$. 
Hulth, S., Aller, R.C., Gilbert, F., 1999. Coupled anoxic nitrification manganese reduction in marine sediments. Geochim. Cosmochim. Acta 63, 49-66.

Kalvelage, T., Jensen, M.M., Contreras, S., Revsbech, N.P., Lam, P., Gunter, M., LaRoche, J., Lavik, G., Kuypers, M.M.M., 2011. Oxygen Sensitivity of Anammox and Coupled N-Cycle Processes in Oxygen Minimum Zones. Plos One, doi:

10.1371/journal.pone.0029299.

Kroeger, K.D., Charette, M.A., 2008. Nitrogen biogeochemistry of submarine groundwater discharge. Limnol. Oceanogr. 53, 1025-1039.

Langevin, C.D., Jr., D.T.T., Daussman, A.M., Sukop, M.C., Guo, W., 2008. SEAWAT Version 4: A computer program for simulation of multi-species solute and heat transport, U. S. Geological Survey Techniques and Methods Book 6, p. 39.

Lee, Y.W., Kim, G., 2007. Linking groundwater-borne nutrients and dinoflagellate redtide outbreaks in the southern sea of Korea using a Ra tracer. Estuar. Coast. Shelf Sci. 71, 309-317.

Liu, T., Xia, X.H., Liu, S.D., Mou, X.L., Qiu, Y.W., 2013. Acceleration of Denitrification in Turbid Rivers Due to Denitrification Occurring on Suspended Sediment in Oxic Waters. Environ. Sci. Technol. 47, 4053-4061.

Loveless, A.M., Oldham, C.E., 2010. Natural attenuation of nitrogen in groundwater discharging through a sandy beach. Biogeochemistry 98, 75-87.

Michael, H.A., 2004. Seasonal dynamics in coastal aquifers: investigations of submarine groundwater discharge through field measurements and numerical models. Doctoral thesis, Massachusetts Institute of Technology.

Michael, H.A., Charette, M.A., Harvey, C.F., 2011. Patterns and variability of groundwater flow and radium activity at the coast: A case study from Waquoit Bay, Massachusetts. Mar. Chem. 127, 100-114.

Michael, H.A., Lubetsky, J.S., Harvey, C.F., 2003. Characterizing submarine groundwater discharge: a seepage meter study in Waquoit Bay, Massachusetts. Geophys. Res. Lett. 30, doi:10.1029/2002g1016000.

Michael, H.A., Mulligan, A.E., Harvey, C.F., 2005. Seasonal oscillations in water exchange between aquifers and the coastal ocean. Nature 436, 1145-1148.

Moore, W.S., 1999. The subterranean estuary: a reaction zone of ground water and sea water. Mar. Chem. 65, 111-125. 
Mulligan, A.E., Charette, M.A., 2006. Intercomparison of submarine groundwater discharge estimates from a sandy unconfined aquifer. J. Hydrol. 327, 411-425.

Mulligan, A.E., Langevin, C., Post, V.E.A., 2011. Tidal Boundary Conditions in SEAWAT. Ground Water 49, 866-879.

Niencheski, L.F.H., Windom, H.L., Moore, W.S., Jahnke, R.A., 2007. Submarine groundwater discharge of nutrients to the ocean along a coastal lagoon barrier, Southern Brazil. Mar. Chem. 106, 546-561.

Null, K.A., Dimova, N.T., Knee, K.L., Esser, B.K., Swarzenski, P.W., Singleton, M.J., Stacey, M., Paytan, A., 2012. Submarine Groundwater Discharge-Derived Nutrient Loads to San Francisco Bay: Implications to Future Ecosystem Changes. Estuaries Coasts 35, 1299-1315.

Paytan, A., Shellenbarger, G.G., Street, J.H., Gonneea, M.E., Davis, K., Young, M.B., Moore, W.S., 2006. Submarine groundwater discharge: An important source of new inorganic nitrogen to coral reef ecosystems. Limnol. Oceanogr. 51, 343-348.

Rao, A.M.F., McCarthy, M.J., Gardner, W.S., Jahnke, R.A., 2008. Respiration and denitrification in permeable continental shelf deposits on the South Atlantic Bight: N-2 : Ar and isotope pairing measurements in sediment column experiments. Cont. Shelf Res. $28,602-613$.

Robinson, C., Gibbes, B., Carey, H., Li, L., 2007. Salt-freshwater dynamics in a subterranean estuary over a spring-neap tidal cycle. J. Geophys. Res.-Oceans 112.

Robinson, C., Gibbes, B., Li, L., 2006. Driving mechanisms for groundwater flow and salt transport in a subterranean estuary. Geophys. Res. Lett., doi: 10.1029/2005g1025247.

Rogers, D.R., Casciotti, K.L., 2010. Abundance and Diversity of Archaeal Ammonia Oxidizers in a Coastal Groundwater System. Appl. Environ. Microbiol. 76, 7938-7948.

Ryther, J.H., Dunstan, W.M., 1971. Nitrogen, phosphorus, and eutrophication in coastal marine environment. Science 171, 1008-1013.

Saenz, J.P., Hopmans, E.C., Rogers, D., Henderson, P.B., Charette, M.A., Schouten, S., Casciotti, K.L., Damste, J.S.S., Eglinton, T.I., 2012. Distribution of anaerobic ammoniaoxidizing bacteria in a subterranean estuary. Mar. Chem. 136, 7-13.

Santoro, A.E., 2010. Marine nitrogen cycling at the saltwater-freshwater interface. Hydrogeo. J. 18, 187-202. 
Santos, I.R., Burnett, W.C., Dittmar, T., Suryaputra, I., Chanton, J., 2009. Tidal pumping drives nutrient and dissolved organic matter dynamics in a Gulf of Mexico subterranean estuary. Geochim. Cosmochim. Acta 73, 1325-1339.

Santos, I.R., Burnett, W.C., Misra, S., Suryaputra, I.G.N.A., Chanton, J.P., Dittmar, T., Peterson, R.N., Swarzenski, P.W., 2011. Uranium and barium cycling in a salt wedge subterranean estuary: The influence of tidal pumping. Chem. Geo. 287, 114-123.

Santos, I.R., de Weys, J., Tait, D.R., Eyre, B.D., 2013. The Contribution of Groundwater Discharge to Nutrient Exports from a Coastal Catchment: Post-Flood Seepage Increases Estuarine N/P Ratios. Estuaries Coasts 36, 56-73.

Slomp, C.P., Van Cappellen, P., 2004. Nutrient inputs to the coastal ocean through submarine groundwater discharge: controls and potential impact. J. Hydrol. 295, 64-86.

Spiteri, C., Regnier, P. Slomp, C.P. and Charette, M.A., 2006. pH-Dependent ironoxide precipitation in a subterranean estuary. J. of Geochem. Explor. 88, 399-403.

Spiteri, C., Slomp, C.P., Charette, M.A., Tuncay, K. and Meile, C., 2008. Flow and nutrient dynamics in a subterranean estuary (Waquoit Bay, MA, USA): Field data and reactive transport modeling. Geochim. Cosmochim. Acta 72, 3398-3412.

Sweet, W.V., Zervas, C., 2011. Cool-Season Sea Level Anomalies and Storm Surges along the U.S. East Coast: Climatology and Comparison with the 2009/10 El Nino. Mon. Weather Rev. 139, 2290-2299.

Testa, J.M., Charette, M.A., Sholkovitz, E.R., Allen, M.C., Rago, A., Herbold, C.W., 2002. Dissolved iron cycling in the subterranean estuary of a coastal bay: Waquoit Bay, Massachusetts. Biol. Bull. 203, 255-256.

Valiela, I., Collins, G., Kremer, J., Lajtha, K., Geist, M., Seely, B., Brawley, J., Sham, C.H., 1997. Nitrogen loading from coastal watersheds to receiving estuaries: New method and application. Ecol. Appl. 7, 358-380.

Valiela, I., Foreman, K., Lamontagne, M., Hersh, D., Costa, J., Peckol, P., Demeoandreson, B., Davanzo, C., Babione, M., Sham, C.H., Brawley, J., Lajtha, K., 1992. Couplings of watersheds and coastal waters - sources and consequences of nutrient enrichment in Waquoit Bay, Massachusetts. Estuaries 15, 443-457.

Valiela, I., Geist, M., McClelland, J., Tomasky, G., 2000. Nitrogen loading from watersheds to estuaries: Verification of the Waquoit Bay Nitrogen Loading Model. Biogeochemistry 49, 277-293. 
van de Graaf, A.A., Mulder, A., Debruijn, P., Jetten, M.S.M., Robertson, L.A., Kuenen, J.G., 1995. Anaerobic oxidation of ammonium is a biologically mediated process. Appl. Environ. Microbiol. 61, 1246-1251.

Weinstein, Y., Yechieli, Y., Shalem, Y., Burnett, W.C., Swarzenski, P.W., Herut, B., 2011. What Is the Role of Fresh Groundwater and Recirculated Seawater in Conveying Nutrients to the Coastal Ocean? Environ. Sci. Technol. 45, 5195-5200.

Zhang, G.S., Liu, H.J., Liu, R.P., Qu, J.H., 2009. Removal of phosphate from water by a Fe-Mn binary oxide adsorbent. J. Colloid Interface Sci. 335, 168-174. 

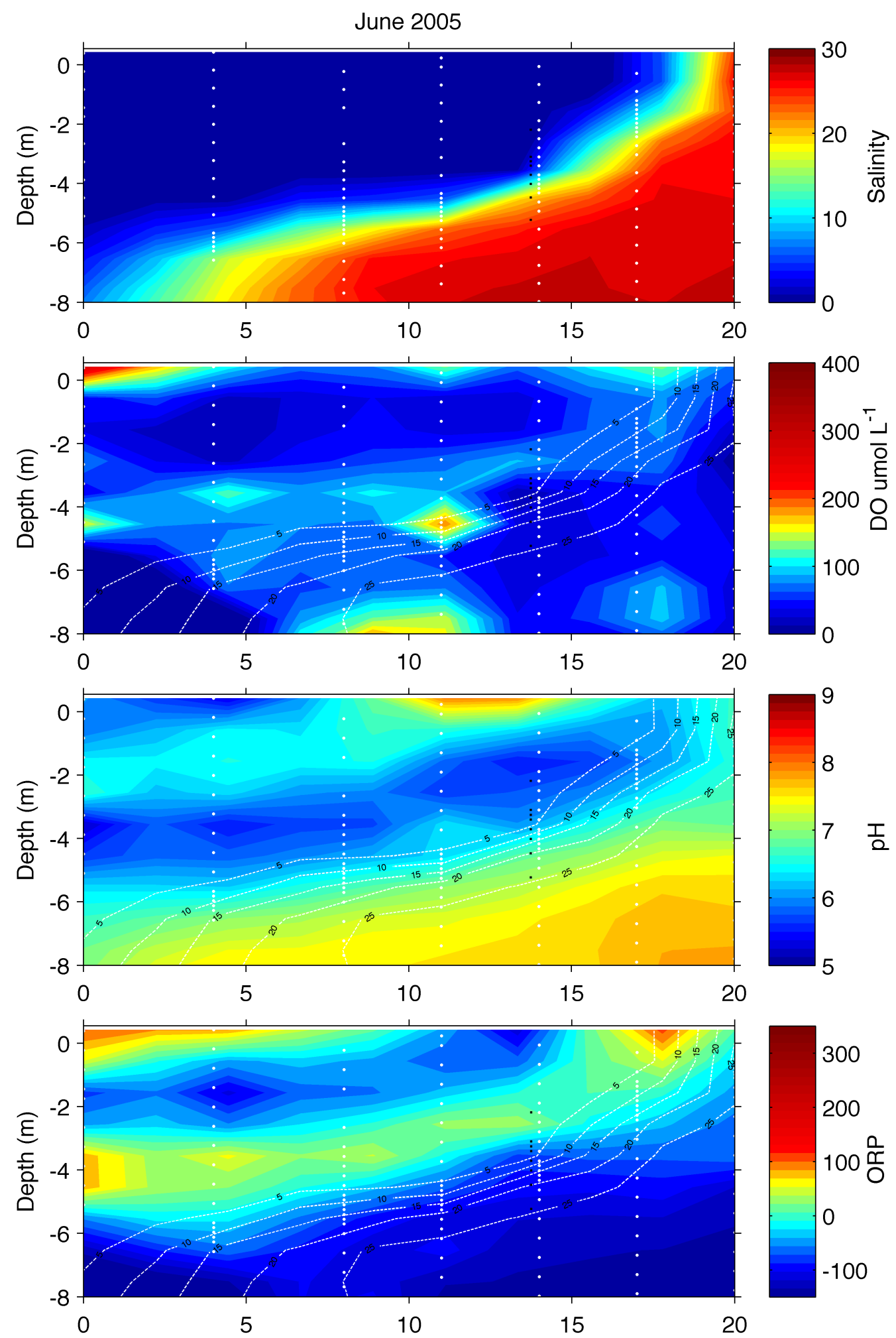

Figure S1 a-d. 

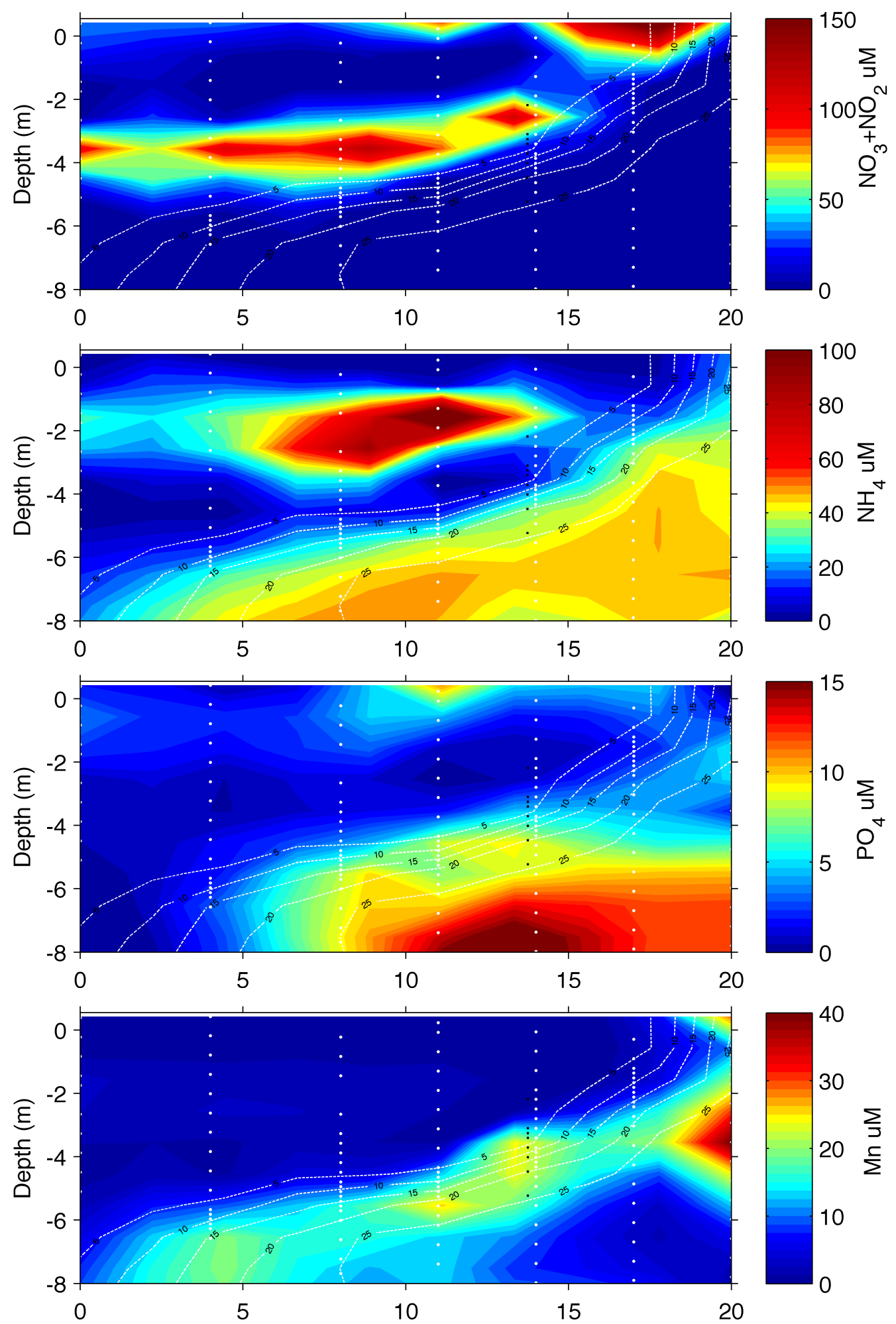

Figure S1 e-h. 


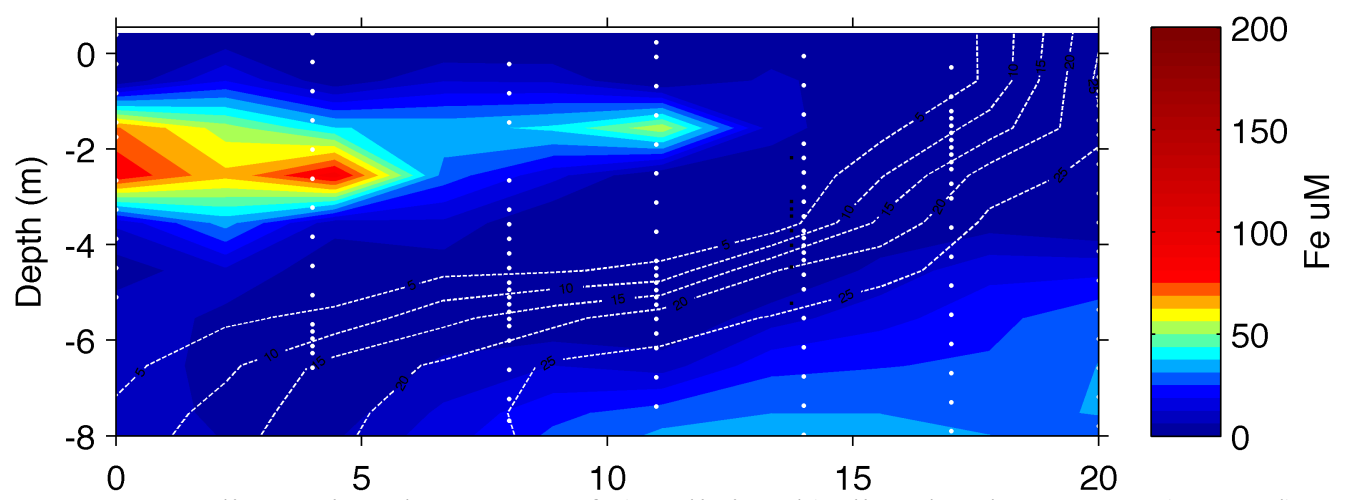

Figure S1: Two-dimensional transect of a) salinity, b) dissolved oxygen, c) pH, d) ORP, e) nitrate + nitrite, f) ammonium, g) phosphate (acidified upon collection), h) manganese and i) iron in June 2005. White circles are the sampling locations contoured, and the location of the time series wells is noted with black squares. 

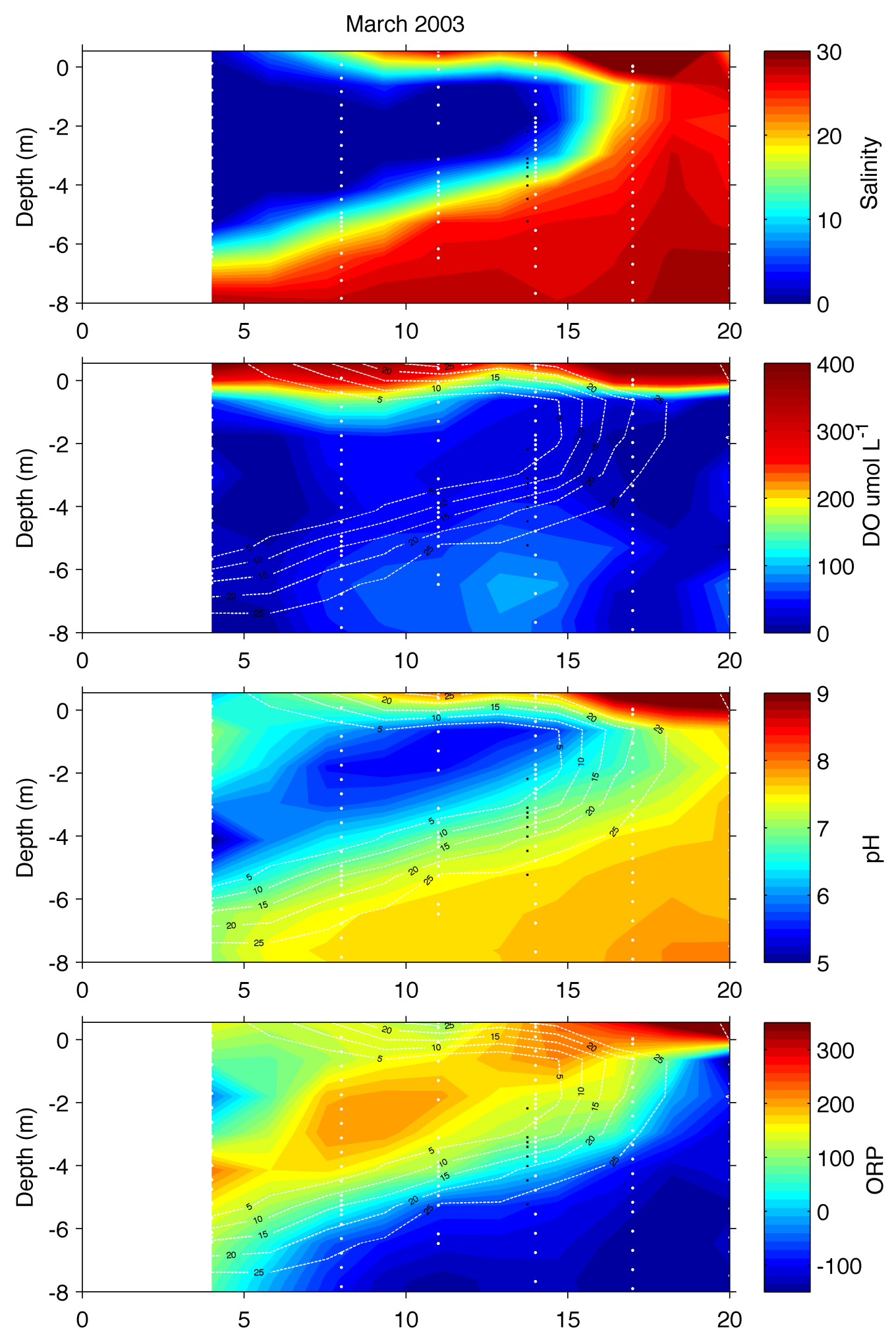

Figure S2 a-d. 

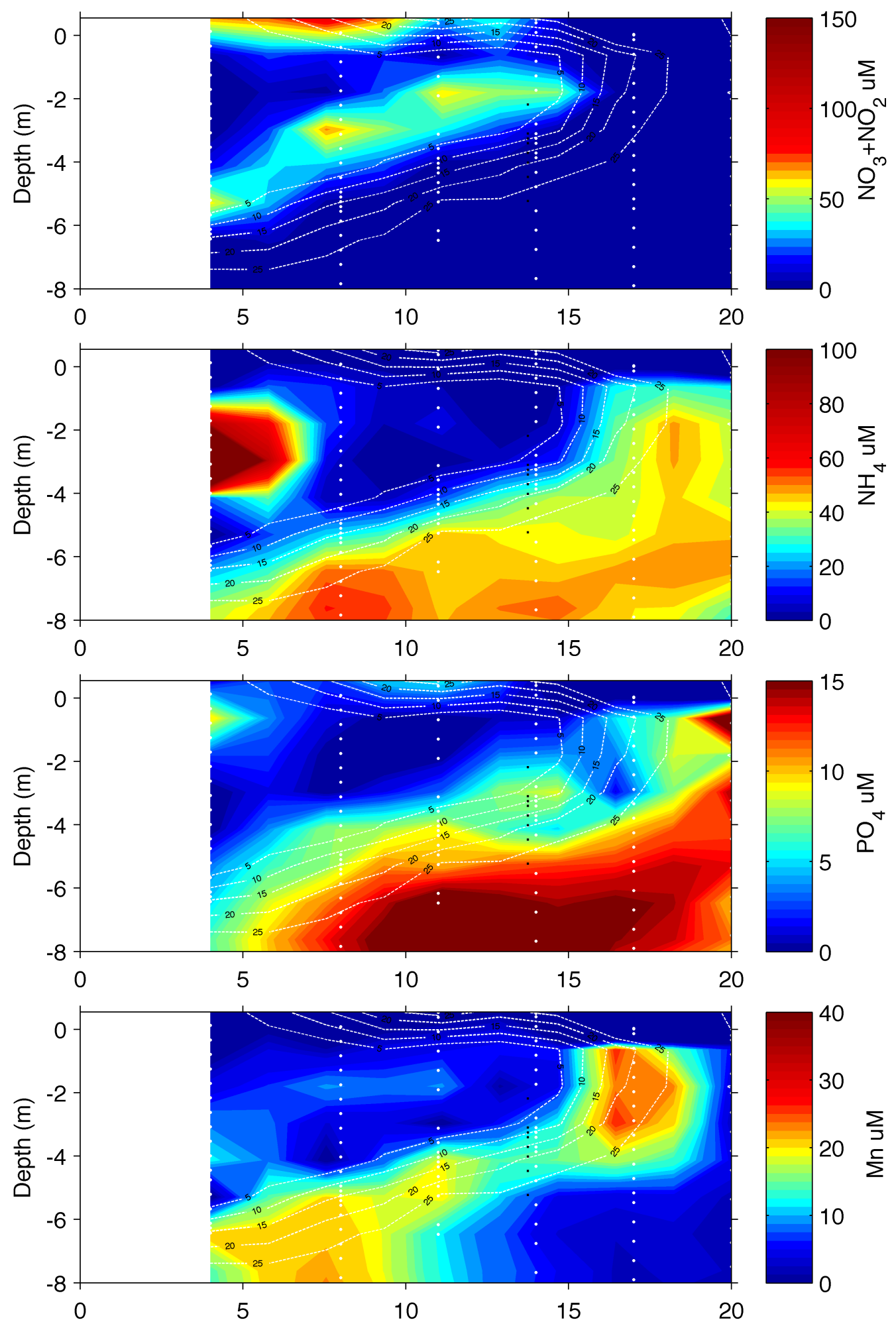

Figure S2 e-h. 


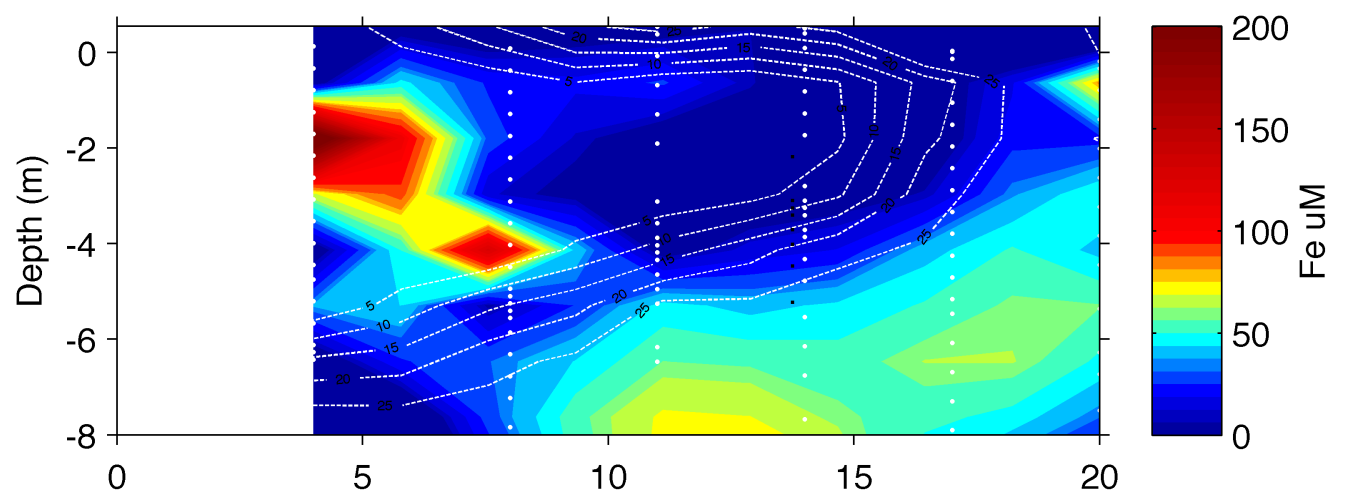

Figure S2: Two-dimensional transect of a) salinity, b) dissolved oxygen, c) pH, d) ORP, e) nitrate + nitrite, f) ammonium, g) phosphate (acidified upon collection), h) manganese and i) iron in March 2003 (nitrogen data published in Kroeger \& Charette, 2008). The locations used to contour are indicated in white while the location of the time series wells is noted with black squares. 

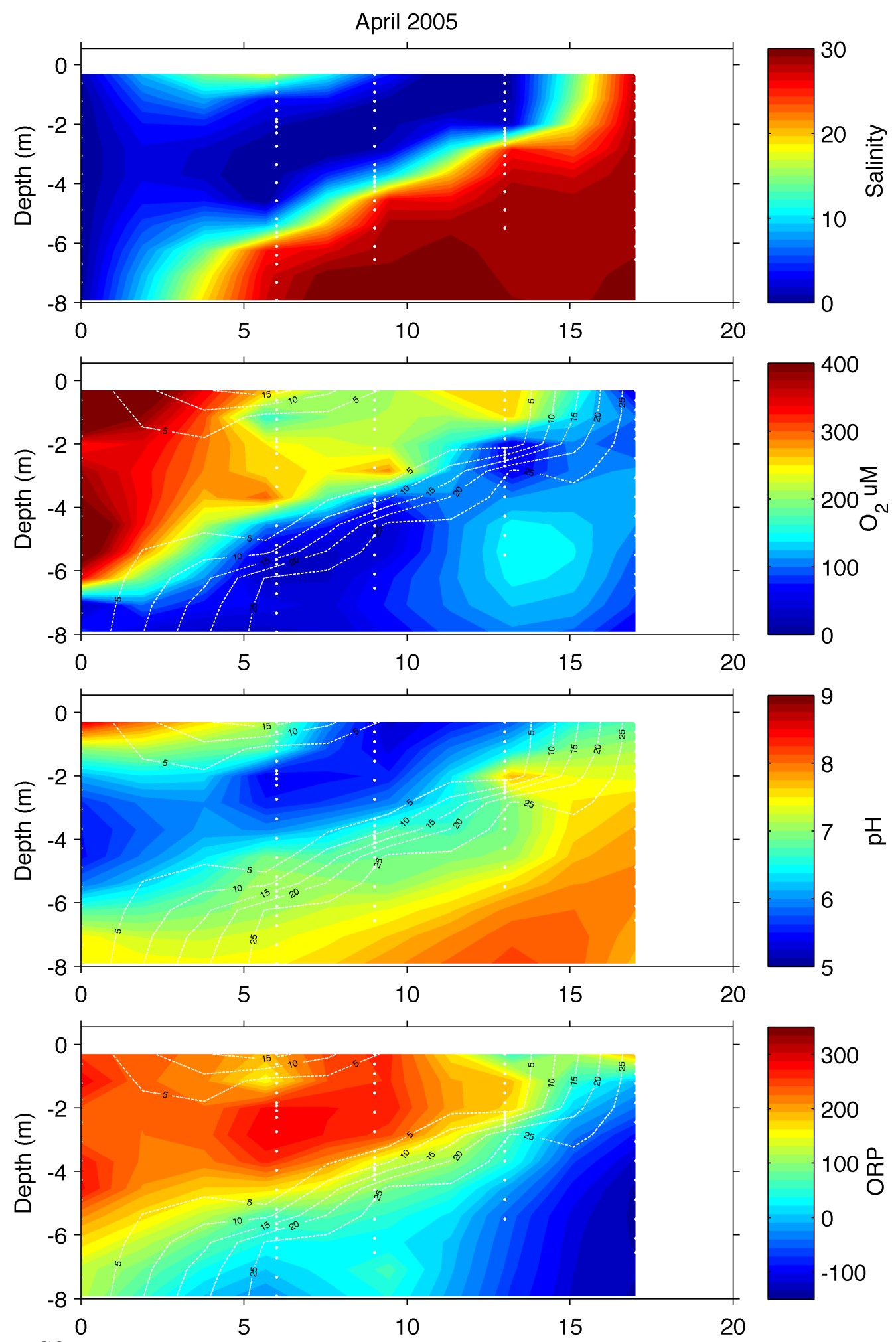

Figure S3 a-d. 


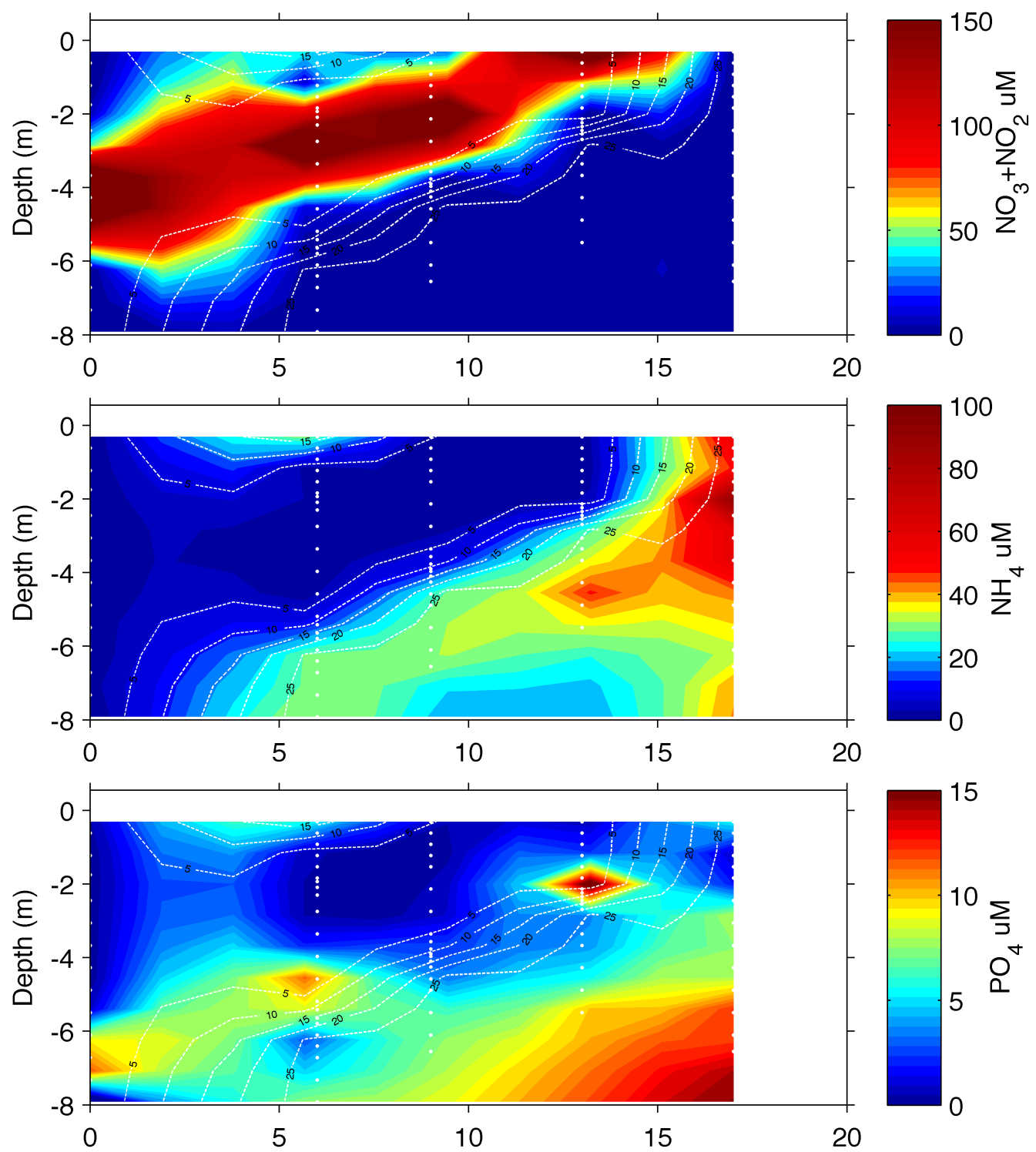

Figure S3: Two-dimensional transect of a) salinity, b) dissolved oxygen, c) pH, d) nitrate + nitrite, e) ammonium and f) phosphate (acidified upon collection) in April 2005. This transect was collected $80 \mathrm{~m}$ west of all other transects, in a region where terrestrial groundwater flow rates are greater (Mulligan \& Charette, 2006). 

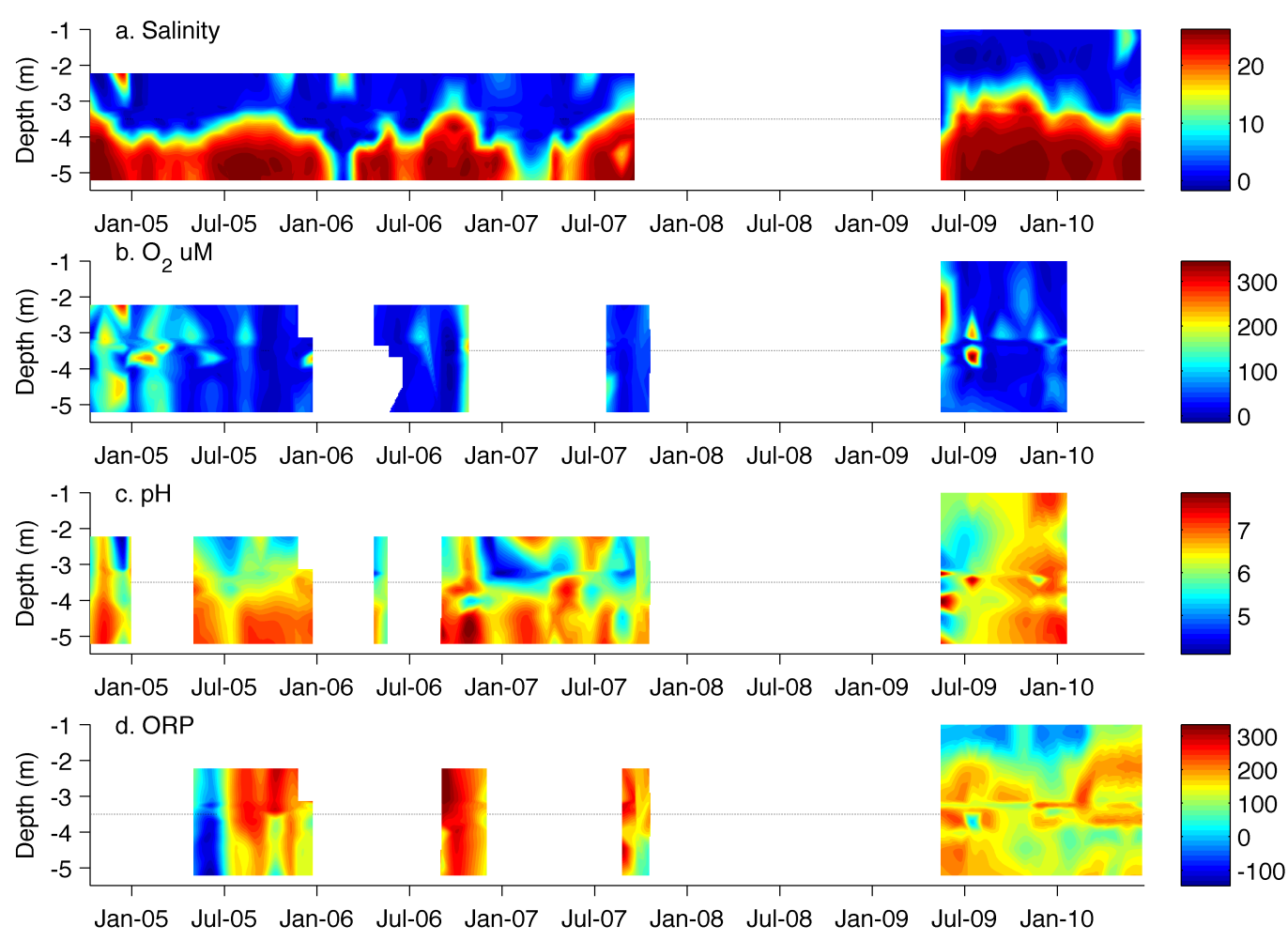

Figure S4: a) Salinity, b) dissolved oxygen, c) pH and d) ORP for the time series. There are data gaps due to probe malfunction. 

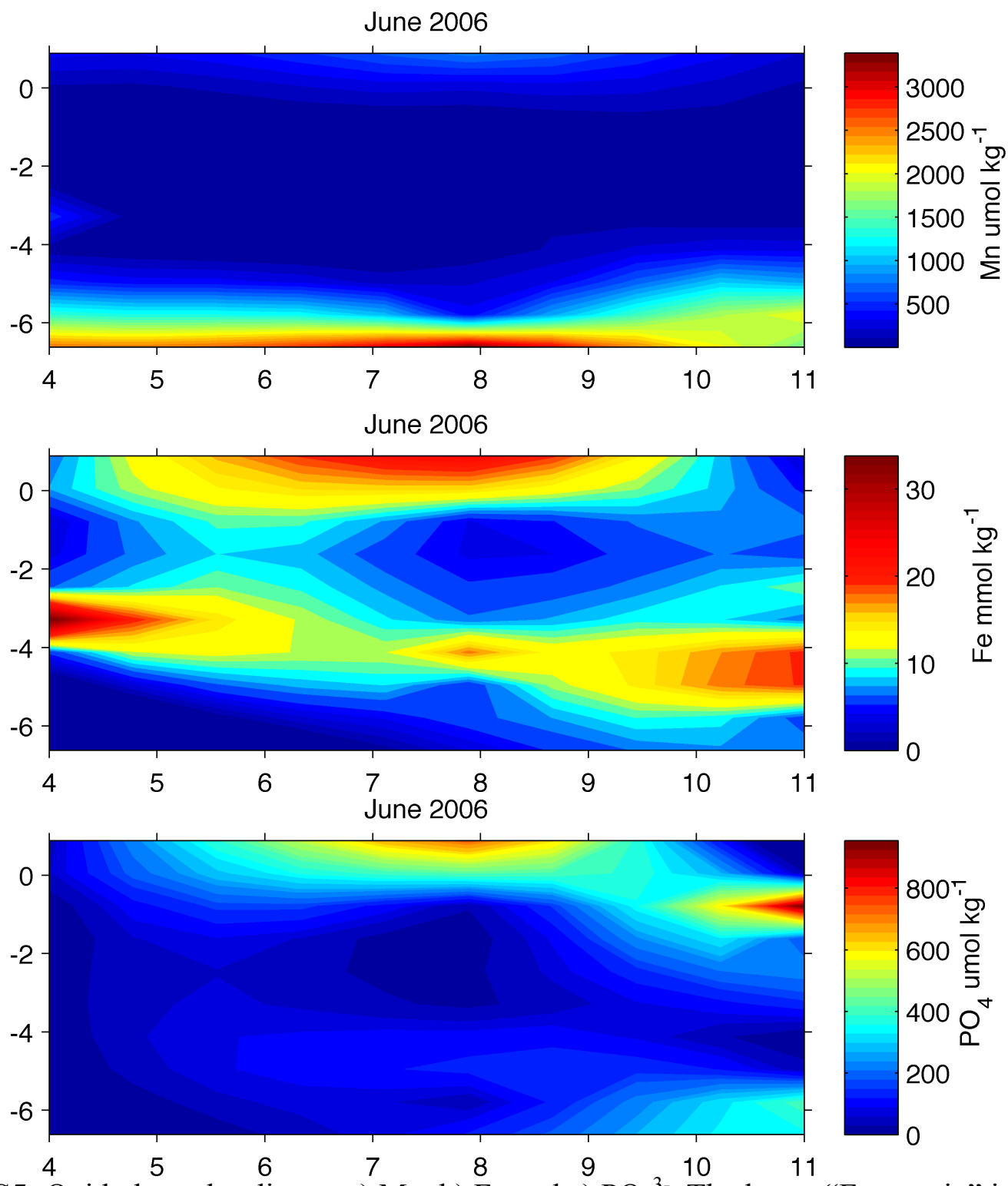

Figure S5: Oxide-bound sediment a) $\mathrm{Mn}, \mathrm{b}) \mathrm{Fe}$ and c) $\mathrm{PO}_{4}{ }^{3-}$. The lower "Fe curtain" is associated with low oxide associated phosphate, while the upper one is enriched in phosphate. Note the horizontal distance scale is referenced to the same location as Figures 2, S1 and S2, but does not capture the location of the time series wells. 


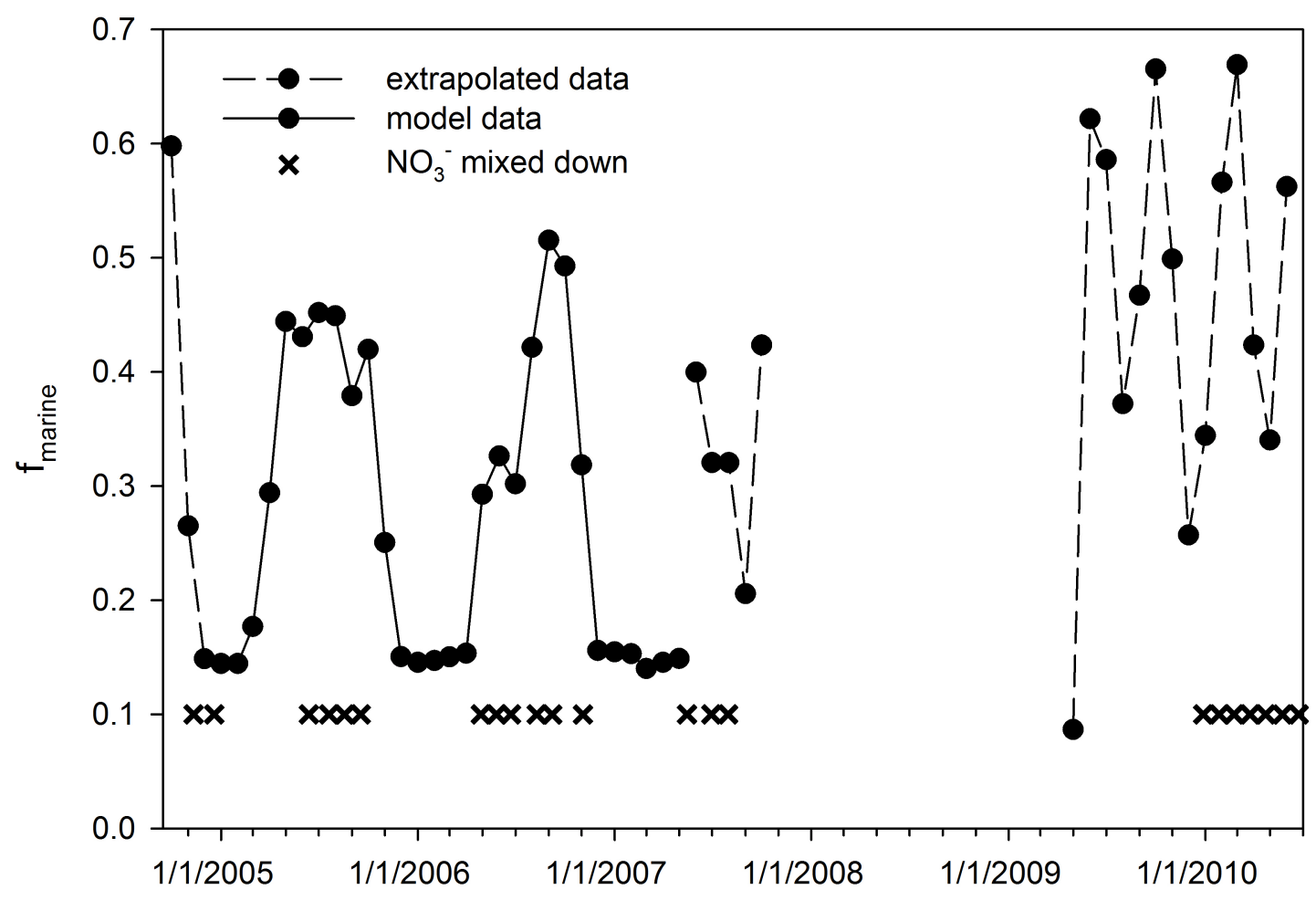

Figure S6: Fraction of marine groundwater in total groundwater discharge ( $\left.f_{\text {marine }}\right)$ plotted from hydrologic model results (solid line) and extrapolated for the remainder of the time series (dashed line). Also indicated are the time periods when terrestrial $\mathrm{NO}_{3}{ }^{-}$is mixed across the salinity interface, which predominantly occurs during periods of enhanced mixing. 


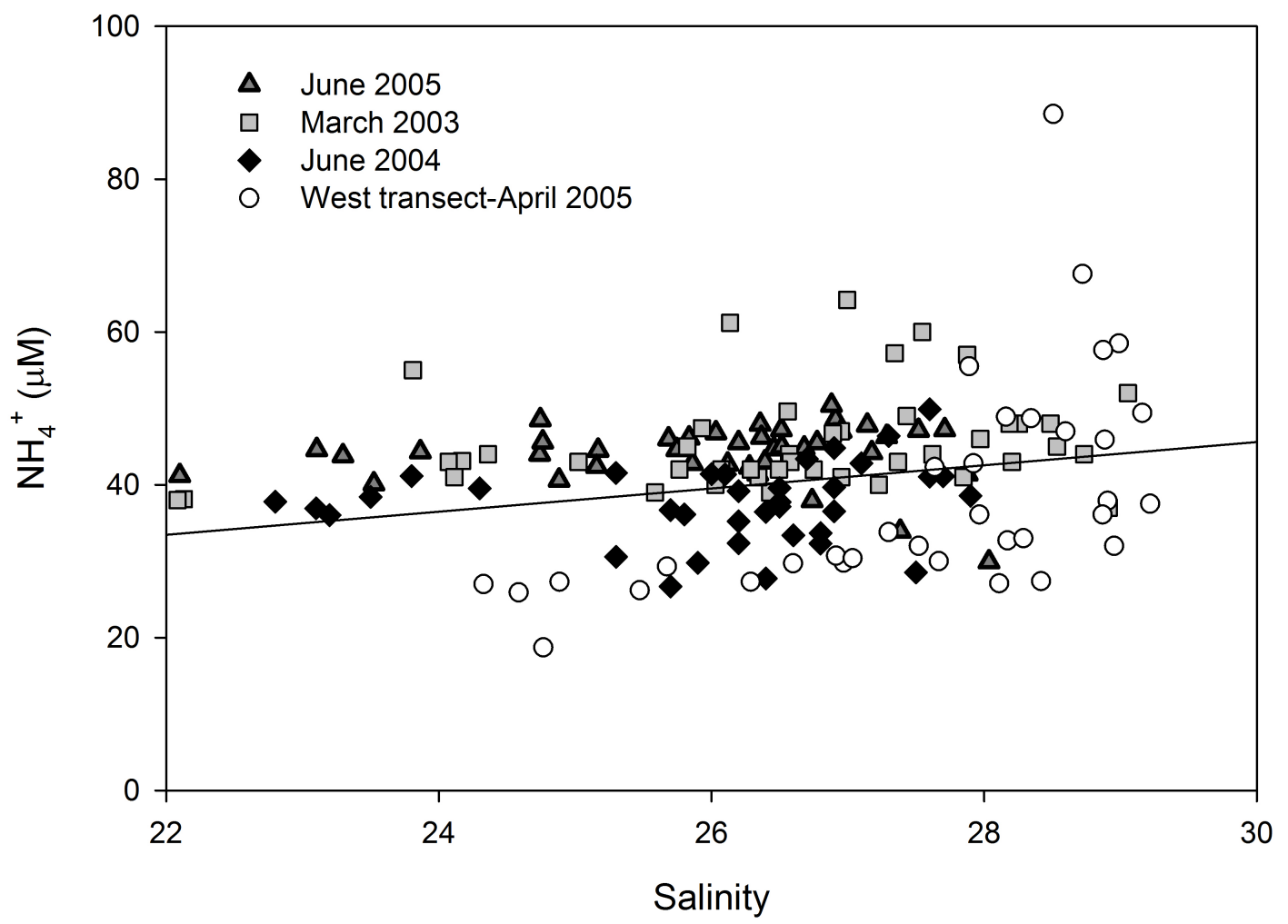

Figure S7: Ammonium within the deep ( $>3 \mathrm{~m})$ subterranean estuary marine groundwater on March 2003, June 2004, and April and June 2005. Also shown is the conservative mixing line used to evaluate $\mathrm{NH}_{4}{ }^{+}$removal within the mixing zone $\left(\mathrm{NH}_{4}{ }^{+}=\right.$salinity $\left.\times 1.52\right)$. Samples from April 2005 transect were collected 80 to the west of the other transects. 


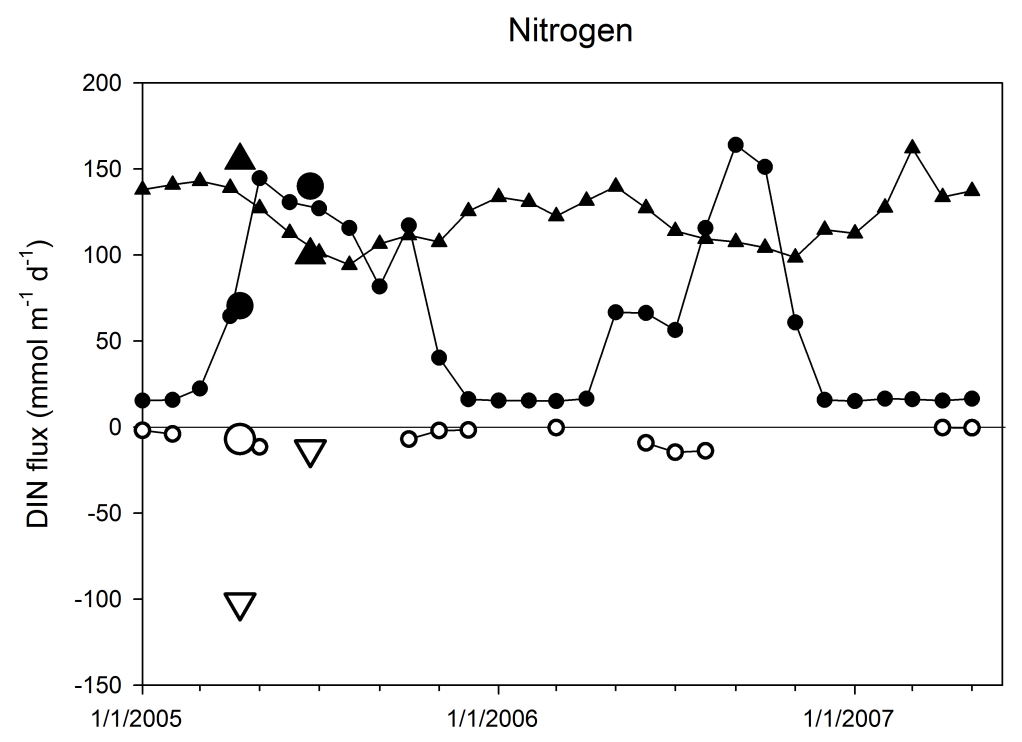

Phosphorous

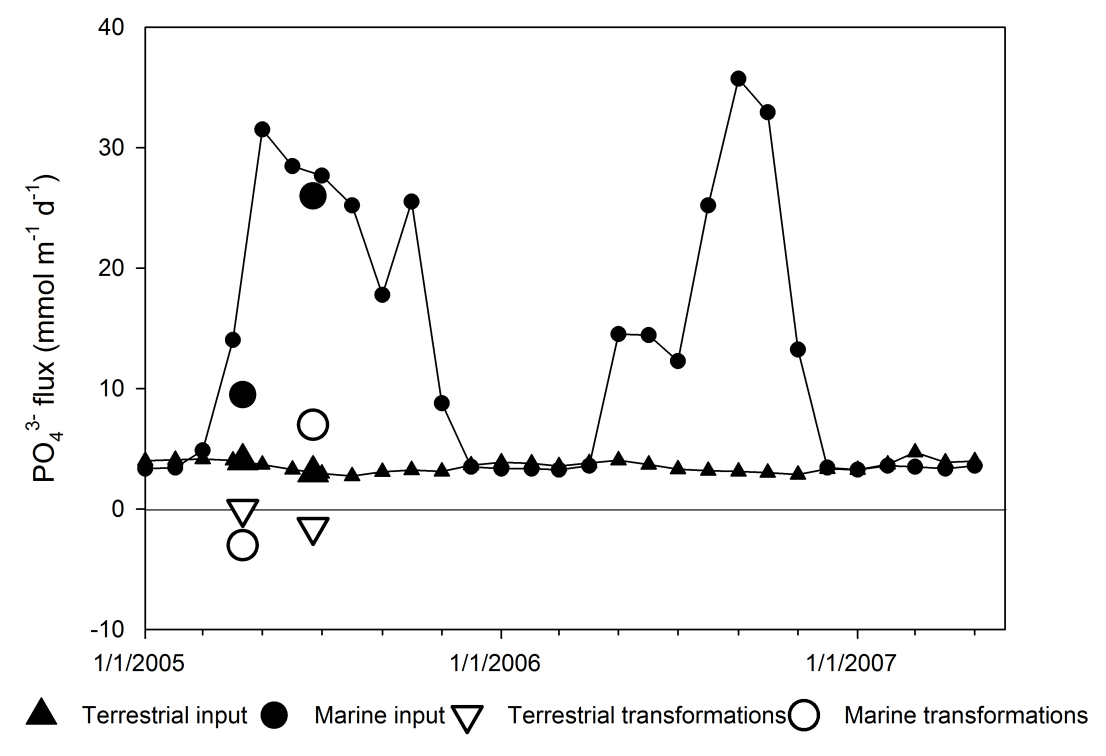

Figure S8: Total terrestrial and marine fluxes into the subterranean estuary (filled symbols) as well as transformation rates within this region (empty symbols). Large symbols represent fluxes calculated from the STE transects in March 2003, June 2004 and April and June 2005. Smaller symbols are estimates from the time series data. 


\section{Chapter 5:}

\section{Trace element geochemistry of groundwater in a karst subterranean estuary (Yucatan Peninsula, Mexico)}

Meagan Eagle Gonneea ${ }^{1}$, Matthew A. Charette ${ }^{1}$, Qian Liu ${ }^{2}$, Jorge A. Herrera-Silveira ${ }^{3}$, Sara M. Morales-Ojeda ${ }^{3}$

Submitted to Geochimica et Cosmochimica Acta

${ }^{1}$ Department of Marine Chemistry and Geochemistry, Woods Hole Oceanographic Institution, Woods Hole, MA, USA

${ }^{2}$ State Key Laboratory of Marine Environmental Science, Xiamen University, Xiamen, China

${ }^{3}$ CINVESTAV-IPN, Unidad Mérida, A.P. 73 CORDEMEX, Mérida, Yucatán, Mexico 
Abstract: Trace element cycling within subterranean estuaries frequently alters the chemical signature of groundwater and may ultimately control the total chemical load to the coastal ocean associated with submarine groundwater discharge. Globally, karst aquifers make up $12 \%$ of all subterranean estuaries. These subterranean estuaries are highly permeable, resulting in rapid infiltration of precipitation and transport of groundwater to the coast, and the predominant carbonate minerals are readily soluble. We studied the chemical cycling of barium (Ba), strontium (Sr), manganese (Mn), uranium $(\mathrm{U})$, calcium $(\mathrm{Ca})$ and radium $(\mathrm{Ra})$ within the carbonate karst subterranean estuary of the Yucatan Peninsula, which is characterized by a terrestrial groundwater lens overlying marine groundwater intrusion with active submarine discharge through coastal springs. Terrestrial groundwater calcium (1-5 mmol kg$\left.{ }^{-1}\right)$ and alkalinity $\left(3-8 \mathrm{mmol} \mathrm{kg}^{-1}\right)$ are enriched over that predicted by equilibrium between recharging precipitation and calcite at in situ temperature and salinity, which can be accounted for by groundwater organic matter respiration and subsequent dissolution of calcite, dolomite and gypsum. There is a close agreement between the observed terrestrial groundwater $\mathrm{Sr} / \mathrm{Ca}, \mathrm{Mn} / \mathrm{Ca}, \mathrm{Ba} / \mathrm{Ca}$ and $\mathrm{Ra} / \mathrm{Ca}$ and that predicted by equilibrium dissolution of calcite, thus the trace element content of terrestrial groundwater is largely due to mineral dissolution. Subsequent mixing between terrestrial groundwater and the ocean within the actively discharging springs is characterized by conservative mixing of $\mathrm{Sr}, \mathrm{Mn}, \mathrm{Ba}$ and $\mathrm{Ca}$, while $\mathrm{U}$ is variable and Ra displays a large enrichment (salinity: 1.9-34.9, Ba: 60-300 nmol kg-1, Sr: 15-110 $\mu \mathrm{mol} \mathrm{kg}{ }^{-1}, \mathrm{U}:$ 0.3-35 $\mathrm{nmol} \mathrm{kg}{ }^{-1}$, Mn: 0.3-200 $\mathrm{nmol} \mathrm{kg}^{-1}$, Ca: 4.3-12.9 mmol kg ${ }^{-1}{ }^{226} \mathrm{Ra}$ 18-2140 dpm $\left.100 \mathrm{~L}^{-1}\right)$. The deep groundwater sampled through cenotes, local dissolution 
features, is typified by elevated $\mathrm{Ba}, \mathrm{Sr}, \mathrm{Ca}, \mathrm{Mn}$ and $\mathrm{Ra}$ and the absence of $\mathrm{U}$ within marine groundwater, due to enhanced dissolution of the aquifer matrix following organic matter degradation and redox processes including sulfate reduction (salinity: 0.2-36.6, Ba: 7-1630 nmol kg ${ }^{-1}$, Sr: 1.3-210 $\mu \mathrm{mol} \mathrm{kg}{ }^{-1}$, U: 0.3-18 nmol kg-1 , Mn: 0.6-2600 nmol kg${ }^{1}$, Ca: 2.1-15.2 $\left.\mathrm{mmol} \mathrm{kg}^{-1},{ }^{226} \mathrm{Ra} 20-5120 \mathrm{dpm} 100 \mathrm{~L}^{-1}\right)$. However, there is no evidence in the spring geochemistry that deep marine groundwater within this reaction zone exchanges with the coastal ocean via spring discharge. Total submarine groundwater discharge rates calculated from radium tracers are $40-95 \mathrm{~m}^{3} \mathrm{~m}^{-1} \mathrm{~d}^{-1}$, with terrestrial discharge contributing $75 \pm 25 \%$ of the total. Global estimates of chemical loading from karst subterranean estuaries suggest $\mathrm{Sr}$ and $\mathrm{U}$ fluxes are potentially $12-22 \%$ and $6-26 \%$ of total ocean inputs $\left(6.8-12 \mathrm{~mol} \mathrm{y}^{-1}\right.$ and 3.4-6.0 $\left.\mathrm{mol} \mathrm{y}^{-1}\right)$, respectively. Radium-226 inputs just from karst subterranean estuaries are up to 1.6 times river inputs $\left(4.0-6.6 \times 10^{15} \mathrm{dpm}\right.$ $\left.\mathrm{y}^{-1}\right)$.

Highlights: 1) Chemical cycling of $\mathrm{Ba}, \mathrm{Sr}, \mathrm{Ca}, \mathrm{U}, \mathrm{Mn}$ and $\mathrm{Ra}$ within a karst subterranean estuary is evaluated. 2) Terrestrial groundwater reflects aquifer rock trace element content for $\mathrm{Sr}, \mathrm{Ca}, \mathrm{Ba}, \mathrm{Mn}$ and Ra. 3) Ra and Ba chemical cycling is decoupled; both demonstrate low salinity desorption. 4) Spring mixing zone $\mathrm{Ba}, \mathrm{Sr}, \mathrm{Ca}$ and Mn cycling is largely conservative between terrestrial groundwater and the ocean. 5) Karst subterranean estuaries are a significant source of $\mathrm{Ra}, \mathrm{Sr}$ and $\mathrm{U}$ to the ocean.

Keywords: submarine groundwater discharge; subterranean estuary; karst; barium; radium; uranium; strontium; manganese; Yucatan Peninsula 


\section{Introduction}

Submarine groundwater discharge (SGD) is the transport of terrestrially sourced groundwater and groundwater of marine origin across the ocean-aquifer interface (Burnett et al., 2006). Many studies have shown that SGD is an important source of trace elements to the coastal ocean (Shaw et al., 1998; Basu et al., 2001; Moore et al., 2006; Beck et al., 2007; Bone et al., 2007; Moore, 2010; Santos et al., 2011; Beck et al., 2013; Gonneea et al., 2013). However, uncertainty remains concerning the total chemical flux via SGD, due in part to groundwater transit through the subterranean estuary (STE), the region of the coastal aquifer where sharp gradients in salinity, oxygen and redox state facilitate the biogeochemical cycling of trace elements (Moore, 1999; Charette and Sholkovitz, 2006; Kaleris, 2006; Beck et al., 2007; Gonneea et al., 2008; Santos et al., 2011). To fully understand the impact SGD has on the coastal ocean and the role SGD plays in global ocean element budgets, we need to quantify how chemical cycling within the subterranean estuary impacts transport of dissolved species to the ocean.

Geochemical transformations within the salinity-mixing zone of the subterranean estuary have been observed at many sites characterized by permeable sand and dominated by aluminosilicate minerals (Charette and Sholkovitz, 2006; Beck et al., 2007; Gonneea et al., 2008; Santos et al., 2011). Karst subterranean estuaries, however, have three unique characteristics: 1) the water to rock ratio is much higher and more variable due to multiple scales of permeability; 2) carbonate minerals are readily soluble; and 3) groundwater mixing occurs during channelized conduit flow of both terrestrial and marine groundwater, with springs being the primary route of water exchange with the 
coastal ocean (Perry et al., 2002; Beddows et al., 2007; Fleury et al., 2007; Charette et al., 2008; Garcia-Solsona et al., 2010; Einsiedl, 2012). The key processes that may alter dissolved trace element distributions in the subterranean estuary include mineral dissolution/precipitation, adsorption/desorption reactions, redox cycling, and mixing between water sources. In the case of radioactive trace elements such as the isotopes of radium, radioactive production or decay must also be considered.

Globally, $12 \%$ of submarine groundwater discharge flows through karst subterranean estuaries (as reported in Beck et al. (2013) calculated from aquifer lithologies presented in Gibbs and Kump (1994) and regional SGD estimates in Zekster et al. (2006)). This study evaluates trace element and radionuclide cycling within the Yucatan Peninsula karst subterranean estuary of barium (Ba), uranium (U), strontium (Sr), manganese $(\mathrm{Mn})$, calcium $(\mathrm{Ca})$ and radium $\left({ }^{226} \mathrm{Ra},{ }^{228} \mathrm{Ra}\right.$ and $\left.{ }^{223} \mathrm{Ra}\right)$. These elements are of interest given their utility as tracers of environmental processes. For example, past oceanic productivity can be reconstructed from $\mathrm{BaSO}_{4}$ burial rates (Dymond et al. 1992; Paytan et al., 1996) while the oceanic Sr isotope record serves as a proxy for continental inputs to the ocean, which may not be at steady state (Hess et al., 1986; Krabbenhōft, et al., 2010), hydrothermal circulation (Palmer and Edmond, 1992) and submarine groundwater discharge (Basu et al., 2001; Allègre et al., 2010; Beck et al., 2013). Variability in oceanic $\mathrm{Ca}$ isotopes may be related to changes in ocean carbon cycling on long time scales (Griffith et al., 2008) and Ra is used extensively as a tracer of groundwater discharge (Moore, 1996). Uranium serves as a proxy of ocean redox state (Tribovillard et al., 2006) and seawater uranium isotopes reflect the influence of climate 
on continental weathering (Robinson et al., 2004). More recently, studies have shown SGD associated fluxes and chemical transformations within the subterranean estuary should be considered in oceanic element budgets (Dunk et al., 2002; Santos et al., 2011; Holmden et al., 2012; Beck et al., 2013). To this end, SGD-derived chemical fluxes are determined for the Yucatan Peninsula. We then extrapolate the karst end members reported here to calculate potential global SGD derived chemical fluxes through karst subterranean estuaries and compare them to ocean element budgets.

\section{Methods}

\subsection{Field site}

The Yucatan Peninsula is a large karst platform $\left(165,000 \mathrm{~km}^{2}\right)$ that is bordered by the Gulf of Mexico along the west and north coasts and by the Caribbean Sea on the east coast (Fig. 1). The peninsula is characterized by a humid tropical climate, with maximum daily temperatures ranging from 25 to $35^{\circ} \mathrm{C}$ and average rainfall that varies spatially across the Peninsula from $555-1500 \mathrm{~mm} \mathrm{y}^{-1}$. Evapotranspiration rates are $\sim 80 \%$ of total precipitation and invariant over the course of the year due to a low seasonal temperature difference and sustained vegetation growth (Bautista et al., 2009). The rainy season is from June through October with dry conditions prevailing from December through May, coinciding with cool temperatures (Giddings and Soto, 2003). From November through February temperatures are typically cool and north winds prevail. Tropical depressions, which frequently make landfall on the Yucatan Peninsula, result in large precipitation events (Boose, 2006). 
The Yucatan Peninsula consists of limestone, dolomite and evaporite deposits, which can reach up to $1,500 \mathrm{~m}$ thickness (Bauer-Gottwein et al., 2011). The permeability of the aquifer is so great that there are no streams or rivers. Preferential flow paths in the karst aquifer range in scale from large dissolution conduits (10-100's of meters) to smaller scale fractures $(1-10 \mathrm{~cm})$, thus aquifer permeability is largely scale dependent. The hydraulic gradient is very low $\left(1-10 \mathrm{~cm} \mathrm{~km}^{-1}\right)$ and flow is generally perpendicular to the coast (Hanshaw and Back, 1980; Beddows et al., 2007; Gondwe et al., 2010). Marine groundwater lies beneath a freshwater lens across the entire Peninsula, with the depth to the saltwater interface increasing with hydraulic head elevation, as predicted by the Dupuit-Ghyben-Herzberg model. Close to the coast $(<20 \mathrm{~km})$, the halocline is at $<40 \mathrm{~m}$ and it is possible to sample both terrestrial and marine groundwater through sinkholes, which are locally known as "cenotes" (Perry et al., 2009; Bauer-Gottwein et al., 2011). The freshwater portion of cenotes is typically oxic, with reducing conditions developing in the saline portions due to reduction of organic matter and presumably longer water residence times than terrestrial groundwater (Cervantes-Martinez et al., 2002; Perry et al., 2002; Schmitter-Soto et al., 2002; Torres-Talamante et al., 2011). A region of high permeability exists along the perimeter of the Cretaceous asteroid impact crater; known as the 'Ring of Cenotes', it bisects the coast at the Celestun and Bocas de Dzilam Lagoons (Perry et al., 1995).

The degree of karstification of the Yucatan Peninsula results in high permeability with minimal surface flow (Perry et al., 2009; Bauer-Gottwein et al., 2011). Since the major vector for terrestrial freshwater transport to the coast is via SGD, many studies 
have evaluated its impact on the coastal ocean, with a particular focus on nutrient loading and eutrophication (Smith, 1999; Herrera-Silveira et al., 2002; ArandaCirerol et al., 2006; Young et al., 2008; Morales-Ojeda et al., 2010; Price et al., 2010). Seminal studies by Perry et al. $(2002,2009)$ have utilized groundwater major ion (i.e. $\mathrm{Cl}^{-}, \mathrm{Ca}^{2+}, \mathrm{Mg}^{2+}, \mathrm{K}^{+}$, $\left.\mathrm{Na}^{+}, \mathrm{SO}_{4}{ }^{2-}\right)$ and strontium isotope chemistry to infer the subsurface geostratigraphy of the Yucatan Peninsula and groundwater flow paths across the region.

\subsection{Field Methods}

Samples were collected during four field campaigns (May 26-29, 2007; Dec. 4-9, 2009; Feb. 12-17, 2011; and Oct. 22-25, 2011) from cenotes, springs, wells and coastal ocean waters (Fig. 1). Springs were actively discharging into the coastal ocean and were either submerged or within the tidal zone. Well samples were collected only from the east coast and were pumped from $15 \mathrm{~cm}$ diameter wells with slotted casings extending down to 5-18 m. Ocean samples were collected within $60 \mathrm{~km}$ of the coast. Cenotes were sampled with a Niskin bottle in 2007 and a Proactive Mega-Typhoon ${ }^{\mathrm{TM}}$ submersible pump in 2009 and 2011. Cenote radium samples in 2007 were combined from multiple Niskin bottles and ranged from 3.4-10 L, while sample volume in 2009 and 2011 was 22$30 \mathrm{~L}$. Spring samples were collected by placing a submersible pump within the outflowing water, with 4-30 L collected for radium. Coastal trace metal samples were collected from a Niskin bottle deployed at $2 \mathrm{~m}$ and radium samples (44-84 L) were collected from the same depth using a pump. Trace metal samples were $0.2 \mu \mathrm{m}$ filtered into clean LDPE bottles and acidified to $\mathrm{pH} 1$ with Optima nitric acid. Dissolved inorganic carbon (DIC) and total alkalinity samples were $0.2 \mu \mathrm{m}$ filtered into $125 \mathrm{~mL}$ 
glass bottles, poisoned with $50 \mu \mathrm{L}$ saturated mercuric chloride upon sample collection and were kept free of air bubbles. Samples for radium were filtered through $\mathrm{MnO}_{2}$ impregnated acrylic fibers (hereafter referred to as Mn fibers) at a flow rate of 0.2-0.8 L $\min ^{-1}$ to quantitatively sorb Ra onto the $\mathrm{MnO}_{2}$ (Moore and Reid, 1973).

Basic water chemistry data including salinity, dissolved oxygen, temperature, $\mathrm{pH}$ and oxidation-reduction potential (ORP, converted to Eh) were measured in the field with a YSI 600XLM or a YSI 6920V2 multi-parameter sonde in a flow-through cell (springs and cenotes) or directly in the coastal ocean. In addition, separate water samples were collected in 2009 and 2011 for salinity and were analyzed by a Guideline AutoSal instrument. Three samples of the surficial aquifer rock were collected in 2009 from the east coast.

\subsection{Analytical Methods}

Uranium, barium, and strontium were measured via isotope dilution on a 20 times diluted sample. Briefly, $0.075 \mathrm{~g}$ of sample was spiked with ${ }^{135} \mathrm{Ba},{ }^{236} \mathrm{U}$ and ${ }^{84} \mathrm{Sr}$ and diluted to $1.8 \mathrm{~g}$ with $5 \%$ Optima nitric acid. The resulting solution was analyzed on a Finnigan Element 2 high-resolution inductively coupled plasma mass spectrometer at the Woods Hole Oceanographic Institution ICPMS Facility for masses ${ }^{84} \mathrm{Sr},{ }^{88} \mathrm{Sr},{ }^{135} \mathrm{Ba},{ }^{138} \mathrm{Ba}$,

${ }^{236} \mathrm{U}$ and ${ }^{238} \mathrm{U}$. The ${ }^{84} \mathrm{Sr}$ peak was corrected for krypton-84 interferences by monitoring the krypton-82 peak. Manganese and calcium (for a subset of samples) were determined separately by diluting samples 20 -fold with $5 \%$ Optima nitric acid and adding Indium (In) as an internal standard to account for instrument drift and matrix interferences of the solution. Count rates were normalized to In and concentrations were calculated from a six 
point standard curve. The standard curve was calculated from a linear regression between standard concentrations and $\mathrm{E} / \mathrm{In}$ count ratios. An additional subset of samples was run for Ca on a Dionex ion chromatograph. NASS-5, SLEW-3, SLRS-4 and IAPSO reference standards were analyzed to determine accuracy, which was better than $1 \%$ for $\mathrm{Ca}, 5 \%$ for $\mathrm{U}, \mathrm{Sr}$ and $\mathrm{Ba}$, and $15 \%$ for $\mathrm{Mn}$ (Table S1). DIC and total alkalinity were measured within two weeks of collection. DIC was determined by acidification of $0.5 \mathrm{~mL}$ of a water sample and the subsequent quantification of $\mathrm{CO}_{2}$ with a non-dispersive IR detector (LiCor 6252). The analytical precision is $\pm 3 \mathrm{mmol} \mathrm{kg}^{-1}$. Total alkalinity was determined using Gran titration (Metrohm 808 Titrando with $1 \mathrm{~mL}$ burette) with precision of \pm 4 $m m o l ~ \mathrm{~kg}^{-1}$ ( \pm denotes one standard deviation throughout). Both DIC and total alkalinity were calibrated by certified reference materials from A.G. Dickson of Scripps Institution of Oceanography. One aquifer rock sample was drilled to a fine powder, dissolved in 5\% nitric acid and then trace elements were analyzed as described above. Elemental concentrations reported for this rock sample are thereby totals not leaches.

The Mn fibers were rinsed with Ra-free water to remove salts, which interfere with counting (Sun and Torgersen, 1998), partially dried and placed within a delayed coincidence counter to measure ${ }^{223} \mathrm{Ra}$ and ${ }^{224} \mathrm{Ra}$ 1-6 days after collection (Moore and Arnold, 1996). For the oldest samples (6 days), there was only $30 \%$ of the initial ${ }^{224} \mathrm{Ra}$ remaining. Samples from 2007 were counted at four weeks and two months post sampling to correct ${ }^{223} \mathrm{Ra}$ for ${ }^{227} \mathrm{Ac}$ adsorbed to the Mn fibers. In 2009 and 2011, an additional count was done at 11 to 17 days post sampling to improve ${ }^{223}$ Ra measurements. Due primarily to low ${ }^{224} \mathrm{Ra}$ activities and decay during transit from Mexico, the majority 
of groundwater ${ }^{224} \mathrm{Ra}$ values were below detection and are not reported here. ${ }^{1}$ Note that several water samples collected from deep cenotes for radium analysis were highly reducing, and despite aeration, the Ra could not effectively be removed from these samples due to loss of Mn oxide coating. Radium-223 activities of the surficial rock samples were determined by dissolving $20-30 \mathrm{~g}$ of powdered carbonate in $20 \% \mathrm{HCl}$, which was then neutralized to $\mathrm{pH} 8$ with $\mathrm{NaOH}$. Mn fibers were added to each solution and shaken for $24 \mathrm{~h}$ to remove radium. The Mn fibers were then rinsed and counted as above.

Manganese fibers were ashed $\left(820^{\circ} \mathrm{C}, 16 \mathrm{~h}\right)$, homogenized and capped with epoxy, prior to being placed within a well-type gamma spectrometer to measure ${ }^{228} \mathrm{Ra}$ (via ${ }^{228} \mathrm{Ac}$ at $911 \mathrm{keV}$ ) and ${ }^{226} \mathrm{Ra}$ (via ${ }^{214} \mathrm{~Pb}$ at $351.9 \mathrm{keV}$ ) (Charette et al., 2001). All detectors were standardized using a ${ }^{226}$ Ra NIST-certified Standard Reference Material (\#4967A) and a gravimetrically prepared $\mathrm{ThNO}_{3}$ powder, with Th daughters $\left({ }^{228} \mathrm{Ra}\right)$ in equilibrium, which was dissolved and calibrated via isotope dilution MC-ICP-MS with the ${ }^{226}$ Ra NIST standard. These solutions were sorbed to Mn fibers and prepared in the same manner as the samples. Detection limits calculated with the Currie Hypothesis test for these gamma detectors was $0.2 \mathrm{dpm}$ (i.e. $5 \mathrm{dpm} 100 \mathrm{~L}^{-1}$ for $4 \mathrm{~L}$ cenote and spring samples and $0.2 \mathrm{dpm}$ $100 \mathrm{~L}^{-1}$ for $84 \mathrm{~L}$ offshore samples) (De Greer, 2004). ${ }^{223} \mathrm{Ra}$ and ${ }^{228} \mathrm{Ra}$ activities were decay corrected to the time of collection. ${ }^{228} \mathrm{Ra}$ and ${ }^{226} \mathrm{Ra}$ in aquifer solids were gamma counted on a fine powder drilled from surficial rocks and capped with epoxy as above. 


\section{Results}

\subsection{Barium}

Barium concentrations in cenote waters are elevated over ocean end members, with the highest concentrations found in reducing cenote waters $(\mathrm{Eh}<200,400-600 \mathrm{nmol}$ $\mathrm{kg}^{-1}$; Fig. 2a and Table S2); at $35 \mathrm{~m}$ in Cenote Xlabom, Ba values exceeded $1400 \mathrm{nmol}$ $\mathrm{kg}^{-1}$. In contrast, low salinity spring, well and cenote samples had lower, but very similar Ba concentrations $\left(\sim 125 \mathrm{nmol} \mathrm{kg}^{-1}\right)$ with peak values observed at salinity $\sim 2$. This type of non-conservative enrichment has been previously observed for $\mathrm{Ba}$ in subterranean estuaries (Shaw et al., 1998; Charette and Sholkovitz, 2006; Santos et al., 2011). Spring samples $\left(140 \pm 60 \mathrm{nmol} \mathrm{\textrm {kg } ^ { - 1 }}\right)$ fall along a conservative mixing line between coastal ocean Ba values $\left(65 \pm 10 \mathrm{nmol} \mathrm{kg}^{-1}\right)$ and the salinity $\sim 2$ end member (dashed line in Fig. 2a, Table S3). In the reducing cenote waters, Ba would appear to be supersaturated with respect to barite $\left(\mathrm{BaSO}_{4}\right)$ formation (Rushdi et al., 2000), however, this is likely due to the absence of $\mathrm{SO}_{4}{ }^{2-}$ in this region of the aquifer (Perry et al., 2002, 2009).

\subsection{Uranium}

Low salinity cenote waters range from 1.6 to $15.7 \mathrm{nmol} \mathrm{kg}^{-1} \mathrm{U}$, and low salinity spring and well samples typically have $U$ concentrations $>10 \mathrm{nmol} \mathrm{kg}^{-1}$ (Fig. $2 \mathrm{~b}$ and Table S2). High salinity, reducing cenote samples are marked by depletion of $U$ relative to predicted values for oxygenated seawater. Spring U concentrations are largely invariant across the salinity-mixing zone between terrestrial groundwater and the coastal ocean value $\left(14 \pm 0.5 \mathrm{nmol} \mathrm{kg}^{-1}\right)$. 


\subsection{Strontium}

There are two conservative mixing relationships apparent in the strontium data (Fig. 2c and Table S2). Strontium concentrations range from 1 to $34 \mu \mathrm{mol} \mathrm{kg}{ }^{-1}$ in low salinity spring, well and cenote samples although some well samples reach $50 \mu \mathrm{mol} \mathrm{kg}{ }^{-1}$ at salinities 2 to 5 . Reducing cenote samples then follow a conservative mixing line to peak values of $210 \mu \mathrm{mol} \mathrm{kg}{ }^{-1}$ at salinity 36.6. Spring samples fall along a separate mixing line between a $20 \mu \mathrm{mol} \mathrm{kg}-1$ low salinity end member and the coastal ocean $(96 \pm 3 \mu \mathrm{mol}$ $\left.\mathrm{kg}^{-1}\right)$ with the exception of a few low salinity well samples that are enriched in $\operatorname{Sr}(\sim 60$ $\left.\mu \mathrm{mol} \mathrm{kg}{ }^{-1}\right)$. All samples are undersaturated with respect to celestite $\left(\mathrm{SrSO}_{4}\right)$, which reaches saturation at $450 \mu \mathrm{mol} \mathrm{kg}^{-1}$ at salinity greater than 15 (Rushdi et al., 2000).

\subsection{Manganese}

Manganese concentrations are generally less than $100 \mathrm{nmol} \mathrm{kg}^{-1}$ in the low salinity cenote groundwater (Fig. 2d and Table S3). Higher salinity, reducing groundwater is comparatively enriched in manganese $\left(10-2600 \mathrm{nmol} \mathrm{kg}^{-1}\right)$. Mixed salinity spring and coastal well samples mix conservatively between terrestrial groundwater $\left(80 \pm 160 \mathrm{nmol} \mathrm{kg}^{-1}\right)$ and coastal ocean $\left(9.6 \pm 4 \mathrm{nmol} \mathrm{kg}^{-1}\right)$ end members (Table S3).

\subsection{Calcium}

Calcium was only measured on a subset of the samples. Calcium is conservative with salinity, with two distinct mixing relationships (Fig. 2e and Table S2). Terrestrial groundwater is enriched in $\mathrm{Ca}\left(3.8 \pm 0.9 \mathrm{mmol} \mathrm{kg}^{-1}\right)$ with spring samples falling on a mixing line (slope of 0.23 and intercept of 3.4 ) with the coastal ocean value (10.7 mmol 
$\mathrm{kg}^{-1}$ ). Previously reported Ca values for Yucatan groundwater fall along a similar mixing line as the terrestrial groundwater and mixed salinity springs and wells (slope 0.19 and intercept 3.4, (Stoessell et al., 1989); slope 0.18 and intercept 4.2, (Reeve and Perry, 1994)). The mixing line for the deep reducing cenote samples from Sabtun Cenote shown here (slope of 0.59 and intercept of 3.7) intersects deep (UNAM2, $300 \mathrm{~m}$ ) samples enriched in Ca reported in Perry et al. (2002), although the high Ca samples shown here are from a maximum depth of $35 \mathrm{~m}$. Other reducing cenote samples are enriched in Ca to a lesser extent.

\subsection{Radium isotopes}

Radium-226 $\left(\mathrm{t}_{1 / 2}=1600 \mathrm{y}\right)$ and ${ }^{223} \mathrm{Ra}\left(\mathrm{t}_{1 / 2}=11.4 \mathrm{~d}\right)$ are enriched 100 and 230 times, respectively in groundwater compared to coastal ocean activities. Radium-228 $\left(\mathrm{t}_{1 / 2}\right.$ $=5.7 \mathrm{y})$ is comparatively less enriched (14 times) since its particle reactive parent $\left({ }^{232} \mathrm{Th}\right)$ occurs in very low abundance in both seawater and carbonate minerals (Fig. 3). This pattern is also observed in low salinity groundwater, from both cenotes and wells, which are approximately 20 times enriched in ${ }^{226} \mathrm{Ra}\left(360 \pm 380 \mathrm{dpm} 100 \mathrm{~L}^{-1}\right.$, Fig. 3a) and ${ }^{223} \mathrm{Ra}$ $\left(21 \pm 35 \mathrm{dpm} 100 \mathrm{~L}^{-1}\right.$, Fig. 3c) compared to coastal ocean activities, while ${ }^{228} \mathrm{Ra}$ is only four times higher in low salinity groundwater $\left(24 \pm 20 \mathrm{dpm} 100 \mathrm{~L}^{-1}\right.$, Fig. $\left.3 \mathrm{~b}\right)$ than in the coastal ocean. The two long-lived isotopes peak in spring samples at a salinity of $\sim 5$ $\left({ }^{226} \mathrm{Ra}: 2200 \mathrm{dpm} 100 \mathrm{~L}^{-1},{ }^{228} \mathrm{Ra}: 180 \mathrm{dpm} 100 \mathrm{~L}^{-1}\right)$, while the short-lived ${ }^{223} \mathrm{Ra}$ spring samples do not display a distinct peak (Fig. 3). Several high salinity cenote samples have very high ${ }^{226} \mathrm{Ra}\left(>3000 \mathrm{dpm} 100 \mathrm{~L}^{-1}\right)$ and ${ }^{228} \mathrm{Ra}\left(>400 \mathrm{dpm} 100 \mathrm{~L}^{-1}\right)$ without a corresponding enrichment of ${ }^{223} \mathrm{Ra}$. 


\subsection{Aquifer rock trace elements and radium}

The bulk trace element content of the Yucatan surficial aquifer rock collected 10 $\mathrm{km}$ inland is: $\mathrm{Ba}=0.17 \mu \mathrm{mol} \mathrm{g}{ }^{-1}, \mathrm{Sr}=3.3 \mu \mathrm{mol} \mathrm{g}{ }^{-1}, \mathrm{U}=3.2 \mathrm{nmol} \mathrm{g}^{-1}, \mathrm{Mn}=0.24 \mu \mathrm{mol} \mathrm{g}^{-1}$ (Table 1). Radium isotopes were also measured on two additional samples (collected 0.5 and $20 \mathrm{~km}$ from the coast) and displayed a large range: ${ }^{228} \mathrm{Ra}=0.17-0.28 \mathrm{dpm} \mathrm{g}^{-1},{ }^{226} \mathrm{Ra}$ $=1.8-6.1 \mathrm{dpm} \mathrm{g}^{-1}$ and ${ }^{223} \mathrm{Ra}=0.02-0.22 \mathrm{dpm} \mathrm{g}^{-1}($ Table 1$)$.

\section{Discussion}

\subsection{Aquifer rock geochemistry}

The $\mathrm{Ba}, \mathrm{Sr}, \mathrm{U}$ and $\mathrm{Mn}$ content of the Yucatan aquifer rock reported here is slightly lower than global limestone values, likely due to some aluminosilicate inclusions in the global average limestone (Bowen, 1979). The Yucatan carbonate aquifer we measured has minimal terrestrially-derived inclusions evidenced by a much lower Mn content, however there is a high silicate content due to the presence of diatom frustrules. Studies of the Chicxulub meteorite impact zone (northwest Yucatan) include analysis of unaltered carbonate rocks with trace metal concentrations close to those reported here (Table 1). Ba concentrations in unaltered carbonates ranged from 0.07-0.22 $\mu \mathrm{mol} \mathrm{g}^{-1}$, in close agreement with samples from the East coast $\left(0.17 \mu \mathrm{mol} \mathrm{g} \mathrm{g}^{-1}\right.$, Table 1$)$ (Tuchscherer et al., 2005). Sr content was slightly higher in the sample reported here (3.3 versus 2.3$2.6 \mu \mathrm{mol} \mathrm{g}{ }^{-1}$ ), while $\mathrm{U}$ and Mn concentrations are 30-40\% lower in the sample analyzed here than near the impact zone. These differences are potentially due to alteration associated with the bolide impact or subsequent changes in hydrogeology and weathering (Schmitt et al., 2004; Tuchscherer et al., 2005). There was a larger range in the sediment 
radium activities, particularly for ${ }^{223} \mathrm{Ra}$ and ${ }^{226} \mathrm{Ra}$ (within the ${ }^{235} \mathrm{U}$ and ${ }^{238} \mathrm{U}$ decay series respectively). The radium content of carbonate minerals is largely determined by the $\mathrm{U}$ present at the time of formation, leading to a large range in radium activities (Langmuir and Riese, 1985).

\subsection{Geochemical controls on karst subterranean estuary terrestrial end member}

Numerous studies of this aquifer have shown that groundwater is in equilibrium with calcite, the primary aquifer mineral (Stoessell et al., 1989; Reeve and Perry, 1994; Perry et al., 2002, 2009;). In addition, aragonite, celestite $\left(\mathrm{SrSO}_{4}\right)$ and evaporite layers (gypsum and anhydrite) are occasionally found and dissolution of these minerals may further modify groundwater chemistry (Stoessell et al., 1989, 1993; Perry et al., 2002, 2009). Water in equilibrium with atmospheric $\mathrm{CO}_{2}$ has a $\mathrm{pH}$ of 5.6; when this water reacts with calcite the resulting solution has a $\mathrm{pH}$ of 8.2 , an alkalinity of $1100 \mu \mathrm{mol} \mathrm{kg}{ }^{-1}$ and a dissolved $\mathrm{Ca}$ concentration of $0.5 \mathrm{mmol} \mathrm{kg}$. In contrast, our samples of Yucatan terrestrial (salinity $<2$ ) groundwater had an alkalinity of $6460 \pm 1210 \mu \mathrm{eq} \mathrm{kg}^{-1}$, DIC of $6630 \pm 1230 \mu \mathrm{mol} \mathrm{kg}{ }^{-1}, \mathrm{pH}$ of $7.25 \pm 0.56$ and $3.8 \pm 0.9 \mathrm{mmol} \mathrm{kg}^{-1}$ dissolved Ca. To acquire these elevated alkalinity, DIC and $\mathrm{Ca}$ concentrations, further mineral dissolution must be induced under elevated groundwater $\mathrm{pCO}_{2}$ concentration and reduced $\mathrm{pH}$.

We used model simulations to determine how organic matter respiration could alter the groundwater chemistry through enhanced mineral dissolution. All groundwater speciation and mineral solubility calculations were performed with PHREEQ (Parkhurst and Appelo, 2013). The modeling was done with the Pitzer aqueous ion-interaction model using the PHREEQ reaction database. The actual composition of groundwater 
organic matter was not determined, so in our model we chose a simple organic substrate $\left(\mathrm{CH}_{2} \mathrm{O}\left(\mathrm{NH}_{3}\right)\right)$ to react at a fixed pressure of $1.1 \mathrm{~atm}$. Organic matter was first reacted in the groundwater and then the modeled solution was allowed to equilibrate with various minerals. In addition to calcite, dolomite $\left(\mathrm{MgCa}\left(\mathrm{CO}_{3}\right)_{2}\right)$ and gypsum/anhydrite $\left(\mathrm{CaSO}_{4} / \mathrm{CaSO}_{4}\left(\mathrm{H}_{2} \mathrm{O}\right)\right)$ are also present in the Yucatan aquifer. Typical contributions of dolomite to the aquifer matrix are 5\%; however, in regions of the aquifer where dolomitization has occurred, such as near the impact crater, it may be as much as $50 \%$ (Escobar-Sanchez and Urrutia-Fucugauchi, 2010; Schmitt et al., 2004; Tuchscherer et al., 2005). Since all of our groundwater samples are from the top $50 \mathrm{~m}$ of the aquifer, an upper limit dolomite to calcite ratio of $5 \%$ is used in the modeling here.

The resulting total dissolved calcium, alkalinity and DIC of the modeled groundwater were compared to a subset of samples (collected in 2009) for which carbonate chemistry (i.e. alkalinity, dissolved inorganic carbon) was determined. This modeling exercise is primarily meant to demonstrate the potential coupling between organic matter respiration and mineral dissolution that is necessary to explain the elevated dissolved $\mathrm{Ca}$ (and by proxy $\mathrm{CaCO}_{3}$ related trace elements) in terrestrial groundwaters and is not exhaustive due to the paucity of carbonate chemistry available for this data set.

We reacted 0.1 to $16 \mathrm{mmol} \mathrm{kg}^{-1}$ organic matter and then allowed the resulting solution to reach equilibrium with calcite $\left(1 \mathrm{~mol} \mathrm{~L}^{-1}\right)$, a mixture of calcite and dolomite (5\%), and a mixture of calcite, dolomite (4.75\%) and gypsum (0.25\%) (Fig. 4). The dissolution of gypsum with at least $8 \mathrm{mmol} \mathrm{kg}^{-1}$ of organic matter respiration is needed to 
explain the highest dissolved Ca values ( $>3 \mathrm{mmol} \mathrm{kg}^{-1}$ (Fig. 5). We observed excess alkalinity in our samples above model predicted values, while DIC values largely agreed with modeled values (Supplemental Fig. 1). This is potentially due to organic matter contributions to total alkalinity that may be difficult to quantify without further sampling and analyses (Kim et al., 2006; Kim \& Lee, 2009).

The dissolved $\mathrm{Ca}$ load of terrestrial groundwater is a function of the amount of organic matter respiration that has occurred during transit of the groundwater through the aquifer and the aquifer mineral matrix, resulting in a range of potential $\mathrm{pH}$, alkalinity, DIC and $\mathrm{Ca}$ concentrations for the terrestrial end member. With the available data it is not possible to determine the exact combination of organic matter respiration and calcite, dolomite and gypsum dissolution that has occurred within each terrestrial groundwater sample, rather we use the model results and data to place bounds on the potential for enhanced dissolution and to explain the relatively high groundwater trace element concentrations we report here.

If chemical equilibrium with aquifer minerals, as discussed above, controls the terrestrial groundwater elemental concentrations (i.e. outside of the salinity mixing zone), the relative proportion of the element/calcium ratio $(\mathrm{E} / \mathrm{Ca})$ in the aquifer matrix $\left(\mathrm{E} / \mathrm{Ca}_{\text {solid }}\right)$ to groundwater $\left(\mathrm{E} / \mathrm{Ca}_{\text {groundwater }}\right)$ can be predicted from the partition coefficient $\left(\mathrm{K}_{\mathrm{d}}\right)$ :

1) $\mathrm{K}_{\mathrm{d}}=\frac{\mathrm{E} / \mathrm{Ca}_{\text {solid }}}{\mathrm{E} / \mathrm{Ca}_{\text {groundwater }}}$ 
Calcite partition coefficients are readily available to calculate the equilibrium groundwater $\mathrm{E} / \mathrm{Ca}$ for $\mathrm{Ba}, \mathrm{Sr}, \mathrm{U}, \mathrm{Mn}$ and $\mathrm{Ra}$ (Table 2). The partition coefficient varies with temperature and environmental conditions (Kitano and Oomori, 1971; Lorens, 1981; Rihs et al., 2000). The values used here are based on empirical studies of modern calcite, but may vary for the specific conditions present in the Yucatan aquifer. The partition coefficients used here are sufficient to evaluate whether the trace element content of terrestrial groundwater results from equilibrium dissolution of aquifer rocks. In addition, the extent to which $\mathrm{E} / \mathrm{Ca}_{\text {groundwater }}$ due to dissolution can be constrained also depends on potential variability in $\mathrm{E} / \mathrm{Ca}_{\text {solid. }}$. The available data for the Yucatan (Table 1) suggests the range of $\mathrm{E} / \mathrm{Ca}$ in the unaltered aquifer matrix is small. Dolomite is a minor mineral in the portion of the aquifer studied here, but may have a different trace element content than calcite (Dawson and Hinton, 2003).

The $\mathrm{Sr} / \mathrm{Ca}$ ratio of the terrestrial end member $\left(2.4 \pm 2.6 \mathrm{mmol} \mathrm{mol}^{-1}\right)$ is near that predicted by equilibrium with calcite $\left(3.3 \mathrm{mmol} \mathrm{mol}^{-1}\right.$, Fig. 6 and Table 2). Some well samples have much larger $\mathrm{Sr} / \mathrm{Ca}$ ratios, coincident with the high $\mathrm{Ba} / \mathrm{Ca}$ ratios, potentially due to groundwater interactions with aragonite and/or celestite, which have a higher $\mathrm{Sr}$ content than calcite. Predicted equilibrium dissolved $\mathrm{Ba} / \mathrm{Ca}$ is slightly greater than the value observed in the terrestrial groundwater samples (Fig. 6, Table 2). Some well samples (from the east coast) have much higher Ba and ${ }^{228} \mathrm{Ra}$ than expected, potentially due to interaction with aragonite, which has a higher Ba content than calcite. Terrestrial groundwater $\mathrm{U} / \mathrm{Ca}$ ratios $\left(2.1 \pm 1.4 \mu \mathrm{mol} \mathrm{mol}{ }^{-1}\right.$, Fig. 6$)$ are within error of the predicted value due to chemical equilibrium with calcite $\left(1.6 \mu \mathrm{mol} \mathrm{mol}^{-1}\right.$, Table 2$)$. Terrestrial 
groundwater $\mathrm{Mn} / \mathrm{Ca}$ ratios $\left(16 \pm 70 \mu \mathrm{mol} \mathrm{mol}{ }^{-1}\right.$, Fig. 6$)$ also agree with those predicted by equilibrium with calcite (26 $\mu \mathrm{mol} \mathrm{mol}^{-1}$, Table 2). Terrestrial groundwater ${ }^{226} \mathrm{Ra} / \mathrm{Ca}$, ${ }^{228} \mathrm{Ra} / \mathrm{Ca}$ and ${ }^{223} \mathrm{Ra} / \mathrm{Ca}$ fall within the predicted ranges (Fig. 7). Terrestrial groundwater trace element and radium concentrations thus appear to largely be explained by dissolution of calcite, the main aquifer mineral, although $\mathrm{U}$ is elevated potentially due to complexation with carbonate (see section 4.3.3 below).

\subsection{Geochemical controls on karst subterranean estuary mixing zone and marine groundwater}

The processes that may modify groundwater geochemistry within the mixing zone include: 1) chemical equilibrium between groundwater and the aquifer matrix as discussed in section 4.2,2) conservative mixing between terrestrial and ocean end members, 3) desorption/sorption exchanges with mineral surfaces and 4) in situ production and decay for radium isotopes. Mixing between seawater and terrestrial groundwater is predicted to enhance dissolution (Hanshaw and Back, 1980; Stoessell et al., 1989). To determine if mixing-induced dissolution was important for the subterranean estuary under study here, we modeled mixing between terrestrial groundwater and the ocean. The calcite saturation index (SI) is calculated according to:

(2) $\mathrm{SI}=\log \left(\frac{\mathrm{aCa}^{2+} \mathrm{aHCO}_{3}^{-}}{\mathrm{aH}^{+} \mathrm{K}_{\text {calcite }}}\right)$

Where $\mathrm{aCa}^{2+}$ refers to the dissolved $\mathrm{Ca}$ activity, $\mathrm{aHCO}_{3}{ }^{-}$is the carbonate activity and $\mathrm{aH}^{+}$ is $\mathrm{pH} . \mathrm{K}$ is the equilibrium constant for the formation of calcite $\left(\mathrm{CaCO}_{3}\right)$ calculated using the temperature-salinity dependence as founding PHREEQ. Even with the limited set of 
samples from 2009 where carbonate chemistry was determined, we observed a range of possible terrestrial end members. The two groundwater end members with a $\mathrm{pH}$ of 7.44 and 8.44 , alkalinity of 6890 and $7410 \mu \mathrm{mol} \mathrm{kg}^{-1}$ and $2.8 \mathrm{mmol} \mathrm{kg}^{-1} \mathrm{Ca}$ did not result in corrosive mixing with seawater, however, a groundwater end member with a $\mathrm{pH}$ of 6.95 , alkalinity of $6321 \mu \mathrm{mol} \mathrm{kg}{ }^{-1}$ and $3.4 \mathrm{mmol} \mathrm{kg}^{-1} \mathrm{Ca}$ was corrosive upon mixing (Fig. 8).

Such a groundwater end member results only after respiration of $16 \mathrm{mmol} \mathrm{kg}^{-1}$ of organic matter and equilibration with calcite.

In addition, as is discussed in the element specific sections below, nonconservative addition of $\mathrm{Sr}, \mathrm{Mn}, \mathrm{Ba}$ and $\mathrm{U}$, as might be expected upon mixing induced dissolution, are not observed in the spring samples ranging in salinity from 2-35. We thus conclude that dissolution may occur during some groundwater mixing, but this phenomenon is not ubiquitous across the Yucatan Peninsula.

\subsubsection{Strontium and calcium}

Strontium and calcium concentrations within the subterranean estuary are primarily controlled by two processes: 1) chemical equilibrium between groundwater and the aquifer matrix and 2) conservative mixing between end members. Strontium is largely conservative with respect to salinity in subterranean estuaries (Beck et al., 2013) and enrichment in the terrestrial end member is known to occur in groundwater in karst aquifers (Perry et al., 2002, 2009). Two conservative mixing trends are apparent in the Sr data (dashed lines in Fig. 2c and Table S3). Springs fall along a mixing line between the terrestrial end member in equilibrium with calcite and seawater, while the high salinity reducing cenote end member is enriched in Sr. Calcium follows similar mixing 
relationships, with spring Ca concentrations falling between the terrestrial end member and seawater, while reducing cenote samples are generally enriched with $\mathrm{Ca}$, coincident with elevated dissolved $\mathrm{Ba}, \mathrm{Sr}$ and $\mathrm{Ra}$ due to enhanced dissolution in this zone.

\subsubsection{Barium and radium}

Barium and radium concentrations within the subterranean estuary can be modified through: 1) solid-solution equilibrium, encompassing both mineral precipitation and dissolution; 2) conservative mixing between different end members; 3 ) desorption/sorption exchanges with mineral surfaces and 4) in situ production for radium isotopes. Ba serves as a chemical analogue for Ra since they are both group II alkaline earth metals and have comparable ionic radii (within 7\%, Table 3). Similar distributions of barium and long-lived radium isotopes have been observed in subterranean estuaries where conservative mixing dominates (Kiro et al., 2012), where ionic strength dependent desorption occurs (Gonneea et al., 2013) and in carbonate groundwater systems where precipitation/adsorption reactions dominate (Rihs et al., 2000).

Long-lived $\mathrm{Ra}$ isotopes are expected to be in secular equilibrium with parent nuclides in marine carbonate deposits of this age (surface outcrops are largely Pliocene, with older rocks deeper in the aquifer (Perry et al., 2009)). The parent nuclide activity is a function of seawater ${ }^{232} \mathrm{Th}$ and ${ }^{238} \mathrm{U}$ at the time of deposition, the calcite partition coefficient for the parent nuclide (equation 1) and any subsequent weathering or alteration that may impact $\mathrm{U}$ or $\mathrm{Th}$ content. Considering the limited number and large range of $\mathrm{Ra} / \mathrm{Ca}$ in rock samples measured here, the potential range in aquifer rock $\mathrm{Ra} / \mathrm{Ca}$ 
may be even greater. However, the ${ }^{228} \mathrm{Ra}:{ }^{226} \mathrm{Ra}$ groundwater activity ratio largely falls within the bounds of the measured rock ratios (Fig. 7).

Spring Ba concentrations fall on a conservative mixing line with a zero salinity intercept of $200 \mathrm{nmol} \mathrm{kg}^{-1}$ (dashed line in Fig. 2a), greater than the observed terrestrial end member $\left(122 \pm 75 \mathrm{nmol} \mathrm{kg}^{-1}\right)$. Ba concentrations peaks at salinity $\sim 2$, the lowest salinity spring sample. Conversely, there is no evidence of conservative mixing in spring ${ }^{226} \mathrm{Ra},{ }^{228} \mathrm{Ra}$ or ${ }^{223} \mathrm{Ra}$ activities, nor is there a clear trend of salinity dependent desorption influencing all spring samples.

Decoupling between long-lived $\mathrm{Ra}$ isotopes and $\mathrm{Ba}$ is unusual within the subterranean estuary (Fig. 10). One potential explanation is that adsorption of alkaline earth elements increases with ionic radius, thus $\mathrm{Ra}$, with a slightly larger ionic radius than $\mathrm{Ba}$, would be less mobile than $\mathrm{Ba}$ (Stumm and Morgan, 1996). Sorption of divalent cations onto calcite has been shown to inhibit movement of dissolved species within aquifers. Under the $\mathrm{pH}$ and carbonate ion concentrations present in the Yucatan STE (Stoessell et al., 1989), empirical adsorption coefficients for Ra and Ba predict little change in adsorption across the mixing zone (Zhu, 2002). In addition, there is much greater variability in terrestrial end member ${ }^{226} \mathrm{Ra}$ and ${ }^{228} \mathrm{Ra}$ activities than in $\mathrm{Ba}$ concentrations due a greater range in aquifer rock Ra.

Deep cenotes were reducing and anoxic as evidenced by the presence of $\mathrm{H}_{2} \mathrm{~S}$ in these samples (indicated by strong $\mathrm{H}_{2} \mathrm{~S}$ smell upon sampling). Perry et al. (2002) suggests that these conditions are due to reduction of terrestrial organic matter that has accumulated in the bottom of cenotes. This organic matter is reduced first using oxygen, 
then $\mathrm{NO}_{3}{ }^{-}, \mathrm{MnO}_{2}$ and finally $\mathrm{SO}_{4}{ }^{2-}$ (Stumm and Morgan, 1996). Ba concentrations in reducing cenotes in excess of that predicted by barite $\left(\mathrm{BaSO}_{4}\right)$ solubility (Fig. 2a) are presumably due to the absence of $\mathrm{SO}_{4}{ }^{2-} \cdot{ }^{226} \mathrm{Ra}$ and ${ }^{228} \mathrm{Ra}$ activities are quite high in

reducing cenote waters, with a large range in ${ }^{226} \mathrm{Ra} / \mathrm{Ca}$ and ${ }^{228} \mathrm{Ra} / \mathrm{Ca}$ ratios $(0.01-13$ and 0.003-0.703 dpm mmol ${ }^{-1}$ respectively) suggesting that in addition to enhanced aquifer matrix dissolution, Mn-oxide cycling in these reducing environments may maintain elevated Ra activities.

\subsubsection{Manganese and uranium}

In addition to the processes listed above including solid-solution equilibrium and conservative mixing, the groundwater redox environment controls $\mathrm{Mn}$ and $\mathrm{U}$ concentrations. Also, $\mathrm{U}$ readily complexes with carbonate, increasing the mobility of uranium in groundwater (Langmuir, 1978). Indeed, terrestrial groundwater U/Ca ratios $\left(2.1 \pm 1.4 \mu \mathrm{mol} \mathrm{mol}^{-1}\right.$, Fig. 6) are higher than predicted by chemical equilibrium with calcite $\left(1.6 \mu \mathrm{mol} \mathrm{mol}{ }^{-1}\right.$, Table 2$)$. At the high alkalinity $\left(>3 \mathrm{mmol} \mathrm{kg}^{-1}\right)$ and neutral $\mathrm{pH}$ values of terrestrial groundwater, dissolved $U$ is largely present as uranyl carbonate complexes, which impede sorption and thus maintain the high $U$ concentrations in terrestrial groundwater and across the spring mixing zone. Deep cenote samples were reducing and anoxic as evidenced by the presence of $\mathrm{H}_{2} \mathrm{~S}$ in these samples (indicated by strong $\mathrm{H}_{2} \mathrm{~S}$ smell upon sampling). Under these $\mathrm{pH}$ and Eh conditions, reduction of uranyl (VI) species to U(IV) results in precipitation of highly insoluble uranium minerals or sorption onto calcite, accounting for the observed removal of $U$ from groundwater (Fig. 2b) (Langmuir, 1978). 
Spring Mn samples fall along a conservative mixing line between terrestrial groundwater and ocean values $\left(10 \pm 4 \mathrm{nmol} \mathrm{kg}^{-1}\right)$ (dashed line in Fig. $2 \mathrm{~d}$ and Table S2). Mn is elevated (100-2600 nmol kg ${ }^{-1}$ ) in reducing cenote waters likely due to $\mathrm{Mn}(\mathrm{IV})$ reduction.

\subsection{Chemical fluxes associated submarine groundwater discharge}

Both the water flux and concentration of discharging water must be known to calculate chemical fluxes associated with SGD. We first calculate the radium-tracer based total SGD and compare these values with terrestrial groundwater fluxes derived from recharge-based estimates. We then assign end member concentrations to discharging water and calculate potential trace element fluxes from the Yucatan Peninsula to the coastal ocean. Finally, we explore the potential magnitude of fluxes from karst subterranean estuaries globally and place these estimates in the context of ocean element cycles.

\subsubsection{Ra-tracer based SGD estimates}

Despite the large variability in Ra activities, these isotopes remain the best tracers of SGD due to the high concentration gradient between groundwater and seawater. Radium based estimates of SGD were calculated along the west and north coasts of the Yucatan Peninsula in May 2007 and December 2009 (Table 3). In addition, data from offshore radium transects completed in October 2001 and July 2002 were used to extend the temporal and seasonal range of SGD estimates (Young et al., 2008). SGD fluxes are based on coastal ocean radium surveys (Fig. 11). These surveys extend from the coast 3.5 to $60 \mathrm{~km}$, however the near-shore ${ }^{226} \mathrm{Ra}$ gradient was very steep. In addition, production 
of ${ }^{223} \mathrm{Ra}$ from shelf sediments (max water depth of $10 \mathrm{~m}$ out to $60 \mathrm{~km}$ ) appears to be large relative to the SGD-derived ${ }^{223}$ Ra flux over the full transect distance (see discussion below). Thus, we used ${ }^{226} \mathrm{Ra}$ data within $2 \mathrm{~km}$ of shore (shaded area in Fig. 11) to calculate the inventory of the long-lived ${ }^{226} \mathrm{Ra}$ according to:

(3) ${ }^{226} \mathrm{Ra}_{\mathrm{SGD}}=\frac{\left[\left({ }^{226} \mathrm{Ra}_{\text {transect }}{ }^{226} \mathrm{Ra}_{\text {exchange }}\right) \times \mathrm{V}_{\text {transect }}\right]}{\mathrm{T}_{\mathrm{w}}}-{ }^{226} \mathrm{Ra}_{\text {sediment }}$

where ${ }^{226} \mathrm{Ra}$ transect is the average activity of the coastal ocean, ${ }^{226} \mathrm{Ra} \mathrm{a}_{\text {exchange }}$ is the activity of the water exchanging with this volume, (shelf waters $>2 \mathrm{~km}: 20 \mathrm{dpm} 100 \mathrm{~L}^{-1}$ ); $\mathrm{V}_{\text {transect }}$ is the volume of the coastal ocean box; $T_{w}$ is the average residence time of the water in the box; and ${ }^{226} \mathrm{Ra}_{\text {sediment }}$ is the sediment flux (Moore, 1996; Charette et al., 2001). Sediment production of ${ }^{226} \mathrm{Ra}$ was calculated assuming ${ }^{230} \mathrm{Th}$ activities in offshore sediments were in secular equilibrium with the sediment ${ }^{226} \mathrm{Ra}$ activity measured in onshore carbonate sands with a partition coefficient of 1 (Beck and Cochran, 2013). ${ }^{226} \mathrm{Ra}_{\text {sed }}$ fluxes were calculated according to:

(4) ${ }^{226} \mathrm{Ra}_{\text {sediment }}={ }^{226} \mathrm{Ra}_{\text {rock }} \times \rho \times$ depth $\times \mathrm{f}_{\text {desorb }} \times$ area $\times \lambda_{226}$

Where ${ }^{226} \mathrm{Ra}_{\text {rock }}$ is the activity of the rock (Table 1 ), $\rho$ is the density of carbonate sands $\left(2.7 \mathrm{~g} \mathrm{~cm}^{-3}\right)$, the sediment depth which is flushed with overlying water is $10 \mathrm{~cm}$, the area is shoreline normalized out to $2 \mathrm{~km}$ and $\lambda_{226}$ is the decay constant of ${ }^{226} \mathrm{Ra}$. Sediment regenerated fluxes are minimal at $30 \mathrm{dpm} \mathrm{m}^{-1} \mathrm{~d}^{-1}$ along a $2 \mathrm{~km}$ transect, compared to a ${ }^{226} \mathrm{Ra}_{\mathrm{SGD}}$ of $10^{5}$ to $10^{6} \mathrm{dpm} \mathrm{m}^{-1} \mathrm{~d}^{-1}$ of shoreline calculated according to equation (3). We used the short-lived ${ }^{223} \mathrm{R}$ a to calculate $\mathrm{T}_{\mathrm{w}}$, water residence time, according to: 
(5) $\mathrm{T}_{\mathrm{w}}=\frac{\ln \left(\frac{{ }^{223 / 226} \mathrm{Ra}_{\text {transect }}}{{ }^{223 / 226} \mathrm{Ra}_{\mathrm{SGD}}}\right)}{\lambda_{223}}$

Where ${ }^{223 / 226} \mathrm{Ra}_{\text {transect }}$ is the activity ratio of the coastal ocean, ${ }^{223 / 226} \mathrm{Ra} \mathrm{SGD}_{\mathrm{S}}$ is the activity ratio of discharging groundwater (spring average of 0.12 ) and $\lambda_{223 \mathrm{Ra}}$ is the decay constant for ${ }^{223} \mathrm{Ra}$ (Moore, 2000). This model assumes a discrete input at the coast, with mixing and decay controlling the ${ }^{223 / 226} \mathrm{Ra}_{\text {transect. }}$ An alternative method for calculating residence time is the continuous input model whereby a radium source with a known 223:226 activity ratio is added along the entire transect (Moore et al., 2006). Sediment generated ${ }^{223} \mathrm{Ra}$ inputs likely occur along the shallow Yucatan coast, however, it is unlikely that the 223:226 activity ratio via sediment production will be the same as groundwater discharge, since dissolution and desorption control long-lived concentrations in groundwater, while radioactive decay would be the primary source from coastal sediments. The sediment generated ${ }^{223}$ Ra flux (calculated according equation 4) is $10^{4} \mathrm{dpm} \mathrm{m}^{-1} \mathrm{~d}^{-1}, 16-40 \%$ of SGD-derived ${ }^{223} \mathrm{Ra}$ flux. This production of ${ }^{223} \mathrm{Ra}$ along the transect is apparent in 223:226 activity ratios that increase with distance from shore (Fig. 11b). Thus, the ages calculated for the Yucatan coast may be an underestimated.

${ }^{226} \mathrm{Ra}_{\mathrm{SGD}}$ can be converted from a radium flux to a water flux if the ${ }^{226} \mathrm{Ra}$ activity of groundwater $\left({ }^{226} \mathrm{Ra}_{\mathrm{GW}}\right)$ discharge is known:

(6) $\mathrm{SGD}=\frac{{ }^{226} \mathrm{Ra}_{\mathrm{SGD}}}{{ }^{226} \mathrm{Ra}_{\mathrm{GW}}}$

Here we use the average spring activity for ${ }^{226} \mathrm{Ra}_{\mathrm{GW}}\left(1180 \pm 490 \mathrm{dpm} 100 \mathrm{~L}^{-1}\right)$.

Uncertainty is introduced into these estimates primarily from uncertainty in the ${ }^{226} \mathrm{Ra}$ 
inventory $(10 \%)$, water ages $(30-60 \%)$ and in the groundwater end member (40\%). Error propagation results in $80-100 \%$ uncertainty in total SGD estimates.

Total SGD ranged from 40-95 $\mathrm{m}^{3} \mathrm{~m}^{-1} \mathrm{~d}^{-1}$. In May 2007 we had measurements along both coasts, and discharge was greater along the North coast $\left(95 \mathrm{~m}^{3} \mathrm{~m}^{-1} \mathrm{~d}^{-1}\right)$ than the West coast $\left(40 \mathrm{~m}^{3} \mathrm{~m}^{-1} \mathrm{~d}^{-1}\right.$, Table 3$)$. The salinity of the spring samples used to calculate the Ra end member ranged from 2 to 35 , with an average of $9 \pm 9$, suggesting approximately $75 \pm 25 \%$ of the discharge was terrestrial, with the remainder due to mixing with marine groundwater. This is in contrast to many other shelf-scale SGD studies where the majority of the SGD is marine in origin (e.g. Burnett et al., 2007; Moore, 1996; Prieto and Destouni, 2011).

The hydrology of the Yucatan Peninsula has been explored in depth through both field studies and modeling approaches (Hanshaw and Back, 1980; Beddows et al., 2007; Gondwe et al., 2010; Bauer-Gottwein et al., 2011). Such studies have assumed that terrestrial discharge was balanced by net groundwater recharge, which was reported to be $26 \mathrm{~m}^{3} \mathrm{~m}^{-1} \mathrm{~d}^{-1}$ averaged annually over the 1,650 km coastline (Hanshaw and Back, 1980; Gondwe et al., 2010). In all instances the Ra-tracer based discharge shown here is greater than the previously reported terrestrial discharge (Table 3). Patterns of temporal variability in either the marine or terrestrial component of discharge cannot be constrained by the limited number of SGD estimates presented here. Assuming $75 \%$ of total discharge is of terrestrial origin, as indicated by spring salinity, we estimate this flux for our study to be $45 \pm 20 \mathrm{~m}^{3} \mathrm{~m}^{-1} \mathrm{~d}^{-1}$. 


\subsubsection{Yucatan Peninsula trace element fluxes}

We extrapolated the spring element concentrations and terrestrial and total SGD estimates across the entire Yucatan coast $(1,650 \mathrm{~km})$ to calculate trace element fluxes to the ocean. Such an extrapolation is possible for several reasons. First, the conservative mixing behavior observed in actively discharging springs (over a relatively wide spatial scale) for $\mathrm{Sr}, \mathrm{Ba}$ and $\mathrm{Mn}$ and relatively invariant $\mathrm{U}$ concentrations simplifies estimates of SGD-derived fluxes since end member concentrations are well constrained. Spring $\mathrm{Sr}$ and Mn concentrations lie along a mixing line between terrestrial groundwater in equilibrium with the aquifer rocks and seawater. While spring Ba concentrations are conservative, enrichment at salinity $2\left(200 \mathrm{nmol} \mathrm{kg}^{-1}\right)$ is observed compared to terrestrial groundwater in chemical equilibrium with aquifer rocks, thus it is the flux of this low salinity spring water that will determine the SGD-associated Ba load. Spring Ra activities display a much larger range and were enriched compared to the terrestrial end member, resulting in a Ra end member that is less well constrained than the other elements. Thus, we conclude that there is minimal alteration of the chemical signature of SGD upon subterranean mixing, except in the case of barium and radium as noted above. Secondly, terrestrial SGD dominates the total SGD flux and is fairly well constrained. We use the water recharge estimate of $26 \mathrm{~m}^{3} \mathrm{~m}^{-1} \mathrm{~d}^{-1}$ as a minimum flux and the $45 \mathrm{~m}^{3} \mathrm{~m}^{-1} \mathrm{~d}^{-1}$ reported here as a maximum terrestrial flux. Uncertainty in the marine component of SGD will have minimal impact on the SGD-derived chemical fluxes, especially for Sr, U and Mn. Even for elements where mixed salinity discharge must be considered, the component of marine discharge at salinity 5 (for Ra) and salinity 2 (for Ba) is small. 
Submarine groundwater discharge associated Ba fluxes from the Yucatan are 3.2$5.4 \times 10^{6} \mathrm{~mol} \mathrm{y}^{-1}$ or 1.9-3.3 $\mathrm{mol} \mathrm{m}^{-1} \mathrm{y}^{-1}$ (Table 4). The Ba flux calculated for the Yucatan is only $2-12 \%$ of the shoreline normalized flux to the South Atlantic Bight (28-114 mol $\mathrm{m}^{-1} \mathrm{y}^{-1}$, Shaw et al., 1998), but is $\sim 4$ times greater than shoreline normalized fluxes reported for a site in the northeast Gulf of Mexico (Santos et al., 2011) and Waquoit Bay, MA (Gonneea et al., 2013). Radium-226 export on the Yucatan Peninsula is 1.9-3.1 $\mathrm{x}$ $10^{14} \mathrm{dpm} \mathrm{y}^{-1}$ (Table 4). This flux (at salinity 5) is within a factor of two of the shoreline normalized fluxes to the South Atlantic Bight (Moore, 1996) and the Mediterranean coast of Spain (Garcia-Solsona et al., 2010), both locations with karst aquifers. In contrast, shoreline normalized ${ }^{226}$ Ra flux from the sandy aluminosilicate dominated STE of Waquoit Bay is two orders of magnitude less (Gonneea et al., 2013). Sr fluxes calculated for the Yucatan are 3.5-5.6 x $10^{8} \mathrm{~mol} \mathrm{y}^{-1}$ (Table 4), 5-8\% of the total global terrestrial SGD Sr flux (Beck et al., 2013). Yucatan U SGD-associated fluxes are 1.6-2.8 x 105 mol $\mathrm{y}^{-1}$ (Table 4). U removal occurs within the deep groundwater reaction zone, however, the residence time with regards to coastal ocean exchange within this region is unknown, but appears to be long (Beddows et al., 2007). This removal would result in a lower net flux of $U$, which cannot be fully constrained in the present study. The Yucatan $U$ flux is $\sim 2 \%$ of the global SGD-derived U input of $9.3 \pm 8.7 \times 10^{6} \mathrm{~mol} \mathrm{y}^{-1}$ proposed by Dunk et al. (2002). Mn fluxes associated with SGD are 1.6-2.9 x $10^{6} \mathrm{~mol} \mathrm{y}^{-1}$, much less than those reported from a site in Brazil (Sanders et al., 2012), due to the low Mn content of carbonate rock. We did attempt to measure iron in these samples, however our detection limit was $200 \mathrm{nmol} \mathrm{kg}^{-1}$ and all but a few of the reducing cenote samples were below this. 
Thus, it is unlikely that karst subterranean estuaries represent a significant iron flux globally.

\subsubsection{Global karst subterranean estuary element fluxes}

Many oceanic elemental budgets consider the following sources: chemical loading associated with riverine discharge (including both the dissolved load and desorption from particles), diffusion from ocean sediments, hydrothermal alteration, and aeolian inputs. For many elements, submarine groundwater discharge-associated fluxes have not been considered, due to a lack of data on the potential magnitude of this source.

To evaluate potential global element fluxes associated with submarine groundwater discharge from karst subterranean estuaries, we extrapolate the fluxes for the Yucatan to the $12 \%$ of global subterranean estuaries that are karst (Beck et al., 2013). This scaling exercise assumes that: 1) trace element concentrations reported for the Yucatan are representative of those in other karst STEs, 2) there is minimal alteration of the chemical signature of SGD upon subterranean mixing, except as discussed above for $\mathrm{Ba}$ and $\mathrm{Ra}$, and 3) discharge of terrestrial (or low salinity) SGD dominates the chemical transport and is of a similar magnitude in other karst settings.

Terrestrial groundwater within carbonate aquifers appears to largely derive its chemical signature due to solid-solution equilibrium. Since Yucatan aquifer bedrock trace element content is at the lower range of global limestone values (Bowen, 1979), this may also apply to groundwater trace element concentrations. The terrestrial groundwater flux (26-45 $\left.\mathrm{m}^{3} \mathrm{~m}^{-1} \mathrm{~d}^{-1}\right)$ is well within the expected range; averaged globally, terrestrial groundwater discharge is $18 \mathrm{~m}^{3} \mathrm{~m}^{-1} \mathrm{~d}^{-1}$ (Zekster et al., 2006). While the discharge of 
terrestrial groundwater is ultimately linked to inland recharge rates, it is likely that discharge along karstic coastlines is greater than the global average due to the high permeability of these aquifers and typically high precipitation rates. A wide range of terrestrial groundwater discharge rates in karst regions have been reported, from $2 \mathrm{~m}^{3} \mathrm{~m}^{-1}$ $\mathrm{d}^{-1}$ at one site in Ireland (Einsied1, 2012) to $120 \mathrm{~m}^{3} \mathrm{~m}^{-1} \mathrm{~d}^{-1}$ along the Spanish coast (Garcia-Solsona et al., 2010). Taken together, these global fluxes represent a reasonable estimate of chemical export from karstic subterranean estuaries. We have not attempted to propagate errors on these estimates, due to limited data on global karst STE end member concentrations and water fluxes.

The major input of uranium to the ocean is via riverine discharge $\left(23-59 \times 10^{6}\right.$ mol y ${ }^{-1}$ (Barnes and Cochran, 1990; Dunk et al., 2002; Gaillardet et al., 2003)). We found that the Yucatan $U$ end member was 6.4 times greater than the global riverine end member (Table 4, Gaillardet et al., 2003) making carbonate karst subterranean estuaries potentially an important global source of $\mathrm{U}\left(3.4-6.0 \times 10^{6} \mathrm{~mol} \mathrm{y}^{-1}, 6-26 \%\right.$ of river flux). Dunk et al. (2002) calculated global SGD-derived U inputs of $9.3 \pm 8.7 \times 10^{6} \mathrm{~mol} \mathrm{y}^{-1}$. The global flux we report here is $37-65 \%$ of this value, but is derived only from the $12 \%$ of the global coastline that is karstic.

Riverine input is also the main source of barium to the global ocean $\left(6.3 \times 10^{9}\right.$ mol $\mathrm{y}^{-1}$, Gaillardet et al., 2003). The flux of Ba from karst subterranean estuaries is comparatively small (6.9-12 x $10^{7} \mathrm{~mol} \mathrm{y}^{-1}, \sim 1 \%$ of river flux $)$, since $\mathrm{Ba}$ is not highly enriched in groundwater in these systems compared to the riverine end member $(120 \%$ of river end member, Table 4). 
There are many components to the oceanic Mn cycle (Shiller, 1997; Statham et al., 1998). Rivers (6\%), hydrothermal venting (17\%), aeolian deposition (3\%) and particle weathering (74\%) fluxes are the main sources of Mn to the ocean $\left(80 \times 10^{9} \mathrm{~mol} \mathrm{y}^{-1}\right)$ (Bender et al., 1977; Martin and Knauer, 1980). The groundwater flux we calculate from karst subterranean estuaries is only $\sim 0.2 \%$ of the river flux $\left(3.5-6.2 \times 10^{7} \mathrm{~mol} \mathrm{y}^{-1}\right)$ and thus is a very minor source to the ocean.

Strontium inputs to the ocean include rivers $\left(47 \mathrm{x} 10^{9} \mathrm{~mol} \mathrm{y}^{-1}\right.$, PeuckerEhrenbrink et al., 2010), hydrothermal processes $\left(4.3 \times 10^{9} \mathrm{~mol} \mathrm{y}^{-1}\right)$ and sediment diagenesis (3.4 x $10^{9} \mathrm{~mol} \mathrm{y}^{-1}$, Palmer and Edmond, 1989). The average Sr concentration in Yucatan terrestrial groundwater samples $\left(20.1 \mu \mathrm{mol} \mathrm{kg}{ }^{-1}\right)$ was 17 times greater than the global riverine end member $\left(1.21 \mu \mathrm{mol} \mathrm{kg}^{-1}\right.$, Peucker-Ehrenbrink et al., 2010) resulting in a Sr flux from karstic subterranean estuaries of $6.8-12 \times 10^{9} \mathrm{~mol} \mathrm{y}^{-1}, \sim 25 \%$ of total riverderived Sr flux. This value is within the global meteoric SGD derived Sr flux to the ocean reported by Beck et al. (2013) $\left(7-28 \times 10^{9} \mathrm{~mol} \mathrm{y}^{-1}\right)$. In addition, the global karst SGD Sr flux is about an order of magnitude larger than the SGD derived Sr flux from groundwater discharge in the Ganges-Brahmaputra River system $\left(9 \times 10^{8} \mathrm{~mol}^{-1}\right)$ reported by Basu et al. (2001).

The dominance of groundwater as a source of radium to the ocean has long been recognized (e.g. Moore, 1996; Moore et al., 2008). Here we focus on export of the longest-lived isotope, ${ }^{226} \mathrm{Ra}$, since it makes up the majority of the ocean radium inventory. Sparse measurements of riverine dissolved ${ }^{226} \mathrm{Ra}$ activities suggest a median end member of $10 \mathrm{dpm} 100 \mathrm{~L}^{-1}$ (Chabaux et al., 2003), although Gaillardet et al. (2003) reports a 
lower value of $5 \mathrm{dpm} 100 \mathrm{~L}^{-1}$, resulting in a dissolved river flux of $1.9-3.6 \times 10^{15} \mathrm{dpm} \mathrm{y}^{-}$

${ }^{1}$ (Table 4). The karst groundwater end member was averaged across all spring samples $\left(1000 \mathrm{dpm} 100 \mathrm{~L}^{-1}\right)$. The global ${ }^{226} \mathrm{Ra}$ flux from karst STEs is $4.0-6.6 \times 10^{15} \mathrm{dpm} \mathrm{y}^{-1}, 1$ 3 times the riverine flux.

\subsection{Conclusions}

Groundwater trace element chemistry within the karst Yucatan aquifer is influenced by a variety of processes. Terrestrial groundwater with elevated $\mathrm{pCO}_{2}$ due to organic matter degradation results in enhanced dissolution of aquifer minerals and elevated dissolved trace element concentrations. This finding has important implications for both the trace metal signature of groundwater within karst aquifers and the SGDassociated chemical flux from these subterranean estuaries. In regions when organic matter inputs are increasing due to anthropogenic activities, such as high population density and heavy dependence on septic system for sewage management, as found on the Yucatan Peninsula, aquifers may experience enhanced organic matter remineralization and associated chemical weathering rates. In such regions, the trace metal load of submarine groundwater discharge that is derived from aquifer dissolution may not be at steady state.

In addition to dissolution, desorption at low salinity within the mixing zone elevates $\mathrm{Ba},{ }^{226} \mathrm{Ra}$ and ${ }^{228} \mathrm{Ra}$, while carbonate complexation maintains high $\mathrm{U}$ concentrations. $\mathrm{Ba}, \mathrm{Sr}, \mathrm{Ca}$, and $\mathrm{Mn}$ all display conservative mixing in the shallow subterranean estuary typified by coastal springs. Thus there is no evidence of mixing induced dissolution in this portion of the Yucatan STE. Within the deep reducing 
groundwater, redox processes result in $\mathrm{U}$ removal and high $\mathrm{Mn}$ concentrations, while $\mathrm{Ba}$, $\mathrm{Ca}, \mathrm{Sr},{ }^{226} \mathrm{Ra}$ and ${ }^{228} \mathrm{Ra}$ are elevated due to enhanced dissolution. Submarine groundwater discharge associated transport of $\mathrm{U}, \mathrm{Mn}$ and $\mathrm{Sr}$ may be calculated with a relatively straightforward approach since there is no chemical alteration upon mixing within the Yucatan karst STE. Even for Ba, which exhibits a peak at low salinities (2), the terrestrial component of discharge dominates the chemical flux.

Since we do not observe a large enrichment in $\mathrm{Ba}, \mathrm{Ca}, \mathrm{Sr}$ and $\mathrm{Ra}$ or depletion of $\mathrm{U}$ in spring samples, we conclude that the deep reducing marine groundwater is not actively discharging. Rather, we suggest that the deep anoxic cenote is a groundwater reaction zone that does not take part in shallow subterranean estuary mixing. Additionally, there is no evidence of elevated $\mathrm{Sr}$ or depleted $\mathrm{U}$ in near shore samples (Charette et al., 2008). Thus, chemical cycling within the regional terrestrial-marine groundwater mixing zone (such as U removal) is not expected to affect large scale SGD associated chemical transport to the coastal ocean. However, it is possible that the deep aquifer dominated by reducing marine groundwater exchanges with the coastal ocean outside the bounds of our study domain (60 km from shore).

Submarine groundwater discharge estimates for the Yucatan Peninsula range from 50 to $95 \mathrm{~m}^{3} \mathrm{~m}^{-1} \mathrm{~d}^{-1}$, and contained as much as $75 \pm 25 \%$ terrestrial groundwater, in contrast to many other shelf-scale studies where the recirculated marine component dominates. First order estimates of global fluxes of $\mathrm{Sr}, \mathrm{U}$ and $\mathrm{Ra}$ from karst subterranean estuaries, which only make up $12 \%$ of all coastal aquifers, indicate that submarine groundwater discharge fluxes are significant contributors to the global ocean budgets of 
Sr, U, and Ra. Recently Beck et al. (2013), presented evidence that SGD is an important source of $\mathrm{Sr}$ to the ocean and that isotopic exchange within the subterranean estuary results in groundwater discharge of a more radiogenic end member. Uranium cycling within the subterranean estuary and subsequent discharge via SGD has been posited as both a potential source (Dunk et al., 2002) and sink (Charette and Sholkovitz, 2006; Moore and Shaw, 2008; Santos et al., 2011). There is a need to expand the study of chemical cycling within subterranean estuaries to include a greater diversity of aquifer lithologies and morphologies, as well as mixing regimes, to more fully constrain the potential role SGD plays in global ocean element budgets. For example, relatively little is known about either discharge or chemical cycling within fractured bedrock (Oberdorfer et al., 2008) or volcanic island systems (Peterson et al., 2009; Knee et al., 2010; Povinec et al., 2012), although a substantial amount of groundwater discharge and/or enriched fluid concentrations may result in enhanced chemical fluxes from these types of subterranean estuaries.

\section{Footnotes:}

${ }^{1}$ The delayed coincidence counter employs a timed gate to differentiate between decay events associated with ${ }^{224} \mathrm{Ra}\left({ }^{224} \mathrm{Ra}\left(\mathrm{t}_{1 / 2}=3.6 \mathrm{~d}\right)-{ }^{220} \mathrm{Rn}\left(\mathrm{t}_{1 / 2}=55 \mathrm{~s}\right)-{ }^{216} \mathrm{Po}\left(\mathrm{t}_{1 / 2}=150 \mathrm{~ms}\right)\right)$ and ${ }^{223} \operatorname{Ra}\left({ }^{223} \operatorname{Ra}\left(\mathrm{t}_{1 / 2}=11.4 \mathrm{~d}\right)-{ }^{219} \mathrm{Rn}\left(\mathrm{t}_{1 / 2}=4.0 \mathrm{~s}\right)-{ }^{215} \mathrm{Po}\left(\mathrm{t}_{1 / 2}=1.78 \mathrm{~ms}\right)\right)$, and records decay events associated with each isotope in two different channels on the detector (Moore and Arnold, 1996). However, some counts recorded in each channel are not associated with the targeted $\mathrm{Ra}$ isotope. These are known as chance coincidence events, and can be subtracted based on probability statistics (Giffin et al., 1963). Since the 
chance coincidence rate increases as the square of the total count rate of the system, ${ }^{224} \mathrm{Ra}$ and ${ }^{223} \mathrm{Ra}$ uncertainties increase at high total count rates and at very high total count rates, the chance coincidence corrections break down, particularly for ${ }^{224} \mathrm{Ra}$ (Moore and Arnold, 1996). This is observed in the detector counting logs as an increase in the chance coincidence corrected values over time. Thus, we evaluated the counting logs from every sample to ensure that there were no anomalous increases in either corrected ${ }^{219} \mathrm{Rn}$ (for measurement of ${ }^{223} \mathrm{Ra}$ ) or ${ }^{220} \mathrm{Rn}$ (for measurement of ${ }^{224} \mathrm{Ra}$ ). If the difference in the corrected cpm between the beginning and end of the counting period differed by more than $20 \%$, that data was considered unreliable. We observed that many of the ${ }^{224} \mathrm{Ra}$ values in cenote and spring samples could not be measured with the RaDeCC system, likely due to high ${ }^{223} \mathrm{Ra}$ and ${ }^{226} \mathrm{Ra}$ activities in these samples. ${ }^{224} \mathrm{Ra}$ values are not reported since they were either below detection or unreliable due to the breakdown in chance coincidence calculations. 


\section{Figures:}

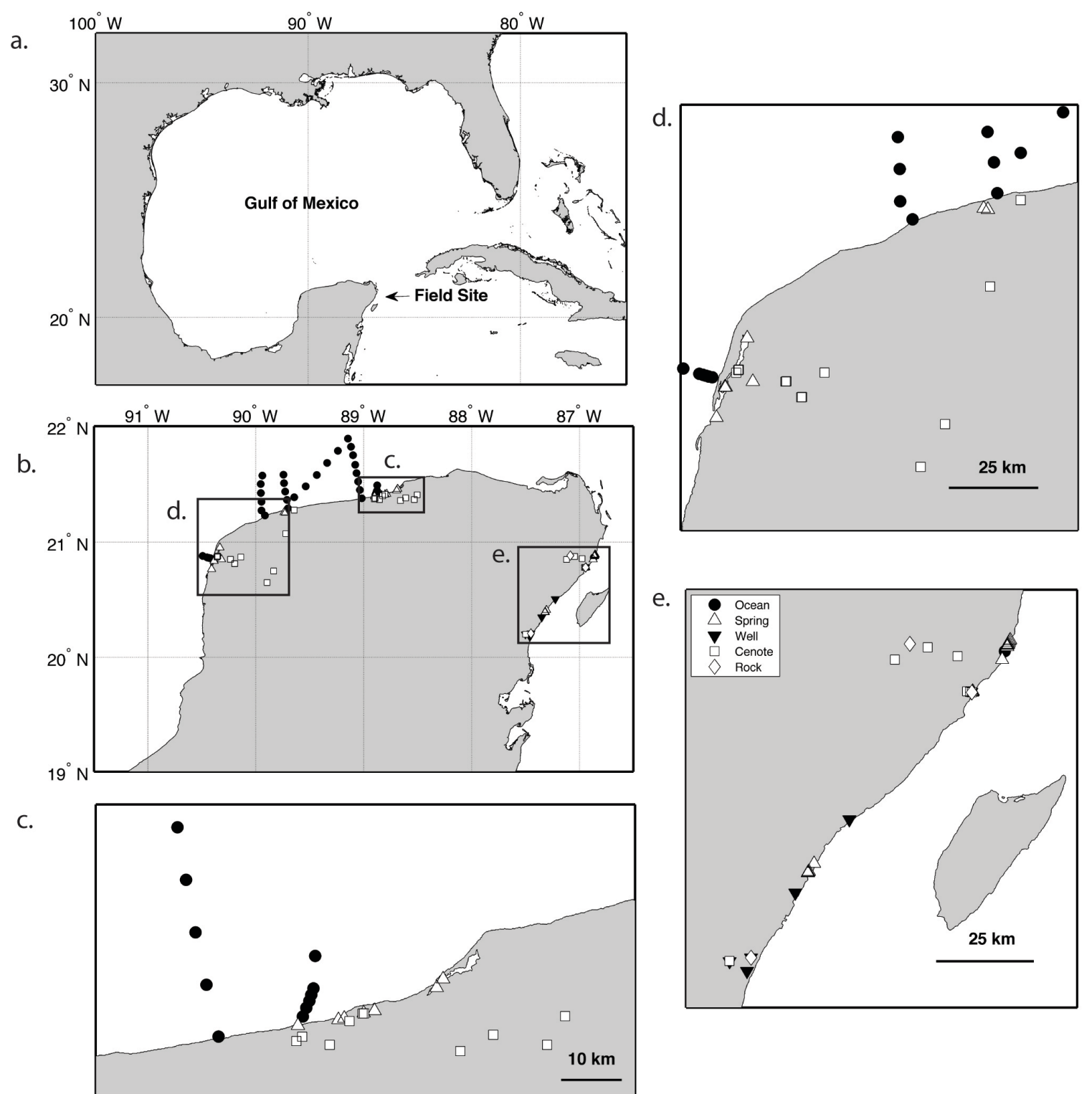

Figure 1: Yucatan Peninsula field site. Samples were collected in 2007, 2009 and 2011, although not every site was sampled each year. 

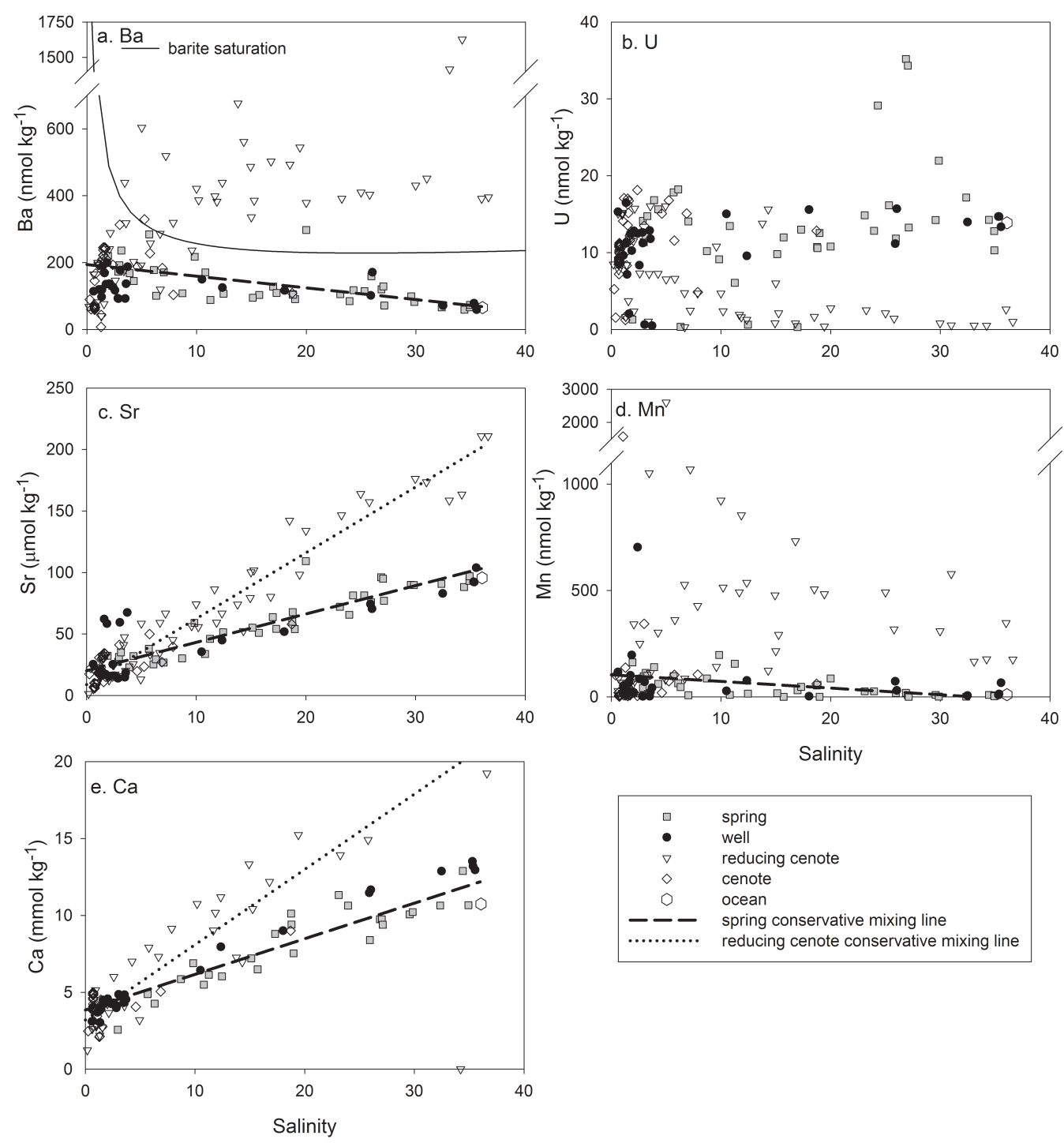

Figure 2: Element plotted against salinity for a) barium, b) uranium, c) strontium, d) manganese, and e) calcium. The barite solubility line is shown in (a). Statistically significant $(\mathrm{p}<0.0001)$ conservative mixing lines for spring samples (dashed lines) and reducing cenote samples (dotted lines) are shown (Table S3). Spring samples were taken from actively discharging groundwater in the coastal ocean, well samples were pumped from shallow drilled wells near the coast, and cenote samples were collected from natural dissolution features. Note scale break in a and $\mathrm{d}$. 

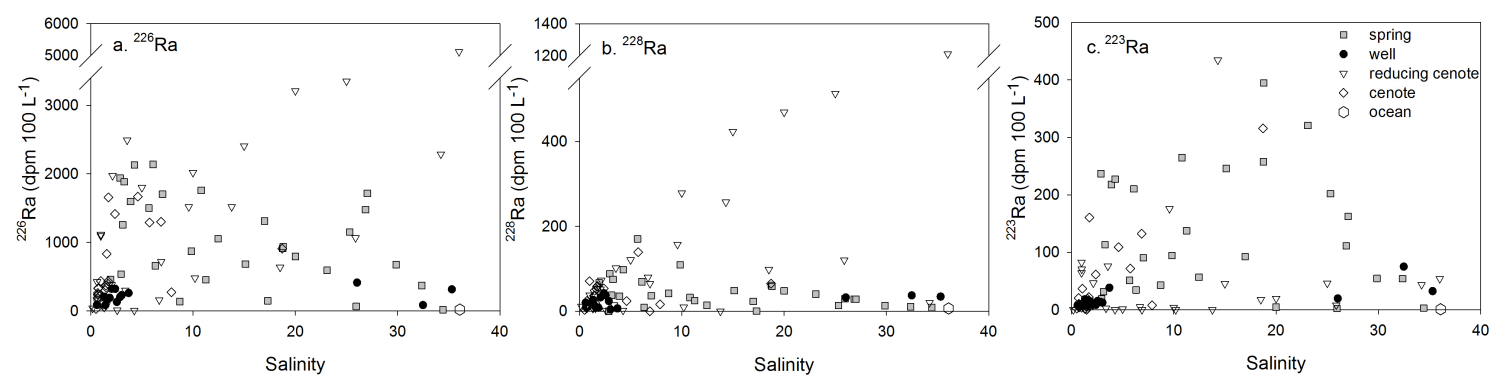

Figure 3: a) $\left.{ }^{226} \mathrm{Ra}, \mathrm{b}\right){ }^{228} \mathrm{Ra}$ and c) ${ }^{223} \mathrm{Ra}$ plotted against salinity. Note scale breaks in a and $b$. 


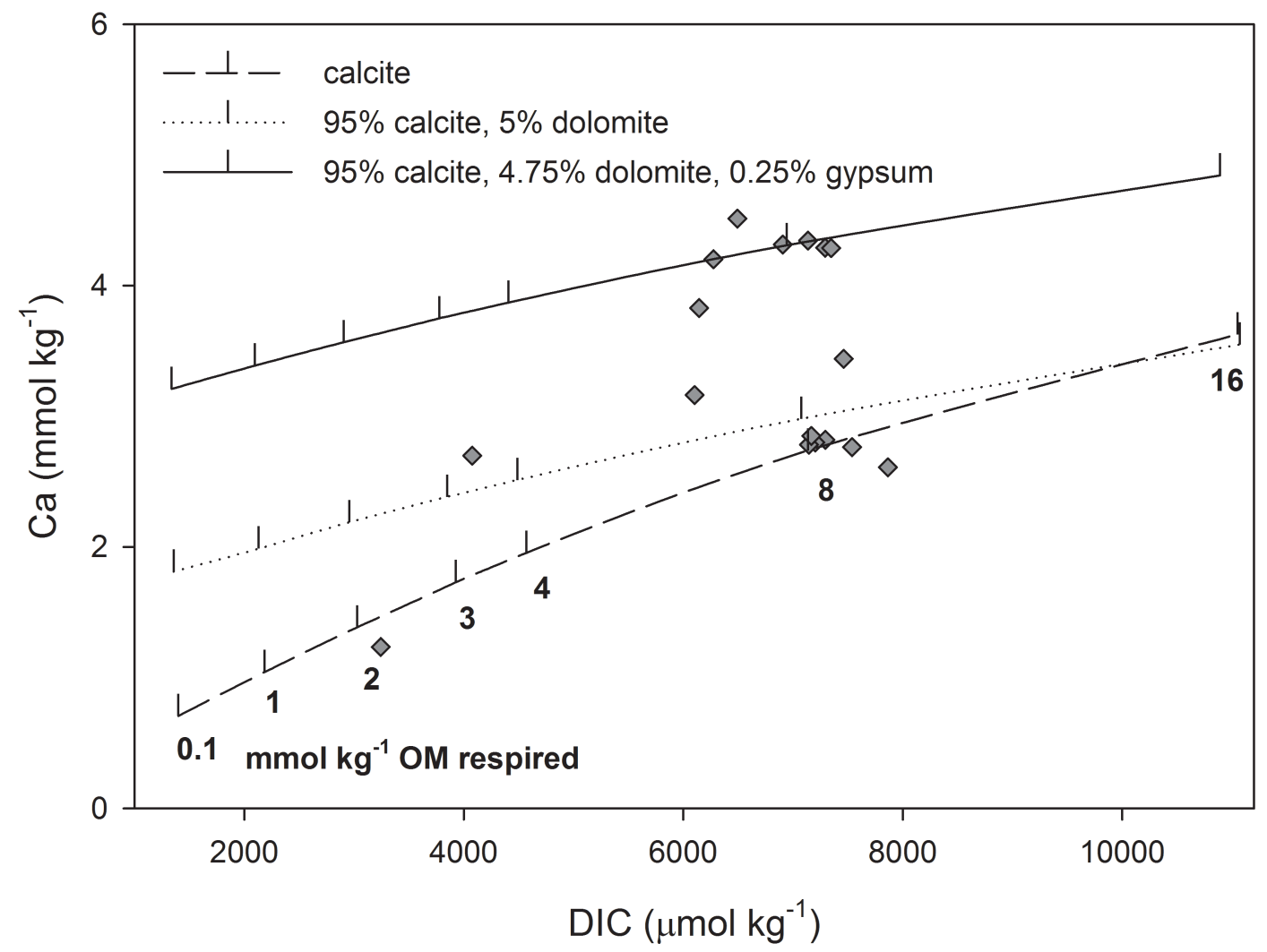

Figure 4: $\mathrm{Ca} v$ DIC for terrestrial (salinity <2) groundwater samples collected in Dec. 2009 (diamonds). Also shown is the predicted Ca:DIC during organic matter degradation as modeled using PHREEQ (Parkhurst and Appelo, 2013) for equilibrium with $1 \mathrm{~mol} \mathrm{~L}^{-1}$ calcite (dashed line); 95\% calcite, $5 \%$ dolomite (dotted line) and 95\% calcite, $4.75 \%$ dolomite and $0.25 \%$ gypsum (solid line). Vertical hatch marks and numbers in bold indicate the amount of organic matter respired at each point. 


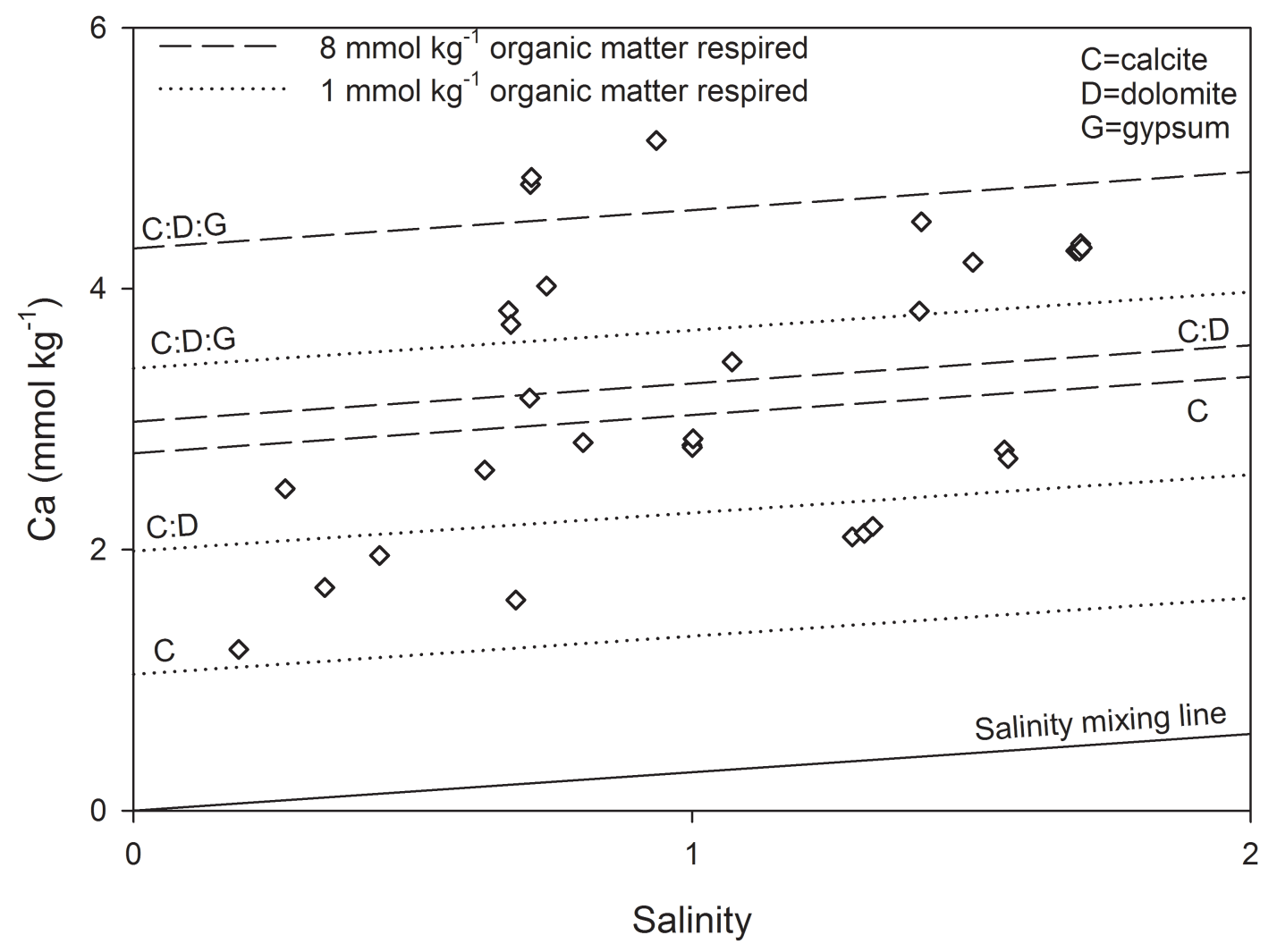

Figure 5: Predicted terrestrial groundwater dissolved $\mathrm{Ca}$ versus salinity following 1 mmol kg ${ }^{-1}$ (dotted lines) and $8 \mathrm{mmol} \mathrm{kg}^{-1}$ (dashed lines) organic matter respiration in equilibrium with $1 \mathrm{~mol} \mathrm{~L}^{-1}$ calcite; $95 \%$ calcite (C), 5\% dolomite (D); and 95\% calcite $4.75 \%$ dolomite and $0.25 \%$ gypsum (G). Addition of dissolved Ca through conservative mixing with ocean waters is shown in the solid line; this contribution has also been added to the mineral equilibrium lines. See Fig. 4 for dissolved $\mathrm{Ca}$ in terrestrial groundwater at additional organic matter respiration amounts. All terrestrial (salinity $<2$ ) groundwater samples with measured $\mathrm{Ca}$ are shown. 


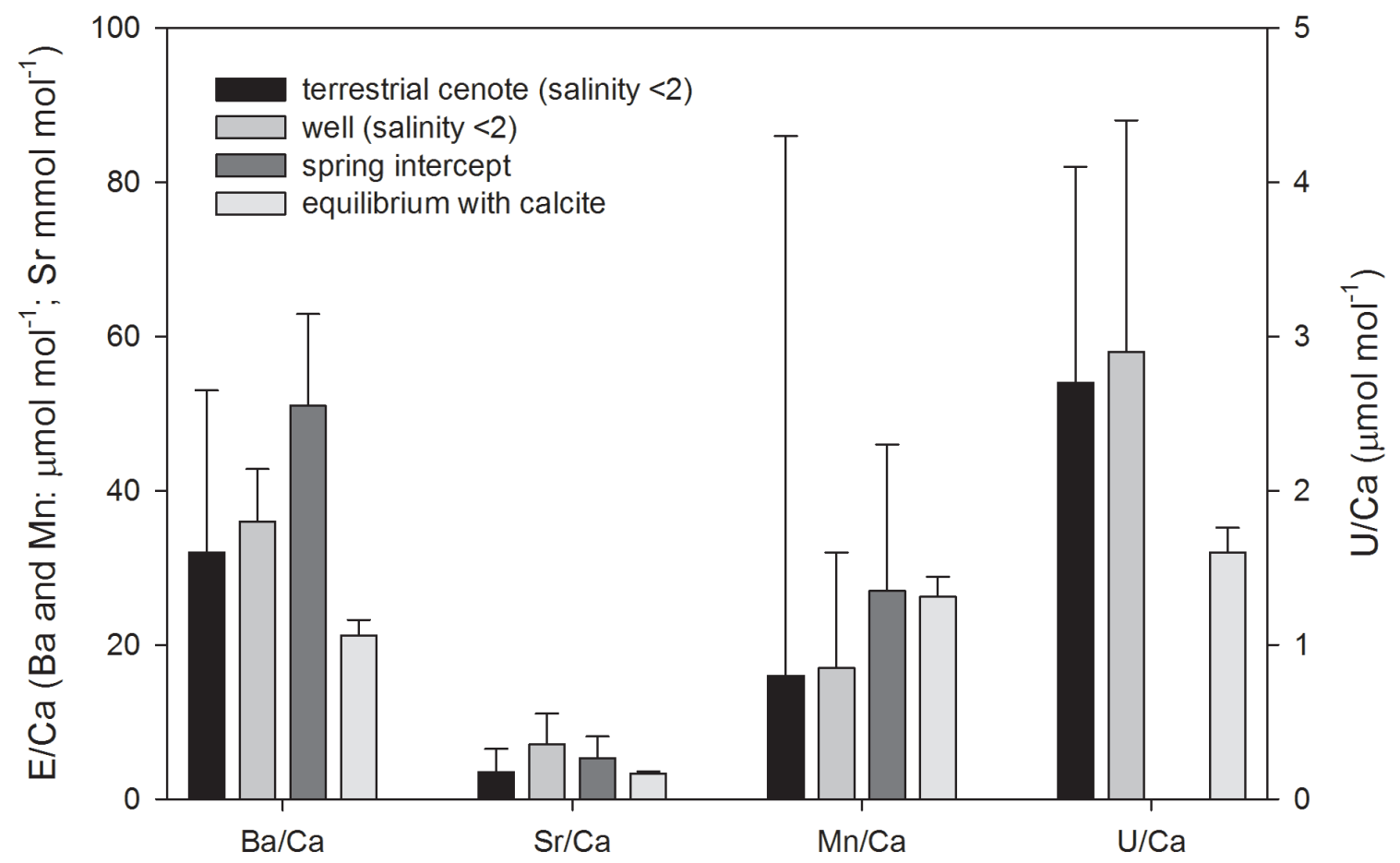

Figure 6: $\mathrm{Ba} / \mathrm{Ca}, \mathrm{Sr} / \mathrm{Ca}, \mathrm{Mn} / \mathrm{Ca}$ and $\mathrm{U} / \mathrm{Ca}$ ratios for terrestrial cenote and well (salinity $<2)$ samples. Also shown are the predicted ratio from the statistically significant spring mixing relationships (i.e. Ba intercept/Ca intercept, Table S3). The groundwater $\mathrm{E} / \mathrm{Ca}$ ratio in equilibrium with aquifer calicite according to equation (1) is also shown. Note separate axis for $\mathrm{U} / \mathrm{Ca}$ on right. 


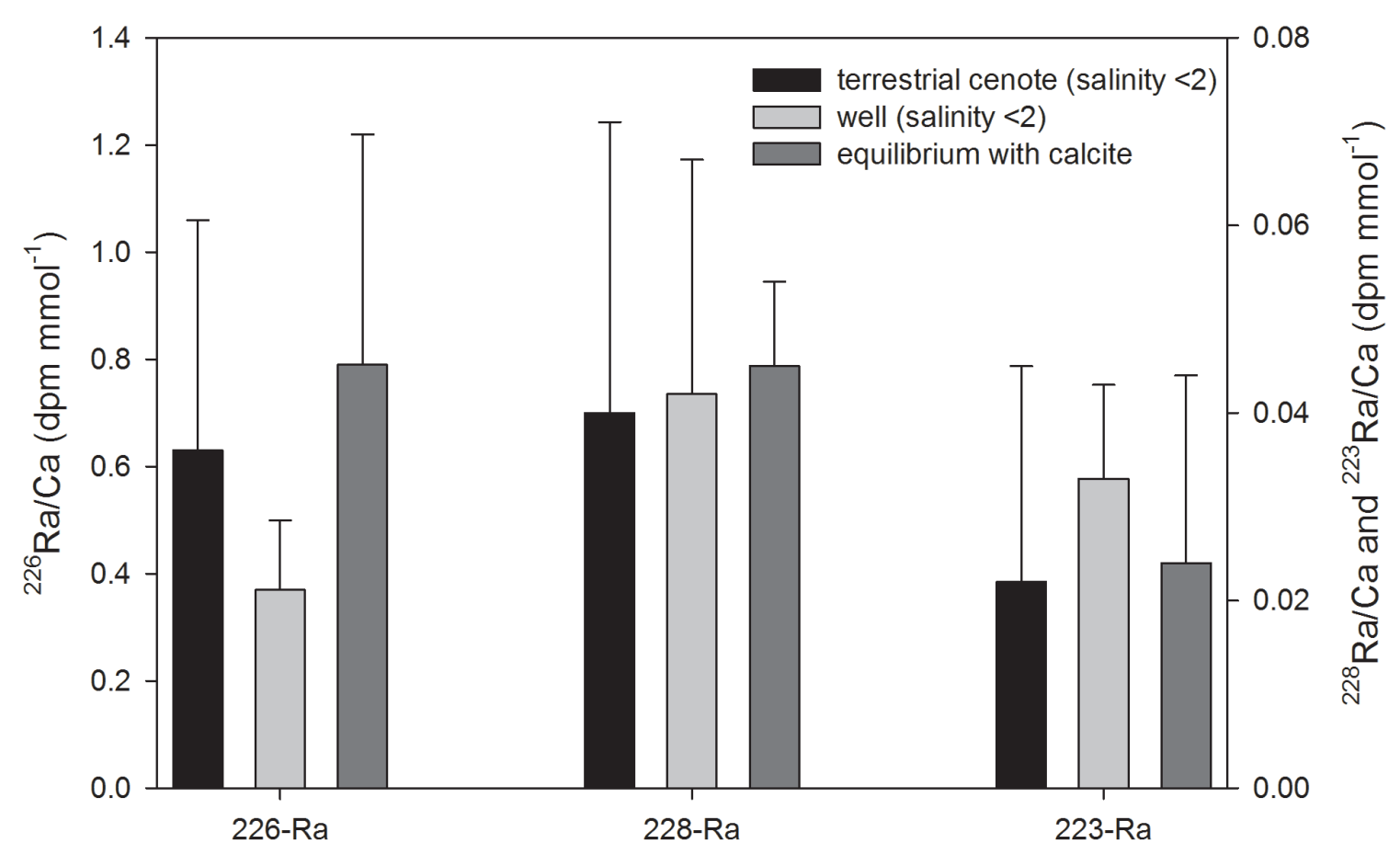

Figure 7: ${ }^{226} \mathrm{Ra} / \mathrm{Ca},{ }^{228} \mathrm{Ra} / \mathrm{Ca}$ and ${ }^{223} \mathrm{Ra} / \mathrm{Ca}$ ratios for terrestrial cenote and well samples (salinity $<2$ ) as well as that predicted by rock dissolution according to equation (1). Note separate axis for ${ }^{228} \mathrm{Ra} / \mathrm{Ca}$ and ${ }^{223} \mathrm{Ra} / \mathrm{Ca}$ on right. 


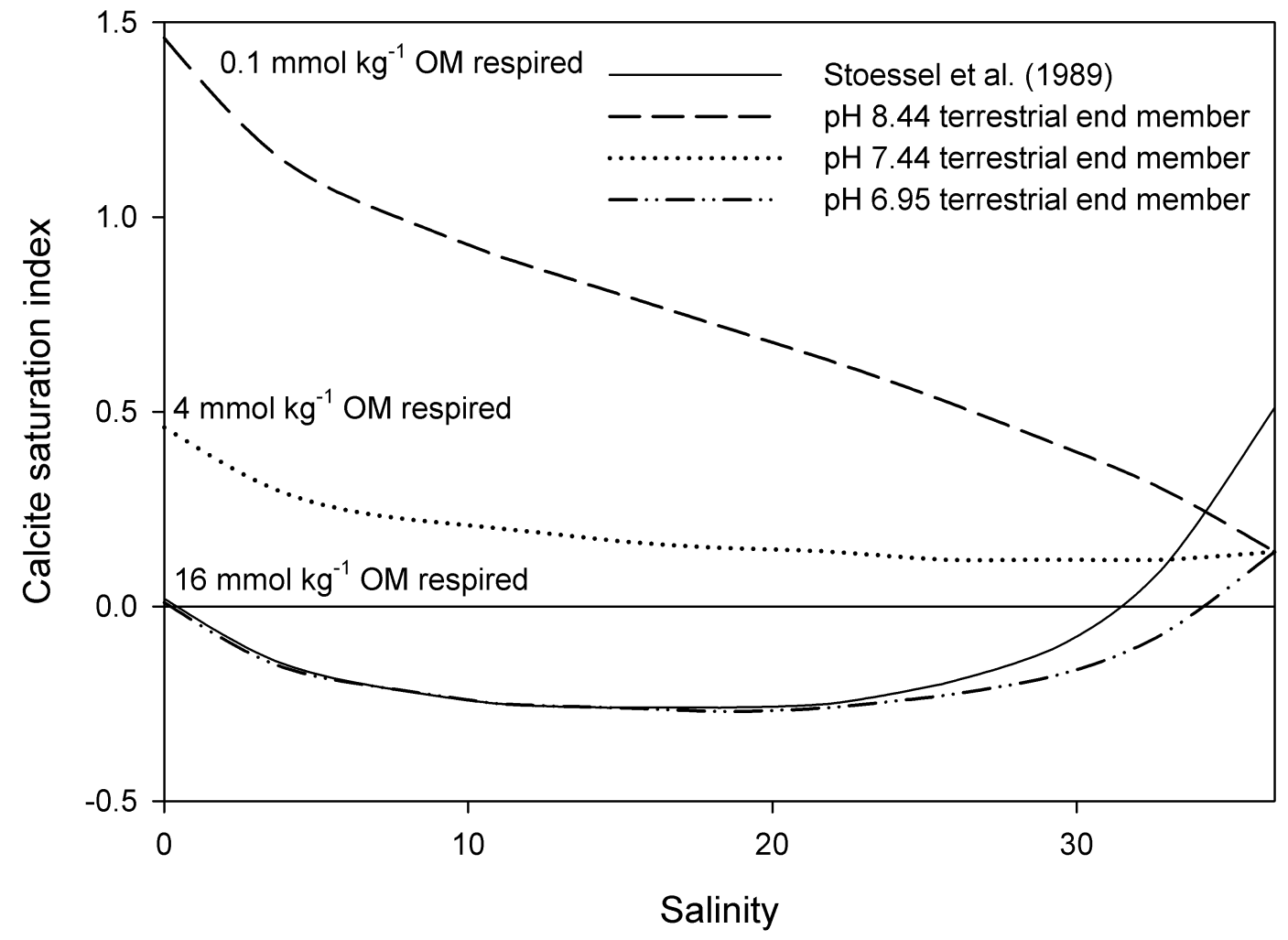

Figure 8: Predicted calcite saturation index (equation 2) based on mixing between three different terrestrial end members and ocean waters. Mixing between the $\mathrm{pH} 8.44$ and 7.44 (resulting from 0.1 and $4 \mathrm{mmol} \mathrm{kg}^{-1}$ organic matter respiration in equilibrium with calcite respectively) and ocean waters does not result in undersaturation. However, the $\mathrm{pH} 6.95$ terrestrial end member does produce corrosive waters upon mixing with the ocean. Also shown (solid line) is the mixing relationship predicted by Stoessell et al. (1989) for Yucatan groundwaters. Mixing induced dissolution is therefore a function of the amount of organic matter respired in the terrestrial end member. 

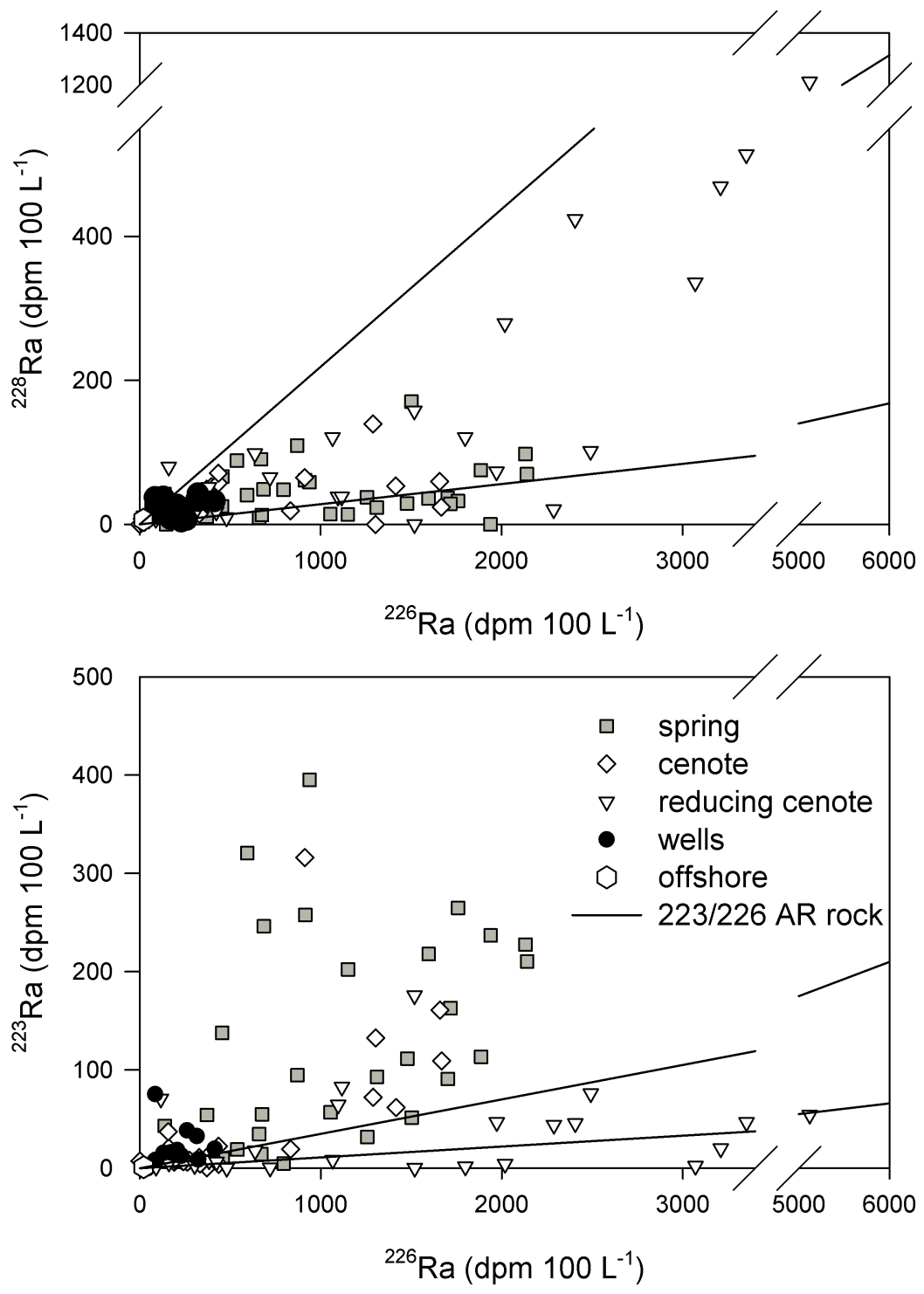

Figure 9: a) ${ }^{228} \mathrm{Ra}:{ }^{226} \mathrm{Ra}$ activity ratios and b) ${ }^{223} \mathrm{Ra}:{ }^{226} \mathrm{Ra}$ activity ratios. Solid lines denote the measured aquifer rock activity ratios. 


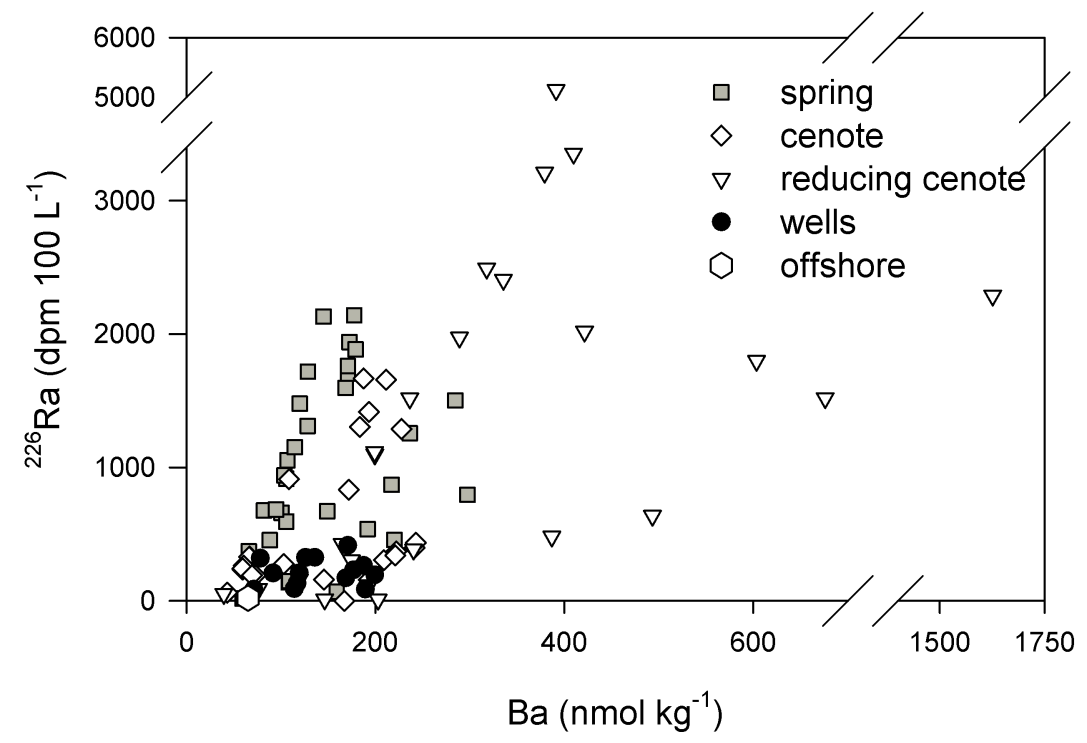

Figure 10: Relationship between ${ }^{226} \mathrm{Ra}$ and $\mathrm{Ba}$. The relationship between these elements is somewhat decoupled, particularly in the terrestrial cenote and well samples, potentially due to reduced mobility of the large $\mathrm{Ra}^{2+}$ ion compared to $\mathrm{Ba}^{2+}$. There is a linear relationship between a subset of spring (gray squares) and reducing cenote (triangles) samples. 

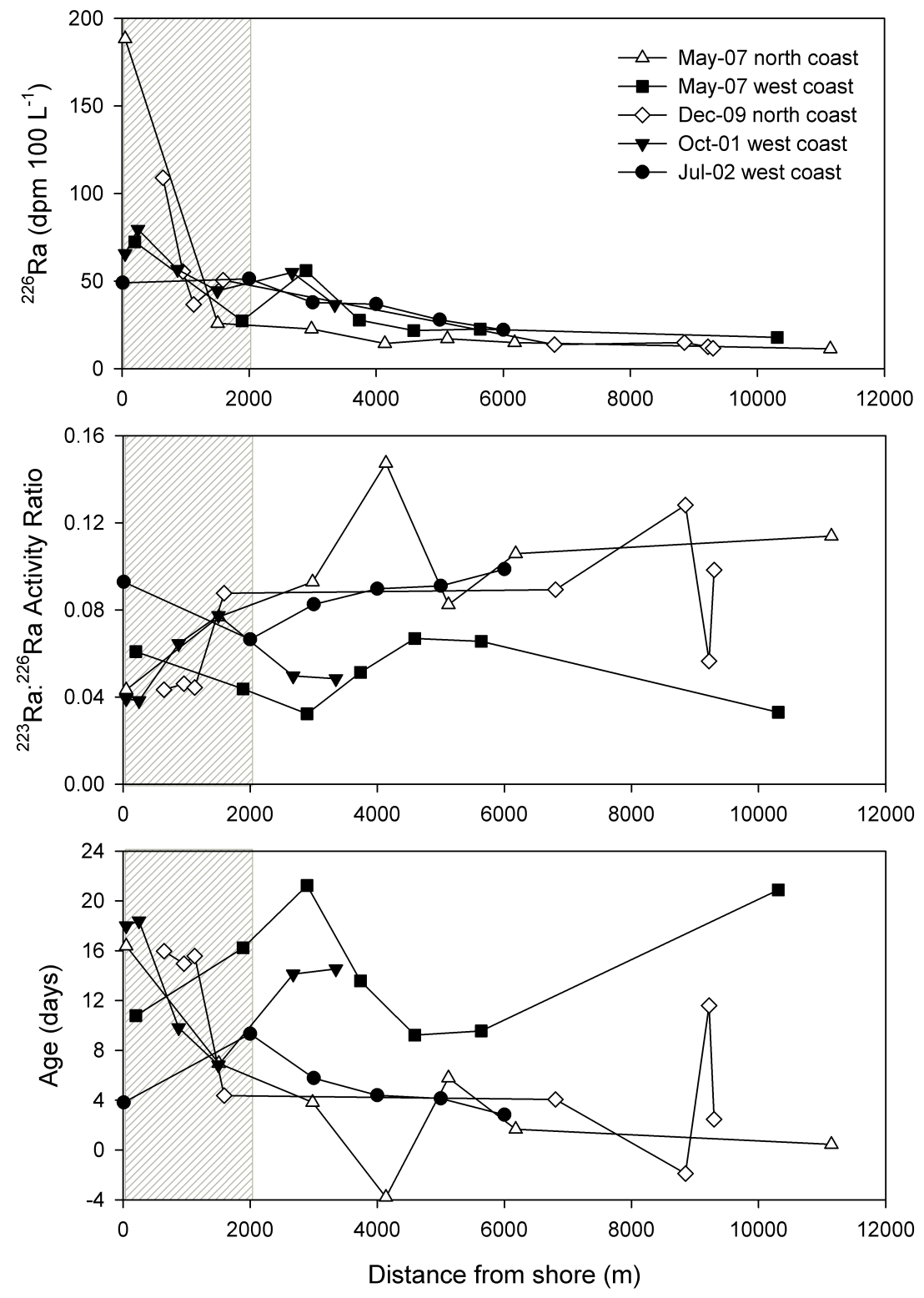

Figure 11: a) ${ }^{226} \mathrm{Ra}$ activity, b) ${ }^{223} \mathrm{Ra}:{ }^{226} \mathrm{Ra}$ activity ratio and c) water age (calculated according to equation (5) for offshore transects in 2001, 2002, 2007 and 2009 along the north and west coast of the Yucatan Peninsula. The shaded area indicates the region used to calculated radium inventories for the tracer-based estimate of submarine groundwater discharge (Table 3). 
Table 1: Yucatan aquifer and global average limestone $\mathrm{Ba}, \mathrm{Sr}, \mathrm{U}, \mathrm{Mn}$ and $\mathrm{Ra}$ isotope concentrations

\begin{tabular}{|c|c|c|c|c|}
\hline Element & $\begin{array}{l}\mu \mathrm{mol} \mathrm{g}^{-1} \text { or } \\
\text { (Ra) dpm } \mathrm{g}^{-1}\end{array}$ & $\begin{array}{c}\mathrm{E} / \mathrm{Ca}\left(\mu \mathrm{mol} \mathrm{mol} \mathrm{m}^{-1}\right. \\
\text { or }(\mathrm{Ra}) \mathrm{dpm} \\
\left.\mathrm{mmol}^{-1}\right)\end{array}$ & Location & Reference: \\
\hline \multirow[t]{3}{*}{$\mathrm{Ba}$} & 0.17 & 17 & Yucatan & This study \\
\hline & $0.07-0.22$ & $8-30$ & Yucatan & $\begin{array}{c}\text { Tuchscherer et al. } \\
\text { (2004) }\end{array}$ \\
\hline & 0.66 & 66 & Global limestone & Bowen (1979) \\
\hline \multirow[t]{4}{*}{$\mathrm{Sr}$} & 3.3 & 330 & Yucatan & This study \\
\hline & $2.3-2.6$ & $300-320$ & Yucatan & $\begin{array}{l}\text { Tuchscherer et al. } \\
\text { (2004) }\end{array}$ \\
\hline & $2.3-3.3$ & $250-390$ & Yucatan & $\begin{array}{l}\text { Schmitt et al. } \\
\text { (2004) }\end{array}$ \\
\hline & 7.0 & 700 & Global limestone & Bowen (1979) \\
\hline \multirow[t]{4}{*}{$\mathrm{U}$} & 0.0032 & 0.32 & Yucatan & This study \\
\hline & $0.0073-$ & & & Tuchscherer et al. \\
\hline & 0.0078 & $0.9-1.1$ & Yucatan & (2004) \\
\hline & 0.009 & 0.9 & Global limestone & Bowen (1979) \\
\hline \multirow[t]{3}{*}{$\mathrm{Mn}$} & 13.1 & 1310 & Yucatan & This study \\
\hline & $38-55$ & $5200-6400$ & Yucatan & $\begin{array}{c}\text { Tuchscherer et al. } \\
\text { (2004) }\end{array}$ \\
\hline & 11 & 1130 & Global limestone & Bowen (1979) \\
\hline${ }^{226} \mathrm{Ra}$ & $1.8-6.1$ & $0.18-0.61$ & Yucatan & This study \\
\hline${ }^{228} \mathrm{Ra}$ & $0.17-0.28$ & $0.017-0.028$ & Yucatan & This study \\
\hline${ }^{223} \mathrm{Ra}$ & $0.02-0.22$ & $0.011-0.035$ & Yucatan & This study \\
\hline
\end{tabular}

${ }^{1}$ Global limestone from Bowen 1979 
Table 2: Element radius, calcite partition coefficient and predicted dissolved E/Ca

\begin{tabular}{|c|c|c|c|c|}
\hline Element & Radius $^{1}$ & $K_{d}$ calcite & $\begin{array}{c}\text { Predicted dissolved } \\
\text { E/Ca }\left(\mu \mathrm{mol} \mathrm{mol}^{-1} \text { or }\right. \\
\left.\mathrm{dpm} \mathrm{mmol}{ }^{-1}\right)\end{array}$ & $K_{d}$ Reference \\
\hline $\mathrm{Ba}$ & 1.38 & 0.8 & 21.25 & Rihs et al. (2000) \\
\hline $\mathrm{Sr}$ & 1.21 & 0.1 & 3300 & Kitano et al. (1971) \\
\hline $\mathrm{U}$ & 1.00 & 0.2 & 1.6 & Rihs et al. (2000) \\
\hline $\mathrm{Mn}$ & 0.83 & 50 & 26.24 & Lorens (1981) \\
\hline${ }^{226} \mathrm{Ra}$ & 1.48 & 0.5 & $0.36-1.2$ & Rihs et al. (2000) \\
\hline${ }^{228} \mathrm{Ra}$ & 1.48 & 0.5 & $0.034-0.056$ & Rihs et al. (2000) \\
\hline $\begin{array}{l}{ }^{223} \mathrm{Ra} \text { (in equilibrium } \\
\text { with }{ }^{227} \mathrm{Ac} \text { ) } \\
\mathrm{Ca}\end{array}$ & $\begin{array}{l}1.48 \\
1.06\end{array}$ & 0.5 & $0.004-0.044$ & Rihs et al. (2000) \\
\hline
\end{tabular}

${ }^{1}$ Ionic radii from Shannon (1976). 
Table 3: Radium-tracer based submarine groundwater discharge estimates

\begin{tabular}{lrcc}
\hline \multicolumn{1}{c}{ Location } & Date & $\begin{array}{c}\text { SGD } \\
\left(\mathbf{m}^{-\mathbf{3}} \mathbf{~ m}^{-\mathbf{1}} \mathbf{d}^{-\mathbf{1}}\right)\end{array}$ & $\begin{array}{c}\mathbf{T}_{\mathbf{w}} \\
(\mathbf{d a y s})\end{array}$ \\
\hline West coast & Oct-01 & 50 & 13 \\
West coast & Jul-02 & $73(40)^{*}$ & 7 \\
North coast & May-07 & 95 & 12 \\
West coast & May-07 & 36 & 14 \\
North coast & Dec-09 & 84 & 13 \\
\hline \multicolumn{5}{c}{} \\
& Average & $\mathbf{6 7}(61)$ & \\
\hline
\end{tabular}

* $\mathrm{T}_{\mathrm{w}}$ of July 2002 transect is much lower than the other time periods. Value in parentheses indicates SGD if average $T_{w}$ from all time periods is used rather than 7 days. 
Table 4: Trace element flux from the Yucatan Peninsula and global karst subterranean estuaries compared to global river fluxes

\begin{tabular}{|c|c|c|c|c|c|c|c|c|}
\hline & $\begin{array}{c}\text { River EM } \\
\left(\mathrm{nmol} \mathrm{kg}^{-}\right. \\
1 \text { or Ra } \\
\text { dpm } 100 \\
\left.\mathrm{~L}^{-1}\right) \\
\end{array}$ & $\begin{array}{c}\text { Karst EM } \\
\left(\text { nmol kg }^{-1}\right. \\
\text { or Ra dpm } \\
\left.100 \mathrm{~L}^{-1}\right)\end{array}$ & $\begin{array}{c}\text { Karst/ } \\
\text { River } \\
\text { EM }\end{array}$ & $\begin{array}{c}\text { Yucatan } \\
\text { karst } \\
\text { flux }{ }^{3}(\mathrm{~mol} \\
\text { or } \mathrm{Ra}^{-1} \\
\left.\text { dpm } \mathbf{y r}^{-1}\right)\end{array}$ & $\begin{array}{c}\text { River flux } \\
(\text { mol or Ra } \\
\left.\text { dpm } \mathbf{y r}^{-1}\right)\end{array}$ & $\begin{array}{c}\text { Global } \\
\text { karst flux } \\
\text { (mol or } \\
\text { Ra dpm } \\
\text { yr }^{-1} \text { ) }\end{array}$ & $\begin{array}{c}\text { Global } \\
\text { karst } \\
\text { SGD/River } \\
\text { flux } \\
\end{array}$ & $\begin{array}{l}\text { River } \\
\text { Ref. }\end{array}$ \\
\hline $\begin{array}{l}\text { Ba- } \\
\text { salinity } \\
2^{1} \\
\end{array}$ & 168 & $190^{2}$ & 1.2 & $\begin{array}{c}3.2-5.4 \times \\
10^{6} \\
\end{array}$ & $6.3 \times 10^{9}$ & $\begin{array}{c}6.9-12 \times \\
10^{7} \\
\end{array}$ & $0.01-0.02$ & $\mathrm{a}$ \\
\hline $\mathrm{Sr}$ & $\begin{array}{c}685 \\
1208 \\
\end{array}$ & $\begin{array}{l}20100 \\
20100\end{array}$ & $\begin{array}{l}29 \\
17 \\
\end{array}$ & $\begin{array}{c}3.5-5.6 \times \\
10^{8}\end{array}$ & $\begin{array}{l}2.9 \times 10^{10} \\
4.7 \times 10^{10}\end{array}$ & $\begin{array}{c}6.8-12 \times \\
10^{9}\end{array}$ & $\begin{array}{l}0.26-0.46 \\
0.14-0.26\end{array}$ & $\begin{array}{l}\mathrm{a} \\
\mathrm{b}\end{array}$ \\
\hline $\mathrm{U}$ & $\begin{array}{l}1.56 \\
2.14\end{array}$ & 10 & $\begin{array}{l}6.4 \\
4.7\end{array}$ & $\begin{array}{c}1.6-2.8 \times \\
10^{5}\end{array}$ & $\begin{array}{l}5.9 \times 10^{7} \\
2.3 \times 10^{7}\end{array}$ & $\begin{array}{c}3.4-6.0 \times \\
10^{6}\end{array}$ & $\begin{array}{c}0.057-0.10 \\
0.15-0.26\end{array}$ & $\begin{array}{l}\mathrm{a} \\
\mathrm{c}\end{array}$ \\
\hline $\mathrm{Mn}$ & $\begin{array}{l}620 \\
127 \\
\end{array}$ & 103 & $\begin{array}{l}0.17 \\
0.81 \\
\end{array}$ & $\begin{array}{c}1.6-2.9 \times \\
10^{6}\end{array}$ & $\begin{array}{l}2.3 \times 10^{10} \\
4.6 \times 10^{9} \\
\end{array}$ & $\begin{array}{c}3.5-6.2 \times \\
10^{7}\end{array}$ & $\begin{array}{c}0.0015- \\
0.0030 \\
0.0076- \\
0.013 \\
\end{array}$ & $\mathrm{~d}$ \\
\hline $\begin{array}{l}{ }^{226} \mathrm{Ra}- \\
\text { salinity } \\
5^{1}\end{array}$ & $\begin{array}{l}5.3 \\
9.6\end{array}$ & $\begin{array}{l}1000^{2} \\
1000^{2}\end{array}$ & $\begin{array}{c}190 \\
96\end{array}$ & $\begin{array}{c}1.9-3.1 \times \\
10^{14}\end{array}$ & $\begin{array}{l}2.0 \times 10^{14} \\
3.6 \times 10^{14}\end{array}$ & $\begin{array}{c}4.0-6.6 \times \\
10^{16}\end{array}$ & $\begin{array}{c}1.0-1.6 \\
0.53-0.86\end{array}$ & $\begin{array}{l}\mathrm{a} \\
\mathrm{c}\end{array}$ \\
\hline
\end{tabular}

${ }^{1} \mathrm{Ba}$ and $\mathrm{Ra}$ concentrations peak at salinities greater than the pure terrestrial groundwater end member. Thus the SGD flux at salinity 2 (for $\mathrm{Ba}$ ) and 5 (for $\mathrm{Ra}$ ) is calculated according to: $\mathrm{SGD}_{\mathrm{x}}$ $=\mathrm{SGD}_{\text {terrestrial }}+\mathrm{SGD}_{\text {marine }} \mathrm{x}$ ( salinity $/$ salinity $_{\text {TotalSGD }}$ ), where $\mathrm{x}$ refers to the salinity of interest. $\mathrm{SGD}_{\text {terrestrial }}$ is 26-45 $\mathrm{m}^{3} \mathrm{~m}^{-1} \mathrm{~d}^{-1}$ (Gondwe et al., 2010; Hanshaw and Back, 1980), $\mathrm{SGD}_{\text {marine }}$ is 10 $\mathrm{m}^{3} \mathrm{~m}^{-1} \mathrm{~d}^{-1}$ (this study) and salinity

${ }^{2}$ Karst $\mathrm{Ba}$ and ${ }^{226} \mathrm{Ra}$ end members were modified to exclude the component from recirculated marine groundwater. Thus $200 \mathrm{nmol} \mathrm{kg}{ }^{-1} \mathrm{Ba}$ was reduced to $190 \mathrm{nmol} \mathrm{kg}^{-1}$ to account for seawater Ba in the SGD flux at salinity 2, while ${ }^{226} \mathrm{Ra}$ was reduced from 1000 to $996 \mathrm{dpm} 100 \mathrm{~L}^{-1}$ at SGD flux at salinity 5 .

${ }^{3}$ Yucatan Peninsula fluxes are calculated for the entire 1,650 $\mathrm{km}$ coastline.

${ }^{a}$ Gaillardet, Viers and Dupre (2003)

${ }^{\mathrm{b}}$ Peucker-Ehrenbrink, et al. (2010)

${ }^{\mathrm{c}}$ Chabaux, Riotte and Dequincey (2003)

${ }^{\mathrm{d}}$ Bender et al. (1997) 
Acknowledgements: Field assistance was provided by Jessica Fitzsimmons, Alexandra Rao, Simon Richards, Paul Henderson, Crystaline Breier and Dr. Carolina Ruiz Fernandez. Permission to sample groundwater wells was granted by Dr. Arnulk Schiller. Daniel Diamant provided access to his property to sample. Dr. Paul Blanchon and Dr. Roberto Iglesias Prieto provided assistance for work along the east Yucatan coast. DIC and alkalinity measurements were carried out in the laboratories of Dr. Daniel McCorkle and Dr. William Martin at WHOI. Sean Sylva assisted with Ca measurements. M.E.G. was supported by a NDSEG graduate fellowship. Funding for this research was provided by the NSF Chemical Oceanography program (OCE-0751525) and by the Coastal Ocean Institute and the Ocean and Climate Change Institute at Woods Hole Oceanographic Institution. 


\section{References}

Allègre C. J., Louvat P., Gaillardet J., Meynadier L., Rad S. and Capmas F., 2010. The fundamental role of island arc weathering in the oceanic Sr isotope budget. Earth Planet. Sci. Lett., 292: 51-56.

ArandaCirerol, N., Herrera-Silveira, J.A. and Comin, F.A., 2006. Nutrient water quality in a tropical coastal zone with groundwater discharge, northwest Yucatan, Mexico. Estuarine Coastal and Shelf Science, 68(3-4): 445-454.

Barnes, C.E. and Cochran, J.K., 1990. Uranium removal in oceanic sediments and the oceanic-U balance. Earth and Planetary Science Letters, 97(1-2): 94-101.

Basu, A.R., Jacobsen, S.B., Poreda, R.J., Dowling, C.B. and Aggarwal, P.K., 2001. Large groundwater strontium flux to the oceans from the bengal basin and the marine strontium isotope record. Science, 293(5534): 1470-1473.

Bauer-Gottwein, P. et al., 2011. Review: The Yucatan Peninsula karst aquifer, Mexico. Hydrogeology Journal, 19(3): 507-524.

Bautista, F., Bautista, D. and Delgado-Carranza, C., 2009. Calibration of the equations of Hargreaves and Thornthwaite to estimate the potential evapotranspiration in semi-arid and subhumid tropical climates for regional applications. Atmosfera, 22(4): 331-348.

Beck, A.J., Charette, M.A., Cochran, J.K., Gonneea, M.E. and Peucker-Ehrenbrink, B., 2013. Dissolved strontium behavior in the subterranean estuary- Implications for the $\mathrm{Sr}$ isotope budget of the global ocean. Geochimica et Cosmochimica Acta: http://dx.doi.org/10.1016/j.gca.2013.03.021.

Beck, A.J. and Cochran, M.A., 2013. Controls on solid-solution partitioning of radium in saturated marine sands. Marine Chemistry, http://dx.doi.org/10.1016/j.marchem.2013.01.008.

Beck, A.J. et al., 2007. Importance of geochemical transformations in determining submarine groundwater discharge-derived trace metal and nutrient fluxes. Applied Geochemistry, 22(2): 477-490.

Beddows, P.A., Smart, P.L., Whitaker, F.F. and Smith, S.L., 2007. Decoupled freshsaline groundwater circulation of a coastal carbonate aquifer: Spatial patterns of temperature and specific electrical conductivity. Journal of Hydrology, 346(1-2): 18-32.

Bender, M.L., Klinkhammer, G.P. and Spencer, D.W., 1977. Manganese in seawater and the marine manganese balance. Deep Sea Research, 24(9): 799-812. 
Bone, S.E., Charette, M.A., Lamborg, C.H. and Gonneea, M.E., 2007. Has submarine groundwater discharge been overlooked as a source of mercury to coastal waters?

Environmental Science \& Technology, 41(9): 3090-3095.

Boose, E.a.F., D., 2006. Ecological Impacts of Hurricanes Across the Yucatan Peninsula. Harvard Forest Data Archive, \#HF071.

Bowen, H.J.M., 1979. Environmental Chemistry of the Elements. Academic Press London, UK and New York, NY, USA, 333 pp.

Burnett, W.C. et al., 2006. Quantifying submarine groundwater discharge in the coastal zone via multiple methods. Science of the Total Environment, 367(2-3): 498-543.

Burnett, W.C., Wattayakorn, G., Taniguchi, M., Dulaiova, H., Sojisuporn, P., Rungsupa, S., Ishitobi, T., 2007. Groundwater-derived nutrient inputs to the Upper Gulf of Thailand. Continental Shelf Research 27, 176-190.

Cervantes-Martinez, A., Elias-Gutieerrez, M. and Suarez-Morales, E., 2002.

Limnological and morphometrical data of eight karstic systems 'cenotes' of the Yucatan Peninsula, Mexico, during the dry season (February-May, 2001). Hydrobiologia, 482(13): 167-177.

Chabaux, F., Riotte, J. and Dequincey, O., 2003. U-Th-Ra fractionation during weathering and river transport, Reviews in Mineralogy \& Geochemistry: Uranium-Series Geochemistry, pp. 533-576.

Charette, M.A., Buesseler, K.O. and Andrews, J.E., 2001. Utility of radium isotopes for evaluating the input and transport of groundwater-derived nitrogen to a Cape Cod estuary. Limnology and Oceanography, 46(2): 465-470.

Charette, M.A., Gonneea, M.E., Henderson, P.B., Rao, A. and Herrera-Silveira, J., 2008. Trace Metal Biogeochemistry in Karstic Subterranean Estuaries, AGU/ASLO Ocean Sciences Meeting, Orlando Florida.

Charette, M.A. and Sholkovitz, E.R., 2006. Trace element cycling in a subterranean estuary: Part 2. Geochemistry of the pore water. Geochimica et Cosmochimica Acta, 70(4): 811-826.

Dawson, J.B., Hinton, R.W., 2003. Trace-element content and partitioning in calcite, dolomite and apatite in carbonatite, Phalaborwa, South Africa. Mineralogical Magazine 67, 921-930.

Dunk, R.M., Mills, R.A. and Jenkins, W.J., 2002. A reevaluation of the oceanic uranium budget for the Holocene. Chemical Geology, 190(1-4): 45-67. 
Dymond, J., E. Suess, and M. Lyle, 1992. Barium in deep-sea sediment: A geochemical proxy for paleoproductivity, Paleoceanography, 7, 163-181.

Einsiedl, F., 2012. Sea-water/groundwater interactions along a small catchment of the European Atlantic coast. Applied Geochemistry, 27(1): 73-80.

Escobar-Sanchez, J.E. and Urrutia-Fucugauchi, J., 2010. Chicxulub crater post-impact hydrothermal activity - evidence from Paleocene carbonates in the Santa Elena borehole. Geofisica Internacional, 49(2): 97-106.

Fleury, P., Bakalowicz, M. and de Marsily, G., 2007. Submarine springs and coastal karst aquifers: A review. Journal of Hydrology, 339(1-2): 79-92.

Gaillardet, J., Viers, J. and Dupre, B., 2003. 5.09 - Trace Elements in River Waters. In: D.H. Heinrich and K.T. Karl (Editors), Treatise on Geochemistry. Pergamon, Oxford, pp. 225-272.

Garcia-Solsona, E. et al., 2010. Groundwater and nutrient discharge through karstic coastal springs (Castello, Spain). Biogeosciences, 7(9): 2625-2638.

Gibbs, M.T. and Kump, L.R., 1994. Global chemical erosion during the last glacial maximum and the present- sensitivity to changes in lithology and hydrology Paleoceanography, 9(4): 529-543.

Giddings, L. and Soto, M., 2003. Rhythms of Precipitation in the Yucatan Peninsula. In: A. Gomez-Pompa, M.F. Allen, S.L. Fedick and J.J. Jimene-Osornio (Editors), The Lowland Maya Area:Three Millennia at the Human-Wildland Interface. Food Products Press, pp. 659.

Giffin, C., Kaufman, A. and Broecker, W., 1963. Delayed Coincidence Counter for the Assay of Actinon and Thoron. Journal of Geophysical Research, 68(6): 1749-1757.

Gondwe, B.R.N. et al., 2010. Hydrogeology of the south-eastern Yucatan Peninsula: New insights from water level measurements, geochemistry, geophysics and remote sensing. Journal of Hydrology, 389(1-2): 1-17.

Gonneea, M.E., Morris, P.J., Dulaiova, H. and Charette, M.A., 2008. New perspectives on radium behavior within a subterranean estuary. Marine Chemistry, 109(3-4): 250-267. Gonneea, M.E., Mulligan, A. and Charette, M.A., 2013. Seasonal cycles in radium and barium within a subterranean estuary: Implications for groundwater derived chemical fluxes to surface waters. Geochimica et Cosmochimica Acta: doi:10.1016/j.gca.2013.05.034.

Griffith, E.M., Paytan, A., Caldeira, K., Bullen, T.D. and Thomas, E., 2008. A Dynamic Marine Calcium Cycle During the Past 28 Million Years. Science, 322(5908): 1671-1674. 
Hanshaw, B.B. and Back, W., 1980. Chemical mass-wasting of the norhtern Yucatan Peninsula by groundwater dissolution. Geology, 8(5): 222-224.

Herrera-Silveira, J.A., Medina-Gomez, I. and Colli, R., 2002. Trophic status based on nutrient concentration scales and primary producers community of tropical coastal lagoons influenced by groundwater discharges. Hydrobiologia, 475(1): 91-98.

Hess, J., Bender, M.L. and Schilling, J.G., 1986. Evolution of the ratio of Sr-87 to Sr-86 in seawater from Cretaceous to present. Science, 231(4741): 979-984.

Holmden, C., Papanastassiou, D.A., Blanchon, P. and Evans, S., 2012. delta Ca-44/40 variability in shallow water carbonates and the impact of submarine groundwater discharge on Ca-cycling in marine environments. Geochimica et Cosmochimica Acta, 83: 179-194.

Kaleris, V., 2006. Submarine groundwater discharge: Effects of hydrogeology and of near shore surface water bodies. Journal of Hydrology, 325(1-4): 96-117.

Kim, H., Lee, K. and Choi, W., 2006. Contribution of phytoplankton and bacterial cells to the measured alkalinity of seawater. Limnology and Oceanography, 51(1): 331-338.

Kim, H. and Lee, K., 2009. Significant contribution of dissolved organic matter to seawater alkalinity. Geophysical Research Letters, doi: 10.1029/2009GL040271.

Kiro, Y., Yechieli, Y., Voss, C.I., Starinsky, A. and Weinstein, Y., 2012. Modeling radium distribution in coastal aquifers during sea level changes: The Dead Sea case. Geochimica Et Cosmochimica Acta, 88: 237-254.

Kitano, Y. and Oomori, T., 1971. The coprecipitation of uranium with calcium carbonate. Journal of the Oceanography Society of Japan, 27: 34-42.

Knee, K.L., Street, J.H., Grossman, E.E., Boehm, A.B. and Paytan, A., 2010. Nutrient inputs to the coastal ocean from submarine groundwater discharge in a groundwaterdominated system: Relation to land use (Kona coast, Hawaii, USA). Limnology and Oceanography, 55(3): 1105-1122.

Krabbenhōft A., Eisenhauer A., Bōhm F., Vollstaedt H., Fietzke J., Liebetrau V., Augustin N., Peucker-Ehrenbrink B., Mūller M. N., Horn C., Hansen B. T., Nolte N. and Wallmann K., 2010. Constraining the marine strontium budget with natural strontium isotope fractionations $\left(87 \mathrm{Sr} / 86 \mathrm{Sr}^{*}, \delta 88 / 86 \mathrm{Sr}\right.$ ) of carbonates, hydrothermal solutions and river waters. Geochim. Cosmochim. Acta 74, 4097-4109. 
Langmuir, D., 1978. Uranium solution-mineral equilibria at low-temperatures with applications to sedimentary ore-deposits. Geochimica et Cosmochimica Acta, 42(6): 547569.

Langmuir, D. and Riese, A.C., 1985. The thermodynamic properties of radium. Geochimica Et Cosmochimica Acta, 49(7): 1593-1601.

Lorens, R.B., 1981. Sr, Cd, Mn and Co distribution coefficients in calcite as a functino of calcite precipitation rate. Geochimica et Cosmochimica Acta, 45(4): 553-561.

Martin, J.H. and Knauer, G.A., 1980. Manganese cycling in Northeast Pacific waters. Earth and Planetary Science Letters, 51(2): 266-274.

Moore, W.S., 1996. Large groundwater inputs to coastal waters revealed by Ra-226 enrichments. Nature, 380(6575): 612-614.

Moore, W.S., 1999. The subterranean estuary: a reaction zone of ground water and sea water. Marine Chemistry, 65(1-2): 111-125.

Moore, W.S., 2000. Determining coastal mixing rates using radium isotopes. Continental Shelf Research, 20(15): 1993-2007.

Moore, W.S., 2010. The Effect of Submarine Groundwater Discharge on the Ocean. Annual Review of Marine Science, 2: 59-88.

Moore, W.S. and Arnold, R., 1996. Measurement of Ra-223 and Ra-224 in coastal waters using a delayed coincidence counter. Journal of Geophysical Research-Oceans, 101(C1): 1321-1329.

Moore, W.S., Blanton, J.O. and Joye, S.B., 2006. Estimates of flushing times, submarine groundwater discharge, and nutrient fluxes to Okatee Estuary, South Carolina. Journal of Geophysical Research-Oceans, doi:10.1029/2005jc003041.

Moore, W.S. and Reid, D.F., 1973. Extraction of Radium from Natural Waters Using Manganese-Impregnated Acrylic Fibers. Journal of Geophysical Research, 78(36): 88808886.

Moore, W.S., Sarmiento, J.L. and Key, R.M., 2008. Submarine groundwater discharge revealed by Ra-228 distribution in the upper Atlantic Ocean. Nature Geoscience, 1(5): 309-311.

Moore, W.S. and Shaw, T.J., 2008. Fluxes and behavior of radium isotopes, barium, and uranium in seven Southeastern US rivers and estuaries. Marine Chemistry, 108(3-4): 236254. 
Morales-Ojeda, S.M., Herrera-Silveira, J.A. and Montero, J., 2010. Terrestrial and oceanic influence on spatial hydrochemistry and trophic status in subtropical marine near-shore waters. Water Research, 44(20): 5949-5964.

Oberdorfer, J.A., Charette, M., Allen, M., Martin, J.B. and Cable, J.E., 2008. Hydrogeology and geochemistry of near-shore submarine groundwater discharge at Flamengo Bay, Ubatuba, Brazil. Estuarine Coastal and Shelf Science, 76(3): 457-465. Palmer, M.R. and Edmond, J.M., 1989. The strontium isotope budget of the modern ocean. Earth and Planetary Science Letters, 92(1): 11-26.

Parkhurst, D.L. and Appelo, C.A.J., 2013. Description of input and examples for PHREEQC version 3-A computer program for speciation, batch-reaction, onedimensional transport, and inverse geochemical calculations: U.S. Geological Survey Techniques and Methods, book 6, chap. A43. available only at http://pubs.usgs.gov/tm/06/a43/, 497 pp.

Paytan, A., Kastner, M. and Chavez, F.P., 1996. Glacial to interglacial fluctuations in productivity in the equatorial Pacific as indicated by marine barite. Science, 274(5291): 1355-1357.

Perry, E., Marin, L., McClain, J. and Velazquez, G., 1995. Ring of cenotes (sinkholes), northwest Yucatan, Mexico- its hydrogeologic characteristics and possible association with the Chicxulub impact crater. Geology, 23(1): 17-20.

Perry, E., Paytan, A., Pedersen, B. and Velazquez-Oliman, G., 2009. Groundwater geochemistry of the Yucatan Peninsula, Mexico: Constraints on stratigraphy and hydrogeology. Journal of Hydrology, 367(1-2): 27-40.

Perry, E., Velazquez-Oliman, G. and Marin, L., 2002. The hydrogeochemistry of the karst aquifer system of the northern Yucatan Peninsula, Mexico. International Geology Review, 44(3): 191-221.

Peterson, R.N., Burnett, W.C., Glenn, C.R. and Johnson, A.G., 2009. Quantification of point-source groundwater discharges to the ocean from the shoreline of the Big Island, Hawaii. Limnology and Oceanography, 54(3): 890-904.

Peucker-Ehrenbrink, B., Miller, M.W., Arsouze, T. and Jeandel, C., 2010. Continental bedrock and riverine fluxes of strontium and neodymium isotopes to the oceans.

Geochemistry Geophysics Geosystems, doi: 10.1029/2009gc002869.

Prieto, C., Destouni, G., 2011. Is submarine groundwater discharge predictable? Geophys. Res. Lett., doi: 10.1029/2010g1045621. 
Povinec, P.P. et al., 2012. Isotopic, geophysical and biogeochemical investigation of submarine groundwater discharge: IAEA-UNESCO intercomparison exercise at Mauritius Island. Journal of Environmental Radioactivity, 103(2): 24-45.

Price, R.M., Savabi, M.R., Jolicoeur, J.L. and Roy, S., 2010. Adsorption and desorption of phosphate on limestone in experiments simulating seawater intrusion. Applied Geochemistry, 25(7): 1085-1091.

Reeve, A.S. and Perry, E.C., 1994. Carbonate geochemistry and the concentrations of aqueous $\mathrm{Mg} 2+, \mathrm{Sr} 2+$ and $\mathrm{Ca} 2+-$ Western North coast of the Yucatan, Mexico. Chemical Geology, 112(1-2): 105-117.

Rihs, S., Condomines, M. and Sigmarsson, O., 2000. U, Ra and Ba incorporation during precipitation of hydrothermal carbonates: Implications for Ra-226-Ba dating of impure travertines. Geochimica et Cosmochimica Acta, 64(4): 661-671.

Robinson, L.F., Henderson, G.M., Hall, L. and Matthews, I., 2004. Climatic Control of Riverine and Seawater Uranium-Isotope Ratios. Science, 305: 851-854.

Rushdi, A.I., McManus, J. and Collier, R.W., 2000. Marine barite and celestite saturation in seawater. Marine Chemistry, 69(1-2): 19-31.

Sanders, C.J., Santos, I.R., Barcellos, R. and Silva, E.V., 2012. Elevated concentrations of dissolved $\mathrm{Ba}, \mathrm{Fe}$ and $\mathrm{Mn}$ in a mangrove subterranean estuary: Consequence of sea level rise? Continental Shelf Research, 43: 86-94.

Santos, I.R. et al., 2011. Uranium and barium cycling in a salt wedge subterranean estuary: The influence of tidal pumping. Chemical Geology, 287(1-2): 114-123.

Schmitt, R.T., Wittmann, A. and Stoffler, D., 2004. Geochemistry of drill core samples from Yaxcopoil-1, Chicxulub impact crater, Mexico. Meteoritics \& Planetary Science, 39(6): 979-1001.

Schmitter-Soto, J.J. et al., 2002. Hydrogeochemical and biological characteristics of cenotes in the Yucatan Peninsula (SE Mexico). Hydrobiologia, 467(1-3): 215-228.

Shaw, T.J., Moore, W.S., Kloepfer, J. and Sochaski, M.A., 1998. The flux of barium to the coastal waters of the southeastern USA: The importance of submarine groundwater discharge. Geochimica et Cosmochimica Acta, 62(18): 3047-3054.

Shiller, A.M., 1997. Manganese in surface waters of the Atlantic Ocean. Geophysical Research Letters, 24(12): 1495-1498. 
Smith, S.V., Crossland, J.I.M., Crossland, C.J., 1999. Land-Ocean Interactions in the Coastal Zone (LOICZ): Mexican and Central American Coastal Lagoon Systems: Carbon, Nitrogen and Phosphorous Fluxes (Regional Workshop II).

Statham, P.J., Yeats, P.A. and Landing, W.M., 1998. Manganese in the eastern Atlantic Ocean: processes influencing deep and surface water distributions. Marine Chemistry, 61(1-2): 55-68.

Stoessell, R.K., Moore, Y.H. and Coke, J.G., 1993. The occurrence and effect of sulfate reduction and sulfide oxidation on coastal limestone dissolution in Yucatan cenotes. Ground Water, 31(4): 566-575.

Stoessell, R.K., Ward, W.C., Ford, B.H. and Schuffert, J.D., 1989. Water chemistry and $\mathrm{CaCO} 3$ dissolution in the saline part of an open-flow mixing zone, coastal Yucatan Peninsula, Mexico. Geological Society of America Bulletin, 101(2): 159-169.

Stumm, W. and Morgan, J.J., 1996. Aquatic Chemistry. John Wiley \& Sons, Inc., 1022 pp.

Torres-Talamante, O., Alcocer, J., Beddows, P.A., Escobar-Briones, E.G. and Lugo, A., 2011. The key role of the chemolimnion in meromictic cenotes of the Yucatan Peninsula, Mexico. Hydrobiologia, 677(1): 107-127.

Tribovillard, N., Algeo, T.J., Lyons, T. and Riboulleau, A., 2006. Trace metals as paleoredox and paleoproductivity proxies: An update. Chemical Geology, 232(1-2): 1232.

Tuchscherer, M.G., Reimold, W.U., Koeberl, C. and Gibson, R.L., 2005. Geochemical and petrographic characteristics of impactites and Cretaceous target rocks from the Yaxcopoil-1 borehole, Chicxulub impact structure, Mexico: Implications for target composition. Meteoritics \& Planetary Science, 40(9-10): 1513-1536.

Young, M.B. et al., 2008. Characterizing sources of groundwater to a tropical coastal lagoon in a karstic area using radium isotopes and water chemistry. Marine Chemistry, 109(3-4): 377-394.

Zekster, I.S., Everett, L.G. and Dzhamalov, R.G., 2006. Submarine Groundwater. CRC Press, $466 \mathrm{pp}$.

Zhu, C., 2002. Estimation of surface precipitation constants for sorption of divalent metals onto hydrous ferric oxide and calcite. Chemical Geology, 188(1-2): 23-32. 

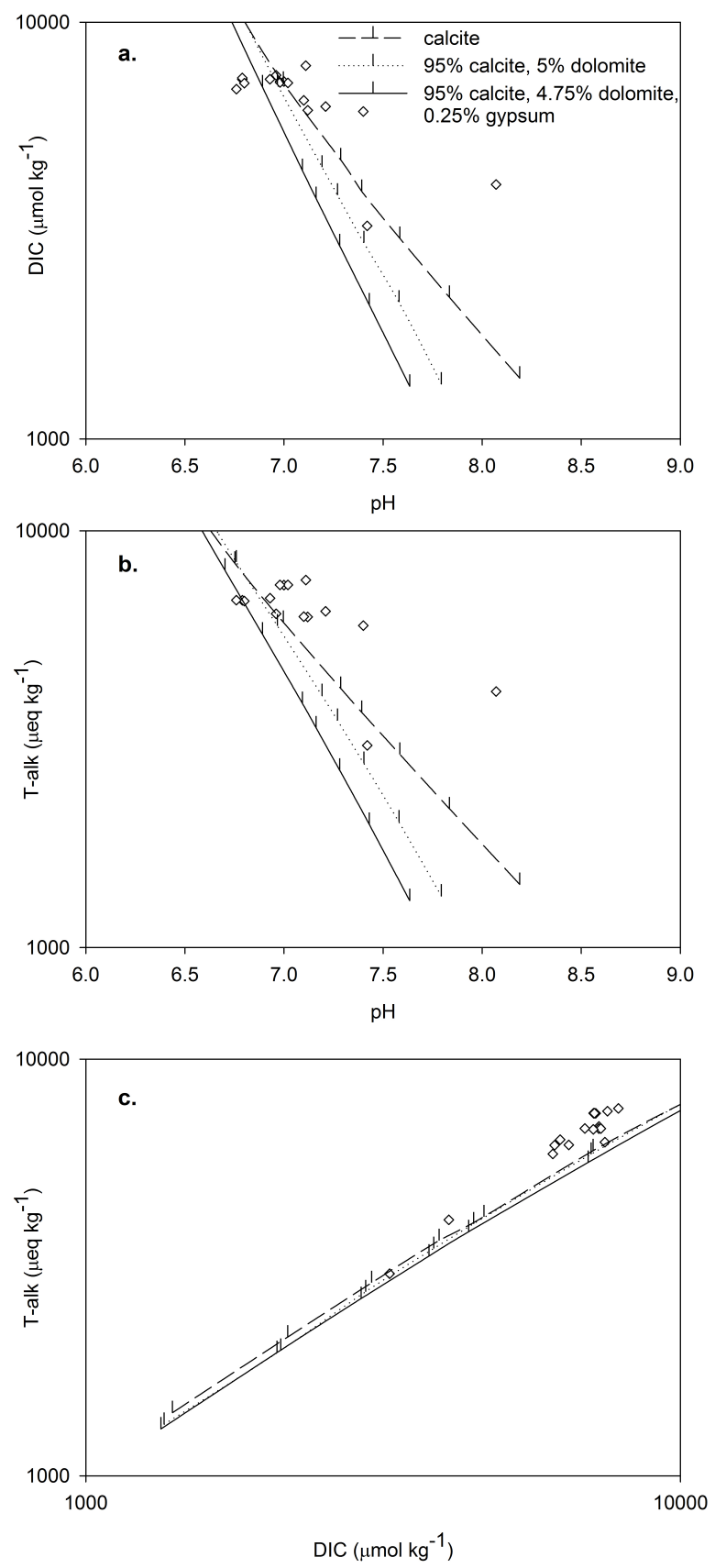

Figure S1: a) DIC v pH (measured in field), b) T-alk v pH and c) T-alk v DIC for organic matter degradation as modeled using PHREEQ (Parkhurst and Appelo, 2013) for equilibrium with $1 \mathrm{~mol} \mathrm{~L}^{-1}$ calcite (dashed line); $95 \%$ calcite, $5 \%$ dolomite (dotted line) and $95 \%$ calcite, $4.75 \%$ dolomite and $0.25 \%$ gypsum (solid line). Terrestrial groundwater samples are shown in diamonds. T-alk appears to compared to model predicted values, likely due to organic matter contributions to alkalinity. 
Table S1: Certified Reference Material elemental concentrations

\begin{tabular}{llcc}
\hline Element & \multicolumn{2}{l}{$\begin{array}{l}\text { CRM reported } \\
\text { value }\end{array}$} & $\begin{array}{l}\text { Measured value } \mathbf{\pm} \\
\text { standard } \\
\text { deviation) }\end{array}$ \\
\hline $\mathrm{Ca} \mathrm{mmol} \mathrm{kg}^{-1}$ & IAPSO & 10.3 & $10.5 \pm 0.1$ \\
$\mathrm{U} \mathrm{nmol} \mathrm{kg}^{-1}$ & NASS-5 & 10.9 & $11.0 \pm 0.1$ \\
& SLRS-5 & 0.21 & $0.20 \pm 0.01$ \\
$\mathrm{Ba} \mathrm{nmol} \mathrm{kg}^{-1}$ & SLEW-3 & 7.6 & $7.6 \pm 0.05$ \\
& NASS-5 & na & $45 \pm 0.5$ \\
& SLRS-5 & 88.8 & $89.3 \pm 1.8$ \\
$\mathrm{Sr} \mu \mathrm{mol} \mathrm{kg}$ & SLEW-3 & na & $179 \pm 2$ \\
& NASS-5 & na & $80 \pm 2.5$ \\
& SLRS-5 & 0.30 & $0.31 \pm 0.05$ \\
$\mathrm{Mn} \mathrm{nmol} \mathrm{kg}$ & SLEW-3 & na & $45 \pm 5$ \\
na=value not available & 29 & $30 \pm 4$ \\
\hline
\end{tabular}




\begin{tabular}{|c|c|c|c|c|c|c|c|c|c|}
\hline$I$ & II & III & IV & $\mathrm{V}$ & VI & VII & VIII & IX & $x$ \\
\hline $\begin{array}{l}\text { Internal } \\
\text { sample ID }\end{array}$ & Date & $\begin{array}{l}\text { Latitude } \mathrm{N} \\
\text { degrees }\end{array}$ & $\begin{array}{l}\text { Longitude W } \\
\text { degrees }\end{array}$ & Sample Type & $\begin{array}{l}\text { Sample } \\
\text { distance to } \\
\text { shoreline } m\end{array}$ & $\begin{array}{l}\text { Sample } \\
\text { Depth m }\end{array}$ & $\begin{array}{l}\text { Salinometer } \\
\text { salinity }\end{array}$ & $\begin{array}{l}\text { Collection } \\
\text { Temp C }\end{array}$ & $\begin{array}{l}\text { Collection DO } \\
\text { sat \% }\end{array}$ \\
\hline YT 172 & $3 / 23 / 10$ & 21.45778 & 88.69341 & lagoon & & 0.5 & 2.1016 & 26.92 & 56.2 \\
\hline YT 155 & $3 / 24 / 10$ & 20.87317 & 90.35902 & lagoon & & 0.5 & 4.3837 & 24.85 & 39 \\
\hline YT 156 & $3 / 25 / 10$ & 20.85318 & 90.384 & lagoon & & 0.5 & 9.1429 & 26.45 & 66.7 \\
\hline YT 158 & $3 / 26 / 10$ & 20.83113 & 90.38724 & lagoon & & 0.5 & 9.7507 & 25.81 & 70 \\
\hline YT 154 & $3 / 27 / 10$ & 20.87621 & 90.36466 & lagoon & & 0.5 & 9.883 & 25.78 & 65.8 \\
\hline YT 152 & $3 / 28 / 10$ & 20.89486 & 90.35472 & lagoon & & 0.5 & 9.9851 & 24.94 & 17.4 \\
\hline YT 162 & $3 / 29 / 10$ & 20.81212 & 90.39497 & lagoon & & 0.5 & 10.0049 & 26.3 & 47.1 \\
\hline YT 151 & $3 / 30 / 10$ & 20.921 & 90.3483 & lagoon & & 0.5 & 10.4326 & 24.68 & 62.9 \\
\hline YT 159 & $3 / 31 / 10$ & 20.78356 & 90.4042 & lagoon & & 0.5 & 11.8162 & 26.38 & 53 \\
\hline YT 150 & $4 / 1 / 10$ & 20.94791 & 90.3341 & lagoon & & 0.5 & 12.3576 & 24.72 & 34.6 \\
\hline YT 66 & $4 / 2 / 10$ & 21.397 & 88.905 & lagoon & & 0.5 & 13.33 & 27.81 & 60.2 \\
\hline YT 61 & $4 / 3 / 10$ & 20.9155 & 90.3435 & lagoon & & 0 & 16.9 & 29.7 & \\
\hline YT 62 & $4 / 4 / 10$ & 20.9008 & 90.3467 & lagoon & & 0 & 19.38 & 29.52 & \\
\hline YT 57 & $4 / 5 / 10$ & 20.83305 & 90.38807 & lagoon & & 0 & 20.63 & & \\
\hline YT 63 & $4 / 6 / 10$ & 20.8775 & 90.3555 & lagoon & & 0 & 21.05 & 30.5 & \\
\hline YT 60 & $4 / 7 / 10$ & 20.93 & 90.3372 & lagoon & & 0 & 21.12 & 28.63 & \\
\hline YT 161 & $4 / 8 / 10$ & 20.77484 & 90.41497 & lagoon & & 0.5 & 24.8374 & 28.55 & 107.1 \\
\hline YT 72 & $4 / 9 / 10$ & 21.45497 & 88.6926 & lagoon & & 0 & 25.45 & & \\
\hline YT 58 & $4 / 10 / 10$ & 20.9545 & 90.3332 & lagoon & & 0 & 26.73 & 27.13 & \\
\hline YT 171 & $4 / 11 / 10$ & 21.44771 & 88.69475 & lagoon & & 0.5 & 29.1907 & 27.95 & 267.4 \\
\hline YT 56 & $4 / 12 / 10$ & 20.77534 & 90.41159 & lagoon & & 0 & 32.72 & & \\
\hline YT253 & $4 / 13 / 10$ & 20.38818 & 87.32047 & lagoon & & 0 & 34.0031 & 24.82 & \\
\hline YT300 & $4 / 14 / 10$ & 20.39568 & 87.31467 & lagoon & & 0 & 34.265 & 27.73 & 107.2 \\
\hline YT256 & $4 / 15 / 10$ & 20.78003 & 86.94127 & lagoon & & 0 & 34.8953 & 28.34 & 75.6 \\
\hline YT249 & $4 / 16 / 10$ & 20.38536 & 87.32301 & lagoon & & 0 & 34.9227 & 26.79 & 114 \\
\hline TS10_11 & $4 / 17 / 10$ & 20.86799 & 86.86685 & lagoon & & & 34.9237 & & \\
\hline YT 71 & $4 / 18 / 10$ & 21.43218 & 88.71754 & lagoon & & 0 & 34.94 & & \\
\hline YT331 & $4 / 19 / 10$ & 20.86799 & 86.86685 & lagoon & & 0 & 35.0606 & 25.27 & 78.9 \\
\hline YT260 & $4 / 20 / 10$ & 20.89147 & 86.8606 & lagoon & & 0 & 35.1091 & 25.13 & 81 \\
\hline YT211 & $4 / 21 / 10$ & 20.73847 & 86.95443 & lagoon & & 0 & 35.2729 & 24.59 & 100.4 \\
\hline YT219 & $4 / 22 / 10$ & 20.88021 & 86.86139 & lagoon & & 0 & 35.2741 & 24.89 & 98.9 \\
\hline YT191 & $4 / 23 / 10$ & 20.391583 & 87.307933 & lagoon & & 2.3 & 35.3918 & & \\
\hline YT192 & $4 / 24 / 10$ & 20.39085 & 87.31545 & lagoon & & 2.3 & 35.3981 & & \\
\hline YT216 & $4 / 25 / 10$ & 20.87768 & 86.86098 & lagoon & & 0 & 35.4089 & 24.8 & 94.1 \\
\hline YT194 & $4 / 26 / 10$ & 20.74093 & 86.871683 & lagoon & & 2.5 & 35.4604 & & \\
\hline YT342 & $4 / 27 / 10$ & 20.86799 & 86.86685 & lagoon & & 0 & 35.5001 & 27.06 & 104 \\
\hline TS9_11 & $4 / 28 / 10$ & 20.86799 & 86.86685 & lagoon & & & 35.5115 & & \\
\hline YT224 & $4 / 29 / 10$ & 20.88293 & 86.85896 & lagoon & & 0 & 35.5571 & 24.97 & 98 \\
\hline TS4_11 & $4 / 30 / 10$ & 20.86799 & 86.86685 & lagoon & & & 35.5882 & & \\
\hline YT193 & $5 / 1 / 10$ & 20.738633 & 86.954283 & lagoon & & 6 & 35.6885 & & \\
\hline TS8_11 & $5 / 2 / 10$ & 20.86799 & 86.86685 & lagoon & & & 35.6891 & & \\
\hline YT208 & $5 / 3 / 10$ & 20.39162 & 87.3333 & lagoon & & 0 & 35.7124 & 25.59 & 116 \\
\hline TS6_11 & $5 / 4 / 10$ & 20.86799 & 86.86685 & lagoon & & & 35.7258 & & \\
\hline YT213 & $5 / 5 / 10$ & 20.8323 & 86.87909 & lagoon & & 0 & 35.7379 & 25.32 & 115 \\
\hline TS_0211 & $5 / 6 / 10$ & 20.86799 & 86.86685 & lagoon & & 0 & 35.8167 & & \\
\hline TS3_11 & $5 / 7 / 10$ & 20.86799 & 86.86685 & lagoon & & & 35.8222 & & \\
\hline TS7_11 & $5 / 8 / 10$ & 20.86799 & 86.86685 & lagoon & & & 35.8773 & & \\
\hline YT 70 & $5 / 9 / 10$ & 21.4276 & 88.72505 & lagoon & & 0 & 36 & & \\
\hline TS5_11 & $5 / 10 / 10$ & 20.86799 & 86.86685 & lagoon & & & 36.0285 & & \\
\hline YT 173 & $5 / 11 / 10$ & 21.46456 & 88.70526 & lagoon & & 1 & 36.4249 & 25.38 & 68.1 \\
\hline YT 68 & $5 / 12 / 10$ & 21.4705 & 88.6538 & lagoon & & 0 & 39.1 & 29.45 & \\
\hline YT 69 & $5 / 13 / 10$ & 21.46112 & 88.67467 & lagoon & & 0 & 39.27 & 29.74 & \\
\hline YT 67 & $5 / 14 / 10$ & 21.47691 & 88.64499 & lagoon & & 0 & 44.61 & 28.69 & \\
\hline YT 66 & $5 / 15 / 10$ & 21.48742 & 88.63655 & lagoon & & 0 & 46.93 & 28.87 & \\
\hline YT185 & $5 / 16 / 10$ & 20.83192 & 86.88018 & lagoon & & 0 & & & \\
\hline YT186 & $5 / 17 / 10$ & 18.70612 & 87.70643 & lagoon & & 0 & & & \\
\hline YT187 & $5 / 18 / 10$ & 18.64572 & 87.722203 & lagoon & & 0 & & & \\
\hline YT188 & $5 / 19 / 10$ & 20.74093 & 86.95502 & lagoon & & 0 & & & \\
\hline YT189 & $5 / 20 / 10$ & 20.39158 & 87.31632 & lagoon & & 2 & & & \\
\hline YT190 & $5 / 21 / 10$ & 20.91402 & 86.8344 & lagoon & & 0 & & & \\
\hline YT 53 & $5 / 22 / 10$ & 20.86412 & 90.43668 & offshore & 3736.50201 & 0 & 23.29 & & \\
\hline YT 51 & $5 / 23 / 10$ & 20.86884 & 90.45311 & offshore & 5636.06291 & 0 & 31.23 & & \\
\hline YT 52 & $5 / 24 / 10$ & 20.86621 & 90.44408 & offshore & 4590.95701 & 0 & 32.92 & & \\
\hline YT 54 & $5 / 25 / 10$ & 20.86208 & 90.4294 & offshore & 2896.38777 & 0 & 33.72 & & \\
\hline YT 132 & $5 / 26 / 10$ & 21.37999 & 89.01791 & offshore & 645 & 0.5 & 35.7892 & 24.43 & 90.1 \\
\hline YT212 & $5 / 27 / 10$ & 20.73737 & 85.94062 & offshore & & 0 & 35.8663 & 25.64 & 99.1 \\
\hline YT 121 & $5 / 28 / 10$ & 21.29303 & 89.70294 & offshore & 1126 & 0.5 & 35.921 & 24.42 & 93 \\
\hline YT 183 & $5 / 29 / 10$ & 20.86799 & 86.86685 & offshore & 20 & 3 & 36.0827 & 28.83 & \\
\hline YT 131 & $5 / 30 / 10$ & 21.23153 & 89.91616 & offshore & 958 & 0.5 & 36.095 & 24.43 & 94.5 \\
\hline YT 142 & $5 / 31 / 10$ & 21.57996 & 89.43559 & offshore & 28000 & 0.5 & 36.2984 & 25.69 & 102.1 \\
\hline YT 122 & $6 / 1 / 10$ & 21.36537 & 89.71155 & offshore & 9221.15698 & 0.5 & 36.3928 & 24.96 & 94.8 \\
\hline YT 123 & $6 / 2 / 10$ & 21.43665 & 89.72758 & offshore & 17339.6113 & 0.5 & 36.4164 & 25.26 & 97.1 \\
\hline YT 126 & $6 / 3 / 10$ & 21.57535 & 89.93972 & offshore & 40500.3307 & 0.5 & 36.4224 & 25.56 & 97.2 \\
\hline YT 127 & $6 / 4 / 10$ & 21.5031 & 89.95437 & offshore & 32308.5291 & 0.5 & 36.4299 & 25.71 & 97 \\
\hline YT 137 & $6 / 5 / 10$ & 21.75101 & 89.09975 & offshore & 42882.7684 & 0.5 & 36.4303 & 25.85 & 101.4 \\
\hline YT 128 & $6 / 6 / 10$ & 21.42432 & 89.95311 & offshore & 23553.376 & 0.5 & 36.434 & 25.31 & 100.2 \\
\hline YT 125 & $6 / 7 / 10$ & 21.58237 & 89.74397 & offshore & 33652.1935 & 0.5 & 36.4354 & 25.67 & 100.2 \\
\hline YT 140 & $6 / 8 / 10$ & 21.78832 & 89.24014 & offshore & 48000 & 0.5 & 36.4406 & 25.7 & 102.2 \\
\hline YT 124 & $6 / 9 / 10$ & 21.50959 & 89.73926 & offshore & 25547.9623 & 0.5 & 36.4459 & 25.58 & 96.7 \\
\hline YT 138 & $6 / 10 / 10$ & 21.82341 & 89.11778 & offshore & 51173.5722 & 0.5 & 36.4638 & 25.88 & 100.7 \\
\hline
\end{tabular}




\begin{tabular}{|c|c|c|c|c|c|c|c|c|c|}
\hline $\mathrm{I}$ & II & III & IV & $\mathrm{V}$ & VI & VII & VIII & IX & $\mathrm{X}$ \\
\hline $\begin{array}{l}\text { Internal } \\
\text { sample ID }\end{array}$ & Date & $\begin{array}{l}\text { Latitude } \mathrm{N} \\
\text { degrees }\end{array}$ & $\begin{array}{l}\text { Longitude W } \\
\text { degrees }\end{array}$ & Sample Type & $\begin{array}{l}\text { distance to } \\
\text { shoreline } m\end{array}$ & $\begin{array}{l}\text { Sample } \\
\text { Depth m }\end{array}$ & $\begin{array}{l}\text { Salinometer } \\
\text { salinity }\end{array}$ & $\begin{array}{l}\text { Collection } \\
\text { Temp C }\end{array}$ & $\begin{array}{l}\text { Collection DO } \\
\text { sat \% }\end{array}$ \\
\hline YT 136 & $6 / 11 / 10$ & 21.66875 & 89.07882 & offshore & 33450.7993 & 0.5 & 36.4703 & 25.82 & 100.5 \\
\hline YT 130 & $6 / 12 / 10$ & 21.27374 & 89.94758 & 3 offshore & 6805.17252 & 0.5 & 36.4748 & 24.9 & 94.7 \\
\hline YT 139 & $6 / 13 / 10$ & 21.89399 & 89.146 & offshore & 59620.0846 & 0.5 & 36.4754 & 25.88 & 100.5 \\
\hline YT 129 & $6 / 14 / 10$ & 21.34979 & 89.94863 & 3 offshore & 15256.6539 & 0.5 & 36.476 & 25.31 & 99.1 \\
\hline YT 141 & $6 / 15 / 10$ & 21.68505 & 89.33921 & offshore & 37200 & 0.5 & 36.4842 & 25.66 & 103 \\
\hline YT 143 & $6 / 16 / 10$ & 21.48256 & 89.53748 & 3 offshore & 18750 & 0.5 & 36.5137 & 25.61 & 103.8 \\
\hline YT 135 & $6 / 17 / 10$ & 21.59636 & 89.06622 & offshore & 25285.8819 & 0.5 & 36.5234 & 25.92 & 100.9 \\
\hline YT 134 & $6 / 18 / 10$ & 21.52387 & 89.0521 & offshore & 17079.4051 & 0.5 & 36.5299 & 25.61 & 99.9 \\
\hline YT 144 & $6 / 19 / 10$ & 21.38774 & 89.64385 & offshore & 9300 & 0.5 & 36.5618 & 25.3 & 101.5 \\
\hline YT 133 & $6 / 20 / 10$ & 21.45161 & 89.03587 & offshore & 8849.83022 & 0.5 & 36.6616 & 25.33 & 97.1 \\
\hline YT 32 & $6 / 21 / 10$ & 21.44655 & 88.87713 & 3 offshore & 6177.63492 & 0 & 37.4 & & \\
\hline YT 33 & $6 / 22 / 10$ & 21.43763 & 88.88045 & offshore & 5120.01533 & 0 & 37.5 & & \\
\hline YT 31 & $6 / 23 / 10$ & 21.4912 & 88.87455 & 5 offshore & 11147.4189 & 0 & 37.53 & & \\
\hline YT 34 & $6 / 24 / 10$ & 21.42925 & 88.8833 & offshore & 4136.45016 & 0 & 37.57 & & \\
\hline YT 55 & $6 / 25 / 10$ & 20.86035 & 90.42051 & offshore & 1890 & 0 & 37.65 & & \\
\hline YT 35 & $6 / 26 / 10$ & 21.41985 & 88.88773 & offshore & 2981.73798 & 0 & 37.86 & & \\
\hline YT 36 & $6 / 27 / 10$ & 21.40765 & 88.893 & 3 offshore & 1505 & 0 & 38.59 & & \\
\hline YT 50 & $6 / 28 / 10$ & 20.88102 & 90.49338 & 3 offshore & 10311.0667 & 0 & 39.96 & & \\
\hline YT 19 & $6 / 29 / 10$ & 20.85034 & 90.31839 & spring & & 0 & 1.93 & 25.89 & \\
\hline YT 24 & $6 / 30 / 10$ & 21.45944 & 88.68481 & spring & & 3.156 & 2.88 & 26.11 & \\
\hline YT 157 & $7 / 1 / 10$ & 20.8369 & 90.38849 & spring & & 0.5 & 2.9634 & 26.2 & 25.6 \\
\hline YT 9 & $7 / 2 / 10$ & 20.83714 & 90.38638 & 3 spring & & 4 & 3.14 & 26.22 & \\
\hline YT 27 & $7 / 3 / 10$ & 21.41557 & 88.78642 & spring & & 1.2 & 3.28 & 29.91 & \\
\hline YT 65 & $7 / 4 / 10$ & 21.395 & 88.9 & spring & & 0 & 3.9 & 26.99 & 36.1 \\
\hline YT 22 & $7 / 5 / 10$ & 21.44751 & 88.69441 & spring & & 1.941 & 4.28 & 26.19 & \\
\hline YT 146 & $7 / 6 / 10$ & 21.25438 & 89.72637 & spring & & 0.5 & 5.6901 & 26.98 & 8.6 \\
\hline YT 25 & $7 / 7 / 10$ & 21.41237 & 88.80241 & spring & & 4.015 & 6.1 & 29.44 & 50 \\
\hline YT221 & $7 / 8 / 10$ & 20.88293 & 86.85896 & spring & & 4.6 & 6.3224 & 27.62 & 5.4 \\
\hline YT 20 & $7 / 9 / 10$ & 21.403 & 88.84 & spring & & 2.5 & 7.03 & 27.73 & \\
\hline YT301 & $7 / 10 / 10$ & 20.39343 & 87.31703 & 3 spring & & 0 & 8.7142 & 26.91 & 31.8 \\
\hline YT 160 & $7 / 11 / 10$ & 20.76581 & 90.40974 & spring & & 0.5 & 9.8388 & 26.58 & 49.9 \\
\hline YT 174 & $7 / 12 / 10$ & 21.40511 & 88.8314 & spring & & 0.5 & 10.8027 & 27.55 & 58.9 \\
\hline YT223 & $7 / 13 / 10$ & 20.88957 & 86.85599 & spring & & 4 & 12.4647 & 25.98 & 10 \\
\hline YT251 & $7 / 14 / 10$ & 20.39079 & 87.31953 & 3 spring & & 0 & 15.7118 & 24.08 & \\
\hline YT 182 & $7 / 15 / 10$ & 20.89202 & 86.85413 & 3 spring & & 5 & 16.9917 & 27.19 & \\
\hline YT303 & $7 / 16 / 10$ & 20.39069 & 87.31944 & spring & & 0 & 17.3068 & 26.4 & 19.5 \\
\hline YT255 & $7 / 17 / 10$ & 20.78013 & 86.94135 & spring & & 0 & 18.7592 & 25.27 & 9.5 \\
\hline YT250 & $7 / 18 / 10$ & 20.39059 & 87.31953 & 3 spring & & 0 & 18.9931 & 26.52 & 113.5 \\
\hline YT 59 & $7 / 19 / 10$ & 20.9525 & 90.332 & spring & & 0 & 20 & 27.75 & \\
\hline YT254 & $7 / 20 / 10$ & 20.78184 & 86.94052 & spring & & 0 & 23.1086 & 25.18 & 4.8 \\
\hline YT305 & $7 / 21 / 10$ & 20.41082 & 87.3055 & spring & & 0 & 23.9589 & 26.74 & 28.9 \\
\hline YT 181 & $7 / 22 / 10$ & 20.87771 & 86.86105 & spring & & 6 & 24.311 & 27.71 & \\
\hline YT 180 & $7 / 23 / 10$ & 20.87771 & 86.86105 & spring & & 6 & 25.3194 & 27.83 & \\
\hline YT 145 & $7 / 24 / 10$ & 21.25726 & 89.73708 & 3 spring & & 0.5 & 25.946 & 23.73 & 88 \\
\hline YT214 & $7 / 25 / 10$ & 20.87768 & 86.86098 & 3 spring & & 6.4 & 26.8666 & 27.41 & 18.4 \\
\hline YT215 & $7 / 26 / 10$ & 20.87768 & 86.86098 & 3 spring & & 5.8 & 27.0362 & 27.45 & 6.5 \\
\hline YT252 & $7 / 27 / 10$ & 20.39051 & 87.31972 & spring & & 0 & 27.1266 & 24.03 & \\
\hline YT220 & $7 / 28 / 10$ & 20.88114 & 86.86015 & spring & & 6.4 & 29.5748 & 26.32 & 27.7 \\
\hline YT218 & $7 / 29 / 10$ & 20.88021 & 86.86139 & spring & & 5.5 & 29.8533 & 26.2 & 32.8 \\
\hline YT217 & $7 / 30 / 10$ & 20.88021 & 86.86139 & spring & & 5.5 & 32.3665 & 25.48 & 64.6 \\
\hline YT302 & $7 / 31 / 10$ & 20.39208 & 87.31873 & 3 spring & & 0 & 34.4312 & 28.61 & 85 \\
\hline YT 179 & $8 / 1 / 10$ & 20.84962 & 86.8726 & spring & & 4 & 34.905 & 28.26 & \\
\hline YT222 & $8 / 2 / 10$ & 20.88625 & 86.85738 & 3 spring & & 4.3 & 34.9278 & 25.14 & 84 \\
\hline YT 64 & $8 / 3 / 10$ & 20.83714 & 90.38638 & 3 spring & & 0 & & & \\
\hline YT244 & $8 / 4 / 10$ & 20.7797 & 86.94233 & 3 spring & 30 & 0 & 15.1332 & 25.12 & 4.5 \\
\hline YT334 & $8 / 5 / 10$ & 20.7797 & 86.94233 & 3 spring & 30 & 1 & 18.8063 & 25 & \\
\hline YT335 & $8 / 6 / 10$ & 20.7797 & 86.94233 & spring & 30 & 0 & 11.2615 & 24.77 & \\
\hline YT324 & $8 / 7 / 10$ & 20.20768 & 87.45031 & well & 1800 & 3 & 0.6172 & 27.72 & 22.6 \\
\hline YT312 & $8 / 8 / 10$ & 20.19956 & 87.49955 & 5 well & 6100 & 2 & 1.1073 & 27.36 & 8.7 \\
\hline YT313 & $8 / 9 / 10$ & 20.19956 & 87.49955 & well & 6100 & 4 & 1.3341 & 26.7 & 2.8 \\
\hline YT306 & $8 / 10 / 10$ & 20.5054 & 87.2233 & 3 well & 500 & 1 & 1.3485 & 27.18 & 100.4 \\
\hline YT314 & $8 / 11 / 10$ & 20.19956 & 87.49955 & well & 6100 & 6 & 1.3779 & 26.56 & 3.5 \\
\hline YT326 & $8 / 12 / 10$ & 20.17866 & 87.45953 & 3 well & 1350 & 2 & 1.4436 & 27 & 95.8 \\
\hline YT246 & $8 / 13 / 10$ & 70.78016 & 86.94344 & 7 well & 155 & 0 & 1.6135 & 22.58 & 15.7 \\
\hline YT315 & $8 / 14 / 10$ & 20.19956 & 87.49955 & well & 6100 & 9 & 1.7452 & 26.4 & 2.9 \\
\hline YT257 & $8 / 15 / 10$ & 20.78016 & 86.94344 & + well & 155 & 0 & 1.8718 & 25.1 & 1.1 \\
\hline YT316 & $8 / 16 / 10$ & 20.19956 & 87.49955 & well & 6100 & 12 & 2.0384 & 26.27 & 3 \\
\hline YT317 & $8 / 17 / 10$ & 20.19956 & 87.49955 & 5 well & 6100 & 15 & 2.0605 & 25.93 & 3.6 \\
\hline YT325 & $8 / 18 / 10$ & 20.20768 & 87.45031 & well & 1800 & 10.5 & 2.3992 & 27.33 & 94.6 \\
\hline YT327 & $8 / 19 / 10$ & 20.3475 & 87.34829 & well & 850 & 3 & 2.5618 & 26.41 & 28.1 \\
\hline YT307 & $8 / 20 / 10$ & 20.5054 & 87.2233 & 3 well & 500 & 4 & 2.8409 & 26.74 & 49 \\
\hline YT308 & $8 / 21 / 10$ & 20.5054 & 87.2233 & 3 well & 500 & 6 & 2.8777 & 26.54 & 51.8 \\
\hline YT259 & $8 / 22 / 10$ & 20.78006 & 86.94371 & well & 175 & & 3.0457 & 27.02 & 6.7 \\
\hline YT309 & $8 / 23 / 10$ & 20.5054 & 87.2233 & 3 well & 500 & 7 & 3.5014 & 26.63 & 50.7 \\
\hline YT318 & $8 / 24 / 10$ & 20.19956 & 87.49955 & well & 6100 & 17.8 & 3.5779 & 25.9 & 1.7 \\
\hline YT245 & $8 / 25 / 10$ & 70.78006 & 86.94371 & well & 175 & 0 & 3.7185 & 27.18 & 24.5 \\
\hline YT320 & $8 / 26 / 10$ & 20.19956 & 87.49955 & well & 6100 & 17.5 & 10.5062 & 26.09 & 2.2 \\
\hline YT328 & $8 / 27 / 10$ & 20.3475 & 87.34829 & well & 850 & 10 & 12.3659 & 26.61 & 14.1 \\
\hline YT310 & $8 / 28 / 10$ & 20.5054 & 87.2233 & 3 well & 500 & 8 & 18.0325 & 26.71 & 33.1 \\
\hline YT329 & $8 / 29 / 10$ & 20.3475 & 87.34829 & well & 850 & 11 & 25.8904 & 26.84 & 34 \\
\hline
\end{tabular}




\begin{tabular}{|c|c|c|c|c|c|c|c|c|c|}
\hline $\mathrm{I}$ & II & III & IV & $\mathrm{V}$ & VI & VII & VIII & IX & $\mathrm{X}$ \\
\hline $\begin{array}{l}\text { Internal } \\
\text { sample ID } \\
\end{array}$ & Date & $\begin{array}{l}\text { Latitude N } \\
\text { degrees }\end{array}$ & $\begin{array}{l}\text { Longitude W } \\
\text { degrees }\end{array}$ & Sample Type & $\begin{array}{l}\text { Sample } \\
\text { distance to } \\
\text { shoreline } \mathrm{m}\end{array}$ & $\begin{array}{l}\text { Sample } \\
\text { Depth m }\end{array}$ & $\begin{array}{l}\text { Salinometer } \\
\text { salinity }\end{array}$ & $\begin{array}{l}\text { Collection } \\
\text { Temp C }\end{array}$ & $\begin{array}{l}\text { Collection DO } \\
\text { sat \% }\end{array}$ \\
\hline YT319 & $8 / 30 / 10$ & 20.19956 & 87.49955 & well & 6100 & 16.8 & 26.0387 & 25.94 & 2.3 \\
\hline YT311 & $8 / 31 / 10$ & 20.5054 & 87.2233 & well & 500 & 8.2 & 32.4807 & 27.09 & 27.6 \\
\hline YT321 & $9 / 1 / 10$ & 20.19956 & 87.49955 & well & 6100 & 20 & 35.3029 & 25.79 & 16.2 \\
\hline YT323 & $9 / 2 / 10$ & 20.19956 & 87.49955 & well & 6100 & 26 & 35.3604 & 26.09 & 18.2 \\
\hline YT330 & $9 / 3 / 10$ & 20.3475 & 87.34829 & well & 850 & 19 & 35.5417 & 27.25 & 67.6 \\
\hline YT337 & $9 / 4 / 10$ & 20.8765 & 87.04403 & reducing cenote & 14800 & 30 & 6.6803 & 24.67 & \\
\hline YT 176 & $9 / 5 / 10$ & 21.35975 & 88.65929 & reducing cenote & 10770 & 62 & 33.0857 & 26.81 & 34.3 \\
\hline YT243 & $9 / 6 / 10$ & 20.8765 & 87.04403 & reducing cenote & 14800 & 37 & 19.424 & 24.49 & 8.2 \\
\hline YT241 & $9 / 7 / 10$ & 20.8765 & 87.04403 & reducing cenote & 14800 & 34.5 & 12.3524 & 24.73 & 7.3 \\
\hline YT242 & $9 / 8 / 10$ & 20.8765 & 87.04403 & reducing cenote & 14800 & 35.5 & 14.9269 & 24.74 & 7.7 \\
\hline YT 177 & $9 / 9 / 10$ & 21.35975 & 88.65929 & reducing cenote & 10770 & 53.2 & 13.7791 & 26.56 & 30.9 \\
\hline YT240 & $9 / 10 / 10$ & 20.8765 & 87.04403 & reducing cenote & 14800 & 32.5 & 10.1948 & 24.72 & 6.7 \\
\hline YT238 & $9 / 11 / 10$ & 20.8765 & 87.04403 & reducing cenote & 14800 & 31.5 & 5.7957 & 24.59 & 5.1 \\
\hline YT239 & $9 / 12 / 10$ & 20.8765 & 87.04403 & reducing cenote & 14800 & 32 & 7.8747 & 24.64 & 6.4 \\
\hline YT 175 & $9 / 13 / 10$ & 21.35975 & 88.65929 & reducing cenote & 10770 & 64 & 34.2219 & 26.68 & 0 \\
\hline YT338 & $9 / 14 / 10$ & 20.8765 & 87.04403 & reducing cenote & 14800 & 31 & 11.8658 & 24.68 & \\
\hline YT237 & $9 / 15 / 10$ & 20.8765 & 87.04403 & reducing cenote & 14800 & 30.5 & 2.5951 & 24.45 & 4.1 \\
\hline YT339 & $9 / 16 / 10$ & 20.8765 & 87.04403 & reducing cenote & 14800 & 35 & 16.7969 & 23.97 & \\
\hline YT 178 & $9 / 17 / 10$ & 21.35975 & 88.65929 & reducing cenote & 10770 & 52 & 4.9456 & 26.72 & 29.4 \\
\hline YT235 & $9 / 18 / 10$ & 20.8765 & 87.04403 & reducing cenote & 14800 & 31 & 4.2668 & 24.97 & 6.6 \\
\hline YT 8 & $9 / 19 / 10$ & 20.871 & 90.36 & reducing cenote & 0 & 1 & 18.51 & & \\
\hline YT 115 & $9 / 20 / 10$ & 20.85028 & 90.23561 & reducing cenote & 12900 & 33.5 & 36.6249 & 27.04 & 0 \\
\hline YT 112 & $9 / 21 / 10$ & 20.85028 & 90.23561 & reducing cenote & 12900 & 31.7 & 23.2546 & 27.62 & \\
\hline YT 113 & $9 / 22 / 10$ & 20.85028 & 90.23561 & reducing cenote & 12900 & 32.1 & 25.7918 & 27.19 & \\
\hline YT236 & $9 / 23 / 10$ & 20.8765 & 87.04403 & reducing cenote & 14800 & 30 & 0.9362 & 24.52 & 4.5 \\
\hline YT 109 & $9 / 24 / 10$ & 20.85028 & 90.23561 & reducing cenote & 12900 & 29.5 & 7.2013 & 29.62 & \\
\hline YT 116 & $9 / 25 / 10$ & 20.85028 & 90.23561 & reducing cenote & 12900 & & 6.8948 & & 7.7 \\
\hline YT 3 & $9 / 26 / 10$ & 20.9451 & 90.3472 & reducing cenote & 0 & 1.3 & 6.7 & & \\
\hline YT 111B & $9 / 27 / 10$ & 20.85028 & 90.23561 & reducing cenote & 12900 & 31.3 & & 27.86 & 0.8 \\
\hline YT 111 & $9 / 28 / 10$ & 20.85028 & 90.23561 & reducing cenote & 12900 & 29.8 & 11.6819 & 28.48 & 4 \\
\hline YT 114 & $9 / 29 / 10$ & 20.85028 & 90.23561 & reducing cenote & 12900 & 33.5 & 29.9797 & 27.02 & 3.8 \\
\hline YT 110 & $9 / 30 / 10$ & 20.85028 & 90.23561 & reducing cenote & 12900 & 31 & 15.2607 & 28.51 & 7.4 \\
\hline YT210 & $10 / 1 / 10$ & 20.78057 & 86.94706 & reducing cenote & 480 & 4 & 1.3237 & 24.45 & 7.4 \\
\hline YT 117 & $10 / 2 / 10$ & 20.85028 & 90.23561 & reducing cenote & 12900 & & 25.8857 & 27.03 & 19.8 \\
\hline YT 12 & $5 / 28 / 11$ & 20.85092 & 90.23347 & reducing cenote & 12900 & 29.1 & 10 & & \\
\hline YT 16 & $5 / 28 / 11$ & 20.85092 & 90.23347 & reducing cenote & 12900 & 30.9 & 31 & & \\
\hline YT 15 & $5 / 28 / 11$ & 20.85092 & 90.23347 & reducing cenote & 12900 & 31.5 & 36 & & \\
\hline YT 17 & $5 / 28 / 11$ & 20.85092 & 90.23347 & reducing cenote & 12900 & 31 & & & \\
\hline YT 11 & $5 / 28 / 11$ & 20.85092 & 90.23347 & reducing cenote & 12900 & 28 & 5 & & \\
\hline YT 13 & $5 / 28 / 11$ & 20.85092 & 90.23347 & reducing cenote & 12900 & 31 & 25 & & \\
\hline YT 14 & $5 / 28 / 11$ & 20.85092 & 90.23347 & reducing cenote & 12900 & 30.5 & 20 & & \\
\hline YT 10 & $5 / 28 / 11$ & 20.85092 & 90.23347 & reducing cenote & 12900 & 30 & 15 & & \\
\hline YT 74 & $5 / 31 / 11$ & 21.37977 & 88.89371 & reducing cenote & 1450 & 1.752 & 2.06 & 26.71 & \\
\hline YT 153 & $12 / 4 / 09$ & 20.87742 & 90.35493 & reducing cenote & 55 & 0.5 & 3.3852 & 23.85 & 58.1 \\
\hline YT340 & $10 / 25 / 11$ & 20.88232 & 86.07121 & reducing cenote & 20800 & 0 & 0.6758 & 23.57 & \\
\hline YT 148 & $12 / 8 / 09$ & 21.27666 & 89.64419 & reducing cenote & 1460 & 1 & 14.3125 & 26.49 & 6 \\
\hline YT322 & $10 / 23 / 11$ & 20.20041 & 87.49989 & reducing cenote & 6200 & 0 & 2.0147 & 25.4 & 16.9 \\
\hline YT 166 & $12 / 5 / 09$ & 21.4082 & 88.50388 & reducing cenote & 14200 & 15 & 0.1885 & 25.6 & 11 \\
\hline YT 101 & $12 / 4 / 09$ & 20.8714 & 90.13792 & reducing cenote & 21600 & 0.5 & 1.5659 & 26.4 & 110 \\
\hline YT 163 & $12 / 5 / 09$ & 21.35975 & 88.65929 & reducing cenote & 10770 & 1 & 1.0005 & 27.02 & 57.9 \\
\hline YT 149 & $12 / 8 / 09$ & 21.27666 & 89.64419 & reducing cenote & 1460 & 1 & 2.1367 & 26.77 & 17 \\
\hline YT 164 & $12 / 5 / 09$ & 21.35975 & 88.65929 & reducing cenote & 10770 & 15 & 0.9998 & 26.84 & 73.5 \\
\hline YT 147 & $12 / 8 / 09$ & 21.27666 & 89.64419 & reducing cenote & 1460 & 1 & 3.561 & 26.84 & 8.6 \\
\hline YT 167 & $12 / 5 / 09$ & 21.38233 & 88.61064 & reducing cenote & 10900 & 28 & 0.629 & 26.39 & 41.7 \\
\hline YT 108 & $12 / 5 / 09$ & 20.85028 & 90.23561 & reducing cenote & 12900 & 28 & 3.4526 & 26.85 & 4.8 \\
\hline YT 165 & $12 / 5 / 09$ & 21.35975 & 88.65929 & reducing cenote & 10770 & 28 & 1.0018 & 26.73 & 70.7 \\
\hline YT 7 & $5 / 27 / 11$ & 20.87825 & 90.35334 & reducing cenote & 0 & 0 & 9.59 & 27 & \\
\hline YT 102 & $12 / 5 / 09$ & 20.85028 & 90.23561 & reducing cenote & 12900 & 1 & 1.4069 & 27.29 & 97.5 \\
\hline YT 168 & $12 / 6 / 09$ & 21.36857 & 88.85308 & cenote & 3060 & 1 & 1.559 & 26.6 & 21.2 \\
\hline YT 1 & $5 / 26 / 11$ & 20.81391 & 90.19435 & cenote & 19700 & 0.5 & 1.5 & 29.82 & \\
\hline YT 6 & $5 / 27 / 11$ & 20.87825 & 90.35334 & cenote & 0 & 0 & 5.75 & 25.96 & \\
\hline YT 103 & $12 / 5 / 09$ & 20.85028 & 90.23561 & cenote & 12900 & 5 & 1.4104 & 27.07 & 88.2 \\
\hline YT 21 & $5 / 30 / 11$ & 21.40126 & 88.82375 & cenote & 0 & 5.448 & 2.38 & 26.81 & \\
\hline YT195 & $2 / 12 / 11$ & 20.77969 & 86.94273 & cenote & 60 & 0 & 7.8851 & 24.62 & 4.5 \\
\hline YT 104 & $12 / 5 / 09$ & 20.85028 & 90.23561 & cenote & 12900 & 7 & 1.6869 & 26.9 & 10.7 \\
\hline YT 26 & $5 / 30 / 11$ & 21.412 & 88.80204 & cenote & 20 & 0.288 & 5.25 & 28.86 & \\
\hline YT 105 & $12 / 5 / 09$ & 20.85028 & 90.23561 & cenote & 12900 & 12 & 1.6935 & 26.74 & 8.5 \\
\hline YT 169 & $12 / 7 / 09$ & 21.36858 & 88.5307 & cenote & 18300 & 0.5 & 4.6095 & 26.8 & 19.6 \\
\hline YT248 & $2 / 17 / 11$ & 20.85745 & 86.97532 & cenote & 8000 & 0 & 0.2716 & 20.43 & 66.8 \\
\hline YT 170 & $12 / 7 / 09$ & 21.41167 & 88.80422 & cenote & 30 & 0.5 & 6.8799 & 27.01 & 82.5 \\
\hline YT 73 & $5 / 31 / 11$ & 21.37368 & 88.90251 & cenote & 1930 & 0.45 & 1.75 & 27.03 & \\
\hline YT 106 & $12 / 5 / 09$ & 20.85028 & 90.23561 & cenote & 12900 & 17 & 1.6956 & 26.98 & 13.7 \\
\hline YT 107 & $12 / 5 / 09$ & 20.85028 & 90.23561 & cenote & 12900 & 22 & 1.6985 & 26.94 & 7.9 \\
\hline YT 2-1 & $5 / 26 / 11$ & 20.85026 & 90.23559 & cenote & 12900 & 27 & 3 & & \\
\hline YT 119 & $12 / 5 / 09$ & 20.64949 & 89.89567 & cenote & 54900 & 0.5 & 0.7092 & 27.17 & 143 \\
\hline YT 118 & $12 / 5 / 09$ & 20.81322 & 90.19634 & cenote & 19400 & 0.5 & 1.503 & 26 & 88.1 \\
\hline YT341 & $10 / 25 / 11$ & 20.78057 & 86.94706 & cenote & 480 & 0 & 1.2871 & 27.61 & 18 \\
\hline YT 120 & $12 / 5 / 09$ & 20.75019 & 89.83429 & cenote & 56000 & 0.5 & 1.0716 & 27.42 & 120.9 \\
\hline YT333 & $10 / 24 / 11$ & 20.77969 & 86.94273 & cenote & 60 & 0.5 & 0.5126 & 24.82 & \\
\hline YT209 & $2 / 13 / 11$ & 20.78057 & 86.94706 & cenote & 480 & 1 & 1.3086 & 25.3 & 79.4 \\
\hline
\end{tabular}




\begin{tabular}{|c|c|c|c|c|c|c|c|c|c|}
\hline $\bar{I}$ & II & III & IV & $\mathrm{V}$ & VI & VII & VIII & IX & $x$ \\
\hline $\begin{array}{l}\text { Internal } \\
\text { sample ID }\end{array}$ & Date & $\begin{array}{l}\text { Latitude } \mathrm{N} \\
\text { degrees }\end{array}$ & $\begin{array}{l}\text { Longitude W } \\
\text { degrees }\end{array}$ & Sample Type & $\begin{array}{l}\text { Sample } \\
\text { distance to } \\
\text { shoreline } \mathrm{m}\end{array}$ & $\begin{array}{l}\text { Sample } \\
\text { Depth m }\end{array}$ & $\begin{array}{l}\text { Salinometer } \\
\text { salinity }\end{array}$ & $\begin{array}{l}\text { Collection } \\
\text { Temp C }\end{array}$ & $\begin{array}{l}\text { Collection DO } \\
\text { sat \% }\end{array}$ \\
\hline YT 2-5 & $5 / 26 / 11$ & 20.85026 & 90.23559 & cenote & 12900 & 3 & 1.16 & & \\
\hline YT206 & $2 / 12 / 11$ & 20.85 & 87.11973 & 3 cenote & 19700 & 28 & 0.7459 & 23.71 & 30.8 \\
\hline YT207 & $2 / 12 / 11$ & 20.85 & 87.11973 & 3 cenote & 19700 & 31 & 0.7449 & & \\
\hline YT332 & $10 / 24 / 11$ & 20.77969 & 86.94273 & 3 cenote & 60 & 3 & 18.7202 & 25.01 & \\
\hline YT205 & $2 / 12 / 11$ & 20.85 & 87.11973 & 3 cenote & 19700 & 25 & 0.7424 & 23.71 & 35 \\
\hline YT204 & $2 / 12 / 11$ & 20.85 & 87.11973 & 3 cenote & 19700 & 22 & 0.7424 & 23.72 & 37.2 \\
\hline YT203 & $2 / 12 / 11$ & 20.85 & 87.11973 & 3 cenote & 19700 & 19 & 0.7403 & 23.73 & 38.3 \\
\hline YT202 & $2 / 12 / 11$ & 20.85 & 87.11973 & 3 cenote & 19700 & 16 & 0.7402 & 23.75 & 38.7 \\
\hline YT201 & $2 / 12 / 11$ & 20.85 & 87.11973 & 3 cenote & 19700 & 13 & 0.7398 & 23.76 & 38.9 \\
\hline YT200 & $2 / 12 / 11$ & 20.85 & 87.11973 & 3 cenote & 19700 & 10 & 0.7398 & 23.75 & 39.1 \\
\hline YT199 & $2 / 12 / 11$ & 20.85 & 87.11973 & 3 cenote & 19700 & 7 & 0.7395 & 23.76 & 39.3 \\
\hline YT198 & $2 / 12 / 11$ & 20.85 & 87.11973 & 3 cenote & 19700 & 4 & 0.742 & 23.76 & 39.4 \\
\hline YT234 & $2 / 16 / 11$ & 20.8765 & 87.04403 & 3 cenote & 14800 & 28 & 0.7124 & 24.21 & 5.5 \\
\hline YT197 & $2 / 12 / 11$ & 20.85 & 87.11973 & 3 cenote & 19700 & 1 & 0.742 & 23.76 & 40.4 \\
\hline YT233 & $2 / 16 / 11$ & 20.8765 & 87.04403 & 3 cenote & 14800 & 25 & 0.7111 & 24.21 & 7.7 \\
\hline YT232 & $2 / 16 / 11$ & 20.8765 & 87.04403 & 3 cenote & 14800 & 22 & 0.7107 & 24.21 & 9.1 \\
\hline YT231 & $2 / 16 / 11$ & 20.8765 & 87.04403 & 3 cenote & 14800 & 19 & 0.7106 & 24.21 & 9.6 \\
\hline YT229 & $2 / 16 / 11$ & 20.8765 & 87.04403 & 3 cenote & 14800 & 13 & 0.7106 & 24.21 & 9.7 \\
\hline YT230 & $2 / 16 / 11$ & 20.8765 & 87.04403 & 3 cenote & 14800 & 16 & 0.7105 & 24.21 & 9.7 \\
\hline YT228 & $2 / 16 / 11$ & 20.8765 & 87.04403 & 3 cenote & 14800 & 10 & 0.7105 & 24.22 & 10 \\
\hline YT227 & $2 / 16 / 11$ & 20.8765 & 87.04403 & 3 cenote & 14800 & 7 & 0.7106 & 24.22 & 10.1 \\
\hline YT226 & $2 / 16 / 11$ & 20.8765 & 87.04403 & 3 cenote & 14800 & 4 & 0.7105 & 24.21 & 10.5 \\
\hline YT225 & $2 / 16 / 11$ & 20.8765 & 87.04403 & 3 cenote & 14800 & 1 & 0.7114 & 24.22 & 12.4 \\
\hline YT 2-4 & $5 / 26 / 11$ & 20.85026 & 90.23559 & cenote & 12900 & 9 & 1.5 & & \\
\hline YT 2-3 & $5 / 26 / 11$ & 20.85026 & 90.23559 & cenote & 12900 & 15 & 1.6 & & \\
\hline YT336 & $10 / 25 / 11$ & 20.8765 & 87.04403 & 3 cenote & 14800 & 2 & 0.6713 & 24.82 & 24 \\
\hline YT 100 & $12 / 4 / 09$ & 21.07374 & 89.72098 & 3 cenote & 22000 & 4 & 0.805 & 27.61 & 24.4 \\
\hline YT 18 & $5 / 28 / 11$ & 20.85092 & 90.23347 & cenote & 12900 & 23 & 1 & & \\
\hline YT 2-2 & $5 / 26 / 11$ & 20.85026 & 90.23559 & cenote & 12900 & 21 & 1.5 & & \\
\hline YT 184 & $12 / 9 / 09$ & 20.78164 & 86.95326 & cenote & 1100 & 0.5 & 0.3935 & 27.67 & \\
\hline
\end{tabular}




\begin{tabular}{|c|c|c|c|c|c|c|c|c|c|c|}
\hline $\mathrm{I}$ & XI & $\mathrm{XI}$ & XII & XIII & XIV & $\mathrm{XV}$ & XVI & XVII & XVIII & $\mathrm{XIX}$ \\
\hline $\begin{array}{l}\text { Internal } \\
\text { sample ID }\end{array}$ & $\begin{array}{l}\text { Collection DO } \\
\mathrm{mg} / \mathrm{L}\end{array}$ & Collection $\mathrm{pH}$ & $\begin{array}{l}\text { Collection Eh } \\
(\mathrm{mV})\end{array}$ & $\begin{array}{l}226 \mathrm{Ra} \\
\mathrm{dpm} / 100 \mathrm{~L}\end{array}$ & $\begin{array}{l}226 \mathrm{Ra} \\
\mathrm{dpm} / 100 \mathrm{~L} \\
\text { error }\end{array}$ & $\begin{array}{l}228 \mathrm{Ra} \\
\mathrm{dpm} / 100 \mathrm{~L}\end{array}$ & $\begin{array}{l}228 \mathrm{Ra} \\
\mathrm{dpm} / 100 \mathrm{~L} \\
\text { error }\end{array}$ & $\begin{array}{l}224 \mathrm{ex} \\
\mathrm{dpm} / 100 \mathrm{~L}\end{array}$ & $\begin{array}{l}223 \mathrm{ex} \\
\mathrm{dpm} / 100 \mathrm{~L}\end{array}$ & Ba nmol/kg \\
\hline$\frac{5 d 172}{\text { YT } 172}$ & 4.3 & 6.97 & 175.3 & 1090.6 & 10.9 & 22.1 & 7.5 & & $\frac{252.1}{252}$ & 184.3 \\
\hline YT 155 & 3.19 & 7.34 & 113.6 & 415.8 & 4.6 & 32.9 & 5.0 & 22.1 & 13.1 & 194.8 \\
\hline YT 156 & 5.1 & 7.99 & 239 & 378.5 & 6.7 & 20.8 & 6.4 & 7.5 & 2.0 & 242.6 \\
\hline YT 158 & 5.37 & 7.56 & 245.2 & 319.5 & 4.1 & 13.4 & 4.3 & 5.4 & 2.6 & 246.0 \\
\hline YT 154 & 5.6 & 8.09 & 192.3 & 341.9 & 4.2 & 12.8 & 4.2 & 15.7 & 1.0 & 258.2 \\
\hline YT 152 & 1.29 & 7.53 & -64 & 401.5 & 4.9 & 13.1 & 4.6 & 4.2 & 0.5 & 261.3 \\
\hline YT 162 & 3.56 & 7.94 & 263.1 & 275.9 & 5.7 & 12.1 & 5.1 & 5.6 & 2.9 & 232.3 \\
\hline YT 151 & 4.96 & 8.04 & 289.5 & 334.9 & 4.4 & 19.2 & 4.3 & 15.4 & 0.8 & 268.7 \\
\hline YT 159 & 4.01 & 7.91 & 236.3 & 247.8 & 5.7 & 13.2 & 5.8 & 6.9 & 3.6 & 204.0 \\
\hline YT 150 & 2.69 & 7.61 & 297.3 & 399.0 & 5.2 & 18.8 & 5.1 & 15.2 & 9.2 & 315.8 \\
\hline YT 66 & & 8.12 & 282.5 & 812.9 & & 36.7 & & 31.0 & 63.0 & 182.3 \\
\hline YT 61 & & & & 846.6 & & 57.0 & & 15.7 & 15.5 & 229.2 \\
\hline YT 62 & & & & 1479.4 & & 104.6 & & 47.0 & 51.1 & 236.4 \\
\hline YT 57 & & & & 579.6 & & 44.2 & & 61.5 & 10.9 & 177.5 \\
\hline YT 63 & & & & 1130.3 & & 66.1 & & 55.4 & 65.5 & 216.2 \\
\hline YT 60 & & & & 812.4 & & 42.8 & & 15.8 & 5.6 & 275.8 \\
\hline YT 161 & 7.44 & 8.13 & 267.9 & 152.3 & 4.8 & 17.8 & 6.7 & 6.9 & 3.2 & 128.0 \\
\hline YT 72 & & & & 188.3 & & 17.7 & & 6.9 & 8.2 & 86.3 \\
\hline YT 58 & & & & 543.6 & & 51.3 & & 24.0 & 0.9 & 291.1 \\
\hline YT 171 & 17.5 & 8.52 & 285.6 & 304.1 & 5.7 & 14.5 & 6.4 & 14.6 & 20.6 & 99.4 \\
\hline YT 56 & & & & 82.4 & & 14.9 & & 5.3 & 4.4 & 75.7 \\
\hline YT253 & & 7.27 & 297.2 & & & & & & & 63.9 \\
\hline YT300 & 7.05 & 8.17 & 203 & 19.1 & 0.3 & 9.1 & 0.6 & 9.3 & 4.4 & 67.8 \\
\hline YT256 & 5.17 & 8.24 & 311 & 44.3 & 0.5 & 8.5 & 0.7 & 3.8 & 8.1 & 69.7 \\
\hline YT249 & 7.53 & 7.21 & 290.7 & & & & & & & 67.4 \\
\hline TS10_11 & & & & 21.1 & 0.6 & 10.4 & 1.3 & & & 71.2 \\
\hline YT 71 & & & & 1730.1 & & 65.0 & & 67.7 & 19.4 & 132.5 \\
\hline YT331 & 5.36 & 8.11 & 134.2 & 28.6 & 1.0 & 7.8 & 1.8 & 14.1 & 2.8 & 59.8 \\
\hline YT260 & 9.68 & 7.98 & 321 & 29.5 & 0.4 & 5.3 & 0.9 & 7.5 & 1.5 & 60.2 \\
\hline YT211 & 7.22 & 8.15 & 320 & 24.1 & 0.5 & 7.6 & 1.0 & 6.0 & 2.2 & 56.1 \\
\hline YT219 & 6.95 & 8.09 & 175 & & & & & & & 55.7 \\
\hline YT191 & & & & & & & & & & 55.2 \\
\hline YT192 & & & & & & & & & & 54.4 \\
\hline YT216 & 6.63 & 8.11 & 294 & 68.2 & 1.0 & 6.8 & 1.2 & 6.2 & 4.5 & 56.0 \\
\hline YT194 & & & & & & & & & & 56.3 \\
\hline YT342 & 6.89 & 8.11 & 287.8 & 19.3 & 0.5 & 7.4 & 0.9 & 3.4 & 0.9 & 54.6 \\
\hline TS9_11 & & & & 24.4 & 0.6 & 8.7 & 1.1 & & & 58.2 \\
\hline YT224 & 6.62 & 8.15 & 73 & 20.0 & 0.8 & 7.4 & 1.4 & 4.0 & 0.9 & 56.9 \\
\hline TS4_11 & & & & 27.1 & 0.7 & 10.1 & 1.3 & & & 57.8 \\
\hline YT193 & & & & & & & & & & 54.1 \\
\hline TS8_11 & & & & 29.7 & 0.7 & 12.5 & 1.4 & & & 55.0 \\
\hline YT208 & 8.2 & 8.22 & 298.1 & 18.7 & 0.4 & 8.5 & 0.9 & 8.9 & 0.9 & 55.8 \\
\hline TS6_11 & & & & 20.8 & 0.6 & 7.2 & 1.2 & & & 58.2 \\
\hline YT213 & 8.18 & 8.26 & 353 & 11.3 & 0.5 & 7.6 & 1.0 & 4.5 & 0.3 & 54.6 \\
\hline TS_0211 & & & & 17.8 & 0.8 & 8.9 & 1.5 & 4.7 & 0.4 & 56.9 \\
\hline TS3_11 & & & & 17.7 & 0.6 & 10.0 & 1.3 & & & 53.5 \\
\hline TS7_11 & & & & 16.9 & 0.6 & 6.8 & 1.2 & & & 64.7 \\
\hline YT 70 & & & & 977.4 & & 26.8 & & 26.4 & 11.2 & 150.7 \\
\hline TS5_11 & & & & 18.9 & 0.5 & 10.0 & 1.1 & & & 53.8 \\
\hline YT 173 & 4.56 & 7.96 & 210.9 & 50.6 & 2.8 & 4.4 & 3.3 & 4.6 & 4.4 & 62.9 \\
\hline YT 68 & & & & 338.4 & & 23.5 & & 16.8 & 9.7 & 97.0 \\
\hline YT 69 & & & & 167.3 & & 19.8 & & 4.4 & 8.9 & 78.7 \\
\hline YT 67 & & & & 438.8 & & 22.6 & & 22.2 & 5.0 & 142.8 \\
\hline YT 66 & & & & 416.8 & & 21.7 & & 8.3 & 3.0 & 143.6 \\
\hline YT185 & & & & & & & & & & 53.2 \\
\hline YT186 & & & & & & & & & & 53.1 \\
\hline YT187 & & & & & & & & & & 54.0 \\
\hline YT188 & & & & & & & & & & 54.5 \\
\hline YT189 & & & & & & & & & & 55.5 \\
\hline YT190 & & & & & & & & & & 53.0 \\
\hline YT 53 & & & & 30.6 & & 15.1 & & 1.5 & 1.4 & 62.9 \\
\hline YT 51 & & & & 25.0 & & 6.8 & & 2.2 & 1.5 & 59.5 \\
\hline YT 52 & & & & 23.9 & & 5.5 & & 1.2 & 1.5 & 57.7 \\
\hline YT 54 & & & & 62.3 & & 11.7 & & 2.8 & 1.8 & 71.5 \\
\hline YT 132 & 6.3 & 7.38 & 363.2 & 108.9 & 2.2 & 8.3 & 2.1 & 4.0 & 4.7 & 68.9 \\
\hline YT212 & 7 & 8.21 & 366.9 & 12.5 & 0.5 & 4.7 & 0.8 & 2.6 & 0.0 & 55.5 \\
\hline YT 121 & 6.51 & 8.24 & 284.9 & 36.6 & 0.9 & 5.0 & 1.3 & 3.1 & 1.6 & 81.6 \\
\hline YT 183 & & 8.28 & & 25.0 & 1.6 & 7.4 & 3.2 & 14.3 & 0.4 & 59.0 \\
\hline YT 131 & 6.56 & 7.63 & 386.4 & 55.4 & 1.5 & 6.8 & 1.8 & 4.6 & 2.6 & 69.9 \\
\hline YT 142 & 6.89 & 7.73 & 362.7 & 10.7 & 0.6 & 7.4 & 1.3 & 2.2 & 0.7 & 61.0 \\
\hline YT 122 & 6.53 & 7.91 & 319.2 & 12.5 & 0.6 & 1.8 & 0.9 & 1.8 & 0.7 & 61.2 \\
\hline YT 123 & 6.66 & 7.93 & 325 & 9.7 & 0.9 & 4.4 & 1.7 & 1.9 & 1.0 & 62.0 \\
\hline YT 126 & 6.62 & 7.89 & 321.1 & 8.9 & 0.8 & 6.1 & 1.7 & 0.9 & 0.5 & 61.2 \\
\hline YT 127 & 6.58 & 7.89 & 323.7 & 8.5 & 0.6 & 4.5 & 1.1 & 0.1 & 0.5 & 62.5 \\
\hline YT 137 & 6.84 & 7.68 & 368.6 & 10.0 & 0.6 & 5.3 & 1.3 & 1.8 & 0.1 & 62.0 \\
\hline YT 128 & 6.84 & 7.85 & 334.3 & 10.2 & 0.6 & 6.4 & 1.2 & 1.6 & 0.8 & 57.8 \\
\hline YT 125 & 6.81 & 7.94 & 330.8 & 9.2 & 0.6 & 4.0 & 1.1 & 4.8 & 0.8 & 56.8 \\
\hline YT 140 & 6.9 & 7.73 & 367.8 & 9.7 & 0.5 & 3.8 & 1.0 & 2.1 & 0.2 & 66.8 \\
\hline YT 124 & 6.6 & 7.95 & 344.8 & 14.2 & 0.6 & 7.4 & 1.3 & 2.3 & 0.8 & 61.4 \\
\hline YT 138 & 6.79 & 7.74 & 364.2 & 10.2 & 0.6 & 7.0 & 1.3 & 1.3 & 0.1 & 63.4 \\
\hline
\end{tabular}




\begin{tabular}{|c|c|c|c|c|c|c|c|c|c|c|}
\hline $\mathrm{I}$ & $X I$ & XI & XII & XIII & XIV & $\mathrm{XV}$ & XVI & XVII & XVIII & XIX \\
\hline $\begin{array}{l}\text { Internal } \\
\text { sample ID }\end{array}$ & $\begin{array}{l}\text { Collection DO } \\
\mathrm{mg} / \mathrm{L}\end{array}$ & Collection $\mathrm{pH}$ & $\begin{array}{l}\text { Collection Eh } \\
(\mathrm{mV})\end{array}$ & $\begin{array}{l}226 \mathrm{Ra} \\
\mathrm{dpm} / 100 \mathrm{~L}\end{array}$ & $\begin{array}{l}\mathrm{dpm} / 100 \mathrm{~L} \\
\text { error }\end{array}$ & $\begin{array}{l}228 \mathrm{Ra} \\
\mathrm{dpm} / 100 \mathrm{~L}\end{array}$ & $\begin{array}{l}\mathrm{dpm} / 100 \mathrm{~L} \\
\text { error }\end{array}$ & $\begin{array}{l}224 \mathrm{ex} \\
\mathrm{dpm} / 100 \mathrm{~L}\end{array}$ & $\begin{array}{l}223 \mathrm{ex} \\
\mathrm{dpm} / 100 \mathrm{~L}\end{array}$ & $\mathrm{Ba} \mathrm{nmol} / \mathrm{kg}$ \\
\hline YT 136 & 6.8 & 6.79 & 368.6 & 9.5 & 50.6 & 6.0 & 1.2 & 1.7 & 0.4 & 65.0 \\
\hline YT 130 & 6.51 & 7.79 & 341 & 13.7 & 1.8 & 10.9 & 3.9 & 1.6 & 1.2 & 62.6 \\
\hline YT 139 & 6.78 & 7.73 & 369.3 & 10.9 & 0.6 & 6.3 & 1.3 & 1.0 & 0.1 & 62.2 \\
\hline YT 129 & 6.77 & 7.83 & 339.3 & 10.2 & 0.6 & 7.8 & 1.3 & 1.3 & 0.6 & 61.8 \\
\hline YT 141 & 6.96 & 7.71 & 361.9 & 8.4 & 0.6 & 3.6 & 1.2 & 1.6 & 0.5 & 61.0 \\
\hline YT 143 & 7.02 & 7.7 & 382.1 & 10.7 & 0.6 & 4.4 & 1.3 & 2.0 & 0.6 & 59.6 \\
\hline YT 135 & 6.81 & 7.75 & 361.5 & 12.9 & 0.7 & 7.4 & 1.4 & 1.7 & 0.8 & 66.3 \\
\hline YT 134 & 6.79 & 7.61 & 340.6 & 9.9 & 0.6 & 5.4 & 1.3 & 3.4 & 0.7 & 64.5 \\
\hline YT 144 & 6.88 & 7.67 & 365.7 & 11.6 & 0.6 & 5.1 & 1.1 & 1.8 & 1.1 & 57.6 \\
\hline YT 133 & 6.63 & 7.56 & 364.3 & 14.9 & 0.6 & 5.5 & 1.2 & 3.0 & 1.9 & 65.6 \\
\hline YT 32 & & & & 16.6 & & 7.2 & & 2.8 & 1.6 & 66.0 \\
\hline YT 33 & & & & 18.3 & & 7.2 & & 2.3 & 1.4 & 64.8 \\
\hline YT 31 & & & & 13.0 & & 8.9 & & 2.4 & 1.3 & 128.5 \\
\hline YT 34 & & & & 16.6 & & 7.4 & & 3.4 & 2.1 & 65.8 \\
\hline YT 55 & & & & 32.1 & & 5.0 & & 2.2 & 1.2 & 70.4 \\
\hline YT 35 & & & & 26.3 & & 7.6 & & 3.4 & 2.1 & 65.8 \\
\hline YT 36 & & & & 30.7 & & 6.0 & & 2.6 & 2.0 & 68.7 \\
\hline YT 50 & & & & 18.2 & & 0.0 & & 2.3 & 0.6 & 59.2 \\
\hline YT 19 & & 7.62 & 236.9 & 457.8 & & 66.5 & & 47.0 & 9.6 & 220.1 \\
\hline YT 24 & & 7.47 & 223.5 & 1939.1 & & 0.0 & & 46.1 & 236.8 & 172.4 \\
\hline YT 157 & 1.99 & 7.36 & 262.4 & 538.1 & 7.5 & 88.5 & 9.2 & 68.1 & 18.9 & 191.7 \\
\hline YT 9 & 3.46 & 7.64 & 128.7 & 1257.0 & & 37.5 & & 118.2 & 31.6 & 236.3 \\
\hline YT 27 & & 8.07 & 222.2 & 1885.1 & & 75.0 & & 95.6 & 113.2 & 179.0 \\
\hline YT 65 & & 8.17 & 246.2 & 1596.1 & & 35.8 & & & 217.9 & 168.4 \\
\hline YT 22 & & 7.5 & 284.2 & 2131.5 & & 97.7 & & 54.4 & 227.4 & 144.8 \\
\hline YT 146 & 0.67 & 6.71 & 274.2 & 1502.5 & 10.2 & 170.4 & 11.7 & 107.8 & 51.4 & 284.5 \\
\hline YT 25 & & 7.69 & 281.9 & 2140.1 & & 69.6 & & 44.0 & 210.4 & 177.5 \\
\hline YT221 & 0.41 & 7.27 & -94 & 660.0 & 1.8 & 9.3 & 1.5 & & 34.5 & 100.6 \\
\hline YT 20 & & 8 & 230 & 1702.3 & & 36.6 & & 30.6 & 90.7 & 170.7 \\
\hline YT301 & 1.78 & 7.15 & 357 & 138.3 & 1.2 & 42.2 & 1.9 & & 43.0 & 108.2 \\
\hline YT 160 & 3.74 & 7.18 & 234.1 & 870.6 & 6.8 & 109.4 & 8.1 & 123.8 & 94.6 & 217.1 \\
\hline YT 174 & 4.36 & 6.87 & 279 & 1759.3 & 15.3 & 32.4 & 11.7 & & 264.9 & 170.8 \\
\hline YT223 & 0.72 & 7.29 & -98 & 1054.4 & 2.5 & 14.1 & 2.1 & & 56.9 & 106.9 \\
\hline YT251 & & 7.08 & 242.9 & & & & & & & 103.1 \\
\hline YT 182 & & 7.13 & & 1311.2 & 8.4 & 23.2 & 7.9 & & 92.7 & 128.3 \\
\hline YT303 & 1.44 & 6.96 & 401 & 146.7 & 2.4 & 0.0 & 0.0 & & & 108.8 \\
\hline YT255 & 0.71 & 7.12 & 95.4 & 914.0 & 4.5 & 61.1 & 4.3 & & 257.7 & 105.6 \\
\hline YT250 & 8.21 & 7.3 & 297.8 & & & & & & & 90.7 \\
\hline YT 59 & & & & 794.3 & & 48.1 & & 25.9 & 4.7 & 297.4 \\
\hline YT254 & 0.35 & 7.1 & 155.8 & 593.8 & 3.4 & 40.6 & 3.2 & & 320.6 & 105.5 \\
\hline YT305 & 2.04 & 7.19 & 414 & & & & & & & 84.5 \\
\hline YT 181 & & 7.07 & & & & & & & & 117.4 \\
\hline YT 180 & & 7.18 & & 1150.7 & 12.4 & 13.5 & 7.2 & 45.4 & 202.0 & 114.6 \\
\hline YT 145 & 6.43 & 7.77 & 322.1 & 67.1 & 0.6 & 29.4 & 4.2 & 11.7 & 2.4 & 159.0 \\
\hline YT214 & 1.24 & 7.25 & -17 & 1477.8 & 3.3 & 28.6 & 2.5 & & 111.4 & 119.8 \\
\hline YT215 & 0.45 & 7.2 & -23 & 1716.9 & 4.1 & 28.4 & 2.9 & & 162.9 & 128.6 \\
\hline YT252 & & 7.03 & 303.7 & & & & & & & 71.4 \\
\hline YT220 & 2.04 & 7.4 & 78 & & & & & & & 98.7 \\
\hline YT218 & 2.31 & 7.49 & 76.6 & 675.9 & 2.6 & 12.9 & 2.2 & & 54.8 & 82.0 \\
\hline YT217 & 4.56 & 7.85 & 119.1 & 370.3 & 1.4 & 10.5 & 1.2 & & 54.1 & 66.0 \\
\hline YT302 & 5.56 & 8.13 & 90 & 18.3 & 0.6 & 8.8 & 1.1 & & 3.0 & 59.2 \\
\hline YT 179 & & 8.16 & & & & & & & & 66.1 \\
\hline YT222 & 5.88 & 8.05 & 48 & & & & & & & 73.1 \\
\hline YT 64 & & & & 671.1 & & 90.3 & & 74.1 & 14.3 & 148.9 \\
\hline YT244 & 0.35 & 7.57 & 6 & 684.8 & 2.7 & 48.5 & 2.6 & & 246.0 & 94.7 \\
\hline YT334 & & 6.97 & 113.4 & 938.4 & 6.0 & 58.5 & 5.5 & & 394.9 & 103.7 \\
\hline YT335 & & 7.78 & 159 & 455.3 & 2.1 & 25.0 & 1.9 & & 137.8 & 88.1 \\
\hline YT324 & 1.77 & 7.08 & 211.5 & 88.3 & 1.2 & 20.3 & 1.8 & 12.7 & 8.3 & 114.1 \\
\hline YT312 & 0.68 & 7.09 & 352.6 & & & & & & & 119.2 \\
\hline YT313 & 0.23 & 7.03 & 322.5 & 207.1 & 0.9 & 26.4 & 1.1 & 26.6 & 18.4 & 119.4 \\
\hline YT306 & 7.34 & 7.45 & 328 & & & & & & & 97.1 \\
\hline YT314 & 0.31 & 7.06 & 342.9 & & & & & & & 118.4 \\
\hline YT326 & 7.63 & 7.44 & 323.8 & 85.1 & 1.8 & 14.7 & 2.5 & 9.0 & 8.0 & 189.3 \\
\hline YT246 & 1.32 & 7.29 & 25 & 169.3 & 1.4 & 7.7 & 1.4 & & 15.9 & 168.6 \\
\hline YT315 & 0.23 & 6.97 & 329.5 & & & & & & & 134.9 \\
\hline YT257 & 0.09 & 7.18 & -62 & 191.5 & 1.6 & 8.0 & 1.2 & 6.4 & 14.7 & 199.1 \\
\hline YT316 & 0.24 & 6.96 & 319.3 & & & & & & & 136.6 \\
\hline YT317 & 0.29 & 6.96 & 309.4 & 323.8 & 1.8 & 32.5 & 1.9 & 39.3 & 8.8 & 135.7 \\
\hline YT325 & 7.54 & 7.02 & 32.2 & 321.8 & 2.0 & 42.4 & 2.4 & 24.9 & 8.7 & 126.0 \\
\hline YT327 & 2.23 & 7.07 & 349 & 131.3 & 2.1 & 37.8 & 3.4 & 18.0 & 15.4 & 116.9 \\
\hline YT307 & 3.92 & 7.14 & 190.8 & & & & & & & 92.9 \\
\hline YT308 & 3.71 & 7.13 & 361 & 204.9 & 2.2 & 23.9 & 2.6 & 23.9 & 13.5 & 91.7 \\
\hline YT259 & 0.53 & 7.1 & -16.7 & 230.3 & 1.2 & 4.0 & 0.9 & 5.5 & 12.6 & 176.8 \\
\hline YT309 & 3.99 & 7.11 & 362 & & & & & & & 92.1 \\
\hline YT318 & 0.15 & 6.94 & 304.9 & & & & & & & 136.5 \\
\hline YT245 & 1.87 & 7.52 & -49 & 261.2 & 1.7 & 6.4 & 1.5 & & 38.3 & 187.2 \\
\hline YT320 & 0.17 & 6.9 & 289.1 & & & & & & & 149.7 \\
\hline YT328 & 1.06 & 7.07 & 329.7 & & & & & & & 125.2 \\
\hline YT310 & 2.42 & 7.01 & 367 & & & & & & & 116.4 \\
\hline YT329 & 2.36 & 7.16 & 323.6 & & & & & & & 101.5 \\
\hline
\end{tabular}




\begin{tabular}{|c|c|c|c|c|c|c|c|c|c|c|}
\hline $\mathrm{I}$ & $\mathrm{XI}$ & $\mathrm{XI}$ & XII & XIII & XIV & $\mathrm{XV}$ & $\mathrm{XVI}$ & XVII & XVIII & XIX \\
\hline $\begin{array}{l}\text { Internal } \\
\text { sample ID }\end{array}$ & $\begin{array}{l}\text { Collection DO } \\
\mathrm{mg} / \mathrm{L}\end{array}$ & Collection pH & $\begin{array}{l}\text { Collection Eh } \\
(\mathrm{mV})\end{array}$ & $\begin{array}{l}226 \mathrm{Ra} \\
\mathrm{dpm} / 100 \mathrm{~L}\end{array}$ & $\begin{array}{l}\mathrm{dpm} / 100 \mathrm{~L} \\
\text { error }\end{array}$ & $\begin{array}{l}228 \mathrm{Ra} \\
\mathrm{dpm} / 100 \mathrm{~L}\end{array}$ & $\begin{array}{l}\mathrm{dpm} / 100 \mathrm{~L} \\
\text { error }\end{array}$ & $\begin{array}{l}224 \mathrm{ex} \\
\mathrm{dpm} / 100 \mathrm{~L}\end{array}$ & $\begin{array}{l}223 e x \\
d p m / 100 \mathrm{~L}\end{array}$ & $\mathrm{Ba} \mathrm{nmol} / \mathrm{kg}$ \\
\hline YT319 & 0.16 & 7.01 & 294.8 & 413.9 & 2.8 & 32.4 & 2.8 & $\begin{array}{ll}38 & 38.9\end{array}$ & 19.8 & 170.7 \\
\hline YT311 & 1.81 & 7.37 & 346 & 84.8 & 1.4 & 37.3 & 2.3 & & 75.1 & 71.2 \\
\hline YT321 & 1.09 & 7.32 & 295.9 & 315.4 & 2.4 & 34.3 & 2.7 & & 32.5 & 78.2 \\
\hline YT323 & 1.24 & 7.35 & 256.1 & & & & & & & 73.8 \\
\hline YT330 & 4.23 & 7.34 & 330.6 & & & & & & & 58.9 \\
\hline YT337 & & 6.43 & -244 & & & & & & & 286.4 \\
\hline YT 176 & 2.43 & 6.67 & -206.4 & & & & & & & 1415.8 \\
\hline YT243 & 0.62 & 7.63 & -193.1 & & & & & & & 544.7 \\
\hline YT241 & 0.57 & 7.53 & -183 & & & & & & & 439.2 \\
\hline YT242 & 0.6 & 7.43 & -182 & & & & & & & 486.9 \\
\hline YT 177 & 2.29 & 6.82 & -175 & 1519.8 & 14.6 & 0.0 & 0.0 & 25.9 & 0.0 & 676.1 \\
\hline YT240 & 0.52 & 7.26 & -173 & 480.6 & 2.1 & 9.3 & 1.6 & 10.9 & 0.1 & 386.6 \\
\hline YT238 & 0.41 & 7.28 & -172 & & & & & & & 258.0 \\
\hline YT239 & 0.51 & 7.14 & -170 & & & & & & & 319.2 \\
\hline YT 175 & 0 & 6.65 & -159.9 & 2287.7 & 21.3 & 20.4 & 4.1 & 12.0 & 43.9 & 1626.4 \\
\hline YT338 & & 6.32 & -159.6 & & & & & & & 382.7 \\
\hline YT237 & 0.34 & 7.24 & -155 & 11.2 & 0.5 & 1.7 & 0.9 & & & 146.3 \\
\hline YT339 & & 6.33 & -154 & & & & & & & 502.7 \\
\hline YT 178 & 2.4 & 7.07 & -152.6 & & & & & & & 191.8 \\
\hline YT235 & 0.54 & 7.23 & -127.9 & 7.6 & 0.4 & 2.0 & 0.6 & & 0.2 & 202.8 \\
\hline YT 8 & & 7.31 & -127 & 636.7 & & 98.1 & & 57.5 & 17.7 & 493.3 \\
\hline YT 115 & 0 & 6.8 & -107 & & & & & & & 395.8 \\
\hline YT 112 & & 6.76 & -106.1 & & & & & & & 391.5 \\
\hline YT 113 & & 6.72 & -101.9 & & & & & & & 403.3 \\
\hline YT236 & 0.37 & 7.14 & -100.8 & & & & & & & 81.3 \\
\hline YT 109 & & 7.09 & -98.6 & & & & & & & 519.3 \\
\hline YT 116 & 0.67 & 7.48 & -98.6 & 720.3 & 9.3 & 65.0 & 9.4 & 4.0 & 0.3 & \\
\hline YT 3 & 6.8 & 7.6 & -93 & 161.3 & & 79.7 & & 18.9 & 5.4 & 119.7 \\
\hline YT 111B & 0.05 & 6.73 & -88.2 & & & & & & & \\
\hline YT 111 & 0.29 & 6.91 & -84.9 & & & & & & & 398.5 \\
\hline YT 114 & 0.24 & 6.75 & -75.4 & & & & & & & 430.4 \\
\hline YT 110 & 0.52 & 6.78 & -65.8 & & & & & & & 385.4 \\
\hline YT210 & 0.62 & 7.74 & -34.9 & 52.4 & 0.8 & 6.5 & 1.1 & 7.0 & 1.5 & 39.6 \\
\hline YT 117 & 1.35 & 7.06 & -0.6 & 1066.5 & 13.9 & 120.7 & 15.2 & 17.5 & 8.3 & \\
\hline YT 12 & & & 19 & 2017.9 & & 279.2 & & 1.9 & 4.1 & 421.3 \\
\hline YT 16 & & & 20 & & & & & & & 451.4 \\
\hline YT 15 & & & 20 & 5121.5 & & 1211.2 & & 304.0 & 54.1 & 391.2 \\
\hline YT 17 & & & 20 & 3069.9 & & 336.0 & & 34.1 & 2.2 & \\
\hline YT 11 & & & 24 & 1798.3 & & 120.8 & & 7.3 & 1.4 & 603.5 \\
\hline YT 13 & & & 30 & 3351.8 & & 513.9 & & 89.9 & 46.4 & 409.7 \\
\hline YT 14 & & & 37 & 3210.3 & & 469.1 & & 140.3 & 19.8 & 379.0 \\
\hline YT 10 & & & 44 & 2406.2 & & 423.8 & & 84.3 & 45.4 & 335.5 \\
\hline YT 74 & & 8.03 & 65 & 383.0 & & 51.5 & & 34.7 & 7.8 & 240.5 \\
\hline YT 153 & 4.87 & 7.67 & 80.1 & 303.0 & 4.1 & 14.7 & 4.2 & 11.7 & 2.8 & 174.6 \\
\hline YT340 & & 7.33 & 86 & & & & & & & 69.4 \\
\hline YT 148 & 0.44 & 6.85 & 92.4 & 4965.1 & 27.3 & 257.1 & 25.8 & & 434.4 & 561.3 \\
\hline YT322 & 0.37 & 7.14 & 96 & & & & & & & 134.2 \\
\hline YT 166 & 0.73 & 7.42 & 99.3 & 37.9 & 1.8 & 10.8 & 4.0 & 1.7 & 0.3 & 67.8 \\
\hline YT 101 & 8.91 & 8.07 & 104 & 89.9 & 2.8 & 7.0 & 3.3 & 1.0 & 1.2 & 76.2 \\
\hline YT 163 & 4.39 & 7.02 & 109.9 & 1095.9 & 12.2 & 38.1 & 10.5 & 8.9 & 64.3 & 199.4 \\
\hline YT 149 & 1.37 & 6.97 & 113 & 1972.7 & 7.9 & 72.9 & 8.2 & 43.2 & 46.6 & 288.9 \\
\hline YT 164 & 5.83 & 7 & 154.7 & 1116.3 & 13.7 & 38.2 & 11.3 & 11.3 & 82.6 & 199.2 \\
\hline YT 147 & 0.69 & 6.6 & 162 & 2491.7 & 18.4 & 101.6 & 16.7 & 23.0 & 75.9 & 317.7 \\
\hline YT 167 & 3.34 & 7.11 & 166.2 & 424.2 & 8.4 & 17.5 & 7.7 & 11.1 & 6.4 & 164.8 \\
\hline YT 108 & 0.38 & 7.28 & 172 & & & & & & & 438.9 \\
\hline YT 165 & 5.7 & 6.98 & 176.8 & 116.2 & 0.6 & 37.7 & 6.0 & 4.7 & 70.6 & 193.0 \\
\hline YT 7 & & 7.5 & 189 & 1517.5 & & 157.7 & & 146.0 & 175.8 & 236.5 \\
\hline YT 102 & 7.71 & 7.12 & 190.9 & & & & & & & 206.0 \\
\hline YT 168 & 1.11 & & 193.6 & 833.0 & 7.5 & 18.7 & 5.7 & 15.5 & 19.3 & 171.9 \\
\hline YT 1 & 11.08 & 7.77 & 197 & 370.6 & & 48.7 & & & 0.3 & 222.1 \\
\hline YT 6 & 4.06 & 7.35 & 199.8 & 1288.8 & & 139.4 & & 83.8 & 72.1 & 227.6 \\
\hline YT 103 & 6.97 & 7.1 & 207.6 & 304.7 & 3.7 & 36.5 & 4.3 & 10.1 & 6.1 & 208.9 \\
\hline YT 21 & & 7.48 & 219.6 & 1415.7 & & 53.3 & & 35.1 & 61.8 & 193.1 \\
\hline YT195 & 0.37 & 7.18 & 224.1 & 274.0 & 1.3 & 16.4 & 1.2 & 3.7 & 7.9 & 103.0 \\
\hline YT 104 & 0.84 & 6.79 & 230.2 & & & & & & & 244.1 \\
\hline YT 26 & & 7.53 & 238.2 & & & & & & & 329.3 \\
\hline YT 105 & 0.65 & 6.79 & 241.5 & 397.4 & 5.3 & 52.0 & 6.2 & 13.5 & 16.1 & 241.4 \\
\hline YT 169 & 1.63 & 6.96 & 243.5 & 1667.8 & 13.0 & 23.9 & 9.6 & 45.3 & 109.0 & 187.6 \\
\hline YT248 & 6.02 & 7.09 & 252.9 & & & & & & & 89.5 \\
\hline YT 170 & 5.65 & 6.83 & 262.6 & 1303.3 & 11.3 & & & 56.2 & 132.6 & 183.6 \\
\hline YT 73 & & 7.83 & 268.8 & 1657.4 & & 59.6 & & 22.0 & 160.7 & 211.2 \\
\hline YT 106 & 1.06 & 6.8 & 271.6 & & & & & & & 243.5 \\
\hline YT 107 & 0.69 & 6.76 & 280 & 434.1 & 5.6 & 57.3 & 6.4 & 5.1 & 22.3 & 242.8 \\
\hline YT 2-1 & & & 280 & & & & & & & 313.3 \\
\hline YT 119 & 11.29 & 7.4 & 291.5 & 159.1 & 3.7 & 24.1 & 4.8 & 10.6 & 20.6 & 145.5 \\
\hline YT 118 & 7.09 & 7.21 & 296.6 & 341.1 & 6.7 & 36.6 & 7.6 & 5.4 & 5.1 & 221.0 \\
\hline YT341 & 1.6 & 7.59 & 297.3 & & & & & & & 7.5 \\
\hline YT 120 & 9.55 & 6.96 & 300.8 & 156.8 & 4.5 & 18.1 & 5.6 & 28.9 & 37.1 & 193.0 \\
\hline YT333 & & 8.18 & 319.8 & 28.4 & 0.4 & 3.0 & 0.5 & 2.7 & 2.4 & \\
\hline YT209 & 6.44 & 8.22 & 331.4 & 61.5 & 0.9 & 9.2 & 1.2 & ND & 2.0 & 43.3 \\
\hline
\end{tabular}




\begin{tabular}{|c|c|c|c|c|c|c|c|c|c|c|}
\hline I & XI & XI & XII & XIII & XIV & $\mathrm{XV}$ & XVI & XVII & XVIII & XIX \\
\hline $\begin{array}{l}\text { Internal } \\
\text { sample ID }\end{array}$ & $\begin{array}{l}\text { Collection DO } \\
\mathrm{mg} / \mathrm{L}\end{array}$ & Collection $\mathrm{pH}$ & $\begin{array}{l}\text { Collection Eh } \\
(\mathrm{mV})\end{array}$ & $\begin{array}{l}226 \mathrm{Ra} \\
\mathrm{dpm} / 100 \mathrm{~L}\end{array}$ & $\begin{array}{l}226 \mathrm{Ra} \\
\mathrm{dpm} / 100 \mathrm{~L} \\
\text { error }\end{array}$ & $\begin{array}{l}228 \mathrm{Ra} \\
\mathrm{dpm} / 100 \mathrm{~L}\end{array}$ & $\begin{array}{l}228 \mathrm{Ra} \\
\mathrm{dpm} / 100 \mathrm{~L} \\
\text { error }\end{array}$ & $\begin{array}{l}224 \mathrm{ex} \\
\mathrm{dpm} / 100 \mathrm{~L}\end{array}$ & $\begin{array}{l}223 \mathrm{ex} \\
\mathrm{dpm} / 100 \mathrm{~L}\end{array}$ & $\mathrm{Ba} \mathrm{nmol} / \mathrm{kg}$ \\
\hline YT 2-5 & & & 337 & & & & & & & 193.0 \\
\hline YT206 & 2.59 & 7.08 & 340 & & & & & & & 67.5 \\
\hline YT207 & & & 340 & 333.0 & 1.7 & 16.8 & 1.6 & 12.0 & 4.2 & 66.6 \\
\hline YT332 & & 7 & 347.6 & 911.5 & 5.8 & 64.7 & 5.8 & ND & 315.8 & 108.5 \\
\hline YT205 & 2.95 & 7.09 & 349.5 & & & & & & & 66.5 \\
\hline YT204 & 3.14 & 7.09 & 349.8 & & & & & & & 67.4 \\
\hline YT203 & 3.23 & 7.08 & 350.3 & & & & & & & 66.4 \\
\hline YT202 & 3.26 & 7.08 & 351.2 & & & & & & & 66.1 \\
\hline YT201 & 3.28 & 7.08 & 351.8 & 328.5 & 1.5 & 14.3 & 1.4 & 5.6 & 10.7 & 66.2 \\
\hline YT200 & 3.29 & 7.08 & 351.9 & & & & & & & 67.8 \\
\hline YT199 & 3.31 & 7.09 & 352.6 & & & & & & & 66.2 \\
\hline YT198 & 3.32 & 7.09 & 353.6 & & & & & & & 66.1 \\
\hline YT234 & 0.46 & 7.04 & 354.2 & 263.4 & 2.1 & 11.6 & 2.0 & 0.9 & 6.2 & 60.7 \\
\hline YT197 & 3.41 & 7.1 & 354.4 & & & & & & & 66.4 \\
\hline YT233 & 0.64 & 7.04 & 354.9 & & & & & & & 63.8 \\
\hline YT232 & 0.76 & 7.04 & 355.2 & 189.8 & 1.3 & 11.7 & 1.5 & 3.6 & 6.2 & 73.0 \\
\hline YT231 & 0.8 & 7.04 & 356.4 & & & & & & & 58.8 \\
\hline YT229 & 0.81 & 7.06 & 357.6 & & & & & & & 60.3 \\
\hline YT230 & 0.81 & 7.05 & 358.2 & 232.7 & 1.3 & 6.7 & 1.3 & 3.6 & 7.5 & 59.7 \\
\hline YT228 & 0.83 & 7.06 & 358.4 & 238.6 & 1.1 & 8.4 & 1.1 & 0.9 & 8.6 & 59.1 \\
\hline YT227 & 0.84 & 7.07 & 359.8 & & & & & & & 62.7 \\
\hline YT226 & 0.88 & 7.08 & 361.5 & 242.1 & 1.3 & 9.9 & 1.2 & 1.2 & 6.5 & 59.6 \\
\hline YT225 & 1.03 & 7.12 & 364.4 & & & & & & & 60.0 \\
\hline YT 2-4 & & & 366 & & & & & & & 237.2 \\
\hline YT 2-3 & & & 375 & & & & & & & 245.4 \\
\hline YT336 & 1.99 & 6.97 & 375.2 & 192.6 & 1.1 & 8.3 & 1.1 & 5.6 & 8.5 & 69.3 \\
\hline YT 100 & 1.91 & 6.93 & 378.4 & & & & & 23.4 & 7.2 & 167.1 \\
\hline YT 18 & & & 380 & 435.3 & & 70.8 & & 4.6 & 4.0 & \\
\hline YT 2-2 & & & 380 & & & & & & & 244.7 \\
\hline YT 184 & & 7.68 & & & & & & & & 60.3 \\
\hline
\end{tabular}




\begin{tabular}{|c|c|c|c|c|c|c|}
\hline$I$ & $X X$ & XXI & XXII & XXIII & XXIV & $\mathrm{XXV}$ \\
\hline $\begin{array}{l}\text { Internal } \\
\text { sample ID }\end{array}$ & $\mathrm{U} \mathrm{nmol} / \mathrm{kg}$ & $\mathrm{Mn} \mathrm{nmol} / \mathrm{kg}$ & Srumol/kg & Ca mmol/kg & $\begin{array}{l}\text { TA umol/kg- } \\
\text { SW }\end{array}$ & $\begin{array}{l}\text { TC umol/kg- } \\
\text { SW }\end{array}$ \\
\hline YT 172 & 15.1 & 24.6 & 13.8 & & & \\
\hline YT 155 & 5.1 & 41.0 & 52.1 & & & \\
\hline YT 156 & 1.9 & 35.9 & 83.5 & & & \\
\hline YT 158 & 1.9 & 40.5 & 86.5 & & & \\
\hline YT 154 & 1.6 & 32.4 & 87.5 & & & \\
\hline YT 152 & 1.5 & 39.9 & 87.6 & & & \\
\hline YT 162 & 15.4 & 60.2 & 104.3 & & & \\
\hline YT 151 & 1.4 & 37.3 & 90.6 & & & \\
\hline YT 159 & 4.2 & 28.4 & 77.6 & & & \\
\hline YT 150 & 0.8 & 76.0 & 103.5 & & & \\
\hline YT 66 & 13.5 & 28.7 & 52.6 & & & \\
\hline YT 61 & 8.6 & 55.2 & 81.2 & & & \\
\hline YT 62 & 8.9 & 75.2 & 86.1 & & & \\
\hline YT 57 & 11.1 & 19.7 & 89.2 & & & \\
\hline YT 63 & 8.8 & 84.9 & 88.3 & & & \\
\hline YT 60 & 9.2 & 72.1 & 104.1 & & & \\
\hline YT 161 & 9.6 & 20.0 & 86.2 & & & \\
\hline YT 72 & 13.8 & 19.5 & 102.6 & & & \\
\hline YT 58 & 10.2 & 21.8 & 115.9 & & & \\
\hline YT 171 & 14.9 & 21.0 & 77.3 & & & \\
\hline YT 56 & 14.1 & 11.7 & 97.2 & & & \\
\hline YT253 & 13.3 & & 92.3 & 10.6 & & \\
\hline YT300 & 13.8 & 7.8 & 88.1 & 13.4 & & \\
\hline YT256 & 14.5 & 7.1 & 90.4 & 13.5 & & \\
\hline YT249 & 11.3 & & 95.6 & 11.1 & & \\
\hline TS10_11 & 12.2 & 21.8 & 102.8 & 11.9 & & \\
\hline YT 71 & 12.0 & 21.2 & 93.8 & & & \\
\hline YT331 & 13.6 & 87.9 & 89.4 & 12.5 & & \\
\hline YT260 & 14.0 & 7.6 & 89.0 & 13.4 & & \\
\hline YT211 & 12.8 & & 94.9 & 11.2 & & \\
\hline YT219 & 13.4 & bd & 94.1 & 11.4 & & \\
\hline YT191 & 12.9 & 0.1 & 92.5 & 11.1 & & \\
\hline YT192 & 13.5 & bd & 93.2 & 10.8 & & \\
\hline YT216 & 12.8 & bd & 93.6 & 11.1 & & \\
\hline YT194 & 14.2 & 2.1 & 94.3 & 11.1 & & \\
\hline YT342 & 13.5 & 13.2 & 90.5 & 12.7 & & \\
\hline TS9_11 & 12.5 & 5.0 & 94.2 & 12.0 & & \\
\hline YT224 & 13.5 & 0.3 & 96.7 & 10.7 & & \\
\hline TS4_11 & 12.4 & 96.5 & 89.5 & 12.5 & & \\
\hline YT193 & 11.6 & 0.5 & 91.3 & 10.9 & & \\
\hline TS8_11 & 12.3 & 71.7 & 104.0 & 11.6 & & \\
\hline YT208 & 10.1 & & 98.1 & 10.4 & & \\
\hline TS6_11 & 12.6 & 49.7 & 91.0 & 12.3 & & \\
\hline YT213 & 12.6 & 0.4 & 95.5 & 11.6 & & \\
\hline TS_0211 & 6.4 & 2.9 & 98.2 & 12.3 & & \\
\hline TS33_11 & 12.5 & 19.0 & 110.4 & 12.5 & & \\
\hline TS7_11 & 12.5 & 134.4 & 91.9 & 12.2 & & \\
\hline YT 70 & 11.8 & 48.4 & 94.9 & & & \\
\hline TS5_11 & 12.3 & 14.8 & 92.3 & 12.0 & & \\
\hline YT 173 & 13.0 & 24.4 & 94.8 & & & \\
\hline YT 68 & 7.0 & 7.2 & 103.5 & & & \\
\hline YT 69 & 6.6 & 40.5 & 104.5 & & & \\
\hline YT 67 & 11.8 & 21.8 & 113.2 & & & \\
\hline YT 66 & 8.6 & 23.3 & 49.8 & & & \\
\hline YT185 & 13.0 & bd & 99.5 & 11.8 & & \\
\hline YT186 & 13.4 & $\mathrm{bd}$ & 98.3 & 10.6 & & \\
\hline YT187 & 13.2 & & 97.8 & 11.6 & & \\
\hline YT188 & 13.1 & bd & 97.4 & 10.7 & & \\
\hline YT189 & 14.0 & 1.4 & 93.1 & 11.5 & & \\
\hline YT190 & 13.2 & 0.4 & 95.3 & 11.7 & & \\
\hline YT 53 & 14.7 & 15.6 & 96.9 & & & \\
\hline YT 51 & 15.0 & 16.0 & 95.5 & & & \\
\hline YT 52 & 14.6 & 12.9 & 97.3 & & & \\
\hline YT 54 & 14.1 & 10.7 & 97.9 & & & \\
\hline YT 132 & 13.6 & 8.7 & 101.3 & & & \\
\hline YT212 & 12.0 & bd & 94.2 & 11.1 & & \\
\hline YT 121 & 13.4 & 11.5 & 92.3 & 10.7 & 2604 & 2547 \\
\hline YT 183 & 14.0 & 9.7 & 91.8 & & & \\
\hline YT 131 & 13.9 & 10.4 & 91.9 & & & \\
\hline YT 142 & 13.6 & 4.6 & 93.4 & & & \\
\hline YT 122 & 13.1 & 8.7 & 90.6 & & & \\
\hline YT 123 & 13.3 & 8.8 & 96.5 & & & \\
\hline YT 126 & 13.6 & 18.4 & 94.3 & & & \\
\hline YT 127 & 13.9 & 14.4 & 93.4 & & & \\
\hline YT 137 & 13.4 & 3.9 & 96.5 & & & \\
\hline YT 128 & 13.3 & 7.8 & 92.2 & & & \\
\hline YT 125 & 13.8 & 6.4 & 89.3 & & & \\
\hline YT 140 & 13.4 & 7.1 & 91.6 & & & \\
\hline YT 124 & 13.5 & 10.6 & 94.4 & & & \\
\hline & 13.9 & & & & & \\
\hline
\end{tabular}




\begin{tabular}{|c|c|c|c|c|c|c|}
\hline $\mathrm{I}$ & $X X$ & XXI & XXII & XXIII & XXIV & XXV \\
\hline $\begin{array}{l}\text { Internal } \\
\text { sample ID }\end{array}$ & $\mathrm{U} \mathrm{nmol} / \mathrm{kg}$ & $\mathrm{Mn} \mathrm{nmol} / \mathrm{kg}$ & Srumol/kg & Ca $\mathrm{mmol} / \mathrm{kg}$ & $\begin{array}{l}\text { TA umol/kg- } \\
\text { SW }\end{array}$ & $\begin{array}{l}\text { TC umol/kg- } \\
\text { SW }\end{array}$ \\
\hline YT 136 & 13.9 & 3.6 & 99.0 & & & \\
\hline YT 130 & 14.0 & 10.9 & 93.2 & & & \\
\hline YT 139 & 13.1 & 4.6 & 102.9 & & & \\
\hline YT 129 & 13.4 & 4.6 & 94.1 & & & \\
\hline YT 141 & 12.9 & 11.6 & 93.6 & & & \\
\hline YT 143 & 14.2 & 2.9 & 92.9 & & & \\
\hline YT 135 & 13.7 & 5.7 & 99.6 & & & \\
\hline YT 134 & 13.9 & 14.5 & 99.3 & & & \\
\hline YT 144 & 14.0 & & 94.3 & & & \\
\hline YT 133 & 14.0 & 6.4 & 102.9 & & & \\
\hline YT 32 & 14.6 & 8.6 & 95.1 & & & \\
\hline YT 33 & 14.8 & 16.9 & 92.5 & & & \\
\hline YT 31 & 14.3 & 10.6 & 96.0 & & & \\
\hline YT 34 & 14.6 & 9.2 & 94.9 & & & \\
\hline YT 55 & 14.6 & 10.6 & 99.4 & & & \\
\hline YT 35 & 14.4 & 11.6 & 97.5 & & & \\
\hline YT 36 & 13.7 & 13.1 & 98.3 & & & \\
\hline YT 50 & 14.5 & 9.2 & 96.0 & & & \\
\hline YT 19 & 1.3 & 161.7 & 32.3 & & & \\
\hline YT 24 & 14.1 & 41.3 & 27.5 & & & \\
\hline YT 157 & 11.3 & 96.6 & 31.4 & 2.6 & 6197 & 6408 \\
\hline YT 9 & 12.2 & 112.5 & 35.0 & & & \\
\hline YT 27 & 14.7 & 99.3 & 15.0 & & & \\
\hline YT 65 & 16.8 & 139.6 & 22.9 & & & \\
\hline YT 22 & 15.6 & 61.1 & 32.0 & & & \\
\hline YT 146 & 17.8 & 97.7 & 38.0 & 4.9 & 7014 & 7515 \\
\hline YT 25 & 18.2 & 63.5 & 25.4 & & & \\
\hline YT221 & 0.3 & 46.0 & 29.4 & 4.3 & & \\
\hline YT 20 & 14.1 & 7.2 & 26.7 & & & \\
\hline YT301 & 10.2 & 86.5 & 30.2 & 5.8 & & \\
\hline YT 160 & 9.1 & 196.3 & 58.9 & 6.9 & 6094 & 6137 \\
\hline YT 174 & 13.5 & 8.6 & 33.7 & 5.5 & 6874 & 6612 \\
\hline YT223 & 0.6 & 15.0 & 51.4 & 6.0 & & \\
\hline YT251 & 12.0 & 22.2 & 50.9 & 6.5 & & \\
\hline YT 182 & 0.3 & 30.5 & 63.7 & & & \\
\hline YT303 & 13.0 & 46.1 & 54.2 & 8.8 & & \\
\hline YT255 & 10.7 & 52.9 & 60.0 & 10.1 & & \\
\hline YT250 & 12.5 & 22.4 & 54.0 & 7.5 & & \\
\hline YT 59 & 10.8 & 85.7 & 109.2 & & & \\
\hline YT254 & 14.9 & 25.8 & 72.1 & 11.3 & & \\
\hline YT305 & 12.8 & 25.4 & 65.6 & 10.6 & & \\
\hline YT 181 & 29.1 & & 81.3 & & & \\
\hline YT 180 & 16.1 & & 81.4 & & & \\
\hline YT 145 & 11.8 & 17.3 & 75.6 & 8.4 & 3626 & 3363 \\
\hline YT214 & 35.2 & 18.2 & 96.1 & 9.7 & & \\
\hline YT215 & 34.3 & 7.5 & 94.9 & 9.7 & & \\
\hline YT252 & 13.3 & 23.3 & 77.0 & 9.4 & & \\
\hline YT220 & 14.2 & 9.0 & 90.0 & 10.1 & & \\
\hline YT218 & 22.0 & 0.7 & 89.8 & 10.2 & & \\
\hline YT217 & 17.2 & 0.3 & 90.8 & 10.6 & & \\
\hline YT302 & 14.3 & 8.7 & 88.2 & 12.9 & & \\
\hline YT 179 & 12.8 & 6.5 & 93.2 & & & \\
\hline YT222 & 10.3 & 2.5 & 97.0 & 10.7 & & \\
\hline YT 64 & 19.8 & & 40.1 & 0.0 & & \\
\hline YT244 & 9.8 & 16.6 & 55.0 & 7.2 & & \\
\hline YT334 & 10.6 & 56.4 & 67.8 & 9.4 & & \\
\hline YT335 & 6.1 & 155.2 & 46.0 & 6.1 & & \\
\hline YT324 & 15.3 & 116.0 & 25.3 & 3.1 & & \\
\hline YT312 & 9.6 & 51.2 & 18.0 & 3.7 & & \\
\hline YT313 & 11.2 & 14.2 & 16.0 & 3.8 & & \\
\hline YT306 & 16.5 & 7.9 & 19.3 & 3.0 & & \\
\hline YT314 & 11.3 & 17.9 & 16.0 & 3.9 & & \\
\hline YT326 & 7.1 & 29.2 & 19.1 & 3.9 & & \\
\hline YT246 & 2.0 & 69.8 & 62.0 & 4.5 & & \\
\hline YT315 & 12.4 & 100.3 & 17.1 & 4.3 & & \\
\hline YT257 & 10.2 & 195.8 & 58.3 & 4.3 & & \\
\hline YT316 & 12.7 & 20.3 & 15.6 & 4.6 & & \\
\hline YT317 & 12.8 & 15.9 & 15.6 & 4.5 & & \\
\hline YT325 & 12.5 & 702.9 & 25.2 & 4.2 & & \\
\hline YT327 & 8.3 & 83.7 & 15.9 & 4.3 & & \\
\hline YT307 & 12.6 & 2.6 & 14.1 & 4.0 & & \\
\hline YT308 & 11.2 & 1.6 & 13.8 & 4.1 & & \\
\hline YT259 & 0.6 & 70.0 & 59.3 & 4.9 & & \\
\hline YT309 & 12.9 & 1.8 & 14.7 & 4.3 & & \\
\hline YT318 & 11.8 & 23.0 & 18.4 & 4.8 & & \\
\hline YT245 & 0.5 & 41.6 & 67.4 & 4.5 & & \\
\hline YT320 & 15.0 & 27.5 & 35.5 & 6.4 & & \\
\hline YT328 & 9.6 & 76.1 & 44.9 & 8.0 & & \\
\hline YT310 & 15.6 & 2.1 & 51.8 & 9.0 & & \\
\hline YT329 & 11.1 & 72.3 & 74.2 & 11.5 & & \\
\hline
\end{tabular}




\begin{tabular}{|c|c|c|c|c|c|c|}
\hline $\bar{I}$ & $X X$ & XXI & XXII & XXIII & XXIV & $\mathrm{XXV}$ \\
\hline $\begin{array}{l}\text { Internal } \\
\text { sample ID }\end{array}$ & $\mathrm{U} \mathrm{nmol} / \mathrm{kg}$ & $\mathrm{Mn} \mathrm{nmol} / \mathrm{kg}$ & Srumol $/ \mathrm{kg}$ & Ca mmol/kg & $\begin{array}{l}\text { TA umol } / \mathrm{kg}- \\
\text { SW }\end{array}$ & $\begin{array}{l}\text { TC umol/kg- } \\
\text { SW }\end{array}$ \\
\hline YT319 & 15.7 & 29.4 & 70.4 & 11.7 & & \\
\hline YT311 & 14.0 & 5.3 & 82.8 & 12. & & \\
\hline YT321 & 14.7 & 8.4 & 92.3 & 13.5 & & \\
\hline YT323 & 14.7 & 12.4 & 92.1 & 13.2 & & \\
\hline YT330 & 13.3 & 65.3 & 103.8 & $13 . \mathrm{C}$ & & \\
\hline YT337 & 4.7 & 527.0 & 34.6 & 7.3 & & \\
\hline YT 176 & 0.5 & 165.4 & 158.5 & & & \\
\hline YT243 & 0.4 & 482.8 & 98.3 & 15.2 & & \\
\hline YT241 & 1.3 & 536.5 & 66.8 & 11.2 & & \\
\hline YT242 & 0.8 & 477.6 & 79.3 & 13.3 & & \\
\hline YT 177 & 13.8 & & 74.0 & 7.3 & 13644 & 14359 \\
\hline YT240 & 2.4 & 514.0 & 55.6 & 10.7 & & \\
\hline YT238 & 6.6 & 361.3 & 33.4 & 7.5 & & \\
\hline YT239 & 4.7 & 427.4 & 45.2 & 9.1. & & \\
\hline YT 175 & 0.5 & 176.7 & 163.5 & $0 . \mathrm{C}$ & & \\
\hline YT338 & 1.6 & 853.8 & 59.2 & 10.2 & & \\
\hline YT237 & 7.3 & 249.7 & 17.2 & 6.0 & & \\
\hline YT339 & 0.8 & 731.3 & 80.3 & 12.2 & & \\
\hline YT 178 & 16.0 & 80.6 & 13.1 & 3.2 & 7877 & 8085 \\
\hline YT235 & 7.3 & 302.0 & 25.6 & 7.0 & & \\
\hline YT 8 & 1.6 & 505.6 & 142.2 & & & \\
\hline YT 115 & 1.0 & 175.1 & 210.9 & 19.2 & 4903 & 5107 \\
\hline YT 112 & 2.5 & & 146.5 & 13. & 5977 & 6305 \\
\hline YT 113 & 1.4 & 317.3 & 157.3 & 14.5 & 6689 & 6161 \\
\hline YT236 & 8.5 & 66.4 & 7.9 & 5.1 & & \\
\hline YT 109 & 2.4 & 1069.2 & 66.6 & $0 . C$ & 8854 & 9627 \\
\hline \multicolumn{7}{|l|}{ YT 116} \\
\hline YT 3 & 0.3 & 85.6 & 59.1 & & & \\
\hline \multicolumn{7}{|l|}{ YT 111B } \\
\hline YT 111 & 1.9 & 491.7 & 86.4 & $9 . C$ & 7223 & 7780 \\
\hline YT 114 & 0.8 & 308.3 & 176.2 & & 6856 & 6533 \\
\hline YT 110 & 2.1 & 291.2 & 101.7 & 10. & 6647 & 7021 \\
\hline YT210 & 1.6 & 57.7 & 22.8 & 2.2 & & \\
\hline \multicolumn{7}{|l|}{ YT 117} \\
\hline YT 12 & 4.7 & 922.7 & 74.2 & & & \\
\hline YT 16 & 0.5 & 577.3 & 173.5 & & & \\
\hline YT 15 & 2.6 & 347.1 & 210.9 & & & \\
\hline \multicolumn{7}{|l|}{ YT 17} \\
\hline YT 11 & 6.5 & 2599.4 & 58.4 & & & \\
\hline YT 13 & 2.1 & 491.2 & 163.9 & & & \\
\hline YT 14 & 2.8 & & 134.0 & & & \\
\hline YT 10 & 6.0 & 214.7 & 100.2 & & & \\
\hline YT 74 & 2.4 & 340.9 & 12.4 & & & \\
\hline YT 153 & 1.0 & 18.0 & 41.2 & 4. & 6846 & 6848 \\
\hline YT340 & 7.7 & 86.6 & 6.1 & 3.7 & & \\
\hline YT 148 & 15.6 & 123.0 & 52.4 & $7 .($ & 6675 & 6918 \\
\hline YT322 & 11.5 & 62.3 & 15.0 & 4.2 & & \\
\hline YT 166 & 8.5 & & 1.3 & 1.2 & 3055 & 3243 \\
\hline YT 101 & 3.7 & 24.1 & 30.3 & 2.7 & 4116 & 4078 \\
\hline YT 163 & 14.9 & 20.1 & 10.5 & 2.8 & 7416 & 7146 \\
\hline YT 149 & 15.7 & 72.5 & 15.9 & 3.7 & 7129 & 7308 \\
\hline YT 164 & 15.0 & 11.8 & 11.0 & $2 . \varepsilon$ & 7413 & 7203 \\
\hline YT 147 & 16.0 & 112.2 & 20.0 & 4.1 & 7389 & 7948 \\
\hline YT 167 & 15.1 & 27.3 & 5.2 & 2. & 7618 & 7864 \\
\hline YT 108 & 7.2 & 1051.6 & 47.5 & 4.5 & 9399 & 9913 \\
\hline YT 165 & 15.2 & 13.0 & 10.2 & 2.5 & 7414 & 7167 \\
\hline YT 7 & 10.8 & 141.0 & 56.4 & & & \\
\hline YT 102 & 8.4 & 61.9 & 29.1 & 3.8 & 6214 & 6145 \\
\hline YT 168 & 15.1 & 30.9 & 10.9 & 2.8 & 7500 & 7538 \\
\hline YT 1 & 16.3 & 14.7 & 31.3 & & & \\
\hline YT 6 & 11.6 & 103.2 & 49.9 & & & \\
\hline YT 103 & 8.3 & 46.9 & 29.8 & 4.5 & 6226 & 6492 \\
\hline YT 21 & 18.1 & 4.2 & 15.4 & & & \\
\hline YT195 & 4.8 & 104.3 & 39.6 & & & \\
\hline YT 104 & 11.9 & 9.1 & 34.1 & 4.3 & 6811 & 7292 \\
\hline YT 26 & 16.8 & 73.3 & 23.4 & & & \\
\hline YT 105 & 12.2 & 8.1 & 33.6 & 4.3 & 6813 & 7347 \\
\hline YT 169 & 15.1 & 19.0 & 19.7 & 4.1 & 7549 & 7550 \\
\hline YT248 & 5.2 & & 17.4 & 2.5 & & \\
\hline YT 170 & 15.1 & & 27.1 & 5.1 & 7319 & 7183 \\
\hline YT 73 & 12.4 & 71.5 & 15.3 & & & \\
\hline YT 106 & 11.6 & 15.7 & 33.4 & 4.3 & 6781 & 7138 \\
\hline YT 107 & 11.6 & 6.7 & 33.8 & 4.3 & 6815 & 6908 \\
\hline YT 2-1 & 13.5 & 342.9 & 41.0 & & & \\
\hline YT 119 & 7.2 & 22.0 & 10.0 & 3.2 & 5921 & 6103 \\
\hline YT 118 & 10.3 & 22.1 & 30.4 & 4.2 & 6410 & 6275 \\
\hline YT341 & 1.2 & 137.4 & 21.1 & 2.1 & & \\
\hline YT 120 & 14.1 & 1569.9 & 18.4 & 3. & 6321 & 7461 \\
\hline \multicolumn{7}{|l|}{ YT333 } \\
\hline YT209 & 1.7 & 6.7 & 22.9 & 2.1 & & \\
\hline
\end{tabular}




\begin{tabular}{|c|c|c|c|c|c|c|}
\hline $\begin{array}{l}\text { Supplmenta } \\
\text { I }\end{array}$ & $X X$ & XXI & XXII & XXIII & XXIV & $X X V$ \\
\hline $\begin{array}{l}\text { Internal } \\
\text { sample ID }\end{array}$ & $\mathrm{U} \mathrm{nmol} / \mathrm{kg}$ & $\mathrm{Mn} \mathrm{nmol} / \mathrm{kg}$ & Srumol/kg & $\mathrm{Ca} \mathrm{mmol} / \mathrm{kg}$ & $\begin{array}{l}\text { TA umol/kg- } \\
\text { SW }\end{array}$ & $\begin{array}{l}\text { TC umol/kg- } \\
\text { SW }\end{array}$ \\
\hline YT 2-5 & 17.1 & 6.6 & 30.8 & & & \\
\hline YT206 & 11.2 & 0.9 & 6.2 & 4.0 & & \\
\hline YT207 & 10.3 & 4.4 & 6.2 & 4.1 & & \\
\hline YT332 & 12.8 & 60.8 & 57.8 & 9.0 & & \\
\hline YT205 & 9.9 & 0.8 & 6.3 & 3.9 & & \\
\hline YT204 & 11.1 & 2.4 & 6.2 & 4.0 & & \\
\hline YT203 & 10.1 & 0.6 & 6.3 & 3.9 & & \\
\hline YT202 & 10.7 & 0.8 & 6.1 & 3.9 & & \\
\hline YT201 & 10.8 & 8.4 & 6.0 & 4.1 & & \\
\hline YT200 & 11.0 & 1.3 & 5.9 & 4.0 & & \\
\hline YT199 & 11.0 & 1.9 & 5.9 & 4.2 & & \\
\hline YT198 & 10.9 & 1.8 & 6.0 & 4.1 & & \\
\hline YT234 & 9.0 & 2.5 & 6.4 & 4.9 & & \\
\hline YT197 & 10.7 & 1.9 & 6.0 & 4.0 & & \\
\hline YT233 & 9.4 & 2.3 & 6.5 & 4.6 & & \\
\hline YT232 & 9.3 & 2.6 & 6.6 & 4.6 & & \\
\hline YT231 & 9.1 & 1.9 & 6.5 & 4.9 & & \\
\hline YT229 & 8.9 & 2.4 & 7.2 & 4.8 & & \\
\hline YT230 & 8.8 & 6.6 & 6.7 & 4.5 & & \\
\hline YT228 & 8.8 & 2.2 & 6.7 & 5.0 & & \\
\hline YT227 & 8.5 & 3.2 & 6.6 & 4.9 & & \\
\hline YT226 & 8.7 & 3.3 & 6.4 & 4.9 & & \\
\hline YT225 & 8.8 & 2.6 & 7.0 & 4.8 & & \\
\hline YT 2-4 & 13.6 & 42.1 & 33.3 & & & \\
\hline YT 2-3 & 16.7 & 6.6 & 34.3 & & & \\
\hline YT336 & 8.5 & 18.7 & 6.7 & 3.8 & & \\
\hline YT 100 & 10.4 & 10.0 & 9.6 & 2.8 & 6894 & 7295 \\
\hline \multicolumn{7}{|l|}{ YT 18} \\
\hline YT 2-2 & 17.0 & 3.1 & 32.8 & & & \\
\hline YT 184 & 1.6 & 101.3 & 22.3 & & & \\
\hline
\end{tabular}


Table S3: Statistically significant ( $p$ value $<0.0001$ ) conservative mixing relationships for spring and reducing cenote samples.

\begin{tabular}{lcccc}
\hline \multicolumn{1}{c}{ Element } & $\mathbf{r}^{\mathbf{2}}$ & $\begin{array}{c}\text { 0 salinity } \\
\text { intercept }\end{array}$ & $\begin{array}{c}\text { Error on } \\
\text { intercept }\end{array}$ & slope \\
\hline Spring & & & & \\
$\mathrm{Ba}$ & 0.39 & 194 & 47 & -3.5 \\
$\mathrm{Mn}$ & 0.42 & 103 & 41 & -3.1 \\
$\mathrm{Sr}$ & 0.85 & 20 & 10 & 2.3 \\
$\mathrm{Ca}$ & 0.83 & 3.4 & 1.1 & 0.23 \\
\hline Reducing cenote & & & & \\
$\mathrm{Sr}$ & 0.95 & 8.5 & 13.8 & 5.4 \\
$\mathrm{Ca}$ & 0.93 & 3.2 & 0.5 & 0.49 \\
$\mathrm{Ca}$ (Sabtun & & & & \\
cenote only) & 0.93 & 3.7 & 1.6 & 0.59 \\
\hline
\end{tabular}




\section{Chapter 6:}

A reevaluation of the coral $\mathrm{Ba} / \mathrm{Ca}$ environmental proxy: $\mathrm{A}$ submarine groundwater discharge case study 


\section{Introduction}

Knowledge of past oceanic conditions is vital for understanding processes and

linkages within the earth's climate system. To this end, coral skeletal chemistry has been used extensively to reconstruct climatic variability during the recent past. Scleractinian corals form skeletons of aragonite, which incorporates trace elements from seawater. Strontium (Sr) and magnesium $(\mathrm{Mg})$ have been used extensively to reconstruct past sea surface temperatures since seawater $\mathrm{Sr} / \mathrm{Ca}$ (calcium) and $\mathrm{Mg} / \mathrm{Ca}$ are relatively invariant (Broecker, 1982) and good correlations have been observed between coral $\mathrm{Sr} / \mathrm{Ca}$ and/or $\mathrm{Mg} / \mathrm{Ca}$ records and temperature (due to the thermodynamic dependence of elemental partitioning on temperature) (e.g. Beck et al., 1992; Mitsuguchi et al., 1996; Smith et al., 1979; Swart et al., 2002).

The inclusion of other elements, such as uranium $(\mathrm{U})$, barium $(\mathrm{Ba})$ and rare earth elements, have been linked to changes in ocean chemistry. Variability in coral E/Ca records for these elements typically exceeds that due to temperature changes alone. Barium readily substitutes for $\mathrm{Ca}$ within the aragonite skeleton due to similar ionic radii, has elevated concentrations in terrestrial water sources (Gaillardet et al., 2003; Shaw et al., 2008) and the temperature dependent partitioning Ba of inorganic aragonite is well constrained (Dietzel et al., 2004; Gaetani and Cohen, 2006). Indeed, measurement of coral $\mathrm{Ba} / \mathrm{Ca}$ has expanded coral climate proxies beyond sea surface temperature to include proxy records of river discharge (Alibert et al., 2003; Carriquiry and Horta-Puga, 2010; Fleitmann et al., 2007; Jupiter et al., 2008; Sinclair and McCulloch, 2004), river sediment transport (McCulloch et al., 2003; Prouty et al., 2010), upwelling (Alibert and 
Kinsley, 2008; Fallon et al., 1999; Lea et al., 1989; Montaggioni et al., 2006; Tudhope et al., 1996) and groundwater discharge (itself a precipitation proxy, Horta-Puga and Carriquiry, 2012). However, several studies report coral $\mathrm{Ba} / \mathrm{Ca}$ ratios that did not vary in concert with a known driver. For example Sinclair (2005) and Tudhope et al. (1996) reported elevated coral $\mathrm{Ba} / \mathrm{Ca}$ that did not correlate to known upwelling or river runoff sources. Thus some uncertainty exists regarding the use of coral $\mathrm{Ba} / \mathrm{Ca}$ as an environmental proxy.

Coral $\mathrm{Ba} / \mathrm{Ca}$-based climate records are typically constructed by regressing coral $\mathrm{Ba} / \mathrm{Ca}$ against a measure of the parameter of interest (e.g. river discharge or water temperature as a proxy for upwelling) with the underlying assumption that variability in the $\mathrm{Ba} / \mathrm{Ca}$ of the coral skeleton reflects changes in seawater chemistry caused by variability in the environmental driver. In order for this assumption to be true, the following conditions have to be met: first, temperature driven changes in coral $\mathrm{Ba} / \mathrm{Ca}$ should be insignificant compared to the other driver of the $\mathrm{Ba} / \mathrm{Ca}$ signal, or can be adequately corrected for; second, seawater $\mathrm{Ba} / \mathrm{Ca}$ should increase in direct proportion to the proposed driver (i.e. terrestrial input, river flow, and groundwater discharge); and third, corals should incorporate the seawater $\mathrm{Ba} / \mathrm{Ca}$ signal in a predictable fashion.

To gain a mechanistic understanding of the $\mathrm{Ba} / \mathrm{Ca}$ coral proxy and address the three controls listed above, we grew Favia coral polyps in seawater amended with barium at three different concentrations and three different temperatures to quantify solidsolution Ba partitioning as a function of temperature, calcification rate and seawater $\mathrm{Ba}$ concentration. We also developed a model to relate seawater dissolved $\mathrm{Ba}$ and $\mathrm{Ca}$ 
concentrations to different environmental influences, including upwelling, river flow, and groundwater discharge. We applied this model to a site on the Yucatan Peninsula where submarine groundwater discharge is the primary pathway for terrestrial water (recharging precipitation) to enter the coastal ocean (Bauer-Gottwein et al., 2011; Beddows et al., 2007; Gondwe et al., 2010; Gonneea et al., in review). At this site, groundwater and coastal ocean chemistry were well characterized through seasonal water sampling $(\mathrm{Ba})$ and one year of continuous measurements (salinity). We constrained the potential response of coral $\mathrm{Ba} / \mathrm{Ca}$ given the observed coastal ocean chemistry. A twelve-year, monthly-resolved Siderastrea coral $\mathrm{Ba} / \mathrm{Ca}$ record displayed an excellent correlation with precipitation. Finally, we compared this record with the water chemistry model results combined with a Rayleigh fractionation-based model of coral elemental ratios to gain a greater understanding of the coral $\mathrm{Ba} / \mathrm{Ca}$ proxy.

\section{Methods}

\subsection{Experimental conditions}

The coral culture experiments were performed at the Bermuda Institute of Ocean Sciences (BIOS) in July 2011. Nine aquaria (20 L) were established in three different temperature controlled baths $\left(\sim 27.7,24.6\right.$ and $\left.22.5^{\circ} \mathrm{C}\right)$, with each tank having a different temperature/element concentration combination (Table 1). Temperature was monitored in all but one of the tanks with Onset ${ }^{\mathrm{TM}} \mathrm{HOBO}$ water temperature loggers. Ambient $\mathrm{CO}_{2}$ conditions were maintained by directly bubbling air through micropore bubble 'wands' attached at the base of each aquarium thereby maintaining a stable aragonite saturation state; this also served to keep the tanks well mixed. The tanks were drained and refilled 
with filtered seawater $(5 \mu \mathrm{m})$ at the beginning of the experiment and then on days 5 and 11 to prevent the buildup of nutrients during the 14-day experiment. Once the tanks were filled, they were amended with a dissolved barium standard (Fluka® Analytical). Samples for salinity, trace element content and alkalinity/dissolved inorganic carbon (Alk/DIC) were collected at the beginning and end of the experiment, as well as prior to each water change and after the element addition had equilibrated in the tank for one hour (a total of 8 measurements of water chemistry in each tank during the course of the experiment). Some evaporation was observed despite plastic covering on the aquaria, which likely explains in the range in salinities observed among different tanks over time (Table 1).

\subsection{Coral culture}

Mature adult Favia fragum colonies were collected from nearby reefs just prior to the July spawn (Goodbody-Gringley and de Putron, 2009). They were kept in outdoor flow-through aquaria during the day and isolated at night. Zooxanthellate larvae were collected each morning, and then added to plastic containers with mesh tops containing preconditioned ceramic tiles (de Putron et al., 2011). The larvae were then allowed to settle on tiles in aquaria established at experimental conditions for 48 hours to encourage coral polyps to metamorphose and attach to the tiles, at which point calcification of the coral skeleton begins. At this point, the tiles that contained the metamorphosed primary coral polyps were removed from the mesh-topped containers and placed directly in the aquaria. Light levels were maintained at $215 \pm 59 \mu \mathrm{mol}$ quanta $\mathrm{m}^{-2} \mathrm{~s}^{-1}$ for 12 hours of each day ( \pm indicates one standard deviation throughout). The polyps were allowed to 
grow for 14 days, after which the polyps were removed from the aquaria, rinsed with a $5 \%$ bleach solution to remove organic material, subsequently rinsed with deionized water and dried. Additional details are available in Drenkard et al. (2013).

\subsection{Analytical methods}

Tank salinity was measured at BIOS with an Autosal salinometer. The Alk/DIC samples were poisoned with mercuric chloride immediately after collection and analyzed using a Marianda VINDTA-3C analysis system at Woods Hole Oceanographic Institution. Alkalinity was determined by non-linear curve fitting of data obtained by open-cell titrations and DIC concentrations were determined by coulometric analysis. The $\mathrm{pCO}_{2}$ and aragonite saturation state $\left(\Omega_{\mathrm{AR}}\right)$ were calculated from discrete temperature, salinity, Alk, and DIC samples using the CO2SYS program (Lewis and Wallace, 1998; Pelletier et al., 2007) utilizing the constants of Mehrbach et al. (1973) as refit by Dickson and Millero (1987).

Each coral polyp was examined under a microscope, removed from the ceramic tile and weighed on a microbalance (Cohen and Holcomb, 2009). Efforts were made to remove only the corallite, however some material from the heavily encrusted tiles may have adhered to the corallites. These skeletons were identified and removed from the analysis. Elemental analysis was conducted on individuals that weighed at least $70 \mu \mathrm{g}$, otherwise multiple individuals from the same tile were grouped together for analysis. Skeletal material was dissolved in 5\% Optima nitric acid and analyzed via inductively coupled plasma mass spectrometry (ICP-MS) on a Finnigan Element II at the Woods Hole Oceanographic Institution ICP-MS Facility. Ba/Ca elemental standards were 
gravimetrically prepared. Three carbonate reference materials were analyzed, including two fish otolith standards (FEBS-1, Ba/Ca $=4.2 \mu \mathrm{mol} \mathrm{mol}^{-1}$, National Research Council Canada, and one detailed in Yoshinaga et al. (2000), $\mathrm{Ba} / \mathrm{Ca}=2.2 \mu \mathrm{mol} \mathrm{mol}^{-1}$ ) and the JCp-1 coral reference standard $\left(\mathrm{Ba} / \mathrm{Ca}=7.5 \mu \mathrm{mol} \mathrm{mol}^{-1}\right.$, Okai et al. (2002)).

Dissolved barium in Yucatan lagoon water samples and in aliquots from each tank in the coral culture experiment was analyzed by isotope dilution mass spectrometry (Fassett and Paulsen, 1989). Samples were diluted 25 times with 5\% Optima nitric acid, spiked with ${ }^{135} \mathrm{Ba}$ and analyzed via ICP-MS for masses ${ }^{135} \mathrm{Ba}$ and ${ }^{138} \mathrm{Ba}$. Ca concentrations were determined with a Dionex ion chromatograph referenced to the IAPSO standard $\left(10.5 \pm 0.1 \mathrm{mmol} \mathrm{kg}^{-1}, \mathrm{n}=20\right)$. Ba was measured in NASS-5, SLEW-3 and SLRS-4 dissolved reference materials ( $\mathrm{nmol} \mathrm{kg}{ }^{-1}$ in measured and (reference) values, $\mathrm{na}=$ reference value not available: NASS-5: $45 \pm 0.5(\mathrm{na})$, SLRS-5: $89.3 \pm 1.8(88.8)$ and SLEW-3: $179 \pm 2(n a), \mathrm{n}=10)$; we determined our analytical uncertainty to be $2 \mathrm{nmol}$ $\mathrm{kg}^{-1}$ based on these replicate analyses.

\subsection{Coral record}

$\mathrm{Ba} / \mathrm{Ca}$ ratios from an Atlantic Siderastrea siderea coral are reported for twelve years (1997-2008). This coral was collected from a fringing reef (4 m) off the coast of Puerto Morelos, Yucatan Peninsula, in August 2009. Coral age was reconstructed from high and low density peaks identified with computerized tomography (CT) images (Vasquez-Bedoya et al., 2012). Average extension rates for this period were $3.2 \pm 0.4$ $\mathrm{mm} \mathrm{y}^{-1}$. The coral was cut parallel to the main growth axis and a thin section was prepared for analysis. Elemental analysis of this specimen was performed using a New 
Wave Research UP $193 \mathrm{~nm}$ eximer laser ablation system attached to a Finnigan Element 2 high resolution ICP-MS. The laser was operated at $10 \mathrm{~Hz}$ with a $100 \mu \mathrm{m}$ spot size and samples were collected every $200 \mu \mathrm{m}$ along the corallite wall. This approach yielded $\mathrm{Ba} / \mathrm{Ca}$ measurements equivalent to approximately 10 days of growth separated by 10 days of growth. $\mathrm{Ba} / \mathrm{Ca}$ values were standardized to the carbonate reference materials discussed above, which were measured every 8 samples.

\section{Results}

\subsection{Coral barium incorporation experiments}

Conditions within the individual tanks are shown in Table 1. Salinity in all tanks was $\sim 35$, with a standard deviation of $3 \%$. The three temperature conditions $(27.7,24.6$ and $22.5^{\circ} \mathrm{C}$ ) experienced a standard deviation of $1.1^{\circ} \mathrm{C}$. The $\mathrm{CO}_{2}$ content and resulting aragonite saturation state is dependent on the water temperature, thus tanks at lower temperatures had slightly higher $\mathrm{CO}_{2}$ levels and lower saturation states. This was particularly evident in Tank 9, the low temperature, high Ba tank (Table 1). Coral polyps in this tank had the lowest calcification rates (Table 2). However, in general, most tanks had a saturation state of approximately 3 . The three different dissolved Ba concentrations $\left(\sim 73,230\right.$ and $\left.450 \mathrm{nmol} \mathrm{kg}^{-1}\right)$ were maintained in the aquaria for the length of the experiment with a standard deviation of 1-2.5 $\mathrm{nmol} \mathrm{kg}^{-1}$ (Table 1). The resulting water $\mathrm{Ba} / \mathrm{Ca}$ were $6.8-7.5,21-23$ and $42-44 \mu \mathrm{mol} \mathrm{mol}^{-1}$ with a standard deviation of 1-3.5 (Table 1).

Coral polyps grown in seawater amended with Ba incorporated this signal in their skeletal material, demonstrating a positive response to increased seawater $\mathrm{Ba} / \mathrm{Ca}$. Coral 
$\mathrm{Ba} / \mathrm{Ca}$ averaged $\sim 12,31$ and $60 \mu \mathrm{mol} \mathrm{mol}^{-1}$ at the three dissolved Ba concentrations (Fig. 1, Table 2). However, individual polyps displayed a large range in $\mathrm{Ba} / \mathrm{Ca}$ values, with standard deviations for each treatment between 13 and $40 \%$ (Table 2). There is no significant difference in coral $\mathrm{Ba} / \mathrm{Ca}$ between similar element amendments at the three different temperatures (Fig. 1).

The coral polyp calcification rate exhibited a temperature dependence, with higher calcification rates observed at higher temperatures (Fig. 2). In addition to the diminished metabolic response at lower temperatures, these tanks also had a lower saturation state since $\mathrm{CO}_{2}$ is more soluble in water at 22.5 versus $27.7^{\circ} \mathrm{C}$. The range in calcification rates for individual polyps was quite large, with the majority of specimens in the warm tanks $\left(27.7^{\circ} \mathrm{C}\right)$ having calcification rates between 5.4 and $8.5 \mathrm{mg} \mathrm{d}^{-1}$, while rates in the cool tanks $\left(22.5^{\circ} \mathrm{C}\right)$ fell between 1.0 and $4.8 \mathrm{mg} \mathrm{CaCO}_{3} \mathrm{~d}^{-1}$ (Fig. 2 and Table 2). The lowest calcification rates were also coincident with the lowest saturation states, particularly for tanks 9,8 and 6 , although there was no statistical difference between saturation states at the different treatments (likely due to the small sample size and large standard deviation).

\section{Discussion}

\subsection{Coral Ba uptake}

Experimental results indicate the corals incorporate barium in direct proportion to the seawater dissolved barium across a large concentration range $\left(72-463 \mathrm{nmol} \mathrm{kg}^{-1}\right)$. To our knowledge, this is the first time the concentration response of Ba uptake into biogenic aragonite has been demonstrated experimentally. Our results are consistent with those 
observed for marine species that precipitate calcite (foraminifera, Lea and Spero, 1992; and fish otoliths, Bath et al., 2000; Elsdon and Gillanders, 2003). However, there is a large range in individual Ba uptake efficiency (Fig. 1). The partition coefficient must be constrained to use coral $\mathrm{Ba} / \mathrm{Ca}$ as an environmental paleo proxy. Below we consider the potential impact of temperature and calcification rate on this inter-specimen variability.

\subsection{Coral Ba/Ca partition coefficient}

The partitioning of barium between solid aragonite and dissolved phases can be described by the partition coefficient:

1) $\mathrm{K}_{\mathrm{Ba}}=\frac{\mathrm{Ba} / \mathrm{Ca}_{\text {argonite }}}{\mathrm{Ba} / \mathrm{Ca}_{\text {dissolved }}}$.

Experiments with inorganic aragonite over large temperature ranges $\left(10-75^{\circ} \mathrm{C}\right)$ show that the $\mathrm{K}_{\mathrm{Ba}}$ is inversely related to temperature (Dietzel et al., 2004; Gaetani and Cohen, 2006), such that aragonite precipitated at a lower temperature will have a higher $\mathrm{Ba} / \mathrm{Ca}$. There is a large range in polyp $\mathrm{Ba} / \mathrm{Ca}$, hence statistical outliers were identified and excluded from the following $\mathrm{K}_{\mathrm{Ba}}$ calculations (defined as $>1.5$ times the quartile range from the $25^{\text {th }}$ and $75^{\text {th }}$ percentile of the data). We calculated the partition coefficient at each experimental temperature from the regression slope between coral and water $\mathrm{Ba} / \mathrm{Ca}$. At $27.7^{\circ} \mathrm{C}, \mathrm{K}_{\mathrm{Ba}}=$ $1.33(1.24-1.4195 \%$ confidence interval $(\mathrm{CI}))$, at $24.6^{\circ} \mathrm{C}, \mathrm{K}_{\mathrm{Ba}}=1.43(1.30-1.5695 \% \mathrm{CI})$ and at $22.5^{\circ} \mathrm{C}, \mathrm{K}_{\mathrm{Ba}}=1.45(1.34-1.5695 \% \mathrm{CI})$. The 95\% confidence intervals overlap due to the large range in polyp $\mathrm{Ba} / \mathrm{Ca}$. Lea et al. (1989) report similar $\mathrm{K}_{\mathrm{Ba}}$ values for mature colonies of Diploria labyrinthiformis (Bermuda) and Montastrea annularis (Bermuda) $\left(\mathrm{K}_{\mathrm{Ba}}=1.27 \pm 0.03\right)$ and for Pavona Clavus (Galapagos $)\left(\mathrm{K}_{\mathrm{Ba}}=1.41 \pm 0.14\right)$. The 
temperature dependence of the partition coefficient for the Favia polyps falls along this regression line (Fig. 3):

2) $\mathrm{K}_{\mathrm{Ba}}=-0.024 \mathrm{~T}+2.00$

where $\mathrm{T}$ is temperature in ${ }^{\circ} \mathrm{C}$, however, the slope is not significant due to the large spread in data.

The $\mathrm{K}_{\mathrm{Ba}}$ values calculated here are similar to those determined for inorganic aragonite reported by Dietzel et al. (2004) and Holcomb et al. (2009), but are significantly less than the values predicted by Gaetani and Cohen (2006) (Fig. 3). These three experiments induced precipitation by creating supersaturated conditions with respect to aragonite. The Dietzel et al. (2004) study utilized an experimental design whereby aragonite precipitation was induced by diffusing $\mathrm{CO}_{2}$ across a membrane, while Gaetani and Cohen (2006) and Holcomb et al. (2009) directly added a concentrated $\mathrm{Na}_{2} \mathrm{CO}_{3}$ solution to seawater. Assuming that the mass precipitated in both studies was linear for the duration of the experiment, the precipitation rate in Dietzel et al. was $\sim 10$ $\mathrm{mg} \mathrm{d}^{-1}$, similar to those reported for the Favia experiment described here, while the rates ranged from 40-70 $\mathrm{mg} \mathrm{d}^{-1}$ in the Gaetani and Cohen experiment. The growth rate in the Holcomb et al. experiment is not reported, although Gaetani and Cohen (2010) indicate that it was lower than $40-70 \mathrm{mg} \mathrm{d}^{-1}$. If the observed differences in the predicted $\mathrm{K}_{\mathrm{Ba}}$ temperature dependence between these experiments are due to precipitation rate, this would argue for a higher $\mathrm{K}_{\mathrm{Ba}}$ with higher precipitation rates (Cohen and Gaetani, 2010). The range in precipitation rates in the current culture experiments is likely too small compared to the individual polyp variability to discern a precipitation rate dependence on 
$\mathrm{K}_{\mathrm{Ba}}$. Furthermore, experimentally precipitated inorganic aragonite displays a greater temperature dependence than we observe for the Favia polyps. Over the temperature range used in these experiments $\left(22.5\right.$ to $\left.27.7^{\circ} \mathrm{C}\right)$, Dietzel et al. (2004) predicts a decrease in $\mathrm{K}_{\mathrm{Ba}}$ of 0.19 while Gaetani and Cohen (2006) predict a decrease of 0.37 , compared to the 0.12 reduction that we observed, although the temperature dependence of the Favia experiment is very weakly constrained.

The $\mathrm{K}_{\mathrm{Ba}}$ is a function of both calcification rate and temperature, since in these experiments both variables are linked. We observed an increase in calcification at higher temperatures, as reported previously (Favia, Barkley, 2011; Stylophora pistillata, Reynaud et al., 2003; Cladocora caespitosa, Rodolfo-Metalpa et al., 2008), although evidence has been presented elsewhere for a decline in calcification at the highest temperature used in these experiments $\left(27.7^{\circ} \mathrm{C}\right.$, Galaxea fascicularis and Dendrophyllia, Marshall and Clode, 2004) (Fig. 2). This increase in calcification is potentially due to higher efficiency in the enzyme-regulated processes associated with calcification at increased temperatures, although species dependence cannot be ruled out (Marshall and Clode, 2004). However, the impact of coral calcification and extension rates on element partitioning in corals remains uncertain. Reynaud et al. (2007) report no change in $\mathrm{Sr} / \mathrm{Ca}$ due to calcification rate enhancement at higher light levels, while Saenger et al. (2008) found a greater coral $\mathrm{Sr} / \mathrm{Ca}$ at lower extension rates, suggesting that $\mathrm{K}_{\mathrm{Sr}}$ increases as growth rate decreases. Pingitore et al. (1989) observed that different coral species (Montastrea annularis compared to Acropora palmata) growing in the same location that had higher growth rates also had higher $\mathrm{Ba} / \mathrm{Ca}$, suggesting increased $\mathrm{K}_{\mathrm{Ba}}$ at higher growth 
rates. While calcification rate and the partition coefficient are both correlated to temperature in this experiment, there is no correlation between the calcification rate and the $\mathrm{K}_{\mathrm{Ba}}$ (Fig. 4). In addition, the aragonite saturation state, which is also known to affect coral growth rates, increases at higher temperatures as observed here (Table 1) (e.g. Kleypas et al., 1999). We conclude that the calcification rate does not control the coral $\mathrm{Ba} / \mathrm{Ca}$ for Favia fragum coral polyps.

\subsection{Modeled coral $\mathrm{Ba} / \mathrm{Ca}$ in response to environmental perturbations}

The weak temperature dependence of $\mathrm{K}_{\mathrm{Ba}}$ shown here for Favia polyps suggests that over a temperature change of $5^{\circ} \mathrm{C}\left(23-28^{\circ} \mathrm{C}\right)$ at typical seawater conditions of $40 \mathrm{nM}$ $\mathrm{Ba}$ and $10.3 \mathrm{mmol} \mathrm{Ca}\left(\mathrm{Ba} / \mathrm{Ca}_{\text {seawater }}=3.9 \mu \mathrm{mol} \mathrm{mol}^{-1}\right)$, the potential resulting decrease in coral $\mathrm{Ba} / \mathrm{Ca}$ would be $0.47 \mu \mathrm{mol} \mathrm{mol}^{-1}$ or $9 \%$. Over the same temperature range, inorganic aragonite $\mathrm{Ba} / \mathrm{Ca}$ would decrease $0.7-1.4 \mu \mathrm{mol} \mathrm{mol}^{-1}$ (11-15\%) (Dietzel et al., 2004; Gaetani and Cohen, 2006). Thus, if coral $\mathrm{Ba} / \mathrm{Ca}$ primarily reflects the temperature dependence of $\mathrm{K}_{\mathrm{Ba}}$, variability in $\mathrm{Ba} / \mathrm{Ca}$ should not exceed this range. Many studies, however, report much greater variability in coral $\mathrm{Ba} / \mathrm{Ca}$, with large peaks in $\mathrm{Ba} / \mathrm{Ca}$ attributed to a number of environmental influences on the coastal ocean, including river flow, sediment loading, upwelling and groundwater discharge, as determined by matching records of river flux, erosion or upwelling to the coral $\mathrm{Ba} / \mathrm{Ca}$ record (Table 3, e.g. Fleitmann et al., 2007; Lea et al., 1989; McCulloch et al., 2003; Sinclair, 2005; Sinclair and McCulloch, 2004; Tudhope et al., 1996). While many of these studies have similar baseline $\mathrm{Ba} / \mathrm{Ca}$ values of $4-5 \mu \mathrm{mol} \mathrm{mol}^{-1}$, the $\mathrm{Ba} / \mathrm{Ca}$ peaks are as high as $10-20$ $\mu \mathrm{mol} \mathrm{mol}{ }^{-1}$, many times greater than potentially due to temperature affects alone. One 
potential cause of these coral $\mathrm{Ba} / \mathrm{Ca}$ peaks is elevated seawater $\mathrm{Ba} / \mathrm{Ca}$. In this section, we evaluate how various environmental perturbations influence seawater $\mathrm{Ba} / \mathrm{Ca}$ and ultimately coral $\mathrm{Ba} / \mathrm{Ca}$.

\subsubsection{Water chemistry model}

To model water column dissolved $\mathrm{Ba}$ and $\mathrm{Ca}$ concentrations, we consider the case where the system is at steady state with respect to fluxes. This model is appropriate for water chemistry changes that occur in a system over the time scale of water exchange (i.e. residence time). River and groundwater discharge are common terrestrial sources of $\mathrm{Ba}$ and $\mathrm{Ca}$ to the coastal ocean. River water and groundwater are highly enriched in $\mathrm{Ba}$, so a relatively small flux can exert a proportionally large control on dissolved $\mathrm{Ba}$ concentrations (hereby $[\mathrm{Ba}]$ ). Coastal $[\mathrm{Ba}]$ in regions impacted by rivers and groundwater may be $50-150 \mathrm{nmol} \mathrm{kg}^{-1}$ and is controlled by the end member [Ba] and the water flux (Coffey et al., 1997; Lin et al., 2010; Moore, 1997; Shaw et al., 1998). In addition, upwelling may raise surface water $[\mathrm{Ba}]$ dependent on the rate of deep water (150 nmol $\left.\mathrm{kg}^{-1}\right)$ advection and subsequent mixing with surface water $\left(30 \mathrm{nmol} \mathrm{kg}{ }^{-1}\right)$ (Chan et al., 1976).

The following expression describes changing $[\mathrm{Ba}]$ if groundwater discharge is considered:

3) $\frac{d B a}{d t}=[B a]_{G W} F_{G W}+[B a]_{\text {coast }} F_{\text {out }}-[B a]_{\text {ocean }} F_{\text {in }}$ where $[\mathrm{Ba}]_{\mathrm{GW}},[\mathrm{Ba}]_{\mathrm{coast}}$, and $[\mathrm{Ba}]_{\text {ocean }}$ are the concentrations of the inflowing groundwater, the coastal ocean (where the corals grow), and the seawater exchanging with the coastal ocean respectively; $F_{G W}$ is the water flux into the area $\left(\mathrm{m}^{3} \mathrm{~d}^{-1}\right) ; \mathrm{F}_{\text {out }}$ is the water flow from 
the coastal region to the ocean and $F_{\text {in }}$ is rate of ocean water entering the coastal zone, where the water flow balance is:

4) $F_{\text {out }}=F_{\text {in }}+F_{G W}$

We can constrain $\mathrm{F}_{\text {out }}$ :

5) $F_{\text {out }}=\frac{V}{\tau_{w}}$

where $\mathrm{V}$ is the volume of the coastal region and $\tau_{\mathrm{w}}$ is the residence time of the water with respect to coastal exchange. For a system at steady state, the following solution is used:

6) $[B a]_{\text {coast }}=\tau_{w}\left(\frac{[B a]_{G W} F_{G W}+[B a]_{\text {ocean }}\left(\frac{V}{\tau_{w}}-F_{G W}\right)}{V}\right)$

A similar equation can be written for any tracer of interest, including $\mathrm{Ca}$ and salinity, and riverine or upwelling end members can be substituted for groundwater if another perturbation is under consideration.

\subsubsection{Groundwater, river and upwelling chemistry}

To model the potential influence of river flow, groundwater discharge, and upwelling on the coastal ocean $\mathrm{Ba} / \mathrm{Ca}$, the concentration of these elements in the end member of interest must be known. Compared to the surface ocean, Ba concentrations are typically elevated in rivers, groundwater and deep ocean water, while $\mathrm{Ca}$ is usually lower in rivers and groundwater than seawater but similar to seawater in the case of upwelling (Chan et al., 1977; Chan et al., 1976; Gaillardet et al., 2003; Gonneea et al., in review; Livingston, 1963; Moore and Shaw, 1998; Shaw et al., 1998). Hence, the resulting fluxes from rivers, groundwater discharge, and upwelling tend to have a greater $\mathrm{Ba} / \mathrm{Ca}$ ratio than seawater. 
For the general model presented here, groundwater has a [Ba] of $400 \mathrm{nmol} \mathrm{kg}^{-1}$ and $[\mathrm{Ca}]$ of $1 \mathrm{mmol} \mathrm{kg}^{-1}$ with a $\mathrm{Ba} / \mathrm{Ca}$ ratio of $400 \mu \mathrm{mol} \mathrm{mol}^{-1}$, rivers have a [Ba] of 215 $\mathrm{nmol} \mathrm{kg}{ }^{-1}$ ). and [Ca] of $0.38 \mathrm{mmol} \mathrm{kg}^{-1}$ with a Ba/Ca ratio of $263 \mu \mathrm{mol} \mathrm{mol}{ }^{-1}$, while upwelled water has a [Ba] of $150 \mathrm{nmol} \mathrm{kg}^{-1}$ and [Ca] of $10.28 \mathrm{mmol} \mathrm{kg}^{-1}$ with a $\mathrm{Ba} / \mathrm{Ca}$ ratio of $14 \mu \mathrm{mol} \mathrm{mol}^{-1}$ (Table 4). The river value consists of $150 \mathrm{nmol} \mathrm{kg}^{-1}$ in the freshwater end member plus a further $65 \mathrm{nmol} \mathrm{kg}{ }^{-1}$ desorbed from suspended particles in the estuary (Livingston, 1963). Dissolved [Ba] and [Ca] in groundwater, river water and deep ocean water may vary by location, thus these values may not be applicable at all study sites.

\subsubsection{Modeled coral $\mathrm{Ba} / \mathrm{Ca}$ in response to groundwater, river and upwelling flux}

We tested the sensitivity of groundwater discharge, river flow, and upwelling on coral $\mathrm{Ba} / \mathrm{Ca}$ by calculating the impact on water $\mathrm{Ba} / \mathrm{Ca}$, according to equation 6 written for both $\mathrm{Ba}$ and $\mathrm{Ca}$, and multiplying by the partition coefficient (equation 1). For each scenario we constructed a representative physical model (Fig. 5). For example, we considered submarine groundwater discharge into a lagoon with a water depth of $10 \mathrm{~m}, 5$ $\mathrm{km}$ long shoreline and $0.5 \mathrm{~km}$ wide, a similar geometry to the reef lagoon system discussed later. The influence of river discharge was modeled for a coral growing $50 \mathrm{~km}$ from the main delta, similar to the Porites coral growing in the Great Barrier Reef near the Burdekin River presented in McCulloch et al. (2003) (Fig. 5). $\mathrm{K}_{\mathrm{Ba}}$ was invariant at 1.49 (calculated from equation 2 at $25^{\circ} \mathrm{C}$ ), although the impact of a potential 23 to $28^{\circ} \mathrm{C}$ temperature change (coral $\mathrm{Ba} / \mathrm{Ca}$ decreases by 0.4 based on $\mathrm{K}_{\mathrm{Ba}}$ temperature dependence of equation 2) is compared to modeled coral $\mathrm{Ba} / \mathrm{Ca}$ (Fig. 6). The model tested how the 
magnitude of the environmental flux (i.e. a water flux due to river flow, groundwater discharge, or upwelling) and the residence time of the water altered coastal dissolved $\mathrm{Ba} / \mathrm{Ca}$ and subsequently coral $\mathrm{Ba} / \mathrm{Ca}$. In the case of groundwater discharge and upwelling, this flux was $<1 \%$ of the total exchange in the system in all model scenarios, thus input rate will not alter the water residence time. For the case of river discharge and a 45 day residence time, river discharge was $50 \%$ of the total exchange in the system.

Under all model scenarios, as residence time increases there is less exchange with low $[\mathrm{Ba}]$ offshore waters, resulting in elevated coral Ba/Ca (Fig. 6). River and groundwater discharge had a larger impact on modeled coral $\mathrm{Ba} / \mathrm{Ca}$ than did upwelling due to the high $\mathrm{Ba} / \mathrm{Ca}$ in the terrestrial end member compared to seawater, with $\mathrm{Ba} / \mathrm{Ca}$ ratios reaching up to $11.2 \mu \mathrm{mol} \mathrm{mol}^{-1}$ for a residence time of 4 days and a groundwater flux of $120 \mathrm{~m}^{3} \mathrm{~m}^{-1} \mathrm{~d}^{-1}$; while to achieve a similar $\mathrm{Ba} / \mathrm{Ca}$ a residence time of 45 days and river flux of $10^{8} \mathrm{~m}^{3} \mathrm{~d}^{-1}$ into the 50 square $\mathrm{km}$ coastal region is needed. Groundwater discharge of this magnitude is quite large, and would represent extreme events. Groundwater discharge to coral reefs located in Hawaii, USA; Florida, USA; Mauritius; and the Yucatan Peninsula, Mexico, range between 15-205 $\mathrm{m}^{3} \mathrm{~m}^{-1} \mathrm{~d}^{-1}$ (Gonneea et al., in review; Paytan et al., 2006). Groundwater discharge may spike after large rainfall events, but the magnitude of temporal variability is generally dampened compared to riverine flow (Michael et al., 2005; Moore, 2010; Santos et al., 2009). For example, the Burdekin River that flows into the Great Barrier Reef coastal region has peak flows that reach $2 \times$ $10^{8} \mathrm{~m}^{3} \mathrm{~d}^{-1}$ during flooding events, which are of short duration (McCulloch et al., 2003). 
In comparison, the maximum coral $\mathrm{Ba} / \mathrm{Ca}$ from upwelling rates of $3.2 \mathrm{~m} \mathrm{~d}^{-1}$ with a 4 day residence time was $5.9 \mu \mathrm{mol} \mathrm{mol}^{-1}$. Upwelled water is typically less enriched in $[\mathrm{Ba}]$ than river or groundwater flow and has the same [Ca], with $\mathrm{Ba} / \mathrm{Ca}$ of $14 \mu \mathrm{mol} \mathrm{mol}^{-1}$. Typical upwelling rates in the equatorial Pacific are 0.2 to $0.9 \mathrm{~m} \mathrm{~d}^{-1}$ (Fiedler et al., 1991; Quay et al., 1983). Higher rates are reported for coastal upwelling systems, such as found in New Calendonia ( $5 \mathrm{~m} \mathrm{~d}^{-1}$, Marchesiello et al., 2010), however coastal upwelling events tend to be of short duration (days). In this model, upwelling occurs only outside the lagoon and is then advected into the lagoon where the coral is growing; this model geometry may not be applicable at every site.

\subsubsection{Model sensitivity to temporally dynamic residence time and Ba flux}

In order to demonstrate how the modeled coral $\mathrm{Ba} / \mathrm{Ca}$ may vary temporally as environmental factors change, the model was run with a sinusoidally varying groundwater discharge and residence time (Fig. 7). In the first model run, residence time varied from 1 to 5 days seasonally, while groundwater inputs varied from $10-90 \mathrm{~m}^{3} \mathrm{~m}^{-1} \mathrm{~d}^{-}$

${ }^{1}$ (in the $5 \mathrm{~km}$ long lagoon). In the second run, residence time was held constant at 3 days, while groundwater discharge was allowed to vary as in the first model. In the third model, groundwater discharge was held constant at $50 \mathrm{~m}^{3} \mathrm{~m}^{-1} \mathrm{~d}^{-1}$ and residence time again varied between 1 and 5 days. For the fourth model, groundwater discharge was allowed to vary as in models one and two, but the phase of the residence time was changed. Residence time is at a minimum at day 91 in this model, concurrent with maximum groundwater discharge. Since the highest flushing rate now occurs simultaneously with maximum 
groundwater discharge, the coastal dissolved $\mathrm{Ba}$ concentration and hence the coral $\mathrm{Ba} / \mathrm{Ca}$, is relatively dampened.

The largest range in the coral $\mathrm{Ba} / \mathrm{Ca}\left(5.9\right.$ to $12 \mu \mathrm{mol} \mathrm{mol}^{-1}$ for the specified model conditions) occurs when both groundwater discharge and residence time co-vary, since when they are in phase the greatest discharge occurs during the longest residence times thereby elevating seawater $\mathrm{Ba} / \mathrm{Ca}$. When the residence time was held constant, the same groundwater flux resulted in coral $\mathrm{Ba} / \mathrm{Ca}$ of $6.0-9.1 \mu \mathrm{mol} \mathrm{mol}{ }^{-1}$. When groundwater flux was constant and residence time fluctuated $\mathrm{Ba} / \mathrm{Ca}$ was $6.4-8.8 \mu \mathrm{mol} \mathrm{mol}^{-1}$. A double peak in $\mathrm{Ba} / \mathrm{Ca}$ was observed when residence time and groundwater flux were out of phase (6.1-7.5 $\left.\mu \mathrm{mol} \mathrm{mol}{ }^{-1}\right)$. These results highlight the importance of understanding the physical dynamics of the water body surrounding the coral for interpretation of elemental records derived from either terrestrial or upwelling fluxes to the coastal ocean. Multiple forcings, groundwater discharge rate and water residence time in this modeled example, may have seasonal or longer phase variability that are in phase with one another, for instance if the rainy season occurs during a relatively calm wind period, thereby increasing water residence times. However, if seawater $\mathrm{Ba} / \mathrm{Ca}$ responds to multiple environmental influences, then the coral $\mathrm{Ba} / \mathrm{Ca}$ may be misinterpreted if only one is considered when evaluating the significance of the $\mathrm{Ba} / \mathrm{Ca}$ signal. Thus some effort must be made to constrain the range of possible residence times that might occur over the temporal resolution of the coral elemental record (typically seasonal to yearly). 


\subsection{Model application to Yucatan Peninsula lagoon and coral Ba/Ca}

\subsubsection{Groundwater and coastal lagoon chemistry}

The Yucatan Peninsula is a porous karst platform, resulting in relatively rapid infiltration of rainfall and subsequent transport of freshwater to the coast via groundwater flow (Bauer-Gottwein et al., 2011). Groundwater interacts with the carbonate aquifer as it flows to the coast and is enriched in barium through dissolution of the aquifer matrix (Gonneea et al., in review; Perry et al., 2002). Submarine groundwater discharge occurs within coastal lagoons via underwater springs and diffuse seepage; rates are variable (45$90 \mathrm{~m}^{3} \mathrm{~m}^{-1} \mathrm{~d}^{-1}$ ) and generally higher during or immediately after the rainy season (Gonneea et al., in review). There are no rivers or streams entering the lagoon, thus groundwater discharge is the main mechanism delivering terrestrially derived $\mathrm{Ba}$ to the coastal ocean. The Puerto Morelos reef lagoon lies $\sim 25 \mathrm{~km}$ south of Cancun on the northeast coast of the Yucatan Peninsula. It stretches $4 \mathrm{~km}$ alongshore, with an average width of $1 \mathrm{~km}$ and average depth of $4 \mathrm{~m}$. These physical parameters are used to apply the model to this site.

Gonneea et al. (in review) explores the geochemical cycling of barium and calcium within the karst subterranean estuary and reports a terrestrial groundwater [Ba] and $\left[\mathrm{Ca}\right.$ ] end member of 200-300 $\mathrm{nmol} \mathrm{kg}^{-1}$ and $3.4 \mathrm{mmol} \mathrm{kg}^{-1}$, respectively, across the entire Yucatan Peninsula. In the coastal ocean, which exchanges with the lagoon, [Ba] is $\sim 52 \mathrm{nmol} \mathrm{kg}^{-1}$ and [Ca] is $\sim 12 \mathrm{mmol} \mathrm{kg}^{-1}$, elevated from an offshore (60 km) [Ca] values

of 10.7. Here we evaluate the agreement between lagoon [Ba] and the model predicted 
[Ba]:salinity relationship (according to equation 6) using the groundwater end member described by Gonneea et al. (in review).

The lagoon samples were collected during 2010, 2011 and 2012 across multiple seasons including a time series in the Puerto Morelos lagoon (at the UNAM pier, approximately $4.5 \mathrm{~km}$ from the coral site) from February 2011 to October 2011 and June 2012 to December 2012 (Table 5, Fig. 8). The lagoon salinity range was 34-36 and [Ba] was $53-71 \mathrm{nmol} \mathrm{kg}^{-1}$. Since the source of $\mathrm{Ba}$ is terrestrial groundwater, the model presented above predicts a linear mixing relationship between $[\mathrm{Ba}]$ and salinity, with the slope of the relationship dependent upon the $[\mathrm{Ba}]$ in terrestrial groundwater. Both the groundwater discharge rate and lagoon residence time, which impact $[\mathrm{Ba}]$ and salinity in a linear fashion, influence where lagoon samples fall along the mixing line.

When we compare the model predicted $[\mathrm{Ba}] /$ salinity relationship for different end members at the observed lagoon salinities, we see that most samples fall between the model predicted $\mathrm{Ba} /$ salinity relationships for groundwater end members between 200 and $300 \mathrm{nmol} \mathrm{kg}^{-1}$ (Fig. 9). However, there are multiple samples that fall closer to a modeled mixing line for a groundwater [Ba] end member of $500 \mathrm{nmol} \mathrm{kg}^{-1}$. These elevated [Ba] samples occur in different locations within the lagoon and were collected at different times. However, there is no evidence in either the terrestrial groundwater or discharging springs for a terrestrial end member with [Ba] of this magnitude (Gonneea et al., in review). The deep marine groundwater does have [Ba] of $400-600 \mathrm{nmol} \mathrm{kg}^{-1}$ across a salinity range of 5 to 38 , but this water is depleted in uranium and elevated in strontium, neither of which are observed in the four lagoon samples with high [Ba]. In addition, 
Gonneea et al. (in review) presents data for spring (groundwater actively discharging into the lagoon) [Ba] over a much larger salinity range with a zero salinity intercept of 200 $\mathrm{nmol} \mathrm{kg}{ }^{-1}$. Based on these observations, we will assume a groundwater end member range 200 and $300 \mathrm{nmol} \mathrm{kg}^{-1}$ when interpreting our coral record.

\subsubsection{Observed lagoon Ba and salinity constraints on modeled groundwater flux}

In addition to the lagoon [Ba] samples described above, we can further constrain temporal variability in lagoon chemistry with a continuous salinity record from October 2011 to October 2012. Rainfall was monitored concurrently at the same location. Both discrete salinity samples and continuous salinity measurements indicate that potential variability is typically $\sim 35$ to 36.5 , the salinity of the offshore end member. Several extreme low excursions (salinity 29-31) of short duration were observed during the passage of a tropical storm (Rina, October 2011) during which rainfall was near $300 \mathrm{~mm}$ $\mathrm{d}^{-1}$ (Fig. 10). The low salinity excursions generally follow large rainfall events, suggesting a rapid response time for groundwater discharge. When a two-week filter is applied to the data, the reduction in lagoon salinity both coincident and following the precipitation event is evident. However, no clear seasonal trend emerges, with low salinity periods observed in October 2011, February-April 2012 and July, September and October 2012. This may be due to rainfall in February-April that was anomalously high for this season (Bauer-Gottwein et al., 2011). The predicted range in lagoon [Ba] based on a $35-36.5$ salinity range is $52-58$ (200 nmol kg ${ }^{-1}$ end member) and $52-63$ (300 nmol $\mathrm{kg}^{-1}$ end member), with the lowest salinity excursion (29) rising to 83 and $104 \mathrm{nmol} \mathrm{kg}^{-1}$ (200 and $300 \mathrm{nmol} \mathrm{kg}^{-1}$ end member respectively). These ranges agree well with the 
observed lagoon [Ba] (53-71 $\left.\mathrm{nmol} \mathrm{kg}^{-1}\right)$, however, we do not have a lagoon sample collected during the extreme low salinity excursion.

\subsubsection{Coral Ba/Ca from the Yucatan Peninsula}

The $\mathrm{Ba} / \mathrm{Ca}$ record from a Siderastrea coral collected off Puerto Morelos, Yucatan, Mexico spans May 1997 to January 2009 and has an annual cycle that varies from baseline values of 4-5 $\mu \mathrm{mol} \mathrm{mol}^{-1}$ to peaks of 8-12 $\mu \mathrm{mol} \mathrm{mol}^{-1}$ with a single peak in 2002 of $18 \mu \mathrm{mol} \mathrm{mol}^{-1}$ (Fig. 11, Table S1). Though the lagoon surface chemistry discussed above relates to a period outside the time frame encompassed by this coral record, we assume this variability is representative of typical years and thus we use these results to constrain the coral $\mathrm{Ba} / \mathrm{Ca}$ response under a given $\mathrm{K}_{\mathrm{Ba}}$ temperature dependence. Monthly mean sea surface temperatures for the $0.5^{\circ}$ grid near the coral site $(86.5 \mathrm{~W}, 20.5 \mathrm{~N}$, IGOSS SST v2, Reynolds et al., 2002) vary between 25.5 and $30^{\circ} \mathrm{C}$ during this period, in good agreement with average monthly SST reported from a site within the Puerto Morelos lagoon (Rodriguez-Martinez et al., 2010). Based on equation 2, $\mathrm{K}_{\mathrm{Ba}}$ should be $\sim 1.44$ in the summer and 1.54 in the winter.

We use two lines of evidence to determine that the observed coral record is not greatly influenced by temperature dependent changes in $\mathrm{K}_{\mathrm{Ba}}$. First, the peak $\mathrm{Ba} / \mathrm{Ca}$ values occur during the summer, when the temperature dependence of $\mathrm{K}_{\mathrm{Ba}}$ predicts the lowest $\mathrm{Ba} / \mathrm{Ca}$ values (Fig. 11). Second, and most importantly, the coral $\mathrm{Ba} / \mathrm{Ca}$ response based on temperature dependence alone for $\sim 5^{\circ} \mathrm{C}$ is $\sim 0.5 \mu \mathrm{mol} \mathrm{mol}^{-1}$, yet we observed a seasonal amplitude of 4-8 $\mu \mathrm{mol} \mathrm{mol}^{-1}$. Thus some other factor must be influencing the coral $\mathrm{Ba} / \mathrm{Ca}$. 
Given the covarying coral $\mathrm{Ba} / \mathrm{Ca}$ and rainfall signals, we hypothesize that groundwater discharge in phase with the monthly average rainfall (precipitation data is from GPCP (http://www.gewex.org/gpcp-data.htm, downloaded for $20^{\circ} 50^{\prime}$ North, $86^{\circ}$ $52^{\prime}$ West) may be altering the surface water chemistry (Fig. 11). In fact, when each yearly coral $\mathrm{Ba} / \mathrm{Ca}$ peak and its corresponding precipitation record is integrated across the 19982008 (complete years) record, there is a good correspondence between the two signals (Fig. 12). Previously Horta-Puga et al. (2010) reported a similar finding for interannual variability in a Montastrea record from Nichupte Lagoon near Cancun, but with a much steeper slope (58). Furthermore, we observe coincident shorter frequency extrema in both records, such as the signal caused by Hurricane Isadore in October 2002. We posit that submarine groundwater discharge is the probable link between the precipitation and Siderastrea $\mathrm{Ba} / \mathrm{Ca}$ records.

Based on the observed variability in water column $\mathrm{Ba} / \mathrm{Ca}\left(4.2-5.3 \mu \mathrm{mol} \mathrm{mol}{ }^{-1}\right.$, with extreme peaks up to 7.8-9.7 $\left.\mu \mathrm{mol} \mathrm{mol}^{-1}\right)$, the range in coral $\mathrm{Ba} / \mathrm{Ca}\left(\mathrm{K}_{\mathrm{Ba}}=1.49\right)$ would be 6.2-7.9, with potential extreme peaks of $11.7-14.7 \mu \mathrm{mol} \mathrm{mol}^{-1}$. This is a much smaller amplitude and higher baseline than is observed. If we accept these constraints on the lagoon water $\mathrm{Ba} / \mathrm{Ca}$, then the range in "effective" $\mathrm{K}_{\mathrm{Ba}}$ needed to account for the observed amplitude in the coral $\mathrm{Ba} / \mathrm{Ca}$ signal is $0.95-2.26$, with the highest values coincident with the summer months.

Recent studies have demonstrated that coral element to calcium ratios can be described by Rayleigh fractionation that takes place during aragonite precipitation (Cohen and Gaetani, 2010; Gaetani and Cohen, 2006; Gaetani et al., 2011; Gagnon et al., 
2007). In this model, calcification takes place in a confined calcifying space, which exchanges fluid with seawater on turnover times of hours (Gagnon et al., 2012). Microsensor evidence suggests $\mathrm{Ca}^{2+}$ ATPase catalyzes the exchange of protons $\left(2 \mathrm{H}^{+}\right)$for $\mathrm{Ca}^{2+}$ within the calcifying space (Al-Horani, 2005). Such $\mathrm{Ca}^{2+}$ pumping will alter the element to calcium ratios within the calcifying fluid, effectively dilution $\mathrm{E} / \mathrm{Ca}$ ratios. A Rayleigh fractionation-based approach has been utilized to account for varying proportions of aragonite precipitated from the calcifying fluid between each flushing and exchange with seawater. The use of this approach is thought to effectively account for the influence of "vital effects" on coral elemental ratios. The analytic solution to the Rayleigh fractionation equation is:

7) $\left(\frac{\bar{C}_{S r}}{\bar{C}_{C a}}\right)^{\text {aragonite }}=\frac{C_{S r}^{0}}{C_{C a}^{0}} \times\left[\frac{1-(F L \times f C a)^{D_{S r / C a}^{\text {aragonite-seawater }}}}{1-(F L \times f C a)}\right]$

where $\left(\frac{\bar{C}_{S r}}{\bar{C}_{C a}}\right)^{\text {aragonite }}$ is the ratio of $\mathrm{Sr}$ and $\mathrm{Ca}$ in the aragonite, $C_{S r}^{0}$ and $C_{C a}^{0}$ are the concentrations in the calcifying fluid, FL is the fraction of initial fluid weight that remains after precipitation ends, $D_{S r / C a}^{\text {argonite-seawater }}$ is the ratio of the Nernst aragoniteseawater partition coefficients for $\mathrm{Sr}$ and $\mathrm{Ca}$ and $\mathrm{fCa}$ is calculated according to:

8) $f_{C a}=\frac{\left(C_{C a}^{0}-(1-F L)\right) * M W_{C a C O}}{C_{C a}^{0}}$

where $\mathrm{MW}_{\mathrm{Ca}}$ is the molecular weight of $\mathrm{CaCO}_{3}\left(100.78 \mathrm{~g} \mathrm{~mol}^{-1}\right)($ Gaetani and Cohen, 2006; Gaetani et al., 2011). The utility of this approach in constraining temperature comes from the temperature dependence of Nernst partition coefficients. It is possible to 
build a system of equations with multiple element to calcium ratios (substituting the appropriate element for $\mathrm{Sr}$ in the above equation) to solve for temperature.

We utilize this approach to constrain the potential influence of Rayleigh based fractionation on the observed $\mathrm{Ba} / \mathrm{Ca}$ ratio in the Siderastrea record and ultimately to extract a predicted $[\mathrm{Ba}]$ concentration of the calcifying fluid. The partition coefficients are calculated directly from the sea surface temperatures (Fig.11). FL is determined from application of equations (7) and (8) on measured $\mathrm{Sr} / \mathrm{Ca}$ and $\mathrm{Mg} / \mathrm{Ca}$ ratios (Fig. S1). For our record, fCa typically varies between 0.6 and nearly 1 (indicating little aragonite formation) (Fig. S2).

Having solved for FL, it is then possible to solve for $C_{B a}^{0}$ using equation 7 and the observed coral Ba/Ca. We assume a constant seawater [Ca] of $10.7 \mathrm{mmol} \mathrm{kg}^{-1}$; allowing [Ca] to vary conservatively over the observed seasonal salinity range (1.5) would influence $\mathrm{Ba} / \mathrm{Ca}$ by $4 \%$. The purpose of this exercise is to constrain the potential impact Rayleigh based fractionation (and its temperature dependence through the Nernst partition coefficient) has on this coral $\mathrm{Ba} / \mathrm{Ca}$ record. The lagoon dissolved $\mathrm{Ba} / \mathrm{Ca}$ calculated in this manner has an average of $4.7 \pm 1.4$ (minimum 2.3 and maximum 9.8 $\mu \mathrm{mol} \mathrm{mol}{ }^{-1}$ ). If a $20 \%$ dilution of Ba occurs within the calcifying fluid due to Ca pumping as predicted for $\mathrm{Sr}$ and $\mathrm{Mg}$ (Al-Horani, 2005), then the predicted $\mathrm{Ba} / \mathrm{Ca}$ is $5.6 \pm 1.7$ (minimum 2.7, maximum $11.8 \mathrm{nmol} \mathrm{kg}^{-1}$, Fig. 13). The observed range in lagoon $\mathrm{Ba} / \mathrm{Ca}$ is 4.9-5.9, with larger excursions (up to $7.8 \mu \mathrm{mol} \mathrm{mol}^{-1}$ ) possible during extreme low salinity events. Thus the Rayleigh fractionation model does not adequately predict lagoon $\mathrm{Ba} / \mathrm{Ca}$. 
It is evident that there is an additional component to the coral $\mathrm{Ba} / \mathrm{Ca}$ signal. This may be the coral calcification rate, which has not been constrained on interannual time scales for this specimen. Despite the aquaria experiments with the Favia polyps displaying no dependence of $\mathrm{K}_{\mathrm{Ba}}$ on calcification rate, it is possible that one exists (Gaetani and Cohen, 2006; Pingitore et al., 1989; Saenger et al., 2008b). However, the inorganic aragonite $\mathrm{K}_{\mathrm{Ba}}$ reported by Holcomb et al. (2009) for lower calcification rates would elevate lagoon $[\mathrm{Ba}]$ similar to increasing the dilution factor (see previous paragraph), not improving model fit further. It is possible that the partition coefficient is sensitive to other parameters not considered here, including crystal growth rate and carbonate saturation state (Cohen and Gaetani, 2010). In addition, Ba is enriched in organic matter, which may be preserved within the coral skeleton (Ingalls et al., 2003). In this coral, the tissue layer extends to a depth of $5 \mathrm{~mm}$ (the beginning of 2006). Barium is also associated with productivity through barite precipitation in organic matter microenvironments during remineralization (Ganeshram, et al. 2003). Indeed preservation of sedimentary $\mathrm{Ba}$ is a commonly utilized paleoproductivity proxy (Dymond et al., 1992). The Ba/Ca of clams (calcite) has been implicated as a productivity signal (e.g. Stecher et al., 1996), but other studies have discounted the link between estuarine productivity and clam $\mathrm{Ba} / \mathrm{Ca}$ (e.g. Gillikin et al., 2006).

\section{Conclusions}

Through coral culture work we have shown that corals incorporate barium in direct proportion to seawater concentrations up to $>400 \mathrm{nmol} \mathrm{kg}^{-1}$. However, there is a wide range in individual $\mathrm{Ba} / \mathrm{Ca}$ ratios for the Favia polyps. Calcification rates were also 
highly variable amongst individuals, although there was a significant positive relationship with temperature. There was no relationship, however, between the partition coefficient and calcification rate in the aquaria experiments.

The significant, positive regression between precipitation and coral $\mathrm{Ba} / \mathrm{Ca}$ on interannual time scales and the corresponding coral $\mathrm{Ba} / \mathrm{Ca}$ peaks coincident with extreme precipitation events suggest that precipitation, coastal ocean chemistry and the coral elemental record are interlinked. In doing so, this approach has revealed several points that must be considered when employing coral $\mathrm{Ba} / \mathrm{Ca}$ as an environmental proxy. First, the physics of the system under consideration must be evaluated to determine which environmental forcings may be important. Many environmental cycles or perturbations covary (for instance seasonal variability in rainfall, sea surface temperature and winds), but the influence of each may be compounded or diminished within the coastal ocean and coral geochemical record. Second, we were not able to fully predict the coral response with the Rayleigh fractionation based model given the observed water chemistry constraints; the coral $\mathrm{Ba} / \mathrm{Ca}$ amplitude was greater than accounted for in the model. There may be additional, biological "vital effects" unaccounted for with application of the Rayleigh fractionation model to this coral record.

Observed fluctuations in both $[\mathrm{Ba}]$ and salinity across multiple years and seasons in the Puerto Morelos reef lagoon fall along [Ba]/salinity relationship predicted by conservative mixing between terrestrial groundwater and the ocean. We conclude that, since the groundwater end member has been well constrained and there are no additional inputs of barium to the coastal ocean at this site, variability in $[\mathrm{Ba}]$ and salinity observed 
in the lagoon was indeed linked to submarine groundwater discharge. The coherence between the coral $\mathrm{Ba} / \mathrm{Ca}$ and precipitation records, particularly the coincident high $\mathrm{Ba} / \mathrm{Ca}$ value $\left(18 \mu \mathrm{mol} \mathrm{mol}^{-1}\right)$ with the extreme rainfall of Hurricane Isadore in 2002, indicates $\mathrm{Ba} / \mathrm{Ca}$ may serve as a paleo proxy for submarine groundwater discharge in appropriate coastal environments. However, further efforts are needed to fully resolve Ba inclusion in corals growing in coastal environments. For example, concurrent records of water column $[\mathrm{Ba}]$ and coral $\mathrm{Ba} / \mathrm{Ca}$, particularly on temporal scales relevant to coral skeletal chemistry measurements (i.e. weeks), are needed to provide further insight into the coral $\mathrm{Ba} / \mathrm{Ca}$ proxy. 
Acknowledgements: In memory of Dr. Luis Vásquez-Bedoya, without whom this work would not have been possible. Luis generously offered access to coral cores, constructed the coral age model and facilitated field sampling in Mexico. Simon Richards and Paul Henderson also were invaluable in the field. Dr. Paul Blanchon and Dr. Roberto Iglesias Prieto assisted with work within the Puerto Morelos lagoon and housed our rain and CTD sensors at UNAM. Dr. Samantha de Putron hosted the coral growth experiments at BIOS. Liz Drenkard guided the coral culturing experiments, while Alice Zicht assisted with aquaria maintenance. DIC and alkalinity measurements were carried out in the laboratories of Dr. Daniel McCorkle and Dr. William Martin at WHOI. Sean Sylva assisted with Ca measurements. Glen Gaetani and Thomas DeCarlo developed the Matlab code for Rayleigh fractionation model. M.E.G. was supported by a NDSEG graduate fellowship. Funding for this research came from the NSF Chemical Oceanography program (OCE-0751525) and the Coastal Ocean Institute, the Ocean and Climate Change Institute and the Ocean Ventures Fund at Woods Hole Oceanographic Institution. 


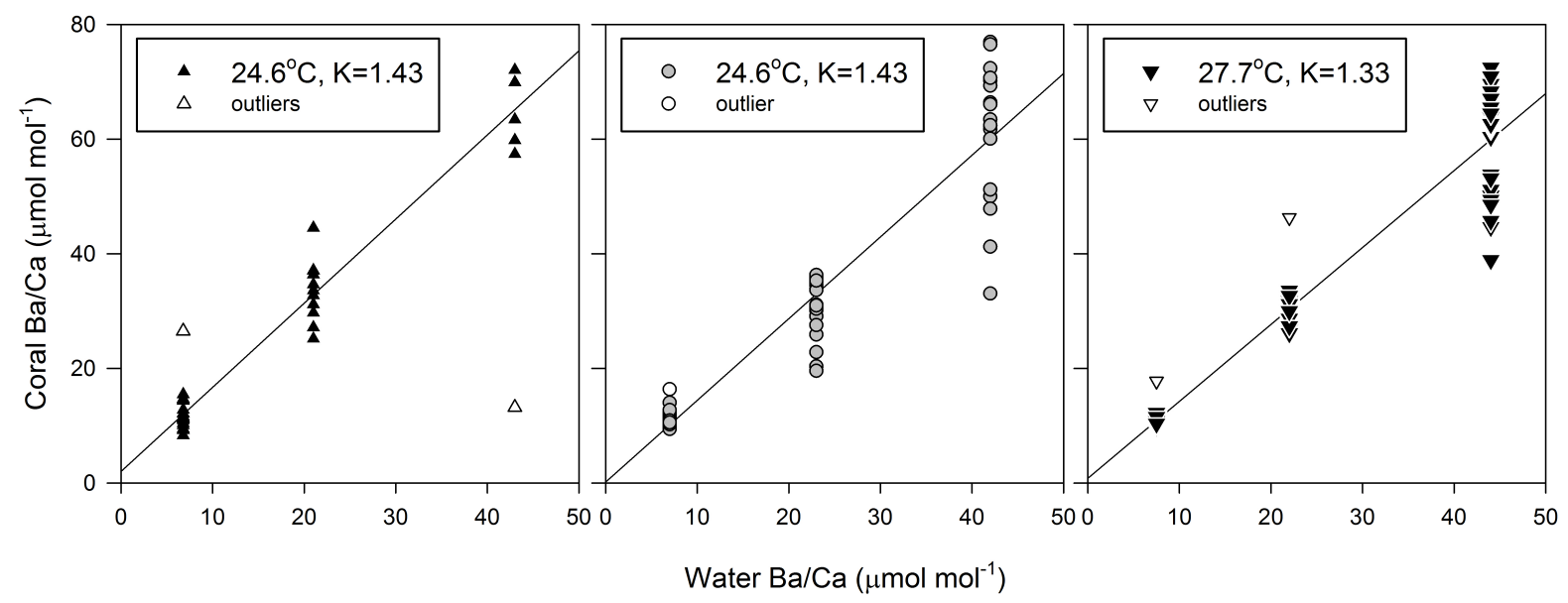

Figure 1: Coral $\mathrm{Ba} / \mathrm{Ca}$ versus water $\mathrm{Ba} / \mathrm{Ca}$ for Favia fragum polyps grown in barium ammended aquaria at three different temperatures (right: 27.7, middle: 24.6 and left: $\left.22.5^{\circ} \mathrm{C}\right)$. Best-fit lines are solid with slopes predicting the partition coefficient $(\mathrm{K})$. The large vertical range of the coral $\mathrm{Ba} / \mathrm{Ca}$ values indicates that $\mathrm{Ba}$ incorporation is highly variable in individual polyps. Empty symbols are statistical outliers. 

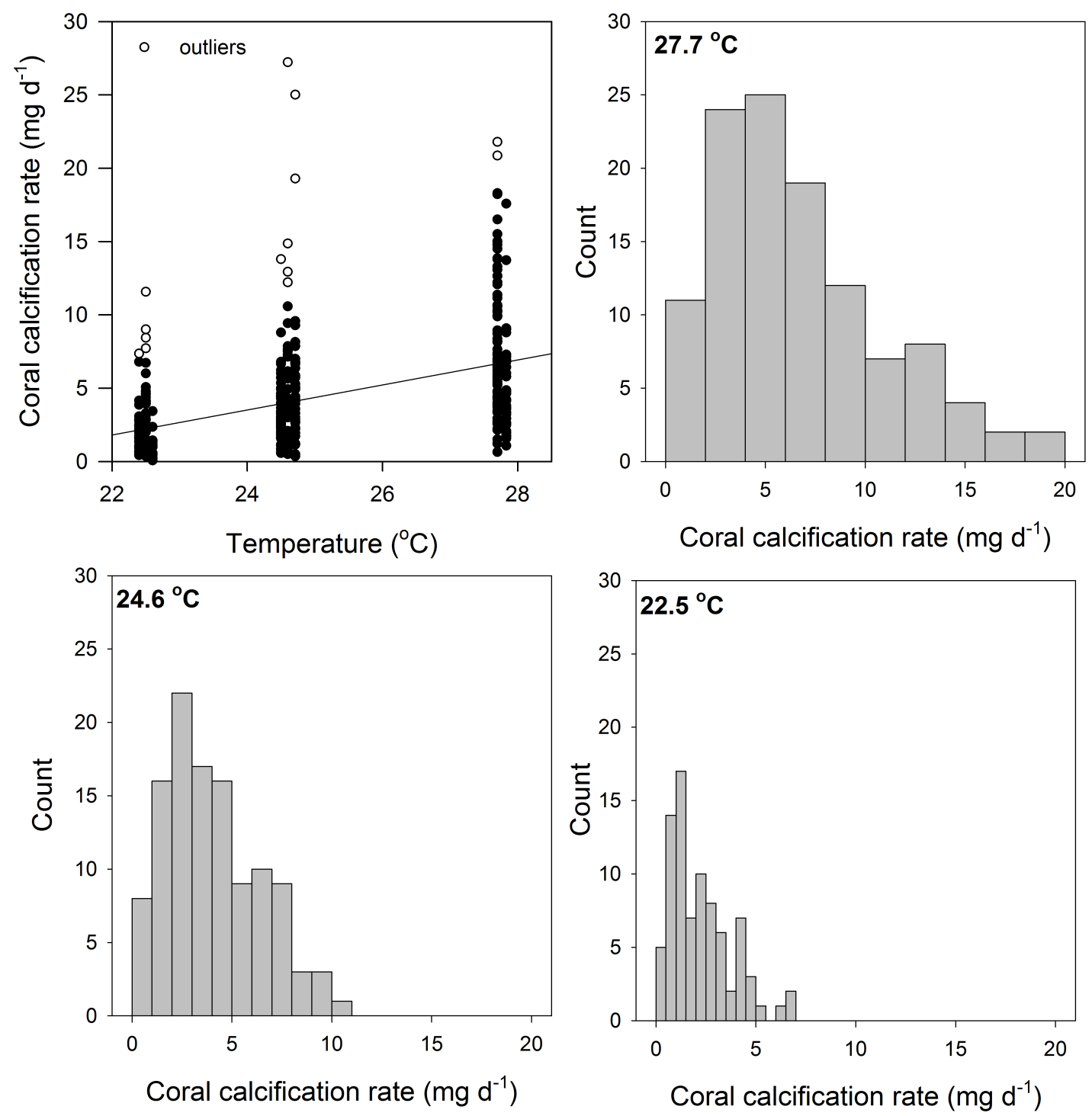

Figure 2: Coral calcification rate versus temperature and histograms for calcification rate in each temperature treatment. Data at each temperature includes polyps from each of the three different $[\mathrm{Ba}]$ treatments. The best-fit line (solid) is shown for the relationship: coral calcification rate $=0.85 \times$ temperature $-16.9(\mathrm{p}<0.0001)$. Empty circles are statistical outliers. Calcification rates from each treatment were grouped into an equal number of bins in the histograms, corresponding to different bin ranges for each temperature. Statistical outliers are not included in the histograms. 


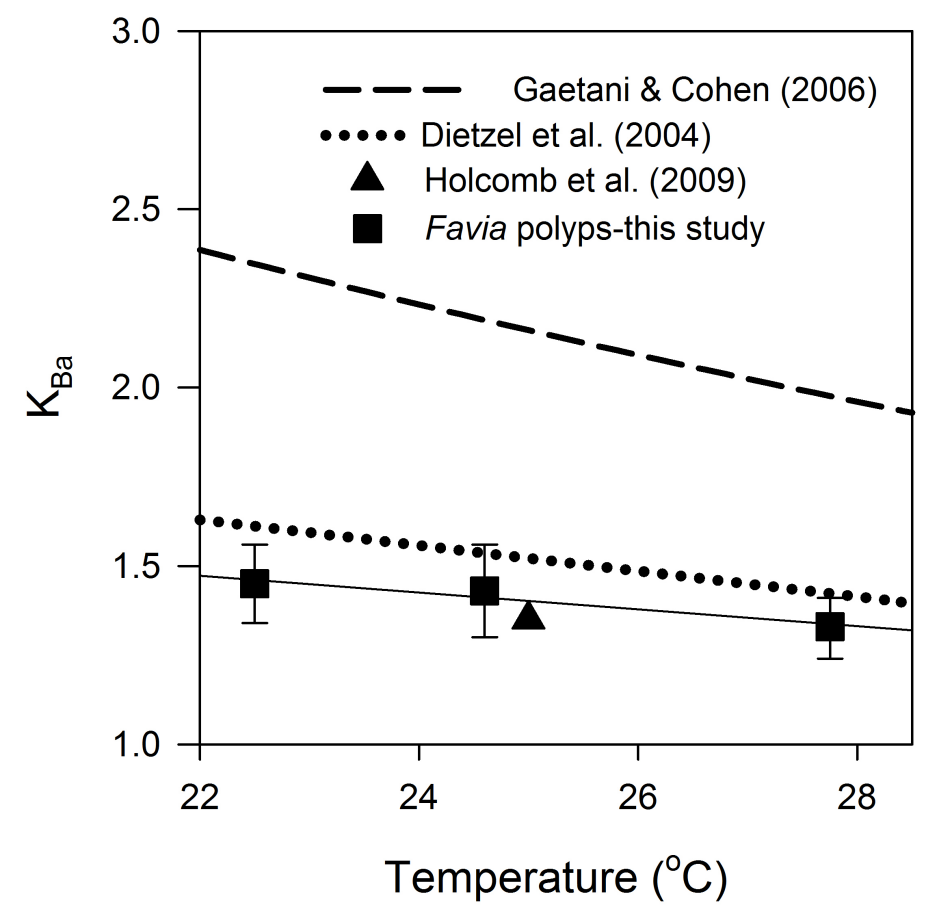

Figure 3: Temperature dependence of the Ba partition coefficient $\left(\mathrm{K}_{\mathrm{Ba}}\right)$ for the Favia polyps grown in culture. The best-fit line (solid) is shown for the relationship: $\mathrm{K}_{\mathrm{Ba}}=$ $-0.024 \times$ temperature +2.00 , with the $95 \%$ confidence intervals for $\mathrm{K}_{\mathrm{Ba}}$ at each temperature indicated by error bars. The observed $\mathrm{K}_{\mathrm{Ba}}$ falls below both inorganic $\mathrm{K}_{\mathrm{Ba}}$ values determined by Dietzel et al. (2004) and Gaetani and Cohen (2006). 


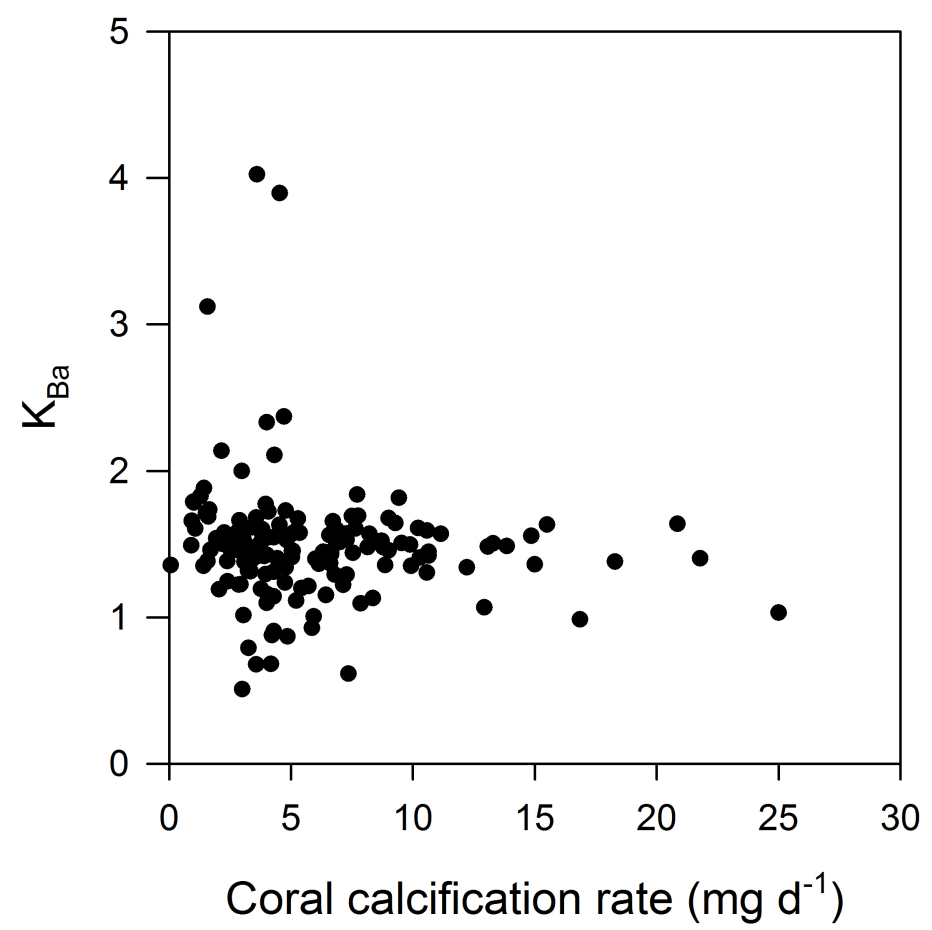

Figure 4: The partition coefficient for $\mathrm{Ba}\left(\mathrm{K}_{\mathrm{Ba}}\right)$ does not show any change with polyp calcification rate over the 14 day experiment. All data is shown. 


\section{Submarine groundwater discharge}
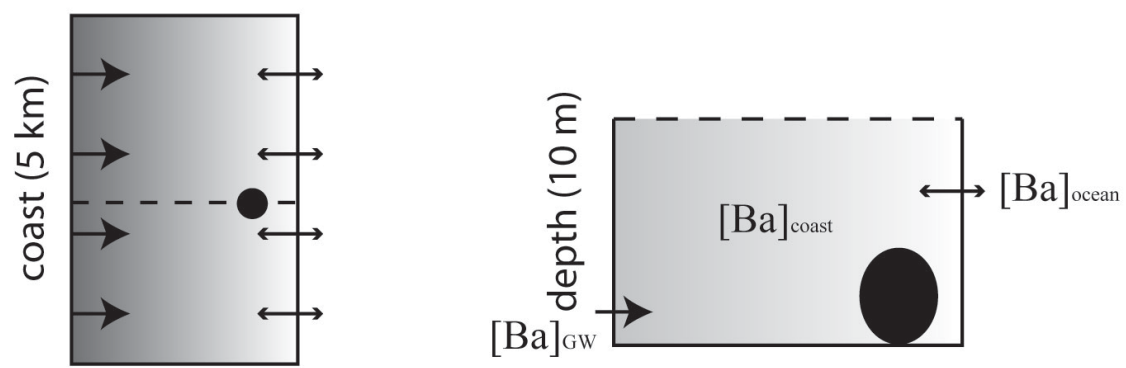

lagoon $(0.5 \mathrm{~km})$

River Discharge
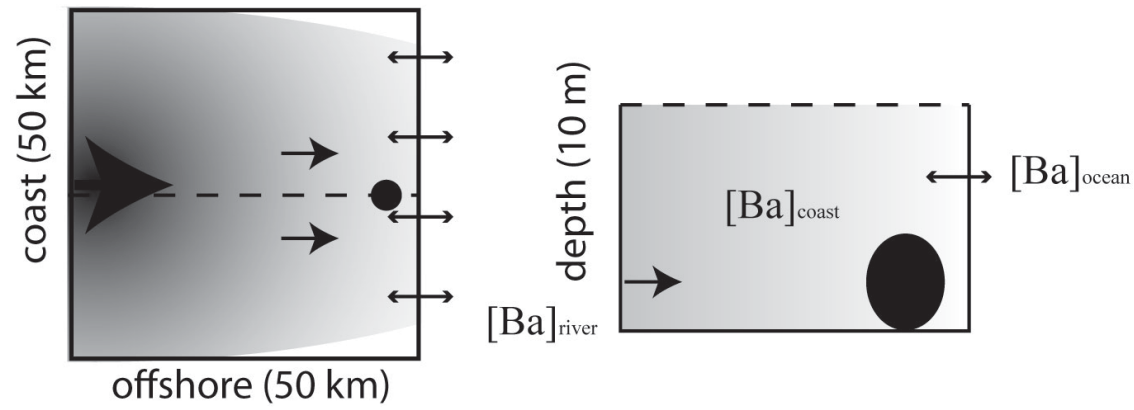

Upwelling
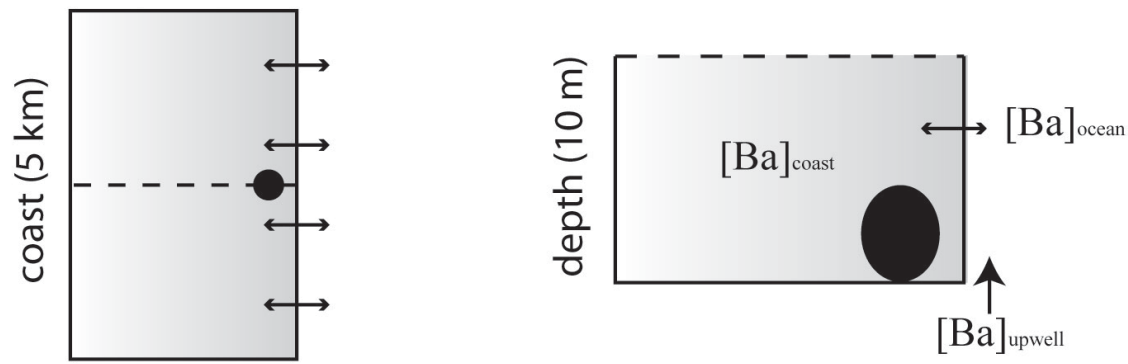

lagoon $(0.5 \mathrm{~km})$

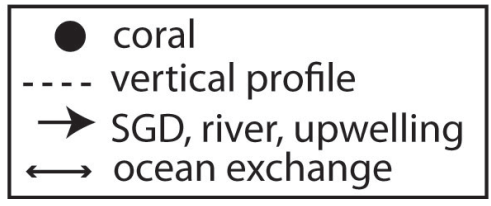

Figure 5: Schematic of physical parameters of the water chemistry model used to determine how submarine groundwater discharge, river flow and upwell influence surface water chemistry as a function of changing input flux and coastal water residence time. Diagrams on the left are an aerial view of the coastal region, while depth cross sections of the coastal region are shown on the right. Grey shaded regions represent the relative $[\mathrm{Ba}]$. 

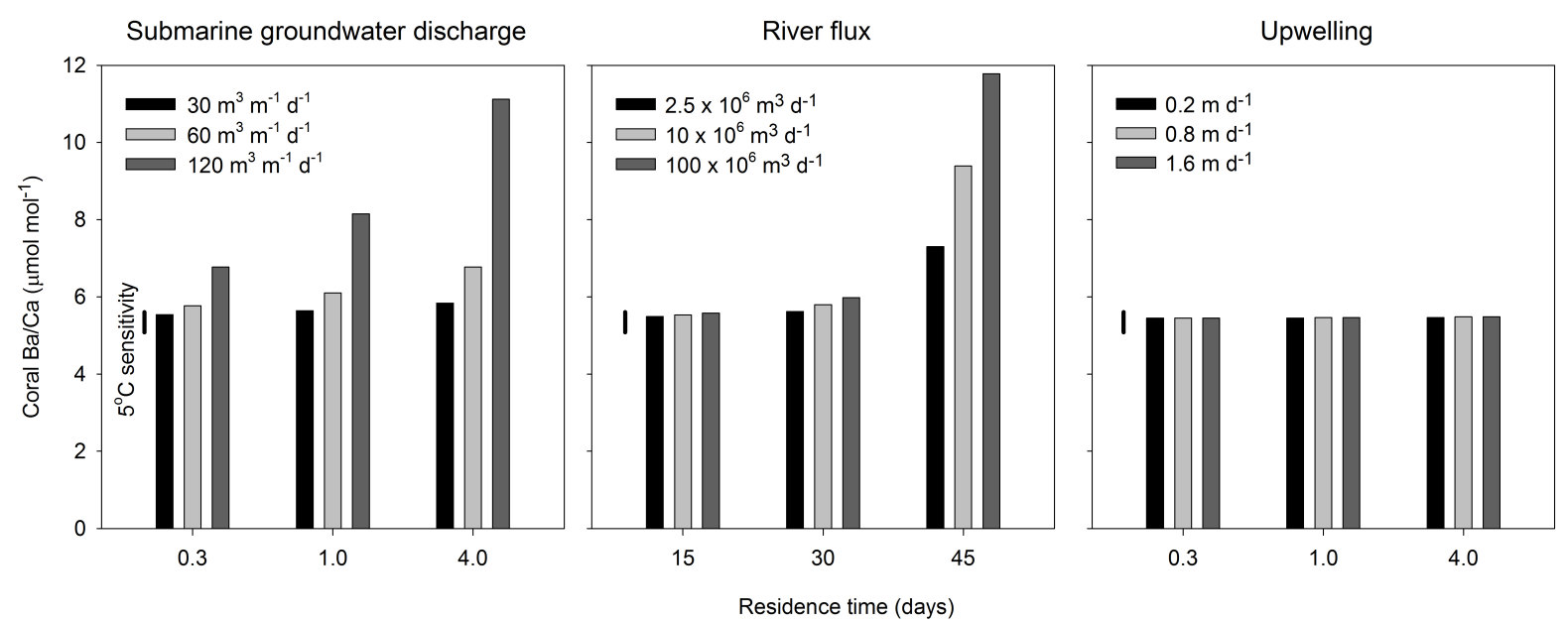

Figure 6: Modeled coral $\mathrm{Ba} / \mathrm{Ca}$ in response to groundwater discharge, river flow and upwelling. $\mathrm{T}_{\mathrm{w}}$ was $0.3,1$ and 4 days for groundwater discharge and upwelling and 15, 30 and 45 days for river discharge based on the different model geometries (Fig. 5). The potential temperature sensitivity of $\mathrm{Ba} / \mathrm{Ca}$ based on $5^{\circ} \mathrm{C}$ temperature variation is shown as a vertical bar $\left(0.5 \mu \mathrm{mol} \mathrm{mol}{ }^{-1}, 23-28^{\circ} \mathrm{C}\right)$. Note this temperature sensitivity is not fixed to the $\mathrm{y}$-axis since baseline seawater $\mathrm{Ba} / \mathrm{Ca}$ will impact its absolute value. 
1. Variable groundwater flux and Tw
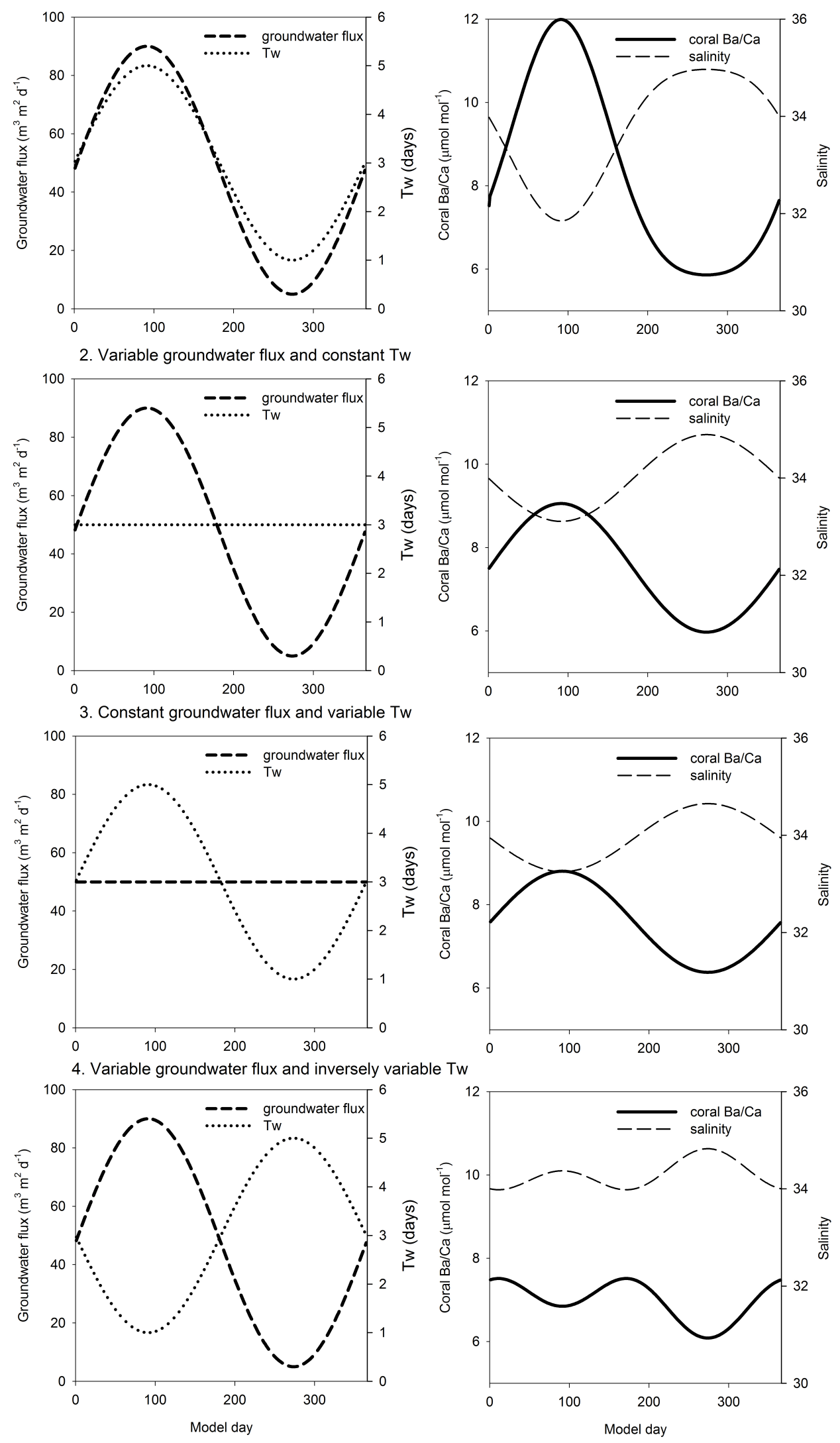
Figure 7: Modeled coral $\mathrm{Ba} / \mathrm{Ca}$ sensitivity to changes in groundwater input and residence time (Tw). All panels on the left show groundwater flux (dashed) and Tw (dotted), while right side panels show coral $\mathrm{Ba} / \mathrm{Ca}$ (bold) and salinity (dashed). The top plots show the model with variable SGD and Tw; the second panel shows model results with Tw held constant at 3 days; the third panel has a constant groundwater flux of $50 \mathrm{~m}^{3} \mathrm{~m}^{-1} \mathrm{~d}^{-1}$; and the bottom panel shows groundwater flux and residence time varying inversely. The amplitude of variability in coral $\mathrm{Ba} / \mathrm{Ca}$ is greatest when the highest SGD rates coincide with the longest $\mathrm{Tw}$ (top panels). 

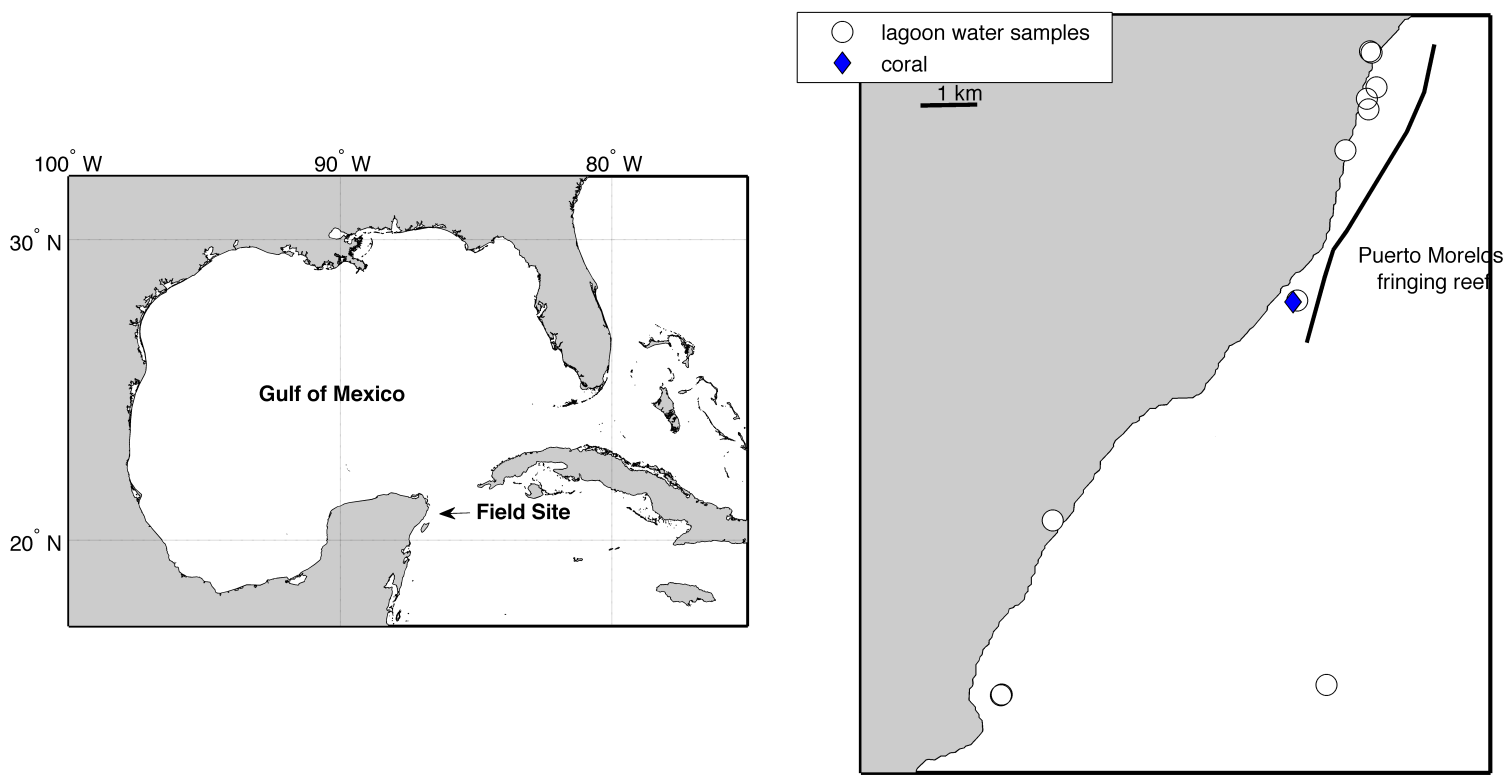

Figure 8: Map of lagoon water samples and coral site. 


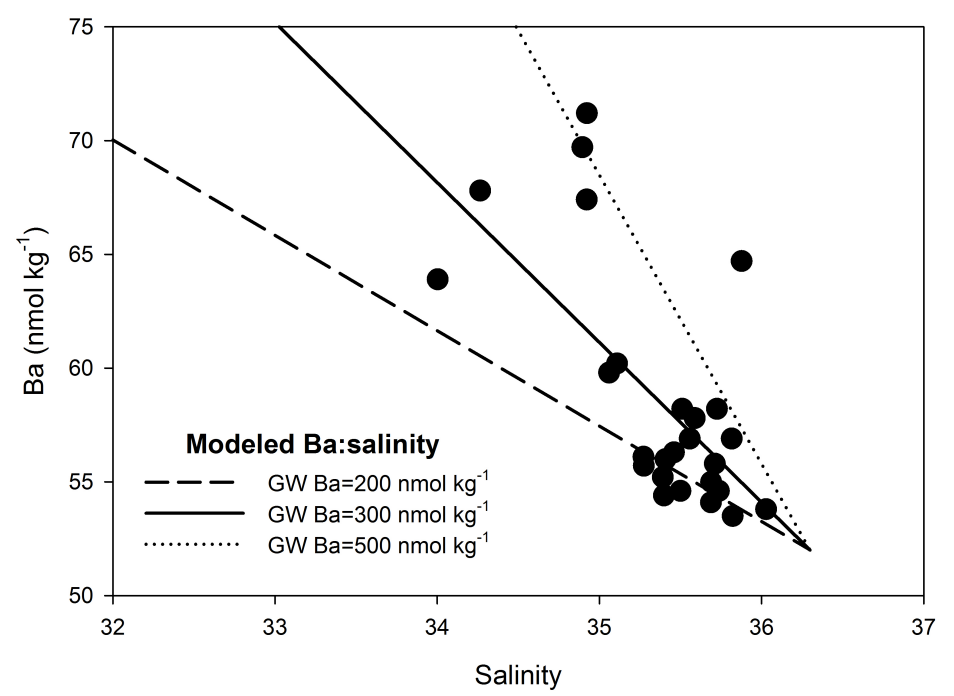

Figure 9: Dissolved Ba versus salinity for Puerto Morelos lagoon and other sites (within $2 \mathrm{~km}$ of shore). The dashed and solid lines show the model predicted relationship (equation 6) for groundwater [Ba] of 200 and $300 \mathrm{nmol} \mathrm{kg}^{-1}$ respectively. The dotted line is the model relationship for a higher groundwater end member $\left(500 \mathrm{nmol} \mathrm{kg}^{-1}\right)$. 

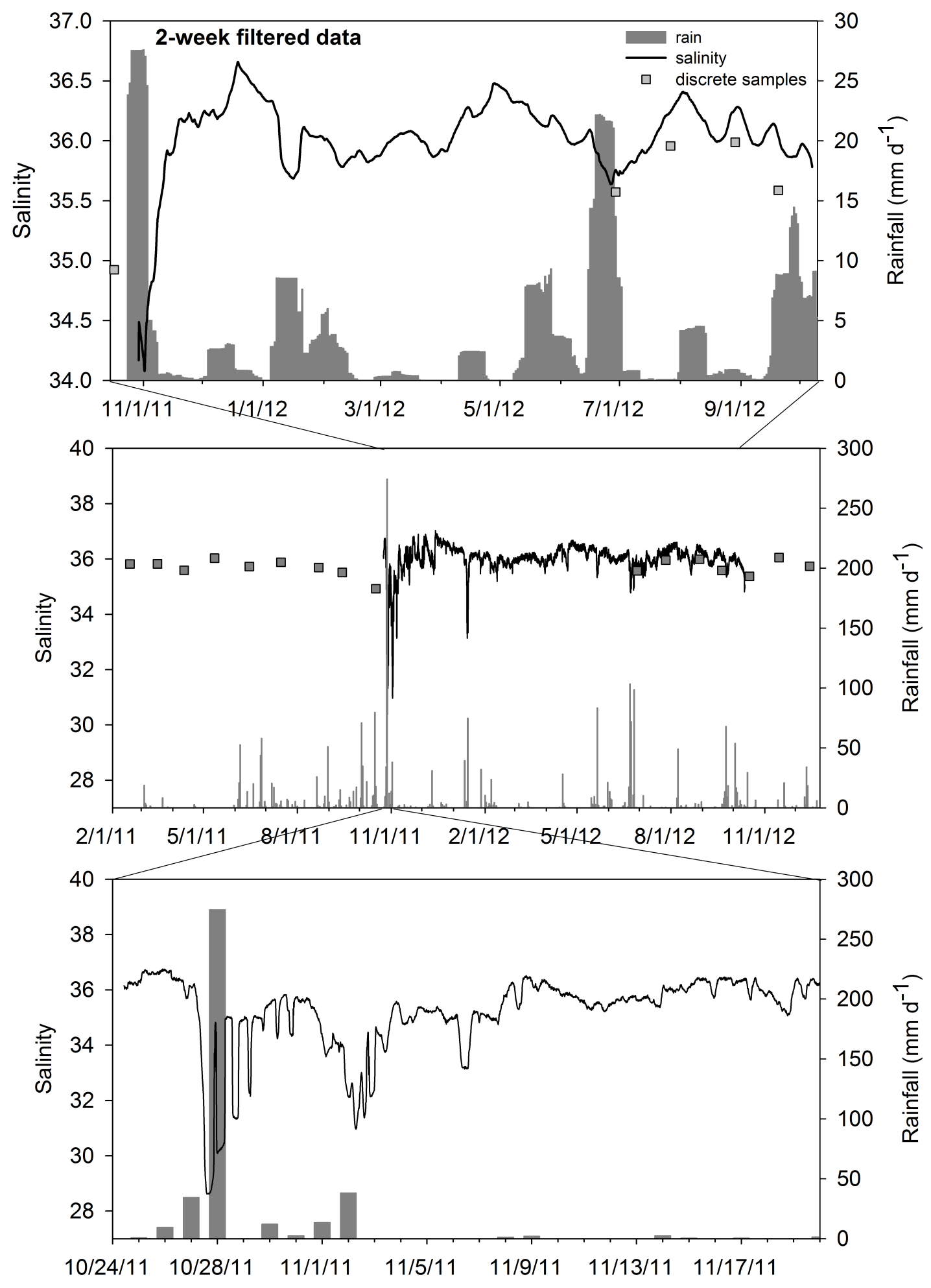
Figure 10: Salinity and rainfall in the Puerto Morelos lagoon and from February 2011 to December 2012. A continuous salinity meter was installed at the UNAM pier in approximately 3 meters water depth from October 2011 to October 2012. Squares indicate discrete samples collected from the same location. The top panel shows salinity and rainfall with a two-week filter. No clear seasonal trend is apparent, due to the anomalously high rainfall in the January-March period. During October 2011 (bottom panel) the passage of tropical storm Rina over the region resulted in a large rainfall event with subsequent low salinity excursions. Salinity was suppressed in the lagoon for several weeks afterwards. 


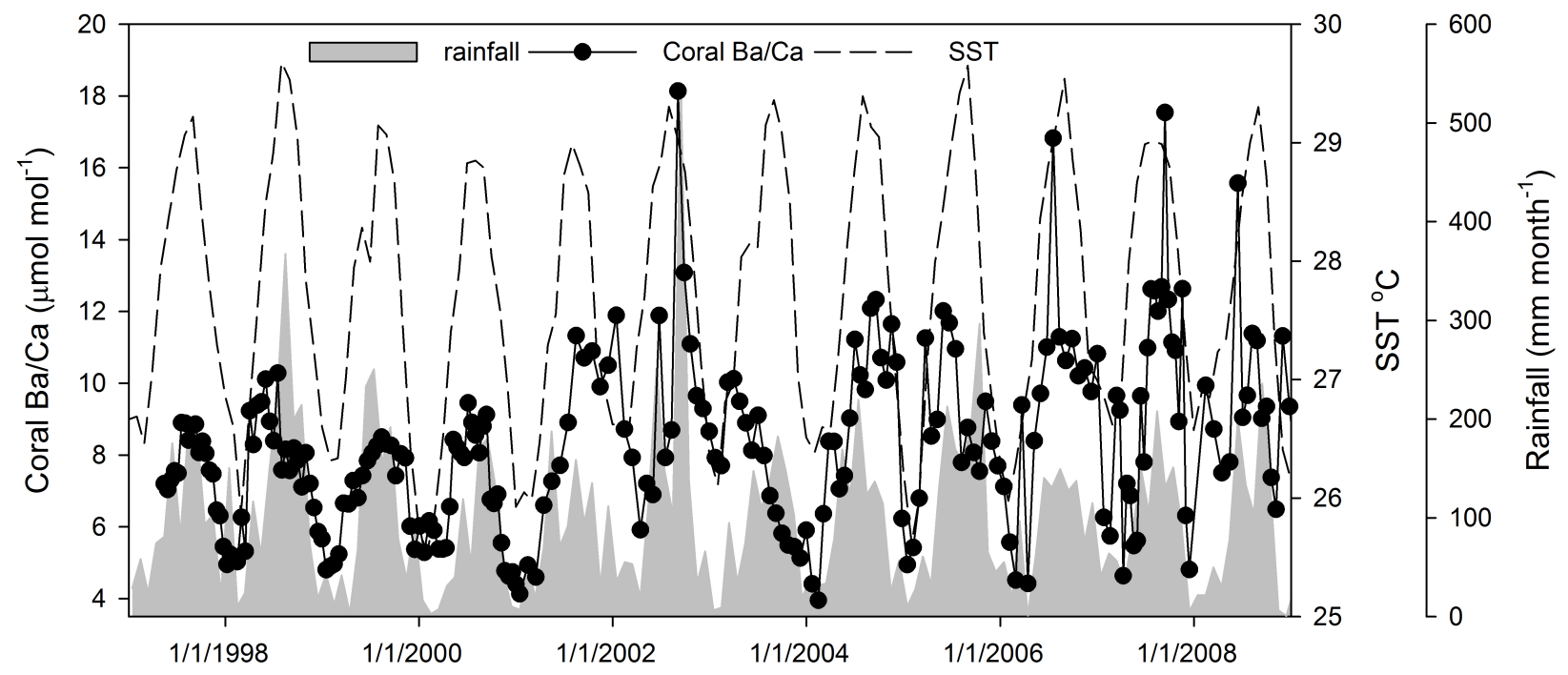

Figure 11: The Siderastrea $\mathrm{Ba} / \mathrm{Ca}$ record, monthly mean SST (IGOSS) and rainfall from January 2009 to May 1997. Rainfall, SST and coral Ba/Ca all peak during the summer months. Note the peak rainfall in October 2002 coincided with the passage of Hurricane Isadore over the study site and is captured in the coral $\mathrm{Ba} / \mathrm{Ca}$ record. It is not possible to explain the coral $\mathrm{Ba} / \mathrm{Ca}$ peaks in summer based on the observed inverse relationship between temperature and $\mathrm{K}_{\mathrm{Ba}}$. 


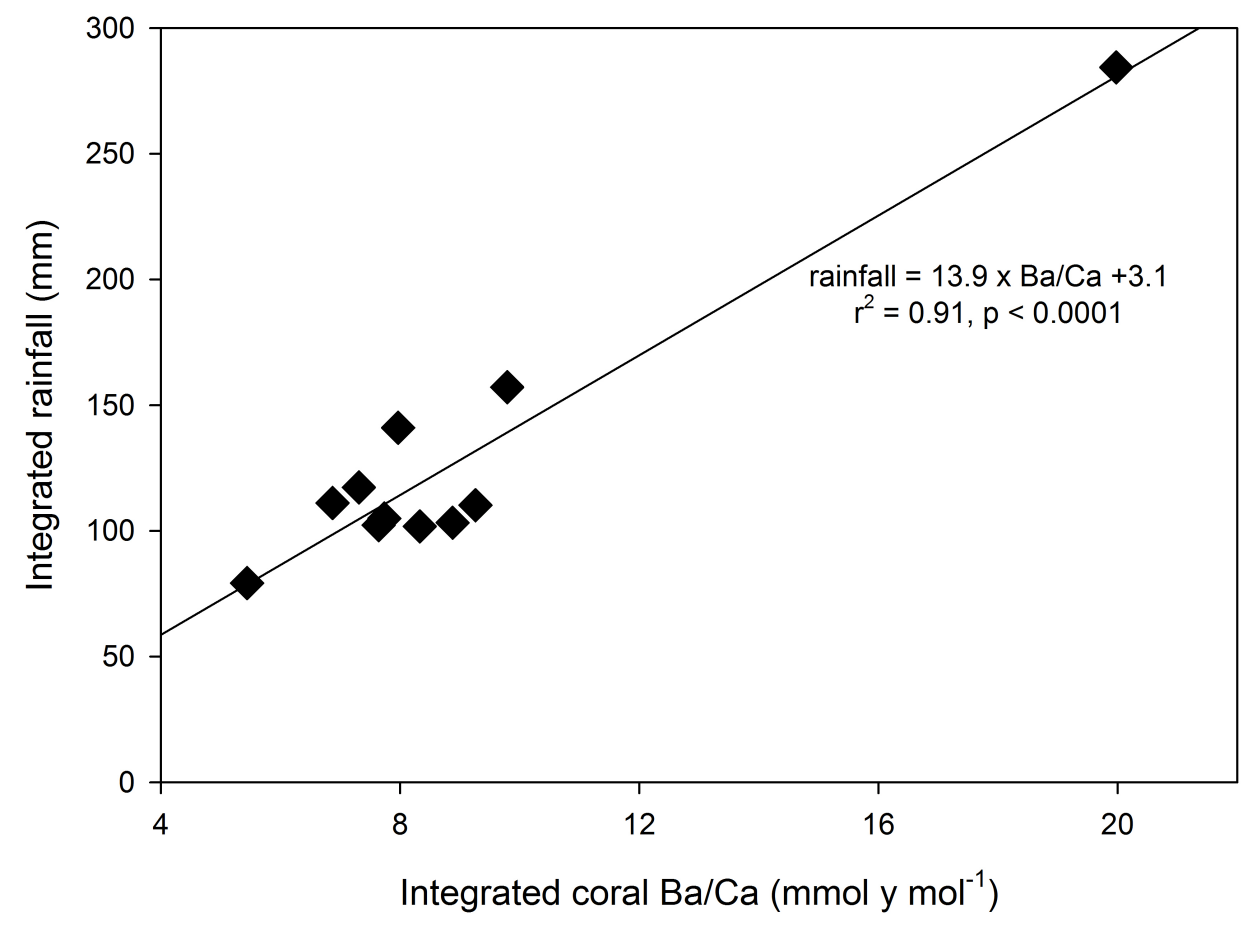

Figure 12: The integrated values for corresponding coral $\mathrm{Ba} / \mathrm{Ca}$ and rainfall yearly cycles (i.e. area under the respective curves) from 2008 to 1997 show a significant positive linear relationship, with elevated precipitation resulting in greater inventory of $\mathrm{Ba} / \mathrm{Ca}$ within the coral matrix. The $\mathrm{r}^{2}$ for the fit without the highest value is $0.46, \mathrm{p}<0.0001$. 


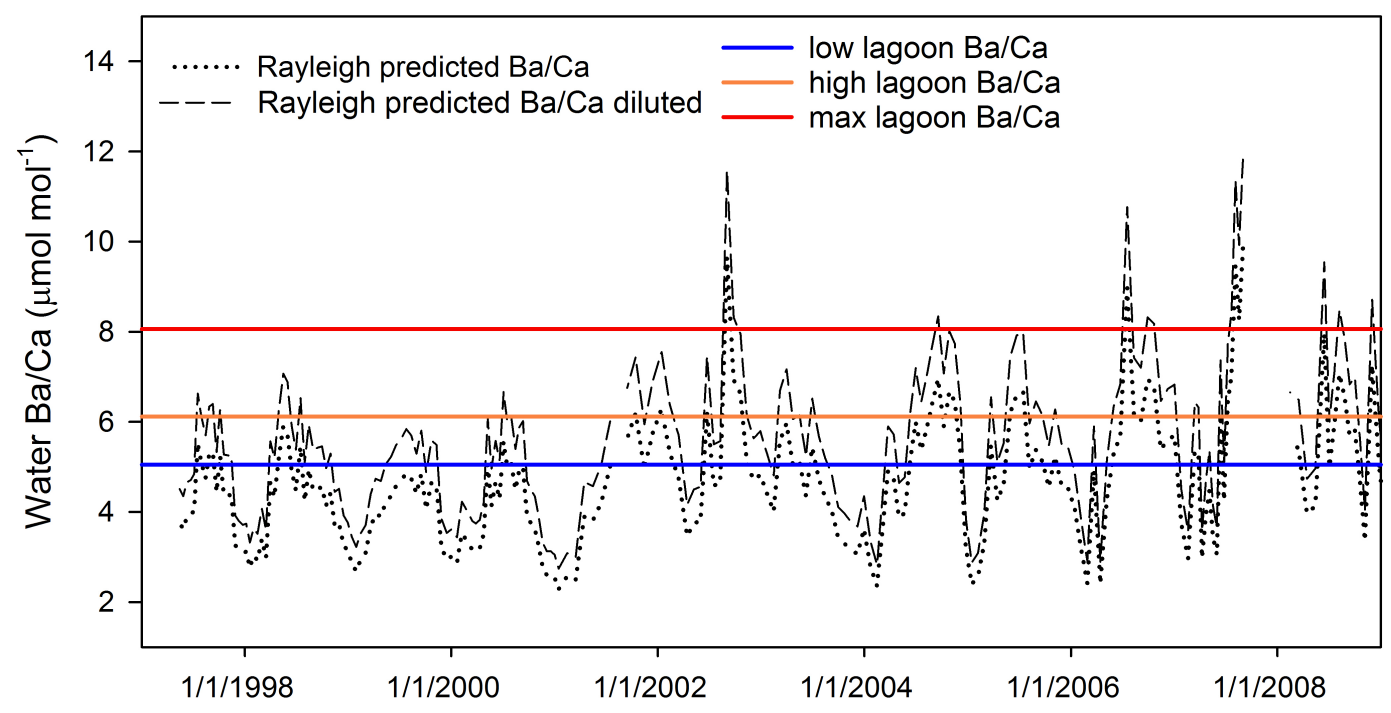

Figure 13: Predicted lagoon $\mathrm{Ba} / \mathrm{Ca}$ based on Rayleigh model and the Siderastrea $\mathrm{Ba} / \mathrm{Ca}$ record from the Puerto Morelos lagoon. Also shown are the predicted values upon a 20\% dilution of $[\mathrm{Ba}]$ within the calcifying fluid. The seasonal range in $\mathrm{Ba} / \mathrm{Ca}$ is indicated in blue and orange lines, with the maximum predicted $\mathrm{Ba} / \mathrm{Ca}$ shown in red, based on the extreme low salinity excursion that was observed following intense rainfall from tropical storm Rina in October 2011. 
Table 1: Aquaria experimental conditions

\begin{tabular}{|c|c|c|c|c|c|c|}
\hline Tank\# & $\begin{array}{l}\text { Salinity } \pm \\
\text { SD }\end{array}$ & $\begin{array}{c}\text { Temperature } \\
\left({ }^{\circ} \mathrm{C} \pm \mathrm{SD}\right)\end{array}$ & $\begin{array}{c}\mathrm{CO}_{2} \\
(\mathrm{ppmv} \pm \\
\text { SD) }\end{array}$ & $\begin{array}{c}\Omega_{\mathrm{AR}} \\
( \pm \mathrm{SD})\end{array}$ & $\begin{array}{c}{[\mathrm{Ba}]} \\
\left(\mathrm{nmol} \mathrm{kg}^{-1} \pm\right. \\
\text { SD) }\end{array}$ & 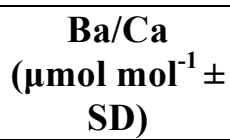 \\
\hline 1 & $34.7 \pm 1.1$ & $27.7 \pm 0.9$ & $320 \pm 50$ & $3.2 \pm 0.3$ & $79 \pm 23$ & $7.5 \pm 2.0$ \\
\hline 2 & $34.9 \pm 1.1$ & $27.8 \pm 1.0$ & $320 \pm 30$ & $3.3 \pm 0.2$ & $223 \pm 26$ & $22 \pm 2.4$ \\
\hline 3 & $35.2 \pm 0.5$ & $27.7 \pm 0.9$ & $350 \pm 80$ & $2.9 \pm 0.5$ & $463 \pm 24$ & $44 \pm 2.4$ \\
\hline 4 & $35.3 \pm 0.6$ & $24.7 \pm 0.9$ & $410 \pm 30$ & $3.0 \pm 0.1$ & $73 \pm 12$ & $7.0 \pm 1.1$ \\
\hline 5 & $35.3 \pm 0.4$ & $24.6 \pm 0.6$ & $380 \pm 60$ & $3.1 \pm 0.4$ & $236 \pm 22$ & $23 \pm 2.1$ \\
\hline 6 & $35.3 \pm 0.3$ & $24.5 \pm 0.5$ & $520 \pm 100$ & $2.4 \pm 0.4$ & $439 \pm 9$ & $42 \pm 1.0$ \\
\hline 7 & $35.4 \pm 0.5$ & na $(22.5 \pm 1.1)$ & $490 \pm 30$ & $3.0 \pm 0.0$ & $72 \pm 13$ & $6.8 \pm 1.1$ \\
\hline 8 & $35.3 \pm 0.5$ & $22.4 \pm 1.1$ & $550 \pm 20$ & $2.7 \pm 0.1$ & $220 \pm 38$ & $21 \pm 3.5$ \\
\hline 9 & $35.3 \pm 0.3$ & $22.6 \pm 1.1$ & $700 \pm 30$ & $2.1 \pm 0.1$ & $440 \pm 11$ & $43 \pm 1.8$ \\
\hline
\end{tabular}

na: Temperature was not measured in tank 7 , so temperature is the average of tanks 8 and 9 , which shared the same temperature-controlled water bath. 
Table 2: Coral calcification rate, $\mathrm{Ba} / \mathrm{Ca}$ and $\mathrm{K}_{\mathrm{Ba}}$

\begin{tabular}{|c|c|c|c|c|c|}
\hline Tank\# & $\begin{array}{c}\text { Temperature } \\
\left({ }^{\circ} \mathbf{C} \pm \text { SD }\right)\end{array}$ & $\begin{array}{l}\text { Calcification } \\
\text { rate (mg d } \\
\text { SD) }\end{array}$ & $\begin{array}{c}\text { Coral Ba/Ca } \\
\left(\mu \mathrm{mol} \mathrm{mol}{ }^{-1} \pm\right. \\
\text { SD) }\end{array}$ & $\mathbf{K}_{\mathrm{Ba}}$ & $\begin{array}{c}\text { Individuals/ } \\
\text { Measurements* }\end{array}$ \\
\hline 1 & $27.7 \pm 0.9$ & $8.5 \pm 4.7$ & $11.4 \pm 1.6$ & $1.52 \pm 0.61$ & $43 / 25$ \\
\hline 2 & $27.8 \pm 1.0$ & $5.4 \pm 4.0$ & $30.8 \pm 4.1$ & $1.40 \pm 0.34$ & $37 / 21$ \\
\hline 3 & $27.7 \pm 0.9$ & $9.1 \pm 4.4$ & $60.0 \pm 9.1$ & $1.35 \pm 0.28$ & $36 / 30$ \\
\hline 4 & $24.7 \pm 0.9$ & $6.8 \pm 5.4$ & $11.5 \pm 1.5$ & $1.64 \pm 0.47$ & $38 / 23$ \\
\hline 5 & $24.6 \pm 0.6$ & $6.6 \pm 3.9$ & $30.5 \pm 5.4$ & $1.35 \pm 0.36$ & $33 / 18$ \\
\hline 6 & $24.5 \pm 0.5$ & $4.3 \pm 2.8$ & $61.1 \pm 12$ & $1.46 \pm 0.32$ & $48 / 19$ \\
\hline 7 & na $(22.5 \pm 1.1)$ & $4.8 \pm 3.6$ & $12.5 \pm 3.9$ & $1.84 \pm 0.88$ & $47 / 19$ \\
\hline 8 & $22.4 \pm 1.1$ & $3.7 \pm 3.8$ & $33.6 \pm 5.4$ & $1.60 \pm 0.52$ & $26 / 11$ \\
\hline 9 & $22.6 \pm 1.1$ & $1.0 \pm 0.5$ & $56.0 \pm 22$ & $1.27 \pm 0.56$ & $23 / 6$ \\
\hline
\end{tabular}

*Calcification rates were calculated for each individual, while groups of individuals were combined for elemental analysis on samples of $\geq 70 \mu \mathrm{g}$. $\mathrm{K}_{\mathrm{Ba}}$ was calculated from these combined samples.

na: Temperature was not measured in tank 7, so temperature is the average of tanks 8 and 9 , which shared the same temperature-controlled water bath. 
Table 3: Coral Ba/Ca environmental proxy studies

\begin{tabular}{|c|c|c|c|c|c|c|}
\hline Reference & $\begin{array}{l}\mathrm{Ba} / \mathrm{Ca} \\
\text { baseline } \\
(\mu \mathrm{mol} \\
\left.\mathrm{mol}^{-1}\right) \\
\end{array}$ & $\begin{array}{l}\text { Ba/Ca } \\
\text { peak } \\
(\mu \mathrm{mol} \\
\left.\text { mol }^{-1}\right)\end{array}$ & $\begin{array}{l}\text { \% increase } \\
\text { (peak- } \\
\text { baseline)/ } \\
\text { baseline }\end{array}$ & Proxy & Species & Location \\
\hline This study & 4.5 & 12 & 170 & groundwater & Favia & $\begin{array}{l}\text { Puerto Morelos } \\
\text { Lagoon, Yucatan } \\
\text { Peninsula }\end{array}$ \\
\hline \multirow{3}{*}{$\begin{array}{l}\text { (Jupiter et } \\
\text { al., 2008) }\end{array}$} & 3.5 & 7 & 100 & river & Porities & $\begin{array}{l}\text { Round Top island, } \\
\text { Great Barrier Reef }\end{array}$ \\
\hline & 4 & 6 & 50 & river & Porities & $\begin{array}{l}\text { Keswick Island, } \\
\text { Great Barrier Reef } \\
\text { Scawfell Island, }\end{array}$ \\
\hline & 3 & 8 & 167 & river & Porities & Great Barrier Reef \\
\hline \multirow{6}{*}{$\begin{array}{l}\text { (Prouty et } \\
\text { al., 2010) }\end{array}$} & 3.4 & 8.0 & 136 & sediment & $\begin{array}{l}\text { Porities } \\
\text { lobata } \\
\text { Porities }\end{array}$ & $\begin{array}{l}\text { Kamalo, Molok'a } \\
\text { Reef, Hawaii } \\
\text { One Ali'i, Molok'a }\end{array}$ \\
\hline & 5.5 & 10.2 & 85 & sediment & lobata & Reef, Hawaii \\
\hline & & & & & Porities & Umpipa'a, Molok'a \\
\hline & 2.8 & 21.6 & 686 & sediment & lobata & Reef, Hawaii \\
\hline & & & & & Porities & Pala'au, Molok'a \\
\hline & 3 & 17.8 & 492 & sediment & lobata & Reef, Hawaii \\
\hline \multirow[b]{2}{*}{$\begin{array}{l}\text { (Wyndham } \\
\text { et al., 2004) }\end{array}$} & 4 & 15 & 275 & unknown & Porities & $\begin{array}{l}\text { Havannah Island, } \\
\text { Great Barrier Reef }\end{array}$ \\
\hline & 4 & 15 & 275 & unknown & Porities & $\begin{array}{l}\text { Pandora Reef, Great } \\
\text { Barrier Reef }\end{array}$ \\
\hline $\begin{array}{l}\text { (McCulloch } \\
\text { et al., 2003) }\end{array}$ & 4 & 12 & 200 & river & Porities & $\begin{array}{l}\text { Havannah Island } \\
\text { and Pandora Reef, } \\
\text { Great Barrier Reef }\end{array}$ \\
\hline $\begin{array}{l}\text { (Reuer et al., } \\
\text { 2003) }\end{array}$ & 4.7 & 5.7 & 21 & upwelling & $\begin{array}{l}\text { Montastrea } \\
\text { annularis }\end{array}$ & $\begin{array}{l}\text { Isla Tortuga, } \\
\text { Venezuela }\end{array}$ \\
\hline \multirow{2}{*}{$\begin{array}{l}\text { (Sinclair and } \\
\text { McCulloch, } \\
\text { 2004) }\end{array}$} & 4 & 12 & 200 & river & Porities & $\begin{array}{l}\text { King Reef, Great } \\
\text { Barrier Reef }\end{array}$ \\
\hline & 4 & 17 & 325 & river & Porities & Barrier Reef \\
\hline \multirow[b]{2}{*}{$\begin{array}{l}\text { (Chen et al., } \\
\text { 2011) }\end{array}$} & 6 & 15 & 150 & physiological & Porities & $\begin{array}{l}\text { Daya Bay, South } \\
\text { China Sea }\end{array}$ \\
\hline & 6 & 15 & 150 & physiological & Porities & $\begin{array}{l}\text { Daya Bay, South } \\
\text { China Sea }\end{array}$ \\
\hline \multirow{2}{*}{$\begin{array}{l}\text { (Fleitmann } \\
\text { et al., 2007) }\end{array}$} & 4 & 50 & 1150 & $\begin{array}{l}\text { river/ } \\
\text { sediment } \\
\text { river/ }\end{array}$ & Porities & Kenya \\
\hline & 4 & 9.5 & 138 & sediment & Porities & Kenya \\
\hline \multirow[b]{2}{*}{$\begin{array}{l}\text { (Tudhope et } \\
\text { al., 1996) }\end{array}$} & 5 & 15 & 200 & upwelling & Porities & $\begin{array}{l}\text { Marbat, Oman, Red } \\
\text { Sea }\end{array}$ \\
\hline & 3 & 6 & 100 & upwelling & Porities & $\begin{array}{l}\text { Wadi Ayn, Oman, } \\
\text { Red sea }\end{array}$ \\
\hline
\end{tabular}


Table 3 cont.: Coral Ba/Ca environmental proxy studies

\begin{tabular}{|c|c|c|c|c|c|c|}
\hline Reference & $\begin{array}{l}\mathrm{Ba} / \mathrm{Ca} \\
\text { baseline } \\
(\mu \mathrm{mol} \\
\left.\mathrm{mol}^{-1}\right)\end{array}$ & $\begin{array}{l}\mathrm{Ba} / \mathrm{Ca} \\
\text { peak } \\
(\mu \mathrm{mol} \\
\left.\text { mol }^{-1}\right)\end{array}$ & $\begin{array}{l}\text { \% } \\
\text { increase } \\
\text { (peak- } \\
\text { baseline)/ } \\
\text { baseline }\end{array}$ & Proxy & Species & Location \\
\hline $\begin{array}{l}\text { (Sinclair, } \\
2005 \text { ) }\end{array}$ & 4 & 12 & 225 & $\begin{array}{l}\text { unknown } \\
\text { unknown }\end{array}$ & $\begin{array}{l}\text { Porities } \\
\text { Porities }\end{array}$ & $\begin{array}{l}\text { Cow Island, Great } \\
\text { Barrier Reef } \\
\text { Orpheus Island, } \\
\text { Great Barrier Reef }\end{array}$ \\
\hline $\begin{array}{l}\text { (Alibert et } \\
\text { al., 2003) }\end{array}$ & 4.5 & 14 & 100 & $\begin{array}{l}\text { river } \\
\text { river }\end{array}$ & $\begin{array}{l}\text { Porities } \\
\text { Porities }\end{array}$ & $\begin{array}{l}\text { Pandora Reef, Great } \\
\text { Barrier Reef } \\
\text { Davies Reef, Great } \\
\text { Barrier Reef }\end{array}$ \\
\hline $\begin{array}{l}\text { (Montaggion } \\
\text { i et al., 2006) }\end{array}$ & $\begin{array}{l}4.3 \\
1.3\end{array}$ & 5.2 & 388 & $\begin{array}{l}\text { upwelling } \\
\text { river }\end{array}$ & $\begin{array}{l}\text { Porities } \\
\text { lobata } \\
\text { Porities } \\
\text { lobata }\end{array}$ & $\begin{array}{l}\text { Amedee Islet, New } \\
\text { Calendonia } \\
\text { Vata Ricaudy Reef, } \\
\text { New Calendonia }\end{array}$ \\
\hline $\begin{array}{l}\text { (Lea et al., } \\
1989)\end{array}$ & 4.1 & 5.1 & 24 & upwelling & $\begin{array}{l}\text { Pavona } \\
\text { clavus }\end{array}$ & Galapagos Islands \\
\hline $\begin{array}{l}\text { (Alibert and } \\
\text { Kinsley, } \\
\text { 2008) }\end{array}$ & 4 & 25 & 525 & upwelling & Porities & $\begin{array}{l}\text { New Ireland, Papua } \\
\text { New Guinea }\end{array}$ \\
\hline $\begin{array}{l}\text { (Carriquiry } \\
\text { and Horta- } \\
\text { Puga, 2010) }\end{array}$ & 7.5 & 9.3 & 24 & river & $\begin{array}{l}\text { Montastrea } \\
\text { Faveolata } \\
\text { Montastrea } \\
\text { Faveolata } \\
\end{array}$ & $\begin{array}{l}\text { Anegada de Adentro } \\
\text { Reef, Veracruz Reef } \\
\text { System, Gulf of } \\
\text { Mexico } \\
\text { Isla Verde, Veracruz } \\
\text { Reef System, Gulf } \\
\text { of Mexico }\end{array}$ \\
\hline $\begin{array}{l}\text { (Horta-Puga } \\
\text { and } \\
\text { Carriquiry, } \\
\text { 2012) }\end{array}$ & 4.7 & 7.5 & 61 & $\begin{array}{l}\text { groundwater } \\
\text { groundwater }\end{array}$ & $\begin{array}{l}\text { Montastrea } \\
\text { annularis } \\
\text { Montastrea } \\
\text { annularis }\end{array}$ & $\begin{array}{l}\text { Cancun, Mexico } \\
\text { Cancun, Mexico }\end{array}$ \\
\hline $\begin{array}{l}\text { (Fallon et } \\
\text { al., 1999) }\end{array}$ & 3.9 & 5.1 & 31 & upwelling & $\begin{array}{l}\text { Porities } \\
\text { lobata }\end{array}$ & Shirigai Bay, Japan \\
\hline $\begin{array}{l}\text { (Moyer et } \\
\text { al., 2012) }\end{array}$ & 3.3 & 4.8 & 46 & river & $\begin{array}{l}\text { Montastrea } \\
\text { Faveolata }\end{array}$ & Fajardo Puerto Rico \\
\hline
\end{tabular}


Table 4: Coral $\mathrm{Ba} / \mathrm{Ca}$ model parameters

\begin{tabular}{|c|c|c|c|c|c|}
\hline $\begin{array}{l}\text { Environmental } \\
\text { influence }\end{array}$ & Salinity & $\begin{array}{c}{[\mathrm{Ba}]} \\
\left.(\mathrm{nmol} \mathrm{kg})^{-1}\right)\end{array}$ & $\begin{array}{c}{[\mathrm{Ca}]} \\
\left.(\mathrm{mmol} \mathrm{kg})^{-1}\right)\end{array}$ & $\begin{array}{c}\mathrm{Ba} / \mathrm{Ca} \\
\left(\mu \mathrm{mol} \mathrm{mol}^{-1}\right)\end{array}$ & Reference \\
\hline Groundwater & & & & & \multirow{6}{*}{$\begin{array}{l}\text { Shaw et al. (1998) } \\
\text { Santos et a. (2011) } \\
\text { Gaillardet et al. } \\
\text { (2003) } \\
\text { Livingston (1963) } \\
\text { Chan et al. (1976, } \\
\text { 1977) } \\
\text { Chan et al. (1976, } \\
\text { 1977) }\end{array}$} \\
\hline discharge & 0 & 400 & 1 & 400 & \\
\hline River & & & & & \\
\hline discharge* & 0 & 215 & 0.38 & 395 & \\
\hline Upwelling & 35 & 150 & 10.28 & 14 & \\
\hline $\begin{array}{l}\text { Seawater } \\
\text { Yucatan values }\end{array}$ & 35 & 40 & 10.28 & 3.9 & \\
\hline $\begin{array}{l}\text { Groundwater } \\
\text { discharge }\end{array}$ & 0 & $200-300$ & 3.4 & $80-200$ & \multirow{2}{*}{$\begin{array}{l}\text { Gonneea et al. (in } \\
\text { review) } \\
\text { Gonneea et al. (in } \\
\text { review) }\end{array}$} \\
\hline Seawater & 36.6 & 52 & 10.66 & 4.9 & \\
\hline
\end{tabular}

*Includes $65 \mathrm{nmol} \mathrm{kg}{ }^{-1}$ from sediment desorption, see text. 
Table 5: Yucatan coastal lagoon barium and salinity

\begin{tabular}{|c|c|c|c|c|c|}
\hline Sample ID & Date & Latitude N & Longitude W & Salinity & Ba $\left(\mathrm{nmol} \mathrm{kg}^{-1}\right)$ \\
\hline YT191 & $8 / 4 / 10$ & 20.39158 & 87.30793 & 35.3918 & 55.2 \\
\hline YT192 & $8 / 5 / 10$ & 20.39085 & 87.31545 & 35.3981 & 54.4 \\
\hline YT193 & $8 / 6 / 10$ & 20.73863 & 86.95428 & 35.6885 & 54.1 \\
\hline YT194 & $8 / 7 / 10$ & 20.74093 & 86.87168 & 35.4604 & 56.3 \\
\hline YT208 & 2/13/11 & 20.39162 & 87.33330 & 35.7124 & 55.8 \\
\hline YT211 & 2/14/11 & 20.73847 & 86.95443 & 35.2729 & 56.1 \\
\hline YT213 & $2 / 14 / 11$ & 20.83230 & 86.87909 & 35.7379 & 54.6 \\
\hline YT219 & 2/15/11 & 20.88021 & 86.86139 & 35.2741 & 55.7 \\
\hline YT216 & $2 / 15 / 11$ & 20.87768 & 86.86098 & 35.4089 & 56.0 \\
\hline YT224 & $2 / 15 / 11$ & 20.88293 & 86.85896 & 35.5571 & 56.9 \\
\hline YT253 & $2 / 17 / 11$ & 20.38818 & 87.32047 & 34.0031 & 63.9 \\
\hline YT249 & 2/17/11 & 20.38536 & 87.32301 & 34.9227 & 67.4 \\
\hline TS2_11 & $2 / 18 / 11$ & 20.86799 & 86.86685 & 35.8167 & 56.9 \\
\hline TS3_11 & $3 / 17 / 11$ & 20.86799 & 86.86685 & 35.8222 & 53.5 \\
\hline TS4_11 & $4 / 12 / 11$ & 20.86799 & 86.86685 & 35.5882 & 57.8 \\
\hline TS5_11 & $5 / 12 / 11$ & 20.86799 & 86.86685 & 36.0285 & 53.8 \\
\hline TS6_11 & $6 / 15 / 11$ & 20.86799 & 86.86685 & 35.7258 & 58.2 \\
\hline TS7_-11 & $7 / 16 / 11$ & 20.86799 & 86.86685 & 35.8773 & 64.7 \\
\hline TS8_11 & $8 / 22 / 11$ & 20.86799 & 86.86685 & 35.6891 & 55.0 \\
\hline TS9_11 & $9 / 14 / 11$ & 20.86799 & 86.86685 & 35.5115 & 58.2 \\
\hline TS10_11 & $10 / 17 / 11$ & 20.86799 & 86.86685 & 34.9237 & 71.2 \\
\hline YT300 & $10 / 22 / 11$ & 20.39568 & 87.31467 & 34.2650 & 67.8 \\
\hline YT256 & $10 / 24 / 11$ & 20.78003 & 86.94127 & 34.8953 & 69.7 \\
\hline YT331 & $10 / 24 / 11$ & 20.86799 & 86.86685 & 35.0606 & 59.8 \\
\hline YT260 & $10 / 25 / 11$ & 20.89147 & 86.86060 & 35.1091 & 60.2 \\
\hline YT342 & $10 / 25 / 11$ & 20.89119 & 86.86023 & 35.5001 & 54.6 \\
\hline TS6_12 & $6 / 29 / 12$ & 20.86799 & 86.86685 & 35.5721 & \\
\hline TS7_12 & $7 / 27 / 12$ & 20.86799 & 86.86685 & 35.9576 & \\
\hline TS8_12 & $8 / 29 / 12$ & 20.86799 & 86.86685 & 35.9882 & \\
\hline TS9_12 & $9 / 20 / 12$ & 20.86799 & 86.86685 & 35.5861 & \\
\hline TS $10 \_12$ & $10 / 17 / 12$ & 20.86799 & 86.86685 & 35.3707 & \\
\hline TS11_12 & $11 / 15 / 12$ & 20.86799 & 86.86685 & 36.0479 & \\
\hline $\mathrm{TS} 12^{-} 12$ & $12 / 15 / 12$ & 20.86799 & 86.86685 & 35.7347 & \\
\hline
\end{tabular}

TS samples were collected as part of a time series at the UNAM pier WGS84 datum used. 


\section{References:}

Al-Horani, F.A., 2005. Effects of changing seawater temperature on photosynthesis and calcification in the scleractinian coral Galaxea fascicularis, measured with $\mathrm{O}-2, \mathrm{Ca} 2+$ and pH microsensors. Sci. Mar. 69, 347-354.

Alibert, C., Kinsley, L., 2008. A 170-year Sr/Ca and Ba/Ca coral record from the western Pacific warm pool: 1. What can we learn from an unusual coral record? J. Geophys. Res.Oceans 113, doi:10.1029/2006jc003979.

Alibert, C., Kinsley, L., Fallon, S.J., McCulloch, M.T., Berkelmans, R., McAllister, F., 2003. Source of trace element variability in Great Barrier Reef corals affected by the Burdekin flood plumes. Geochim. Cosmochim. Acta 67, 231-246.

Barkley, H.C., 2011. Establishing Links Between Basin-Scale Climate and the Growth of Atlantic Corals: The Effect of Temperature and Feeding on Favia fragum, Ecology and Evolutionary Biology Department. Princeton University, p. 96.

Bath, G.E., Thorrold, S.R., Jones, C.M., Campana, S.E., McLaren, J.W., Lam, J.W.H., 2000. Strontium and barium uptake in aragonitic otoliths of marine fish. Geochim. Cosmochim. Acta 64, 1705-1714.

Bauer-Gottwein, P., Gondwe, B.R.N., Charvet, G., Marin, L.E., Rebolledo-Vieyra, M., Merediz-Alonso, G., 2011. Review: The Yucatan Peninsula karst aquifer, Mexico. Hydrogeol. J. 19, 507-524.

Beck, J.W., Edwards, R.L., Ito, E., Taylor, F.W., Recy, J., Rougerie, F., Joannot, P., Henin, C., 1992. Sea-surface temperature from coral skeletal strontium calcium ratios. Science 257, 644-647.

Beddows, P.A., Smart, P.L., Whitaker, F.F., Smith, S.L., 2007. Decoupled fresh-saline groundwater circulation of a coastal carbonate aquifer: Spatial patterns of temperature and specific electrical conductivity. J. Hydrol. 346, 18-32.

Broecker, W.S., 1982. Glacial to interglacial changes in ocean chemistry. Prog. Oceanogr. 11, 151-197.

Carriquiry, J.D., Horta-Puga, G., 2010. The Ba/Ca record of corals from the Southern Gulf of Mexico: Contributions from land-use changes, fluvial discharge and oil-drilling muds. Mar. Pollut. Bull. 60, 1625-1630.

Chan, L.H., Drummond, D., Edmond, J.M., Grant, B., 1977. Barium data from Atlantic GEOSECS expedition. Deep-Sea Res. 24, 613-649.

Chan, L.H., Edmond, J.M., Stallard, R.F., Broecker, W.S., Chung, Y.C., Weiss, R.F., Ku, T.L., 1976. Radium and barium at GEOSECS stations in Atlantic and Pacific. Earth Planet. Sci. Lett. 32, 258-267. 
Chen, T.R., Yu, K.F., Li, S., Chen, T.G., Shi, Q., 2011. Anomalous Ba/Ca signals associated with low temperature stresses in Porites corals from Daya Bay, northern South China Sea. J. Environ. Sci. 23, 1452-1459.

Coffey, M., Dehairs, F., Collette, O., Luther, G., Church, T., Jickells, T., 1997. The behaviour of dissolved barium in estuaries. Estuar. Coast. Shelf Sci. 45, 113-121.

Cohen, A.L., Gaetani, G.A., 2010. Ion Partitioning and the Geochemistry of Coral Skeletons: Solving the Mystery of the "Vital Effect", in: Prieto, M., Stoll, H. (Eds.), On partitioning in low temperature aqueous systems: from fundamentals to applications in climate proxies and environmental geochemistry. European Mineralogical Union, Notes in Mineralogy.

Cohen, A.L., Holcomb, M., 2009. Why Corals Care About Ocean Acidification: Uncovering the Mechanism. Oceanography 22, 118-127.

de Putron, S.J., McCorkle, D.C., Cohen, A.L., Dillon, A.B., 2011. The impact of seawater saturation state and bicarbonate ion concentration on calcification by new recruits of two Atlantic corals. Coral Reefs 30, 321-328.

Dickson, A., Millero, F., 1987. A comparison of the equilibrium constants for the dissociation of carbonic acid in seawater media. Deep Sea Res. Part A 34, 1733-1743.

Dietzel, M., Gussone, N., Eisenhauer, A., 2004. Co-precipitation of $\mathrm{Sr}^{2+}$ and $\mathrm{Ba}^{2+}$ with aragonite by membrane diffusion of $\mathrm{CO}_{2}$ between 10 and $50 \mathrm{C}$. Chem. Geol. 203, 139151.

Drenkard, E.J., Cohen, A.L., McCorkle, D.C., de Putron, S.J., Starczak, V.R., Zicht, A.E., 2013. Calcification by juvenile corals under heterotrophy and elevated $\mathrm{CO}_{2}$. Coral Reefs, doi:10.1007/s00338-00013-01021-00335.

Dymond, J., E. Suess, and M. Lyle, 1992. Barium in deep-sea sediment: A geochemical proxy for paleoproductivity, Paleoceanography, 7, 163-181.

Elsdon, T.S., Gillanders, B.M., 2003. Relationship between water and otolith elemental concentrations in juvenile black bream Acanthopagrus butcheri. Mar. Ecol. Prog. Ser. 260, 263-272.

Fallon, S.J., McCulloch, M.T., van Woesik, R., Sinclair, D.J., 1999. Corals at their latitudinal limits: laser ablation trace element systematics in Porites from Shirigai Bay, Japan. Earth Planet. Sci. Lett. 172, 221-238.

Fassett, J.D., Paulsen, P.J., 1989. Isotope Dilution Mass Spectrometry for Accurate Elemental Analysis. Anal. Chem. 61, 643A-649A. 
Fiedler, P.C., Philbrick, V., Chavez, F.P., 1991. Oceanic upwelling and productivity in the Eastern Tropical Pacific. Limnol. Oceanogr. 36, 1834-1850.

Fleitmann, D., Dunbar, R.B., McCulloch, M., Mudelsee, M., Vuille, M., McClanahan, T.R., Cole, J.E., Eggins, S., 2007. East African soil erosion recorded in a 300 year old coral colony from Kenya. Geophys. Res. Lett. 34, doi:10.1029/2006g1028525.

Gaetani, G.A., Cohen, A.L., 2006. Element partitioning during precipitation of aragonite from seawater: A framework for understanding paleoproxies. Geochim. Cosmochim. Acta 70, 4617-4634.

Gaetani, G.A., Cohen, A.L., Wang, Z., Crusius, J., 2011. Rayleigh-based, multi-element coral thermometry: A biomineralization approach to developing climate proxies.

Geochim. Cosmochim. Acta 75, 1920-1932.

Gagnon, A.C., Adkins, J.F., Erez, J., 2012. Seawater transport during coral biomineralization. Earth Planet. Sci. Lett. 329, 150-161.

Gagnon, A.C., Adkins, J.F., Fernandez, D.P., Robinson, L.F., 2007. Sr/Ca and Mg/Ca vital effects correlated with skeletal architecture in a scleractinian deep-sea coral and the role of Rayleigh fractionation. Earth Planet. Sci. Lett. 261, 280-295.

Gaillardet, J., Viers, J., Dupre, B., 2003. 5.09 - Trace Elements in River Waters, in: Heinrich, D.H., Karl, K.T. (Eds.), Treatise on Geochemistry. Pergamon, Oxford, pp. 225272.

Ganeshram, R.S., François, R., Commeau, J., Brown-Leger, S.L., 2003. An experimental investigation of barite in seawater. Geochim. Cosmochim. Acta 67, 2599-2605.

Gillikin, Steenmans, D., Baevens, W. Andre, L., 2006. Barium uptake into the shells of the common mussel (Mytilus edulis) and the potential for estuarine paleo-chemistry reconstruction. Geochim. Cosmochim. Acta 70, 395-407.

Gondwe, B.R.N., Lerer, S., Stisen, S., Marin, L., Rebolledo-Vieyra, M., Merediz-Alonso, G., Bauer-Gottwein, P., 2010. Hydrogeology of the south-eastern Yucatan Peninsula: New insights from water level measurements, geochemistry, geophysics and remote sensing. J. Hydrol. 389, 1-17.

Gonneea, M.E., Charette, M.A., Liu, Q., Herrera-Silveira, J., Morales-Ojeda, S.M., in review. Trace element geochemistry of groundwater in a karst subteranean estuary (Yucatan Peninsula, Mexico). Geochim. Cosmochim. Acta., doi:10.1016/j.gca.2013.05.034.

Goodbody-Gringley, G., de Putron, S.J., 2009. Planulation patterns of the brooding coral Favia fragum (Esper) in Bermuda. Coral Reefs 28, 959-963. 
Horta-Puga, G., Carriquiry, J.D., 2012. Coral Ba/Ca molar ratios as a proxy of precipitation in the northern Yucatan Peninsula, Mexico. Appl. Geochem. 27, 1579-1586.

Ingalls, A.E., Lee, C., Druffel, E.R.M., 2003.Preservation of organic matter in moundforming coral skeletons. Geochim. Cosmochim. Acta 67, 2827-2841.

Jupiter, S., Roff, G., Marion, G., Henderson, M., Schrameyer, V., McCulloch, M., Hoegh-Guldberg, O., 2008. Linkages between coral assemblages and coral proxies of terrestrial exposure along a cross-shelf gradient on the southern Great Barrier Reef. Coral Reefs 27, 887-903.

Kleypas, J.A., Buddemeier, R.W., Archer, D., Gattuso, J.P., Langdon, C., Opdyke, B.N., 1999. Geochemical consequences of increased atmospheric carbon dioxide on coral reefs. Science 284, 118-120.

Lea, D.W., Shen, G.T., Boyle, E.A., 1989. Coralline barium records temporal variability in Equatorial Pacific upwelling. Nature 340, 373-376.

Lea, D.W., Spero, H.J., 1992. Experimental-determination of barium uptake in shels of the planktonic-foraminifera Orbulina-universa at 22-degrees-C. Geochim. Cosmochim. Acta 56, 2673-2680.

Lewis, E., Wallace, D., 1998. Program developed for CO2 system calculations. ORNL/CDIAC-105, Carbon Dioxide Information Analysis Center Oak Ridge Natl Lab. US Dept of Energy, Oak Ridge, TN.

Lin, I.T., Wang, C.H., You, C.F., Lin, S., Huang, K.F., Chen, Y.G., 2010. Deep submarine groundwater discharge indicated by tracers of oxygen, strontium isotopes and barium content in the Pingtung coastal zone, southern Taiwan. Mar. Chem. 122, 51-58.

Livingston, D.A., 1963. Chemical composition of rivers and lakes. United States Geological Survey Professional Paper 440-G.

Marchesiello, P., Lefevre, J., Vega, A., Couvelard, X., Menkes, C., 2010. Coastal upwelling, circulation and heat balance around New Caledonia's barrier reef. Mar. Pollut. Bull. 61, 432-448.

Marshall, A.T., Clode, P., 2004. Calcification rate and the effect of temperature in a zooxanthellate and an azooxanthellate scleractinian reef coral. Coral Reefs 23, 218-224.

McCulloch, M., Fallon, S., Wyndham, T., Hendy, E., Lough, J., Barnes, D., 2003. Coral record of increased sediment flux to the inner Great Barrier Reef since European settlement. Nature 421, 727-730. 
Mehrbach, C., Culberso, C., JE, H., R, P., 1973. Measurement of apparent dissociationconstants of carbonic-acid in seawater at atmospheric-pressure. Limnol. Oceanogr. 18, 897-907.

Michael, H.A., Mulligan, A.E., Harvey, C.F., 2005. Seasonal oscillations in water exchange between aquifers and the coastal ocean. Nature 436, 1145-1148.

Mitsuguchi, T., Matsumoto, E., Abe, O., Uchida, T., Isdale, P.J., 1996. Mg/Ca thermometry in coral-skeletons. Science 274, 961-963.

Montaggioni, L.F., Le Cornec, F., Correge, T., Cabioch, G., 2006. Coral barium/calcium record of mid-Holocene upwelling activity in New Caledonia, South-West Pacific. Paleogeogr. Paleoclimatol. Paleoecol. 237, 436-455.

Moore, W.S., 1997. High fluxes of radium and barium from the mouth of the GangesBrahmaputra river during low river discharge suggest a large groundwater source. Earth Planet. Sci. Lett. 150, 141-150.

Moore, W.S., 2010. The Effect of Submarine Groundwater Discharge on the Ocean. Annu. Rev. Mar. Sci. 2, 59-88.

Moore, W.S., Shaw, T.J., 1998. Chemical signals from submarine fluid advection onto the continental shelf. J. Geophys. Res.-Oceans 103, 21543-21552.

Moyer, R.P., Grottoli, A.G., Olesik, J.W., 2012. A multiproxy record of terrestrial inputs to the coastal ocean using minor and trace elements $(\mathrm{Ba} / \mathrm{Ca}, \mathrm{Mn} / \mathrm{Ca}, \mathrm{Y} / \mathrm{Ca})$ and carbon isotopes (delta C-13, Delta C-14) in a nearshore coral from Puerto Rico. Paleoceanography 27, doi:10.1029/2011pa002249.

Okai, T., Suzuki, A., Kawahata, H., Terashima, S., Imai, N., 2002. Preparation of a new Geological Survey of Japan geochemical reference material: Coral JCp-1. Geostand. Newsl. 26, 95-99.

Paytan, A., Shellenbarger, G.G., Street, J.H., Gonneea, M.E., Davis, K., Young, M.B., Moore, W.S., 2006. Submarine groundwater discharge: An important source of new inorganic nitrogen to coral reef ecosystems. Limnol. Oceanogr. 51, 343-348.

Pelletier, G., Lewis, E., Wallace, D., 2007. CO2sys.xls: A Calculator for the CO2 System in Seawater for Microsoft Excel/VBA. Washington State Department of Ecology/Brookhaven National Laboratory, Olympia, WA/Upton, NY, USA.

Perry, E., Velazquez-Oliman, G., Marin, L., 2002. The hydrogeochemistry of the karst aquifer system of the northern Yucatan Peninsula, Mexico. Int. Geol. Rev. 44, 191-221.

Pingitore, N.E., Rangel, Y., Kwarteng, A., 1989. Barium variation in Acropora-palmata and Montastrea-annularis. Coral Reefs 8, 31-36. 
Prouty, N.G., Field, M.E., Stock, J.D., Jupiter, S.D., McCulloch, M., 2010. Coral Ba/Ca records of sediment input to the fringing reef of the southshore of Moloka'i, Hawai'i over the last several decades. Mar. Pollut. Bull. 60, 1822-1835.

Quay, P.D., Stuiver, M., Broecker, W.S., 1983. Upwelling rates for the Equatorial Pacific Ocean derived from the bomb C-14 distribution. J. Mar. Res. 41, 769-792.

Reuer, M.K., Boyle, E.A., Cole, J.E., 2003. A mid-twentieth century reduction in tropical upwelling inferred from coralline trace element proxies. Earth Planet. Sci. Lett. 210, 437452.

Reynaud, S., Ferrier-Pages, C., Meibom, A., Mostefaoui, S., Mortlock, R., Fairbanks, R., Allemand, D., 2007. Light and temperature effects on $\mathrm{Sr} / \mathrm{Ca}$ and $\mathrm{Mg} / \mathrm{Ca}$ ratios in the scleractinian coral Acropora sp. Geochim. Cosmochim. Acta 71, 354-362.

Reynaud, S., Leclercq, N., Romaine-Lioud, S., Ferrier-Pages, C., Jaubert, J., Gattuso, J.P., 2003. Interacting effects of $\mathrm{CO} 2$ partial pressure and temperature on photosynthesis and calcification in a scleractinian coral. Glob. Change Biol. 9, 1660-1668.

Reynolds, R.W., Rayner, N.A., Smith, T.M., Stokes, D.C., Wang, W., 2002. An imporoved in situ and satellite SST analysis for cliate. J. Climate 15, 1609-1625.

Rodolfo-Metalpa, R., Peirano, A., Houlbreque, F., Abbate, M., Ferrier-Pages, C., 2008. Effects of temperature, light and heterotrophy on the growth rate and budding of the temperate coral Cladocora caespitosa. Coral Reefs 27, 17-25.

Rodriguez-Martinez, R.E., Ruiz-Renteria, F., van Tussenbroek, B., Barba-Santos, G., Escalante-Mancera, E., Jordan-Garz, G., Jordan-Dahlgren, E., 2010. Environmental state and tendencies of the Puerto Morelos CARIMOP site, Mexico. Rev. Biol. Trop. 58, 2343.

Saenger, C., Cohen, A.L., Oppo, D.W., Hubbard, D., 2008a. Interpreting sea surface temperature from strontium/calcium ratios in Montastrea corals: Link with growth rate and implications for proxy reconstructions. Paleoceanography 23, doi:10.1029/2007pa001572.

Saenger, C., Cohen, A.L., Oppo, D.W., Hubbard, D., 2008b. Interpreting sea surface temperature from strontium/calcium ratios in Montastrea corals: Link with growth rate and implications for proxy reconstructions. Paleoceanography 23, doi:10.1029/2007PA001572.

Santos, I.R., Dimova, N., Peterson, R.N., Mwashote, B., Chanton, J., Burnett, W.C., 2009. Extended time series measurements of submarine groundwater discharge tracers (Rn-222 and CH4) at a coastal site in Florida. Mar. Chem. 113, 137-147. 
Shaw, T.J., Moore, W.S., Kloepfer, J., Sochaski, M.A., 1998. The flux of barium to the coastal waters of the southeastern USA: The importance of submarine groundwater discharge. Geochim. Cosmochim. Acta 62, 3047-3054.

Sinclair, D.J., 2005. Non-river flood barium signals in the skeletons of corals from coastal Queensland, Australia. Earth Planet. Sci. Lett. 237, 354-369.

Sinclair, D.J., McCulloch, M.T., 2004. Corals record low mobile barium concentrations in the Burdekin River during the 1974 flood: evidence for limited Ba supply to rivers? Paleogeogr. Paleoclimatol. Paleoecol. 214, 155-174.

Smith, S.V., Buddemeier, R.W., Redalje, R.C., Houck, J.E., 1979. Strontium-calcium thermometry in coral skeletons. Science 204, 404-407.

Stecher, H.A., Krantz, D.E., Lord, C.J., Luther, G.W., Bock, K.W., 1996. Profiles of strontium and barium in Mercenaria mercenaria and Spisula solidissima shells. Geochim. Cosmochim. Acta 60, 3445-3456.

Swart, P.K., Elderfield, H., Greaves, M.J., 2002. A high-resolution calibration of Sr/Ca thermometry using the Caribbean coral Montastraea annularis. Geochem. Geophys. Geosyst., doi:10.1029/GC000306.

Tudhope, A.W., Lea, D.W., Shimmield, G.B., Chilcott, C.P., Head, S., 1996. Monsoon climate and Arabian sea coastal upwelling recorded in massive corals from southern Oman. Palaios 11, 347-361.

Vasquez-Bedoya, L.F., Cohen, A.L., Oppo, D.W., Blanchon, P., 2012. Corals record persistent multidecadal SST variability in the Atlantic Warm Pool since 1775 AD. Paleoceanography 27, doi:10.1029/2012pa002313.

Wyndham, T., McCulloch, M., Fallon, S., Alibert, C., 2004. High-resolution coral records of rare earth elements in coastal seawater: Biogeochemical cycling and a new environmental proxy. Geochim. Cosmochim. Acta 68, 2067-2080.

Yoshinaga, J., Nakama, A., Morita, M., Edmonds, J.S., 2000. Fish otolith reference material for quality assurance of chemical analyses. Mar. Chem. 69, 91-97. 


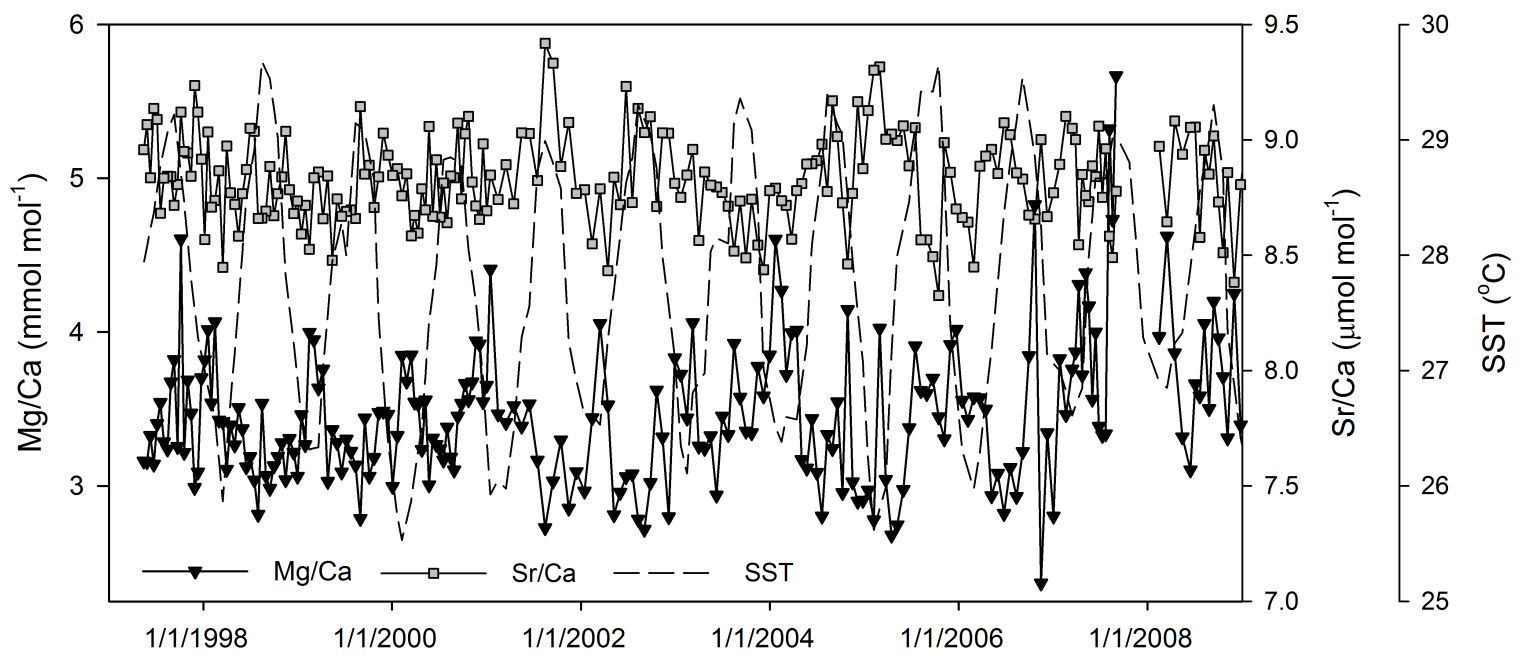

Figure S1: Sr/Ca and Mg/Ca in the Siderastrea collected from the Puerto Morelos lagoon. 


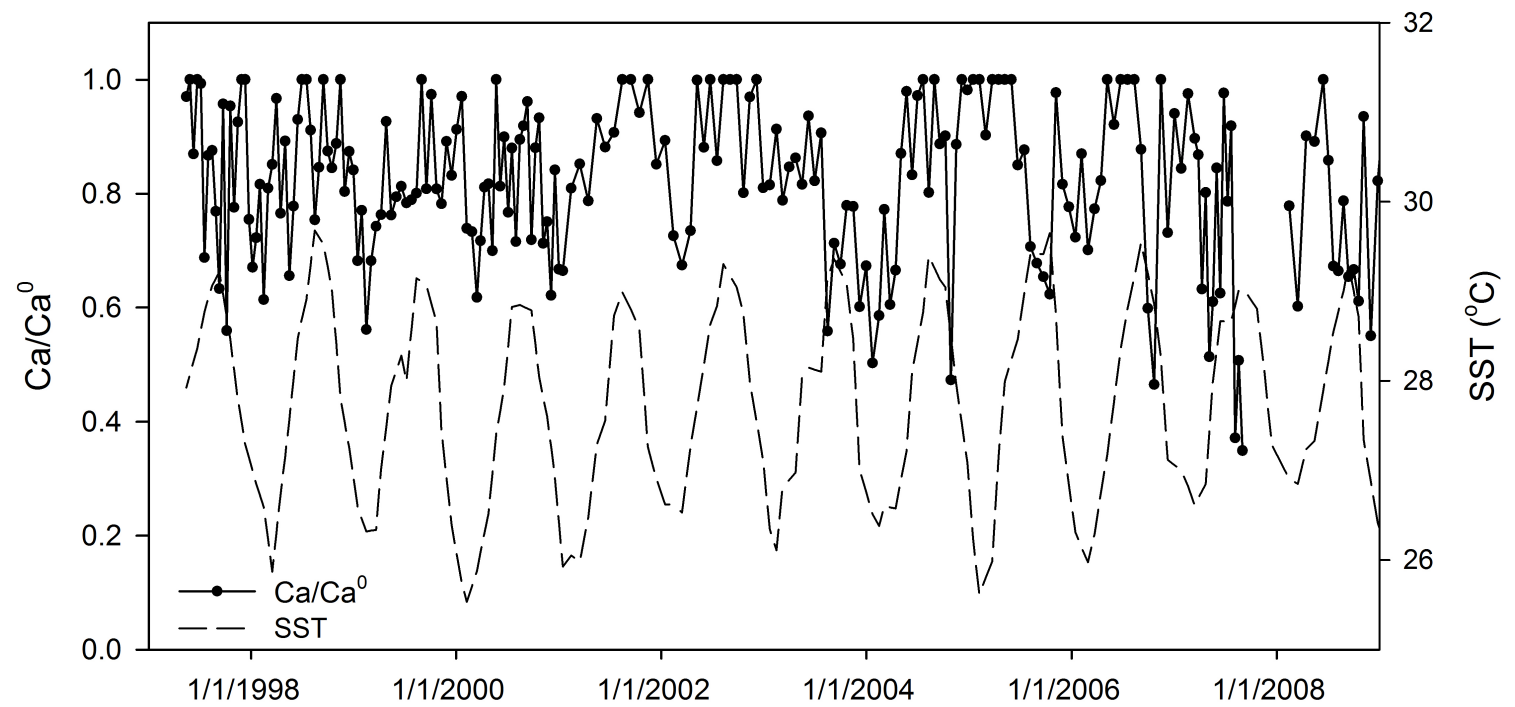

Figure S2: Sea surface temperature (IGOOS) for the $0.5^{\circ}$ grid encompassing Puerto Morelos lagoon and $\mathrm{f}_{\mathrm{Ca}}$, the fraction of $[\mathrm{Ca}]$ remaining after aragonite precipitation in the calcifying fluid. 


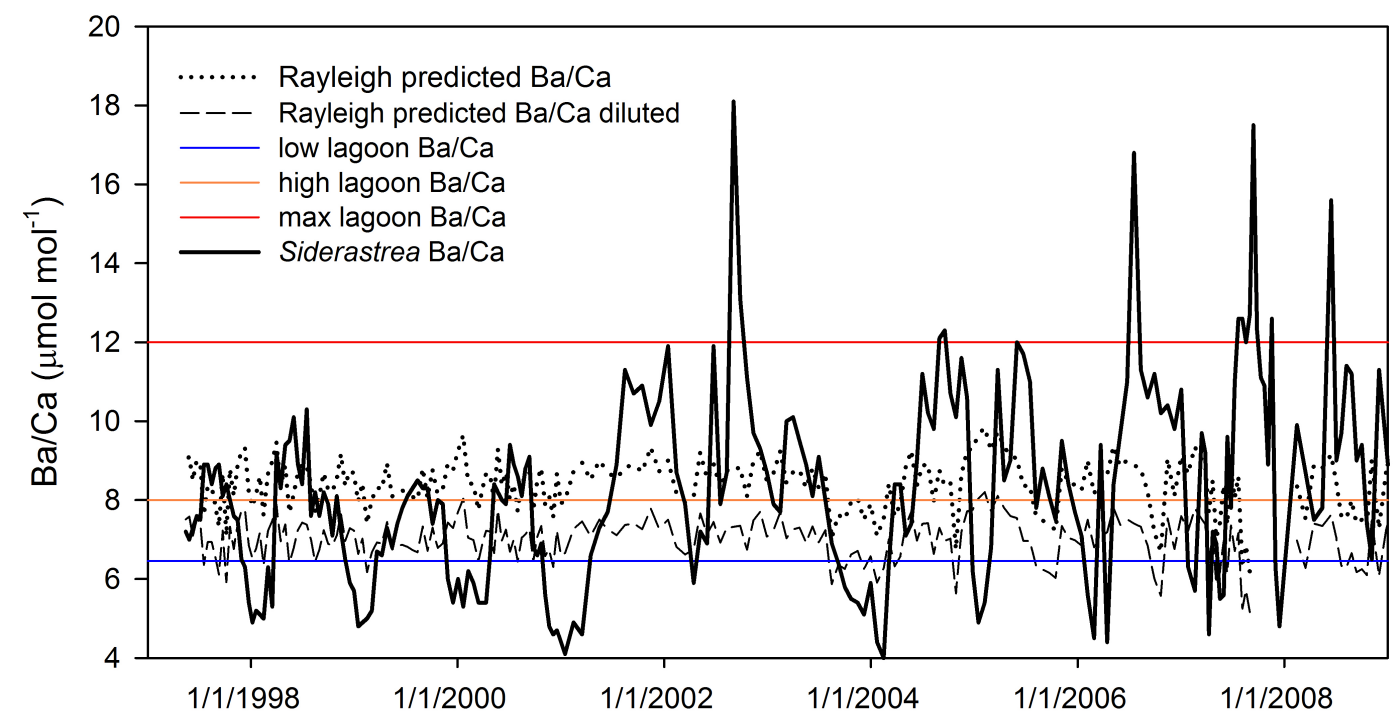

Figure S3: Coral $\mathrm{Ba} / \mathrm{Ca}$ from the Siderastrea and Rayleigh fractionation model predicted $\mathrm{Ba} / \mathrm{Ca}$ for undiluted calcifying fluid and a $20 \%[\mathrm{Ba}]$ dilution in the calcifying fluid. This model assumes a constant lagoon [Ba] $\left(50 \mathrm{nmol} \mathrm{kg}^{-1}\right)$ and [Ca] $\left(10.8 \mathrm{mmol} \mathrm{kg}{ }^{-1}\right)$. Also shown are the minimum and maximum seasonal $\mathrm{Ba} / \mathrm{Ca}$ observed in the Puerto Morelos lagoon and the extreme high value predicted from lagoon salinity during the passage of tropical storm Rina in October 2011 ( $\mathrm{K}_{\mathrm{Ba}}$ of 1.5). The amplitude of the Siderastrea record is much larger than the Rayleigh model predicted values. 
Table S1: Yucatan Siderastrea coral elemental ratios

\begin{tabular}{|c|c|c|c|c|c|}
\hline $\begin{array}{l}\text { Distance } \\
\mathbf{m m}\end{array}$ & Date & $\begin{array}{l}\mathrm{Ba} / \mathrm{Ca} \\
\mathrm{umol} / \mathrm{mol}\end{array}$ & $\begin{array}{l}\mathrm{Mg} / \mathrm{Ca} \\
\mathrm{mmol} / \mathrm{mol}\end{array}$ & $\begin{array}{l}\mathrm{Sr} / \mathrm{Ca} \\
\mathrm{mmol} / \mathrm{mol}\end{array}$ & $\begin{array}{l}\mathrm{U} / \mathrm{Ca} \\
\mathrm{umol} / \mathrm{mol}\end{array}$ \\
\hline 0.3 & $7 / 19 / 09$ & 10.02 & 3.95 & 8.48 & 1.01 \\
\hline 0.45 & $6 / 27 / 09$ & 12.88 & 3.48 & 8.54 & 1.06 \\
\hline 0.6 & 6/5/09 & 10.20 & 3.29 & 8.75 & 1.09 \\
\hline 0.75 & $5 / 14 / 09$ & 13.05 & 2.87 & 8.96 & 1.11 \\
\hline 0.9 & $4 / 22 / 09$ & 17.75 & 3.01 & 8.88 & 1.10 \\
\hline 1.05 & $3 / 31 / 09$ & 13.64 & 2.81 & 9.19 & 1.14 \\
\hline 1.2 & $3 / 9 / 09$ & 9.53 & 2.62 & 9.51 & 1.18 \\
\hline 1.35 & $2 / 15 / 09$ & 5.43 & 3.86 & 9.06 & 1.07 \\
\hline 1.5 & $1 / 20 / 09$ & 7.39 & 3.36 & 9.02 & 1.17 \\
\hline 1.65 & $12 / 26 / 08$ & 9.35 & 3.40 & 8.81 & \\
\hline 1.8 & $12 / 1 / 08$ & 11.31 & 4.25 & 8.38 & 1.15 \\
\hline 1.95 & $11 / 6 / 08$ & 6.49 & 3.31 & 8.86 & 1.07 \\
\hline 2.1 & $10 / 19 / 08$ & 7.37 & 3.71 & 8.51 & 1.06 \\
\hline 2.25 & $10 / 1 / 08$ & 9.35 & 3.96 & 8.73 & 1.07 \\
\hline 2.4 & $9 / 13 / 08$ & 9.02 & 4.20 & 9.02 & 1.02 \\
\hline 2.55 & $8 / 26 / 08$ & 11.19 & 3.50 & 8.85 & 1.01 \\
\hline 2.7 & $8 / 8 / 08$ & 11.38 & 4.06 & 8.96 & 1.01 \\
\hline 2.85 & $7 / 21 / 08$ & 9.66 & 3.58 & 8.58 & 1.02 \\
\hline 3 & $7 / 3 / 08$ & 9.05 & 3.66 & 9.06 & 1.05 \\
\hline 3.15 & $6 / 15 / 08$ & 15.57 & 3.10 & 9.05 & 1.10 \\
\hline 3.3 & $5 / 15 / 08$ & 7.80 & 3.32 & 8.94 & 1.10 \\
\hline 3.45 & $4 / 15 / 08$ & 7.50 & 3.86 & 9.08 & 1.07 \\
\hline 3.6 & $3 / 16 / 08$ & 8.72 & 4.62 & 8.64 & 1.14 \\
\hline 3.75 & $2 / 15 / 08$ & 9.94 & 3.97 & 8.97 & 1.09 \\
\hline 3.9 & $12 / 15 / 07$ & 4.81 & na & na & 0.96 \\
\hline 4.05 & $12 / 1 / 07$ & 6.32 & na & na & 1.04 \\
\hline 4.2 & $11 / 18 / 07$ & 12.63 & na & na & 0.98 \\
\hline 4.35 & $11 / 5 / 07$ & 8.93 & na & na & 1.04 \\
\hline 4.5 & $10 / 23 / 07$ & 10.91 & na & na & 0.98 \\
\hline 4.65 & $10 / 10 / 07$ & 11.14 & na & na & 1.02 \\
\hline 4.8 & $9 / 27 / 07$ & 12.33 & na & na & 0.95 \\
\hline 4.95 & $9 / 14 / 07$ & 17.54 & na & na & 1.04 \\
\hline 5.1 & $9 / 1 / 07$ & 12.68 & 5.67 & 8.78 & 1.03 \\
\hline 5.25 & $8 / 19 / 07$ & 12.01 & 4.73 & 8.49 & 1.04 \\
\hline 5.4 & $8 / 6 / 07$ & 12.57 & 5.32 & 8.58 & 1.08 \\
\hline 5.55 & $7 / 23 / 07$ & 12.62 & 3.34 & 8.96 & 1.08 \\
\hline 5.7 & $7 / 10 / 07$ & 10.99 & 3.33 & 8.75 & 1.11 \\
\hline 5.85 & $6 / 27 / 07$ & 7.80 & 3.39 & 9.06 & 1.04 \\
\hline 6 & $6 / 14 / 07$ & 9.64 & 4.00 & 8.84 & 1.08 \\
\hline 6.15 & $6 / 1 / 07$ & 5.62 & 3.56 & 8.89 & 1.01 \\
\hline 6.3 & $5 / 19 / 07$ & 5.48 & 4.17 & 8.73 & 1.06 \\
\hline 6.45 & $5 / 6 / 07$ & 6.87 & 4.39 & 8.76 & 1.01 \\
\hline 6.6 & $4 / 23 / 07$ & 7.21 & 3.72 & 8.85 & 0.98 \\
\hline 6.75 & $4 / 10 / 07$ & 4.64 & 4.31 & 8.55 & 0.97 \\
\hline
\end{tabular}


Table S1: Yucatan Siderastrea coral elemental ratios

\begin{tabular}{|c|c|c|c|c|c|}
\hline $\begin{array}{l}\text { Distance } \\
\text { mm }\end{array}$ & Date & $\begin{array}{l}\mathrm{Ba} / \mathrm{Ca} \\
\mathrm{umol} / \mathrm{mol}\end{array}$ & $\begin{array}{l}\mathrm{Mg} / \mathrm{Ca} \\
\mathrm{mmol} / \mathrm{mol}\end{array}$ & $\begin{array}{l}\mathrm{Sr} / \mathrm{Ca} \\
\mathrm{mmol} / \mathrm{mol}\end{array}$ & $\begin{array}{l}\mathrm{U} / \mathrm{Ca} \\
\mathrm{umol} / \mathrm{mol}\end{array}$ \\
\hline 6.9 & $3 / 28 / 07$ & 9.24 & 3.87 & 9.00 & 1.00 \\
\hline 7.05 & $3 / 15 / 07$ & 9.65 & 3.76 & 9.05 & 0.98 \\
\hline 7.2 & $2 / 19 / 07$ & 5.74 & 3.46 & 9.10 & 0.99 \\
\hline 7.35 & $1 / 26 / 07$ & 6.26 & 3.83 & 8.89 & 0.94 \\
\hline 7.5 & $1 / 2 / 07$ & 10.82 & 2.80 & 8.77 & 1.00 \\
\hline 7.65 & $12 / 9 / 06$ & 9.76 & 3.35 & 8.67 & 1.04 \\
\hline 7.8 & $11 / 15 / 06$ & 10.42 & 2.37 & 9.00 & 1.06 \\
\hline 7.95 & $10 / 22 / 06$ & 10.21 & 4.83 & 8.66 & 1.00 \\
\hline 8.1 & 9/29/06 & 11.24 & 3.85 & 8.67 & 1.01 \\
\hline 8.25 & $9 / 5 / 06$ & 10.63 & 3.22 & 8.83 & 1.08 \\
\hline 8.4 & $8 / 12 / 06$ & 11.29 & 2.93 & 8.86 & 1.08 \\
\hline 8.55 & $7 / 19 / 06$ & 16.82 & 3.12 & 9.02 & 1.12 \\
\hline 8.7 & $6 / 25 / 06$ & 11.01 & 2.82 & 9.07 & 1.11 \\
\hline 8.85 & $6 / 1 / 06$ & 9.71 & 3.08 & 8.85 & 1.09 \\
\hline 9 & $5 / 8 / 06$ & 8.40 & 2.94 & 8.96 & 1.11 \\
\hline 9.15 & $4 / 15 / 06$ & 4.42 & 3.50 & 8.93 & 1.09 \\
\hline 9.3 & $3 / 23 / 06$ & 9.39 & 3.57 & 8.89 & 0.97 \\
\hline 9.45 & $2 / 28 / 06$ & 4.52 & 3.58 & 8.45 & 0.90 \\
\hline 9.6 & $2 / 5 / 06$ & 5.57 & 3.43 & 8.64 & 0.92 \\
\hline 9.75 & $1 / 14 / 06$ & 7.12 & 3.56 & 8.66 & 1.01 \\
\hline 9.9 & $12 / 22 / 05$ & 7.70 & 4.02 & 8.70 & 0.95 \\
\hline 10.05 & $11 / 29 / 05$ & 8.38 & 3.92 & 8.86 & 0.97 \\
\hline 10.2 & $11 / 6 / 05$ & 9.49 & 3.31 & 8.99 & 1.05 \\
\hline 10.35 & $10 / 15 / 05$ & 7.54 & 3.45 & 8.32 & 1.02 \\
\hline 10.5 & $9 / 22 / 05$ & 8.07 & 3.70 & 8.49 & 1.00 \\
\hline 10.65 & $8 / 30 / 05$ & 8.76 & 3.60 & 8.57 & 1.01 \\
\hline 10.8 & $8 / 7 / 05$ & 7.79 & 3.62 & 8.57 & 1.01 \\
\hline 10.95 & $7 / 16 / 05$ & 10.96 & 3.91 & 9.05 & 0.98 \\
\hline 11.1 & $6 / 23 / 05$ & 11.68 & 3.38 & 8.89 & 1.06 \\
\hline 11.25 & $5 / 31 / 05$ & 12.01 & 2.98 & 9.06 & 1.12 \\
\hline 11.4 & $5 / 8 / 05$ & 8.99 & 2.75 & 9.00 & 1.10 \\
\hline 11.55 & $4 / 16 / 05$ & 8.53 & 2.68 & 9.03 & 1.25 \\
\hline 11.7 & $3 / 24 / 05$ & 11.25 & 3.04 & 9.00 & 1.08 \\
\hline 11.85 & $3 / 1 / 05$ & 6.79 & 4.02 & 9.32 & 1.16 \\
\hline 12 & $2 / 6 / 05$ & 5.42 & 2.78 & 9.30 & 1.43 \\
\hline 12.15 & $1 / 15 / 05$ & 4.94 & 2.97 & 9.13 & 1.21 \\
\hline 12.3 & $12 / 26 / 04$ & 6.23 & 2.91 & 8.88 & 1.24 \\
\hline 12.45 & $12 / 6 / 04$ & 10.59 & 2.90 & 9.17 & 1.25 \\
\hline 12.6 & $11 / 16 / 04$ & 11.65 & 3.03 & 8.77 & 1.11 \\
\hline 12.75 & $10 / 28 / 04$ & 10.09 & 4.15 & 8.46 & 0.96 \\
\hline 12.9 & $10 / 8 / 04$ & 10.71 & 2.96 & 8.73 & 1.14 \\
\hline 13.05 & $9 / 18 / 04$ & 12.33 & 3.55 & 9.01 & 1.11 \\
\hline 13.2 & $8 / 30 / 04$ & 12.09 & 3.24 & 9.17 & 1.20 \\
\hline 13.35 & $8 / 10 / 04$ & 9.82 & 3.33 & 8.78 & 1.10 \\
\hline
\end{tabular}


Table S1: Yucatan Siderastrea coral elemental ratios

\begin{tabular}{|c|c|c|c|c|c|}
\hline $\begin{array}{l}\text { Distance } \\
\text { mm }\end{array}$ & Date & $\begin{array}{l}\mathrm{Ba} / \mathrm{Ca} \\
\mathrm{umol} / \mathrm{mol}\end{array}$ & $\begin{array}{l}\mathrm{Mg} / \mathrm{Ca} \\
\mathrm{mmol} / \mathrm{mol}\end{array}$ & $\begin{array}{l}\mathrm{Sr} / \mathrm{Ca} \\
\mathrm{mmol} / \mathrm{mol}\end{array}$ & $\begin{array}{l}\text { U/Ca } \\
\text { umol/mol }\end{array}$ \\
\hline 13.5 & $7 / 21 / 04$ & 10.23 & 2.80 & 8.98 & 1.18 \\
\hline 13.65 & $7 / 1 / 04$ & 11.22 & 3.09 & 8.91 & 1.15 \\
\hline 13.8 & $6 / 12 / 04$ & 9.02 & 3.44 & 8.90 & 1.12 \\
\hline 13.95 & $5 / 23 / 04$ & 7.43 & 3.11 & 8.90 & 1.14 \\
\hline 14.1 & $5 / 3 / 04$ & 7.06 & 3.17 & 8.81 & 1.10 \\
\hline 14.25 & $4 / 14 / 04$ & 8.37 & 4.01 & 8.78 & 0.99 \\
\hline 14.4 & $3 / 25 / 04$ & 8.38 & 4.00 & 8.57 & 0.98 \\
\hline 14.55 & $3 / 5 / 04$ & 6.36 & 3.72 & 8.72 & 1.00 \\
\hline 14.7 & $2 / 15 / 04$ & 3.96 & 4.27 & 8.74 & 0.99 \\
\hline 14.85 & $1 / 23 / 04$ & 4.41 & 4.60 & 8.79 & 0.98 \\
\hline 15 & $12 / 31 / 03$ & 5.91 & 3.85 & 8.78 & 1.03 \\
\hline 15.15 & $12 / 8 / 03$ & 5.13 & 3.58 & 8.44 & 1.02 \\
\hline 15.3 & $11 / 15 / 03$ & 5.44 & 3.78 & 8.54 & 1.02 \\
\hline 15.45 & $10 / 23 / 03$ & 5.49 & 3.34 & 8.74 & 1.07 \\
\hline 15.6 & $10 / 1 / 03$ & 5.81 & 3.36 & 8.49 & 1.04 \\
\hline 15.75 & $9 / 8 / 03$ & 6.38 & 3.58 & 8.74 & 1.03 \\
\hline 15.9 & $8 / 16 / 03$ & 6.86 & 3.93 & 8.52 & 1.00 \\
\hline 16.05 & $7 / 24 / 03$ & 7.98 & 3.33 & 8.71 & 1.07 \\
\hline 16.2 & $7 / 1 / 03$ & 9.10 & 3.45 & 8.77 & 1.07 \\
\hline 16.35 & $6 / 9 / 03$ & 8.13 & 2.94 & 8.80 & 1.07 \\
\hline 16.5 & $5 / 17 / 03$ & 8.89 & 3.33 & 8.80 & 1.12 \\
\hline 16.65 & $4 / 24 / 03$ & 9.49 & 3.24 & 8.86 & 1.09 \\
\hline 16.8 & $4 / 1 / 03$ & 10.12 & 3.26 & 8.56 & 1.06 \\
\hline 16.95 & $3 / 9 / 03$ & 10.03 & 4.06 & 8.96 & 1.09 \\
\hline 17.1 & $2 / 15 / 03$ & 7.70 & 3.44 & 8.85 & 1.10 \\
\hline 17.25 & $1 / 22 / 03$ & 7.92 & 3.72 & 8.75 & 1.04 \\
\hline 17.4 & $12 / 29 / 02$ & 8.66 & 3.83 & 8.81 & 1.06 \\
\hline 17.5 & $12 / 6 / 02$ & 9.29 & 2.80 & 9.03 & 1.11 \\
\hline 17.65 & $11 / 12 / 02$ & 9.65 & 3.32 & 9.03 & 1.08 \\
\hline 17.8 & $10 / 20 / 02$ & 11.09 & 3.62 & 8.71 & 1.05 \\
\hline 17.95 & $9 / 26 / 02$ & 13.08 & 3.02 & 9.10 & 1.16 \\
\hline 18.1 & $9 / 3 / 02$ & 18.14 & 2.72 & 9.03 & 1.13 \\
\hline 18.25 & $8 / 10 / 02$ & 8.69 & 2.78 & 9.14 & 1.16 \\
\hline 18.4 & $7 / 18 / 02$ & 7.93 & 3.08 & 8.73 & 1.03 \\
\hline 18.55 & $6 / 24 / 02$ & 11.88 & 3.06 & 9.23 & 1.06 \\
\hline 18.7 & $6 / 1 / 02$ & 6.89 & 2.96 & 8.72 & 1.05 \\
\hline 18.85 & $5 / 8 / 02$ & 7.20 & 2.81 & 8.84 & 1.10 \\
\hline 19 & $4 / 15 / 02$ & 5.92 & 3.53 & 8.43 & 1.00 \\
\hline 19.15 & $3 / 15 / 02$ & 7.93 & 4.05 & 8.79 & 0.97 \\
\hline 19.3 & $2 / 13 / 02$ & 8.72 & 3.44 & 8.55 & 0.96 \\
\hline 19.45 & $1 / 14 / 02$ & 11.89 & 2.97 & 8.78 & 1.02 \\
\hline 19.6 & $12 / 14 / 01$ & 10.50 & 3.09 & 8.77 & 1.02 \\
\hline 19.75 & $11 / 14 / 01$ & 9.90 & 2.86 & 9.08 & 1.08 \\
\hline 19.9 & $10 / 15 / 01$ & 10.90 & 3.30 & 8.88 & 1.11 \\
\hline
\end{tabular}


Table S1: Yucatan Siderastrea coral elemental ratios

\begin{tabular}{|c|c|c|c|c|c|}
\hline $\begin{array}{l}\text { Distance } \\
\text { mm }\end{array}$ & Date & $\begin{array}{l}\mathrm{Ba} / \mathrm{Ca} \\
\mathrm{umol} / \mathrm{mol}\end{array}$ & $\begin{array}{l}\mathrm{Mg} / \mathrm{Ca} \\
\mathrm{mmol} / \mathrm{mol}\end{array}$ & $\begin{array}{l}\mathrm{Sr} / \mathrm{Ca} \\
\mathrm{mmol} / \mathrm{mol}\end{array}$ & $\begin{array}{l}\mathrm{U} / \mathrm{Ca} \\
\mathrm{umol} / \mathrm{mol}\end{array}$ \\
\hline 20.05 & $9 / 14 / 01$ & 10.71 & 3.03 & 9.33 & 1.23 \\
\hline 20.2 & $8 / 15 / 01$ & 11.33 & 2.73 & 9.42 & 1.30 \\
\hline 20.35 & $7 / 16 / 01$ & 8.91 & 3.17 & 8.82 & 1.13 \\
\hline 20.5 & $6 / 15 / 01$ & 7.71 & 3.53 & 9.03 & 1.10 \\
\hline 20.65 & $5 / 16 / 01$ & 7.27 & 3.39 & 9.03 & 1.16 \\
\hline 20.8 & $4 / 16 / 01$ & 6.60 & 3.52 & 8.72 & 1.03 \\
\hline 20.95 & $3 / 16 / 01$ & 4.60 & 3.41 & 8.89 & 1.05 \\
\hline 21.1 & $2 / 14 / 01$ & 4.93 & 3.47 & 8.74 & 1.05 \\
\hline 21.25 & $1 / 15 / 01$ & 4.13 & 4.41 & 8.85 & 0.99 \\
\hline 21.4 & $1 / 1 / 01$ & 4.40 & 3.65 & 8.69 & 0.99 \\
\hline 21.55 & $12 / 18 / 00$ & 4.74 & 3.55 & 8.98 & 1.07 \\
\hline 21.7 & $12 / 4 / 00$ & 4.63 & 3.92 & 8.65 & 1.02 \\
\hline 21.85 & $11 / 20 / 00$ & 4.77 & 3.94 & 8.71 & 1.01 \\
\hline 22 & $11 / 6 / 00$ & 5.55 & 3.67 & 8.82 & 1.06 \\
\hline 22.15 & $10 / 23 / 00$ & 6.91 & 3.56 & 9.10 & 1.08 \\
\hline 22.3 & $10 / 9 / 00$ & 6.65 & 3.67 & 9.03 & 1.09 \\
\hline 22.45 & $9 / 25 / 00$ & 6.76 & 3.54 & 8.75 & 1.05 \\
\hline 22.6 & $9 / 11 / 00$ & 9.12 & 3.45 & 9.07 & 1.09 \\
\hline 22.75 & $8 / 28 / 00$ & 8.80 & 3.10 & 8.84 & 1.08 \\
\hline 22.9 & $8 / 15 / 00$ & 8.06 & 3.19 & 8.84 & 1.08 \\
\hline 23.05 & $8 / 1 / 00$ & 8.55 & 3.38 & 8.64 & 1.02 \\
\hline 23.2 & $7 / 18 / 00$ & 8.90 & 3.17 & 8.81 & 1.08 \\
\hline 23.35 & $7 / 4 / 00$ & 9.45 & 3.24 & 8.67 & 1.05 \\
\hline 23.5 & $6 / 20 / 00$ & 7.93 & 3.27 & 8.91 & 1.09 \\
\hline 23.65 & $6 / 6 / 00$ & 8.05 & 3.31 & 8.67 & 1.08 \\
\hline 23.8 & $5 / 23 / 00$ & 8.21 & 3.01 & 9.06 & 1.19 \\
\hline 23.95 & $5 / 9 / 00$ & 8.43 & 3.56 & 8.70 & 1.11 \\
\hline 24.1 & $4 / 25 / 00$ & 6.56 & 3.24 & 8.79 & 1.09 \\
\hline 24.25 & $4 / 11 / 00$ & 5.41 & 3.53 & 8.60 & 1.06 \\
\hline 24.4 & $3 / 28 / 00$ & 5.37 & 3.54 & 8.67 & 1.07 \\
\hline 24.55 & $3 / 15 / 00$ & 5.38 & 3.85 & 8.58 & 1.05 \\
\hline 24.7 & $2 / 26 / 00$ & 5.90 & 3.68 & 8.85 & 1.07 \\
\hline 24.85 & $2 / 8 / 00$ & 6.16 & 3.85 & 8.76 & 1.08 \\
\hline 25 & $1 / 21 / 00$ & 5.29 & 3.33 & 8.88 & 1.11 \\
\hline 25.15 & $1 / 3 / 00$ & 6.02 & 3.00 & 8.85 & 1.27 \\
\hline 25.3 & $12 / 16 / 99$ & 5.37 & 3.47 & 8.93 & 1.05 \\
\hline 25.45 & $11 / 28 / 99$ & 6.01 & 3.49 & 9.03 & 1.06 \\
\hline 25.6 & $11 / 10 / 99$ & 7.92 & 3.48 & 8.84 & 1.01 \\
\hline 25.75 & $10 / 23 / 99$ & 8.03 & 3.18 & 8.71 & 0.96 \\
\hline 25.9 & $10 / 5 / 99$ & 7.42 & 3.06 & 8.89 & 1.10 \\
\hline 26.05 & $9 / 17 / 99$ & 8.27 & 3.44 & 8.85 & 1.03 \\
\hline 26.2 & 8/31/99 & 8.31 & 2.79 & 9.14 & 1.26 \\
\hline 26.35 & $8 / 13 / 99$ & 8.50 & 3.14 & 8.66 & 1.10 \\
\hline 26.5 & $7 / 26 / 99$ & 8.25 & 3.22 & 8.70 & 1.13 \\
\hline
\end{tabular}


Table S1: Yucatan Siderastrea coral elemental ratios

\begin{tabular}{|c|c|c|c|c|c|}
\hline $\begin{array}{l}\text { Distance } \\
\text { mm }\end{array}$ & Date & $\begin{array}{l}\mathrm{Ba} / \mathrm{Ca} \\
\mathrm{umol} / \mathrm{mol}\end{array}$ & $\begin{array}{l}\mathrm{Mg} / \mathrm{Ca} \\
\mathrm{mmol} / \mathrm{mol}\end{array}$ & $\begin{array}{l}\mathrm{Sr} / \mathrm{Ca} \\
\mathrm{mmol} / \mathrm{mol}\end{array}$ & $\begin{array}{l}\mathrm{U} / \mathrm{Ca} \\
\mathrm{umol} / \mathrm{mol}\end{array}$ \\
\hline 26.65 & $7 / 8 / 99$ & 8.06 & 3.30 & 8.69 & 1.10 \\
\hline 26.8 & $6 / 20 / 99$ & 7.84 & 3.09 & 8.67 & 1.11 \\
\hline 26.95 & $6 / 2 / 99$ & 7.42 & 3.28 & 8.74 & 1.08 \\
\hline 27.1 & $5 / 15 / 99$ & 6.81 & 3.37 & 8.48 & 1.06 \\
\hline 27.25 & $4 / 27 / 99$ & 7.29 & 3.03 & 8.84 & 1.16 \\
\hline 27.4 & 4/9/99 & 6.63 & 3.76 & 8.66 & 1.02 \\
\hline 27.55 & $3 / 22 / 99$ & 6.65 & 3.64 & 8.86 & 1.02 \\
\hline 27.7 & $3 / 4 / 99$ & 5.24 & 3.95 & 8.84 & 1.03 \\
\hline 27.85 & 2/15/99 & 4.96 & 4.00 & 8.53 & 0.99 \\
\hline 28 & $1 / 30 / 99$ & 4.89 & 3.27 & 8.72 & 1.12 \\
\hline 28.15 & $1 / 15 / 99$ & 4.80 & 3.46 & 8.59 & 1.09 \\
\hline 28.3 & $12 / 31 / 98$ & 5.67 & 3.06 & 8.73 & 1.15 \\
\hline 28.45 & $12 / 16 / 98$ & 5.86 & 3.22 & 8.68 & 1.10 \\
\hline 28.6 & $11 / 30 / 98$ & 6.53 & 3.31 & 8.78 & 1.06 \\
\hline 28.75 & $11 / 15 / 98$ & 7.21 & 3.04 & 9.04 & 1.18 \\
\hline 28.9 & $10 / 31 / 98$ & 8.06 & 3.28 & 8.84 & 1.12 \\
\hline 29.05 & $10 / 16 / 98$ & 7.11 & 3.19 & 8.77 & 1.06 \\
\hline 29.2 & $10 / 1 / 98$ & 7.86 & 3.13 & 8.67 & 1.03 \\
\hline 29.35 & $9 / 15 / 98$ & 8.19 & 2.98 & 8.88 & 1.11 \\
\hline 29.5 & $8 / 31 / 98$ & 7.57 & 3.07 & 8.69 & 1.13 \\
\hline 29.65 & $8 / 16 / 98$ & 8.16 & 3.54 & 8.66 & 1.12 \\
\hline 29.8 & $8 / 1 / 98$ & 7.58 & 2.81 & 8.66 & 1.17 \\
\hline 29.95 & $7 / 17 / 98$ & 10.28 & 3.04 & 9.04 & 1.13 \\
\hline 30.1 & $7 / 1 / 98$ & 8.39 & 3.19 & 9.05 & 1.09 \\
\hline 30.25 & $6 / 16 / 98$ & 8.93 & 3.12 & 8.87 & 1.11 \\
\hline 30.4 & $6 / 1 / 98$ & 10.11 & 3.37 & 8.77 & 1.04 \\
\hline 30.55 & $5 / 17 / 98$ & 9.48 & 3.51 & 8.58 & 1.01 \\
\hline 30.7 & $5 / 2 / 98$ & 9.39 & 3.27 & 8.72 & 1.06 \\
\hline 30.85 & $4 / 16 / 98$ & 8.29 & 3.39 & 8.77 & 1.08 \\
\hline 31 & $4 / 1 / 98$ & 9.23 & 3.11 & 8.97 & 1.14 \\
\hline 31.15 & $3 / 17 / 98$ & 5.32 & 3.42 & 8.45 & 1.06 \\
\hline 31.3 & $3 / 2 / 98$ & 6.26 & 3.43 & 8.87 & 1.10 \\
\hline 31.45 & $2 / 15 / 98$ & 5.03 & 4.07 & 8.74 & 1.06 \\
\hline 31.6 & $2 / 1 / 98$ & 5.10 & 3.54 & 8.71 & 1.09 \\
\hline 31.75 & $1 / 19 / 98$ & 5.23 & 4.02 & 9.03 & 1.08 \\
\hline 31.9 & $1 / 6 / 98$ & 4.95 & 3.82 & 8.57 & 1.06 \\
\hline 32.05 & $12 / 24 / 97$ & 5.45 & 3.70 & 8.92 & 1.04 \\
\hline 32.2 & $12 / 11 / 97$ & 6.31 & 3.09 & 9.12 & 1.14 \\
\hline 32.35 & $11 / 28 / 97$ & 6.46 & 2.99 & 9.23 & 1.15 \\
\hline 32.5 & $11 / 15 / 97$ & 7.47 & 3.47 & 8.84 & 1.14 \\
\hline 32.65 & $11 / 1 / 97$ & 7.57 & 3.69 & 8.94 & 1.17 \\
\hline 32.8 & $10 / 19 / 97$ & 8.04 & 3.22 & 8.95 & 1.10 \\
\hline 32.95 & $10 / 6 / 97$ & 8.38 & 4.61 & 9.12 & 1.12 \\
\hline 33.1 & $9 / 23 / 97$ & 8.06 & 3.26 & 8.81 & 1.11 \\
\hline
\end{tabular}


Table S1: Yucatan Siderastrea coral elemental ratios

\begin{tabular}{|c|c|c|c|c|c|}
\hline $\begin{array}{l}\text { Distance } \\
\text { mm }\end{array}$ & Date & $\begin{array}{l}\mathrm{Ba} / \mathrm{Ca} \\
\text { umol/mol }\end{array}$ & $\begin{array}{l}\mathrm{Mg} / \mathrm{Ca} \\
\mathrm{mmol} / \mathrm{mol}\end{array}$ & $\begin{array}{l}\mathrm{Sr} / \mathrm{Ca} \\
\mathrm{mmol} / \mathrm{mol}\end{array}$ & $\begin{array}{l}\mathrm{U} / \mathrm{Ca} \\
\mathrm{umol} / \mathrm{mol}\end{array}$ \\
\hline 33.25 & $9 / 10 / 97$ & 8.86 & 3.82 & 8.72 & 1.09 \\
\hline 33.4 & $8 / 28 / 97$ & 8.82 & 3.68 & 8.84 & 1.12 \\
\hline 33.55 & $8 / 15 / 97$ & 8.41 & 3.24 & 8.84 & 1.14 \\
\hline 33.7 & $8 / 1 / 97$ & 8.88 & 3.29 & 8.83 & 1.18 \\
\hline 33.85 & $7 / 19 / 97$ & 8.90 & 3.54 & 8.68 & 1.10 \\
\hline 34 & $7 / 6 / 97$ & 7.49 & 3.40 & 9.09 & 1.14 \\
\hline 34.15 & $6 / 23 / 97$ & 7.56 & 3.14 & 9.14 & 1.27 \\
\hline 34.3 & $6 / 10 / 97$ & 7.31 & 3.33 & 8.84 & 1.12 \\
\hline 34.45 & $5 / 28 / 97$ & 7.04 & 3.16 & 9.07 & 1.18 \\
\hline 34.6 & $5 / 15 / 97$ & 7.20 & 3.16 & 8.96 & 1.19 \\
\hline
\end{tabular}


Appendix A:

Solenastrea coral record from North Carolina 
Large submarine groundwater discharge (SGD) fluxes occur along the relatively wide and shallow continental margin of the U.S. mid-Atlantic (Moore, 1996; Moore and Shaw, 1998). In Chapter 6, I discuss how submarine groundwater discharge may elevate coastal ocean dissolved Ba concentrations. This region was identified as a potential site to test the applicability of the coral barium to calcium ration $(\mathrm{Ba} / \mathrm{Ca})$ paleoproxy of submarine groundwater discharge since SGD has been reported in Onslow Bay (McCoy et al., 2007; Moore, 1996). In this location within the South Atlantic Bight, dissolved Ba was 50-60 $\mathrm{nmol} \mathrm{kg}^{-1}$ in August 1995, indicative of SGD inputs (Shaw et al., 1998). Indeed, Shaw et al. (1998) demonstrated that riverine input of Ba at this site could only supply $20 \%$ of the Ba input.

The $\mathrm{Ba} / \mathrm{Ca}, \mathrm{Sr} / \mathrm{Ca}, \mathrm{Mg} / \mathrm{Ca}$ and $\mathrm{U} / \mathrm{Ca}$ of a Solenastrea sp. coral were measured and compared to environmental records of sea level, precipitation and groundwater level. Corals of this species are not commonly used in paleo proxy studies due to analytical challenges associated with their slow growth rate. However, elemental records from Solenastrea corals have been used in Florida Bay to reconstruct freshwater flow from the Everglades (Smith et al., 1989; Swart et al., 1999).

In 1996 a Solenastrea haydaes coral specimen was collected in Onslow Bay,

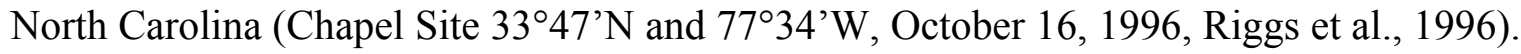
A thin section was prepared from the top $100 \mathrm{~mm}$ and analyzed via laser ablation ICPMS in 2008 utilizing the same standardization as described in Chapter 6. However, instead of discrete spots, a "track" 50 microns wide was continuously ablated down the corallite wall. This method generated a large amount of data $\left(10^{5}\right.$ samples over $\left.100 \mathrm{~mm}\right)$, 
thus the data was filtered (Matlab function "filter" which is a general tapped delay-line filter) and then subsampled to reduce to $10^{4}$ samples. This procedure also smoothed out some of the commonly observed noise in the elemental ratios inherent to this analytical method (Fallon et al., 1999).

An age model was built from computerized tomography (CT) images that allow determination of density banding in corals (Figure 1) (Cantin et al., 2010; VasquezBedoya et al., 2012). In this method, low-density bands are identified, marking each new year of growth, and the age is determined by "counting" bands from the modern coral top. However, much of the banding apparent in Figure 1 corresponds to aragonite layers interspersed with voids in the coral itself. Thus, there is some uncertainty whether the density bands seen are yearly or if they are related to coral structure changes on some other time scale. Strontium/calcium and $\mathrm{Mg} / \mathrm{Ca}$ cycles do not correspond to yearly density variations determined from the CT scan. Currently the poor constraints on the age model are a limiting factor in the interpretation of this coral record.

If we assume the density banding does indeed constrain the coral age, the oldest samples from this specimen correspond to 1914. Extension rates were low $(1.3 \pm 0.4 \mathrm{~mm}$ $\mathrm{y}^{-1}$ ) for this species, which is growing at its northern-most extent due to low temperature tolerance (Figure 2). Similar extension rates were determined from ${ }^{228} \mathrm{Ra}$ and ${ }^{210} \mathrm{~Pb}$ decay for another North Carolina Solenastrea coral (Moore and Krishnaswami, 1972). Extension rates for Solenastrea corals from Everglades and Florida Bays, Florida, were approximately double those observed for the North Carolina specimen, likely due to the warmer sea surface temperatures (Smith et al., 1989; Swart et al., 1999). 
A five-year running average reveals multi-decadal peaks in the extension rate were centered around 1929,1949, 1962, 1974 and 1990. This pattern is not coherent with mean yearly sea surface temperatures or the Atlantic multidecadal oscillation (AMO), another SST parameter for this region (not shown).

Strontium/calcium, $\mathrm{Mg} / \mathrm{Ca}$ and $\mathrm{U} / \mathrm{Ca}$ displayed linear relationships, as predicted based on their temperature dependent partitioning between aragonite and seawater (Figure 3) (Cohen and Gaetani, 2010). Barium/calcium however, did not covary with the other elemental ratios. The $\mathrm{Ba} / \mathrm{Ca}$ record does show variability with typical baseline values of 6 and peaks of $12 \mu \mathrm{mol} \mathrm{mol}^{-1}$ (Figure 4). Thus we hypothesized that the $\mathrm{Ba} / \mathrm{Ca}$ record could potentially be influenced by dissolved Ba delivery to the coastal ocean via SGD.

To test the potential influence of changing water [Ba] (denotes dissolved concentration), we performed a similar analysis as described in Chapter 6, whereby we calculated the Rayleigh fractionation model predicted $\mathrm{Ba} / \mathrm{Ca}$ for a coral growing in a constant seawater [Ba] of $50 \mathrm{nmol} \mathrm{kg}^{-1}$ and [Ca] $10.28 \mathrm{mmol} \mathrm{kg}^{-1}$ and a $20 \%$ dilution of $\mathrm{Ba} / \mathrm{Ca}$ within the calcifying fluid (Figure 5). The Rayleigh predicted $\mathrm{Ba} / \mathrm{Ca}(7.4 \pm 0.9$, minimum 5.1, maximum $10.5 \mu \mathrm{mol} \mathrm{mol}^{-1}$ ) compared well with the Solenastrea $\mathrm{Ba} / \mathrm{Ca}$ $\left(7.4 \pm 1.6\right.$, minimum 4.3, maximum $\left.13.4 \mu \mathrm{mol} \mathrm{mol}^{-1}\right)$. However, the range of the coral $\mathrm{Ba} / \mathrm{Ca}$ was greater than predicted and the maximum values were higher.

To determine if there was any link between coral $\mathrm{Ba} / \mathrm{Ca}$ and environmental forcings, we subtracted the Rayleigh fractionation model estimated $\mathrm{Ba} / \mathrm{Ca}$ from the observed $\mathrm{Ba} / \mathrm{Ca}$ (Figure 6). We then compared this residual with groundwater level and 
precipitation records from Chapel Hill, $\mathrm{NC}$ and the mean sea level anomaly from Wilmington, NC. These records extend to 1948, 1947 and 1935 respectively. Elevated precipitation and groundwater levels (relative to mean sea level) are both expected to drive a greater flux of terrestrial groundwater discharge and potentially more groundwater [Ba] from this source $\left(25-2,000 \mathrm{nmol} \mathrm{kg}^{-1}\right.$ (Shaw et al., 1998)). The relationship between MSL changes and $\mathrm{Ba}$ export has additional complexities. In Chapter 2, I demonstrated that the groundwater Ba flux may be decoupled from total SGD. This is due to two factors. Variability in the marine groundwater end member arises due to sorption/desorption cycles tied to the location of the mixing zone, which responds to changes in MSL such that low MSL results in sorption and low [Ba], while high MSL causes Ba desorption and high concentrations (500-2,000 $\mathrm{nmol} \mathrm{kg}^{-1}$ (Shaw et al., 1998)). At the same time, MSL largely controls total marine recharge and subsequent discharge. Translating the results of Chapter 2 to this location, we would anticipate a greater flux of [Ba] due to terrestrial groundwater during low MSL, but a greater flux associated with marine groundwater during high MSL.

The residual coral $\mathrm{Ba} / \mathrm{Ca}$ peaks generally correspond to high $\mathrm{MSL}$ anomalies (Figure 6). This may perhaps be interpreted as a dominance of marine groundwater exchange during these periods. However, there is also some agreement between precipitation and groundwater level records, indicating terrestrial Ba loading may be recorded in this coral specimen. To further utilize this coral $\mathrm{Ba} / \mathrm{Ca}$ record as an environmental proxy, a better constraint on the coral age model is needed, as well as 
further consideration of the sources of Ba to Onslow Bay and potential constraints on expected water column [Ba] temporal variability. 


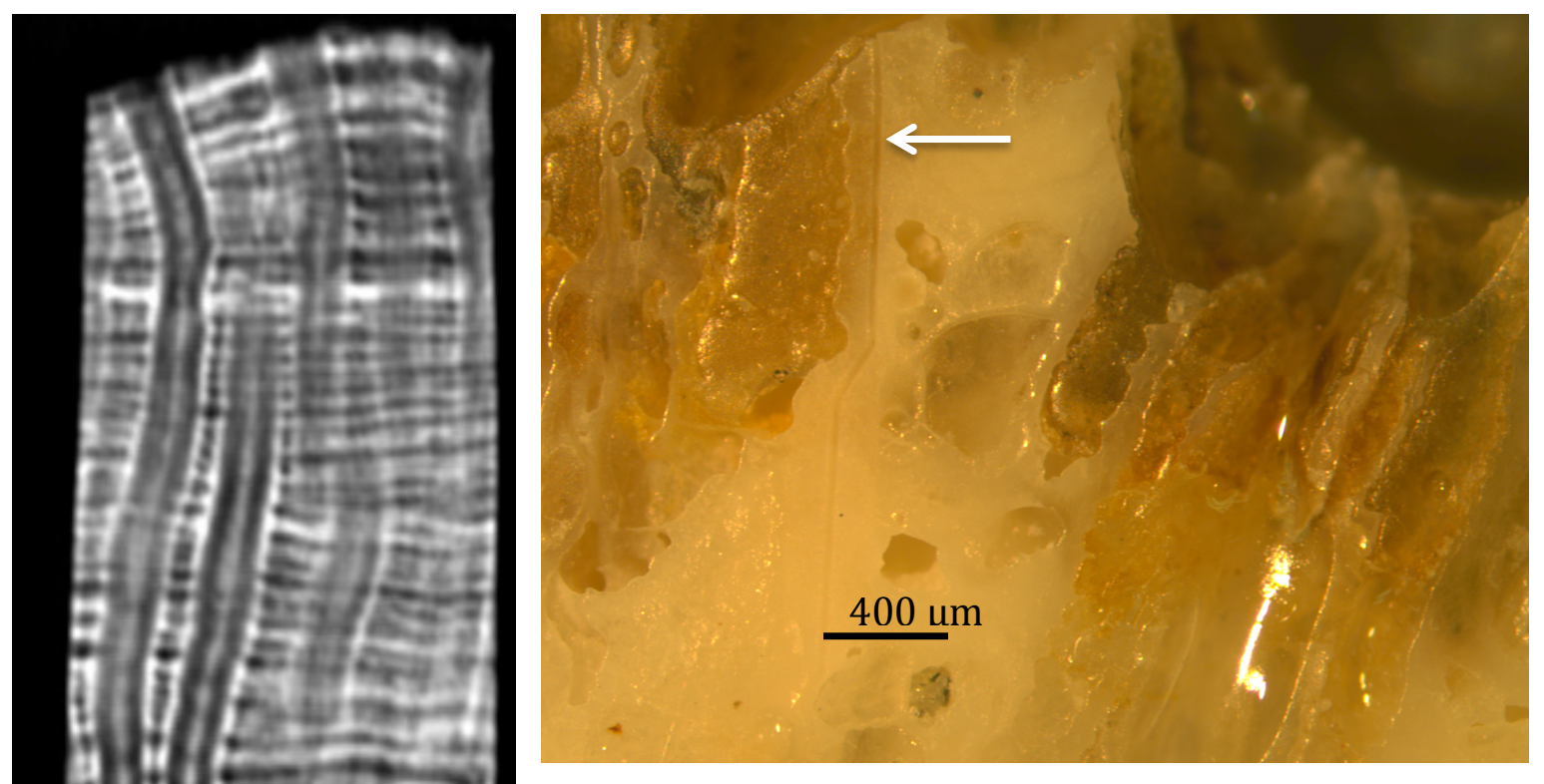

Figure 1: CT image of Solenastrea slab. The white bands are high-density layers and were used to construct an age model for this coral. The base age was determined to be 1914. The laser track is indicated by the arrow in the above photo. 


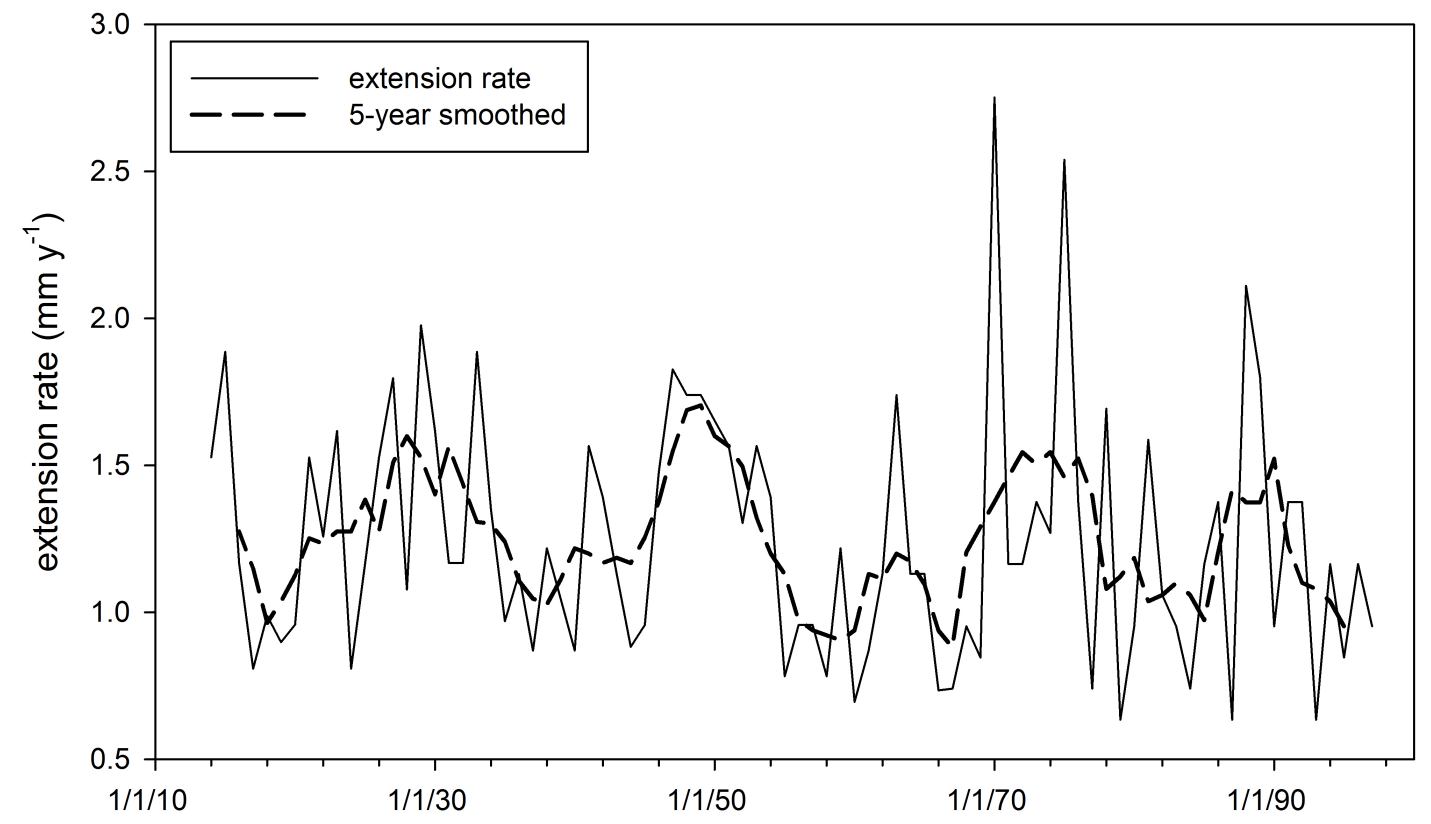

Figure 2: Extension rate for North Carolina Solenastrea and 5-year smoothed trace. 

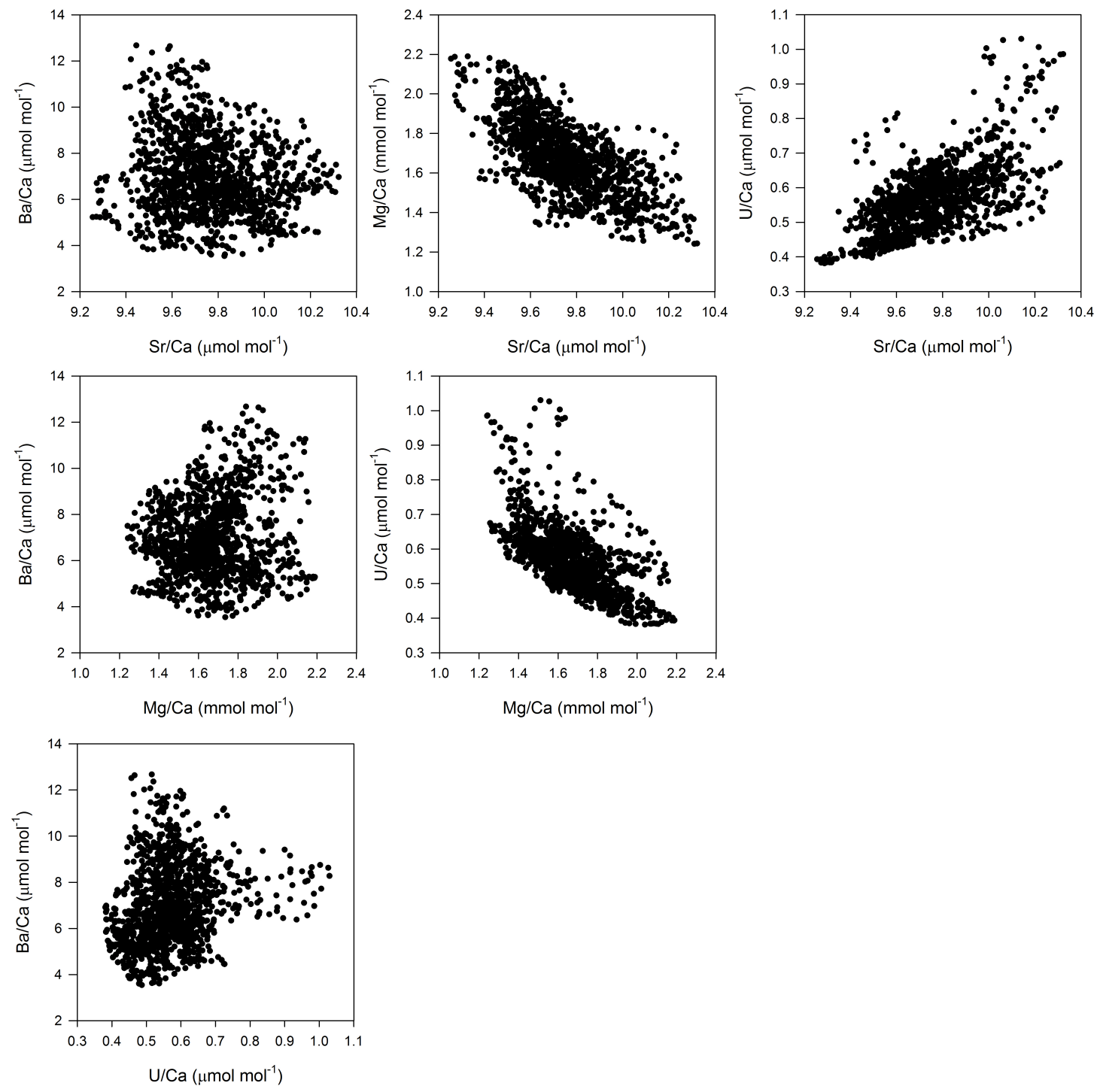

Figure 3: $\mathrm{Ba} / \mathrm{Ca}, \mathrm{Mg} / \mathrm{Ca}, \mathrm{Sr} / \mathrm{Ca}$ and $\mathrm{U} / \mathrm{Ca}$ relationships in a Solenastrea coral from Onslow Bay, North Carolina. $\mathrm{Mg} / \mathrm{Ca}, \mathrm{Sr} / \mathrm{Ca}$ and $\mathrm{U} / \mathrm{Ca}$ display the expected temperature dependent relationship, while $\mathrm{Ba} / \mathrm{Ca}$ is not correlated with any other element ratio. 

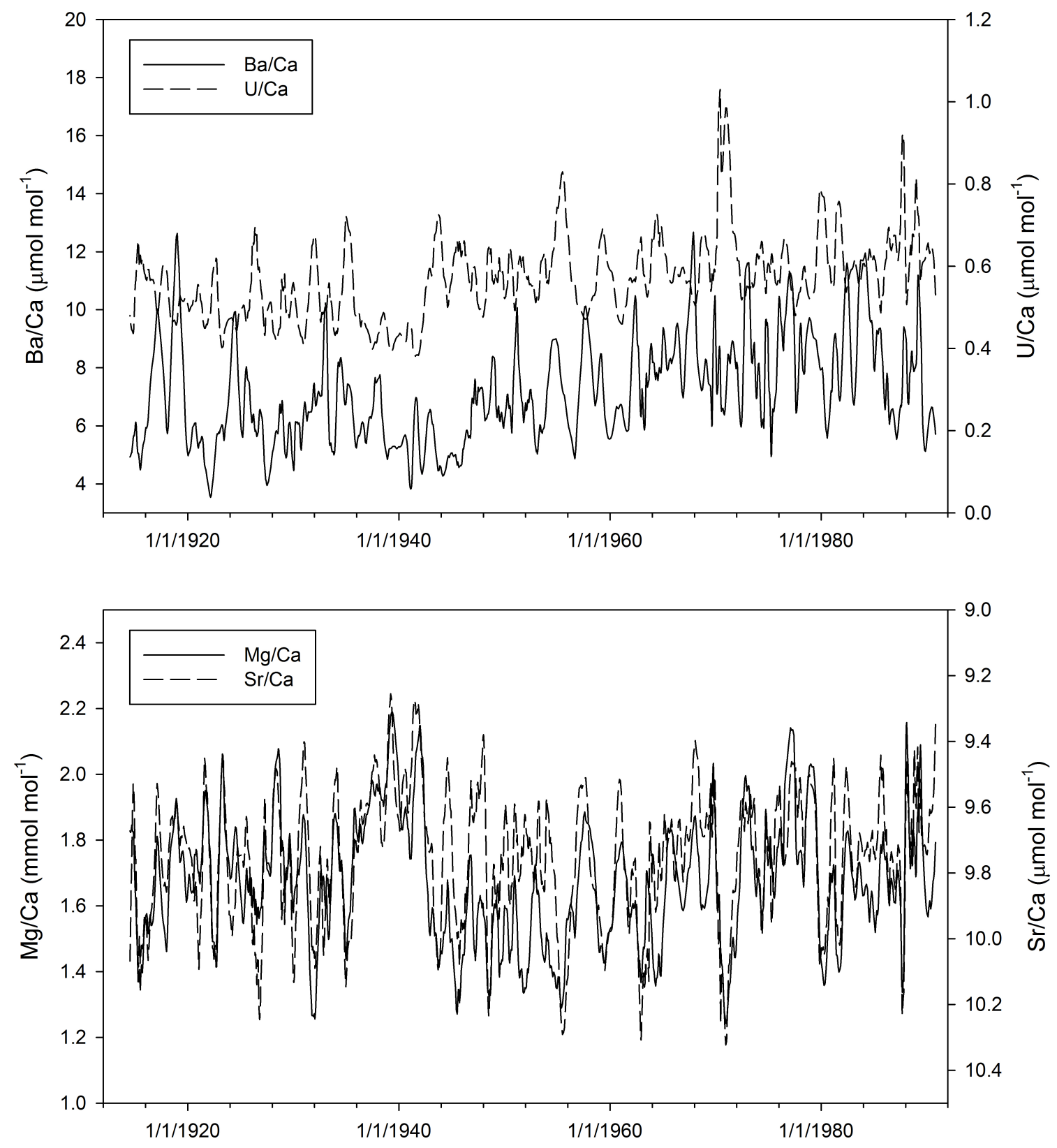

Figure 4: Eighty-year record of $\mathrm{Ba} / \mathrm{Ca}, \mathrm{U} / \mathrm{Ca}, \mathrm{Sr} / \mathrm{Ca}$ and $\mathrm{Mg} / \mathrm{Ca}$ for Solenastrea coral from Onslow Bay, North Carolina. $\mathrm{Sr} / \mathrm{Ca}$ and $\mathrm{Mg} / \mathrm{Ca}$ are inversely related (note inverse axis for $\mathrm{Sr} / \mathrm{Ca}$ ). 


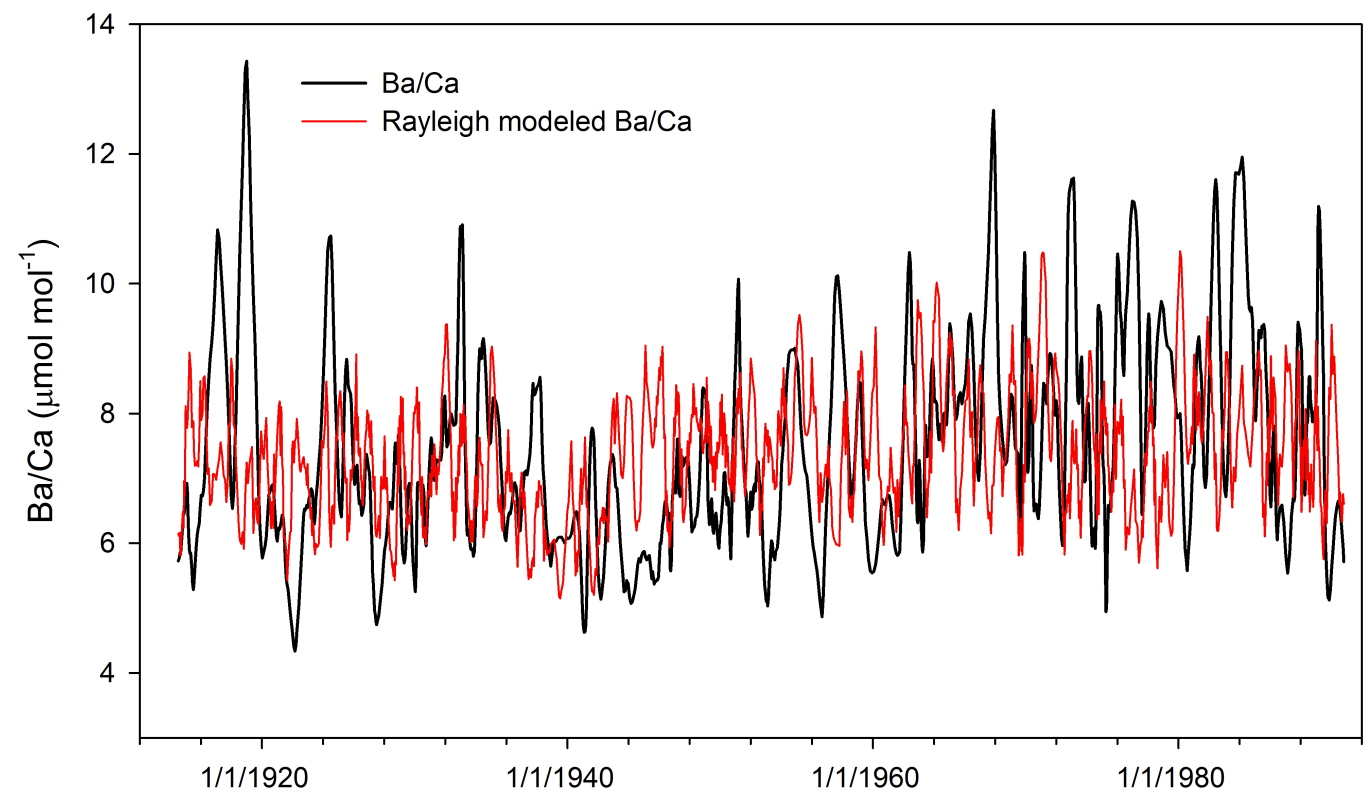

Figure 5: Measured Solenastrea $\mathrm{Ba} / \mathrm{Ca}$ and Rayleigh fractionation model predicted $\mathrm{Ba} / \mathrm{Ca}$ assuming constant seawater [Ba] of $50 \mathrm{nmol} \mathrm{kg}^{-1}$ and [Ca] $10.28 \mathrm{mmol} \mathrm{kg}^{-1}$ and a $20 \%$ dilution of $\mathrm{Ba} / \mathrm{Ca}$ within the calcifying fluid. The two records have a similar average and standard deviation, suggesting much of the $\mathrm{Ba} / \mathrm{Ca}$ variability is due to variability in the fraction precipitated. 

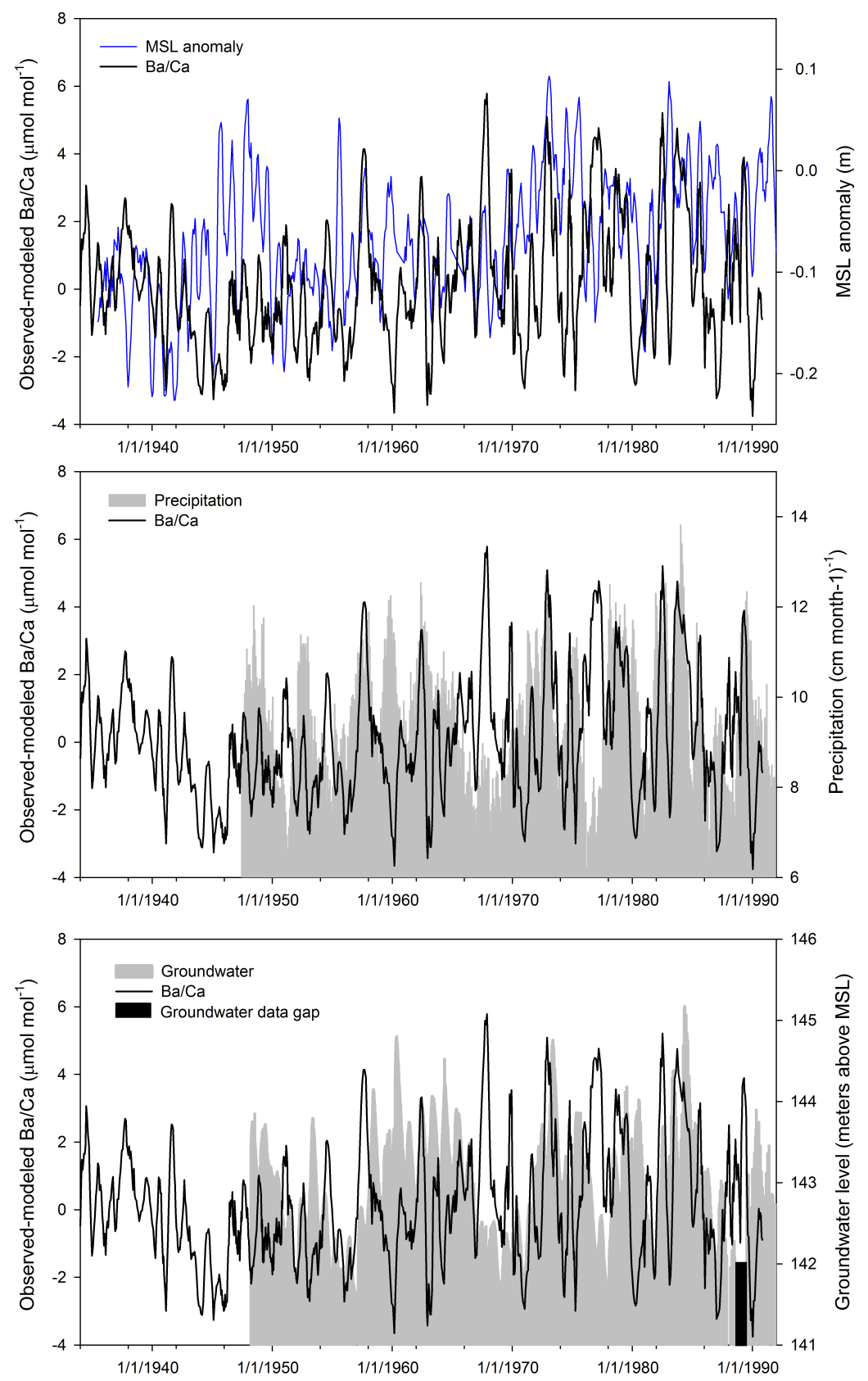

Figure 6: Mean sea level anomaly (top, Wilmington, NC), precipitation (middle), and groundwater (bottom) levels (Chapel Hill, NC) compared to the residual coral $\mathrm{Ba} / \mathrm{Ca}$ signal after the Rayleigh fractionation model $\mathrm{Ba} / \mathrm{Ca}$ has been subtracted from the coral $\mathrm{Ba} / \mathrm{Ca}$ record. Generally, $\mathrm{Ba} / \mathrm{Ca}$ aligns with positive $\mathrm{MSL}$ anomalies. Some peak $\mathrm{Ba} / \mathrm{Ca}$ values correspond to high precipitation events and elevated groundwater level. 


\section{References:}

Cantin, N.E., Cohen, A.L., Karnauskas, K.B., Tarrant, A.M., McCorkle, D.C., 2010. Ocean Warming Slows Coral Growth in the Central Red Sea. Science 329, 322-325.

Cohen, A.L., Gaetani, G.A., 2010. Ion Partitioning and the Geochemistry of Coral Skeletons: Solving the Mystery of the "Vital Effect", in: Prieto, M., Stoll, H. (Eds.), On partitioning in low temperature aqueous systems: from fundamentals to applications in climate proxies and environmental geochemistry. European Mineralogical Union, Notes in Mineralogy, v. 10.

Fallon, S.J., McCulloch, M.T., van Woesik, R., Sinclair, D.J., 1999. Corals at their latitudinal limits: laser ablation trace element systematics in Porites from Shirigai Bay, Japan. Earth Planet. Sci. Lett. 172, 221-238.

McCoy, C.A., Corbett, D.R., Cable, J.E., Spruill, R.K., 2007. Hydrogeological characterization of southeast coastal plain aquifers and groundwater discharge to Onslow Bay, North Carolina (USA). J. Hydrol. 339, 159-171.

Moore, W.S., 1996. Large groundwater inputs to coastal waters revealed by Ra-226 enrichments. Nature 380, 612-614.

Moore, W.S., Krishnaswami, S., 1972. Coral growth rates using 228-Ra and 210-Pb. Earth Planet. Sci. Lett. 15, 187-190.

Moore, W.S., Shaw, T.J., 1998. Chemical signals from submarine fluid advection onto the continental shelf. J. Geophys. Res.-Oceans 103, 21543-21552.

Riggs, S.R., Snyder, S.W., Hine, A.C., Mearns, D.L., 1996. Hardbottom morphology and relationship to the geologic framework: Mid-Atlantic continental shelf. Journal of Sedimentary Research 66, 830-846.

Shaw, T.J., Moore, W.S., Kloepfer, J., Sochaski, M.A., 1998. The flux of barium to the coastal waters of the southeastern USA: The importance of submarine groundwater discharge. Geochim. Cosmochim. Acta 62, 3047-3054.

Smith, T.J., Hudson, J.H., Robblee, M.B., Powell, G.V.N., Isdale, P.J., 1989. Fresh-water flow from the Everglades to Florida Bay - A historical reconstruction based on flourescent banding in the coral Solenastrea-bournoni Bulletin of Marine Science 44, 274-282.

Swart, P.K., Healy, G., Greer, L., Lutz, M., Saied, A., Anderegg, D., Dodge, R.E., Rudnick, D., 1999. The Use of Proxy Chemical Records in Coral Skeletons to Ascertain Past Environmental Conditions in Florida Bay. Estuaries 22, 384-397. 
Vasquez-Bedoya, L.F., Cohen, A.L., Oppo, D.W., Blanchon, P., 2012. Corals record persistent multidecadal SST variability in the Atlantic Warm Pool since 1775 AD. Paleoceanography 27, doi:10.1029/2012pa002313. 
Appendix B:

Porites coral record from Guam 
The island of Guam lies in the equatorial western Pacific Ocean. This region impacts meridional and zonal atmospheric heat transport and plays an important role in global climate (Wang and Enfield, 2001). A 200-year coral record from a massive Porites collected off Guam has shown multi-decadal variability in sea surface temperature and salinity (Asami et al., 2005). Guam is a karst platform lying atop older volcanic bedrock. Locally, submarine groundwater discharge to the coastal ocean has been observed (Gamble et al., 2003; Matson, 1993; Taborosi et al., 2013). Thus, this site was selected as a potential place to obtain a coral-based record of groundwater discharge. In June 2009, we collected coral cores from two coastal sites. One was within Tumon Bay (identified as $\left.\mathrm{TB}, 13.51016^{\circ} \mathrm{N} 144.79974^{\circ} \mathrm{E}\right)$, a shallow ( $<1 \mathrm{~m}$ at low tide) back reef lagoon, while the other two cores were collected on the northwest coast at Haputo Bay (Figure 1). One core was collected from $5 \mathrm{~m}$ (identified as $\mathrm{HO}, 13.68367^{\circ} \mathrm{N} 144.82944^{\circ} \mathrm{E}$ ), while a second was collected within the shallow back reef (identified as HI, $13.66092^{\circ} \mathrm{N} 144.83079^{\circ} \mathrm{E}$ ).

Age models were constructed from computerized tomography (CT) images of density banding in the coral cores as described in Chapter 6 and Appendix A (Cantin et al., 2010). Extension rates ranged from 6-16 $\mathrm{mm} \mathrm{y}^{-1}$. The base age for the cores was 1930 for HO, 1984 for TB and 1998 for HI. Only TB was analyzed for elemental ratios. Coral powder was drilled every millimeter along the growth axis, corresponding to approximately 0.75 to 2 months sampling resolution. This powder was dissolved in $5 \%$ nitric acid; the resulting solution was analyzed via ICP-MS at Woods Hole Oceanographic Institution, using the same standardization described in Chapter 6 and Appendix A for the laser ablation work. 
The extension rate of the deep dwelling $\mathrm{HO}$ core corresponds to the average annual sea surface temperature (ERSST, downloaded for $144^{\circ} \mathrm{E}, 10^{\circ} \mathrm{N}$ ). During periods of elevated SST, the coral extension rate is greater (Figure 2). The correspondence between extension rate and SST indicates that the $\mathrm{HO}$ core may potentially be useful for regional climate reconstruction (Alibert and Kinsley, 2008a, b). Extension rates for TB and $\mathrm{HI}$ increase with time, with TB showing $\sim 5$ year cycles in growth rate. It is interesting to note that the growth rate of TB has increased so dramatically $(\sim 300 \%)$ given the potential anthropogenic impact on Tumon Bay, which is a major tourist destination in Guam, over the same period. Drenkard et al. (2013) saw a 140\% increase in coral calcification rates with juvenile Favia fragum corals that were fed versus unfed (i.e. fed corals had energy stores derived from both direct consumption and from photosynthetic products of zooxanthelle) in aquaria rearing experiments (Drenkard et al., 2013). The nutrient delivery to Tumon Bay is likely dependent in part on groundwater transport, since terrestrial groundwater in this region has total dissolved nitrogen concentrations of up to $100 \mu \mathrm{M}$ (Matson, 1993, Figure 6). Such a link between growth rate and nutrient loading at this site bears further analysis.

Elemental ratios from the Tumon Bay core (TB) are shown in Figures 3 and 4 and provided in Table 1. Regressions between $\mathrm{Ba} / \mathrm{Ca}, \mathrm{Sr} / \mathrm{Ca}, \mathrm{Mg} / \mathrm{Ca}$ and $\mathrm{U} / \mathrm{Ca}$ reveal the expected relationship predicted by the temperature dependence of their respective partition coefficients. In particular, $\mathrm{Ba} / \mathrm{Ca}$ ratios were quite low $(2.3 \pm 0.07$, minimum 2.1 , maximum $2.6 \mu \mathrm{mol} \mathrm{mol}^{-1}$ ) in this Guam Porites record compared to the Yucatan Siderastrea Solenastrea $\left(8.3 \pm 2.5\right.$, minimum 4.0 , maximum $18.8 \mu \mathrm{mol} \mathrm{mol}^{-1}$, Chapter 6) 
and North Carolina Solenastrea $\left(7.4 \pm 1.6\right.$, minimum 4.3, maximum $13.4 \mu \mathrm{mol} \mathrm{mol}^{-1}$, Appendix A) records. We applied the Rayleigh fractionation model to determine whether the model constrained the observed $\mathrm{Ba} / \mathrm{Ca}$ record (Figure 5). The modeled $\mathrm{Ba} / \mathrm{Ca}$ amplitude generally agrees well with the observed range but underestimates the $\mathrm{Ba} / \mathrm{Ca}$ at times.

Upon examination of the groundwater, spring (actively discharging groundwater) and lagoon water chemistry, it is apparent why $[\mathrm{Ba}]$ is not enriched in this coral record (Figure 6). Groundwater [Ba] in June 2009 was 10-30 nmol kg-1, while offshore values

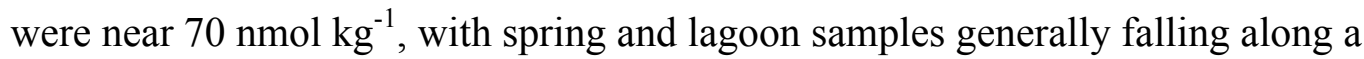
conservative mixing line between these two end members. Thus, the lagoon [Ba] is expected to be inversely related to groundwater discharge, as opposed to the other two sites (Yucatan and North Carolina) where groundwater discharge enriched the coastal ocean $[\mathrm{Ba}]$ over offshore values. In addition, precipitation is seasonal, with most rainfall occurring July through November (Jucson et al., 2002), when temperature is high. Thus a low $\mathrm{Ba} / \mathrm{Ca}$ ratio is expected in corals during the summer due to both the temperature dependence of $\mathrm{K}_{\mathrm{Ba}}$ and to the dilution of lagoon [Ba] with terrestrial groundwater discharge. Resolving an elemental cycle with low amplitude and absolute concentration would be difficult, and it is likely this coral $\mathrm{Ba} / \mathrm{Ca}$ record primarily reflects the temperature dependence of elemental partitioning into aragonite. This example demonstrates the need to constrain both the physics and chemistry of the system to develop an effective proxy. 

a.
b.

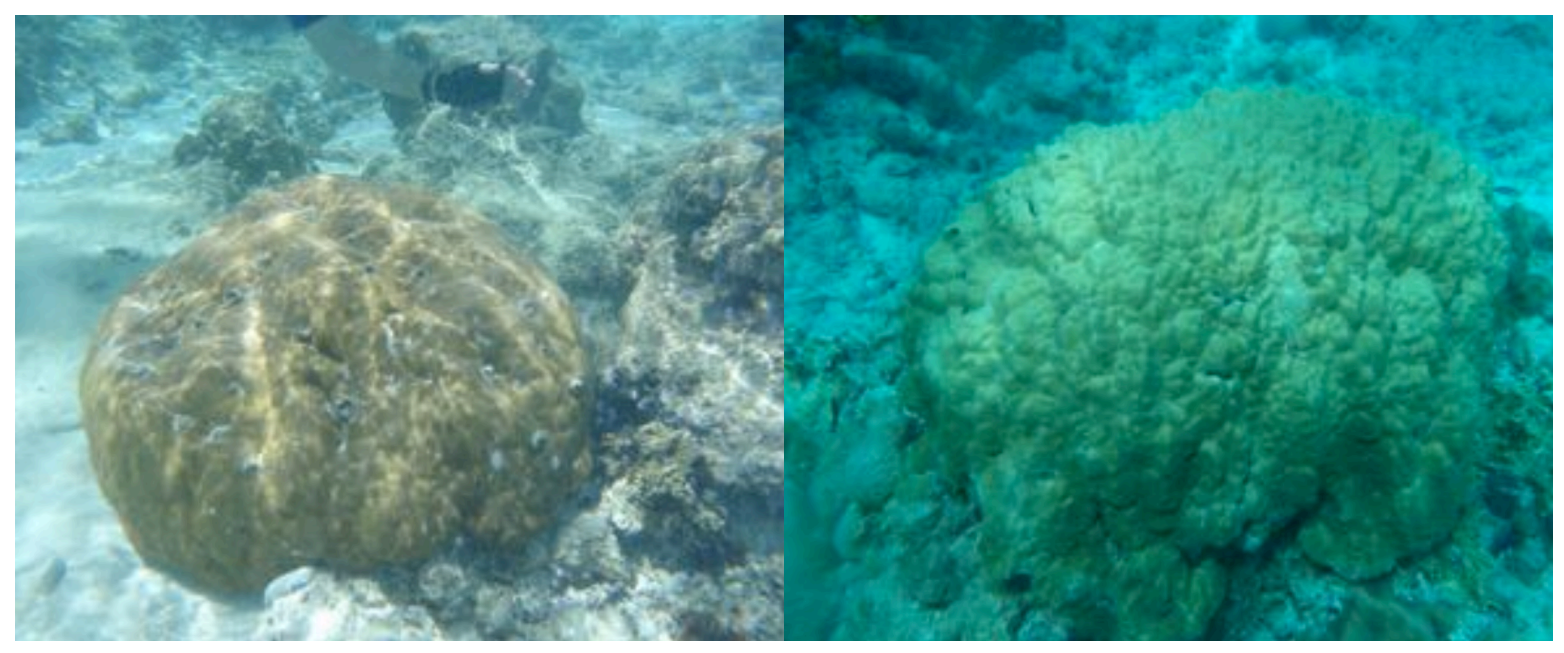

c.

Figure 1: Photos of Porites coral

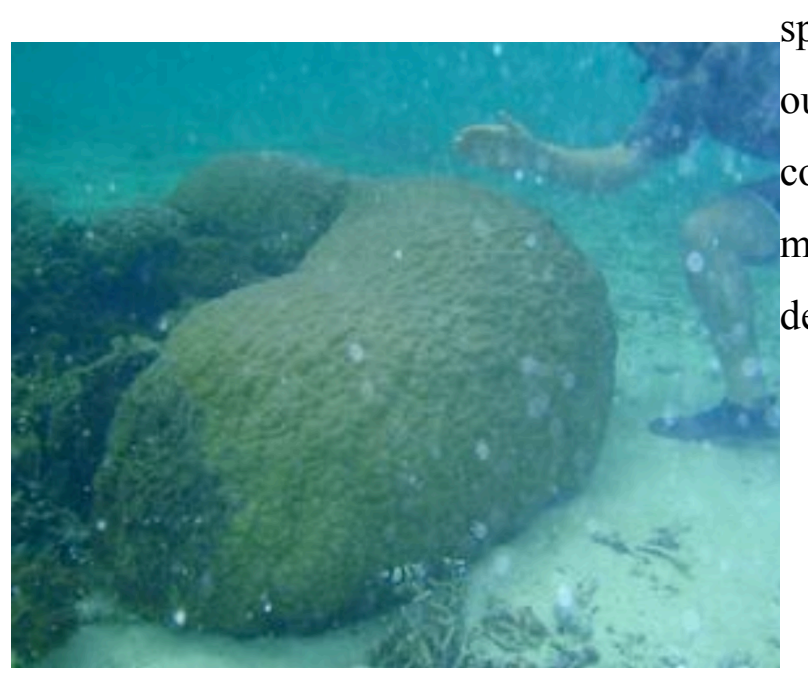

specimens from Haputo Bay inner (a), outer (b) and Tumon Bay (c) prior to coring. $\mathrm{HI}$ and $\mathrm{TB}$ were growing in $\sim 1$ meter of water, while $\mathrm{HO}$ was at $5 \mathrm{~m}$ water depth. 

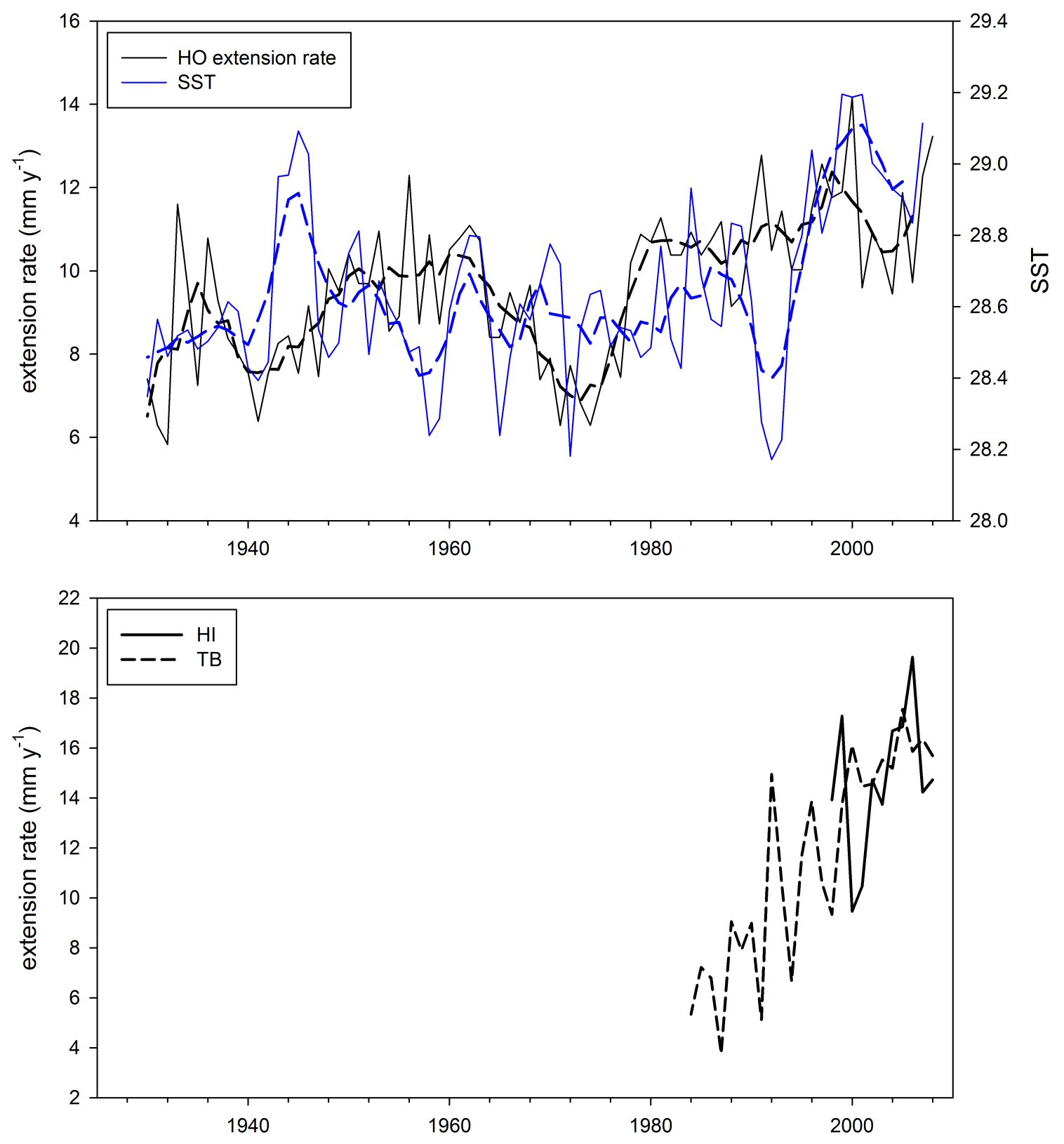

Figure 2: The extension rate of the longest core from Haputo Bay, Guam (HO) shows some similarity to yearly mean SST (Top). The two cores collected within Haputo and Tumon Bays both show a large increase in extension rate from 1990. 

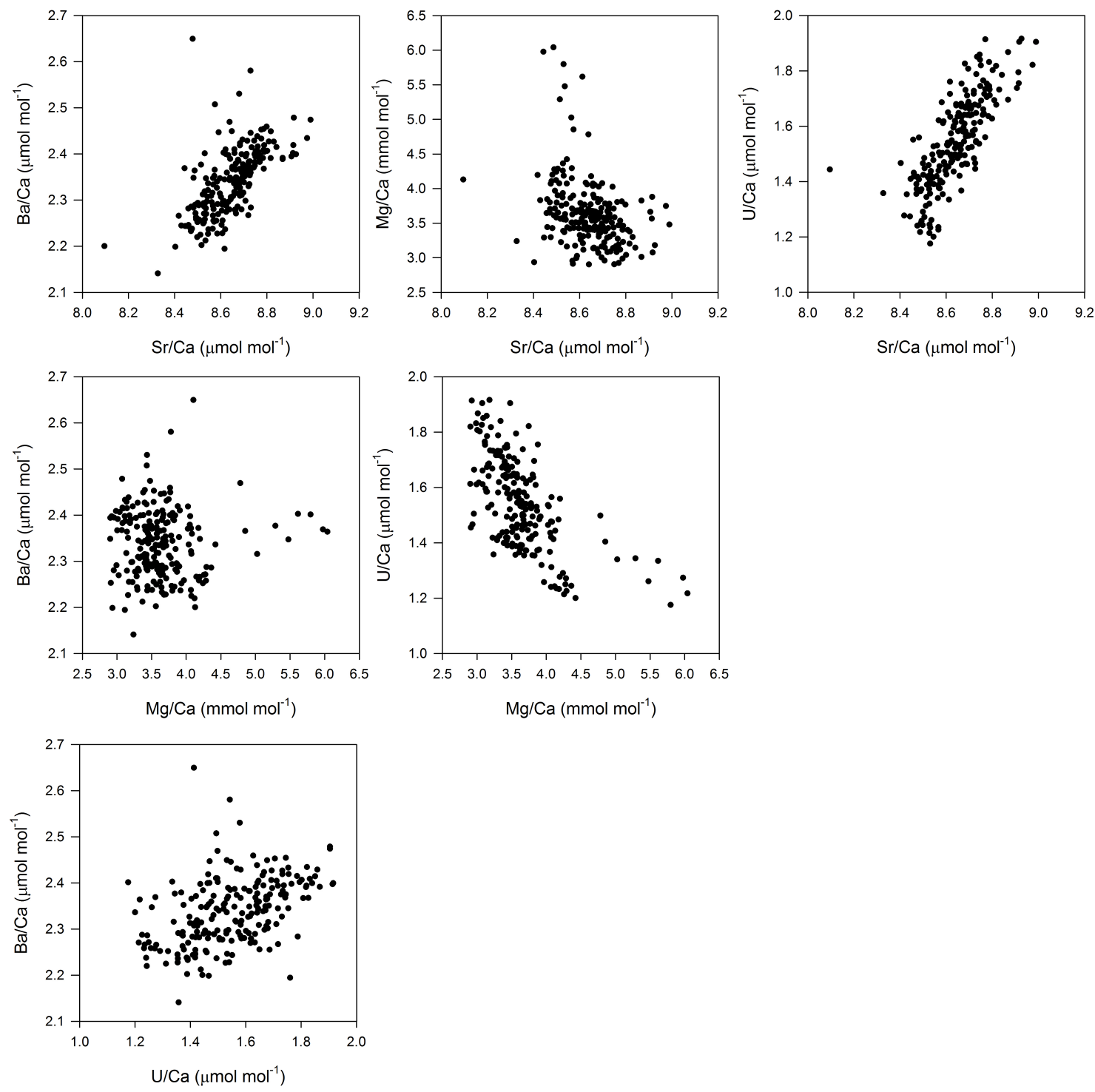

Figure 3: $\mathrm{Ba} / \mathrm{Ca}, \mathrm{Mg} / \mathrm{Ca}, \mathrm{Sr} / \mathrm{Ca}$ and $\mathrm{U} / \mathrm{Ca}$ relationships in a Porites coral from Tumon Bay, Guam. All elemental ratios display the expected temperature dependent relationship. 

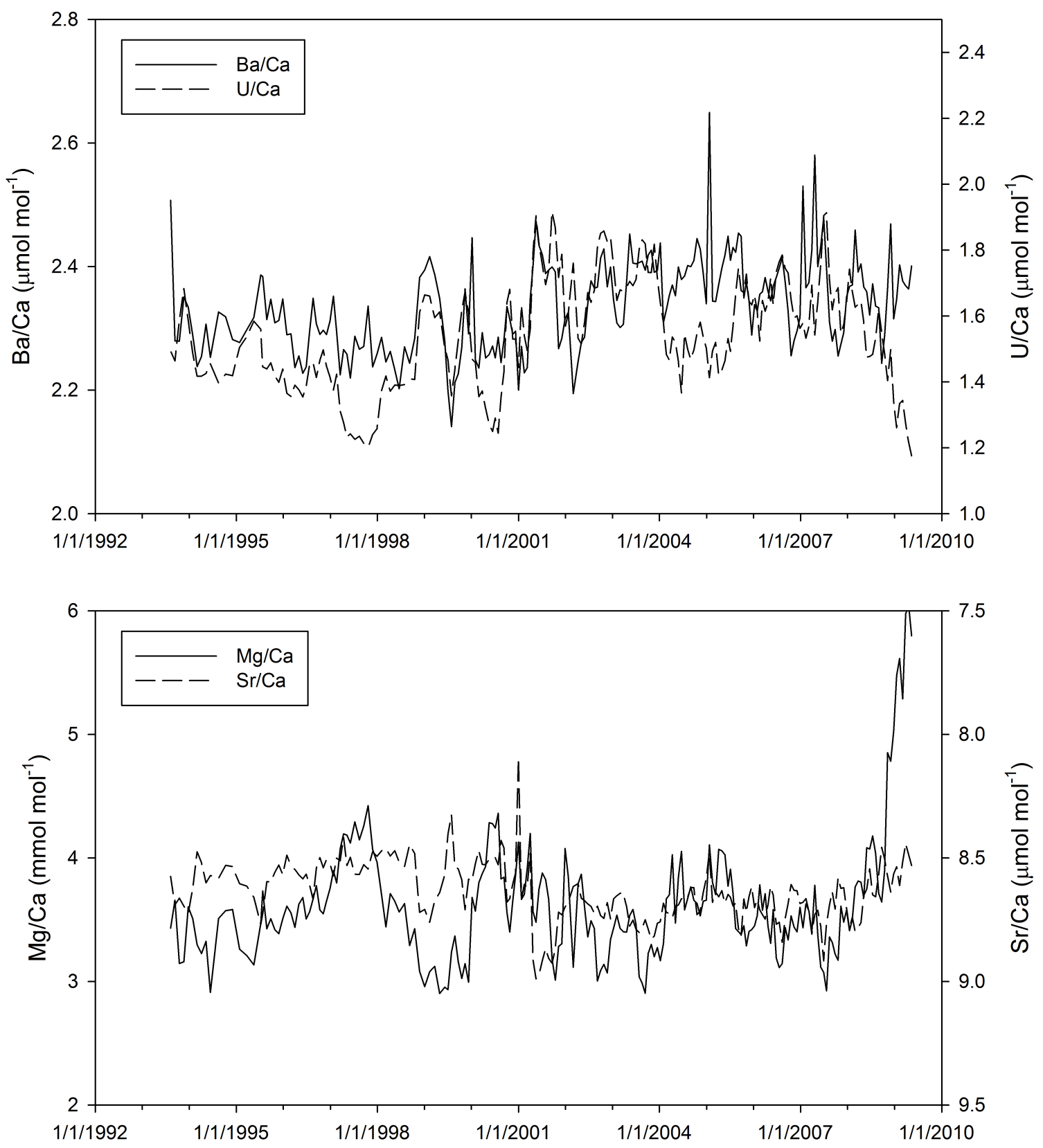

Figure 4: Sixteen-year record of $\mathrm{Ba} / \mathrm{Ca}, \mathrm{U} / \mathrm{Ca}, \mathrm{Sr} / \mathrm{Ca}$ and $\mathrm{Mg} / \mathrm{Ca}$ for Tumon Bay (Guam) Porites coral. $\mathrm{Sr} / \mathrm{Ca}$ and $\mathrm{Mg} / \mathrm{Ca}$ are inversely related (note inverse axis for $\mathrm{Sr} / \mathrm{Ca}$ ) while $\mathrm{Ba} / \mathrm{Ca}$ and $\mathrm{U} / \mathrm{Ca}$ are positively correlated. 


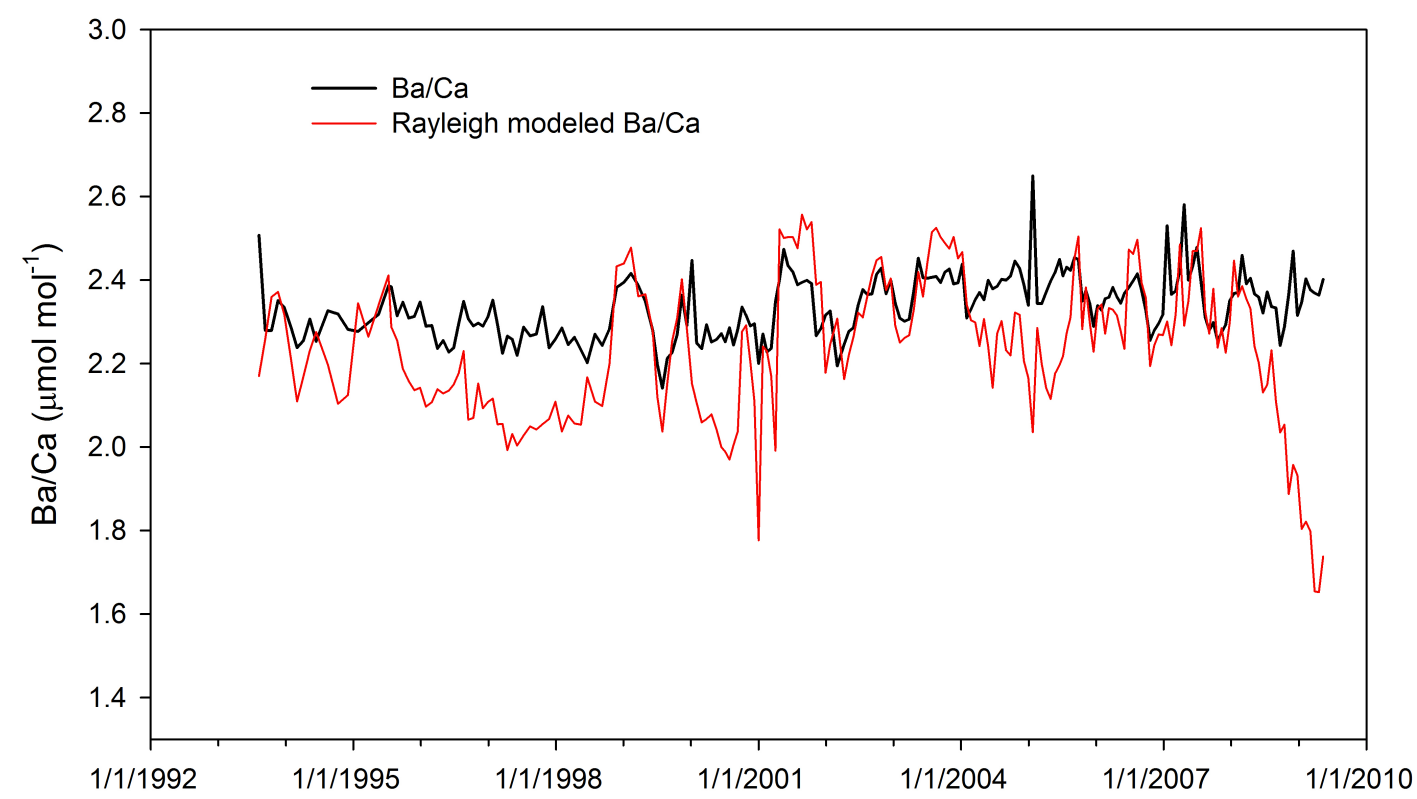

Figure 5: Tumon Bay Porites coral $\mathrm{Ba} / \mathrm{Ca}$ and Rayleigh fractionation predicted coral $\mathrm{Ba} / \mathrm{Ca}$ ratio assuming constant seawater [Ba] of $40 \mathrm{nmol} \mathrm{kg}^{-1}$ and [Ca] $10.28 \mathrm{mmol} \mathrm{kg}^{-1}$ and a three-fold dilution of $\mathrm{Ba} / \mathrm{Ca}$ within the calcifying fluid. The beginning of the modeled record clearly is impacted by the anomalously high $\mathrm{Mg} / \mathrm{Ca}$, which influenced the FL calculation. The modeled $\mathrm{Ba} / \mathrm{Ca}$ generally corresponds quite well to the coral $\mathrm{Ba} / \mathrm{Ca}$. 

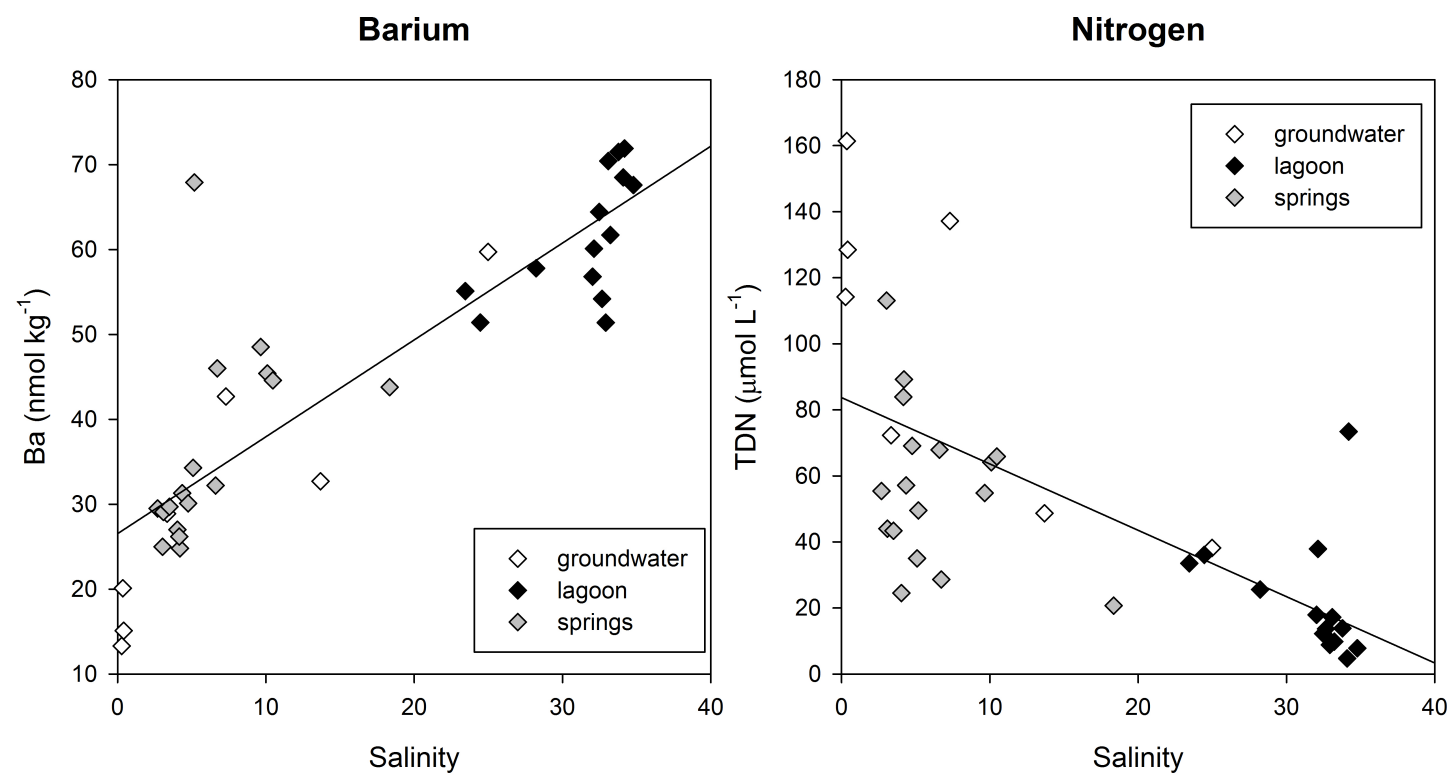

Figure 6: Barium and nitrogen concentrations in groundwater, spring and lagoon samples. Barium concentrations are clearly low in these groundwater samples, with a low salinity, low Ba input effectively diluting higher offshore concentrations during mixing in the lagoon. In contrast, total dissolved nitrogen concentrations are higher in groundwater, with lagoon waters behaving somewhat conservatively during mixing. Lagoon TDN values are quite high (3-30 $\left.\mu \mathrm{mol} \mathrm{L}^{-1}\right)$ for surface waters. Linear regressions of all data are indicated by solid lines. 


\begin{tabular}{|c|c|c|c|c|c|}
\hline $\begin{array}{c}\text { Distance } \\
\mathrm{mm} \\
\end{array}$ & Date & $\begin{array}{c}\mathrm{Ba} / \mathrm{Ca} \\
\mathrm{umol} / \mathrm{mol}\end{array}$ & $\begin{array}{c}\mathrm{Mg} / \mathrm{Ca} \\
\mathrm{mmol} / \mathrm{mol}\end{array}$ & $\begin{array}{c}\mathrm{Sr} / \mathrm{Ca} \\
\mathrm{mmol} / \mathrm{mol}\end{array}$ & $\begin{array}{c}\mathrm{U} / \mathrm{Ca} \\
\mathrm{umol} / \mathrm{mol}\end{array}$ \\
\hline 2 & $5 / 12 / 09$ & 2.40 & 5.80 & 8.53 & 1.18 \\
\hline 3 & 4/19/09 & 2.36 & 6.04 & 8.49 & 1.22 \\
\hline 4 & 3/27/09 & 2.37 & 5.98 & 8.44 & 1.27 \\
\hline 5 & $3 / 4 / 09$ & 2.38 & 5.29 & 8.51 & 1.34 \\
\hline 6 & $2 / 8 / 09$ & 2.40 & 5.61 & 8.61 & 1.33 \\
\hline 7 & $1 / 16 / 09$ & 2.35 & 5.48 & 8.54 & 1.26 \\
\hline 8 & $12 / 24 / 08$ & 2.32 & 5.03 & 8.56 & 1.34 \\
\hline 9 & $12 / 1 / 08$ & 2.47 & 4.78 & 8.64 & 1.50 \\
\hline 10 & $11 / 7 / 08$ & 2.37 & 4.85 & 8.57 & 1.40 \\
\hline 11 & $10 / 15 / 08$ & 2.29 & 3.90 & 8.51 & 1.48 \\
\hline 12 & $9 / 22 / 08$ & 2.24 & 3.64 & 8.46 & 1.55 \\
\hline 13 & $8 / 30 / 08$ & 2.33 & 3.71 & 8.57 & 1.62 \\
\hline 14 & 8/6/08 & 2.34 & 4.04 & 8.66 & 1.53 \\
\hline 15 & $7 / 14 / 08$ & 2.37 & 4.18 & 8.65 & 1.48 \\
\hline 16 & $6 / 21 / 08$ & 2.32 & 4.07 & 8.54 & 1.48 \\
\hline 17 & $5 / 29 / 08$ & 2.36 & 4.08 & 8.63 & 1.48 \\
\hline 18 & $5 / 6 / 08$ & 2.37 & 3.68 & 8.65 & 1.58 \\
\hline 19 & $4 / 14 / 08$ & 2.40 & 3.80 & 8.76 & 1.65 \\
\hline 20 & $3 / 23 / 08$ & 2.39 & 3.81 & 8.78 & 1.64 \\
\hline 21 & 2/29/08 & 2.46 & 3.77 & 8.80 & 1.63 \\
\hline 22 & $2 / 7 / 08$ & 2.37 & 3.51 & 8.74 & 1.67 \\
\hline 23 & $1 / 16 / 08$ & 2.37 & 3.41 & 8.79 & 1.74 \\
\hline 24 & $12 / 24 / 07$ & 2.35 & 3.58 & 8.70 & 1.64 \\
\hline 25 & $12 / 2 / 07$ & 2.29 & 3.48 & 8.62 & 1.57 \\
\hline 26 & $11 / 10 / 07$ & 2.27 & 3.61 & 8.62 & 1.55 \\
\hline 27 & $10 / 19 / 07$ & 2.26 & 3.17 & 8.58 & 1.69 \\
\hline 28 & $9 / 26 / 07$ & 2.30 & 3.22 & 8.71 & 1.67 \\
\hline 29 & $9 / 4 / 07$ & 2.28 & 3.32 & 8.64 & 1.62 \\
\hline 30 & $8 / 13 / 07$ & 2.31 & 3.36 & 8.69 & 1.71 \\
\hline 31 & $7 / 21 / 07$ & 2.40 & 2.92 & 8.77 & 1.91 \\
\hline 32 & 6/29/07 & 2.48 & 3.07 & 8.92 & 1.90 \\
\hline 33 & $6 / 6 / 07$ & 2.43 & 3.12 & 8.78 & 1.75 \\
\hline 34 & $5 / 14 / 07$ & 2.40 & 3.38 & 8.71 & 1.64 \\
\hline 35 & $4 / 21 / 07$ & 2.58 & 3.78 & 8.73 & 1.54 \\
\hline 36 & 3/29/07 & 2.43 & 3.40 & 8.81 & 1.69 \\
\hline 37 & $3 / 6 / 07$ & 2.37 & 3.57 & 8.72 & 1.57 \\
\hline 38 & $2 / 11 / 07$ & 2.37 & 3.63 & 8.66 & 1.53 \\
\hline 39 & $1 / 19 / 07$ & 2.53 & 3.44 & 8.68 & 1.58 \\
\hline 40 & $12 / 27 / 06$ & 2.32 & 3.60 & 8.68 & 1.56 \\
\hline 41 & $12 / 4 / 06$ & 2.30 & 3.40 & 8.63 & 1.60 \\
\hline 42 & $11 / 11 / 06$ & 2.28 & 3.44 & 8.63 & 1.59 \\
\hline 43 & $10 / 19 / 06$ & 2.26 & 3.53 & 8.61 & 1.65 \\
\hline 44 & $9 / 26 / 06$ & 2.33 & 3.34 & 8.68 & 1.73 \\
\hline 45 & 9/3/06 & 2.38 & 3.44 & 8.75 & 1.74 \\
\hline 46 & $8 / 11 / 06$ & 2.41 & 3.14 & 8.84 & 1.79 \\
\hline 47 & $7 / 19 / 06$ & 2.40 & 3.11 & 8.76 & 1.77 \\
\hline 48 & $6 / 26 / 06$ & 2.38 & 3.19 & 8.77 & 1.73 \\
\hline 49 & $6 / 2 / 06$ & 2.37 & 3.58 & 8.65 & 1.63 \\
\hline 50 & $5 / 13 / 06$ & 2.34 & 3.31 & 8.62 & 1.72 \\
\hline 51 & $4 / 22 / 06$ & 2.36 & 3.45 & 8.69 & 1.64 \\
\hline 52 & 4/1/06 & 2.38 & 3.71 & 8.75 & 1.61 \\
\hline 53 & $3 / 11 / 06$ & 2.36 & 3.58 & 8.73 & 1.65 \\
\hline 54 & $2 / 18 / 06$ & 2.36 & 3.78 & 8.71 & 1.52 \\
\hline 55 & $1 / 29 / 06$ & 2.33 & 3.53 & 8.67 & 1.62 \\
\hline
\end{tabular}


Table 1: Guam Porites elemental ratios

\begin{tabular}{|c|c|c|c|c|c|}
\hline $\begin{array}{c}\text { Distance } \\
\text { mm }\end{array}$ & Date & $\begin{array}{c}\mathrm{Ba} / \mathrm{Ca} \\
\mathrm{umol} / \mathrm{mol}\end{array}$ & $\begin{array}{c}\mathrm{Mg} / \mathrm{Ca} \\
\mathrm{mmol} / \mathrm{mol}\end{array}$ & $\begin{array}{c}\mathrm{Sr} / \mathrm{Ca} \\
\mathrm{mmol} / \mathrm{mol}\end{array}$ & $\begin{array}{c}\mathrm{U} / \mathrm{Ca} \\
\mathrm{umol} / \mathrm{mol}\end{array}$ \\
\hline 56 & $1 / 8 / 06$ & 2.34 & 3.45 & 8.70 & 1.66 \\
\hline 57 & $12 / 18 / 05$ & 2.29 & 3.42 & 8.62 & 1.63 \\
\hline 58 & $11 / 27 / 05$ & 2.34 & 3.41 & 8.66 & 1.64 \\
\hline 59 & $11 / 6 / 05$ & 2.37 & 3.29 & 8.72 & 1.73 \\
\hline 60 & $10 / 17 / 05$ & 2.35 & 3.45 & 8.67 & 1.67 \\
\hline 61 & $9 / 26 / 05$ & 2.45 & 3.38 & 8.82 & 1.68 \\
\hline 62 & $9 / 5 / 05$ & 2.45 & 3.40 & 8.79 & 1.74 \\
\hline 63 & $8 / 15 / 05$ & 2.42 & 3.43 & 8.68 & 1.67 \\
\hline 64 & $7 / 25 / 05$ & 2.43 & 3.72 & 8.69 & 1.57 \\
\hline 65 & 7/5/05 & 2.41 & 3.91 & 8.66 & 1.49 \\
\hline 66 & $6 / 16 / 05$ & 2.45 & 3.77 & 8.65 & 1.53 \\
\hline 67 & $5 / 23 / 05$ & 2.42 & 4.03 & 8.68 & 1.46 \\
\hline 68 & $4 / 29 / 05$ & 2.40 & 4.06 & 8.63 & 1.44 \\
\hline 69 & 4/5/05 & 2.37 & 4.07 & 8.66 & 1.42 \\
\hline 70 & $3 / 12 / 05$ & 2.34 & 3.70 & 8.64 & 1.52 \\
\hline 71 & $2 / 16 / 05$ & 2.34 & 3.80 & 8.68 & 1.49 \\
\hline 72 & $1 / 23 / 05$ & 2.65 & 4.11 & 8.48 & 1.41 \\
\hline 73 & $12 / 30 / 04$ & 2.34 & 3.66 & 8.58 & 1.50 \\
\hline 74 & $12 / 6 / 04$ & 2.39 & 3.65 & 8.64 & 1.54 \\
\hline 75 & $11 / 12 / 04$ & 2.43 & 3.53 & 8.71 & 1.58 \\
\hline 76 & $10 / 18 / 04$ & 2.45 & 3.63 & 8.73 & 1.55 \\
\hline 77 & $9 / 24 / 04$ & 2.41 & 3.66 & 8.62 & 1.50 \\
\hline 78 & $8 / 31 / 04$ & 2.40 & 3.77 & 8.62 & 1.47 \\
\hline 79 & $8 / 7 / 04$ & 2.40 & 3.67 & 8.66 & 1.50 \\
\hline 80 & $7 / 14 / 04$ & 2.38 & 3.58 & 8.68 & 1.54 \\
\hline 81 & $6 / 20 / 04$ & 2.38 & 4.05 & 8.67 & 1.37 \\
\hline 82 & $5 / 27 / 04$ & 2.40 & 3.84 & 8.69 & 1.46 \\
\hline 83 & $5 / 4 / 04$ & 2.35 & 3.47 & 8.70 & 1.52 \\
\hline 84 & $4 / 10 / 04$ & 2.37 & 4.03 & 8.74 & 1.54 \\
\hline 85 & $3 / 18 / 04$ & 2.35 & 3.70 & 8.73 & 1.47 \\
\hline 86 & $2 / 23 / 04$ & 2.33 & 3.67 & 8.72 & 1.48 \\
\hline 87 & $1 / 31 / 04$ & 2.31 & 3.30 & 8.68 & 1.58 \\
\hline 88 & $1 / 7 / 04$ & 2.44 & 3.17 & 8.76 & 1.64 \\
\hline 89 & $12 / 15 / 03$ & 2.39 & 3.27 & 8.76 & 1.72 \\
\hline 90 & $11 / 21 / 03$ & 2.39 & 3.20 & 8.82 & 1.82 \\
\hline 91 & $10 / 29 / 03$ & 2.43 & 3.30 & 8.83 & 1.73 \\
\hline 92 & $10 / 5 / 03$ & 2.42 & 3.23 & 8.79 & 1.73 \\
\hline 93 & $9 / 12 / 03$ & 2.39 & 2.90 & 8.75 & 1.82 \\
\hline 94 & $8 / 19 / 03$ & 2.41 & 2.99 & 8.79 & 1.83 \\
\hline 95 & $7 / 27 / 03$ & 2.41 & 3.04 & 8.80 & 1.80 \\
\hline 96 & $7 / 3 / 03$ & 2.40 & 3.46 & 8.79 & 1.71 \\
\hline 97 & $6 / 9 / 03$ & 2.41 & 3.58 & 8.75 & 1.69 \\
\hline 98 & $5 / 15 / 03$ & 2.45 & 3.53 & 8.78 & 1.71 \\
\hline 99 & $4 / 20 / 03$ & 2.38 & 3.40 & 8.70 & 1.69 \\
\hline 100 & $3 / 26 / 03$ & 2.31 & 3.40 & 8.64 & 1.67 \\
\hline 101 & $3 / 1 / 03$ & 2.30 & 3.43 & 8.64 & 1.68 \\
\hline 102 & $2 / 4 / 03$ & 2.31 & 3.54 & 8.65 & 1.65 \\
\hline 103 & $1 / 10 / 03$ & 2.35 & 3.43 & 8.67 & 1.75 \\
\hline 104 & $12 / 16 / 02$ & 2.40 & 3.34 & 8.75 & 1.84 \\
\hline 105 & $11 / 21 / 02$ & 2.37 & 3.07 & 8.68 & 1.83 \\
\hline 106 & $10 / 26 / 02$ & 2.43 & 3.14 & 8.74 & 1.86 \\
\hline 107 & $10 / 1 / 02$ & 2.41 & 3.09 & 8.73 & 1.85 \\
\hline 108 & $9 / 6 / 02$ & 2.37 & 3.00 & 8.70 & 1.81 \\
\hline 109 & $8 / 12 / 02$ & 2.37 & 3.43 & 8.72 & 1.68 \\
\hline 110 & $7 / 18 / 02$ & 2.38 & 3.49 & 8.70 & 1.64 \\
\hline 111 & $6 / 23 / 02$ & 2.34 & 3.36 & 8.69 & 1.67 \\
\hline 112 & $5 / 29 / 02$ & 2.29 & 3.60 & 8.67 & 1.58 \\
\hline 113 & $5 / 4 / 02$ & 2.28 & 3.87 & 8.66 & 1.52 \\
\hline
\end{tabular}


Table 1: Guam Porites elemental ratios

\begin{tabular}{|c|c|c|c|c|c|}
\hline $\begin{array}{c}\text { Distance } \\
\mathbf{m m}\end{array}$ & Date & $\begin{array}{c}\mathrm{Ba} / \mathrm{Ca} \\
\mathrm{umol} / \mathrm{mol}\end{array}$ & $\begin{array}{c}\mathrm{Mg} / \mathrm{Ca} \\
\mathrm{mmol} / \mathrm{mol}\end{array}$ & $\begin{array}{c}\mathrm{Sr} / \mathrm{Ca} \\
\mathrm{mmol} / \mathrm{mol}\end{array}$ & $\begin{array}{c}\mathrm{U} / \mathrm{Ca} \\
\mathrm{umol} / \mathrm{mol}\end{array}$ \\
\hline 114 & $4 / 9 / 02$ & 2.25 & 3.79 & 8.60 & 1.53 \\
\hline 115.5 & $3 / 2 / 02$ & 2.19 & 3.11 & 8.62 & 1.76 \\
\hline 117 & $1 / 23 / 02$ & 2.33 & 3.85 & 8.68 & 1.61 \\
\hline 118 & $12 / 29 / 01$ & 2.32 & 4.08 & 8.70 & 1.56 \\
\hline 119 & $12 / 3 / 01$ & 2.28 & 3.31 & 8.73 & 1.79 \\
\hline 120 & $11 / 8 / 01$ & 2.27 & 3.28 & 8.72 & 1.72 \\
\hline 121 & $10 / 14 / 01$ & 2.39 & 3.01 & 8.87 & 1.87 \\
\hline 122 & $9 / 19 / 01$ & 2.40 & 3.18 & 8.93 & 1.92 \\
\hline 123 & $8 / 24 / 01$ & 2.39 & 3.66 & 8.91 & 1.74 \\
\hline 124 & $7 / 30 / 01$ & 2.39 & 3.83 & 8.87 & 1.70 \\
\hline 125 & 7/5/01 & 2.42 & 3.88 & 8.91 & 1.75 \\
\hline 126 & $6 / 9 / 01$ & 2.43 & 3.75 & 8.97 & 1.82 \\
\hline 127 & $5 / 17 / 01$ & 2.47 & 3.48 & 8.99 & 1.90 \\
\hline 128 & $4 / 24 / 01$ & 2.40 & 3.56 & 8.91 & 1.79 \\
\hline 129 & $4 / 2 / 01$ & 2.35 & 4.20 & 8.48 & 1.56 \\
\hline 130 & $3 / 10 / 01$ & 2.24 & 3.92 & 8.62 & 1.49 \\
\hline 131 & $2 / 15 / 01$ & 2.23 & 3.70 & 8.61 & 1.54 \\
\hline 132 & $1 / 24 / 01$ & 2.27 & 3.66 & 8.67 & 1.63 \\
\hline 133 & $1 / 1 / 01$ & 2.20 & 4.13 & 8.10 & 1.44 \\
\hline 134 & $12 / 9 / 00$ & 2.30 & 3.86 & 8.56 & 1.53 \\
\hline 135 & $11 / 17 / 00$ & 2.29 & 3.65 & 8.61 & 1.53 \\
\hline 136 & $10 / 25 / 00$ & 2.32 & 3.40 & 8.66 & 1.68 \\
\hline 137 & $10 / 3 / 00$ & 2.34 & 3.56 & 8.68 & 1.64 \\
\hline 138 & $9 / 10 / 00$ & 2.28 & 3.84 & 8.46 & 1.43 \\
\hline 139 & $8 / 18 / 00$ & 2.24 & 3.83 & 8.43 & 1.35 \\
\hline 140 & $7 / 27 / 00$ & 2.29 & 4.36 & 8.53 & 1.24 \\
\hline 141 & $7 / 4 / 00$ & 2.25 & 4.24 & 8.50 & 1.29 \\
\hline 142 & $6 / 13 / 00$ & 2.27 & 4.28 & 8.49 & 1.25 \\
\hline 143 & $5 / 18 / 00$ & 2.26 & 4.29 & 8.51 & 1.27 \\
\hline 144 & $4 / 21 / 00$ & 2.25 & 3.93 & 8.53 & 1.32 \\
\hline 145 & $3 / 25 / 00$ & 2.29 & 3.87 & 8.53 & 1.37 \\
\hline 146 & $2 / 28 / 00$ & 2.24 & 3.80 & 8.47 & 1.36 \\
\hline 147 & $2 / 1 / 00$ & 2.25 & 3.57 & 8.52 & 1.46 \\
\hline 148 & $1 / 6 / 00$ & 2.45 & 3.68 & 8.59 & 1.47 \\
\hline 149 & $12 / 10 / 99$ & 2.29 & 2.99 & 8.59 & 1.61 \\
\hline 150 & $11 / 13 / 99$ & 2.36 & 3.14 & 8.71 & 1.67 \\
\hline 151 & $10 / 18 / 99$ & 2.27 & 3.02 & 8.59 & 1.62 \\
\hline 152 & $9 / 21 / 99$ & 2.23 & 3.16 & 8.54 & 1.53 \\
\hline 153 & $8 / 26 / 99$ & 2.21 & 3.37 & 8.53 & 1.44 \\
\hline 154 & $7 / 30 / 99$ & 2.14 & 3.24 & 8.33 & 1.36 \\
\hline 155 & $7 / 3 / 99$ & 2.20 & 2.93 & 8.40 & 1.47 \\
\hline 156 & $6 / 8 / 99$ & 2.28 & 2.95 & 8.57 & 1.50 \\
\hline 157 & 4/30/99 & 2.35 & 2.90 & 8.64 & 1.61 \\
\hline 158 & $3 / 22 / 99$ & 2.39 & 3.12 & 8.68 & 1.59 \\
\hline 159 & $2 / 11 / 99$ & 2.42 & 3.08 & 8.76 & 1.66 \\
\hline 160 & $1 / 3 / 99$ & 2.39 & 2.96 & 8.71 & 1.66 \\
\hline 161 & $11 / 25 / 98$ & 2.38 & 3.08 & 8.72 & 1.61 \\
\hline 162 & $10 / 17 / 98$ & 2.28 & 3.43 & 8.48 & 1.41 \\
\hline 163 & $9 / 8 / 98$ & 2.24 & 3.29 & 8.45 & 1.41 \\
\hline 164 & $7 / 31 / 98$ & 2.27 & 3.63 & 8.54 & 1.39 \\
\hline 165 & $6 / 19 / 98$ & 2.20 & 3.56 & 8.52 & 1.39 \\
\hline 166 & $5 / 16 / 98$ & 2.23 & 3.65 & 8.47 & 1.39 \\
\hline 167 & $4 / 11 / 98$ & 2.26 & 3.71 & 8.49 & 1.37 \\
\hline 168 & $3 / 8 / 98$ & 2.25 & 3.44 & 8.46 & 1.42 \\
\hline 169 & $2 / 2 / 98$ & 2.29 & 3.70 & 8.47 & 1.37 \\
\hline 170 & $12 / 29 / 97$ & 2.26 & 3.97 & 8.49 & 1.26 \\
\hline 171 & $11 / 25 / 97$ & 2.24 & 4.07 & 8.47 & 1.24 \\
\hline 172 & $10 / 21 / 97$ & 2.34 & 4.42 & 8.54 & 1.20 \\
\hline 173 & $9 / 17 / 97$ & 2.27 & 4.26 & 8.53 & 1.21 \\
\hline
\end{tabular}


Table 1: Guam Porites elemental ratios

\begin{tabular}{|c|c|c|c|c|c|}
\hline $\begin{array}{c}\text { Distance } \\
\mathbf{m m}\end{array}$ & Date & $\begin{array}{c}\mathrm{Ba} / \mathrm{Ca} \\
\mathrm{umol} / \mathrm{mol}\end{array}$ & $\begin{array}{c}\mathrm{Mg} / \mathrm{Ca} \\
\mathrm{mmol} / \mathrm{mol}\end{array}$ & $\begin{array}{c}\mathrm{Sr} / \mathrm{Ca} \\
\mathrm{mmol} / \mathrm{mol}\end{array}$ & $\begin{array}{c}\mathrm{U} / \mathrm{Ca} \\
\mathrm{umol} / \mathrm{mol}\end{array}$ \\
\hline 174 & $8 / 14 / 97$ & 2.27 & 4.15 & 8.57 & 1.23 \\
\hline 175 & $7 / 10 / 97$ & 2.29 & 4.29 & 8.57 & 1.23 \\
\hline 176 & $6 / 5 / 97$ & 2.22 & 4.12 & 8.50 & 1.24 \\
\hline 177 & $5 / 9 / 97$ & 2.26 & 4.18 & 8.53 & 1.23 \\
\hline 178 & $4 / 13 / 97$ & 2.27 & 4.20 & 8.42 & 1.28 \\
\hline 179 & $3 / 18 / 97$ & 2.22 & 4.07 & 8.51 & 1.31 \\
\hline 180 & $2 / 19 / 97$ & 2.29 & 3.80 & 8.50 & 1.42 \\
\hline 181 & $1 / 24 / 97$ & 2.35 & 3.90 & 8.57 & 1.38 \\
\hline 182 & $12 / 29 / 96$ & 2.31 & 3.75 & 8.52 & 1.41 \\
\hline 183 & $12 / 2 / 96$ & 2.29 & 3.65 & 8.51 & 1.45 \\
\hline 184 & $11 / 6 / 96$ & 2.30 & 3.55 & 8.54 & 1.50 \\
\hline 185 & $10 / 11 / 96$ & 2.29 & 3.58 & 8.50 & 1.47 \\
\hline 186 & $9 / 14 / 96$ & 2.31 & 3.77 & 8.54 & 1.41 \\
\hline 187 & $8 / 19 / 96$ & 2.35 & 3.67 & 8.67 & 1.46 \\
\hline 188 & $7 / 24 / 96$ & 2.30 & 3.57 & 8.61 & 1.45 \\
\hline 189 & $6 / 27 / 96$ & 2.24 & 3.51 & 8.57 & 1.39 \\
\hline 190 & $6 / 1 / 96$ & 2.23 & 3.68 & 8.58 & 1.35 \\
\hline 191 & $5 / 1 / 96$ & 2.26 & 3.63 & 8.57 & 1.38 \\
\hline 192 & $3 / 31 / 96$ & 2.24 & 3.44 & 8.55 & 1.39 \\
\hline 193 & 2/29/96 & 2.29 & 3.56 & 8.53 & 1.36 \\
\hline 194 & $1 / 29 / 96$ & 2.29 & 3.61 & 8.49 & 1.37 \\
\hline 195 & $12 / 28 / 95$ & 2.35 & 3.51 & 8.57 & 1.44 \\
\hline 196 & $11 / 27 / 95$ & 2.31 & 3.39 & 8.53 & 1.40 \\
\hline 197 & $10 / 27 / 95$ & 2.31 & 3.42 & 8.56 & 1.42 \\
\hline 198 & $9 / 26 / 95$ & 2.35 & 3.51 & 8.60 & 1.46 \\
\hline 199 & $8 / 26 / 95$ & 2.31 & 3.43 & 8.60 & 1.44 \\
\hline 200 & $7 / 25 / 95$ & 2.38 & 3.73 & 8.73 & 1.45 \\
\hline 201 & $7 / 10 / 95$ & 2.39 & 3.47 & 8.77 & 1.56 \\
\hline 202 & $5 / 17 / 95$ & 2.32 & 3.13 & 8.66 & 1.58 \\
\hline 203 & $3 / 23 / 95$ & 2.30 & 3.21 & 8.61 & 1.54 \\
\hline 204 & $1 / 27 / 95$ & 2.28 & 3.26 & 8.60 & 1.51 \\
\hline 205 & $12 / 3 / 94$ & 2.28 & 3.58 & 8.54 & 1.42 \\
\hline 206 & $10 / 10 / 94$ & 2.32 & 3.57 & 8.53 & 1.42 \\
\hline 207 & $8 / 16 / 94$ & 2.33 & 3.51 & 8.58 & 1.40 \\
\hline 208 & $6 / 14 / 94$ & 2.25 & 2.91 & 8.57 & 1.45 \\
\hline 209 & $5 / 11 / 94$ & 2.31 & 3.33 & 8.60 & 1.43 \\
\hline 210 & $4 / 6 / 94$ & 2.25 & 3.23 & 8.52 & 1.42 \\
\hline 211 & $3 / 3 / 94$ & 2.24 & 3.30 & 8.47 & 1.42 \\
\hline 212 & $1 / 28 / 94$ & 2.29 & 3.51 & 8.62 & 1.49 \\
\hline 213 & $12 / 24 / 93$ & 2.33 & 3.60 & 8.72 & 1.59 \\
\hline 214 & $11 / 20 / 93$ & 2.35 & 3.16 & 8.70 & 1.68 \\
\hline 215 & $10 / 16 / 93$ & 2.28 & 3.15 & 8.66 & 1.58 \\
\hline 216 & $9 / 12 / 93$ & 2.28 & 3.66 & 8.69 & 1.46 \\
\hline 217 & $8 / 9 / 93$ & 2.51 & 3.43 & 8.57 & 1.49 \\
\hline
\end{tabular}




\section{References:}

Alibert, C., Kinsley, L., 2008a. A 170-year Sr/Ca and Ba/Ca coral record from the western Pacific warm pool: 1 . What can we learn from an unusual coral record? J. Geophys. Res.-Oceans, doi:10.1029/2006jc003979.

Alibert, C., Kinsley, L., 2008b. A 170-year Sr/Ca and Ba/Ca coral record from the western Pacific warm pool: 2. A window into variability of the New Ireland Coastal Undercurrent. J. Geophys. Res.-Oceans, doi:10.1029/2007jc004263.

Asami, R., Yamada, T., Iryu, Y., Quinn, T.M., Meyer, C.P., Paulay, G., 2005. Interannual and decadal variability of the western Pacific sea surface condition for the years 17872000: Reconstruction based on stable isotope record from a Guam coral. J. Geophys. Res.-Oceans, doi:10.1029/2004jc002555.

Cantin, N.E., Cohen, A.L., Karnauskas, K.B., Tarrant, A.M., McCorkle, D.C., 2010. Ocean Warming Slows Coral Growth in the Central Red Sea. Science 329, 322-325.

Drenkard, E.J., Cohen, A.L., McCorkle, D.C., Putron, S.J., Starczak, V.R., Zicht, A.E., 2013. Calcification by juvenile corals under heterotrophy and elevated CO2. Coral Reefs $32,727-735$.

Gamble, D.W., Taborosi, D., Mylroie, J.E., Jenson, J.W., Carew, J.L., Jocson, J.M.U., Mylroie, J., Vann, D.T., 2003. The use of water temperature to characterize groundwater discharge of a coastal fracture on Guam, USA. J. Coast. Res. 19, 462-471.

Jucson, J.M.U., Jenson, J.W. and Contractor, D.N., 2002. Recharge and aquifer response: Northern Guam Lens Aquifer, Guam, Mariana Islands. J. Hydro. 260, 231-254.

Matson, E.A., 1993. Nutrient flux through soils and aquifers to the coastal zone of Guam (Mariana Islands) Limnol. Oceanogr. 38, 361-371.

Taborosi, D., Jenson, J.W., Mylroie, J.E., 2013. Field Observations of Coastal Discharge from an Uplifted Carbonate Island Aquifer, Northern Guam, Mariana Islands: A Descriptive Geomorphic and Hydrogeologic Perspective. J. Coast. Res. 29, 926-943.

Wang, C.Z., Enfield, D.B., 2001. The tropical Western Hemisphere warm pool. Geophys. Res. Lett. 28, 1635-1638. 


\section{Appendix C:}

Subterranean estuary geochemical cycling in the Straits of Magellan 
To date there are no studies of submarine groundwater discharge in southernmost region of South America, nor any evaluation of geochemical cycling in the subterranean estuary. This is reflective of the general paucity of submarine groundwater discharge studies in high latitude regions. The Straits of Magellan bisect the southern tip of South America in a $500 \mathrm{~km}$ long waterway between the Pacific and Atlantic Oceans. In the eastern portion, the Straits are wide, narrowing down to $<10 \mathrm{~km}$ in the western portion. In addition, topography is steep with glaciated fjords dominating the western Strait, while elevation decreases and sandy glacial moraine deposits are more typical in the eastern portion. There is a steep east-west gradient in climate, with rainfall intensifying from the east (250-350 $\left.\mathrm{mm} \mathrm{y}^{-1}\right)$ to the west $\left(400-5,000 \mathrm{~mm} \mathrm{y}^{-1}\right)$.

A field campaign to the Straits of Magellan, Chile, took place January 28 through February 6, 2009. Samples were collected from a variety of environments (Figure 1). Groundwater samples were from the top two meters of the coastal aquifer. Estuarine samples were from various surface water mixing environments including fjords receiving glacial outflow and near river and stream mouths. Surface water samples were from the Straits of Magellan and all have a salinity $>30$.

Barium concentrations reveal a mid-salinity peak of $2000 \mathrm{nmol} \mathrm{kg}^{-1}$, compared to surface values of 40-45 nmol kg ${ }^{-1}$, a common feature in Ba cycling in subterranean estuaries (Figure 2, Table 1). Radium-226 is only slightly enriched in groundwater over surface values (70 compared to $10 \mathrm{dpm} 100 \mathrm{~L}^{-1}$, Figure 3). These low groundwater activities are likely reflective of low parent nuclide abundance in the host rock. Radium$228,{ }^{224} \mathrm{Ra}$ and ${ }^{223} \mathrm{Ra}$ groundwater activities (maximum 300,650 and $80 \mathrm{dpm} 100 \mathrm{~L}^{-1}$ ) are 


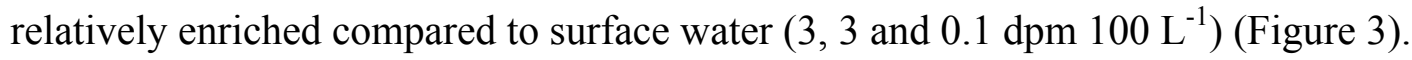
Uranium is removed from solution in reducing groundwater, likely via reduction of uranyl (VI) species to U(IV) resulting in precipitation of highly insoluble uranium minerals as discussed in Chapter 5. Strontium displays conservative behavior. The majority of groundwater samples had iron and manganese $0.1 \mu \mathrm{mol} / \mathrm{kg}$, with a few that exceeded $10 \mu \mathrm{mol} \mathrm{kg}{ }^{-1}$.

Nitrogen is present as both $\mathrm{NH}_{4}{ }^{+}$and $\mathrm{NO}_{3}{ }^{-}$in these groundwater samples (Figure 4). Ammonium concentrations are variable between detection (0.5) and $45 \mu \mathrm{mol} \mathrm{L}^{-1}$, while $\mathrm{NO}_{3}{ }^{-}$is generally less than 5 , with one outlier as high as $40 \mu \mathrm{mol} \mathrm{L} \mathrm{L}^{-1}$. Such low concentrations reflect the minimal anthropogenic inputs to this system. Dissolved organic nitrogen is quite high (up to $300 \mu \mathrm{mol} \mathrm{L}{ }^{-1}$ ) and is many times the largest dissolved nitrogen pool (maximum dissolved inorganic nitrogen is $50 \mu \mathrm{mol} \mathrm{L}^{-1}$ ). Phosphate is mostly $>1 \mu \mathrm{mol} \mathrm{L}^{-1}$, while silicate is elevated in groundwater $\left(50-450 \mu \mathrm{mol} \mathrm{L}^{-1}\right)$.

Given the above trace metal, radium and nutrient patterns, ${ }^{228} \mathrm{Ra}$ appears to be the long-lived radium isotope best suited to track groundwater discharge. The short-lived isotopes are also useful, however given the shallow depths ( $\sim 30 \mathrm{~m}$ in the eastern Strait), a benthic generated source is likely. There is a positive relationship between silicate and ${ }^{228} \mathrm{Ra}$ (Figure 5). DIN and DON are elevated in surface waters of this region, potentially indicative of nitrogen not being the limiting nutrient (common in high nutrient low chlorophyll regions). DIN and DON concentrations do not appear to covary with ${ }^{228} \mathrm{Ra}$, and thus a SGD source is not likely controlling the observed enrichment. 


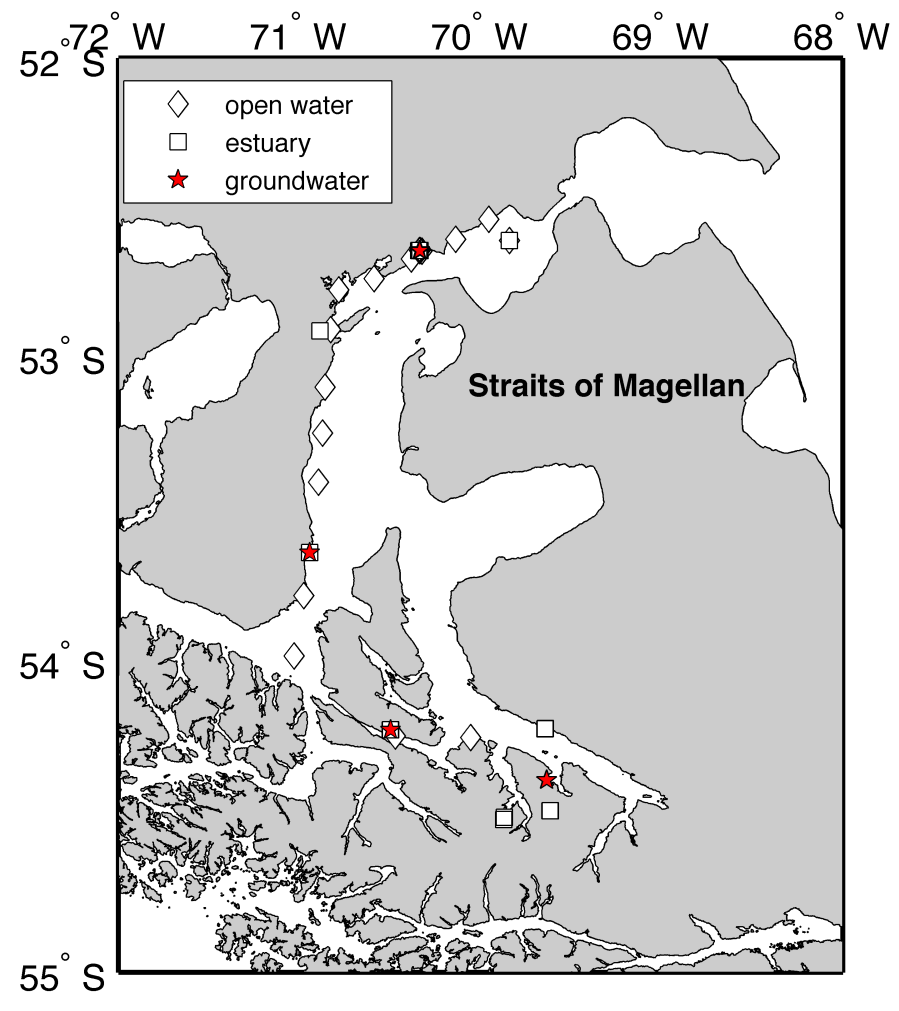

Figure 1: Sampling locations in the Straits of Magellan, Chile. 

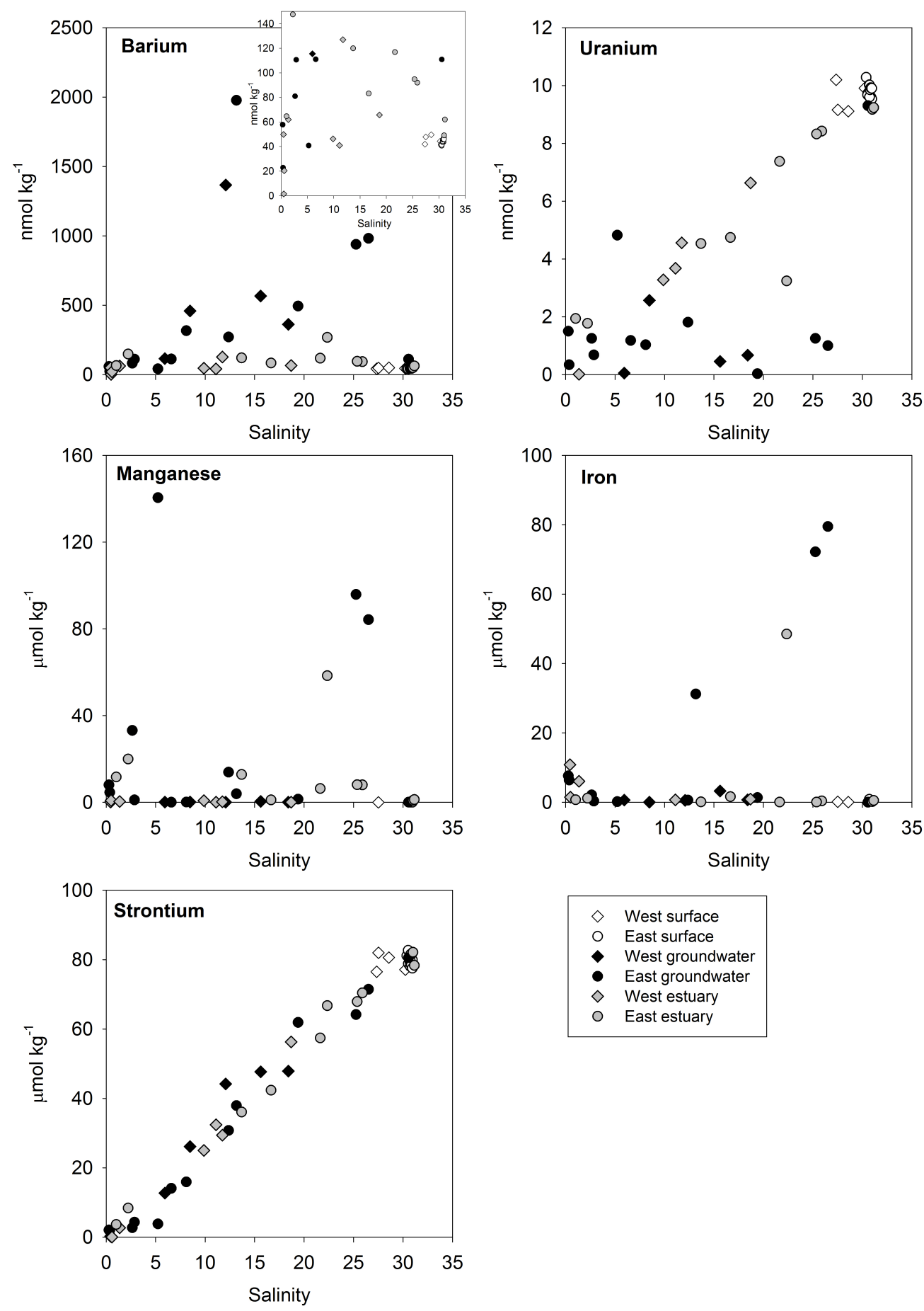

Figure 2: Barium, uranium, manganese, iron and strontium in groundwater, estuarine water and the surface waters of the Straits of Magellan, Chile. The inset shows barium in estuarine surface mixing samples. 

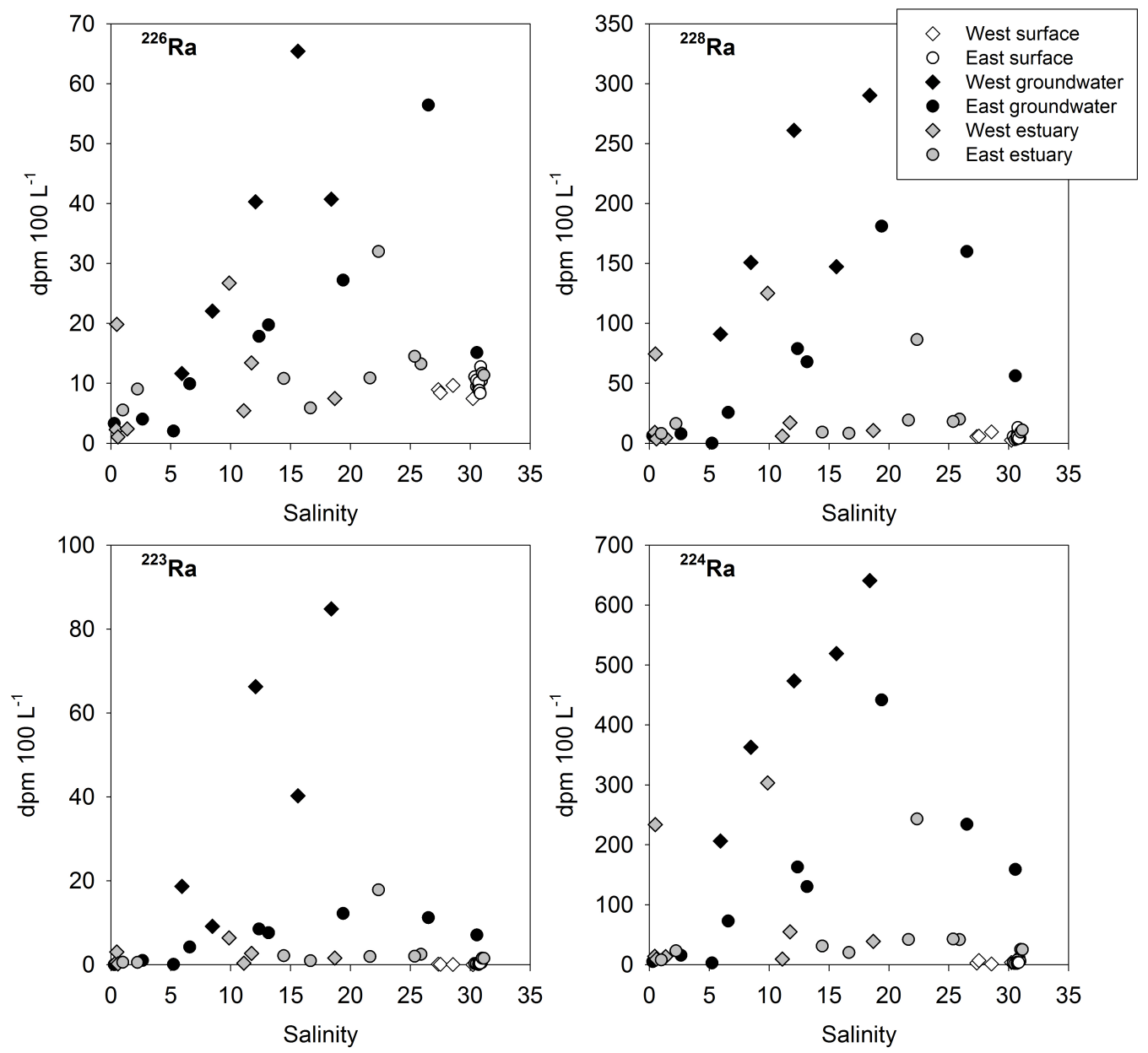

Figure 3: Radium-226, ${ }^{228} \mathrm{Ra},{ }^{223} \mathrm{Ra}$ and ${ }^{224} \mathrm{Ra}$ in groundwater, estuarine water and the surface waters of the Straits of Magellan, Chile. 

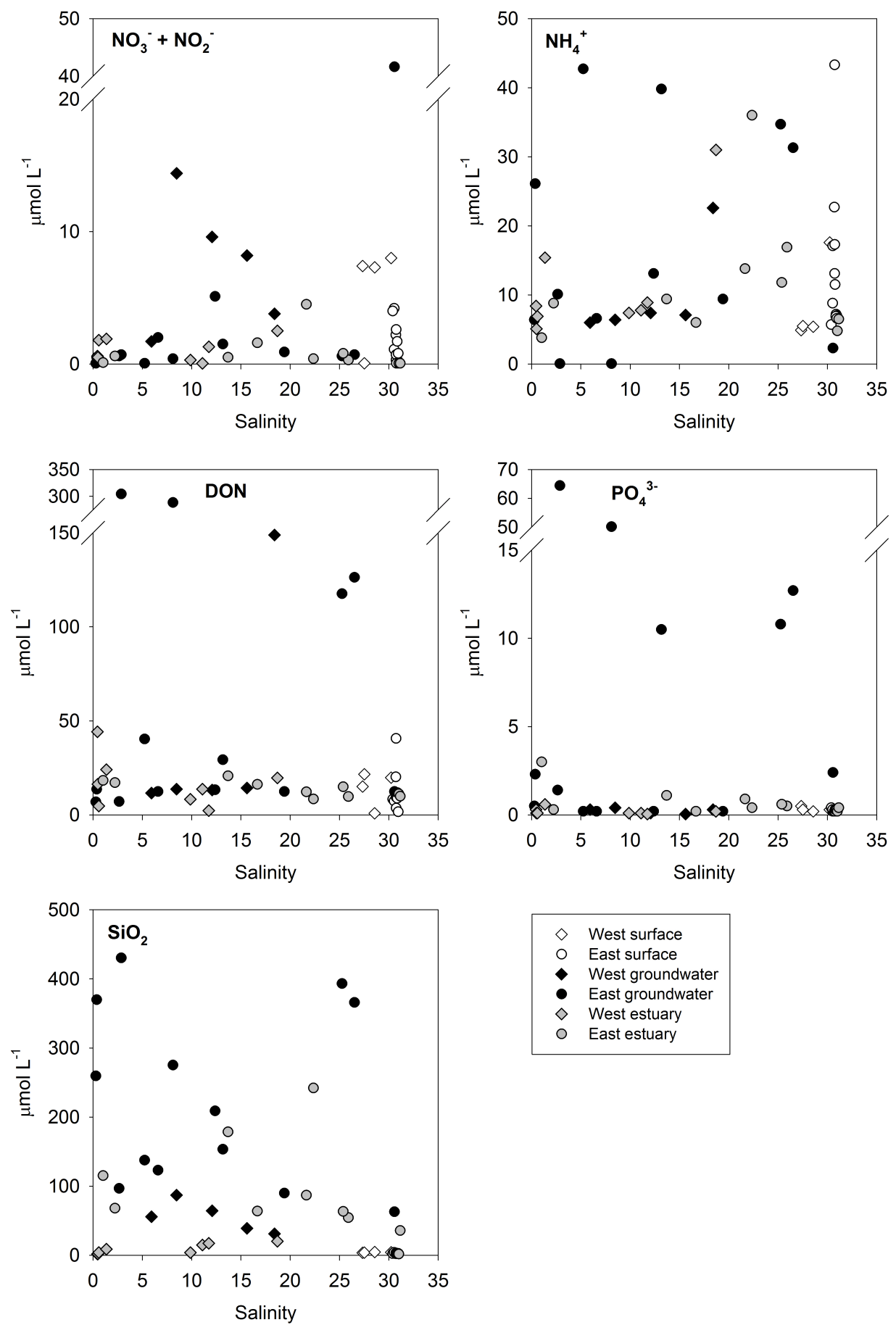

Figure 4: Nitrate, ammonium, dissolved organic nitrogen (DON), phosphate and silicate in groundwater, estuarine water and the surface waters of the Straits of Magellan, Chile. 

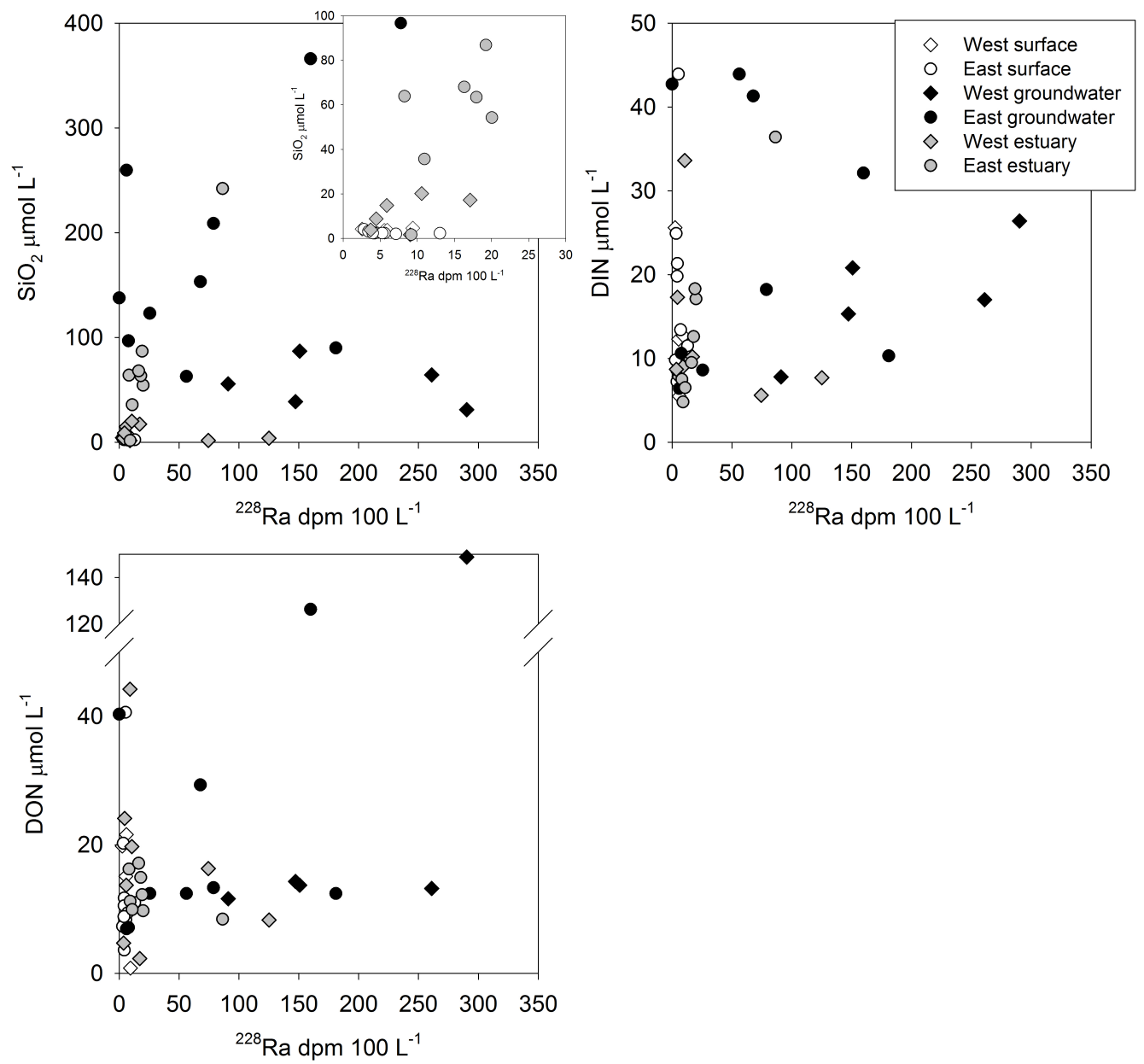

Figure 5: Silicate, dissolved inorganic nitrogen and dissolved organic nitrogen versus ${ }^{228} \mathrm{Ra}$ for all samples. Inset shows estuarine silicate and ${ }^{228} \mathrm{Ra}$ relationship. 
Table 1: Surface, groundwater and estuary samples from Straits of Magellan, Chile

\begin{tabular}{|c|c|c|c|c|c|c|c|c|c|}
\hline Sample Id & $\begin{array}{c}\text { Date and } \\
\text { Time }\end{array}$ & Latitude & Longitude & $\begin{array}{c}\text { Sample } \\
\text { Depth m }\end{array}$ & $\begin{array}{c}\text { 224Raex } \\
\text { dpm/100L }\end{array}$ & $\begin{array}{c}223 \mathrm{Ra} \\
\mathrm{dpm} / 100 \mathrm{~L}\end{array}$ & $\begin{array}{c}226 \mathrm{Ra} \\
\mathrm{dpm} / 100 \mathrm{~L}\end{array}$ & $\begin{array}{c}228 \mathrm{Ra} \\
\mathrm{dpm} / 100 \mathrm{~L}\end{array}$ & NH4 uM \\
\hline \multicolumn{10}{|c|}{ Fjord Surface samples } \\
\hline CL 001 & $1 / 27 / 09$ & -53.78945 & -70.97720 & 2 & 4 & bd & 7.5 & 2.6 & 17.6 \\
\hline CL 002 & $1 / 28 / 09$ & -53.98565 & -71.03040 & 2 & 3 & 0.1 & 9.0 & 5.6 & 4.9 \\
\hline CL 007 & $1 / 28 / 09$ & -54.24480 & -70.47113 & 2 & 7 & 0.1 & 8.4 & 6.0 & 5.5 \\
\hline CL 023 & $2 / 1 / 09$ & -54.25037 & -70.05550 & 2 & 1 & 0.1 & 9.7 & 9.4 & 5.4 \\
\hline \multicolumn{10}{|c|}{ Fjord groundwater samples } \\
\hline CL 005 & $1 / 28 / 09$ & -54.22528 & -70.49698 & 3 & 363 & 9.2 & 22 & 151 & 6.4 \\
\hline CL 015 & $1 / 30 / 09$ & -54.38720 & -69.63517 & 4 & 206 & 18.6 & 12 & 91 & 6.0 \\
\hline CL 016 & $1 / 31 / 09$ & -54.38708 & -69.63428 & 1 & 474 & 66.3 & 40 & 261 & 7.4 \\
\hline CL 017 & $1 / 31 / 09$ & -54.38710 & -69.63508 & 5 & 519 & 40.3 & 65 & 147 & 7.1 \\
\hline CL 019 & $1 / 31 / 09$ & -54.38710 & -69.63508 & 1 & 641 & 84.8 & 41 & 290 & 22.6 \\
\hline \multicolumn{10}{|c|}{ Fjord estuary samples } \\
\hline CL 004 & $1 / 28 / 09$ & -54.22515 & -70.49840 & & 9 & 0.3 & 5.4 & 5.9 & 7.8 \\
\hline CL 006 & $1 / 28 / 09$ & -54.22525 & -70.49670 & & 14 & 0.6 & 2.3 & 9.1 & 8.4 \\
\hline CL 008 & $1 / 29 / 09$ & -54.51378 & -69.87207 & & 234 & 3.0 & 20 & 75 & 5.1 \\
\hline CL 009 & $1 / 29 / 09$ & -54.50650 & -69.86805 & & 303 & 6.4 & 27 & 125 & 7.4 \\
\hline CL 012 & $1 / 30 / 09$ & -54.48583 & -69.61747 & & 9 & 0.2 & 1.1 & 3.7 & 6.9 \\
\hline CL 013 & $1 / 30 / 09$ & -54.48530 & -69.61548 & & 55 & 2.7 & 13 & 17 & 8.9 \\
\hline CL 021 & $1 / 31 / 09$ & -54.22120 & -69.64298 & 0 & 13 & bd & 2.4 & 4.5 & 15.4 \\
\hline CL 022 & $1 / 31 / 09$ & -54.22217 & -69.64397 & 0 & 39 & 1.6 & 7.5 & 10.6 & 31.0 \\
\hline \multicolumn{10}{|c|}{ Atlantic surface samples } \\
\hline CL 028 & $2 / 3 / 09$ & -53.41785 & -70.89643 & 2 & 2 & bd & 9.4 & 4.5 & 17.1 \\
\hline CL 029 & $2 / 3 / 09$ & -53.25600 & -70.87322 & & 3 & 0.3 & 11.1 & 5.6 & 5.7 \\
\hline CL 030 & $2 / 3 / 09$ & -53.10465 & -70.85952 & 1 & 2 & 0.2 & 10.5 & 2.8 & 8.8 \\
\hline CL 032 & $2 / 3 / 09$ & -52.91292 & -70.82765 & & 11 & 0.8 & 12.8 & 4.2 & 7.2 \\
\hline CL 034 & $2 / 4 / 09$ & -52.78075 & -70.78283 & 2 & 6 & 0.4 & 10.4 & 4.2 & 7.0 \\
\hline CL 035 & $2 / 4 / 09$ & -52.74387 & -70.58770 & & 2 & 0.0 & 9.4 & 3.4 & 22.7 \\
\hline CL 036 & $2 / 4 / 09$ & -52.67743 & -70.38253 & 1 & 6 & 0.2 & 9.0 & 4.3 & 17.3 \\
\hline CL 041 & $2 / 4 / 09$ & -52.65133 & -70.32452 & & 7 & 0.5 & 10.1 & 7.1 & 13.1 \\
\hline CL 042 & $2 / 5 / 09$ & -52.61202 & -70.13832 & & 4 & 0.3 & 8.8 & 5.3 & 43.3 \\
\hline CL 043 & $2 / 5 / 09$ & -52.54433 & -69.95557 & & 4 & 0.5 & 8.8 & 13.1 & 11.5 \\
\hline CL 044 & $2 / 5 / 09$ & -52.61610 & -69.84088 & 2 & 3 & 0.3 & 8.3 & 4.0 & 6.9 \\
\hline CL 045 & $2 / 5 / 09$ & -52.61610 & -69.84088 & 25 & & & & & 6.6 \\
\hline \multicolumn{10}{|c|}{ Atlantic groundwater samples } \\
\hline CL 025 & $2 / 2 / 09$ & -53.64918 & -70.94368 & 2 & 130 & 7.6 & 19.7 & 67.9 & 39.8 \\
\hline CL 027 & $2 / 2 / 09$ & -53.64918 & -70.94368 & 1 & 441 & 12.2 & 27.2 & 181.0 & 9.4 \\
\hline CL 037 & $2 / 4 / 09$ & -52.64855 & -70.33402 & 1 & 163 & 8.5 & 17.8 & 78.8 & 13.1 \\
\hline CL 040 & $2 / 4 / 09$ & -52.64855 & -70.33402 & 2 & 73 & 4.2 & 9.9 & 25.6 & 6.6 \\
\hline CL 047 & $2 / 6 / 09$ & -52.64912 & -70.33437 & 1 & 3 & 0.0 & 2.0 & 0.0 & 42.7 \\
\hline CL 049 & $2 / 6 / 09$ & -52.64893 & -70.33433 & 1 & 16 & 1.0 & 4.0 & 7.8 & 10.1 \\
\hline CL 051 & $2 / 6 / 09$ & -52.64913 & -70.33443 & 0 & 159 & 7.0 & 15.1 & 56.2 & 2.3 \\
\hline CL 052 & $2 / 6 / 09$ & -52.64938 & -70.33778 & 2 & 5 & 0.0 & 3.3 & 6.1 & 6.4 \\
\hline CL 055 & $2 / 6 / 09$ & -52.64977 & -70.33408 & 2 & & & & & bd \\
\hline CL 056 & $2 / 6 / 09$ & -52.64915 & -70.33447 & 0 & 234 & 11.2 & 56 & 160 & 31.3 \\
\hline CL 057 & $2 / 6 / 09$ & -52.64915 & -70.33447 & 0 & & & & & 34.7 \\
\hline CL 058 & $2 / 6 / 09$ & -52.64977 & -70.33408 & 2 & & & & & bd \\
\hline CL 059 & $2 / 6 / 09$ & -52.65002 & -70.33422 & 2 & & & & & 26.1 \\
\hline \multicolumn{10}{|c|}{ Atlantic estuary samples } \\
\hline CL 026 & $2 / 2 / 09$ & -53.64918 & -70.94368 & & 20 & 0.9 & 5.9 & 8.3 & 6.0 \\
\hline CL 046 & $2 / 6 / 09$ & -52.64912 & -70.33437 & 0 & 243 & 17.8 & 32.0 & 86.4 & 36.0 \\
\hline CL 031 & $2 / 3 / 09$ & -52.91730 & -70.88653 & 1 & 25 & 1.5 & 11.7 & 9.2 & 4.8 \\
\hline CL 048 & $2 / 6 / 09$ & -52.64912 & -70.33437 & & 42 & 2.4 & 13.2 & 20.1 & 16.9 \\
\hline CL 050 & $2 / 6 / 09$ & -52.64912 & -70.33437 & & 43 & 2.0 & 14.5 & 18.0 & 11.8 \\
\hline CL $053 \mathrm{Ra}$ & $2 / 6 / 09$ & -52.64915 & -70.33447 & & 31 & 2.1 & 10.8 & 9.2 & \\
\hline CL 053 TM+Nut & $2 / 6 / 09$ & -52.64915 & -70.33447 & & & & & & 9.4 \\
\hline CL $054 \mathrm{Ra}$ & $2 / 6 / 09$ & -52.64933 & -70.34093 & & 8 & 0.5 & 5.5 & 8.0 & \\
\hline CL 054 TM+Nut & $2 / 6 / 09$ & -52.64933 & -70.34093 & & & & & & 3.8 \\
\hline CL 060 & $2 / 6 / 09$ & -52.64915 & -70.33447 & & 25 & 1.5 & 11.4 & 11.0 & 6.5 \\
\hline CL 038 & $2 / 4 / 09$ & -52.64982 & -70.33545 & 1 & 42 & 1.9 & 10.9 & 19.2 & 13.8 \\
\hline CL 039 & $2 / 4 / 09$ & -52.64953 & -70.33858 & 0 & 23 & 0.5 & 9.0 & 16.3 & 8.8 \\
\hline
\end{tabular}




\begin{tabular}{|c|c|c|c|c|c|c|c|c|c|c|}
\hline Sample Id & $\begin{array}{c}\text { Silicate } \\
\text { uM }\end{array}$ & PO4 uM & $\begin{array}{c}\mathrm{NO} 2+\mathrm{NO} 3 \\
\mathrm{uM}\end{array}$ & DIN uM & DON uM & TDN uM & $\begin{array}{c}\text { TA } \\
\mu \mathrm{mol} / \mathrm{kg}\end{array}$ & YSI pH & $\begin{array}{c}\text { YSI ORP } \\
\text { mV }\end{array}$ & $\begin{array}{c}\text { YSI DO } \\
\text { mg/L }\end{array}$ \\
\hline \multicolumn{11}{|c|}{ Fjord Surface sa } \\
\hline CL 001 & 4.2 & 0.3 & 8.0 & 25.6 & 19.8 & 45.4 & & & & \\
\hline CL 002 & 3.6 & 0.5 & 7.4 & 12.3 & 15.1 & 27.4 & & & & \\
\hline CL 007 & 3.7 & 0.3 & 0.1 & 5.5 & 21.6 & 27.1 & & & & \\
\hline CL 023 & 4.6 & 0.2 & 7.3 & 12.7 & 0.8 & 13.5 & 1921 & 7.89 & & 10.4 \\
\hline Fjord groundwa & & & & & & & 2297 & & & \\
\hline CL 005 & 86.9 & 0.4 & 14.4 & 20.8 & 13.7 & 34.6 & 2872 & 7.18 & & 7.5 \\
\hline CL 015 & 55.7 & 0.3 & 1.7 & 7.8 & 11.6 & 19.3 & & 7.40 & & 1.1 \\
\hline CL 016 & 64.2 & 0.1 & 9.6 & 17.0 & 13.2 & 30.2 & 690 & 7.10 & 141 & 2.5 \\
\hline CL 017 & 38.7 & 0.1 & 8.2 & 15.3 & 14.3 & 29.6 & 966 & 7.26 & 58 & 1.9 \\
\hline CL 019 & 31.0 & 0.3 & 3.8 & 26.4 & 148.8 & 175.2 & 1240 & 7.29 & & \\
\hline \multicolumn{11}{|l|}{ Fjord estuary sa } \\
\hline CL 004 & 14.8 & 0.1 & 0.1 & 7.8 & 13.7 & 21.5 & & 7.52 & & 9.9 \\
\hline CL 006 & 1.6 & 0.3 & 0.6 & 9.0 & 44.2 & 53.2 & bd & 8.38 & & 10.0 \\
\hline CL 008 & 1.7 & 0.1 & 0.5 & 5.6 & 16.3 & 21.9 & 102 & 9.16 & & 11.7 \\
\hline CL 009 & 3.8 & 0.1 & 0.3 & 7.7 & 8.3 & 16.0 & 731 & 8.09 & & \\
\hline CL 012 & 3.8 & 0.1 & 1.8 & 8.7 & 4.7 & 13.4 & 226 & 9.31 & & \\
\hline CL 013 & 17.2 & 0.1 & 1.3 & 10.2 & 2.3 & 12.5 & 1241 & 7.88 & & \\
\hline CL 021 & 8.8 & 0.6 & 1.9 & 17.3 & 24.1 & 41.4 & 705 & 9.00 & & \\
\hline CL 022 & 20.1 & 0.2 & 2.5 & 33.6 & 19.7 & 53.2 & & 7.67 & & \\
\hline \multicolumn{11}{|l|}{ Atlantic surface } \\
\hline CL 028 & 2.5 & 0.2 & 4.2 & 21.3 & 8.3 & 29.6 & 2216 & 8.00 & 154 & 10.1 \\
\hline CL 029 & 2.3 & 0.4 & 4.0 & 9.7 & 8.3 & 17.9 & & 8.02 & 130 & 9.4 \\
\hline CL 030 & 4.0 & 0.3 & 1.1 & 9.8 & 7.3 & 17.1 & 2047 & 8.12 & 106 & 9.8 \\
\hline CL 032 & 2.2 & 0.2 & 0.1 & 7.2 & 11.7 & 18.9 & & 8.19 & 141 & 10.6 \\
\hline CL 034 & 2.5 & 0.2 & 0.2 & 7.2 & 10.5 & 17.7 & 2057 & 7.78 & 127 & 8.6 \\
\hline CL 035 & 3.1 & 0.2 & 2.2 & 24.9 & 20.2 & 45.1 & 2197 & 7.97 & 148 & 10.4 \\
\hline CL 036 & 2.3 & 0.2 & 2.6 & 19.8 & 3.6 & 23.4 & & 7.83 & 129 & 9.1 \\
\hline CL 041 & 2.0 & 0.2 & 0.3 & 13.4 & 9.4 & 22.8 & 2203 & 7.83 & 231 & 9.8 \\
\hline CL 042 & 2.3 & 0.2 & 0.7 & 43.9 & 40.6 & 84.6 & & 7.96 & 164 & 6.8 \\
\hline CL 043 & 2.2 & 0.3 & 0.1 & 11.5 & 11.0 & 22.5 & & 8.01 & 145 & 8.5 \\
\hline CL 044 & 2.3 & 0.3 & 1.7 & 8.6 & 8.8 & 17.4 & 2037 & 7.78 & 142 & 7.5 \\
\hline CL 045 & 1.9 & 0.3 & 0.8 & 7.5 & 1.6 & 9.1 & 2029 & & & \\
\hline \multicolumn{11}{|l|}{ Atlantic ground } \\
\hline CL 025 & 153.2 & 10.5 & 1.5 & 41.3 & 29.3 & 70.6 & & 6.86 & -183 & 0.8 \\
\hline CL 027 & 89.8 & 0.2 & 0.9 & 10.3 & 12.4 & 22.8 & & 6.31 & -109 & 0.6 \\
\hline CL 037 & 208.8 & 0.2 & 5.1 & 18.2 & 13.3 & 31.5 & 3105 & 6.57 & 117 & 4.5 \\
\hline CL 040 & 122.9 & 0.2 & 2.0 & 8.6 & 12.4 & 20.9 & 3375 & 6.82 & 141 & 4.1 \\
\hline CL 047 & 137.5 & 0.2 & 0.1 & 42.7 & 40.3 & 83.0 & 4656 & 7.31 & -54 & 2.7 \\
\hline CL 049 & 96.6 & 1.4 & 0.6 & 10.6 & 7.1 & 17.8 & 4825 & 7.58 & -43 & 4.5 \\
\hline CL 051 & 62.8 & 2.4 & 41.6 & 43.9 & 12.4 & 56.3 & & 7.37 & 57 & 4.9 \\
\hline CL 052 & 259.5 & 0.5 & 0.1 & 6.4 & 6.9 & 13.3 & & 7.71 & -95 & 8.7 \\
\hline CL 055 & 430.2 & 64.4 & 0.7 & 0.7 & 304.3 & 304.9 & & 8.02 & -241 & 2.0 \\
\hline CL 056 & 365.8 & 12.7 & 0.7 & 32.1 & 126.3 & 158.4 & & 7.52 & 155 & 2.3 \\
\hline CL 057 & 393.1 & 10.8 & 0.6 & 35.2 & 117.6 & 152.8 & & & & \\
\hline CL 058 & 275.1 & 50.1 & 0.4 & 0.4 & 288.3 & 288.8 & & 8.08 & -337 & 0.9 \\
\hline CL 059 & 369.7 & 2.3 & 0.5 & 26.6 & 13.6 & 40.2 & 3625 & 7.91 & -284 & 2.6 \\
\hline \multicolumn{11}{|l|}{ Atlantic estuary } \\
\hline CL 026 & 63.8 & 0.2 & 1.6 & 7.5 & 16.2 & 23.7 & & 7.66 & -44 & 8.7 \\
\hline CL 046 & 241.9 & 0.4 & 0.4 & 36.4 & 8.4 & 44.8 & & 7.39 & -124 & 5.3 \\
\hline CL 031 & 1.6 & 0.2 & 0.1 & 4.8 & 11.2 & 16.0 & & 8.30 & 111 & 8.9 \\
\hline CL 048 & 54.2 & 0.5 & 0.3 & 17.1 & 9.7 & 26.8 & & 7.43 & -10 & 6.5 \\
\hline CL 050 & 63.3 & 0.6 & 0.8 & 12.6 & 14.9 & 27.4 & & 7.45 & 19 & 6.6 \\
\hline CL $053 \mathrm{Ra}$ & & & & & & & & 8.27 & 33 & 5.2 \\
\hline CL 053 TM+Nut & 178.5 & 1.1 & 0.5 & 9.9 & 20.7 & 30.5 & & 8.34 & 33 & 4.9 \\
\hline CL $054 \mathrm{Ra}$ & & & & & & & & 9.09 & -12 & \\
\hline CL 054 TM+Nut & 115.1 & 3.0 & 0.1 & 3.9 & 18.3 & 22.2 & & 8.81 & -214 & 12.3 \\
\hline CL 060 & 35.6 & 0.4 & 0.1 & 6.5 & 9.9 & 16.4 & & 8.09 & & \\
\hline CL 038 & 86.8 & 0.9 & 4.5 & 18.3 & 12.2 & 30.6 & 2623 & 8.05 & 117 & 6.7 \\
\hline CL 039 & 68.0 & 0.3 & 0.6 & 9.5 & 17.1 & 26.5 & 3479 & 8.35 & 55 & 7.7 \\
\hline
\end{tabular}




\begin{tabular}{|c|c|c|c|c|c|c|c|c|c|}
\hline Sample Id & $\begin{array}{c}\text { YSI DO } \\
\text { sat \% }\end{array}$ & $\begin{array}{c}\text { YSI Temp } \\
\infty \mathrm{C}\end{array}$ & Salinity & $\begin{array}{c}\mathrm{Ba} \\
\mathrm{nmol} / \mathrm{kg}\end{array}$ & $\underset{\mathrm{nmol} / \mathrm{kg}}{\mathrm{U}}$ & $\begin{array}{c}\text { Mn } \\
\text { umol/kg }\end{array}$ & $\begin{array}{c}\mathrm{Fe} \\
\mathrm{umol} / \mathrm{kg}\end{array}$ & $\begin{array}{c}\mathrm{Sr} \\
\mathrm{umol} / \mathrm{kg}\end{array}$ & Notes: \\
\hline \multicolumn{10}{|c|}{ Fjord Surface sa } \\
\hline CL 001 & & & 30.2295 & 44 & 9.9 & bd & bd & 77.1 & Bahia El Aquila \\
\hline CL 002 & & & 27.3424 & 42 & 10.2 & bd & bd & 76.5 & Trech Magellena \\
\hline CL 007 & & & 27.5113 & 48 & 9.2 & 0.0 & 0.1 & 82.0 & Bahia Isla \\
\hline CL 023 & 110 & 9.7 & 28.5635 & 50 & 9.1 & bd & 0.1 & 80.6 & Almirantazgo fjord \\
\hline \multicolumn{10}{|l|}{ Fjord groundwa } \\
\hline CL 005 & 75 & 9.9 & 8.4718 & 459 & 2.6 & 0.1 & 0.1 & 26.1 & Bahia Tres Islas \\
\hline CL 015 & 10 & 9.5 & 5.9350 & 116 & 0.1 & 0.2 & 0.7 & 12.7 & Marinelli Fjord \\
\hline CL 016 & 23 & 8.5 & 12.0815 & 1366 & 0.0 & 0.1 & 0.5 & 44.2 & Marinelli Fjord \\
\hline CL 017 & 22 & 11.1 & 15.6210 & 566 & 0.5 & 0.4 & 3.3 & 47.7 & Marinelli Fjord \\
\hline CL 019 & & 12.2 & 18.3984 & 362 & 0.7 & 0.1 & 0.7 & 47.8 & Marinelli Fjord \\
\hline \multicolumn{10}{|l|}{ Fjord estuary sa } \\
\hline CL 004 & 101 & 12.3 & 11.0989 & 41 & 3.7 & 0.1 & 0.7 & 32.4 & lake outflow \\
\hline CL 006 & 90 & 10.2 & 0.4503 & 50 & bd & 0.2 & 10.9 & 0.2 & stream \\
\hline CL 008 & 97 & & 0.5004 & 1 & bd & 0.9 & 1.5 & 0.2 & glacier outflow \\
\hline CL 009 & & & 9.8756 & 46 & 3.3 & 0.8 & bd & 25.0 & glacier estuary \\
\hline CL 012 & & & 0.5907 & 20 & $\mathrm{bd}$ & bd & bd & 0.0 & glacier stream \\
\hline CL 013 & & & 11.7406 & 127 & 4.6 & 0.2 & bd & 29.4 & glacier estuary \\
\hline CL 021 & & & 1.3627 & 62 & 0.0 & 0.4 & 6.1 & 2.7 & \\
\hline CL 022 & & & 18.6993 & 66 & 6.6 & 0.1 & 0.9 & 56.3 & \\
\hline \multicolumn{10}{|l|}{ Atlantic surface } \\
\hline CL 028 & 105 & 9.3 & 30.5415 & 41 & 9.7 & bd & bd & 78.8 & \\
\hline CL 029 & 100 & 9.3 & 30.3826 & 41 & 10.3 & bd & bd & 81.1 & Punta Arenas \\
\hline CL 030 & 106 & 9.8 & 30.5226 & 41 & 9.7 & bd & bd & 82.6 & Punta Arenas \\
\hline CL 032 & 115 & 10.6 & 30.8756 & 44 & 9.6 & bd & bd & 79.6 & Rio Pescado \\
\hline CL 034 & 94 & 10.9 & 30.9426 & 47 & 9.5 & bd & bd & 79.9 & \\
\hline CL 035 & 111 & 9.9 & 30.7025 & 44 & 10.0 & bd & 0.8 & 79.4 & \\
\hline CL 036 & 100 & 10.7 & 30.7334 & 44 & 10.0 & bd & bd & 81.0 & \\
\hline CL 041 & 107 & 10.8 & 30.7222 & 44 & 10.0 & bd & bd & 79.8 & \\
\hline CL 042 & 74 & 10.6 & 30.7214 & 44 & 9.6 & bd & bd & 78.0 & \\
\hline CL 043 & 91 & 10.9 & 30.7689 & 46 & 9.9 & bd & bd & 81.5 & \\
\hline CL 044 & 83 & 11.1 & 30.8407 & 46 & 9.9 & bd & bd & 78.4 & Bahia Santiago \\
\hline CL 045 & & & 30.9407 & 46 & 9.9 & bd & bd & 77.5 & Bahia Santiago \\
\hline \multicolumn{10}{|l|}{ Atlantic ground } \\
\hline CL 025 & 9 & 8.5 & 13.1644 & 1976 & bd & 3.9 & 31.2 & 37.9 & Rio SanJuan \\
\hline CL 027 & & 10.6 & 19.3928 & 493 & 0.0 & 1.4 & 1.4 & 61.9 & Rio SanJuan \\
\hline CL 037 & 44 & 12.1 & 12.3675 & 271 & 1.8 & 13.8 & 0.6 & 30.7 & Rio Susanna \\
\hline CL 040 & 39 & 11.6 & 6.5856 & 111 & 1.2 & bd & 0.0 & 14.0 & Rio Susanna \\
\hline CL 047 & 24 & 10.7 & 5.2330 & 41 & 4.8 & 140.4 & 0.1 & 3.8 & Rio Susanna \\
\hline CL 049 & 39 & 10.3 & 2.6479 & 81 & 1.3 & 33.1 & 2.1 & 2.7 & Rio Susanna \\
\hline CL 051 & 57 & 13.9 & 30.5635 & 111 & 9.3 & 0.01 & bd & 80.5 & Rio Susanna \\
\hline CL 052 & 72 & 9.1 & 0.2870 & 58 & 1.5 & 8.0 & 7.6 & 2.0 & Rio Susanna \\
\hline CL 055 & 19 & 14.1 & 2.8607 & 110 & 0.7 & 1.1 & 0.3 & 4.3 & Rio Susanna \\
\hline CL 056 & 28 & 16.7 & 26.5170 & 981 & 1.0 & 84.2 & 79.5 & 71.4 & Rio Susanna \\
\hline CL 057 & & 14.6 & 25.2468 & 938 & 1.3 & 95.8 & 72.2 & 64.1 & Rio Susanna \\
\hline CL 058 & 10 & 13.6 & 8.1008 & 315 & 1.0 & 0.1 & 0.0 & 15.9 & Rio Susanna \\
\hline CL 059 & 25 & 12.8 & 0.3619 & 23 & 0.3 & 4.6 & 6.4 & 1.9 & Rio Susanna \\
\hline \multicolumn{10}{|l|}{ Atlantic estuary } \\
\hline CL 026 & 91 & 12.7 & 16.6638 & 83 & 4.7 & 1.0 & 1.6 & 42.3 & Rio SanJuan \\
\hline CL 046 & 54 & 11.8 & 22.3510 & 267 & 3.2 & 58.4 & 48.5 & 66.7 & Rio Susanna \\
\hline CL 031 & 108 & 14.6 & 30.9992 & 49 & 9.2 & 0.8 & 0.2 & 82.1 & Rio Pescado \\
\hline CL 048 & 70 & 11.6 & 25.8986 & 92 & 8.4 & 8.0 & 0.4 & 70.4 & Rio Susanna \\
\hline CL 050 & 73 & 13.3 & 25.3694 & 95 & 8.3 & 8.1 & 0.1 & 67.9 & Rio Susanna \\
\hline CL $053 \mathrm{Ra}$ & 60 & 17.7 & 14.4415 & & & & & & Rio Susanna \\
\hline CL 053 TM+Nut & 56 & 17.4 & 13.6958 & 120 & 4.5 & 12.8 & 0.1 & 36.0 & Rio Susanna \\
\hline CL $054 \mathrm{Ra}$ & & 19.5 & 1.0018 & & & & & & Rio Susanna \\
\hline CL 054 TM+Nut & 128 & 17.6 & 1.0218 & 65 & 1.9 & 11.6 & 0.7 & 3.6 & Rio Susanna \\
\hline CL 060 & & & 31.1426 & 62 & 9.2 & 1.2 & 0.5 & 78.3 & Rio Susanna \\
\hline CL 038 & 79 & 17.4 & 21.6314 & 117 & 7.4 & 6.3 & 0.0 & 57.4 & Rio Susanna \\
\hline CL 039 & 75 & 16.2 & 2.2209 & 147 & 1.8 & 19.9 & 1.1 & 8.3 & Rio Cook \\
\hline
\end{tabular}

